\title{
Felix Butzlaff
}

Die neuen Bürgernrotesto

in Doutschlani

Organisatoren - Erwartungen -

Demokratiebilder 
Felix Butzlaff

Die neuen Bürgerproteste in Deutschland

Studien des Göttinger Instituts für Demokratieforschung zur Geschichte politischer und gesellschaftlicher Kontroversen Herausgegeben von Franz Walter | Band to 
Felix Butzlaff (Dr. disc. pol.), geb. I98I, ist wissenschaftlicher Mitarbeiter am Göttinger Institut für Demokratieforschung. Er hat Politikwissenschaft, Volkswirtschaftslehre und Jura in Göttingen und Santiago de Chile studiert und arbeitet zur Geschichte und Gegenwart der Bürgerproteste sowie der deutschen und europäischen Parteienfamilie der Arbeiterbewegung. 
Felix ButzlafF

\section{Die neuen Bürgerproteste in Deutschland}

Organisatoren - Erwartungen - Demokratiebilder

[transcript] 


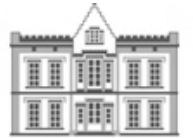

Göttinger Institut für

Demokratieforschung

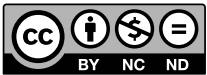

Dieses Werk ist lizenziert unter der Creative Commons Attribution-NonCommercial-NoDerivs 4.0 Lizenz (BY-NC-ND). Diese Lizenz erlaubt die private Nutzung, gestattet aber keine Bearbeitung und keine kommerzielle Nutzung. Weitere Informationen finden Sie unter https://creativecommons.org/licenses/by-nc-nd/4.o/deed.de/.

Um Genehmigungen für Adaptionen, Übersetzungen, Derivate oder Wiederverwendung zu kommerziellen Zwecken einzuholen, wenden Sie sich bitte an rights@transcript-verlag.de

\section{(C) 2015 transcript Verlag, Bielefeld}

\section{Bibliografische Information der Deutschen Nationalbibliothek}

Die Deutsche Nationalbibliothek verzeichnet diese Publikation in der Deutschen Nationalbibliografie; detaillierte bibliografische Daten sind im Internet über http://dnb.d-nb.de abrufbar.

Umschlagkonzept: Kordula Röckenhaus, Bielefeld

Satz: Felix Butzlaff

Druck: Majuskel Medienproduktion GmbH, Wetzlar

Print-ISBN 978-3-8376-3341-2

PDF-ISBN 978-3-8394-3341-6

Gedruckt auf alterungsbeständigem Papier mit chlorfrei gebleichtem Zellstoff. Besuchen Sie uns im Internet: http://www.transcript-verlag.de

Bitte fordern Sie unser Gesamtverzeichnis und andere Broschüren an unter: info@transcript-verlag.de 


\section{Inhalt}

\section{Neue Proteste allerorten |7}

2. Was folgt aus und was möchte Protest? | 15

2.1 Wie entstehen Demokratienormen? | 20

2.2 Die Grossstadt als Kristallisationspunkt | 28

2.3 Protest und Alter: der biographische Ort von Widerspruch | 34

2.4 Zwischenfazit I: zur Fragestellung | 40

3. Herangehensweise, Fallauswahl, Forschungsstand 43

3.1 Ein flanierender Spaziergang als Mittel zur Erkenntnis | 45

3.2 Quellen: Fokusgruppen, Interviews und Teilnehmende Beobachtung | 53

3.3 Fallauswahl | 74

3.4 Forschungsstand 80

3.5 Zwischenfazit II: zur Herangehensweise | 86

4. Die vier Fragen: Generation, Biographie, Alter und Prägung | 89

4.1 Sozialstruktur der Interviewten 93

4.2 Elternhaus, Schule und Vorbildfiguren | 103

4.3 Selbstbewusstsein und Selbstwirksamkeitserwartungen | 118

4.4 Zwischenfazit III: individualisierte Selbstwirksamkeitserwartung in einer alternden Gesellschaft | 135

4.5 Eigendeutungen als Generationseinheit: Was sind wir für eine Gruppe? | 137

4.6 Endliche Reserven: Zeit- und Kraftaufwand von Protest | 148

4.7 Die große Frage: Warum mache ich das eigentlich? | 153

4.8 Zwischenfazit IV: Eckpunkte des Selbstbildes als Protestierende | 163

5. Krisenwahrnehmung und Demokratievorstellungen | 169

5.1 Politische Parteien als Zuspitzung und Symbol der gesellschaftlichen Krise | 176

5.2 Demokratievorstellungen und -erwartungen | 201

5.3 Zwischenfazit V: Demokratie und Krise | 235 
6. Utopien des Zusammenlebens | 241

6.1 Glorifizierung des Selbermachens $\mid 246$

6.2 Gemeinschaft als Hort von Identität | 248

6.3 Effizienz und Avantgarde $\mid 256$

6.4 Zwischenfazit VI: Genossenschaftslogik und Stolz | 263

7. Von guter und böser Vielfalt: Fazit und Zusammenfassung | 269

Abbildungsverzeichnis | 283

Literaturverzeichnis | 285 


\section{Neue Proteste allerorten}

Es scheint sich in der Tat etwas zu verändern in unseren Demokratien. Nicht nur in Deutschland, auch in den europäischen Nachbarländern haben sich in den vergangenen Jahren mehrere Krisendiagnosen und -wahrnehmungen übereinander geschoben und sich in ihren Wirkungen mitunter verstärkt. ${ }^{1}$ Die akademische Landschaft aus Soziologie, Politikwissenschaften, Ökonomie, Psychologie jedenfalls ergeht sich in einer ganzen Reihe von Betrachtungen, Ursachenforschungen und Prognosen über die parallel oder versetzt auftretenden Krisen der Volkswirtschaften und Demokratien unserer Gesellschaften. ${ }^{2}$ Die Feuilletons der

1 Frank Ernst etwa zeichnet in seiner Untersuchung des freiwilligen Engagements in Deutschland eine Krise in den Bereichen „Sozialstaat“, „Arbeitsgesellschaft“ und „Demokratie als Partizipationsgesellschaft“, vgl. Ernst, Frank: Freiwilliges Engagement als Gegenstand von Gruppendiskussionen, in: Bohnsack, Ralf / Aglaja Przyborski / Burkhard Schäffer (Hrsg.): Das Gruppendiskussionsverfahren in der Forschungspraxis, Opladen \& Farmington Hills 2010, S. 169 - 187, hier S. 171. Ernst verweist unter anderem auf Sebastian Braun, der bereits 2001 auf diesen KrisenDreiklang hingewiesen hat, welcher sich mit der eintretenden ökonomischen Krise in Europa ab 2008 noch deutlich verschärft haben dürfte, vgl. Braun, Sebastian: Bürgerschaftliches Engagement - Konjunktur und Ambivalenz einer gesellschaftspolitischen Debatte, in: Leviathan Jg. 29 (2001) H. 1, S. 83 - 109, hier S. 84 und 89ff.

2 Vgl. exemplarisch Wöhl, Stefanie: Die „Krise“ der repräsentativen Demokratie in Europa. Demokratietheoretische und politikfeldbezogene Reflexionen, in: Forschungsjournal Soziale Bewegungen, Jg. 26 (2013) H. 1, S. 42 - 50; Greven, Michael Th.: Fortschritt der Demokratie?, in: Vorgänge, Jg. 50 (2011) H. 3, S. 17 - 29; vgl. auch den Sammelband Agamben, Giorgio / Alain Badiou / Daniel Bensaid u.a.: Democracy - in what state?, New York 2011; vgl. auch Habermas, Jürgen: Zur Verfassung Europas, Frankfurt a.M. 2011; Volkmann, Uwe: Verführung des Absoluten. Warum wir unsere demokratischen Institutionen lieber pflegen statt verachten sollten, in: Merkur, 
großen Zeitungen veröffentlichen in schöner Regelmäßigkeit Artikelserien zu Zustand und Problemen von Demokratie und Gesellschaft. ${ }^{3}$ Und bis in die Gegenwartsliteratur hinein haben die Bestandsaufnahmen einer sich verändern Gesellschaft bereits Eingang gefunden: Wenn Anna Katharina Hahn in „Am Schwarzen Berg" über die Gefühlslage des Stuttgarter Bürgertums schreibt ${ }^{4}$ oder Paul Auster in „Sunset Park “5 junge Amerikaner im Brooklyn der jüngsten Wirtschaftskrise skizziert, dann finden sich die vermeintlich drängenden Themen der Zeit im Roman gespiegelt.

Politische oder wirtschaftliche Krisenlagen sind stets auch Zeiten der Unsicherheit und der zunächst amorphen, sich erst langsam konkretisierenden Suche. Zeiten, in denen etablierte Interpretationsrahmen und Instrumente zu Verständnis und Vermittlung der Fundamente von Gesellschaft, Politik und Wirtschaft nicht so funktioniert haben, wie dies von ihnen erwartet worden ist. ${ }^{6}$ Infolgedessen sind gesellschaftliche Umbrüche, ökonomische Depressionen und als solche empfundene Krisen immer auch verbunden mit einer Verschiebung in der Wahrnehmung der bis dato bekannten und akzeptierten Methoden zur Untersuchung der Welt. Nicht umsonst etwa ist die seit 2008 ausgebrochene Folge von Banken-, Finanz- und Wirtschaftskrisen unter anderem in die Frage gemündet, warum die Volkswirtschaftslehre und die politische Ökonomie als universitäre Fächer nicht besser zum Verständnis und zur Prognose eben dieser Krise beigetra-

Jg. 65 (2011) H. 5, S. 381 - 393; Blühdorn, Ingolfur: Simulative Demokratie. Neue Politik nach der postdemokratischen Wende, Berlin 2013, S. 9 - 59; Schäfer, Armin: Die Folgen sozialer Ungleichheit für die Demokratie in Westeuropa, in: Zeitschrift für Vergleichende Politikwissenschaft, Jg. 4 (2010) H. 1, S. 131 - 156; vgl. auch etwa die Betrachtung von Input- und Output-Legitimitätsquellen der Demokratie bzw. die Diskussion „uneingelöster Versprechen der Demokratie“ bei Salzborn, Samuel: Demokratie. Theorien, Formen, Entwicklungen, Baden Baden 2012, S. 47 - 66.

3 Vgl. exemplarisch: Prizkau, Anna: Die Köpfe der Rebellion. Die Verhältnisse, gegen welche Menschen protestieren, unterscheiden sich. Aber die Rebellen haben sehr viel gemeinsam, in: Frankfurter Allgemeine Sonntagszeitung, 23.06.2013; o.V.: Unsere Zukunft klingt nach Katastrophe, in: Die Zeit, 25.11.2012; Springstein, Hans: Die Elite blickt auf die Demokratie herab, 08.04.2013, online einsehbar unter http://www.freitag.de/autoren/hans-springstein/die-elite-blickt-auf-die-demokratie-her ab [zuletzt eingesehen am 26.06.2013].

4 Vgl. Hahn, Anna Katharina: Am Schwarzen Berg, Berlin 2012.

5 Vgl. Auster, Paul: Sunset Park, Reinbek bei Hamburg 2012.

6 Vgl. Makropoulos, Michael: Über den Begriff der „Krise“. Eine historischsemantische Skizze, in: INDES. Zeitschrift für Politik und Gesellschaft, Jg. 2 (2013) H. 1, S. $13-20$, hier S. 13. 
gen haben. Und in Bezug auf die Funktionsweisen unserer Demokratie werden angesichts immer tiefer sinkender Glaubwürdigkeitswerte von Politik und Parteien an Sozial- und Politikwissenschaften vermehrt die Fragen gerichtet, wo und an welcher Stelle unsere politischen Ordnungen der Nachbesserungen bedürfen, um den Erwartungen der Bevölkerung an ihre jeweiligen Demokratien gerecht zu werden. ${ }^{7}$ Jede Erschütterung der Gesellschaftsordnung wirkt auf unsere Sicht und unser Verständnis von den Mechanismen, nach denen jene Ordnung funktioniert. Und die Suche nach neuen Methoden, um diese besser zu verstehen, nach neuen Perspektiven oder Theorien, bekommt durch die Wahrnehmung einer Krise, welche durch bekannte Interpreten nicht erklärt werden kann, immer wieder neue Nahrung. ${ }^{8}$

Die beschriebenen Phänomene, die man der aktuellen, krisenhaften Situation zurechnet, sind äußerst heterogen und facettenreich: Sie spannen einen weiten Bogen über die eruptiven und gewalttätigen Ausbrüche des Protests in den Banlieus von Paris und anderen französischen, schwedischen oder - etwa unter dem Stichwort von Hogesa, Hooligans gegen Salafismus ${ }^{9}$ - auch deutschen Städten, plündernde Jugendliche in englischen Metropolen, die spanische Protestbewegung Democracia Real Ya! und die Zelte des Occupy Movement ${ }^{10}$ bis hin zu den Protesten gegen große Infrastrukturprojekte in deutschen Großstädten, den sich an Energiewendevorhaben herausbildenden Bürgerinitiativen oder den PegidaDemonstrationen in Dresden im Winter 2014/2015. Gemeinsam ist allen die Frage nach der Beziehung zwischen Politik und Gesellschaft und nach der Stellung des Bürgers in ihr. Der „Wutbürger“ etwa, von der Gesellschaft für deutsche Sprache zum Wort des Jahres 2010 gekürt $^{11}$, hat diese Konflikte für Deutschland auf einen Begriff gebracht, indem ein gewachsenes Unverständnis und Misstrauen der etablierten Politik und den traditionellen Großorganisationen

7 Vgl. Vortkamp, Wolfgang: Wozu braucht die repräsentative Demokratie die Bürger?, in: Forschungsjournal Soziale Bewegungen, Jg. 26 (2013) H. 1, S. 10 - 18.

8 Vgl. Walter, Franz: Ruhe im Sturm? Deutungsverlust und Demokratieschwund in der Krise, in: INDES. Zeitschrift für Politik und Gesellschaft, Jg. 2 (2013) H. 1, S. 6 - 12, hier S. 6.

9 Vgl. Jacobsen, Lenz: Die Presse ist der Feind, in: Zeit.de, 15.11.2014, online einsehbar unter: http://www.zeit.de/politik/deutschland/2014-11/hooligan-demonstrationhannover [zuletzt eingesehen am 11.01.2015].

10 Vgl. Geiges, Lars: Occupy in Deutschland. Die Protestbewegung und ihre Akteure, Bielefeld 2014.

11 Vgl. http://www.gfds.de/publikationen/der-sprachdienst/zeit-woerter/der-wutbuergerin-der-retrospektive/ [zuletzt eingesehen am 29.04.2013]. 
gegenüber von immer mehr und immer selbstbewusster auftretenden Bürgern artikuliert wird. $^{12}$

Anders allerdings als in vergangenen Phasen der Krisendiagnosen in den etablierten oder auch noch ungefestigten Demokratien, von denen zyklisch und oft rasch eine der anderen folgte - von den Debatten um die destruktive Rolle der Parteien in Weimar über die Unregierbarkeitsdebatten der 1970er Jahre bis zur „Politikverdrossenheit“ als Wort des Jahres $1992^{13}$-, spielen die einzelnen Bürger als Organisatoren, Sammelpunkte und Lausprecher der Unzufriedenheit in den vergangenen Jahren eine immer größere Rolle. Die Beziehung dieses Bürgers zu seiner Gesellschaft, die wahrgenommene Verschiebung seiner Position, seiner ganz individuellen Ansprüche und Hoffnungen im politischen Prozess und seine Vorstellungen einer guten und gerechten Organisation von Politik, Wirtschaft und Staat sind bei einer Betrachtung der sinkenden DemokratieZufriedenheit und ihrer Ursachen von großer Wichtigkeit. Wenn etwa die Proteste gegen den Umbau eines Platzes im Istanbuler Stadtzentrum im Frühsommer 2013 oder die Proteste gegen die brasilianischen Ausgaben für den Infrastrukturbau anlässlich der Fußballweltmeisterschaft 2014 als Ausdruck eines neuen bürgerlichen Selbstbewusstseins einer gut ausgebildeten Mittelschicht gedeutet werden, dann geht es im Kern um eine neue Balance in Politik, Demokratie und Gesellschaft. ${ }^{14}$

Gleichzeitig haben sich die traditionellen Großorganisationen wie Gewerkschaften, Kirchen, Parteien als etablierte Sammlungsformationen und Integrationsinstrumente für eben diese Bürger, wenn vielleicht auch noch nicht überholt, so aber doch in ihrer Wirkung und Reichweite deutlich abgeschwächt. ${ }^{15}$ Parteien,

12 Exemplarisch für die Diskussion zum Wutbürger vgl. Kersting, Norbert / Wichard Woyke: Vom Musterwähler zum Wutbürger? Politische Beteiligung im Wandel, Münster 2012; Matzig, Gerhard: Einfach nur dagegen. Wie wir unseren Kindern die Zukunft verbauen, München 2011; Bussemer, Thymian: Die erregte Republik. Wutbürger und die Macht der Medien, Stuttgart 2011; Leggewie, Claus: Mut statt Wut: Aufbruch in eine neue Demokratie, Hamburg 2011; Hildebrandt, Cornelia (Hrsg.): Der Herbst der ,Wutbürger“. Soziale Proteste in Zeiten der Krise, Berlin 2010.

13 Vgl. http://www.gfds.de/aktionen/wort-des-jahres/ [zuletzt eingesehen am 29.04.2013].

14 Vgl. dazu das Interview mit der Schriftstellerin Gaje Boralioglu: „Opposition ist der Geist der Zeit“, in: die tageszeitung, 30.06.2013, online einsehbar unter https://www.taz.de/Schriftstellerin-ueber-tuerkische-Proteste/!118966/ [zuletzt eingesehen am 03.07.2013].

15 Vgl dazu exemplarisch Merkel, Wolfgang /Alexander Petring: Politische Partizipation und demokratische Inklusion, in: Mörschel, Tobias / Christian Krell (Hrsg.): Demo- 
Gewerkschaften und die großen Kirchen verlieren nicht nur in Deutschland seit gut zwei Jahrzehnten kontinuierlich an Mitgliedern, die Wahlbeteiligung geht auf allen Wahlebenen zurück und die Zufriedenheit und das Vertrauen in diese Vermittlungsinstanzen im demokratischen Prozess sind ebenso rückläufig. ${ }^{16}$ Auch sie stellen sich die Frage, ob ihre Organisationsformen und ihre inhaltlichen Integrationsstrategien noch zeitgemäß sind, beziehungsweise, ob sie zukünftig noch in der Lage sein werden, mit der gesellschaftlichen Heterogenität so umzugehen, dass sie wesentliche Gruppen der Bevölkerungen erreichen und einbinden können. ${ }^{17}$

Dieses Buch möchte sich diesen Fragen widmen, allerdings nicht aus der Perspektive der Organisationssoziologie oder der Parteienforschung, sondern mit einem Fokus auf diejenigen, deren Vertrauen in die jeweilige Demokratie verloren gegangen ist. Thomas Zittel hat für die Diskussion einer vermeintlichen „Krise der Demokratie“ herausgestrichen, dass es sich dabei keineswegs automatisch um vermeintlich objektive, harte und nicht anzuzweifelnde Fakten und Problemlagen handeln muss, auf die man bei einer Betrachtung stoße. Vielmehr seien Krisen einer gesellschaftlichen oder politischen Ordnung oft genug Ergebnis sich verschiebender Demokratienormen oder Erwartungen. ${ }^{18}$ Was genau im Detail von einer Demokratie erwartet wird, wann man mit ihr zufrieden ist oder enttäuscht, ist aber das Ergebnis kommunikativer Aushandlungsprozesse zwischen Bürgern. Spezifische Demokratienormen sind also letztlich das, was je-

kratie in Deutschland. Zustand - Herausforderungen - Perspektiven, Wiesbaden 2012, S. $93-119$.

16 Die Diskussion um die gesellschaftliche Entwurzelung gerade der Parteien hat breiten Niederschlag in der Politikwissenschaft gefunden, vgl. exemplarisch Wiesendahl, Elmar: Mitgliederparteien am Ende? Eine Kritik der Niedergangsdiskussion, Wiesbaden 2006; Decker, Frank: Parteiendemokratie im Wandel, in: Decker, Frank / Viola Neu (Hrsg.): Handbuch der deutschen Parteien, Wiesbaden 2007, S. 19 - 61; Mielke, Gerd: Auf verlorenem Posten? Parteien in der Bürgergesellschaft, in: Forschungsjournal Neue Soziale Bewegungen, Jg. 20 (2007) H. 4, S. 63 - 71.

17 Vgl. dazu exemplarisch die für ganz Europa ähnlichen Parteireformprojekte in sozialdemokratischen Parteien, die Matthias Micus zusammengefasst hat: Organisational Identity and Reform of Social Democratic Parties in Europe, in: Friedrich-EbertStiftung: International Policy Analysis, Berlin, Dezember 2010, online einsehbar unter http://library.fes.de/pdf-files/id/ipa/07720.pdf [zuletzt eingesehen am 04.07.2013].

18 Vgl. Zittel, Thomas: Wie viel und welche Partizipation braucht die Demokratie?, in: vorgänge. Zeitschrift für Bürgerrechte und Gesellschaftspolitik, Jg. 51 (2012) H. 3, S. $4-14$, hier S. 5. 
weils als „gesellschaftlich hegemonial erkannt wird.“19 Zittel spricht hier von der „Crux der ,demokratischen Persönlichkeit ““ ${ }^{20}$ Eine Krise der Demokratie oder der Verfasstheit einer Gesellschaftsordnung kann sich folglich aus objektiven Problemlagen ebenso speisen wie aus einem Wandel der Erwartungen oder Hoffnungen, die mit ihnen verbunden werden. Eine sozialwissenschaftliche Herangehensweise, die den Hintergründen einer Krise der Demokratie nachgehen möchte, hat sich folglich um die Entwicklung und Veränderung genau dieser Normen, Hoffnungen und Kommunikationsprozesse zu kümmern. Und während die Gesellschaftswissenschaften wie auch die Ökonomie in der Vergangenheit oft genug den Fokus auf die Interpretation des statistischen Rahmens, die Lohnund Arbeitssituation, die aggregierte Zufriedenheit mit Bezug auf Demokratie, die Aussichten der volkswirtschaftlichen Entwicklung gelegt haben, soll an dieser Stelle denjenigen „demokratischen Persönlichkeiten“ nachgespürt werden, die vielleicht den Kern der aktuellen Krisendiagnosen ausmachen: Bürger, welche mit den klassischen politischen Willens- und Meinungsbildungsprozessen nicht mehr einverstanden sind, die ihr Vertrauen in die Funktionsfähigkeit und Legitimation unserer Demokratie zumindest teilweise verloren haben. Es soll an dieser Stelle um die Phänomene und Ausprägungen der Bürgerproteste der letzten Jahre gehen und um die Protagonisten derselben.

Eine Dissertation zu schreiben ist wohl stets in erster Linie eine Frage der Ausdauer und Fokussierung und in zweiter eine des Umfeldes, welches einem dabei behilflich ist, nicht vorschnell von der Fahne zu gehen. In meinem Falle habe ich ein solches Umfeld in der mir bestmöglich vorstellbaren Weise vorgefunden. Das Göttinger Institut für Demokratieforschung, wie auch der Vorgänger, die Arbeitsgruppe für Parteienforschung, habe ich als Mitarbeiter und Student kennen lernen und dort hineinfinden dürfen. Wir sind darüber, wenn ich das so sagen darf, zu einer Art Familie geworden: Menschen aller Verschroben- und Seltsamheiten, die zusammen forschen, fragen und schreiben, die euphorische und drückende Zeiten, Hochphasen und Zeiten der Defensive geteilt haben und noch teilen und die einander über Jahre auch ans Herz gewachsen sind. Um den Kitsch nicht ausarten zu lassen - natürlich gibt es auch hier, wie in jeder anständigen Familie, Onkel und Tanten, Cousins und Cousinen, denen man bei den Familienfesten lieber aus dem Weg geht, wie der überhebliche, neureiche Onkel, der einem ein wenig peinlich ist. Der enge, verschworene Kern aber ist es, der einen in der Arbeit hält und auffängt, mit dem man strittige Fragen der Wissenschaft diskutiert - manchmal löst -, einander in Kolloquien kritisch beäugt und

19 Ebenda, S. 11.

20 Ebenda. 
seziert und mit dem man hinterher bei einem oder mehreren Gläsern Wein Wissen- und Freundschaft ineinander übergehen lassen kann. Es ist ein ungemein produktives Umfeld, stets leicht entflammbar in der Begeisterung für eine offen daliegende, aber noch unbearbeitete Frage. Natürlich hat der Leiter des Instituts, Franz Walter, daran einen zentralen Anteil, auch als Erstbetreuer dieser Arbeit. Sein Vertrauen, die manchmal bohrend-inspirierenden Gespräche und gemeinsamen Arbeiten und das stete Beharren, den entscheidenden Kern einer Sache zu suchen, haben mich und uns zu der Gemeinschaft gemacht, als die wir uns heute fühlen. Doch auch vielen der Mitarbeiter schulde ich ungemein viel. Da ist Matthias Micus zu nennen, engster Freund seit vielen Jahren, Enfant Terrible und Chefredakteur der Zeitschrift INDES, der mir unzählige hochtrabende Ideen immer wieder unnachgiebig aus dem Kopf geklopft hat. Katharina Rahlf, Robert Lorenz, Michael Lühmann, Robert Müller-Stahl und Robert Pausch haben kommentiert und korrigiert. Dies haben auch Oliver D'Antonio, Lars Geiges, Roland Hiemann, Christoph Hoeft, Johanna Klatt, Leona Koch, Sören Messinger und Jonas Rugenstein. Für ihre Geduld und Konzentration bei der Suche nach unpassenden Metaphern, argumentativen Sackgassen und sprachlichen Holzhämmern danke ich ihnen wirklich sehr. Für alle noch im Manuskript steckenden Grobheiten und Fehler zeichne allein ich verantwortlich.

Steffen Kühnel und Samuel Salzborn als weiteren Betreuern meiner Arbeit bin ich ebenso zu Dank verpflichtet. Und die Zusammenarbeit mit Anke Poppen vom transcript-Verlag gestaltete sich so wunderbar reibungslos, wie man sich dies nur wünschen kann.

Doch ohne meine Familie wäre all dies nichts wert. Natürlich sind es zuallererst meine Eltern und mein Bruder, die mich immer im Glauben (und der Unterstützung) gelassen haben, diesen Weg gehen zu können. Dass dies keine Selbstverständlichkeit ist, die man einfach so übergehen sollte, zeigen wohl alle Statistiken zur leider immer noch viel zu starken Abhängigkeit des Bildungserfolgs von der individuellen familiären Herkunft. Und ohne Iris und die Kinder würde es sowieso nicht gehen. Mit ihnen teile ich mein Leben und alles, was ich mir dafür ausmale und erhoffe, ihnen ist daher dieses ganze Buch gewidmet.

Felix Butzlaff, Göttingen im August 2015 



\section{Was folgt aus und was möchte Protest?}

Das Göttinger Institut für Demokratieforschung, an dem der Autor als wissenschaftlicher Mitarbeiter tätig ist, hat in den letzten Jahren regelmäßig Studien und Forschungsprojekte zur Frage der Bürgerproteste in Deutschland sowie zum Wandel des Engagements durchgeführt. ${ }^{1}$ Dabei ging es vom Ausgangspunkt einer angenommenen Partizipations- und Repräsentationskrise des politischen Systems um die Frage, was Menschen dazu treibt, bewusst außerhalb von Parteien ihren Interessen Gehör zu verschaffen und dem traditionellen Weg der politischen Interessenaggregation über integrierende Großorganisationen die Wirksamkeit abzusprechen, den Mitwirkungserwartungen der Bürger entsprechen zu können.

Doch muss sich eine wahrgenommene Krise der Repräsentation nicht zwangsläufig zu einer Krise der Demokratie auswachsen. Man kann die Diagnose eines beobachteten Anstiegs des politischen Engagements der Bürger bzw.

1 Vgl. exemplarisch Marg, Stine / Lars Geiges / Felix Butzlaff / Franz Walter (Hrsg.): Die neue Macht der Bürger? Was motiviert die Protestbewegungen?, Reinbek bei Hamburg, 2013; Klatt, Johanna u.a.: Entbehrliche der Bürgergesellschaft? Sozial Benachteiligte und Engagement, Bielefeld 2011; vgl. Göttinger Institut für Demokratieforschung: Die Proteste gegen den Flughafen Berlin Brandenburg (Ber/BBI), online einsehbar unter http://www.demokratie-goettingen.de/content/uploads/2011/08/Studie_BBI_Zusammenfassung.pdf [zuletzt eingesehen am 26.01.2015]; Göttinger Institut für Demokratieforschung: Neue Dimensionen des Protests? Eine explorative Studie $\mathrm{zu}$ den Protesten gegen Stuttgart 21, online einsehbar unter: http://www.demokratie-goettingen.de/content/uploads/2010/11/Neue-Dimensionendes-Protests.pdf [zuletzt eingesehen am 15.05.2013]. 
dem Wunsch dazu von sehr unterschiedlichen Prämissen aus interpretieren. ${ }^{2}$ Einige sich auf Alexis de Tocqueville berufende Sozialwissenschaftler gehen grundsätzlich von einer positiven Auswirkung des Mitmachens, Partizipierens oder Aktivseins für die demokratische Verfasstheit einer Gesellschaft aus - etwa, wenn es darum geht, dass die Teilnahme an Protest und Widerstand als Zeichen für eine Emanzipation und einer selbstbewussten Inanspruchnahme der bürgerlichen Freiheiten gewertet wird und als demokratische Revitalisierung. Diese Sicht basiert auf der Annahme, dass ein gemeinsames Anstrengen und Organisieren demokratische Tugenden entstehen ließe bzw. es die Erfahrung einer Eigenorganisation in Gemeinschaft sei, die eine Demokratie fördernde Zivilgesellschaft aufbaue. ${ }^{3}$ Eine solche kommunitaristische Deutung zivilgesellschaftlicher Partizipation etwa - zu der man bürgerlichen Protest ja auch zählen dürfte - hat auch die Enquete-Kommission des Deutschen Bundestages vertreten: „Bürgergesellschaft beschreibt ein Gemeinwesen, in dem die Bürgerinnen und Bürger auf der Basis gesicherter Grundrechte und im Rahmen einer politisch verfassten Demokratie durch das Engagement in selbstorganisierten Vereinigungen und durch die Nutzung von Beteiligungsmöglichkeiten die Geschicke des Gemeinwesens wesentlich prägen können. “4 Protest, Aktivwerden, Einspruch und Teilnahme fungieren hier als Übung demokratischer Grundprinzipien und als Zeichen einer Verinnerlichung derselben, die Beteiligung möglichst aller Bürger als Ziel und damit förderungswürdig. Partizipation und Protest können demnach als Belebung des demokratischen Miteinanders und der demokratischen Reife einer Gesellschaft verstanden werden. Diese Anleihen bei Tocquevilles Betrachtungen der noch jungen US-amerikanischen Demokratie haben international breiten

2 Vgl. hierzu exemplarisch und grundlegend Klatt, Johanna: Partizipation: Ein erstrebenswertes Ziel politischer Bildung?, in: Apuz, Jg. 62 (2012) H. 46 - 47, S. 3 - 9, hier S. $7 f$.

3 Vgl. dazu grundlegend Putnam, Robert D.: Bowling alone: the collapse and revival of American community, New York 2000; vgl. auch Mallory, Peter: Political friendship in the era of 'the social': Theorizing personal relations with Alexis de Tocqueville, in: Journal of classical sociology, Jg. 12 (1012) H. 1, S. 22 - 43.

4 Bericht der Enquete-Kommission „Zukunft des Bürgerschaftlichen Engagements“: Bürgerschaftliches Engagement: Auf dem Weg in eine zukunftsfähige Bürgergesellschaft, Deutscher Bundestag, 14. Wahlperiode, BT-Drucksache 14/8900, S. 24, online einsehbar unter http://dip21.bundestag.de/dip21/btd/14/089/1408900.pdf [zuletzt eingesehen am 25.06.2013]. 
Eingang gefunden in die heutige Debatte über den Stellenwert von zivilgesellschaftlicher Teilhabe. ${ }^{5}$

Demgegenüber gibt es aber auch skeptischere Blicke und Betrachtungen der Rolle von Partizipation und Teilhabe. Thomas Zittel fasst beispielsweise in seiner Betrachtung direktdemokratischer Partizipationsformen Kritikpunkte zusammen, die Johanna Klatt auf die Beteiligung in zivilgesellschaftlichen Bereichen übertragen hat. Hierbei ist besonders die soziale Selektion durch eine Ausweitung der direkten Einfluss- und Beteiligungsmöglichkeiten zu nennen. Aus der empirischen Partizipationsforschung ist mittlerweile breit belegt, dass die Bereitschaft zur Partizipation mit dem sozialökonomischen Status eines Menschen in einem positiven Zusammenhang steht, dass es folglich die besser gebildeten und einkommensstarken Teile einer Gesellschaft sind, die sich und ihren Anliegen durch gesteigerte Beteiligungs- und Partizipationsformen verstärkt Gehör und Aufnahme verschaffen. ${ }^{6}$ Darüber hinaus sind verschiedene Formen und Möglichkeiten von Partizipation und Engagement mit ganz unterschiedlichen Hemmschwellen ausgestattet: Während der reine Wahlakt wenig Aufwand erfordert und in der Folge vergleichsweise hohe Beteiligungsquoten erreicht, sind Demonstrationen, Petitionen, Bürgerinitiativen, Eingaben etc. demgegenüber schon mit einem wesentlich größerem Aufwand verbunden und werden von deutlich weniger Menschen regelmäßig ausgeübt. ${ }^{7}$ Es müsse daher in der Betrachtung eine deutliche Trennung geben von lediglich formalen Möglichkeiten zur Teilhabe, zu Partizipation und Protest und den tatsächlichen, realen Möglichkeiten dazu - denn aus dieser Perspektive bedeutet eine offenere, partizipative Demokratie zunächst einmal ein sozial ungleicheres Gemeinwesen, da eben

5 Vgl. exemplarisch Edwards, Bob / Michael W. Foley: Civil Society and Social Capital: A Primer, in: Edwards, Bob / Michael W. Foley / Mario Diani (Hrsg.): Beyond Tocqueville. Civil Society and the Social Capital Debate in Comparative Perspective, Medford 2001, S. $1-14$.

6 Vgl. hierzu und im Folgenden Zittel: Wie viel und welche Partizipation braucht die Demokratie?, hier S. 7 - 11; vgl. zu diesem Punkt auch Pickel, Susanne: Das politische Handeln der Bürgerinnen und Bürger - ein Blick auf die Empirie, in: Weißeno, Georg / Hubertus Buchstein (Hrsg.): Politisch handeln. Modelle, Möglichkeiten, Kompetenzen, Bonn 2012, S. 39 - 57, hier S. 55; van Deth, Jan: Politische Partizipation, in: Kaina, Viktoria / Andrea Römmele (Hrsg.): Politische Soziologie. Ein Studienbuch, Wiesbaden 2009, S. 141-161, hier S. 153; Jörke, Dirk: Bürgerbeteiligung in der Postdemokratie, in: Apuz, Jg. 61 (2011) H. 1 - 2, S. 13 - 18, hier S. 16ff.; Böhnke, Petra: Ungleiche Verteilung politischer und zivilgesellschaftlicher Partizipation, in: Apuz, Jg. 61 (2011) H. 1 - 2, S. 18 - 25.

7 Vgl. van Deth: Politische Partizipation, hier S. 149. 
die gut situierten, ressourcenstarken sozialen Gruppen noch mehr Möglichkeiten für eine Interessenvertretung an die Hand bekommen.

Auch ist das Risiko eines Trade-offs zwischen verschiedenen Legitimationsquellen einer Demokratie bei der Diskussion um eine Intensivierung von Beteiligung und partizipativer Öffnung keineswegs außer Acht zu lassen, wie etwa Danny Michelsen und Franz Walter betonen. ${ }^{8}$ Eine Öffnung für direktere Partizipationsinstrumente - wie dies implizit durch eine Protestkultur geschehen würde, wenn diese sich festigt und als eine Konstante etabliert, welche die existierenden Strukturen ergänzt - würde nach dieser Lesart einerseits für mehr Vetospieler im politischen Prozess sorgen, und damit für eine gesteigerte Komplexität im politischen Prozess. ${ }^{9}$ Auf der anderen Seite würde dadurch die Frage berührt werden, ob nicht eine gesteigerte Input-Legitimität der Demokratie, wenn möglichst viele Menschen an Entscheidungen direkt beteiligt sind, in einer Spannung steht zu einer vom Output einer Demokratie gestifteten Akzeptanz, d.h. der Fähigkeit einer demokratischen Verfasstheit, „die Lebensbedingungen und -chancen der Herrschaftsunterworfenen in positiver Weise beeinflussen zu können. “10 Für die Frage nach der Interpretation und Einordnung zunehmender gesellschaftlicher Proteste folgt hieraus eine gewisse Janusköpfigkeit, als dass sich die Legitimität demokratischer Organisationen durch eine zunehmende Offenheit gegenüber Protesten und Zivilgesellschaft eben auch negativ entwickeln kann.

Nicht zuletzt unterstreicht Robert A. Dahl, dass es damit zusammenhängend ein Spannungsverhältnis gebe zwischen direkten Einflussmöglichkeiten auf der einen und der Effektivität partizipativer Verfahren auf der anderen Seite. ${ }^{11}$ Angelehnt an die Beobachtung der Zunahme von Vetospielern basiert dieses Argument auf der schlichten Tatsache, dass ein Anstieg der „Mitredenden“, auf die Rücksicht genommen werden muss, erst einmal die Möglichkeit individueller Interessenartikulation verringere. In großen, heterogenen Gesellschaften sei demzufolge eine Garantie ausgleichender Interessenberücksichtigung nur in einer re-

8 Vgl. Michelsen, Danny / Franz Walter: Unpolitische Demokratie. Zur Krise der Repräsentation, Berlin 2013, S. 147 - 162.

9 Auf diesen Punkt wurde schon in den „Unregierbarkeits“-Debatten der 1970er Jahre hingewiesen, vgl. exemplarisch Hennis, Wilhelm: Parteienstruktur und Regierbarkeit, in: Hennis, Wilhelm / Peter Graf Kielmansegg / Ulrich Matz (Hrsg.): Regierbarkeit. Studien zu ihrer Problematisierung, Stuttgart 1977, S. 150 - 195.

10 Zittel: Wie viel und welche Partizipation braucht die Demokratie?, hier S. 8.

11 Vgl. dazu Dahl, Robert A.: A Democratic Dilemma: System Effectiveness versus Citizen Participation, in: Political Science Quarterly, Jg. 109 (1994) H. 1, S. 23 - 34, hier S. $28-30$. 
präsentativen Entscheidungsorganisation möglich, da mit steigender Zahl an Beteiligten ein Durchdringen des Einzelnen immer aufwändiger und voraussetzungsreicher werde und eine Garantie einer Gleichbehandlung damit illusionär. Eine weitere negative systemische Folge daraus sei die implizite Stärkung von Status-Quo-Interessen, gegen die es neu organisierte Gruppen immer schwerer hätten, sich durchzusetzen, je kleinteiliger der politische Willensbildungsprozess angelegt sei.

Weiters verbirgt sich hinter dem Schlagwort der bad civil society eine Debatte, die mit historischen Beispielen und demokratietheoretischer Argumentation vor einem allzu positiven und universell demokratieförderlichen Verständnis der Öffnung für eine umfassende Partizipation warnt. ${ }^{12}$ Mit Bezug auf die Entwicklungen in der Weimarer Republik in Deutschland hat Sheri Berman herausgestrichen, dass eine besonders aktive, partizipative Zivilgesellschaft keineswegs automatisch Menschen auch in ein demokratisches Gemeinwesen integriere. ${ }^{13}$ Zwar kann man mit Fug und Recht einwenden, dass die heutigen demokratischen Institutionen Deutschlands eine völlig andere Verankerung in der Bevölkerung erlangt haben - doch kann man auch im Deutschland des Jahres 2013 sicherlich nicht für alle zivilgesellschaftlichen Gruppierungen und Interessenvertretungen annehmen, dass sie per se demokratiestabilisierend wirken. ${ }^{14}$ Die Vermutung, dass bürgergesellschaftliches Engagement zum Einüben demokratischer Praxen führe, kann sich in der Realität durchaus anders darstellen - es besteht jedenfalls kein Zwang oder Automatismus, dass Protestgruppen sich nach innen offen, tolerant oder gar basisdemokratisch organisieren müssen. ${ }^{15}$ Für Johanna Klatt liegt die Crux in einem demokratischen Wert von Partizipation in ihrem Verhältnis zu den demokratischen Institutionen. Ist dieses Verhältnis gestört oder distanziert, so könne sich eine gesteigerte intensive Partizipation rasch desintegrierend und Demokratie-zersetzend auswirken: „Ein positives Verhältnis der Partizipationsgesellschaft $\mathrm{zu}$ den politischen Institutionen ist jedoch ohne

12 Vgl. dazu exemplarisch Klatt: Partizipation: Ein erstrebenswertes Ziel politischer Bildung?, hier S. 7f.; vgl. auch Chambers, Simone / Jeffrey Kopstein: Bad Civil Society, in: Political Theory, Jg. 29 (2001) H. 6, S. $837-865$.

13 Vgl. Berman, Sheri: Civil Society and the Collapse of the Weimar Republic, in: World Politics, Jg. 49 (1997) H. 3, S. 401 - 429.

14 Vgl. Roth, Roland: Die dunklen Seiten der Zivilgesellschaft, in: Forschungsjournal Neue Soziale Bewegungen, Jg. 16 (2003) H. 2, S. 59 - 73; vgl. auch Geiges, Lars / Stine Marg / Franz Walter: Pegida. Die schmutzige Seite der Zivilgesellschaft?, Bielefeld 2015.

15 Vgl. dazu exemplarisch Reiter, Bernd: Civil Society and Democracy: Weimar Reconsidered, in: Journal of Civil Society, Jg. 5 (2009) H. 1, S. 21 - 34. 
Zweifel ein wesentliches Merkmal einer stabilen Demokratie. “ ${ }^{16}$ Wie sich dieses Verhältnis ausgestaltet, steht eben auch hinter der Frage nach dem Zustand und den Anliegen der betrachteten Bürgerproteste sowie den daraus folgenden Wirkmechanismen auf die demokratische Verfasstheit.

\subsection{Wie EnTStehEn DemOKRATIENORMEn?}

In der deutschen Alltagssprache bezeichnet der Begriff „Diskurs“ ein öffentlich diskutiertes Thema einer meist aktuellen Debatte. Das englische discourse wie das französische discours hingegen können mitunter sehr viel weiter gezogene Bedeutungsumfänge besitzen, und umso weiter gesteckt kann ergo auch der Bereich sein, der mit „Diskursanalyse“ nur sehr schwammig umrissen ist. ${ }^{17} \mathrm{Ur}$ sprünglich als sprachwissenschaftliche Analyse von Sprech- und Diskussionsstrukturen in den verschiedensten Kontexten entstanden, ist die Methodik aber rasch - analog zum weiten Bedeutungsgehalt von „Diskurs“ - der Linguistik entwachsen. Die Bandbreite ist dabei so vielfältig wie unübersichtlich: Fast alles kann Diskurs sein, fast alle sprachlichen wie nichtsprachlichen Interaktionen und Austauschprozesse sind mit diskursanalytischen Methoden schon beforscht und beschrieben worden. ${ }^{18}$ Zentral bleibt dabei stets, die Strukturen und Mechanismen der Entstehung von „Bedeutungssystemen“"19 herauszustreichen, wie sie entstehen, sich ausdrücken, sich durchsetzen, wie sie sich wandeln. Wie letztlich „eine gesellschaftliche Realität fassbar, denkbar, lesbar geworden ist. “20

Die Politikwissenschaft selber hat dabei lange Zeit einen weiten Bogen um die systematische Aufnahme diskursanalytischer Elemente gemacht; die in großen Bereichen der Disziplin vorherrschende, einengende Konzentration auf Rational-Choice-Entscheidungen und auf institutionelle Erklärungsfaktoren haben eine Hinwendung zu diskursanalytischen Methoden erschwert und verstellt. ${ }^{21}$

16 Klatt: Partizipation: Ein erstrebenswertes Ziel politischer Bildung?, hier S. 8.

17 Keller, Reiner: Diskursforschung, Wiesbaden 2004, S.13.

18 Vgl. ebenda.

19 Ebenda, S.27.

20 Chartier, Roger: Die unvollendete Vergangenheit, Frankfurt a.M., 1992, S. 11.

21 Vgl. Nullmeier, Frank: Politikwissenschaft auf dem Weg zur Diskursanalyse?, in: Keller, Reiner / Andreas Hirseland / Werner Schneider / Willy Viehöfer (Hrsg.): Handbuch sozialwissenschaftliche Diskursanalyse. Band 1: Theorien und Methoden, Opladen 2001, S. 285 - 311, hier S. 285; vgl. auch Nonhoff, Martin: Politischer Diskurs und Hegemonie. Das Projekt Soziale Marktwirtschaft, Bielefeld 2006, S. 30. 
Dabei hat die Demokratietheorie schon früh auf die Abhängigkeit und Interdependenz demokratischer Akzeptanz und Legitimität von tief verwurzelten Einstellungsmustern und Demokratienormen hingewiesen. James MacPherson wies in den 1970er Jahren darauf hin: „the workability of any political system depends largely on how all other institutions, social and economic, have shaped, or might shape, the people with whom and by whom the political system must operate. ${ }^{\prime 22}$

Auch stehen in diesem Falle hinter Rational-Choice-Annahmen zur Entscheidungsfindung auf der einen und eher interpretativ motivierten Ansätzen der Politikwissenschaften auf der anderen Seite ganz unterschiedliche Vorstellungen von Rolle, Aufgabe und Fähigkeiten von Wissenschaft. Eine auf Rational Choice basierende Herangehensweise hat eine verallgemeinerbare, überprüfbare Hypothesengenerierung zum Ziel - und demzufolge muss auch die Ebene des Verstehens im Detail abstrakt bleiben, da man ansonsten ,zwar ein Modell hervorbringen könne[...], das unter gewissen Umständen nützlich, aber eben schwierig auf andere Umstände anzuwenden ist, da der kausale Mechanismus, der die Regularität produziert, nicht verstanden wird.“ ${ }^{‘ 23}$ Eine allzu detailgenaue Betrachtung von Fällen ist aus dieser Perspektive methodisch kontraproduktiv, weil sie die Verallgemeinerbarkeit der Ergebnisse mitunter einschränkt. Das Ziel einer auf Rational Choice basierenden Entscheidungstheorie ist - unter Annahme zweckrationalen Verhaltens - das Verifizieren oder Falsifizieren von Hypothesen bzw. die Ausprägung von Vorhersagbarkeiten für (politische) Entscheidungssituationen von Individuen. ${ }^{24}$

Demgegenüber möchte eine interpretative Vorstellung von Politikwissenschaft den soziokulturellen Kontext menschlichen Handelns viel stärker mit verstanden wissen: „Die Annahme, dass nicht das Individuum im Vordergrund steht, sondern eine soziale Konstruktion der Realität, durch welche das Individuum erst gedacht werden kann, bringt die Differenz dieser Forschungsprogrammatiken gut auf den Punkt. “25 Dass es verschiedene Realitäten und Wahrnehmungen gibt, dass Bedeutungen erst generiert werden müssen, dass auch der

22 MacPherson, Crawford Brough: The Life and Times of Liberal Democracy, Oxford 1977, S. 4.

23 Dür, Andreas: Rational Choice: Ein kritisches Plädoyer für Theorien der rationalen Entscheidung, in: Österreichische Zeitschrift für Politikwissenschaft, 41. Jg. (2012) H. 1, S. 73 - 83, hier S. 79.

24 Vgl. ebenda, S. 74 und 80.

25 Durnová, Anna: Über die Rationalität hinaus: für eine interpretative und reflexive Wissenschaft. Reaktion auf Andreas Dür, in: Österreichische Zeitschrift für Politikwissenschaft, Jg. 41 (2012) H. 3, S. 315 - 322, hier S. 316. 
Forscher selbst als Person „seine“ ganz eigene Realität zwangsläufig mit in den Frage- und Forschungsprozess mit einbringt, dass nicht die Reproduzierbarkeit eines erstellten Modells als oberstes Ziel gilt - all dies steht der Kontingenzannahme des Individuums bei Rational-Choice-Vorstellungen entgegen, stringent stets für den individuellen Vorteil zu entscheiden. Es soll an dieser Stelle kein Scheingefecht gegen eine Strohpuppe dieser Entscheidungstheorie geführt und Rational-Choice-Annahmen mit einem methodischen Individualismus verrührt werden. Interpretative Ansätze setzen allerdings im Vergleich weder extern entstandene Präferenzen voraus, noch blicken sie ausschließlich und isoliert auf das einzelne Individuum und seine Entscheidungen. „Durch die Analyse von Bedeutungen impliziert die interpretative Politikwissenschaft eine Reziprozität zwischen einem Phänomen und der konkreten Positionierung seitens des Individuums. Aus dieser Reziprozität heraus werden soziokulturelle und historische $\mathrm{Zu}$ sammenhänge als Kontext konzipiert, wo Präferenzen von AkteurInnen zu verorten sind. ${ }^{26}$ Um diese Zusammenhänge zwischen Umweltbedingungen und Entscheidungen von Akteuren, um die Wahrnehmungen der Protestierenden von der Gesellschaft und Demokratie, in der sie leben, um die Fragen nach ihren Entscheidungs- und Wertehintergründen soll es in dieser Arbeit gehen und folglich ist die Anlehnung dieses Vorhabens an eine solche, eben: interpretativ verstandene Politikwissenschaft deutlich zu unterstreichen.

Für eine Untersuchung der oben skizzierten Fragestellungen erscheint das Vorgehen mittels Anleihen bei der Diskursanalyse durchaus vielversprechend. Denn das Einbeziehen von Demokratienormen, Mentalitäten und Erwartungen an Demokratie und Politik in die Betrachtung setzt - gegenüber institutionell fixierten Erklärungsversuchen und der Suche nach vermeintlich „objektiven“ Entscheidungssituationen - voraus, dass ein Problem nicht einfach als ,naturgegeben" angesehen wird und man sich rein um die administrative Bearbeitung kümmern müsse, sondern dass Diskurse, Krisen und Probleme stets in den Wahrnehmungen und Kausalannahmen der Beteiligten wurzeln: Erst in der Bedeutung und Interpretation, in der ,,politisch-diskursiven Konstitution von Wirklichkeit“227, kann das Porträt eines Diskurses Gestalt annehmen. Auf das hier behandelte Thema des Protests gemünzt, bedeutet dies, die Krisenwahrnehmungen der Protestierenden selber, ihre Motivationen und Begründungen zu verfolgen. Die Produktion und der Wandel von Sinn und Erklärungen, die „Analyse großflächiger Sinnstrukturen“2 ${ }^{\text {, }}$, steht dabei im Zentrum einer sozial- und politikwissenschaftlich orientierten Diskursanalyse. Diskurse werden in diesem Zusam-

26 Ebenda, S. 317.

27 Nullmeier: Politikwissenschaft auf dem Weg zur Diskursanalyse?, S. 288.

28 Nonhoff: Politischer Diskurs und Hegemonie, S. 29. 
menhang als „komplexe Praxis fortlaufender Artikulation“29 betrachtet, die Interpretationsprozesse und -kämpfe um die ideelle Vorherrschaft, um Deutungshoheiten ausfechten. Meinungsführerschaft in einem Diskurs bedeutet folglich, $\mathrm{zu}$ einem bestimmten Zeitpunkt und für einen bestimmten Ort zu definieren, was aus der Sicht der Handelnden ,,wann und auf welche Weise Sinn ergibt ${ }^{* 30}$, welche Wahrnehmung und Strukturierung der gesellschaftlichen Realitäten plausibel und richtig erscheinen. Der soziale Sinn fungiert als eine Art Komplexitätsreduktion der Welt.

Der Begriff der Hegemonie hat bei der Analyse von gesellschaftlichen Diskursen eine Schlüsselrolle inne, denn letztlich läuft der Erklärungsdrang diskursanalytischer Vorhaben meist darauf hinaus, zu begründen, warum sich bestimmte Artikulationsmuster oder Konstellationen sozialen Sinns durchsetzen, warum sich ganz spezifische Formen der Weltdeutung in einer spezifischen Situation zu einer politisch-diskursiven Form der Vorherrschaft aufschwingen können. Ein ganzer Forschungszweig der Soziologie hat sich mit der Frage beschäftigt, welchen Erfolgsbedingungen, welchen Restriktionen und welchen Regelmäßigkeiten diese Etablierung von Hegemonie unterliegt. ${ }^{31}$

Martin Nonhoff beschreibt in seiner Arbeit „Politischer Diskurs und Hegemonie“ dieselbe nicht als schlichten Zwang und Dominanz einer gesellschaftlichen Gruppe und Ideologie, sondern es gehe um einen ,widely shared common sense ${ }^{\text {، } 32}$, um etwas, das diskursiv entsteht und von unterschiedlichen Gruppen und Teilen der Gesellschaft als etwas Gemeinsames verstanden wird. Eine solche Konstellation entstünde allerdings nie voraussetzungslos aus dem Nichts, sondern verknüpfe schon vorhandene gedankliche Elemente in einer neuen Kombination, baue auf existierenden Fundamenten auf. Eine gewisse Flexibilität sei folglich eine der wichtigsten Ressourcen. Und eine hegemoniale Position könne dann erreicht werden, wenn in einem diskursiven Ringen um einen gemeinsamen Willen ein „symbolisches Äquivalent zum Allgemeinwohl“33 reklamiert und dieses von möglichst vielen gesellschaftlichen Gruppen und Personen für sich in Anspruch genommen werde. Die Voraussetzungen für erfolgreiche hegemoniale Projekte seien aber nur schwer $\mathrm{zu}$ verallgemeinern: Nonhoff streicht eher unbestimmt die „Anzahl der rekrutierten Subjekte“, „diskursive Kompetenz“ und „Organisiertheit“ heraus als Fundament für die ,hegemonial ef-

29 Ebenda, S. 32.

30 Ebenda.

31 Vgl. ebenda, S. 91f.; vgl. auch grundlegend Laclau, Ernesto / Chantal Mouffe: Hegemonie und radikale Demokratie: Zur Dekonstruktion des Marxismus, Wien 2006.

32 Mouffe, Chantal: The return of the political, London 2005, S. 53.

33 Nonhoff: Politischer Diskurs und Hegemonie, S. 173. 
fektive Besetzung von Subjektpositionen “34. Die hegemoniale Praxis zielt demnach darauf, einen gemeinsamen Willen gerade der Personen und Gruppen herzustellen, die in einem Diskurs wahrnehmbar und von Gewicht sind, der für diesen speziellen Diskurs relevanten politisch-gesellschaftlichen Kräfte.

Peter Wagner hingegen destilliert in seiner diskursanalytischen Untersuchung von der Wechselbeziehung zwischen Sozialwissenschaften und Staaten ${ }^{35}$ drei mögliche Typen von gesellschaftlichen Durchsetzungsbedingungen für einen (in diesem Fall: sozialwissenschaftlichen) Diskurs heraus: Entscheidend seien jeweils begründete Legitimitäten, die einem Akteur Durchsetzungsmacht bzw. Autorität zugestehen. Wagner unterscheidet eine wissenschaftlich begründete Legitimität, die auf intellektuellen Traditionen fußt und die das ,kognitive Moment ${ }^{\text {(36 }}$ darstellt, eine institutionelle Legitimität, die dem Diskurs qua Amt Autorität verleiht, die eine Art „Moment der Bestimmung der sozialen Organisation “37 verkörpert, sowie eine gesellschaftlich-politische Legitimität, die dem agierenden Sozialwissenschaftler über die Politik Bedeutung zukommen lässt. ${ }^{38}$ Für den Bereich der hier betrachteten Proteste kommt es folglich darauf an, ein Gefühl für die Legitimitäts- und Begründungsstrukturen der Protestierenden zu entwickeln. Wodurch rechtfertigen sie ihren Widerspruch und mit welchen Argumentationen versuchen sie, ihm Kraft zu verleihen?

Als Vehikel für die erfolgreiche, d.h. zu hegemonialer Reichweite gelangende Führung von Diskursen gelten verschiedene Formen von Diskurskoalitionen. Diese stellten das Mittel „,par excellence“39 dar, mit dem sich eine ideelle Vorherrschaft bewerkstelligen ließe. Grundlegend hat dabei Michel Foucault von „Diskursgesellschaften“ gesprochen, der dabei seinen Fokus eher auf einer Beschränkung und Verknappung der teilnehmenden Akteure - wie beispielsweise in intellektuellen oder wissenschaftlichen Kreisen - bzw. auf ausschließende, strenge Kodizes der Diskursführung beließ. ${ }^{40}$ Foucault legte mehr Gewicht auf die Rituale der Diskursführung, die in diesem Fall dafür sorgen sollten, dass Diskurse in einem geschlossenen Raum zirkulieren und verweilen, ,so dass die Inhaber bei dieser Verteilung nicht enteignet werden““41. Er mag daher für die

34 Ebenda, S. 176.

35 Wagner, Peter: Sozialwissenschaften und Staat. Frankreich, Italien, Deutschland 1870 - 1980, Frankfurt / New York 1990.

36 Ebenda, S. 23.

37 Ebenda.

38 Vgl. ebenda, S. 23f. und S. 31f.

39 Nonhoff: Politischer Diskurs und Hegemonie, S. 188.

40 Vgl. Foucault, Michel: Die Ordnung des Diskurses, Frankfurt a.M. 2003, S. $27 f$.

41 Ebenda. 
beabsichtigte Untersuchung, in der es ja um den Diskurs innerhalb von Protestgruppen, aber eben auch um den der Protestierenden mit der sie umgebenden Gesellschaft geht, zumindest nicht zentral bemüht werden.

Für Gruppen mit anerkannter Expertise und einem professionellen Profil und ergo mit einer schon vorhandenen (wissenschaftlichen oder fachlichen) Autorität ist der Ansatz der Epistemic Community ${ }^{42}$ beschrieben worden. ${ }^{43}$ Eine solche Koalition binde Menschen mit gemeinsamen Grundüberzeugungen, Werten und einem gemeinsamen politischen Projekt zusammen, nicht nur über ein gemeinsam vorhandenes Kausalwissen, und kann dabei auch mehrere fachliche Disziplinen vereinen. Eine Epistemic Community sei in Zeiten von allgemeiner Unsicherheit oft besonders einflussreich, denn ,in Zeiten [...] unbefragter Evidenzen und klar strukturierter Deutungen bzw. Interessen (d.h. Zeiten der „Sicherheit“, Anm. F.B.) bestehen geringe Wirkungschancen von neuem Wissen und Wissenschaft in der und auf die Öffentlichkeit. “44 Fehlten diese aber, so würde die fachliche Autorität Orientierung verleihen, Erklärungen und Lösungswege aufzeigen können, nach denen Menschen dann geradezu dürsten. Gerade in als krisenhaft wahrgenommenen Zeiten könne folglich über die fachliche Autorität Glaubwürdigkeit und Durchsetzungsfähigkeit erreicht werden, mit der dem Protest Wucht und Wirkung verliehen werden können.

Davon zu unterscheiden sind in der theoretischen Betrachtung die Advocacy Coalitions $^{45}$, bei denen sich private oder staatliche Akteure, die in verschiedenen Bereichen an der Formulierung und Umsetzung politischer Prozesse teilnehmen, zu Einflussgruppen zusammen schließen, um bestimmte politische Ziele umzusetzen. Diese Koalitionen gehen per Definition über die eng gesteckten Grenzen einer Epistemic Community hinaus und können Menschen mit ganz unterschiedlichem professionellen Hintergrund umfassen, die allerdings wenigstens zum Teil im politischen Prozess engagiert sind. ${ }^{46}$ Auch hier sind es nicht materielle Interessen, die den ,Zement“ einer Advocacy Coalition darstellen, sondern Belief Systems, d.h. gemeinsam geteilte Annahmen über Werte, Kausalitäten, Weltdeu-

42 Epistemisch ist eine Anleihe aus der Erkenntnistheorie, d.h. der Frage, wie Wissen zu Stande kommt.

43 Vgl. Haas, Peter M.: Introduction: Epistemic Communities and international policy coordination, in: International Organization Jg. 46 (1992) H. 1, S. 1 - 35.

44 Nullmeier: Politikwissenschaft auf dem Weg zur Diskursanalyse?, S. 296.

45 Vgl. grundlegend: Sabatier, Paul A. / Hank C. Jenkins-Smith (Hrsg.): Policy Change and Learning. An Advocacy Coalition Approach, Boulder 1993.

46 Vgl. Sabatier, Paul A.: Policy Change over a Decade or More, in: Ders. / Hank C. Jenkins-Smith (Hrsg.): Policy Change and Learning. An Advocacy Coalition Approach, Boulder 1993, S. 13 - 39, hier S. 16f. 
tungen, Wirksamkeiten von politischen Instrumenten. ${ }^{47}$ Sabatier und JenkinsSmith unterteilen diese Belief Systems in drei Ebenen: einen Hauptkern, der grundsätzliche Werte und Annahmen über das Funktionieren der Welt beinhaltet und gleichsam das Fundament darstellt; zweitens, einen politischen Kern, der grundsätzliche politische Überzeugungen enthält und den Glauben an oder die Ablehnung bestimmter politischer Verfahren und Ausrichtungen; zuletzt einen sekundäre Aspekte der detaillierteren Umsetzung der politischen Ziele umfassenden Bereich. ${ }^{48}$ Eine Advocacy Coalition werde zusammen gehalten von der Übereinstimmung ihrer Akteure im Bereich des „Policy-Kerns“, wenn die Einschätzungen, die der Verfolgung der zentralen Wertvorstellungen innerhalb des Subsystems Politik dienen, die gleichen sind. Nötig sei zudem ein „nontrivial degree of coordination over time ${ }^{\text {“49 }}$, um die Handlungen der in unterschiedlichen Bereichen Tätigen aufeinander abzustimmen.

Allen Zugängen über die verschiedenen Diskurskoalitionen ist gemein, dass sie die Bindemittel der Gruppen herauszustellen versuchen, den ideellen Zement, der zwangsläufig notwendig sei, um einen Diskurs oder eine Ideologie in eine hegemoniale Position zu bringen. Dieser entsteht nicht aus gemeinsamen materiellen Interessen, sondern über die Übereinstimmung in grundlegenden Wertesystemen und Sinnstrukturen. Die Sicherheit, dass die „Mitstreiter“ über dieselben oder ähnliche Überzeugungen in den Grundzügen der Weltsicht verfügen, verleihe der Bildung von Diskurskoalitionen eine viel stärkere Rechtfertigung, als dies bei anderen Begründungen der Fall sein könnte. Denn weil Diskurskoalitionen - so sie denn erfolgreich sein sollen - auch möglichst unterschiedliche und weite Kreise umfassende Mitglieder und Mit-Handelnde umfassen sollten, sei darüber hinaus auch eine „beständige Reartikulation der FormationFormierung ${ }^{\star{ }^{50}}$ zwangsläufig notwendig, d.h. die stete Rückversicherung und Beweisführung der eigenen Gesellschaftsdeutung. Zwar unterscheiden sich die verschiedenen Konzepte solcher Diskurskoalitionen hinsichtlich der Annahme, wie stark und statisch oder labil solche „Glaubensfundamente“ sind. Dass der Zusammenhalt von Diskurskoalitionen aber insgesamt als wesentlich weniger fest gemauert angenommen werden muss, als das für fest institutionalisierte Gruppen der Fall sein mag, darüber besteht wenig Zweifel. ${ }^{51}$ Bei diesen könne nämlich die Mitgliedschaft kurz- oder mittelfristig die gemeinsame Weltsicht ersetzen.

47 Vgl. Nonhoff: Politischer Diskurs und Hegemonie, S. 197.

48 Vgl. Sabatier: Policy Change over a Decade or More, S. 31.

49 Nonhoff: Politischer Diskurs und Hegemonie, S. 197.

50 Ebenda, S. 188.

51 Vgl. ebenda. 
Der Weg einer Diskurskoalition hin zu einer hegemonialen Position innerhalb der Gesellschaft kann folglich kein linearer sein, weil sich im Rahmen dieser steten Neuartikulation des eigenen Projekts im Verlaufe des Diskurses auch der Diskurs selbst, die eigenen Deutungen und Ansichten ebenso wandeln: „Das theoretische Problem der Erklärung sozialen Wandels [lässt sich] nur über einen Begriff von „Dualität von Struktur“(Anthony Giddens, Hervorhebung im Original, F.B.), der gleichzeitig die Verfestigung von sozialen Phänomenen und deren Transformierbarkeit begrifflich zugänglich macht, erklären. “52 Über die eigenen und fortlaufenden Positionsbestimmungen schaffen die Handelnden den eigenen Diskurs erst und definieren ihn zeitgleich immer wieder neu. Und, andersherum gedacht, entstehen politische Erfolge und politische Krisen nicht als solche und gleichsam objektiv, sondern auch und vor allem, weil ,ihre Vertreter [...] ihnen Bedeutung geben, sie in anderer Beziehung zur sozialen Realität setzen wollen und ihre Mängel in dieser Hinsicht erkennen. Erst aus diesem Akt entsteht eine Erfordernis zur Änderung von kognitiven Strukturen. “53

Auf das hier verfolgte Vorhaben angewandt, geht es also auch darum, die Belief Systems und Diskurskoalitionen des Protests herauszuarbeiten, um gemeinsame Motivationen und den inneren Kitt und Zusammenhalt der betrachteten Gruppen zu verstehen. Es ist hierbei wichtig zu betonen, dass aus den Betrachtungen zur Diskursanalyse für das hier vorliegende Projekt nicht linear folgt, dass lediglich Binnendiskussionen oder interne Begründungsmuster der Protestgruppen zu betrachten sind. Protest als Artikulationsform besitzt neben der angesprochenen Dimension des Gruppenkitts (i.e. „Was hält die Gruppe zusammen, was motiviert sie?") stets auch eine nach Außen gewandte Seite, die Unterstützung für die Durchsetzung bzw. Zustimmung für den geäußerten Unmut erlangen möchte (,Womit wird der Protest begründet, auf welche historischen Präzedenzfälle wird rekurriert, wer wird eigentlich angesprochen und warum?"). Insofern meint Diskursanalyse an dieser Stelle Hintergrund, Sinnstrukturen, eben: Belief Systems der Protestierenden, und wie diese in den konkreten Protesten durchscheinen sowie was diese für derzeitige und möglicherweise zukünftige Demokratienormen innerhalb unserer Gesellschaft implizieren.

52 Wagner: Sozialwissenschaften und Staat, S. 32.

53 Ebenda, S. 35. 


\subsection{Die Grossstadt als Kristallisationspunkt}

Großstädte als Ort, an dem sich gesellschaftliche Entwicklungen wie unter einem Brennglas betrachten und analysieren lassen, haben bereits früh in der Gesellschaftsanalyse Interpreten und Betrachter gefunden. Denn sie sind oft der physische Punkt, an dem gleichzeitig ablaufende Prozesse und Metamorphosen aufeinander stoßen, sich Widersprüchlichkeiten und Paradoxien innerhalb einer Gesellschaft in einer ansonsten verschleierten Deutlichkeit abzeichnen. Zeitgleich sind Großstädte als zentrale Metropolen ihrer Regionen oder Länder auch die Symbole ihrer Herrschaftsformen, ihrer Demokratien und manifest gewordenen Utopien, nach denen man die Gesellschaften ausformen, realisieren möchte: „Die Stadt als Stein gewordene Mutter ist ein utopisches Versprechen, das die Realität der Gegenwart nicht einlösen kann“, mit der „Architektur als Verräumlichung, als Bildhaftwerden des kollektiven Bewusstseins einer Gesellschaft"“. ${ }^{54}$ Franz Hessel, zu dessen „Spazieren in Berlin“ Bernd Witte das eben zitierte in einer Nachbetrachtung unterstreicht, sprach von der „Straße wie ein Buch“, an dem sich Entwicklung und Mentalitätslage herauslesen ließen. ${ }^{55}$ Und einhundert Jahre früher bereits ließ Carl Ludwig Börne in seinen „Briefen aus Paris“ aus dem Alltag des revolutionären Frankreich 1830 das Porträt einer sich wandelnden, von paradoxen Gleichzeitigkeiten und einer ungeheuren Aufbruchsstimmung geprägten Gesellschaft im Schmelztiegel einer Großstadt entstehen. ${ }^{56}$

Es sind besonders die Zeiten, wenn gesellschaftliche Modernisierungsschübe mit Traditionsbeständen und -mentalitäten ringen, in denen Städte als Treffpunkt zwischen Alt und Neu Gleichzeitigkeiten ermöglichen, an denen einerseits das Unterschiedliche trennscharf hervortritt und andererseits auch eine neue Melange oder Synthese ermöglicht wird. Als Sammelpunkt eben nicht nur der bereits etablierten Gruppen, Ansichten oder Klassen eines Landes, sondern ebenso als Auffangbecken der Marginalisierten, Halbweltgestalten und Ausgestoßenen bieten Städte einen Nährboden, aus dem - gesellschaftlich gesprochen - Neues entstehen und hier Leben eingehaucht bekommen kann. Vor diesem Hintergrund sind Städte als Anschauungsgegenstand und Theaterbühne gesellschaftlicher Entwicklungen nicht nur interessant, sondern auch Erfahrungsraum für die Frage, wie man derartige Veränderungen eigentlich zu erfassen versucht.

54 Witte, Bernd: Traumstadt Berlin. Nachwort zu und in Franz Hessel: Spazieren in Berlin, Berlin 2011, S. 223 - 232, hier S. 230.

55 Ebenda, S. 226.

56 Vgl. Marcuse, Ludwig: Ludwig Börne. Aus der Frühzeit der deutschen Demokratie, Zürich 1977. 
Die gesellschaftlichen Umbrüche und Umwälzungsprozesse etwa, welche die diversen Einwanderungswellen in die Vereinigten Staaten zur Folge gehabt haben, haben indirekt die sozialwissenschaftlichen Methoden mitentscheidend vorbestimmt, nach denen - im Übrigen auch am Göttinger Institut für Demokratieforschung, dessen Mitarbeiter der Verfasser ist - Fragen nach den Folgen gesellschaftlicher Modernisierungsschüben nachgegangen wird. Und es bedarf sicherlich keiner überschäumenden Phantasie, um in grundlegenden Konfliktmustern in und um Städte auch Parallelen zu heutigen Krisenerscheinungen zu entdecken. Die USA etwa befanden sich seit den 1890er Jahren in einer langwierigen ökonomischen Schwächeperiode, die durch zeitgleich stattfindende Wandlungen in der Industriestruktur, einem drastischen Wachstum der Städte und die Wellen der sogenannten New Immigration verschärft wurde. In Chicago als Wirtschaftsmetropole, zentralem Verkehrs- und Eisenbahnknotenpunkt sowie Anlaufpunkt für Einwanderer kamen wie unter einem Brennglas diese Entwicklungen zusammen. Die Stadt hatte sich in ihrer Bevölkerungszahl innerhalb von 50 Jahren verzehnfacht und die traditionellen Gesellschaftsstrukturen, Stadtviertel und Umgangsformen sich aufgelöst oder neu gebildet. ${ }^{57}$

Eine soziologisch motivierte Betrachtung gesellschaftlicher Wandlungsprozesse hatte es auch in den Vereinigten Staaten zuvor bereits gegeben. Doch ähnlich der jungen kontinentaleuropäischen Soziologie waren diese Ansätze mit der Interpretation der schieren Wucht und Geschwindigkeit der Entwicklungen womöglich überfordert. Ferdinand Tönnies, Max Weber oder Émile Durkheim etwa konstatierten mit der eintreffenden Moderne eine brutale, sinnentleerte und gefühlskalte Welt, in der Schutz- und Rückzugsräume der überlieferten Traditionen nicht mehr existierten. Die zunehmende Rationalisierung des Lebens und die Ablösung alter Ordnungen und Hierarchien durch staatliche Gesetze interpretierten sie zwar als Befreiung des Individuums aus dem Zwang und der Einhegung durch Sitte und Religion seiner sozialen Gruppe - sie schufen aber nach dieser Lesart gleichzeitig eine Distanz im emotionalen Bereich, da der Einzelne dem Wellengang des modernen Lebens schutzloser ausgeliefert sei. ${ }^{58}$

Die Wissenschaft der Soziologie in den Vereinigten Staaten war darüber hinaus stark durch eine karitativ ausgerichtete Stiftungslandschaft bestimmt, deren

57 Vgl. Gasser, Karin: Stadt und Delinquenz. Theoretische und empirische Beiträge der frühen Chicago School of Sociology, in: Soz:Mag. Das Soziologie Magazin, H. 2/2002, S. 37 - 40, hier S. 37.

58 Dazu Schubert, Hans-Joachim: The Chicago School of Sociology. Theorie, Empirie und Methode, in: Klingemann, Carsten (Hrsg.): Jahrbuch für Soziologiegeschichte. Soziologisches Erbe: Georg Simmel, Max Weber, Soziologie und Religion, Chicagoer Schule der Soziologie, Wiesbaden 2007, S. 119 - 161, hier S. 121 f. 
Erkenntnisinteresse an den vermeintlichen Pathologien der Moderne ausgerichtet war. Die Aufgabe des Soziologen war es dabei, mit der Perspektive möglicher „Besserungsansätze“ instrumentell an gesellschaftliche Problembereiche heranzutreten und die vom Verfall und moralischer Verkommenheit bedrohten Gemeinschaften - seien es die sozial Schwachen, bestimmte Einwanderergruppen, Kranke, Alkoholiker, Prostituierte etc. - zu untersuchen, um mögliche Hebelpunkte für Sozialprogramme herauszustreichen. Die Moderne war dabei ein statisches Problem, dessen Symptome man bekämpfen wollte. Ein näherer Kontakt zwischen Forscher und Untersuchungsgruppe kam kaum zustande, die Studien wurden fast ausschließlich auf Basis von Sozialstatistiken und Sekundärliteratur erarbeitet. Insofern war die Interpretation klar: Die Moderne war etwas Zerstörerisches, das alte Stabilitäten wanken ließ und durch neue Dynamiken Mensch, Ökonomie, Staat und Gesellschaft durcheinander wirbelte. Etwas, das die Schattenseiten des Daseins hervortreten ließ.

Die Chicagoer Schule der Soziologie, welche in den ersten Jahren des vergangenen Jahrhunderts entstand, hat sich gegen diese beiden Positionen abgegrenzt und als eine Art Gegenbewegung definiert. Dabei war eine zunächst einmal emphatische Neugierde des Beobachters zentral, der sich mit Haut und Haaren in den Untersuchungsgegenstand Stadt hineinbegab, um in tatsächlicher Begegnung mit den Alltagsnormen, Formen, Tönen, Gerüchen und Sprachen der jeweiligen Viertelbewohner ein Gefühl für die konkrete Lebenswelt zu entwickeln. Nicht die Vorannahme einer pathologischen Entwicklung oder einer unumstößlichen Entwurzelung sollte hier der Ausgangspunkt der Forschung sein, sondern das offene Fragen und Schauen, um - da man als Beobachter in einer städtischen Subkultur oder einem Viertel ja kulturell „fremd“ war - subkutane Zeichen und Nuancen mit aufsaugen zu können. Es ist allein aus fachlicher Binnenperspektive heute interessant, jene Diskussionen um die Frage zu verfolgen, welche Auswirkungen Modernisierungen auf ein Gemeinwesen haben können, besonders unter den Vorzeichen wirtschaftlicher Krisenlagen. Die Tatsache, dass sich die aus dem Chicago der ersten Jahrzehnte des 20. Jahrhunderts entwickelten soziologischen Fragen zum Standardrepertoire der Sozialforschung entwickelt haben und ihre Führungsfiguren Robert Ezra Park und William Isaac Thomas mittlerweile als „Väter der Methoden“ und „Ahnherren der qualitativen Sozialforschung “59 geführt werden, macht den Ort als Gegenstand einer sozialwissenschaftlichen Betrachtung interessant. ${ }^{60}$

59 Christmann, Gabriela: Robert E. Park, Konstanz 2007, S. 95.

60 Die Methodenwahl der Chicagoer Schule wird in einem eigenen Unterkapitel 3.1 noch einmal aufgegriffen und expliziert. 
Auch die Weimarer Republik als Kreuzungspunkt gesellschaftlicher Umbrüche hat Bernd Witte zufolge eine ganze Reihe von glänzenden Betrachtern und eine eigene ,geschichtsphilosophische Topographie“ hervorgebracht. ${ }^{61}$ Eine Gesellschaft als Mosaik etwa, vom dem Siegfried Kracauer sprach $^{62}$, mache es notwendig, sich an und vor allem durch die Orte zu begeben, aus denen dieses kleinteilige Gesellschaftsbild zusammengesetzt sei. Walter Benjamin, selbst ein kluger und genauer Beobachter, beschreibt Franz Hessels Herangehensweise an den Kosmos Stadt als „Photomontage“63. Stadtbeobachtung war ihnen Gesellschaftsanalyse und eine Möglichkeit, Phänomene der Moderne fassen zu können. Richard Sennett etwa hat eine ganze Buchtrilogie der Großstadt und ihren Entwicklungen gewidmet und die Stadt stets als Spiegel des jeweiligen Zeitalters begriffen und beleuchtet. ${ }^{64}$

Bei den hier im Zentrum stehenden Bürgerprotesten der vergangenen Jahre sind Städte ebenso oft als Bühnenbretter, aber auch als Streitpunkt und Konfliktgegenstand wichtiger Teil einer Verschiebung von Wahrnehmungen. So sind politisch motivierte „Leuchtturmprojekte“ wie die Großbauten des Stuttgarter Bahnhofs, des Berliner Flughafens oder der Flughafenerweiterungen in München und Frankfurt zu Symbolen genau dieser Bürgerproteste geworden. In den vergangenen Jahrzehnten ist ein regelrechter Wettbewerb um „Leuchtturmprojekte“ entstanden. Von Brücken über Opern und Fußballstadien, Wohnvierteln, Schauspielhäusern und Autobahnkreuzen hin zu Bahnhöfen, Flugzeuglandepisten und Hafenanlagen. Die Liste der „Leuchtturmprojekte“ ist lang - weltweit, auch in Deutschland. Die Logik ist stets die gleiche: Investitionen in ein Leuchtturmprojekt versprechen Aufmerksamkeit, sollen Wachstum entstehen lassen, die Region interessanter und wohlhabender zugleich machen, was wiederum ein Grundstein für weitere neue Investitionen darstelle.

Doch überall dort, wo „Leuchtturmpolitik“ betrieben worden ist, kam es in den vergangenen Jahren auch zu Protesten. ${ }^{65}$ Nicht erst seit der wirtschaftlichen

61 Witte: Traumstadt Berlin, hier S. 230.

62 Zitiert nach Matthias Keidel: Die Wiederkehr der Flaneure: literarische Flanerie und flanierendes Denken zwischen Wahrnehmung und Reflexion, Würzburg 2006, S. 35.

63 Keidel: Die Wiederkehr der Flaneure, S. 32.

64 Sennett, Richard: Verfall und Ende des öffentlichen Lebens: Die Tyrannei der Intimität, Frankfurt a.M. 1983; Ders.: Palais Royal, New York 1986; Ders.: Civitas. Die Großtadt und die Kultur des Unterschieds, Frankfurt a.M. 2011.

65 Vgl. exemplarisch Birke, Peter: Herrscht hier Banko? Die aktuellen Proteste gegen das Unternehmen Hamburg, in: Birke, Peter / Max Henninger (Hrsg.), Krisen Proteste. Beiträge aus Sozial. Geschichte Online, Berlin 2012, S. 183-220; siehe auch den gesamten Band hierzu; vgl. auch Mayer, Margit: Städtische soziale Bewegungen, in: 
Krise ab 2008 sind exponierte und große Leuchtturmprojekte verstärkt in die Kritik geraten, da sie die Logik, Städte als Unternehmen zu begreifen, die mittels Standortbedingungen um „Kunden“ eifern, symbolisch verkörpern: „Schließlich sorgen die neoliberalen Strategien unternehmerischer Stadtentwicklung, die den städtischen Raum ausschließlich als Arena wirtschaftlichen Wachstums begreifen [...] für Zündstoff. ${ }^{\text {“66 }}$ Darüber hinaus führen die großen Summen, die für solche Projekte ausgegeben werden, in einer Krise der öffentlichen Haushalte zu einer Belastung bzw. erwartbaren Verschlechterung anderer Ausgabenbereiche wie etwa der sozialen Versorgung. Insofern spiegelt der hier beschriebene Protestfokus „Stadt“ eine Begründung wider, bei dem sich die Protestierenden immer dem eigenen Staat bzw. seinen planerischen Ideen gegenübersehen - auch, wenn bei der konkreten Umsetzung von Großbauprojekten die öffentliche Hand oft nur mittelbar via Finanzierung, Beteiligungen oder Kreditgarantien beteiligt ist.

Die im Folgenden betrachteten Proteste zeigen deutlich, dass das Konfliktfeld Stadtentwicklung und Infrastruktur oft genug ein Signum von Wachstumsund eben: Modernisierungsregionen ist. In wachsenden Städten, in empordrängenden Regionen bestehen zunächst einmal mehr als anderswo die gefühlte Notwendigkeit und die finanziellen Möglichkeiten, große, der Hoffnung nach identitäts- und bildstiftende, prestigeträchtige Projekte auf den Weg zu bringen.

Darüber hinaus sind Modernisierungsprozesse in Städten aber auch folgenreich für viele Bewohner, da Städte eben nicht nur Symbol und Bühne, sondern als Lebensraum auch selbst und damit die in ihnen lebenden Bürger den Veränderungen unterworfen sind. Unter dem Stichwort der „Gentrifizierung“ hat sich eine ganze Reihe von Soziologen der Problematik zugewandt, welche die ökonomische Aufwertung von Stadtvierteln für die alteingesessenen Bewohner mit sich bringt. ${ }^{67}$ Und etliche Dachverbände protestierender Gruppen widmen sich in den deutschen Großstädten dem Themenfeld Stadtentwicklung, dem urbanen Lebensraum und seinen Bedingungen. ${ }^{68}$

Klein, Ansgar / Hans-Josef Legrand / Thomas Leif (Hrsg.): Neue soziale Bewegungen. Impulse, Bilanzen und Perspektiven, Opladen 1999, S. 257 - 271, hier S. 259 f.

66 Mayer, Margit: Soziale Bewegungen in der neoliberalen Stadt, in: Luxemburg, Jg. 2 (2010) H. 4, S. 6 - 15, hier S. 6.

67 Vgl. dazu exemplarisch Holm, Andrej: Das Recht auf die Stadt, in: Blätter für deutsche und internationale Politik, Jg. 56 (2011) H. 8, S. 89 - 97; vergleiche auch grundlegend Ders. / Klaus Lederer / Matthias Naumann (Hrsg): Linke Metropolenkritik. Erfahrungen und Perspektiven am Beispiel Berlin, Münster 2011.

68 Vgl. Mayer: Soziale Bewegungen in der neoliberalen Stadt, hier S. 11 - 15. 
Großstädte sind jedenfalls ,wieder zu Orten sozialer Bewegungen geworden“, resümmieren Laura Naegler, Rainer Neef und Ute Neumann, wobei das „Städtische“ eben nicht allein als „Austragungsort“, sondern ,,in seiner gesellschaftlichen Kontextualisierung als zentraler Anknüpfungspunkt gegenwärtiger Proteste gesehen wird“". 69

Die Frage, was das Urbane und Städtische für soziale Proteste eigentlich bedeutet, was der Bezugspunkt „Stadt“ an Protestgruppen ausmacht und wie er die Aktiven prägt, kurz: was Stadt und Protest als miteinander verschränkte Phänomene uns für eine Demokratie-Bestandsaufnahme mitteilen können, ist dabei eminent wichtig. Gleichzeitig ist genau dies bislang eine Leerstelle der Stadtsoziologie geblieben. ${ }^{70}$

In den Binnenbetrachtungen der Stadtsoziologie wird dabei - dem Beispiel der Flaneure aus der Literatur und auch dem Vorbild der Chicago School of Sociology folgend - unterstrichen, dass der Schmelztiegel-Charakter von Großstädten es erfordere, methodisch besonders offen, neugierig und wachsam durch das Untersuchungsgebiet zu streifen; ein „transdiziplinäres Umfeld““71 zu integrieren, und sich gleichzeitig kommunikativ mit seinen Untersuchungsergebnissen wieder an die Stadt und die Öffentlichkeit zu wenden. Stadtsoziologie sei dort überzeugend, ,wo sie sich am wenigsten selbstreferentiell generiert und hinsichtlich der eigenen Rolle sich eingliedert in den Chor derjenigen, die sich wissenschaftlich, künstlerisch-gestalterisch, politisch und gesellschaftlich im weitesten Sinne mit den Problemen (in) der Stadt auseinandersetzen“. ${ }^{72}$ Es ist für den Fokus der vorliegenden Arbeit dabei zu unterstreichen, dass „Urbanität“ und „Großstadt“ nicht als ausschließlicher Untersuchungsort zu verstehen sind. Großstädte und Metropolen formen und strukturieren eine Gesellschaft, das schon, daneben aber wirken und strahlen sie in ihre Umgebungsregionen hinein. Und oft genug finden gerade im Grenzbereich zwischen Metropole und Umland Reibungen und Konflikte um den gesellschaftlichen Wandel statt, wie etwa die Beispiels der Konflikte um den Bau und die Erweiterung von Flughäfen zeigen, wie dies in Berlin, München, Frankfurt und etlichen anderen Orten über die letz-

69 Naegler, Laura / Rainer Neef / Ute Neumann: Urbanität und Protest. Neue Herausforderungen der Stadt- und Bewegungsforschung, in: Forschungsjournal Soziale Bewegungen, Jg. 25 (2012) H. 3, S. 121 - 126, hier S. $121 f$.

70 Vgl. ebenda; vgl. auch Eckardt, Frank: Viele Wege nach Rom, oder: Was leistet die Stadtsoziologie heute?, in: Soziologische Revue, Jg. 36 (2013) H. 2, S. 132 - 142.

71 Eckardt: Viele Wege nach Rom, hier S. 132.

72 Vgl. ebenda, S. 142. 
ten Jahre zu sehen war. ${ }^{73}$ An dieser Stelle steht an die Quellen folglich die Frage nach der Bedeutung der „Utopie des Urbanen“" ${ }^{\text {77 }}$ und der Vorstellung eines guten Lebens derjenigen, die sich in den betrachteten Protestgruppen engagieren.

\subsection{Protest und Alter: Der biographische Ort VON WIDERSPRUCH}

Protest und Widerspruch, Engagement und Aktivsein sind Anstrengungen, die nicht jeder Mensch zu jedem Zeitpunkt seines Lebens zu leisten vermag, sondern unterliegen durchaus Wandlungen im Rahmen eines Lebens. Bisherige Studien zu zivilgesellschaftlichem Engagement zeigen jedenfalls deutlich, dass es Altersund Beschäftigungsphasen im Laufe eines Lebens gibt, welche ein freiwilliges Mittun in zivilgesellschaftlichen Zusammenhängen - und dazu zählt ein bürgerschaftlicher Protest zweifelsohne - wahrscheinlicher machen oder anderenfalls enorm erschweren. ${ }^{75}$ Paul Dekker und Erik van Ingen etwa haben für die Niederlande herausgearbeitet, dass sich - über die Gesamtgesellschaft verteilt - das freiwillige Engagement immer mehr verschoben hat zu denjenigen, die besonders viel Zeit und Energie zur Verfügung haben, etwa Pensionäre und Hausfrauen oder -männer. ${ }^{76}$ Und auch für die deutsche Gesellschaft verzeichnet das Freiwilligensurvey 2009 einen „deutlichen Anstieg des Engagements bei den älteren Menschen““ ${ }^{77}$ Gerade bei denjenigen ,jungen Alten“, die zwar aus dem Be-

73 Vgl. dazu Göttinger Institut für Demokratieforschung: Die Proteste gegen den Flughafen Berlin Brandenburg; vgl. auch Butzlaff, Felix / Christoph Hoeft / Julia Kopp: „Wir lassen nicht mehr alles mit uns machen!“ Bürgerproteste an und um den öffentlichen Raum, Infrastruktur und Stadtentwicklung, in: Marg, Stine / Lars Geiges / Felix Butzlaff / Franz Walter (Hrsg.): Die neue Macht der Bürger. Was motiviert die neuen Protestbewegungen?, Reinbek bei Hamburg, 2013, S. 48 - 93.

74 Naegler u.a.: Urbanität und Protest, hier S. 122.

75 Vgl. Oesterle, Sabrina / Monica Kirkpatrick Johnson / Jeylan T. Mortimer: Volunteerism during the Transition to Adulthood. A Life Course Perspective, in: Social Forces. An International Journal of Social Research, Jg. 82 (2004) H. 3, S. 1123 - 1149.

76 Vgl. van Ingen, Erik / Paul Dekker: Changes in the Determinants of Volunteering: Participation and Time Investment Between 1975 and 2005 in the Netherlands, in: Nonprofit and Voluntary Sector Quarterly, Jg. 40 (2011) H. 4, S. 682 - 702.

77 Hauptbericht des Freiwilligensurveys 2009. Zivilgesellschaft, soziales Kapital und freiwilliges Engagement in Deutschland 1999 - 2004 - 2009, Hrsg. vom Bundesministerium für Familie, Senioren, Frauen und Jugend, München 2010, hier S. $155 f$. 
rufsleben ausgeschieden sind, sich aber noch bei durchaus guter Gesundheit und Kräften befinden, sei über die letzten anderthalb Jahrzehnte eine deutliche Steigerung des freiwilligen Engagements zu verzeichnen gewesen.

Auch Bettina Munimus zeigt in ihrer Studie zu den ,,alten“ Parteimitgliedern in SPD und CDU auf, welcher Wandel in Eigen- und Fremdbild und Zuschreibung sich in Bezug auf die älteren Generationen in Deutschland vollzogen hat. ${ }^{78}$ Sie unterstreicht dabei, dass ,die gegenwärtige Generation im Ruhestand [...] zur reichsten [gehört], die es bis her in Deutschland gab“"79, und dass es vor allem die Lebensphase direkt nach dem Ausscheiden aus dem Arbeitsleben sei, die das prägende Bild der vitalen, aktiven Alten in unserer Gesellschaft ausmachte. An dieser Stelle bemühen Franz-Xaver Kaufman und Jürgen Kocka Begriffe wie das „unmerkliche Altern“ ${ }^{40}$ und die „gewonnenen Jahre“"81, um die Bedeutung der demographischen Entwicklung und das wahrgenommene Potenzial einer gesundheitlich robusten, wohlhabenden, beruflich hoch erfahrenen Generation von Alten herauszustreichen, die auch volkswirtschaftlich mittlerweile eine gewichtige Rolle eingenommen hat. Und Silke van Dyk und Stephan Lessenich widmen der „Sozialfigur“ der ,jungen Alten“ einen ganzen Sammelband. ${ }^{82}$ Munimus lehnt sich hierbei an Leopold Rosenmayr an, der zwischen einem dritten, vierten und fünften Alter unterscheidet. ${ }^{83}$ Während im fünften und letzten Lebensalterabschnitt die Kräfte und die Kompetenzen schwinden, bleiben diese Reserven im vierten - zwar schon eingeschränkt - noch halbwegs intakt und sind im dritten Alter noch zur Genüge vorhanden, bieten dann dem ,jungen Alten“ noch die Möglichkeit, für sich und andere ein Engagement einzugehen.

Wolfgang Clemens weist darauf hin, dass die Themenkonjunktur zur Alterung der Gesellschaft und dem Bildwandel des Alterns nicht etwas gänzlich Neues sei, sondern seit den 1980er Jahren und der Zunahme frühzeitiger Verrentung zum Zwecke der Entlastung der Sozialsysteme von der Soziologie bzw. ei-

78 Vgl. Munimus, Bettina: Alternde Volksparteien: Neue Macht der Älteren in CDU und SPD? Studien des Göttinger Instituts für Demokratieforschung, Bd. 5, Bielefeld 2012.

79 Ebenda, S. 45.

80 Kaufmann, Franz-Xaver: Schrumpfende Gesellschaft. Vom Bevölkerungsrückgang und seinen Folgen, Frankfurt a.M. 2005, S. 239.

81 Kocka, Jürgen: Alternde Gesellschaften oder Die gewonnenen Jahre, in: Neue Gesellschaft/Frankfurter Hefte, Jg. 55 (2008) H. 9, S. 4 - 9.

82 Vgl. van Dyk, Silke / Stephan Lessenich (Hrsg.): Die jungen Alten. Analysen einer neuen Sozialfigur, Frankfurt a.M. 2009.

83 Vgl. dazu Rosenmayr, Leopold: Altern im Lebenslauf: soziale Position, Konflikt und Liebe in den späten Jahren, Göttingen 1996, S. 75. 
ner interdisziplinären Gerontologie ins Auge gefasst worden sei. ${ }^{84} \mathrm{Neu}$ an der Beschäftigung mit den Potenzialen sei, dass - so Clemens - „diese Sozialfigur erst im Rahmen der (sozial)politischen Nutzung(sversuche) neoliberaler Provenienz als ,produktive Alte““" ${ }^{85}$ besonders starkes Interesse und Widerhall in der Öffentlichkeit gefunden habe. Ein „Kompetenzmodell“, das Potenziale, Qualifikationen und Erfahrungen der Alten in den Blick nimmt, steht dabei einem „Defizitmodell“" gegenüber, bei dem die eher negativen Seiten des Alters betont werden: eine mögliche Vereinsamung, der körperliche Verfall, drohende Altersarmut oder auch die Schwierigkeit, mit der Einschränkung geistiger Vitalität mit dem technologischen Wandel Schritt halten zu können. ${ }^{86}$ Dahinter steht die Frage nach den Bedürfnissen des Alters, nach der Psychologie älterer Menschen und dem Charakter dieses Lebensabschnitts: Ist die Phase nach dem Ende eines Erwerbslebens geprägt vom Wunsch, nun frei von ökonomischen Zwängen verschnaufen, durchatmen, sich zurückziehen zu können? Oder sind es vielmehr die durch steigendes Lebensalter und die bessere gesundheitliche Versorgung zur Verfügung stehenden Kräfte, die die ,jungen Alten“ zu neuen Großtaten und rastlosem Ausprobieren treiben würden?

Unabhängig von den daraus folgenden Implikationen für die Sozialsysteme, wenn die noch rüstigen, aber doch nicht mehr im Erwerbsleben gebundenen Alten sich freiwillig zivilgesellschaftlich engagieren, gibt es eine verstärkte Aufmerksamkeit für das Thema. Die Makrostudien für Deutschland der letzten Jahre unterstreichen - wie bereits betont - allesamt, dass die Bereitschaft, sich bürgerschaftlich zu engagieren, gerade bei älteren Generationen überproportional angestiegen sei. ${ }^{87}$ Die Frage allerdings, ob es lediglich eine Art Kräfte- und Ressourcenüberschuss ist, der Ältere, nun beschäftigungsärmere Menschen zu einem Engagement motiviert, ist eine andere, die allerdings auch in den Sozialwissen-

84 Vgl. Clemens, Wolfgang: Zwischen „Jungem Alter“ und dem Ende des Lebens Neuere alter(n)ssoziologische und gerontologische Beiträge, in: Soziologische Revue, Jg. 35 (2012) H. 4, S. 437 - 445, hier S. 438.

85 Ebenda; auch der Bericht des Bundesministeriums unterstreicht dieses und spricht von einer „Potenzial- oder Ressourcenperspektive“: BMSFSJ (Hrsg.): Fünfte Bericht zur Lage der älteren Generation in der Bundesrepublik Deutschland. Potenziale des Alters in Wirtschaft und Gesellschaft. Der Beitrag älterer Menschen zum Zusammenhalt der Generationen. Bericht der Sachverständigenkommission, Berlin 2005, S. 338.

86 Vgl. Munimus: Alternde Volksparteien, S. 53f.

87 Vgl. ebenda, S. 55; vgl. auch die bereits zitierten Freiwilligensurveys der Jahre 1999 2004 - 2009 sowie der vom Bundesministerium für Familie, Senioren, Frauen und Jugend herausgegebene Fünfte Bericht zur Lage der älteren Generation in der Bundesrepublik Deutschland. 
schaften theoretisch und empirisch durchdrungen worden ist. Zeit und Energie an sich stellen noch keine hinreichende Bedingung dar, um in Widerspruch, Protest oder in anderweitigem zivilgesellschaftlichen Engagement aktiv zu werden. Zwar ist ein angenommener „Pensionierungseffekt“ intuitiv nachvollziehbar, wenn bislang auf die Erwerbstätigkeit verwandte Zeit und Mühe anschließend eine neue Beschäftigung finden müssen, und sich hunderttausende von Rentnern einen neuen Sinn und Lebensaufgabe suchen. Die Rolle des Endes der Erwerbsarbeits-Periode werde dabei aber überschätzt, stellt Bettina Munimus fest. ${ }^{88}$ Es sei vielmehr die Bedeutung von Prädispositionen für ein Aktivwerden, unterstreicht Marcel Erlinghagen in diesem Zusammenhang: Ein Engagement sei dann in späteren Lebensabschnitten wahrscheinlich oder liege nahe, wenn in jüngeren Lebensabschnitten bereits die Erfahrung freiwilligen Mittuns gemacht worden sei. ${ }^{89}$ Auch Franz Walter fasst im Hinblick auf die engagierten Alten in politischen Protestzusammenhängen zusammen: „Die biologische Kategorie Alter gibt noch keinen Aufschluss über Mitwirkungspotenziale und -wünsche.“90 Bereits im biographischen Verlauf gesammelte Erfahrungen mit Engagement und Partizipation verlängern sich nach dieser Lesart in das Alter hinein und fungierten hier als Erfahrungshintergrund und Anschlussfähigkeit an die Frage nach einem Aktivsein. Auf diese Weise aber bilden die Engagementstrukturen der älteren Generationen auch nur - vor einem unzweifelhaft günstigeren zeit- und kräfteökonomischen Hintergrund - das ab, was gesamtgesellschaftlich determinierende Faktoren für eine ehrenamtliche Tätigkeit sind: Je höher die Bildung, das Einkommen, der sozial-ökonomische Status, auch die Gesundheit einer Person sind, umso größer die Wahrscheinlichkeit, dass sich jemand engagiert, partizipiert, seine Interessen artikuliert etc.

Gerade vor dem Hintergrund der Bedeutung von im Laufe des Lebens gemachten Erfahrungen für ein Aktivwerden im Alter ist für das hier vorliegende Projekt zu schauen nach unterschiedlichen Begründungen für ein Engagement in den Protestgruppen. Denn es ist auffällig, dass es ja nicht allein das „,nichttraditionelle“ Engagement ist, bei dem die älteren Jahrgänge einen Überhang bilden, sondern dass auch Parteien, Gewerkschaften, Kirchen mit der Rekrutierung neuer, junger Mitglieder mitunter arge Probleme haben und analog zur ge-

88 Vgl. Munimus: Alternde Volksparteien, S. 57.

89 Erlinghagen, Marcel: Volunteering after Retirement. Evidence from German Panel Data. In: European Societies, Jg. 12 (2010) H. 5, S. 603 - 625.

90 Walter, Franz: Bürgerlichkeit und Protest in der Misstrauensgesellschaft, in: Marg, Stine / Lars Geiges / Felix Butzlaff / Franz Walter (Hrsg.): Die neue Macht der Bürger? Was motiviert die Protestbewegungen?, Reinbek bei Hamburg 2013, S. 301 344, hier S. 305. 
sellschaftlichen Entwicklung in der Tendenz „,vergreisen“. ${ }^{91}$ Insofern wäre hier die Frage anzusetzen, welche möglicherweise unterschiedlichen Begründungen für ein Mitmachen beim Protest hervorgebracht werden, ob ältere Protestierende als zuvor „klassisch“ Eingebundene ihren Organisationen den Rücken gekehrt haben oder ob sie einer Art „Untergruppe“ entspringen, die auch zuvor nicht in Parteien, Gewerkschaften, Kirchen aktiv gewesen ist.

Weiters deutet die Betonung von Erfahrungen und Prädispositionen im Leben eines Menschen für eine Offenheit gegenüber Protest auf die Notwendigkeit hin, die Frage unterschiedlicher Generationszusammenhänge nicht aus den Augen zu verlieren. Denn trotz aller Kontroversen bei der sozialwissenschaftlichen Diskussion von Generationsanalysen und dem Nutzen des Begriffs kommt David Bebnowski zu dem Urteil, dass eine offene Handhabung des Generationenkonzepts für das Verstehen von sozialem Wandel durch unterschiedliche gesellschaftliche Gruppen sehr hilfreich sein kann. ${ }^{92}$ Der von Karl Mannheim entwickelte Dreiklang aus der Lagerung einer Generation, d.h. ihres objektiven $\mathrm{Zu}$ sammenhangs als Geburtskohorte, dem Generations-Zusammenhang, der auf das Erleben derselben Ereignisse oder Zeitperioden hinweist, gesteigert durch eine sich keineswegs immer ausprägende Generations-Einheit, die auf eine ähnliche Verarbeitung und Deutung dieser Zeit und Ereignisse hinweist, ermöglicht es, sich als zusammenhängende Generation zu fühlen und als solche zu handeln. ${ }^{93}$ Es ist hierbei zentral zu unterstreichen, dass die Eigendeutungen von Generationen nichts Statisches sind, sondern im Zeitverlauf auch einem Wandel unterlaufen, sowie dass es keine feste Aufzählung dessen geben kann, was genau ein solches, Zusammenhang und Einheit stiftendes Ereignis eigentlich ausmacht und ob dieses schon in der Zeit selbst oder erst mit vielen Jahren Verzögerung zur Ausprägung kommt. ${ }^{94}$ Bei den hier untersuchten Protesten und Demokratiedeutungen sollen folglich diese Bezugnahmen der Protestierenden auf ihre eigene Vergangenheit eine wichtige Rolle spielen und die Frage nach Unterschieden im Hinblick auf die Funktion, die man für sich selbst und die Proteste im Rahmen einer Demokratie daraus ableitet.

91 Vgl. exemplarisch Dose, Nicolai / Fischer, Anne-Kathrin: Mitgliederschwund und Überalterung der Parteien: Prognose der Mitgliederzahlen bis 2040, in: Zeitschrift für Parlamentsfragen, Jg. 44 (2013) H. 4, S. 892 - 900.

92 Vgl. Bebnowski, David: Generation und Geltung. Von den „45ern“ zur „Generation Praktikum“ - übersehene und etablierte Generationen im Vergleich. Studien des Göttinger Instituts für Demokratieforschung, Band 4, Bielefeld 2012, S. $14 \mathrm{ff}$.

93 Vgl. hierzu grundlegend Mannheim, Karl: Das Problem der Generationen, in: Mannheim, Karl: Wissenssoziologie: Auswahl aus dem Werk, Berlin 1964, S. 509 - 565.

94 Vgl. Bebnowski: Generation und Geltung, S. 12 - 26. 
In den Betrachtungen zu Engagement und (politischer) Partizipation in einer Bürgergesellschaft ist immer wieder das Konzept der Selbstwirksamkeit bemüht worden. ${ }^{95}$ Dabei geht es um die Annahme, dass Partizipation eines intrinsischen Selbstbewusstseins bedarf, was die Wirksamkeit und Fähigkeit des eigenen Handelns anbelangt. In der Bildungs- und Schulforschung sind die Entstehungsbedingungen von Selbstwirksamkeitserfahrungen und ihre Bedeutung für schulische Erfolge breit untersucht worden. ${ }^{96}$ Wie mit empfundenen Barrieren und Herausforderungen umgegangen wird und wie Erfolge oder Misserfolge im Leben eigentlich verarbeitet und interpretiert werden, steht hierbei im Mittelpunkt. Positive Erwartungshaltungen etwa, das Überzeugt-Sein von den eigenen Fähigkeiten, führen langfristig etwa zu einer optimistischeren Einschätzung fordernder Situationen: ,die subjektive Gewissheit, neue oder schwierige Anforderungssituationen aufgrund eigener Kompetenz bewältigen zu können. “97 Auch Misserfolge werden eher ungünstigen äußeren Umständen zugewiesen und nicht einem eigenen Versagen. Dabei sind es vor allem in der Jugend gemacht Erfolgserfahrungen, die die Basis dieser psychischen Ressource bilden. All dies kann mit dem Thema des Engagements insofern verknüpft werden, als auch für eine Protestteilnahme angenommen werden kann, dass eine gewisse Erwartung an die Wirksamkeit des Mitmachens Voraussetzung sein dürfte.

Diese Selbstwirksamkeitserwartungen werden allerdings, analog zur Beobachtung bezüglich der Prädisposition für ein Engagement oder Protest, nicht über das ganze Leben hinweg ausgebildet, sondern Menschen behalten ,,ihre Attributionsmuster, die sie in ihrer Jugenderworben haben, noch im hohen Alter bei. Man kann also bei dieser psychischen Ressource von einer überdauernden Persönlichkeitseigenschaft sprechen." ${ }^{98}$ Mit der Frage nach Generation, Alter und Protest lässt sich dies insofern verbinden, als dass diese Selbstwirksamkeitserwartungen nicht nur subjektiv, sondern auch kollektiv, als Gruppe bilden und beibehalten lassen. Wenn also eine sich als Einheit begreifende Generation etwa bei Demonstrationen in ihrer Jugend Erfahrungen gemacht hat, die ihnen die Potenziale und Wirkkräfte autonomer Selbstorganisation bzw. ihre politischen Einflussmöglichkeiten vor Augen geführt haben, so werden diese Erfahrungen aller

95 Vgl. exemplarisch Marg u.a.: Die neue Macht der Bürger?, S. 309f.; vgl. auch Klatt: Partizipation: Ein erstrebenswertes Ziel politischer Bildung?, hier S. 6.

96 Vgl. grundlegend Schwarzer, Ralf / Matthias Jerusalem: Das Konzept der Selbstwirksamkeit, in: Jerusalem, Matthias / Diether Hopf (Hrsg.): Selbstwirksamkeit und Motivationsprozesse in Bildungsinstitutionen, Zeitschrift für Pädagogik, 44. Beiheft, Weinheim 2002, S. $28-53$.

97 Ebenda, S. 35.

98 Ebenda, S. 33. 
Wahrscheinlichkeit nach ein Leben lang gespeichert und können eine Prädisposition für einen selbstbewussten Widerspruch im gesellschaftlichen Diskurs stark unterstreichen.

Für die Bürgerproteste und Demokratieerwartungen, die hier im Zentrum stehen, geht es demzufolge bei der Frage nach dem biografischen Ort von Protest um die unterschiedlichen Begründungen und Bezugnahmen, die hinter einer Entscheidung für eine Partizipation stehen. Unterscheiden sich die Motivationen bei verschiedenen Altersgruppen - gibt es unterschiedliche „Protestgenerationen“ dergestalt, dass aus der individuellen oder generationellen Historie Vorbilder oder Schlüsselerfahrungen bemüht werden, die Treibstoff und Hoffnung verdeutlichen sollen? Und nicht zuletzt: Lassen sich aus diesen Fragen vor dem Hintergrund der demographischen Entwicklung Schlussfolgerungen ziehen für die Diskussion zukünftiger Organisation der Entscheidungsfindung in unserer Gesellschaft?

\subsection{ZWISCHENFAZIT I: ZUR FragestelLUNG}

Es soll bei der vorliegenden Studie um die Bürgerproteste in Deutschland gehen, die sich außerhalb von traditionellen Einbindungsformen des demokratischen Systems an ganz unterschiedlichen Themen und Feldern herausbilden. Drei Fragekomplexe stehen dabei im Zentrum: Erstens, die Frage nach dem Ort von Protest im Rahmen eines Lebens, dem biographischen Ort von Widerspruch und den sich verändernden Motiven und Begründungen, die dabei zum Tragen kommen; zweitens, die Utopien von Protest, was Demokratie und Politik und deren Krise sowie die Rolle des Bürgers darin anbelangt; und drittens, die Rolle von Urbanität und Gemeinschaft als Konfliktfeld, aber auch als Bezugspunkt für eine Utopie von Gesellschaftsorganisation. Über eine sozialstatistische Erfassung des Rahmens hinaus, dessen Protest und Engagement bedürfen, sollen auf diese Weise mehr die Motive und Eigenbegründungen von Protest in Deutschland erspürt werden, und darauf aufbauend die Hoffnungen und Erwartungen, die sich an Demokratie, Politik, Parteien und Gesellschaft wenden. Das eingangs betonte Auseinanderklaffen von demokratischer Realität auf der einen und sich verändernden Demokratienormen auf der anderen Seite, welche sich möglicherweise davon entfernt haben, macht eine genauere Betrachtung auch aus einer normativen Demokratieforschungsperspektive wichtig und notwendig. Diese hier herausgeschälten Fragen sind gerade im Verlaufe der letzten Jahre dringlich geworden, während derer sich aus einer zunächst einmal ökonomischen Krisendiskus- 
sion immer mehr und stärker auch eine zur Demokratie und der Einbindung ihrer Bürger entwickelt hat.

Wichtig ist dabei, zu betonen, dass den hier im Zentrum stehenden Bürgerprotesten gleichwohl ein organisatorisches Moment innewohnt, welches sie von erratisch aufflammenden Krawallen oder Revolten unterscheidet. Es geht um diejenigen Menschen, denen eine Veränderungsmotivation innewohnt, welche durch die Anstrengung sichtbar wird, ein Anliegen über Zeit und Hindernisse hinweg zu verfolgen und zu vertreten. Die aber, und das ist das entscheidende Merkmal, die bestehenden Möglichkeiten zur Integration ihrer Interessen in die politischen Vertretungsmechanismen eben nicht mehr als ausreichend erachten. 



\section{Herangehensweise, Fallauswahl, Forschungsstand}

Diese Studie baut auf den Vorarbeiten des Projekts „Die neue Macht der Bürger. Was motiviert die Protestbewegungen?"1 auf und übernimmt damit zu einem großen Teil das methodische Fundament des Datenmaterials. ${ }^{2}$ Was die Charakteristika der Proteste sind, die gegenwärtig bzw. in den letzten Jahren zu den unterschiedlichsten Themen an verschiedenen Orten in der Republik mit jeweils anderer Intensität aufbrechen, wurde am Göttinger Institut für Demokratieforschung versucht zu skizzieren. ${ }^{3}$ Erkenntnisinteresse und Fragehintergrund war dabei die Beobachtung, dass sich einerseits kontinuierlich schwächer werdende schwindende gesellschaftliche Binde- und Integrationskräfte von Parteien, Verbänden und Kirchen konstatieren lassen, während sich andererseits eine aktive und durchaus selbstbewusste Zivilgesellschaft mit neuen Partizipationsformen zu entwickeln scheint, um Einfluss auf Politik und Gesellschaft zu nehmen. ${ }^{4}$

1 Marg u.a.: Die neue Macht der Bürger.

2 Die verwandten Daten und die Beschreibung der dabei angewandten Methodik lehnt sich an die Methodenbegründung der zitierten Proteststudie an. Vgl. Klecha, Stephan / Stine Marg / Felix Butzlaff: Wie erforscht man Protest? Forschungsdesign und Forschungsmethodik, in: Marg u.a.: Die neue Macht der Bürger, S. 14 - 47.

3 Vgl. Walter: Bürgerlichkeit und Protest in der Misstrauensgesellschaft.

4 Vgl. zu diesem Punkt exemplarisch die Publikationen von Klatt, Johanna: Die Macht der Zivilgesellschaft und ihre ungleiche Verteilung, in: Ethik und Gesellschaft. Ökumenische Zeitschrift für Sozialethik, (2012) H. 2: Demokratie und Sozialethik, online abrufbar unter http://www.evangelischer-bildungsserver.de/src/content.php?id=77\&content $=33210$ [zuletzt eingesehen am 24.05.2013]; dies.: Individualisierte Zivilgesellschaft und die Beteiligung sozial Benachteiligter, in: betrifft Bürgergesellschaft, Jg. 8 (2011) Nr. 37, S. 1 - 12. 
Um die Folgen und Konsequenzen dieses Wandels beurteilen zu können, mussten zunächst die Proteste und vor allem deren Träger näher beleuchtet werden. Diejenigen, die Demonstrationen initiieren, Versammlungen leiten, sich Aktionsformen ausdenken und Menschen mobilisieren, standen im Zentrum der vorliegenden Studie und wurden unter dem Arbeitsbegriff des „Aktivisten“ subsummiert. Zentral war hierbei, dass die Protestierenden - „Aktivist“" meinte hierbei Frauen wie Männer gleichermaßen - innerhalb des jeweiligen Protests eine Aufgabe übernommen hatten. Damit umriss das potentielle Sample ein bewusst offen gehaltenes Rekrutierungsfeld, um nicht von Beginn an durch einschränkende Vorannahmen lediglich Gesprächspartner eines bestimmten Typus, etwa den des dominierenden Wortführers, abzubilden. Bei der Proteststudie war es um die Menschen gegangen, die bereit waren, einen nicht unwesentlichen Teil ihrer Energie und Zeit der Protestarbeit zu widmen, welche also ein ,gewisses Aktivitätsniveau“ aufwiesen. Unter welchen Bedingungen investieren Menschen persönliche Ressourcen, um sich für oder gegen etwas einzusetzen und damit die Gesellschaft mitzugestalten? Gibt es unterschiedliche Protestkulturen, die spezifische regionale oder auch historische Wurzeln haben? Welche Wertvorstellungen, Sozialmoral und Tradition prägen die Aktivisten? Welche Wissensbestände und Routinen bringen sie in die Arbeit rund um die jeweilige Bürgerinitiative, den Verein oder das Netzwerk mit ein?

Dazu wurden die Bedingungen näher in den Blick genommen, aus denen heraus eine latente Unzufriedenheit mit dem politischen System, mit seinen Leistungen oder Strukturen entstehen und wie dieses dann in politische Aktion und zivilgesellschaftlichen Protest umschlagen kann. Welche Vorstellungen von Gesellschaft und Demokratie in den Protestformationen prägend sind, welche Erwartungen die Aktivisten an Parteien und Politiker, ganz generell an ,die Politik“ haben und welche Rolle sie „,er Wirtschaft" zuweisen - diese Wahrnehmungen der Gesellschaftsordnung sind von zentraler Bedeutung, wenn die Wirkung und Folgen des gegenwärtigen Protestes und des latent vorhandenen Protestpotentials untersucht werden sollen. Weil seit einiger Zeit ein bürgerschaftliches Engagement ,außerhalb der konventionelle[n] Organisationsverfassungen und -formen"5 wächst, mithin keine abgeschlossene, sondern eine fortwährende Entwicklung darstellt, nimmt diese Fragestellung einen explorativen Charakter ein.

5 Klages, Helmut: Individualisierung als Triebkraft bürgerlichen Engagements. Empirische Fakten und Folgerungen, in: Kistler, Ernst / Heinz-Herbert Noll / Eckhard Priller (Hrsg.): Perspektiven gesellschaftlichen Zusammenhalts. Empirische Befunde, Praxiserfahrungen, Messkonzepte, Berlin, S. 101 - 112, hier S. 104. 


\subsection{Ein flanierender Spaziergang als Mittel zUR ERKENNTNIS}

Im Kapitel zur Stadt unter 2.2 wurde bereits die Entwicklung der Stadtbetrachtung in Chicago und die Chicagoer Schule der Soziologie herausgestellt, die in den ersten Jahrzehnten des letzten Jahrhunderts eine neue Blick- und Fragerichtung für die Soziologie begründete. Was die Entstehung des Chicagoer Blicks auf die Soziologie und ihre Aufgaben spannend macht, ist dabei auch die Verknüpfung mit dem biographischen Gepäck, durch welches ihre beiden exponiertesten Figuren - William I. Thomas und Robert E. Park - geprägt worden sind. Denn besonders die emotionale wie physische Hinwendung zum Untersuchungsgegenstand war es, welche das Neue der Chicagoer Soziologie ausmachte. Robert E. Park brachte jahrelange Berufserfahrung als Reporter in USamerikanischen Großstädten mit, hatte als ,unermüdlicher Fußgänger“ die Metropolen „durchstreift“ und war dem Flaneur Walter Benjamins ähnlich in die verschiedenen Stadtkulturen eingetaucht, um sie aus eigener Anschauung kennen $\mathrm{zu}$ lernen und zu betrachten. ${ }^{6}$ Und noch früher ist es der deutsche Journalist und Volkskundler Wilhelm Heinrich Riehl gewesen, der umfassende Wanderungen durch die deutschen Lande Mitte des 19. Jahrhunderts als Quelle für eine dichte Beschreibung der gesellschaftlichen Umwälzungen durch industrielle und nationale Revolutionen heranzog, ,mit unendlichem Fleiß tief und unmittelbar aus den reichen Lebensquellen des Volkes geschöpft (Hervorhebung im Original, Anm. F.B. ) ". 7 Riehl sah sich dabei auch als Vermittler zwischen einem Volk und den es regierenden Staatsmännern, welche durch komplexer gewordene Regelungszusammenhänge zu direkten Erfahrungen und Einblicken in das Alltagsleben der Bürger gar nicht mehr kamen: „Da nun die Staatsmänner nicht mehr auf die Wanderschaft gehen können, so sollten es wenigstens die politischen Schriftsteller für sie tun. ${ }^{68}$ Der Journalist und Soziologie wurde hier zum Porträtmaler und Seismographen gesellschaftlicher Entwicklungen, und bezog seine methodische Stärke, Riehl zufolge, vor allem aus der Unmittelbarkeit der Erfahrungen,

6 Rolf Lindner zitiert hier René König in Lindner, Rolf: Die Entdeckung der Stadtkultur. Soziologie aus der Erfahrung der Reportage, Frankfurt a.M., S. 10. Zum Konzept des Flaneurs vgl. Keidel: Die Wiederkehr der Flaneure.

7 von Geramb, Viktor: Wilhelm Heinrich Riehl. Leben und Wirken (1823 - 1897), Salzburg 1954, S. 135.

8 Riehl, Wilhelm Heinrich: Die Naturgeschichte des Volkes als Grundlage einer deutschen Sozialpolitik, erster Band: Land und Leute, Stuttgart / Berlin 1925, S. V. 
dem noch kein Abstraktionsfilter vorausgegangen war: „Die Landschaftsmaler wissen, wie gefährlich es ist, an einer Skizze, die im Freien gemalte wurde, hintendrein, und gar nach Jahr und Tag, in der Stube nachzubessern: man tilgt da wohl einzelne Mängel, verdirbt aber das Ganze, man zerstört das beste Teil - die Frische, die sprechende Wahrheit des unmittelbaren Eindrucks.“9

Um zum Chicagoer Beispiel zurückzukehren: Die nordamerikanische Medienlandschaft im späten 19. Jahrhundert hatte insofern eine Evolution durchgemacht, als dass die Zahl derjenigen Zeitungen sprunghaft angewachsen war, die sich keinem politischen Auftrag verpflichtet fühlten, sondern das Leben als solches, und besonders auch die „dunklen Seiten“ der Gesellschaft seinen Lesern durchaus voyeuristisch näher bringen wollte. ${ }^{10}$ Unbekannte Kulturen und Stadtviertel zunächst einmal kennen und verstehen zu lernen, die Binnenperspektive einzunehmen und die lokalen Rationalitäten nicht auszublenden, war dabei entscheidend. Das ,nosing around“ [...] ,to see and to know , life““"11 war das daraus erwachsene Postulat, welches Park seinen Studenten mantrahaft immer wieder einimpfte - sich treiben zu lassen, alle möglichen Quellen und Eindrücke auf sich wirken lassen, um durch große Detailkenntnis zu fundierten Urteilen zu kommen. Er kam damit den Forderungen Richard Swedbergs fast 100 Jahre zuvor, der in einem Artikel in der Zeitschrift Theory and Society im Jahr 2012 anmahnte, Studierende der Sozialwissenschaften viel stärker in den Bereichen „Entdecken“, „Intuition“, „Inspiration“ und „Improvisation“ zu schulen, um den Sozialwissenschaften auf diese Weise wieder stärker die Fähigkeiten zu geben, neue Phänomene und Entwicklungen in unseren Gesellschaften erspüren zu können, und sich nicht im streng methodisch-formalistisch begrenzten Rekurs auf schon bestehende Theorien zu erschöpfen. ${ }^{12}$ Auch Helmuth Plessner hat den Wert von Phantasie und Einfühlungsvermögen unterstrichen und ihn gerade für die Geisteswissenschaften zur unabdingbaren Grundlage gemacht: „Phantasie als das Vermögen, sich von einer Gelegenheit freimachen und mit ihr kombinieren zu können, über das schließlich jeder, sei's auch in bescheidenem Maße, verfügen muß.“"13

9 Ebenda, S. XI.

10 Vgl. dazu grundlegend Lindner: Die Entdeckung der Stadtkultur.

11 Ebenda, S. 9 und 230.

12 Vgl. Swedberg, Richard: Theorizing in sociology and social science: turning to the context of discovery, in: Theory and Society, Jg. 41 (2012) H. 1, S. 1 - 40, hier S. 34.

13 Plessner, Helmuth: Mit anderen Augen, in Ders.: Conditio Humana. Gesammelte Schriften VIII, hrsg. von Dux, Günther u.a., Frankfurt a.M. 2003, S. 88 - 104, hier S. $103 f$. 
Park und Thomas bemängelten an ihren zeitgenössischen Kollegen besonders deren Entfernung zu ihren Untersuchungsobjekten und das darüber zwangsläufig fehlende Einfühlungsvermögen in Kultur und Lebenssituation. Die auf statistische Erhebungen und Sekundärliteratur rekurrierende Soziologie der Jahrhundertwende war ihnen zu wenig objektiv und krankte stark am Selbstbild der Wissenschaft für die Verbesserung der gesellschaftlichen Schattenseiten. Der Unterschied zwischen Reformarbeit und Sozialpolitik auf der einen und einer empirischen, an Gesetzmäßigkeiten und Funktionsweisen der Gesellschaft an sich interessierten Sozialforschung auf der anderen Seite schien ihnen bei den meisten soziologischen Arbeiten der Vereinigten Staaten zu verwischen. Gerade im Hinblick auf eine solch pulsierende Metropole wie das Chicago der Jahre um den Ersten Weltkrieg warfen Park und Thomas - wie auch Richard Swedberg im Übrigen - den Fachkollegen vor, im Verständnis und Einblick in den Gegenstand hinter der Literatur weit hinterher zu hinken: „We are mainly indepted to writers of fiction for our more intimate knowledge of contemporary urban life“". ${ }^{14}$ Es sind denn auch bezeichnenderweise vielfach Mischungen aus Literatur und Gesellschaftsanalyse, denen wir heute die tiefsten Einblicke in die Wucht und Details der Veränderungsschübe der Vergangenheit verdanken: vom bereits bemühten Carl Ludwig Börne über Joseph Roth, Siegfried Kracauer, Walter Benjamin, John Steinbeck bis hin zu Hunter S. Thompson, Susan Sontag oder auch Paul Auster.

Gerade das „urban life“ war es, welches Park und Thomas als den besten Ort erachteten, die Wandlung menschlichen Zusammenlebens zu beobachten. Die Großstadt war das Laboratorium, in dem immer neue Formen, Werte, Normen miteinander rangen, ausprobiert und wieder verworfen wurden. Denn anders als bis dato von den Sozialwissenschaften angenommen, hatte sich Park das Großstadtleben in seinem Werdegang als Journalist und Reporter keineswegs als etwas Statisches dargestellt, welches durch eine Moderne punktuell unter Druck geriet. Park und Thomas gingen vielmehr von einem dynamischen, sich permanent wandelnden Prozess aus, mit dem innerhalb der einzelnen Sozialgruppen und Einwanderergesellschaften Verhaltensnormen und Hierarchien immer wieder neu ausgehandelt werden. „Die zeitdiagnostische Alternative lautete für sie nicht Bewährung versus Verfall von Gemeinschaften, sondern sie sahen, dass die strukturellen Herausforderungen des modernen Großstadtlebens durch „kommunikative“ und „reflexive“ soziale Ordnungen [...] bewältigt werden konnten (Hervorhebung im Original, Anm. F.B.). “15 Insofern war die Modernisierung und

14 Park, Robert Ezra: Human Communities. The City and Human Ecology, New York/London 1952 S.15.

15 Schubert: The Chicago School of Sociology, S. 123. 
das Wachstum der Großstadt für sie auch nicht qua Determinismus ein Weg hin zu einem unpersönlichen, überindividualisierten Leben ohne soziales Umfeld, sondern ein faszinierendes, sich ständig wandelndes, irisierendes Feld. Wenn etwa neue Einwanderergruppen aus Europa auf die bereits etablierten Einwanderer in Chicago trafen, dann veränderten sich beide in ihrem Verhalten. Zwar bildeten sich in Chicago Viertel mit vergleichsweise homogener Zusammensetzung, die dann auch jeweils eigene Ökonomien (,natural order“), Verhaltenscharakteristika und Mentalitäten ausprägten (,,moral order"). Diese blieben jedoch nie hermetisch voneinander getrennt, sondern überschnitten sich oft und weit, so dass sich auch durch gegenseitige Einflüsse die sozialen Ordnungen stets in einem Prozess von Re- und Umdefinition befanden. Und um diesen Zusammenhang ging es Park und Thomas in erster Linie: das Wechselspiel und die gegenseitige Abhängigkeit von „natural“ und „moral order“. Zwischen beiden bestehe ein immer wechselnder, ,kreislaufartiger[r] Reproduktionsprozess“"16. Das "soziale [...] Verhalten in seiner ganzen Komplexität und inneren Differenziertheit “"17 zu erfassen und zum Gegenstand einer ebenso umfassenden Betrachtung zu machen, war das Ziel. Eine Theorie der sozialen Desorganisation entwickelte also den Kreislauf von der Auflösung bekannter Werte und Normen von Sozialgruppen über eine Übergangsphase hin zu einem Prozess der Wiederorganisation in neuer Form. Und anhand des Zusammenhangs von städtebaulichen Veränderungen, der Entwicklung ganz neuer oder andersartiger Industriezweige, Verkehrswege und Kommunikationsmittel einerseits sowie „dem Wandel der soziokulturellen Bindungen moderner Lebenswelten andererseits ${ }^{\text {“18 }}$ sollten sich Parks Studenten der Frage nach den Wegen und Auswirkungen gesellschaftlicher Modernisierung nähern.

Während Wilhelm Heinrich Riehl bereits Mitte des 19. Jahrhunderts von sich ausdifferenzierenden Abgrenzungen zwischen Stadt und Land schrieb und betonte, wie sehr im sich wandelnden Verhältnis von urbanem und ruralen Leben Erklärungsgehalt für gesellschaftliche Entwicklungen lägen ${ }^{19}$, spielte die Großstadt als Versuchsfeld für die Chicagoer Soziologen aus mehreren Gründen eine zentrale Rolle. Zum einen - ganz profan - weil Chicago nun einmal der Ort des Departments war, an dem Thomas und Park lehrten und forschten und das Untersuchungsgebiet direkt vor der Haustür hatten. Zum zweiten, weil sich in der Metropole an den Great Lakes wie in kaum einem anderen Raum zu jener Zeit

16 Schubert: The Chicago School of Sociology, S. 133.

17 Kern, Horst: Empirische Sozialforschung. Ursprünge, Ansätze, Entwicklungslinien, München 1982, S. 185.

18 Schubert: The Chicago School of Sociology, S. 131.

19 Riehl: Die Naturgeschichte des Volkes, S. 89. 
die Modernisierungsphänomene ballten und die verschiedensten Migrantengruppen sowie sozialen Schichten auf eine sich markant wandelnde Industriestruktur trafen. Um es mit fachlichem Segen auszustatten: Man traf in Chicago auf eine Stadt, die man anhand ihrer ,transitiven Phase der Handlungskrise und die daran anschließenden experimentellen und kreativen Versuche, neue Handlungsregeln $\mathrm{zu}$ finden ${ }^{\text {“20 }}$ beleuchten konnte.

Und drittens fanden Thomas und Park nicht nur die Rahmenbedingungen, sondern auch die Verkörperung eines Anschubgebers für einen kulturellen Wandeln vor Ort: Sie konzentrierten sich auf den sogenannten „marginal man“ als personifizierte Übergangsgestalt zwischen verschiedenen Sozialgruppen. Diese Randfiguren spielten nach Park für die Entwicklung von Gesellschaft und Kultur eine entscheidende Rolle, weil sie sich - mehreren Sozialgruppen zugehörig, aber doch nirgendwo beheimatet - in einer Art permanenten Identitätskrise dazu gedrängt fühlen, neue Identitäten und Wertehierarchien auszubilden, und dabei gleichwohl mit einem größeren Abstand und Autonomie auf die Lebensumfelder ihrer Eltern und Nachbarn schauen können. Doch waren gerade diese Lebensumfelder der „,marginal men“ Sektoren der Stadt, die sich dem sozialwissenschaftlichen Beobachter nicht sofort erschlossen und offen zeigten. Dies traf in besonderem Maße auch auf Bereiche der Halbwelt und der „dunklen“ Stadtteile Chicagos zu, die in vielen Studien und Dissertationen bearbeitet wurden: Von „The Hobo“ ${ }^{\text {21 }}$ über die „Taxi Dance-Hall“،22 bis hin zum nebeneinander von „The Gold Coast und the Slum، ${ }^{\prime 23}$ nahmen Schüler und Studenten Parks die Stadt unter die Lupe und verfassten dichte Beschreibungen ihrer Bewohner. Hier war die langwierige, sich vorsichtig annähernde und beobachtende Methode des Reporters angebracht, der sich im Untersuchungsgebiet herumtrieb, zunächst Stimmungen und Eindrücke sammelte, bemüht war, das Leben aus der Sicht seiner Bewohner kennen zu lernen. Auch Matthias Keidel konstatiert für Franz Hessels Betrachtungen Berlins, dass sich ,in der Gestaltung des zufällig Wahrgenommenen [...] eine Ästhetik des Marginalen (manifestiert, Anm. F.B.), die gerade in den Randphänomenen das Typische aufspüren und beschreiben kann. ${ }^{\text {“24 }}$

Die journalistische Brille, die der Soziologie am Chicagoer Department aufgesetzt wurde, war neu und bahnbrechend, weil sie die Person des Betrachters

20 Schubert: The Chicago School of Sociology, S. 142.

21 Andersson, Nels: The Hobo: The sociology of the homeless man, Chicago 1961.

22 Cressey, Paul G.: The Taxi-Dance Hall : A sociological study in commercialized recreation and city life, Chicago 1932.

23 Zorbaugh, Harvey W.: The Gold Coast and the slum: a sociological study of Chicago's near north side, Chicago 1983.

24 Keidel: Die Wiederkehr der Flaneure, S. 31. 
aktiv in die Untersuchungsmethode mit einbezog. Die Unvollkommenheiten jedweder persönlichen Beobachtung, sprich: die Fremdheit jeder Begegnung und Interpretation von „fremden“ Sozialgruppen wurde ganz bewusst thematisiert und nicht einfach mit der Annahme eines „objektiven“ Wissenschaftlers weggewischt. Dies führte aber nicht einfach zu dem Schluss, dass die persönliche Beobachtung oder die subjektiven Eindrücke eines wissenschaftlichen Spaziergangs durch das Forschungsgebiet als unzulänglich angesehen wurden, im Gegenteil. Es erwuchs daraus eben vielmehr die Pflicht, sich intensiv und über einen langen Zeitraum in die kulturellen, psychischen und physischen Gegebenheiten vor Ort einzuarbeiten. Denn nur wenn über möglichst weitgehende Kenntnis der kleinen Rituale, Subtexte, der sprachlichen Feinheiten und der gruppenspezifischen Verhaltensweisen eine große Sensibilität erreicht wurde, konnten viele Beobachtungen ihrer Bedeutung entsprechend eingeordnet werden. Doch nicht nur einer solchen „äußeren Begrenzung“ des Alltagswissens über andersartige kulturelle Phänomene gilt es dabei folglich zu beobachten, sondern auch eine „,innere Begrenzung“, welche aus Charakter und Hintergrund des Fragenden resultiere und seine Wahrnehmung beeinflusse. Nach Thomas müsse man als empirischer Sozialforscher zwei Dinge im Hinterkopf behalten, um der Gefahr allzu schneller Kausalschlüsse zu entgehen: Zum einen eben das Streben nach einem möglichst großen Kontextwissen als Fundament jeder Forschung und zum anderen das Bemühen um einen ständigen und systematischen Vergleich zwischen verschiedenen Biographien, Kulturen und Lebensläufen, um die Subjektivität der eigenen Betrachtung stets zu den Seiten hin abzugleichen. ${ }^{25}$

Zwischen der Kultur als vermeintlich objektiv zu beobachtendem Faktor und der Persönlichkeit der Agierenden, die mit subjektivem Blick Erfahrungen, Werte und Verhaltensmuster verarbeiten und verinnerlichen, steht bei den Chicagoer Soziologen die „Definition der Situation“. Hierbei wird angenommen, dass Individuen in einer Situation jeweils aus einer Vielzahl von Interpretationsmöglichkeiten zu wählen haben, um ihrem Selbstbild und empfundenen Platz in der Gesellschaft zu entsprechen. Genau diese „Pluralität konkurrierender Schablonenkomplexe“ ${ }^{26}$ aber hätten sich mit der Moderne vervielfacht und die alltäglichen Interpretationsaufgaben ungemein verkompliziert, so dass einheitliche Selbstbilder immer schwieriger nachzuzeichnen und auszuleben seien - und folglich auch das Verstehen und Nachvollziehen kohärenter Verhaltensweisen und Wertekonzepte aufgebrochen worden seien. Für die hier behandelten Fragen ist es demnach wichtig, ,die Situationsdefinitionen und symbolischen Interaktionsprozesse

25 Vgl. Schubert: The Chicago School of Sociology, hier S. 157f.

26 Ebenda, S. 131. 
der Handelnden prozessanalytisch [zu] rekonstruieren“'27, um die Motive und Triebkräfte der Protestierenden und ihre Hoffnungen in Bezug auf ihr Engagement und die Demokratie nachzuzeichnen.

Der investigative Reporter-Zugang mit seiner Erfahrung und guten Kenntnis der verschiedensten Stadtviertel und auch ihrer halbseidenen Winkel und Lebensarten war für Park und Thomas abzusichern und methodisch zu reflektieren und zudem die Eindrücke aus erster Hand zu vervollständigen durch alle verfügbaren Quellen, die zum Themenfeld zugänglich waren. Die Studien, die in Chicago entstanden, zogen Stadtpläne, Polizeiberichte, Sozialstatistiken, persönliche Briefe, Familienchroniken, Tagebücher etc. heran. Die direkte Erfahrung aber, ohne Arbeitshypothesen und Vorannahmen, war enorm wichtig, um die Forscherperspektive einer möglichst objektiven Empathie mit dem Untersuchungsgegenstand zu erreichen.

Für die Ausbildung seiner Studenten war Park dies zentral. Er ließ sie immer wieder ausströmen und die verschiedensten Viertel der Stadt durchstreifen, um kleine Beobachtungsaufgaben zu verfassen und in Protokolle und kurze Artikel zu gießen. Einem Chefredakteur gleich, der Neulingen unter den Stadtreportern erste Rechercheaufgaben gab, mussten seine Studenten die Stadt erkunden, um ein Gefühl für die richtigen Fragen zu entwickeln und sich so intensiv wie möglich in die Stadt als soziales Labor der Moderne einzufühlen. Die Methodenschulung zum jungen Sozialwissenschaftler war zu einem nicht geringen Teil die Ausbildung zum kulturell sensiblen Beobachter und die Einführung in den Handlungsraum sah eine große Nähe zu literarischen Verfahren. ${ }^{28}$

Dies ist der Chicagoer Soziologie von Anfang an vorgeworfen worden, und das Department selbst hat diese Anleihen bei den Methoden der Stadtreporter auch deswegen nie groß auf seine Fahnen geschrieben. Sich methodisch auf das schnüffelnde, bohèmehafte Image des investigativen Reporters zu beziehen, bringt im akademischen Milieu geweihter Objektivität eben oft Hautgout mit sich, erst recht, wenn es um die schnell schmuddeligen Kinder der Halbweltviertel geht. Und so malten sich die Chicagoer Soziologen lieber eine Nähe zur Ethnologie und Kulturanthropologie auf den Leib, nannten die langfristige teilnehmende Beobachtung, das Einfühlen in eine komplett fremde Kultur als Vorbilder einer Herangehensweise zum Verstehen von Großstädten. Auch Wilhelm Heinrich Riehl hat sich über lange Jahre des Vorwurfs der Unwissenschaftlichkeit erwehren müssen. Er tat dies, mit der Sicherheit öffentlichen Ansehens durch seine weithin bekannten Bücher und deren hohe Auflagen, durchaus humorvoll. Seinen Gegnern warf er Borniertheit und Standesdünkel vor, wenn sie die direk-

27 Schubert: The Chicago School of Sociology, S. 159.

28 Vgl. Lindner: Die Entdeckung der Stadtkultur, S. 82. 
te Begegnung des Forschers mit dem Volk verächtlich machten. Dass ein interessierter und neugieriger Soziologe sehr wohl und viel in die Niederungen und den Alltag einfacher Menschen herabzusteigen habe, nicht trotz, sondern gerade aus methodischen Einsichten, galt für ihn als selbstverständlich:

„... Ich glaube, es gibt wenige Zweige der historischen Wissenschaften, denen es noch so reichlich vergönnt ist, aus unmittelbaren Quellen zu schöpfen, wie der unsrigen. Doch meinen noch immer manche gelehrten Leute, wenn Einer etwa auf einem alten Schweinsleder eine neue Notiz über das Volksleben unserer Urahnen aufspürt, so sey das allerdings Quellenforschung; wenn aber Einer eine gleich wichtige und neue Notiz über das Volksleben unserer Zeitgenossen aus der unmittelbaren Anschauung des Lebens mit nach Hause bringt, so könne man dies doch nie und nimmer Quellenforschung heißen. Genau genommen finde ich aber zwischen Beiden doch eigentlich nichts Unterscheidendes als das Schweinsleder... “29

Die Chicagoer Art und Weise, sich kulturellen Wandlungsphänomenen und ihren Auswirkungen zu nähern, hat seitdem viele Nachahmer und Schüler gefunden. In ihrer Betonung von soziologischer Phantasie, in dem Unterstreichen von Einfallsreichtum und Findigkeit bei der Recherche liegt ihr Wert, auch nach hundert Jahren noch. Und in der Handreichung, eine gesellschaftliche Entwicklung nie als deterministische Einbahnstraße zu betrachten, sondern als einen ergebnisoffenen Prozess, bei dem eben nicht eine einfach zu strickende Kausalkette vom Hier zum Dort führt. Gerade Politikwissenschaftler scheinen manchmal vergessen zu haben, was kulturelle Sensibilität und ein „Gefühl“ für interessante Fragestellungen bedeuten, und dass gerade Modernitätsschübe über die reinen Daten und Fakten hinaus oft enorme Entwicklungen für Werte und Normen der Menschen zeitigen.

Die Literatur ihrerseits hat sich dem Gegenstand der Modernisierungsprozesse ebenso als Spaziergang, flanierend und schauend genähert, auch und gerade, um sich in die Lage zu versetzen, kleine, noch zarte und nicht offenbar manifeste Verschiebungen erspüren zu können. ${ }^{30}$ Den ,unmittelbaren Sinneseindruck zu fassen“31 sei hierbei das Ziel, und dies ermögliche „die Auseinandersetzung mit den Modernisierungstendenzen und Phänomenen der Großstadtarchitektur, Stra-

29 Riehl, Wilhelm Heinrich: Culturstudien aus drei Jahrhunderten, Stuttgart 1859, S. 219f.

30 Vgl. dazu grundlegend Keidel: Die Wiederkehr der Flaneure; Neumeyer, Harald: Der Flaneur. Konzeptionen der Moderne, Würzburg 1999; Eckhardt Köhn: Straßenrausch. Flanerie und kleine Form. Versuch zur Literaturgeschichte des Flaneurs von 1830 1933, Berlin 1989.

31 Keidel: Die Wiederkehr der Flaneure, S. 12. 
Benbild, Geschäftsanlagen, dem Erscheinungsbild der Passanten und übergreifend die intensive Beschäftigung mit Entfremdungsgefühlen, die in den Metropolen besonders deutlich hervortreten und zum Teil gravierenden Einfluss auf das Identitätsgefühl der Autoren ausüben. ${ }^{\text {(32 }}$ Das kulturelle Gedächtnis vieler Generationen, welches sich in einer Stadt vergegenwärtige, ${ }^{33}$ sei treibend und gerade als kulturell fremder Beobachter nicht durch vorweg systematisierte Annahmen und Hypothesen zu begreifen. Dieser Prozess des „Theoretisierens“, den Richard Swedberg als erste Stufe eines sozialwissenschaftlichen Verstehens beschreibt, hat ein erstes Annähern und Begreifbar-machen zum Ziel. In einem qualitativ-explorativen Vorgehen geht es dabei darum, Beobachtungen über mögliche Kausalitäten und Wirkmechanismen anzustellen, Erklärungsansätze aus dem eigenen Datenmaterial zu formulieren, diese aber nicht gleich erschöpfend quantitativ zu „beweisen“ und zu rechtfertigen. Das Überprüfen einer so entstandenen Theorie oder Erklärung sei zwar langfristig das Ziel wissenschaftlichen Vorgehens, könne aber nie am Anfang stehen, sondern nur in vielen Schritten am Ende erfolgen. ${ }^{34}$ An dieser Stelle soll zunächst eine „entdeckende“ Annäherung an die Protestphänomene erfolgen. Gleich einem Spaziergang durch Gesellschaft und Material sollen Fährten aufgenommen und verknüpft, Beobachtungen verdichtet und gesammelt werden. Nicht der Beweis kann hier das Ziel sein, sondern die Entwicklung von Hypothesen. Nicht das überzeugungsfeste „So ist es“ oder „So war es“, soll am Ende stehen, sondern ein Augen öffnendes, auch fragendes „Möglicherweise“.

\subsection{QUELLEN: FoKUSGRUPPEN, INTERVIEWS UND TEILNEHMENDE BEOBACHTUNG}

Der Zugang zum Verständnis des gesellschaftlichen Protests soll in dieser Arbeit wie betont nicht über Organisationsverständnis oder Kontextbedingungen von Protest erfolgen, sondern über das aktiv gewordene Individuum, über dessen Wertvorstellungen, Präferenzen und politische Einstellungen, aber auch über dessen Einbindung in Protestzusammenhänge erfasst werden. Mit diesem Fragehintergrund bietet sich für die Analyse der Daten- und Textmengen ein methodischer Werkzeugkasten an, der sich aus mehreren Quellen der qualitativen Sozialforschung speist, die sich in ihrer Perspektive wiederum „,dienend“ ergänzen und

32 Ebenda, S. 9f.

33 Vgl. Witte: Traumstadt Berlin, S. 224.

34 Vgl. Swedberg: Theorizing in sociology and social science, hier S. $1-9$. 
so das Erkenntnisinteresse handhabbar machen. Wichtig für jedwedes methodische Korsett bleibt aber die Betonung einer instrumentellen Funktion von Methodik und Forschungsdesign, die sich vor dem Ziel einer zu erlangenden Plausibilität und Sensorik zu rechtfertigen haben.

Gerade an diesem Punkt und unter der angenommenen Anlage des Forschungsfeldes Protest, dass Engagement- und Partizipationsbereitschaft mit steigendem Anspruch an Aufwand sinkt und keineswegs berechenbar konstant bleibt $^{35}$, macht eine offen gehaltene und bewegliche Auswahl möglicher Gesprächspartner Sinn, weil das „Prinzip der Offenheit im Forschungsprozess und bei der Erhebung ${ }^{\star 36} \mathrm{zu}$ einem zentralen Qualitätsmerkmal eines qualitativexplorativen Forschungsvorgehens gezählt wird. Dazu gehört, dass es „nicht möglich [ist], die Stichprobe vorab klar umrissen zu definieren, sondern sie wird im Laufe der Forschung auf der Basis sich zunehmend herauskristallisierender Annahmen gebildet. ${ }^{37}$ Darüber hinaus meint die Anerkennung und Inanspruchnahme eines Offenheits-Gelübdes für den Forscher, Erhebungs- und Auswertungsphasen nicht strikt und dogmatisch zu trennen, sondern durchaus Gleichzeitigkeiten und Übergänge zu schaffen, um Deutungen und erste Ideen abwandeln, modifizieren, überprüfen, aber auch verwerfen zu können. Gerade weil es in der hier vorliegenden Arbeit nicht um das Überprüfen bereits formulierter Hypothesen geht, sondern um das entdeckende „Erspüren“ von Entwicklungen, wäre ein zuvor strikt nach methodischen Überlegungen definiertes Sample kontraproduktiv. ${ }^{38}$ Vor allem aber verlangt Offenheit im Forschungsprozess eine Neugierde und Reflektionsfähigkeit, um sich implizite Vorannahmen des Forschers als eigenständiges Individuum immer wieder bewusst zu machen. Denn die Lösung kann hier keineswegs sein, analog zum Rational Choice Ansatz qua Definition eine Zweckrationalität des betrachteten Individuums vorauszusetzen und die Beobachterposition als geschichtsloses Neutrum der Datenübermittlung zu verstehen, sondern im Gegenteil die eigene Position kenntlich zu machen, um diese nicht als unmerkliche Beeinflussung des Ergebnisses zu verschleiern. ${ }^{39}$

Um die verschiedenen Akteure der Protestlandschaft mit einzubeziehen, wurden die jeweiligen Themenbereiche mit einer mehrschichtigen und nicht le-

35 Vgl. exemplarisch Jörke, Dirk: Bürgerbeteiligung in der Postdemokratie.

36 Vgl. hierzu grundlegend Rosenthal, Gabriele: Interpretative Sozialforschung. Eine Einführung, Weinheim und München 2011, S. 47ff.

37 Ebenda, S.47.

38 Siehe dazu auch Helmuth Plessners Votum für den Einsatz von Phantasie und Offenheit und ihre fundamentale Bedeutung in der Sozialwissenschaft, vgl. Plessner: Mit anderen Augen, S. 103f.

39 Vgl. auch ebenda, S. 49. 
diglich einmaligen Datenerhebung erfasst. Um darüber hinaus einen größeren Perspektivenreichtum der Betrachtung zu erreichen und mögliche Erklärungsmuster oder Deutungen durch andere Quellen oder Blickwinkel abzusichern, wurde die Datenerhebung mittels einer Triangulation auf mehrere Pfeiler gestellt. Das Konzept der Triangulation meint in der qualitativen Sozialforschung die Kombination verschiedener Verfahren, um die „spezifischen Grenzen eines jeden Verfahrens zu berücksichtigen “ ${ }^{\text {40 }}$ und folglich über die Verbindung verschiedener Datenarten und Erhebungsmethoden zusätzliche Perspektiven zu gewinnen. Nach Norman Denzin kann man hierbei die Data-, Investigator-, Theory- und Methodological Triangulation unterscheiden. ${ }^{41}$ Dabei geht es - nachdem dies lange Zeit in der Fachmethodik kontrovers diskutiert worden ist - nicht um die naive Annahme, zusätzliche Perspektiven allein garantierten eine höhere Objektivität oder Validität, sondern um Triangulation „,als Weg zu mehr, umfassenderer oder vielschichtigerer Erkenntnis [...] und [...] dadurch neue Aktualität. “42 Im hier vorliegenden Fall wurden Aspekte der Data Triangulation (bei der Daten aus verschiedenen Quellen, betrachteten Personen oder auch unterschiedlichen Zeitpunkten miteinander kombiniert werden), der Investigator Triangulation (bei der verschiedene Beobachter ihre Deutungen beisteuern) sowie Theory Triangulation (bei der sich dem Forschungsthema von verschiedenen theoretischen Perspektiven genähert wird) miteinander verwoben: Dabei sind Einzelinterviews, Gruppendiskussionen und -gespräche wie auch teilnehmende Beobachtung miteinander kombiniert worden.

Konkret erfolgte eine erste Kontaktaufnahme mit den „Wortführern“ der jeweiligen Protestfelder im Rahmen von teilnehmenden Beobachtungen und Veranstaltungsbesuchen. Dabei wurden diese auch als Gatekeeper angesehen. Über mögliche Weiterempfehlungen sind nach dem Schneeballprinzip oftmals Gesprächspartner ausfindig gemacht und angesprochen worden. Bereits über diesen Feldzugang ließen sich Netzwerke und Machtbeziehungen identifizieren und sich somit der Protest bereits als eigenständiges soziales Phänomen analysieren. Diese vielschichtige Methode der Rekrutierung für die Fokusgruppen und Einzelinterviews war zwar aufwendig und ressourcenintensiv, jedoch auch deutlich erfolgreicher als alle anderen bisherigen Verfahren der Rekrutierung, die etwa auf den Karteien von Marktforschungsinstituten etc. beruhen. Innerhalb anderer Projekte des Göttinger Instituts für Demokratieforschung war zuvor etwa für Fo-

40 Loos, Peter / Burkhard Schäffer: Das Gruppendiskussionsverfahren. Theoretische Grundlagen und empirische Anwendung, Opladen 2001, S. 73.

41 Flick, Uwe: Triangulation, in: Bohnsack, Ralf / Winfried Marotzki / Michael Meuser (Hrsg.): Hauptbegriffe Qualitativer Sozialforschung, Opladen 2006, S. 161 - 162.

42 Flick: Triangulation, S. 161. 
kusgruppen immer wieder auf die Methode der Fremdrekrutierung zurückgegriffen worden. Hierbei wurde Zufallsrekrutierung oder Datenbanksysteme anhand vorgegebener Kriterien wie beispielsweise Einkommen oder Bildungsstand eine vermeintlich repräsentative Stichprobe gezogen. Dies erschien an dieser Stelle angesichts der Geschlossenheit des Feldes und der schon häufig gemachten negativen Erfahrung mit Fehlrekrutierungen in anderen Projekten durch Drittanbieter unpassend. Eine qualitative Studie, mit der suchend ein neues Feld erschlossen wird, liefert Ansätze des Verstehens und vermittelt Erklärungen, ohne dass sie den Anspruch erheben kann, wirklich vollständig und repräsentativ das gesamte Feld zu erfassen. Durch die multiperspektivisch gegliederte Rekrutierung sollte zudem ein möglichst breiter Ausschnitt derjenigen mit einbezogen werden, die die Protestlandschaft gestalten. Allerdings lassen sich auf diese Weise naturgemäß nicht alle Aktivisten beziehungsweise Typen von Aktivisten einfangen. So gibt es - ein Problem, welches viele Sozialwissenschaftler beeinträchtigen dürfte - diejenigen, die gar nicht an Studien teilnehmen wollen, sich in Interviews und Gruppengesprächen nicht offenbaren möchten oder die generell eine Diskussion ihrer politischen Orientierung ablehnen. Dieser Anteil einer Art „Ausfallquote“ variierte je nach Protestfeld. Auch haben vermutlich Bildungsgrad, berufliche Stellung und Alter, mitunter auch das Geschlecht, einen Einfluss auf die Beteiligungsbereitschaft zu einem Gespräch. Bedingt durch das Rekrutierungsmuster, die direkte persönliche Ansprache und durch die Zusicherung einer entsprechenden Anonymität ließ sich ein solcher Drop-Out-Effekt allerdings klein halten.

\section{Einzelinterviews}

Die individuellen Motive, biographischen Hintergründe, die Hoffnungen und Erwartungen der Protestierenden, standen im Zentrum von Einzelinterviews. Für eine erfolgreiche Anwendung dieses Instruments bedarf es variierender Methoden, die offen sind für verschiedene Deutungsformen und die den Blick für die Bildung von Hypothesen weiten. In den Sozialwissenschaften sowie in einigen Kulturwissenschaften ist die Form des narrativen Interviews nach Fritz Schütze ${ }^{43}$

43 Schütze, Fritz: Zur soziologischen und linguistischen Analyse von Erzählungen, in: Dux, Günter / Thomas Luckmann (Hrsg.): Beiträge zur Wissenssoziologie, Beiträge zur Religionssoziologie. Contributions to the sociology of knowledge, contributions to the sociology of religion, Band X, Opladen 1976, S. 7 - 41; Schütze, Fritz: Die Technik des narrativen Interviews in Interaktionsfeldstudien. Dargestellt an einem Projekt zur Erforschung kommunaler Machtstrukturen, Bielefeld 1977. 
seit einiger Zeit etabliert und methodologisch weit entwickelt. ${ }^{44}$ Ausgehend von einem erzählgenerierenden Impuls wird der Interviewte dabei zu einer autobiographisch ausgerichteten Haupterzählung angeregt, die ganz oder in Teilen die Lebensgeschichte des Befragten aus seiner eigenen Sicht wiedergibt. Dabei sollen ausdrücklich subjektive Einstellungen, Werthaltungen und Interessen zum Ausdruck kommen, weshalb der Interviewer seinen Gesprächspartner von Anfang an ermuntert, nach eigenen Schwerpunkten und Eindrücken Dinge zu vertiefen und auszuführen. Der Interviewer zeigt und artikuliert ein starkes Interesse an der Person, mit der er sich unterhält, und an deren Geschichte. Diese Offenheit und das Interesse kommen bereits in der Einleitung des Gesprächs zum Ausdruck und werden auch in den Nachfragen immer wieder deutlich gemacht. Der Interviewer knüpft dazu direkt an die Erzählung seines Gesprächspartners an, um offene Stellen zu schließen und um diesen zur Bilanzierung seines eigenen Handelns zu bewegen. ${ }^{45}$ Er besitzt im Idealfall weder einen Leitfaden noch versucht er, das Gespräch über den erzählgenerierenden Impuls hinaus auf Themen zu lenken, sondern stellt seine Frageweise darauf ab, den Gesprächsfluss am Laufen zu halten. Die Stärke dieses klassischen Verfahrens liegt darin, dass die Befragten sich gegenüber dem Interviewer öffnen und umfassend Auskunft geben, was den Blick auf hintergründige Argumentationsmuster freigibt. Diese Gesprächsform generiert wegen ihrer größtmöglichen Offenheit in beträchtlichem Umfang Informationen, die Auskunft über vergangene Prozesse geben und wie sie der Interviewpartner wahrgenommen hat. ${ }^{46}$

Aus zwei Gründen war die völlig offene Interviewtechnik aber für die hier verfolgte Fragestellung nicht beziehungsweise nur eingeschränkt geeignet. Erstens gehen beide Seiten mit einer gewissen Vorerfahrung in das Interview. Die Auswahl der Gesprächspartner erfolgte nicht vollkommen arbiträr, sondern weil politische Aktivisten und Engagierte der verschiedensten Richtungen bewusst angesprochen worden sind. In der vorangegangenen Gesprächsanbahnung wie in

44 Vgl. Küsters, Ivonne: Narrative Interviews. Grundlagen und Anwendungen, Wiesbaden 2006; Rosenthal: Interpretative Sozialforschung, S. 137; Rosenthal, Gabriele / Wolfram Fischer-Rosenthal: Analyse narrativ-biographischer Interviews, in: Flick, Uwe / Ernst von Kardorff / Ines Steinke (Hrsg.): Qualitative Forschung. Ein Handbuch, Reinbek bei Hamburg 2000, S. 456 - 468.

45 Vgl. Bude, Heinz: Der Sozialforscher als Narrationsanimateur. Kritische Anmerkungen zu einer erzähltheoretischen Fundierung der interpretativen Sozialforschung, in: Kölner Zeitschrift für Soziologie und Sozialpsychologie, Jg. 37 (1985) H. 2, S. 327 336, hier S. 328.

46 Vgl. Brüsemeister, Thomas: Qualitative Forschung. Ein Überblick, Wiesbaden 2000, S. 125. 
der konkreten Gesprächseröffnung wurde zwar ganz bewusst nicht der Begriff des „Aktivisten“ verwendet, doch die Interviewpartner waren sich im Klaren darüber, dass ihr Engagement in einem Protestzusammenhang der Grund dafür war, dass sie für ein Gespräch angefragt worden waren. Ebenso waren die Studienteilnehmer informiert, dass ihnen ein Sozialwissenschaftler gegenüber saß, der an einem „Institut für Demokratieforschung“ tätig ist. Insofern war bei allem Bemühen stets ein durchaus eingegrenztes Erkenntnisinteresse erkennbar oder für die Interviewten zumindest vermutbar, so dass eine gewisse Komponente einer „sozialen Erwünschtheit“ in den Antworten nicht ausgeschlossen werden konnte. ${ }^{47}$ Es stand folglich zu erwarten, dass auf diese Weise nie eine „vollständige" Lebensgeschichte erzählt wird - beziehungsweise das, was den Befragten als wesentlich erscheint -, sondern immer ein mit Bezug auf das Protestengagement beziehungsweise auf die Demokratie hin thematisch und vorauseilend gefilterter Ausschnitt.

Daneben ergibt sich aber als zweites Problem eines narrativen Fragens ein forschungspraktisches: Durch die offene Gesprächsführung erhält der Befragte viel Raum. Das hier verfolgte Erkenntnisinteresse konzentrierte sich aber nicht auf die Lebensgeschichte als solche, sondern auf die politische Lebensgeschichte in Bezug auf das aktive Engagement. Da die offene Methodik des narrativen Interviews erfahrungsgemäß leicht die vorhandenen zeitlichen Ressourcen hinsichtlich einer sachgerechten Auswertung übersteigt ${ }^{48}$, hätten die auf die Art zusätzlich generierten Daten leicht den Rahmen des Projektes gesprengt. Daher war eine stärker problemzentrierte Perspektive geboten. Robert Merton und Patricia Kendall haben dafür das fokussierte Interview in die sozialwissenschaftliche Methodenentwicklung eingebracht. ${ }^{49}$ Dieses versucht ebenfalls über Stimuli, den Gesprächspartner zum Erzählen zu bringen, es ermöglicht zugleich aber eine Engführung des Themas während des gesamten Gesprächs oder einzelner Phasen. Zielsetzung des fokussierten Interviews ist es, die subjektiven Erfahrungen auf der Grundlage einer konkreten Situation zu erfahren. ${ }^{50}$ Obwohl alle Gesprächsteilnehmer in sehr unterschiedlicher Form aktiv waren, bildete ihr jewei-

47 Vgl. dazu Reinecke, Jost: Interviewer- und Befragtenverhalten: theoretische Ansätze und methodische Konzepte, Opladen 1991, S. 94 - 103.

48 Aufenanger, Stefan: Qualitative Analyse semi-struktureller Interviews - ein Werkstattbericht, in: Garz, Detlef / Klaus Kraimer (Hrsg.): Qualitativ-empirische Sozialforschung. Konzepte, Methoden, Analysen, Opladen 2000, S. 35 - 59.

49 Vgl. Merton, Robert K. / Patricia L. Kendall: Das fokussierte Interview, in: Hopf, Christel / Allen H. Barton / Fridlinde Büchner (Hrsg.): Qualitative Sozialforschung, Stuttgart 1979, S. $171-204$.

50 Ebenda, S. 171; auch Kern: Empirische Sozialforschung, S. 175. 
liges aktives Engagement und ihre Partizipation diese konkrete Situation und gemeinsamen Nenner. Es war demnach für das Erkenntnisinteresse des Vorhabens naheliegend, eine Einstiegsfrage so zu wählen, dass die Form und individuelle Motivation der Aktivität in den Fokus gerückt wird und mit dem jeweils biographischen Hintergrund verknüpft werden konnte. Aus der eingangs entwickelten Beobachtung, dass es oftmals sich wandelnde Erwartungen sind, die an die Demokratie oder Politik gerichtet werden, die eine Vertrauenskrise auslösen, bot sich auch hier an, zu fragen, ob sich der jeweilige Protest möglicherweise als Reaktion auf ein gewandeltes Verhältnis zur Politik deuten lässt. Eine gewachsene oder grundsätzliche Unzufriedenheit mit der Funktionsweise der repräsentativen Demokratie und ihrer realen Einflussmöglichkeiten - so ein u.a. von Colin Crouch unter dem Schlagwort Postdemokratie in die wissenschaftliche Debatte eingeführter Gedanke ${ }^{51}$ - könnte jedenfalls dem Handeln bzw. Aktivwerden zugrunde liegen. Ein auf diese Weise vorgehendes Fragen setzt allerdings voraus, dass wir den Gesprächsteilnehmern auch die Gelegenheit bieten, sich zunächst in narrativer Form zu äußern. Nun plädieren Merton und Kendall aber sehr entschieden für die Verwendung eines Leitfadens, der ihnen schon alleine deswegen geboten erscheint, weil nur so die Vergleichbarkeit der Interviews gewährleistet ist. $^{52}$

In der Konsequenz beider Anforderungen (Offenheit und Vergleichbarkeit) wurde eine Verbindung beider Ansätze angewandt, wie sie auch Christel Hopf empfiehlt. ${ }^{53}$ Die Interviews gliederten sich dabei in einen stärker narrativen und einen nachfolgenden fokussierten Teil. Die Einstiegsfrage sollte zunächst zur Erzählung anregen und bezog sich darauf, wann der oder die Gesprächspartner/in das erste Mal in Kontakt mit Politik gekommen sind. Anschließend wurde nachgefragt, wie sich seitdem die Einstellung und die Beziehung zur Politik entwickelt haben. Das Gespräch wurde also auf den Kontext Politik fokussiert, zugleich aber so offen gelassen, dass dieser aus der subjektiven Wahrnehmung und Perspektive und mit individuellen Schwerpunktsetzungen heraus beschrieben werden konnte. Die Narration diente dazu, die Interviewpartner zu veranlassen, ruhig gründlich und umfassend ihre Sicht der Dinge darzustellen. Wie im narrativen Interview üblich, wurden Nachfragen dazu eingesetzt, den Redefluss zu unterstützen, ohne gleichzeitig diesen in Richtung des engeren Fokus zu steuern. Erst im späteren Verlauf des Gesprächs wurde dann, soweit noch

51 Crouch, Colin: Postdemokratie, Bonn 2008.

52 Vgl. Merton: Das fokussierte Interview, S. 184.

53 Vgl. Christel Hopf: Qualitative Interviews - Ein Überblick, in: Flick, Uwe / Ernst von Kardorff / Ines Steinke (Hrsg.): Qualitative Forschung. Ein Handbuch, Reinbek bei Hamburg 2000, S. 349 - 360; Rosenthal: Interpretative Sozialforschung, S. 152. 
erforderlich, flexibel auf Leitfragen zurückgegriffen, um die Unterhaltung auf die drei Kategorien „Politisierung und Aktivismus“, „Einstellung zu konventionellen Beteiligungsformen“ sowie „Arbeit und Ziel in der konkreten Protestgruppe" zu lenken.

Gerade weil Protest von außen häufig mit Gesellschaftskritik identifiziert wird, gaben sich die Studienteilnehmer mitunter vorsichtig bis skeptisch. Um damit umzugehen und mögliche Blockaden abzubauen oder gar nicht erst entstehen zu lassen, wurden Techniken im Sinne des von Kaufmann entwickelten verstehenden Interviews bemüht, welche davon ausgeht, dass der Gegenüber Anhaltspunkte braucht, um seine eigenen Äußerungen entwickeln zu können. ${ }^{54}$ Der Interviewer soll nach dieser Methode möglichst Empathie und Sympathie vermitteln und sich freundlich, positiv und offen für alles zeigen und somit auf den Gesprächspartner eingehen. ${ }^{55}$ Der Befragte soll in die Lage versetzt werden, den Fragenden einzuschätzen und sich stärker auf die Gesprächssituation einlassen können. Auf diese Weise kann, laut Kaufmann, eine entstehende Distanz zwischen Interviewer und Interviewtem durchbrochen und die offene Erzählung einer politischen Biographie unterstützt werden. ${ }^{56}$

Diese kombinierte Herangehensweise lieferte schließlich Erkenntnisse, die es für das Projekt des Göttinger Instituts für Demokratieforschung ermöglichten, insgesamt 80 Einzelinterviews in den sehr verschiedenen Protestfeldern mit einem forschungsökonomisch vertretbaren Zeitaufwand auswerten zu können. Die halbstrukturierte Vorgehensweise vereinfachte die Auswertungsroutinen, ohne dass sie den Erkenntnisgewinn schmälerte.

\section{Gruppendiskussionen}

In den Einzelinterviews sollten durch Frageweise und Nachfragefokus individuelle Motive und Perspektiven herausgearbeitet werden. So lässt sich etwa näherungsweise verstehen, warum und aus welchen Gründen jemand aktiv wird bzw. individuell den Weg zu einer Protest-Betätigung findet. Gleichwohl bleiben in einem Einzelgespräch aber Dimensionen des Protests zwangsläufig ausgeklammert oder unterbelichtet, die für das Verständnis des Phänomens enorm aufschlussreich sein dürften. Denn ein wichtiger Faktor der Entwicklung und Persistenz von Engagement und bürgerlichem Protest ist seine Dynamik und die soziale Interaktion als stabilisierender Faktor der Gruppen. Dies kann zwar auch Thema der Einzelgespräche sein, bleibt aber hier auf die jeweils individuelle

54 Vgl. Kaufmann, Jean-Claude: Das verstehende Interview, Konstanz 1999.

55 Vgl. Kaufmann: Das verstehende Interview, S. 77f.

56 Ebenda, S. 91. 
Perspektive und Reflektion beschränkt. Kollektive Orientierungsmuster hingegen, Gemeinsamkeiten von Protestierenden, dürften in Gruppengesprächen, -diskussionen oder Fokusgruppen sehr viel plastischer herauszustreichen sein. ${ }^{57}$ Anders als bei Einzelinterviews sei man hiermit in der Lage, „die Orientierungsund Legitimitätsmuster der einzelnen Gruppen zu rekonstruieren. “58 Denn die individuelle Rechtfertigung oder Erklärung für ein Aktiv-Werden, ein Engagement oder einen Protest mag jeweils plausibel und folgerichtig in den eigenen Lebenslauf eingepasst werden können, der Schritt von der Erkenntnis zur Aktion nachvollziehbar werden. In der jeweils individualisierten Betrachtung von Wut, Protesthaltung und möglicher Partizipationsbereitschaft soll sich das vorliegende Projekt aber nicht erschöpfen, sondern dezidiert den mehr subkutanen ,gemeinsamen Zentren der Erfahrung "59 nachzuspüren. Deswegen galt es eine Erhebungsform zu finden, die den Ertrag der Einzelinterviews sinnvoll ergänzt. Dabei ist einzubeziehen, dass Menschen sich in einem institutionellen Kontext bewegen, der zur Herausbildung politischer Aktivität essentiell ist. Diese Institutionen sind die formellen und informellen Regeln, welche das Zusammenleben und Zusammenagieren von Menschen beeinflussen. ${ }^{60}$ Wenn Menschen sich mit Gleichgesinnten zusammenschließen, setzen sie bestimmte Umgangsformen voraus und haben bestimmte Erwartungswerte. Sie tasten sich in den Gruppenprozessen vor und testen aus, ob ihre Vorstellungen mit denen ihrer Mitstreiter übereinstimmen. Sie übernehmen dabei bestimmte Strukturmuster oder versuchen, diese zu verändern. Anders ausgedrückt: „Die Meinungsstruktur eines Individuums [...] ist ein soziales Produkt von Interaktionen“. ${ }^{61}$ Und es sind diese Interaktionen und Kommunikationsstrukturen, die in diesem Rahmen von Interesse und Belang sind: „Gruppendiskussionen verstehen das Kollektive aus dem Zusammenhang einer gemeinsamen Kommunikationsgeschichte. “62

Eine Schwierigkeit bei dieser Herangehensweise bleibt, dass bei der Rekonstruktion der Entstehungszusammenhänge von sozialen Bewegungen und gesellschaftlichen Protestformen die tatsächlichen Motivlagen und Konstellationen der ursprünglichen Formierung nicht so rekonstruiert werden können, dass zweifels-

57 Vgl. Ernst: Freiwilliges Engagement als Gegenstand von Gruppendiskussionen, hier S. 170 und 172.

58 Ebenda, S. 172.

59 Loos / Schäffer: Das Gruppendiskussionsverfahren, S. 28.

60 Konstanze, Senge: Zum Begriff der Institution im Neo-Institutionalismus, in: Dies. / Kai-Uwe Hellmann (Hrsg.): Einführung in den Neo-Institutionalismus, Wiesbaden 2006, S. $35-47$.

61 Lamnek, Siegfried: Gruppendiskussion. Theorie und Praxis, Weinheim 2005, S. 132.

62 Ernst: Freiwilliges Engagement, S. 172. 
frei Erkenntnisse darüber gewonnen werden, welche Institutionen das Handeln des Einzelnen in dem Augenblick seiner politischen ,Erweckung' beeinflusst haben. Das Erzählen über vergangene Erfahrungen und Beweggründe ist zwangsläufig perspektivisch eingepasst in die individuelle Schilderung der Lebensgeschichte. Gruppendiskussion bieten sich an dieser Stelle aber als probates Hilfsmittel an, um diese Lücke zumindest zu verkleinern. Sie haben den Vorteil, dass sie im besten Falle eine Diskussion zwischen den Gesprächspartnern erzeugen, die in ihrer Struktur den alltäglichen Meinungsbildungsprozess nachbildet und in der die Teilnehmer über weite Strecken möglichst ohne direkte Lenkung der Forscher miteinander kommunizieren und dabei wie in einer Art diskursivem Vergleich Meinungen, Einstellungen aber eben auch Diskussionsroutinen in verschiedenen Protestkulturen deutlich zu Tage treten lassen. ${ }^{63}$ Dieses Instrument wird in der Markt- und Meinungsforschung gerne verwendet, wohingegen in den Sozialwissenschaften der Einsatz lange Zeit eher selten war und deswegen auch die Methodologie immer noch als ergänzungsbedürftig eingeschätzt wird. ${ }^{64}$ Gleichwohl gibt es seit den 1950er Jahren immer wieder entsprechende Forschungsansätze. ${ }^{65}$ In den letzten Jahren wird sogar eine wachsende Beliebtheit des Instruments konstatiert ${ }^{66}$ und auch das Göttinger Institut für Demokratieforschung hat bereits in früheren Untersuchungen reichliche Erfahrungen mit dieser Methode gesammelt, auf welche der Autor hier zurückgreifen kann. ${ }^{67}$

63 Vgl. hierzu: Przyborski, Aglaja / Julia Riegler: Gruppendiskussion und Fokusgruppe, in: Mey, Günter / Katja Mruck (Hrsg.): Handbuch Qualitative Forschung in der Psychologie, Wiesbaden 2010, S. 436-448., hier S. 440; Bremer, Helmut: Von der Gruppendiskussion zur Gruppenwerkstatt. Ein Beitrag zur Methodenentwicklung in der typenbildenden Mentalitäts-, Habitus- und Milieuanalyse, Münster 2004, S. 105; Lamnek, Siegfried: Qualitative Sozialforschung. Lehrbuch, Weinheim 2005, S. 414ff.; Blank, Renate: Gruppendiskussionsverfahren, in: Naderer, Gabriele / Eva Balzer (Hrsg.): Qualitative Marktforschung in Theorie und Praxis. Grundlagen, Methoden und Anwendungen, Wiesbaden 2011, S. 289-312, hier S. 295.

64 Zum Beispiels von Lamnek, Siegfried: Qualitative Sozialforschung, Lehrbuch, Weinheim 2005, S. 411; Przyborski u.a., Gruppendiskussion, S 444.

65 Für Deutschland maßgeblich: Pollock, Friedrich: Gruppenexperiment. Ein Studienbericht, Frankfurt a. M. 2005; Lamnek: Gruppendiskussion.

66 Blank: Gruppendiskussionsverfahren, S. 292.

67 Vgl. Klatt u.a.: Entbehrliche der Bürgergesellschaft?; Lühmann, Michael u. a.: Zeitgeisteffekt oder grüner Wertewandel? Die neuen grünen Wähler_innen in SchleswigHolstein, online einsehbar unter: http://www.demokratie-goettingen.de/content/uploads/2012/01/BERICHT_Gr\%C3\%BCne_Neuw\%C3\%A4hler_innen_SchleswigHolstein1.pdf [eingesehen am 28.08.2014]. 
Die in der Gruppendiskussion zum Gespräch eingeladenen Teilnehmer sind dabei zumeist keine tatsächlich gemeinsam agierende Realgruppe, denn eine Gruppenprozessanalyse der Meinungsbildung steht nicht in erster Linie im Zentrum des Forschungsinteresses. ${ }^{68}$ Es liegt aber doch ein geteilter Wertehintergrund zugrunde, auf dem gemeinsame Hintergründe, Erfahrungen im Engagement und mit bislang Erreichtem diskutiert werden können. Diese Herangehensweise bewegt sich weniger in der deutschen Tradition der offenen Gruppendiskussion, sondern ist eher am outputorientierten Vorgehen der Fokusgruppen orientiert, welches sich vor allem in der US-amerikanischen Forschung einer großen und wachsenden Beliebtheit erfreut. ${ }^{69}$ Fokusgruppen haben für den Sozialwissenschaftler den besonderen Vorteil, dass die Teilnehmer in ihnen versuchen müssen, ihrer Argumentation ,einen gewissen Grad an Allgemeingültigkeit“" zu verleihen. ${ }^{70}$ Die Bedeutungsgehalte der verwandten Begriffe etwa müssen in der Diskussion plausibel gemacht werden ${ }^{71}$, und auch die ,Kontextualisierungshinweise ${ }^{\text {“72 }}$ der Dramaturgie der Diskussionen geben wertvolle Fingerzeige auf den gemeinsamen Erfahrungshintergrund der Gesprächsteilnehmer - und wie dieser beschaffen ist. „In einem Sich-wechselseitig-Steigern und -Fördern, im diametralen Gegeneinander, in der kommentierenden Ergänzung oder auch in der systematischen Vereinnahmung der anderen finden jeweils andere Formen fundamentaler Sozialität ihren Ausdruck. Damit ist ein empirischer Weg geöffnet, um identifizieren zu können, ob den Beteiligten ein Erfahrungsraum gemeinsam ist oder nicht. “" ${ }^{73}$ Diese Herangehensweise erlaubt es, in der Datenerhebung rasch Hypothesen und weitergehende Fragestellungen zu erarbeiten. Bedingt durch die - allerdings nicht zwingend personenidentische - Kombination mit den Einzelinterviews ermöglicht dieses Forschungsdesign daher eine weitere Reflexionsebene.

68 Vgl. dazu Loos / Schäffer: Das Gruppendiskussionsverfahren, S. 43ff.

69 Blank: Gruppendiskussionsverfahren, S. 294; Krueger, Richard A.: Focus groups. A practical guide for applied research, Los Angeles 2009; Bremer: Gruppendiskussion, S. 109.

70 Puchta, Claudia / Stephan Wolff: Diskursanalysen institutioneller Gespräche - das Beispiel von 'Focus Groups', in: Keller, Reiner (Hrsg.): Handbuch Sozialwissenschaftliche Diskursanalyse, Opladen 2003, S. 439 - 456, hier S. 454.

71 Vgl. Ernst: Freiwilliges Engagement, S. 170.

72 Vgl. Bohnsack, Ralf / Aglaja Przyborski: Diskursorganisation, Gesprächsanalyse und die Methode der Gruppendiskussion, in: Bohnsack, Ralf / Aglaja Przyborski / Burkhard Schäffer (Hrsg.): Das Gruppendiskussionsverfahren in der Forschungspraxis, Opladen \& Farmington Hills 2010, S. 235 - 248, hier S. 234.

73 Vgl. ebenda, S. 235. 
Über sieben Untersuchungsgruppen der Gesellschaftsstudie, deren Daten dieser Arbeit zugrunde liegen, wurden jeweils ein bis vier Gruppendiskussionen geführt, insgesamt 18. Auf diese Weise konnten auch Bereiche und Ebenen identifiziert werden, in denen die Teilnehmer aber doch gemeinsam agiert haben bzw. in denen nicht nur eine gemeinsame Reflexionsebene existierte, sondern es kollektiv geteilte, konkrete Handlungserfahrungen gegeben hat. Dies war etwa der Fall, wenn bei den Gruppendiskussionen zum Protest gegen den Stuttgarter Bahnhofsumbau zwar keine miteinander bereits arbeitenden Protestgruppen zum Gespräch eingeladen waren, aber doch alle Teilnehmer letzten Endes auf gemeinsame Erlebnisse zurückgreifen konnten, da sie an denselben oder ähnlichen Demonstrationen, Mahnwachen, Aktionen etc. teilgenommen hatten. Die Gesprächsrunden standen so - aber nicht ausschließlich - bereits miteinander in einem Handlungszusammenhang oder es war erwartbar, dass sie miteinander hätten agiert haben können, weil sie bereits ähnliche Ziele und Interessen verfolgt hatten. In der konkreten Gruppendiskussion kam es dann darauf an, den Teilnehmern die Möglichkeit zu geben, modellhaft denkbare Arbeitsstrukturen und Protestformen zu entwickeln. Denn der oben erwähnte ,Zusammenhang einer gemeinsamen Kommunikationsgeschichte “74 verlangt für die Beobachtung, dass die Teilnehmer versuchen, von ihren ursprünglich individuellen Bedürfnissen und Zielsetzungen auszugehen und dass sich so in der Gruppe ein mögliches gemeinsames Interesse und Bewusstsein durch ,wechselseitige Bezugnahme und Herausforderung im (Gruppen-)Diskurs“ herausbildet. ${ }^{75}$ Dabei geht es um die Erschließung gemeinsamer Sprach- und Argumentationsmuster, Erfahrungen und Schlüsselmomente, geteilter Interpretationen und Hoffnungen. Somit ergibt sich nicht nur ein tiefer Einblick in das „Innenleben“ der Protestbewegung, sondern auch in ihre Selbstwahrnehmung, Narrationen, Deutungen von Umfeld und Zusammenhängen, Inszenierungs- und Mobilisierungstechniken und hier auch im Bezug zu den beschriebenen Diskurskoalitionen: Um die Frage danach, wie diese Narrationen und Deutungen eigentlich entstehen und wie diese dann für die Protestarbeit gebraucht werden.

Gruppendiskussionen im Allgemeinen folgen meist einer ganz bestimmten Grundstruktur, die eine Aufwärmphase beinhaltet, Rollenstrukturen herausbilden lässt und in der die Debatte am Ende ausklingt. ${ }^{76}$ Hinsichtlich der Reproduzier-

74 Vgl. Ernst: Freiwilliges Engagement, S. 172.

75 Bohnsack, Ralf: Gruppendiskussionsverfahren und Milieuforschung, in: Friebertshäuser, Barbara / Annedore Prengel (Hrsg.): Handbuch qualitative Forschungsmethoden in der Erziehungswissenschaft, Weinheim 1997, S. 492 - 502, hier S. 292.

76 Blank: Gruppendiskussionsverfahren, S. 296 ff.; Lamnek: Gruppendiskussion. S. 135ff.; Loos / Schäffer: Das Gruppendiskussionsverfahren, S. 49 - 55. 
barkeit der Ergebnisse wird eine „gewisse Standardisierung“ als notwendig erachtet. ${ }^{77}$ Aus diesem Grund wurde ein teilstandardisierter Leitfaden verwandt, der die gängige Grundstruktur abbildet und wie im fokussierten Interview dem einzelnen Teilnehmer wie der Gruppe Freiräume zum Assoziieren und Erzählen bietet. Die Fruchtbarkeit der Ergebnisse einer Gruppendiskussion hängen jedoch nicht allein von der geschickten Diskussionslenkung bzw. den Vergleichsgrundlagen durch eine standardisierte Vorgehensweise ab, sondern nicht zuletzt von Fingerspitzengefühl und Situationsgespür des Moderators. Gerade weil der verwandte Themenkatalog und Gesprächsleitfaden, mit einer Dauer von zweieinhalb bis drei Stunden und damit sehr lang angesetzt war, wurden jeweils Moderatorenteams mit der Leitung der Diskussionen bedacht. Dabei wurde stets darauf geachtet, dass sich die Moderatoren möglichst konstruktiv ergänzten. So wurde zumeist ein gemischt geschlechtliches Moderatorenduo eingesetzt, von dem einer der beiden in die Protestthematik der Gruppenteilnehmer eingearbeitet, mit den Details bekannt war, und der zweite als „unwissender“ Moderator auch darauf achtete, dass bestimmte nicht-hinterfragte Begrifflichkeiten oder von den Teilnehmern bereits als selbstverständlich geteilte Bedeutungen entweder zur Sprache kamen oder wenigstens verzeichnet wurden. Die Moderatoren teilten sich im Vornherein die Moderationsblöcke untereinander alternierend auf, waren jedoch auf verabredete Zeichen hin auf die Intervention des Partners eingestellt. So konnten die Gruppendynamik präziser beobachtet und Nachfragen gezielter eingebracht werden.

Um als Moderator eine Gruppe möglichst offen und nicht vorbestimmend steuern zu können, ohne zeitgleich aber eine wünschbare Vergleichbarkeit der verschiedenen Gruppen zu vernachlässigen, muss man den Themenleitfaden verinnerlicht haben und sich frei in der Diskussion bewegen können. Durch ihr $\mathrm{Zu}$ sammenspiel sollten die Moderatoren in der Lage sein, situationsoffen und mit Empathie auf Menschen zuzugehen oder sich auch in den entsprechenden Momenten zurücknehmen zu können, um auf diese Weise den Gesprächsteilnehmern Freiraum und auch Ermutigung für die Entfaltung ihrer Gedanken sowie persönlichen Erfahrungen zu geben. ${ }^{78}$ Der Moderator sollte die gängigen Fragetechniken beherrschen und sich von der offen formulierten Einstiegsfrage oder auch einer offenen Exploration zu immer spezifischeren Vertiefungsfragen steigern, dabei gezielt zu persönlichen Erfahrungen und Einstellungen nachfragen und die anderen Teilnehmer zu einer Auseinandersetzung mit dem Gesagten

77 Bohnsack: Gruppendiskussionsverfahren, S. 499.

78 Vgl. dazu auch grundlegend Werner Mangold: Gegenstand und Methode des Gruppendiskussionsverfahrens: Aus der Arbeit des Instituts für Sozialforschung, Frankfurt a.M. 1960, S. $116-122$. 
animieren. ${ }^{79}$ Das Steuern des Gesprächs mittels aktiven Zuhörens und Paraphrasierens sind dabei die wichtigsten Techniken. ${ }^{80}$ Das Ziel innerhalb der jeweiligen Themenblöcke ist stets eine Selbstläufigkeit der Gruppe, welche dann - möglichst ohne Intervention durch die Moderatoren - mit sich selbst im Gespräch ist und so Werthaltungen und Einstellungen offenlegt.

Diese relativ intimen, persönlichen Informationen können aus Gruppendiskussionen nur dann erschlossen werden, wenn die Gesprächsteilnehmer im Laufe der Unterhaltung die Laborsituation, in der sie sich eigentlich befinden, nach und nach ,vergessen“. Daher musste gerade für das Protestmilieu die Auswahl des Raumes, in dem die Gruppendiskussion stattfand, sehr sorgfältig getroffen werden. Üblicherweise werden Fokusgruppen in Marktforschungsstudios oder in ähnlich sterilen Räumlichkeiten durchgeführt. Hier sind die Kameras häufig unauffällig an der Decke fixiert, Tischmikrofone nehmen das Gesagte auf und eine verspiegelte Scheibe ermöglicht den Beobachtern, versteckt das Geschehen zu verfolgen. Solche Studios befinden sich jedoch nur in (Groß-)Städten. Da im Rahmen der Proteststudie auch Gruppendiskussionen auf dem Land durchgeführt wurden, musste hier auf alternative Räumlichkeiten ausgewichen und die Diskussionen mittels eigenen Kameras und Mikrofonen aufgezeichnet werden. Gelegentlich wurden die Gespräche auch unmittelbar bei den von uns untersuchten Protestgruppen durchgeführt. Dies hatte den Vorteil, dass die sogenannte Aufwärmphase quasi übersprungen wurde, die Teilnehmer kaum mit der Örtlichkeit fremdelten und sich sofort in das Gespräch einfinden konnten. Auf der anderen Seite war es für die Moderatoren mitunter schwieriger, die Gruppe auf Gesprächsregeln beziehungsweise Rahmenbedingungen festzulegen. Es war in

79 Da sich die Sozialwissenschaften bisher relativ wenig mit der Frage einer gelungen Fokusgruppenmoderation auseinandergesetzt hat, muss hier auf Managementliteratur und Arbeitsbücher aus dem Marketingsegment zurückgegriffen werden. Vgl. beispielsweise Seifert, Josef W.: Moderation und Kommunikation, Gruppendynamik und Konfliktmanagement in moderierten Gruppen, Offenbach 1999; Myksok, Alexander D. I Anna E. Jäger: Moderieren in Gruppen und Teams. Handbuch für Moderation, Paderborn 2008; Krueger, Richard A.: Moderating Focus Groups. The Focus Group Kit, Bd. 4, Thousand Oaks 1998; Greenbaum, Thomas L.: Moderating Focus Groups. A Practical Guide for Group Facilitation, Thousand Oaks 2000; Benighaus, Christina / Ludger Benighaus: Moderation, Gesprächsaufbau und Dynamik in Fokusgruppen, in: Schulz, Marlen / Birgit Mack / Ortwin Renn (Hrsg.): Fokusgruppen in der empirischen Sozialwissenschaft. Von der Konzeption bis zur Auswertung, Wiesbaden 2012, S. $111-132$.

80 Hierzu auch: Kühn, Thomas / Kay-Volker Koschel: Gruppendiskussionen. Ein PraxisHandbuch, Wiesbaden 2011, S. 139 - 171. 
diesem Fall aufwändiger, die Teilnehmer für die Dauer der Diskussionsrunde am Tisch zu halten, diese an die zuvor verabredeten Pausen zu binden und den Gegenstand der Diskussion anhand des Gesprächsleitfadens vorzugeben.

Die Fragen nach der im Erkenntnisinteresse ,besten“ Rolle des Moderators und der idealen Räumlichkeit, in der die Fokusgruppe durchgeführt wird, können nicht eindeutig oder allgemeingültig beantwortet werden. Und auch die Entscheidung für eine möglichst produktive Gruppengröße ist nicht universell oder formelhaft zu verstehen. Während die sozialwissenschaftliche Literatur zu dieser Frage eine Spanne von neun bis zwölf Teilnehmern angibt ${ }^{81}$, empfiehlt der Arbeitskreis für qualitative Forschung des Berufsverbands Deutscher Markt- und Sozialforscher eine Größe von acht Teilnehmern. ${ }^{82}$ Die Erfahrung der bisher am Göttinger Institut für Demokratieforschung durchgeführten Gruppengespräche, Kreativ- oder Fokusgruppen lässt hier eine andere Gewichtung sinnvoll erscheinen: Die Gruppengröße hängt dabei stark von den im Gespräch behandelten Themen und der angenommen Nähe der Teilnehmer zu den Diskussionsgegenständen ab. Eine Fokusgruppe mit politikfernen Gästen, die ausschließlich auf die Einstellung zu und Erwartungen an Politik fokussiert ist, kann sicherlich mit acht oder neun Teilnehmern durchgeführt werden. Befragt man allerdings - wie im hier vorliegenden Fall - politisch aktive Menschen, die häufig über das reflektieren, was Gegenstand der Gruppendiskussion sein soll und die es überdies als Wortführer oder zentrale Personen innerhalb ihres Protestzusammenhanges auch gewohnt sind, sich und ihre Meinungen vor einer Gruppe zu präsentieren, ist eine deutlich kleinere Gruppengröße mit fünf bis sieben Teilnehmern wesentlich geeigneter.

Gruppendiskussionen sind eine komplexe Methode, welche einer gründlichen Vorbereitungszeit, einer genauen Rekrutierung, geschulter Moderatoren und einer reflektierten Auswertung bedarf und bei der sich die jeweilige Ausgestaltung dem Untersuchungsgegenstand anpasst. Dies gilt nicht nur für die Räumlichkeit, die Gruppengröße oder auch die Anzahl der Moderatoren, sondern auch und vor allem für die Gesprächsmethoden und auch die Sprache und Begriffe, mit der die Teilnehmer konfrontiert werden. Ein hohes Maß an Reflexion und Flexibilität im Forschungsprozess ist dabei erforderlich. Nur, wenn man in der Gestaltung der Rahmenbedingungen offen, kreativ und dem jeweiligen Forschungsgegenstand situativ angepasst vorgeht, kann die Methode der Gruppendiskussion für die Sozialwissenschaften eine ,entdeckende“ Quelle darstellen.

Der Themenleitfaden allerdings ist dabei eine Art Konstante geblieben, die über die verschiedenen Gruppendiskussionen hinweg trotz aller Betonung der

81 Vgl. beispielsweise Lamnek: Gruppendiskussion, S.111 - 132,

82 Vgl. Kühn u.a.: Gruppendiskussionen, S. 86. 
forschungstechnischen Offenheit in seiner Grundstruktur nicht verändert worden ist. Dies bleibt vor dem Hintergrund einer Fragestellung, die unterschiedliche Protestgruppen und -zusammenhänge in den Blick nimmt, eine Grundbedingung, um eine gewisse Vergleichbarkeit zu gewährleisten. Der für das Projekt entwickelte Themenleitfaden sollte dabei einerseits die Bereiche gegenwärtiger und vergangener Engagement- und Protesterfahrungen abdecken und andererseits die Einstellung zu Politik, Demokratie und Gesellschaft zur Sprache bringen. In verschiedenen Gesprächsphasen sollte sich etwa assoziativ dem Begriff der Demokratie genähert werden, wobei stets die Verknüpfung zwischen konkreten Situationen und ihrer Wahrnehmung und Verarbeitung im Mittelpunkt stand. Unterschiede oder Einigkeit über den Begriff von Demokratie, Protest oder der Rolle von Politik offen zu legen, war dabei auch die Aufgabe der Moderation. ${ }^{83}$ Der Gesprächsleitfaden diente dann als eine Art Drehbuch für punktuelle Nachfragen, um die Diskussion zu fokussieren. Und durch die stete Aufforderung, Beispiele und eigene Erfahrungen anzuführen, sollte die Diskussion weiterhin Raum für freie Assoziationen bieten, gleichzeitig aber analog zur Fragerichtung der Einzelinterviews an den biographischen Erfahrungshintergrund der Diskussionsteilnehmer angekoppelt bleiben. Zu verhindern war allerdings ein zu stark Suggestivkraft entfaltendes Nachhaken von Seiten der Moderatoren, um bei Themen zu Demokratie und Gesellschaft keinen Druck in Richtung einer sozialen Erwünschtheit der Antworten entstehen zu lassen und den Prozess der Selbstvergewisserung innerhalb der Gruppe zu verfälschen. Wichtig war dabei eine Sensibilität der Moderatoren, um eine produktive Balance zwischen Anregung, Nachfragen und emphatischem Zuhören zu finden.

Weiters wurden in den Gruppengesprächen Untergruppen gebildet, in denen die Teilnehmer darüber räsonierten, wie sie als Bürger mit einer sie betreffenden gesellschaftlichen Konfliktsituation umgehen würden. Die persönliche Betroffenheit, die fiktiv mit einer Aufgabe geschaffen wurde, diente als Stimulus, um einen Brückenschlag zum individuellen Interesse und dem realen Engagement herzustellen. Je nach Themengebiet wurde hier eine Situation konstruiert, die den Diskussionsteilnehmern auf Grund ihrer bisherigen Konflikterfahrungen vertraut sein durfte. So wurde etwa bei den Fokusgruppen im Untersuchungsgebiet „Infrastruktur und Stadtentwicklung“ ein an die Dresdner Waldschlösschenbrücke erinnerndes, fiktiv formuliertes Szenario präsentiert, mit dem sich die Teilnehmer in der Kleingruppe auseinandersetzen sollten. Die Aufgabe war, einen Plan zu entwickeln, wie sie in einem solchen Fall handeln würden. Zwei Teilgruppen sollten visualisiert darstellen und anschließend einander präsentieren,

83 Vgl. zu diesen Anliegen und Techniken auch exemplarisch Klebert, Karin: Moderations-Methode. Das Standardwerk, Hamburg 2006. 
wie sie sich organisieren, welche Methoden und Mittel sie anwenden würden und wie ihr Zeitplan aussähe. Ziel und Erkenntnishoffnung war dabei, dass die Gesprächsteilnehmer ihren jeweiligen Erfahrungshintergrund einbringen, um ihre Einstellungen und Positionen nicht nur in der Gruppe zu aktualisieren, sondern dass diese sich auch konkret im Diskurs und in Perspektiven auf Herangehensweise und Arbeitsgang der Kleingruppe wiederspiegeln. ${ }^{84}$ In dem sich daran anschließenden letzten Themenblock wurde nach Wirkungsort und -intention ihres konkreten Protestengagements gefragt und um einen erneuten Perspektivwechsel gebeten: In einem Gedankenexperiment über die „,ideale Gesellschaft“ sollten zum Ende der Diskussion - auch ein wenig resümierend - Visionen und Zukunftshoffnungen sowie mögliche individuelle oder gruppenspezifische politische Zielsetzungen im Zentrum der Debatte stehen.

\section{Teilnehmende Beobachtung}

Eine zusätzlich verwandte Methode, die die Eindrücke aus den Interviews und Fokusgruppen ergänzen und aus anderer Perspektive vervollständigen sollte und die darüber hinaus der Rekrutierung weiterer Studienteilnehmer diente, war die teilnehmende Beobachtung. Diese ist - wie schon in den Abschnitten zur Stadtsoziologie beschrieben - seit der Chicagoer Schule der Soziologie der 1920er Jahre $^{85}$ und seit der für den deutschen Sprachraum zentralen Studie über die Arbeitslosen von Marienthal ${ }^{86}$ durchaus verbreitet, vor allem Ethnologen greifen auf diese Herangehensweise zurück. ${ }^{87}$ Die Marienthal-Studie sowie die Vorgehensweisen der Chicago School wurden auch in der vorliegenden Untersuchung als Inspiration und Anleihe herangezogen. Die von Paul Lazarsfeld angeleiteten Sozialwissenschaftler arbeiteten in Marienthal mit den bis dahin etablierten Methoden wie der Auswertung amtlicher Statistiken und Expertenbefragen, bezogen jedoch auch neue Formen, wie die teilnehmende Beobachtung von Alltagssitua-

84 Loos / Schäffer: Das Gruppendiskussionsverfahren.

85 Vgl. Diekmann, Andreas: Empirische Sozialforschung. Grundlagen, Methoden, Anwendung, Reinbek bei Hamburg 2010, S. 549f.; Schmidt-Lauber, Brigitta: Ethnizität und Migration. Einführung in Wissenschaft und Arbeitsfelder, Berlin 2007, S. 223.

86 Jahoda, Marie / Paul Felix Lazarsfeld / Hans Zeisel: Die Arbeitslosen von Marienthal. Ein soziographischer Versuch über die Wirkung langandauernder Arbeitslosigkeit, Frankfurt a. M. 1996.

87 Vgl. exemplarisch Häuser-Schäublin, Brigitta: Teilnehmende Beobachtung, in: Beer, Bettina (Hrsg.): Methoden und Techniken der Feldforschung, Berlin 2003, S. 33 - 54. 
tionen mit ein. ${ }^{88}$ Diese Offenheit hinsichtlich kreativer Formen der teilnehmenden Beobachtung und ihrer Deutung ist in einigen Forschungsfeldern weit verbreitet. Psychologen oder Marktforscher arbeiten immer wieder mit der Methode der teilnehmenden Beobachtung. In der Politikwissenschaft hingegen gibt es eine schwer zu erklärende Distanz zu diesem Forschungsansatz. Dabei gelten Politologen durchaus als genaue Beobachter politischer Prozesse. Sie verfolgen aufmerksam parlamentarische Vorgänge, begleiten Parteikonferenzen oder parlamentarische Arbeitsweisen und reichern dadurch implizit ihr Wissen über Funktionsweisen der Politik wie der Parteien an. Offensiv wird dieses TeilnahmeWissen jedoch eher selten genutzt. Zweifelsohne besteht die latente Gefahr und Angst, sich selbst zu sehr mit dem Forschungsgegenstand zu identifizieren beziehungsweise in der Beobachtung lediglich Bestätigungen für die eigenen impliziten Vorannahmen zu suchen. ${ }^{89}$ Jedenfalls sind Studien, die sich diesem Forschungsansatz verschrieben haben, sowohl in der amerikanischen als auch in der deutschen Politikwissenschaft bislang rar. ${ }^{90}$ Im Zweifelsfall, so steht zu vermuten, mag für Teile der Politikwissenschaft die Absicherung der Erwägungen in quellengesättigter Form mit verfügbarem, bereits etabliertem Primärmaterial weniger risikoreich und vermeintlich „objektiver“ sein, als dies bei einem offenen Verfahren, welches auf eigenen Beobachtungen beruhte, zu sein scheint. Die Analogie zum Bonmot Wilhelm Heinrich Riehls über seine Kritiker (s. S. 52) springt dabei ins Auge.

Für den Feldzugang, für das Einholen von Impressionen und Stimmungslagen, dem Erschließen neuerer und kleinerer Protestformationen war es für das hier vorliegende Projekt unerlässlich, selbst als Beobachter aufzutreten. Das in anderen sozialwissenschaftlichen Fächern entwickelte Verfahren der teilnehmenden Beobachtung beinhaltet verschiedene Ausprägungen, von der die Form der „unstrukturierten, offenen und passiv teilnehmenden Beobachtung“ für die verfolgten Zwecke am besten geeignet erschien. Als unstrukturiert wird dabei das Fehlen eines vor der Beobachtung entwickelten Beobachtungsschemas bezeichnet, welches die Frage danach, was, wie und wo beobachtet werden soll, beantwortet. Hypothesen sollen aus der unvoreingenommenen Beobachtung und

88 Vgl. Müller, Reinhard: Marienthal. Das Dorf - die Arbeitslosen - die Studie, Innsbruck 2008, S. $293 \mathrm{f}$.

89 Vgl. Lamnek: Qualitative Sozialforschung, S. 591.

90 Vgl. Schöne, Helmar: Die teilnehmende Methode als Datenerhebungsmethode in der Politikwissenschaft. Methodologische Reflexion und Werkstattbericht, in: Historical Social Review, Jg. 30 (2005) H. 1, S. 168-199, hier. 169; Fenno, Richard: Observation, Context and Sequence in the Study of Politics, in: American Political Science Review, Jg. 80 (1986) H. 1, S. 3 - 15, hier S. 14. 
den damit verbundenen theoretischen Überlegungen generiert werden, was nicht ausschließt, „dass gleichwohl gezielt und systematisch nach theoretischen Interessen und Vorstellungen wissenschaftlich beobachtet wird“91. Unter einer offen teilnehmenden Beobachtung ist das Wissen der Beobachteten über den Beobachtungsvorgang zu verstehen, im konkreten Fall bedeutet dies, dass die Teilnehmer an Treffen von Bürgerinitiativen, Besprechungen, Demonstrationen etc. über die Rolle des Göttinger Besuchers informiert sind. Die passive teilnehmende Beobachtung bezeichnet dabei aber die Beschränkung des Forschers auf seine Rolle als Beobachter, bei der er wenig bis gar nicht an den zu analysierenden Interaktionen partizipiert. ${ }^{92}$

Die unstrukturierte, offene und passiv teilnehmende Beobachtung beabsichtigt, ,die natürliche Umwelt von Individuen und Gruppen mittels teilnehmender Beobachtung im Feld zu erfassen, zu beschreiben und zu analysieren“"93, womit die teilnehmende Beobachtung natürlich und authentisch ist, da sie nicht im Laborkontext, sondern im Feldkontext, also in der natürlichen Lebenswelt, stattfindet. ${ }^{94}$ Die Teilnehmer im Feldkontext, ihre Interaktionen, die soziale Situation, in der sie sich befinden (Ort, Zeit etc.) sowie die „Regelmäßigkeit des Beobachteten oder seine Einmaligkeit ${ }^{\star 95}$ werden im Anschluss an die Beobachtung in einer dichten Beschreibung protokolliert. Die daraus entstehenden Notizen werden zunächst für sich analysiert, interpretiert und miteinander verglichen und mit den Erkenntnissen aus den Interviews und Gruppendiskussionen ins Verhältnis gesetzt. Dabei werden zusätzliche Informationen aus der Sekundärliteratur sowie anderen Medien herangezogen. ${ }^{96}$

Die Betonung des offenen, unstrukturierten und passiven Herangehens war aus mehreren Gründen wichtig und zentral. Zunächst ist die Reflektion des „Offenheits"-Paradigmas einer qualitativ-explorativen Annäherung und entdeckenden Forschung zu nennen, die qua Selbstbild und Erkenntnisinteresse verbietet, mit einem zuvor festgelegten Raster an zu beobachtenden Kriterien ein neues Feld zu erschließen. Darüber hinaus stellt die Situation, dass es bei dem verfolgten Forschungsinteresse um das Beobachten und Interpretieren von Weltdeutungen und Sinngenerierungen, also sehr indirekten Vorgängen geht, bei denen man

91 Lamnek: Qualitative Sozialforschung, S. 600; vgl. auch Atteslander, Peter: Methoden der empirischen Sozialforschung, Berlin 2006, S. 87.

92 Vgl. Lamnek, Qualitative Sozialforschung, S. 613; Atteslander: Methoden der empirischen Sozialforschung, S. 85.

93 Lamnek: Qualitative Sozialforschung, S. 573.

94 Vgl. ebenda, S. 575.

95 Ebenda, S. 621.

96 Vgl. ebenda, S. 621 und 631f. 
durch Offenheit und dem Betonen der eigenen „kulturellen Fremdheit“ versucht, die beobachteten Sinnstrukturen nachzuvollziehen, eine gesteigerte Schwierigkeit dar. Denn eine zumindest potentiell kulturell fremde Situation - wenn in einer Protestgruppe etwa andere sprachliche Signalwörter und Umgangsformen anders benutzt und aufgefasst werden - birgt für den Forscher die Klippe, nicht von vornherein Faktoren und Schubladen definieren zu können, da er sich der „Kultur“" seines Interesses ja erst nähert. ${ }^{97}$

Forschungspraktisch ergab sich zuletzt auch die Schwierigkeit, dass gerade in Protestzusammenhängen oftmals ein Freund-Feind-Denken zu finden war, welches großes Misstrauen gegenüber einem wissenschaftlichen Beobachter entstehen ließ. Soweit es vertretbar und in der Beobachtungssituation moralisch zu rechtfertigen war (etwa, wenn es ich um größere, offene Veranstaltungen handelte) wurde auf eine dezidierte Offenlegung verzichtet. In kleineren Gruppen und Rahmen wiederum war eine solche „verdeckte“ Beobachtung kaum möglich und aus forschungsmoralischen Gründen nicht akzeptabel.

\section{Dokumentation, Software und Auswertung}

Für alle Gespräche und Beobachtungen wurden die in den Sozialwissenschaften üblichen Dokumentationserfordernisse und Datenschutzbestimmungen eingehalten. ${ }^{98}$ Da es bei der Studie zu den Bürgerprotesten nicht um eine phonetische oder linguistische Feinanalyse gehen sollte, sondern der Fokus auf dem Inhalt des Gesagten bzw. Beobachteten lag, wurden die aufgezeichneten Aussagen aus den Einzelinterviews wörtlich nach einfachen Transkriptionsregeln verschriftlicht. ${ }^{99}$ Eine Transkription erfolgte ebenfalls für die Fokusgruppen, wobei in diesem Fall nicht nur der Ton, sondern auch ein Videobild aufgezeichnet wurde. Die weitere Auswertung der Einzelinterviews wurde allein auf der Grundlage

$97 \mathrm{Vgl}$ dazu auch Girtler, Roland: Methoden der qualitativen Sozialforschung: Anleitung zur Feldarbeit, Wien 1984, S. 54 - 57.

98 Vgl. hierzu: Hopf, Christel: Forschungsethik und qualitative Forschung, in: Flick, Uwe / Ernst von Kardorff / Ines Steinke (Hrsg.): Qualitative Forschung. Ein Handbuch, Reinbek bei Hamburg 2000, S. 589 - 600; Helfferich, Cornelia: Die Qualität qualitativer Daten. Manual für die Durchführung qualitativer Interviews, Wiesbaden 2011, S. 190 ff.

99 Vgl. zu den einfachen Transkriptionsregeln Dresing, Thorsten: Praxisbuch Transkription. Regelsysteme, Software und praktische Anleitungen für qualitative ForscherInnen, Marburg 2011, online einsehbar unter www.audiotranskription.de/praxisbuch [eingesehen am 06.09.2012], S. 18 - 24; Kuckartz, Udo: Einführung in die computergestützte Analyse qualitativer Daten, Wiesbaden 2008, S. $38 \mathrm{ff}$. 
der Transkriptionsabschriften durchgeführt, während hingegen die Materialbasis der Gruppendiskussionen deutlich breiter war. Hier wurden auch die in den Gruppensitzungen erstellten Materialien wie etwa die Ergebnisse der „Planspiele" als auch die Notizen und notierten Stichworte der Teilnehmer zur Analyse mit herangezogen, um ein multiperspektivisches Bild entstehen zu lassen. Nicht zuletzt wurden von allen Teilnehmern, bei Einzelinterviews wie den Gruppengesprächen, standardisierte Fragebögen zu den sozialstatistischen Daten erfasst, um den Rahmen der Stichprobe einordnen zu können. Es ist allerdings wichtig zu betonen, dass die Auswahl der Gesprächspartner nicht entlang von statistischen Repräsentativitätskriterien erfolgte, sondern den zu Beginn von Kapitel 3.2 niedergelegten Rahmen unterworfen war.

Für das hier vorliegende Buch wurde das in der Proteststudie erstellte Material in eine Auswertung entlang der skizzierten Fragestellungen nach Kapitel 2 einbezogen. Dabei war das Ziel ein mehrschichtiger und intersubjektiv überprüfbarer Prozess des Verstehens, ergänzt durch die Interpretation des immanenten und eher subkutanen Bedeutungsgehaltes. Es ging bei der Analyse eben nicht allein darum, das tatsächlich Gesagte herauszuschälen, sondern auch das zu interpretieren, was unterschwellig, leise und signalhaft mitschwingt und Sinn generiert. Hier waren bei den Fokusgruppen besonders die Meinungsdynamiken und gegenseitigen Interpretationen der Aussagen von Bedeutung. ${ }^{100}$

Eine der großen Stärken der Methode Fokusgruppe ist nicht nur die Analyse des Gesagten, sondern auch die Möglichkeit, Dynamiken in der Herausbildung von Gruppenmeinungen, Bezugnahmen und Themenkonjunkturen nachzuvollziehen. Dazu ist es notwendig, über die entwickelten Fragekataloge hinaus den jeweiligen Hintergrund des Gesagten mit einzubeziehen, sei es das Alter und Geschlecht, die persönlichen Ressourcen (wie Bildung, Kompetenz, Zeit), die bisherigen Erfahrungen mit zivilgesellschaftlichem Engagement und Politik, die Einstellung zur Demokratie, ihren Interessen, die Sicht auf Nicht-Engagierte sowie (traditionelle) Werthaltungen und Einstellungen der Teilnehmer. Auf einer überindividuellen Ebene wurden die Techniken und Methoden der Mobilisierung, die Organisationsrealität des Protestzusammenhanges, die führenden Figuren der Gruppen, auch Erzählstrukturen, Semantiken, Topoi und Metaphern zum Gegenstand der Auswertung. Durch diese Vorgehensweise erscheint es möglich, die Protestzusammenhänge über verschiedene Protestfelder zu vergleichen, Gemeinsamkeiten und Unterschiede herauszuarbeiten sowie Typen zu identifizieren und gleichzeitig flexibel in den einzelnen Arbeitsgruppen nach Spezifika und Besonderheiten zu fragen. Wichtig war bei der Auswertung auch, sich nicht me-

100 Vgl. Dürrenberger, Gregor / Jeanette Behringer: Die Fokusgruppe in Theorie und Anwendung, Stuttgart 1999, S. 26 f. 
thodisch auf eine etablierte Forschungssystematik zu versteifen, sondern verschiedene Blickwinkel wirken zu lassen, um der schon bei der Forschungsfrage wie der Datenerhebung unterstrichenen Offenheit zu genügen und darüber hinaus den zwischen Einzelgesprächen und Gruppendiskussionen wie Beobachtungsprotokollen durchaus unterschiedlichen Bedeutungserzeugungen gerecht $\mathrm{zu}$ werden. Denn während die Methode der Objektiven Hermeneutik zur Auswertung von Einzelinterviews eben die subjektiven Sinnebenen und Intentionen in den Blick nimmt und demnach auf den Einzelfall konzentriert die individuelle Ausprägung der dahinter stehenden „objektiven“ sozio-kulturellen Muster untersucht ${ }^{101}$, hat sich die Dokumentarische Methode für die Analyse von Gruppengesprächen und sozialen Realitäten, Meinungsbildungen und kollektiven Orientierungschemata etabliert, bei der über Einblicke in das Miteinander von sozialen Gruppen auf die Entstehung von Argumentationen und die im Kapitel 2.1 zur Diskursanalyse beschriebenen Mechanismen zu den Demokratienormen und Hegemoniekonzepten Bezug genommen wird. ${ }^{102}$

Für eine Codierung und Feinanalyse der Transkripte wurde auch auf computergestützte Möglichkeiten über das Programm MAXQDA zurückgegriffen, so dass die Materialfülle gehandhabt werden konnte. Dabei waren die Codierungen und Verschlagwortung der Interviews zunächst einmal dienendes Hilfsmittel im Sinne einer gut organisierten und variabel verfügbaren Registratur und Orientierung, ohne ein einengendes Korsett darzustellen oder die betonte Offenheit auch in der Analyse durch ein entwickeltes striktes Codesystem zu unterlaufen.

\subsection{Fallauswahl}

Die Göttinger Studie, welche das Fundament des Rohdatenmaterials der hier vorliegenden Arbeit erhoben hat, näherte sich unterschiedlichen Protestformen über teilnehmende Beobachtungen auf Demonstrationen und Versammlungen. Um hier regional in die Breite zu gehen, Typen, Eigenarten, Gemeinsamkeiten und Unterschiede zu Tage zu fördern, haben wir in urbanen Metropolen wie im ländlichen Raum Eindrücke gesammelt und Gespräche geführt. Ökonomisch boomende Regionen wurden genauso mit in den Blick genommen wie solche, in denen der industriestrukturelle oder demographische Wandel deutliche Spuren hinterlassen hat. In der ersten Jahreshälfte 2012 sind dabei auf insgesamt sieben

101 Vgl. dazu Kleemann, Frank / Uwe Krähnke / Ingo Matuschek: Interpretative Sozialforschung. Eine praxisorientierte Einführung, Wiesbaden 2009, S. $149 f$.

102 Vgl. ebenda, S. 192f. 
verschiedenen Feldern, an denen sich gesellschaftliche Proteste entzündet hatten, Datenerhebungen durchgeführt worden. Entscheidend für die Aufnahme in die Untersuchungsmatrix waren eine Protest-Aktualität in den Monaten oder Jahren vor 2012 sowie eine regional und strukturell breit aufgefächerte Varianz der Protestgruppen. Folgende sieben Themenfelder gesellschaftlicher Proteste wurden dabei untersucht:

- Stadtentwicklung und Infrastruktur

- Occupy und Systemkritik

- Anti-Atomkraft-Proteste

- Projekte im Zuge der Energiewende

- Bildung und Schulreformen

- Anti-EU-Proteste bzw. Anti-Euro-Kampagnen

- Internet-Proteste

- Satirische Protestgruppen

Ziel war es dabei nicht, eine organisationssoziologische Betrachtung der Protestgruppen zu realisieren, sondern in einer Art akteurszentrierten Kulturforschung zu verstehen, was die Organisatoren und Aktivisten antreibt, Zeit und Anstrengung der Protestorganisation zu widmen. Wer sind die Aktiven der jeweiligen Gruppen? Was bringen sie an biographischem Gepäck mit und was hat sie bewogen, ganz bewusst außerhalb von Parteien ihre Interessen zu artikulieren und diese in den politischen Prozess einzuspeisen?

Aus dieser Perspektive ist die Studie ein Beitrag zum Stand der Protestforschung in der Bundesrepublik. Dabei sollte aber Protest nicht mit Methoden der quantitativen Sozialforschung oder mittels einer Auswertung von Polizei- und Zeitungsberichten ${ }^{103}$ indirekt analysiert, sondern mit einer breiten, qualitativen Studie vermessen werden. Dafür wurden insgesamt 80 halboffene, leitfadengestützte themenzentrierte Einzelinterviews mit zentralen Akteuren und Aktivisten und 18 zwei- bis dreistündige Gruppendiskussionen mit jeweils sechs bis elf Teilnehmern geführt. Aus diesen Interviews und Fokusgruppen ergaben sich circa 1.300 Seiten transkribiertes Material, welches dann analytisch aufgearbeitet und verdichtet wurde. Alle in den folgenden Kapiteln angeführten Zitate stammen aus diesen Transkripten, soweit die Herkunft nicht ausdrücklich anderweitig

103 Wie es in Projekten von Dieter Rucht und anderen immer wieder gemacht wurde vgl. exemplarisch Rucht, Dieter / Peter Hocke / Dieter Oremus: Quantitative Inhaltsanalyse, Warum, wo, wann und wie wurde in der Bundesrepublik demonstriert?, in: von Alemann, Ulrich (Hrsg.): Politikwissenschaftliche Methoden, Opladen 1995, S. $261-291$. 
angegeben wird. Das Untersuchungssample der Göttinger Studie umfasst insgesamt 200 Personen, deren politische Aktivitäten und Biographien methodisch geleitet in Einzelinterviews, Gruppendiskussionen und mittels teilnehmender Beobachtung für die Analyse herangezogen werden können.

Gerade die gegenwärtige, heterogene Protestlandschaft der Bundesrepublik ist allerdings analytisch schwierig zu fassen: Themen, Hintergründe sind ebenso vielfältig wie die Größen und Zusammensetzungen der Protestgruppen. Die Auswahl der Protestschwerpunkte, der Gesprächs- und Interviewpartner wie die zu beobachtenden Veranstaltungen - all dies ist aus Forscherperspektive und methodisch sorgsam abzuwägen. Die Betrachtung aktueller Phänomene hängt dabei besonders vom Untersuchungszeitraum ab. Dieser erstreckte sich hier auf die erste Hälfte des Jahres 2012. Ziel des Projektes sollte das Verstehen und Erklären der gegenwärtigen und auch neuen Formen sein, welche die gesellschaftspolitische Diskussion seit den Protesten um den Stuttgarter Bahnhof bestimmen. Auch deshalb standen die Aktivisten gegen Bauprojekte und die Hamburger Schulreform, die Organisatoren der Occupy-Camps und der Internetkampagnen im Fokus und weniger die - in der Protestgeschichte schon etablierten Ostermärsche, die Aktivitäten der Friedens- sowie Umweltbewegung oder die Demonstrationen gegen Rechtsextremismus.

Eine Ausnahme bildeten in diesem Feld die Anti-AKW-Proteste. Diese wurden bewusst mit einbezogen, weil die zahlenmäßig starken Demonstrationen seit dem Reaktorunfall in Fukushima im März 2011 ein aktuelles Phänomen darstellten und gleichzeitig die Aktivisten mit diesem thematischen Engagementschwerpunkt eine Art Kontrollgruppe des Untersuchungsgegenstandes repräsentieren. Denn wenn nach individuellen Antriebskräften für Engagement und Protest, nach biographischen Prägungen, Organisationsformen, Wertefundamenten und politischen Einstellungen gefragt werden soll, ist davon auszugehen, dass Menschen mit einer langen Engagementkarriere in etablierten Konfliktarenen andere Werthierarchien, Präferenzen und vor allem Erfahrungen ausprägen, als diejenigen, die schwungvoll und mit viel Elan die erste Demonstration ihres Lebens organisieren und das womöglich in einem neu entstandenen, vergleichsweise „geschichtslosen“ Konfliktfeld. Insofern enthält das Interview-, Gesprächsund Beobachtungssample sowohl Protagonisten mit einer langen Protestvergangenheit wie auch Neulinge auf dem Gebiet und bietet über die Akteure hinweg damit auch die Möglichkeit zu einer vergleichenden Perspektive, was Gemeinsamkeiten und Unterschiede etablierter und neu-engagierter Akteure anbelangt.

Das hier beschriebene Datenset der Studie zu den Bürgerprotesten bildet also das rohe, unbehauene Fundament dieses Buches, welches jedoch - wie in den Abschnitten zur Fragestellung beschrieben - anders und aus neuen Perspektiven 
angeschaut, gelesen, interpretiert wird. Auch ist die Datenmenge der beschriebenen Interviews, Gruppengespräche, Teilnehmenden Beobachtungen durchaus zu mächtig, um diese mit dem gewählten qualitativ explorativen Vorgehen in Gänze $\mathrm{zu}$ berücksichtigen. Eine Reduktion und Auswahl muss sich folgend nach den hier konzentrierten Erkenntnisinteressen richten und diese zusammen führen. Da Ziel nicht eine abgeschlossene Theoriebildung ist, welche einen erschöpfenden „Zustand theoretischer Sättigung“"104 bei der Datenerhebung erfordern würde, sondern vielmehr eine explorative Hypothesengewinnung, sind an eine Fallauswahl andere Maßstäbe anzulegen. Ein Vergleich, der eine systematische Komparatistik im Sinne eines most similar oder most different cases design erfordern würde, ist ebenfalls nicht das angestrebte Ergebnis. Folglich bilden plausible Erwartungen möglicher Erkenntnisfelder und eine denkbar breite Abdeckung der zu erklärenden Entwicklungslandschaft zentrale Argumente einer Auswahl von Protestfeldern und -orten. Der Autor ist in die Erhebung der Daten zentral involviert gewesen, und konnte schon bei Durchführung der Interviews und Gruppengespräche Eindrücke sammeln, welche diese Auswahl erleichtert haben.

Zur Analyse für die vorliegende Arbeit wurden als Primärquellen die Interviews, Gruppengespräche und Beobachtungsprotokolle aus dreien der oben aufgeführten Protestfelder herangezogen:

- $\quad$ Stadtentwicklung und Infrastruktur

- Bildung und Schulreformen

- Anti-EU-Proteste bzw. Anti-Euro-Kampagnen

Diese drei Themenkomplexe umfassen im Datenset insgesamt sieben Fokusgruppen $^{105}$ und 20 Einzelinterviews - insgesamt 73 Personen plus die Beobachtungsprotokolle der besuchten Veranstaltungen, Treffen, Märsche, Mahnwachen, Demonstrationen. ${ }^{106}$ Hinter dem Thema „Stadtentwicklung und Infrastruktur“ verbergen sich Protestgruppen, die sich in Stuttgart gegen den Bahnhofsneubau, in Freising gegen die Münchener Flughafenerweiterung sowie mit dem Hamburger Gängeviertel und im Umfeld des Zentrums „Rote Flora“ für eine alternative Stadtgestaltung engagieren. Was „Bildung und Schulreformen“ anbelangt, so

104 Kleemann u.a.: Interpretative Sozialforschung, S. 25.

105 Drei Fokusgruppen im Themenbereich Stadtentwicklung und Infrastruktur wurden in Stuttgart (2) und Freising durchgeführt, zwei im Feld Bildung und Schulreformen in Hamburg und zwei Fokusgruppen für die Gruppen der Anti-EU-Proteste in Hannover und Stuttgart.

106 Eine detaillierte Vorstellung der Zusammensetzung der Gruppe der Interviewten findet sich in Kapitel 4.1. 
haben Gespräche und Beobachtungen mit Protestierenden stattgefunden, die in Hamburg bzw. Baden-Württemberg (und hier speziell Stuttgart) entweder für oder gegen die vor 2012 geplanten Bildungsreformen gearbeitet haben. Und der Komplex „Anti-EU-Proteste bzw. Anti-Euro-Kampagnen“ umfasst Personen, die sich in Niedersachsen und wiederum in Baden-Württemberg in Aktivistengruppen versammelten. Das großstädtische wie das ländlich angehauchte Umfeld von Metropolen ist hier gleichermaßen vertreten, ebenso wie Gruppen ganz unterschiedlicher Größe, vom Dachverband der Flughafengegner in Freising bis hin zu beinahe klandestinen Eurogegnern oder Kleininitiativen von Bildungsreformgegnern.

Dass Demokratienormen als ein Fragepfeiler bei den Protestbewegungen eine wichtige Rolle spielen, war schon bei der Auswahl zur vorliegenden Göttinger Studie für alle Felder angenommen worden, spielt ergo in alle Gruppen mit hinein. Gleichwohl bieten die drei Felder mit Blick auf die Perspektive auf Demokratie ganz unterschiedliche Ausgangspunkte, stellen durch ihren Protestfokus unterschiedliche politische Ebenen ins Zentrum ihrer Arbeit: Während bei Infrastruktur und Stadtentwicklung oftmals die lokale Ebene der Ausgangspunkt der Kritik ist, findet sich die Bildungspolitik in der Regelungsverantwortung der Bundesländer und die europäische Einbindung auf der nationalen bzw. europäischen Ebene verankert. Insofern bietet eine Betrachtung dieser drei Protestfelder die Möglichkeit, unterschiedliche Demokratie- und Politikperspektiven nebeneinander zu stellen.

Die Rolle von Stadt und der Utopie vom Zusammenleben hingegen lag bei einigen Protestfeldern stärker im Fokus, namentlich bei den Intrastruktur- und Stadtentwicklungsprotesten - zu denen der Verfasser dieser Arbeit das entsprechende Kapitel in der Göttinger Studie mit beigesteuert hat - und ebenso bei den Bildungs- und Schulprotesten, in welchen das Thema des gemeinsamen Lebens eine große Rolle bei den Interviews gespielt hat. Auch bei den Anti-EU/-EuroProtesten haben diese Diskussionen zur Vorstellung gesellschaftlichen Zusammenlebens einen großen Raum eingenommen - allerdings aus einer völlig anderen Sichtwarte aus. Was soziale Herkunft, Alter und Geschlecht anbelangt, auch die Selbstdarstellung der politischen Couleur, so bilden die beobachteten Protestgruppen in diesen drei Komplexen ein überaus breites Spektrum ab: von heftig unterstrichenen Formulierungen linker Alternativideen in Hamburger Stadtviertelprotesten bis hin zur Betonung eher konservativer Heimatverbundenheit im Rahmen von Infrastrukturprotesten, von den Idealen gemeinsamen Lernens im Schulsystem als symbolhaftes Projekt linker gesellschaftlicher Ideale bis zu einer selbstbewussten Schilderung rechtspopulistischer Elitenkritik bei manchen Protagonisten der Anti-EU-Kampagnen. 
Nicht zuletzt ist die Vorstellung vom politischen Vorgehen der einzelnen Protestfelder für das vorliegende Projekt eine wichtige Entscheidungsgrundlage: Wie stellen sich die Gruppen bzw. ihre Aktiven ihren weiteren Weg in die und in der Politik vor? Denn wenn dieser Arbeit auch die Frage nach einer fehlenden Akzeptanz von Parteipolitik zugrunde liegt und eine Hintergrundfolie die schwindenden Bindungskräfte der Großorganisationen sind, dann fällt auf, dass aus den Anti-EU- und Anti-Euro-Protesten des Jahres 2012 in den Jahren seitdem mit der AfD eben doch eine Partei entstanden ist. Den Übergang von den Protesten gegen eine Euro-Krisen- oder europäische Finanzpolitik in eine parteipolitische Verfestigung haben David Bebnowski und Julika Förster beschrieben. ${ }^{107}$ Es liegt nahe, diesen Faktor bei einer Auswahl mit einzupreisen: Wie stehen die Protagonisten selbst zu parteipolitischer Sammlung bzw. was verbinden sie damit? Dass gerade einige derjenigen Gruppen, die sehr bestimmt eine Kritik an den deutschen politischen Eliten und ihrerVorstellung von Parteien geäußert haben, mittlerweile selbst eine gegründet haben, macht dieses Themenfeld für eine Betrachtung in dieser Arbeit interessant.

Insgesamt ist die Auswahl erfolgt, um eine große Bandbreite an Ausgangspunkten mit einzubeziehen - Sozialstruktur, Generation, Region, politische Verortung, Lautstärke und Charakter politischer Alternativforderungen. Die politische Ausrichtung und das Selbstverständnis der Protestzusammenhänge reicht von weit links und deutlich systemkritisch über ökologisch oder christlich grundiert herüber zu radikalliberal oder gar politisch eher rechten Selbstverständnissen. Generationell und von der Generationenzusammensetzung sind ebenso gänzlich unterschiedliche Konstellationen anzutreffen. Für die hier verfolgten Fragekomplexe - Sozialisation und Selbstbilder, Demokratieperspektiven sowie Gesellschaftsutopien - bildet diese Auswahl einen möglichst breiten Erfahrungshintergrund. Gleichwohl bleibt zu unterstreichen, dass die Auswahl keiner systematischen Beweisführung unterliegt, die im Vorhinein einer mathematischen Logik folgt, sondern sich - wie dies ein exploratives Vorgehen nahelegt durch eine Mischung aus Plausibilitätserwartung und Ergebnisgehalt rechtfertigt und die darüber hinaus noch die im folgenden Abschnitt skizzierten Desiderata des Forschungsstandes zu den Bürgerprotesten ins Auge zu fassen sucht.

107 Bebnowski, David / Lisa Julika Förster: Wettbewerbspopulismus. Die Alternative für Deutschland und die Rolle der Ökonomen, OBS-Arbeitspapier No. 4, Frankfurt a.M. 2014, online einsehbar unter http://www.demokratie-goettingen.de/content/uploads/2014/05/OBS_AP_Wettbewerb_WEB.pdf [zuletzt eingesehen am 13.01.2015]. 


\subsection{FORSCHUNGSSTAND}

Proteste an sich sind kein neues Phänomen in der bundesrepublikanischen Gesellschaft und darüber hinaus. In den Sozialwissenschaften hat sich gar eine darauf spezialisierte Forschungsrichtung, die Bewegungsforschung, etabliert. Mit einem Schwerpunkt am Berliner Wissenschaftszentrum WZB hatte sich Dieter Rucht bis zu seiner Emeritierung um Fragen von Protest und Gesellschaft gekümmert ${ }^{108}$, und auch in historischer Perspektive gibt es etwa mit dem nun von Stefan Berger geleiteten Institut für soziale Bewegungen an der Ruhr Universität Bochum eine institutionelle Anbindung des Themas. ${ }^{109}$ Noch vor den ikonographisch für die Entwicklung der deutschen Demokratie stehenden studentischen Protesten der späten 1960er Jahre gab es beispielsweise Demonstrationen gegen den Bau und die Nutzung der Atombombe und die ersten Ostermärsche. Nach der Spiegelaffäre 1962 rollte bereits eine regelrechte Protestwelle durch das Land. Und auch der vermeintliche Protesthöhepunkt 1968 stellt sich im Rückblick eher als Ouvertüre einer anhaltenden Protestgesellschaft dar, als welche sich die Geschichte der Bundesrepublik ebenfalls deuten ließe: von den AntiAKW-Demonstrationen über die Proteste gegen den Nato-Doppelbeschluss bis hin zu den Massenkundgebungen gegen den Golf-Krieg - um nur einige zu nennen. Wenn man die ostdeutsche Friedensbewegung und natürlich die Umbrüche vom Herbst 1989 einbezieht, kann man ohne weiteres Protest sogar als eine gesamtdeutsche Erfahrung auffassen. Um es zusammen zu fassen: Dass Proteste aufflammen, eine Erregungskurve partizipatorischer Forderungen nach Gehör und Mitsprache laut werden, begleitet die Bundesrepublik seit etlichen Jahrzehnten. ${ }^{110}$ Und dass Protestkulturen und ihre Akzeptanz in der Tendenz in Deutsch-

108 Vgl. hier exemplarisch Roth, Roland / Dieter Rucht (Hrsg.): Die sozialen Bewegungen in Deutschland seit 1945: ein Handbuch, Frankfurt a.M. 2008. Aus dem Dunstkreis dieser Arbeitsgruppe ist nach der Emeritierung Ruchts unlängst das Institut für Protest- und Bewegungsforschung in Berlin aus der Taufe gehoben worden, online einsehbar unter http://protestinstitut.eu/ [zuletzt eingesehen am 26.06.2013].

109 Sebastian Haunss und Peter Ullrich kommen allerdings - bei gleichen Vorzeichen zu dem Ergebnis, dass es in Deutschland eine im internationalen Vergleich erheblich geringere Institutionalisierung der sozialwissenschaftlichen Protestforschung gebe, vgl. Haunss, Sebastian / Peter Ulrich: Viel Bewegung - wenig Forschung. Zu- und Gegenstand von sozialwissenschaftlicher Protest- und Bewegungsforschung in der Bundesrepublik, in: Soziologie, Jg. 42 (2013) H. 3, S. 290 - 304, hier S. 292.

110 Der Politikwissenschaftler Max Kaase etwa hat bereits 1982 von einer „Partizipatorischen Revolution“ gesprochen: Ders.: Partizipatorische Revolution - Ende der Par- 
land und international eher zunehmen, gilt ebenso als ausgemacht, wenn auch stets betont wird, dass diese Entwicklung weder linear noch kontinuierlich, sondern episodisch und bisweilen sprunghaft verläuft. ${ }^{111}$ Bisher wird in den Sozialwissenschaften bei den Fragen nach Protest, Demonstrationen, Partizipationsbegehren und ähnlichem vorzugsweise mit der Begrifflichkeit der ,sozialen Bewegung" operiert. Eine solche wird als eine netzwerkähnliche Struktur gemalt: „von Gruppen und Organisationen, gestützt auf eine kollektive Identität, eine gewisse Kontinuität des Protestgeschehens [...], das mit dem Anspruch auf Gestaltung des gesellschaftlichen Wandels verknüpft ist [...].“" ${ }^{112}$ Mit dem Forschungsjournal Soziale Bewegungen, mit dem Namensannex „Neue Soziale Bewegungen" gegründet, hat sich eine Zeitschrift etabliert, die das Phänomen seit 1988 kontinuierlich begleitet.

Annette Ohme-Reinicke hat dabei zwischen Protest und sozialer Bewegung den Unterschied organisatorischer, identitärer und vor allem programmatischer Verfestigung ausgemacht. Nur, wenn die ,Totalität gesellschaftlicher Verhältnisse ${ }^{113}$ in den Blick genommen und zum Gegenstand des Veränderungsstrebens wird, könne von einer sozialen Bewegung gesprochen werden. „Proteste, die sich gegen bestimmte Erscheinungen des Systems richten, die Veränderungen der sozialen Verhältnisse insgesamt aber nicht intendieren, sind als Protestbewegungen zu bezeichnen. "114 Darüber hinaus macht Ohme-Reinicke in der vermeintlich vorwärts gerichteten Veränderungshaltung von sozialen Bewegungen einen Unterschied gegenüber den oftmals reaktionären Verhinderungsinteressen von Protestbewegungen einen Unterschied aus. Dies ist insofern problematisch, da auf diese Weise, erstens, nur ex post zu beurteilen ist, ob eine Gruppe soziale Bewegung geworden oder Protestbündnis geblieben ist und, zweitens, schon den Begrifflichkeiten eine politische Beurteilung innewohnt, die für eine Analyse an dieser Stelle nicht hilfreich ist. Eine Einordnung und Analyse soll Ergebnis und nicht Anfangspunkt der hier vorliegenden Arbeit sein, insofern liegt es nahe, die Begrifflichkeit der Protestbewegung möglichst offen zu halten. Swen Hutter und

teien?, in: Raschke, Joachim (Hrsg.): Bürger und Parteien. Ansichten und Analysen einer schwierigen Beziehung, Opladen 1982, S. 173 - 189, hier S. 187.

111 Vgl. Rucht, Dieter: Demokratie ohne Protest? Zur Wirkungsgeschichte sozialer Bewegungen, in: Forschungsjournal Soziale Bewegungen, Jg. 26 (2013) H. 3, S. 65 - 70, hier S. 67.

112 Roth, Roland / Dieter Rucht: Einleitung, in: Dies. (Hrsg.): Die sozialen Bewegungen in Deutschland seit 1945: ein Handbuch, Frankfurt a.M. 2008, S. 9 - 37, hier S. 13.

113 Ohme-Reinicke, Annette: Moderne Maschinenstürmer. Zum Technikverständnis sozialer Bewegungen seit 1968, Frankfurt a.M. / New York 2000, S. 38.

114 Ebenda, S. 39. 
Simon Teune haben diese Frage mehr umschrieben als unmissverständlich festgelegt - und können als Paten der Auffassung von Protest für diese Arbeit herangezogen werden: „Protest als kollektiver und öffentlicher Ausdruck von Widerspruch ist vielgestaltig. Vom Infostand zum Straßenkampf, von der Unterschriftensammlung zur Sitzblockade finden politisch Aktive unterschiedliche Formen für ihren Protest. Sie sind mal mehr, mal weniger erfolgreich in der Mobilisierung ihrer Mitbürgerinnen und Mitbürger. Die Größe von Protesten reicht von Mahnwachen mit wenigen Beteiligten bis zu Großdemonstrationen mit mehreren Hunderttausend Beteiligten. “115 Auch weil Ohm-Reinicke in ihrer Definitionsabgrenzung auf eine Langfristigkeit der Perspektive von sozialen Bewegungen abzielt, macht die Benutzung von „Protest“ für diese Arbeit Sinn. Denn es ist noch nicht abschließend zu beurteilen, ob und dass die beobachteten Proteste sich langfristig in stabile Bewegungen überführen, ob etwa die Alternative für Deutschland (AfD) langfristig Eingang in das Parteiensystem finden wird, ob Protestbündnisse wie in Stuttgart und in Freising Bestand haben werden, oder ob sie als mittelfristige Phänomene wieder aus der öffentlichen Diskussion verschwinden. Gleichwohl prägen sie für die gegenwärtige Situation die Debatte um Demokratie entscheidend mit.

Im Forschungsfokus stehen die Kollektivakteure und Proteststrukturen mit ihren gemeinsam ausgebildeten (Gruppen-)Identitäten, ihrem Mobilisierungspotential und ihren organisatorischen Ausprägungen und Techniken, während die individuelle Ebene, die biographische Prägung der Akteure und ihre Motivation oftmals vernachlässigt werden. ${ }^{116}$ Dies folgt auch linear aus der Definition Ohme-Reinickes, wenn es in erster Linie um die Frage geht, was eine Bewegung als Gruppe für Charakteristika und Ziele ihres Strebens ausprägt. Auch im internati-

115 Teune, Simon / Swen Hutter: Politik auf der Straße: Deutschlands Protestprofil im Wandel, in: Aus Politik und Zeitgeschichte, Jg. 62 (2012) H. 25/26, S. 9 - 17, hier S. 10 .

116 Vgl. jüngst Klecha, Stephan: Bürgerprotest und Wissenschaft, 15.04.2013, online einsehbar unter http://www.demokratie-goettingen.de/blog/burgerprotest-undwissenschaft [zuletzt eingesehen am 26.06.2013]; Naegler u.a.: Urbanität und Protest, hier S. 126; vgl. auch Teune, Simon: „Gibt es so etwas überhaupt noch?“ Forschung zu Protest und sozialen Bewegungen, in: Politische Vierteljahresschrift Jg. 49 (2008) H. 3, S. 528 - 547, hier S. 529f.; Dies findet sich auch bei Ullrich, Peter: Postdemokratische Empörung. Ein Versuch über Demokratie, soziale Bewegungen und gegenwärtige Protestforschung, ipb woking papers, Berlin Juli 2015, online einsehbar unter: https://protestinstitut.files.wordpress.com/2015/07/postdemokratischeempc3b6rung_ipb-working-paper_web3.pdf [zuletzt eingesehen am 26.08.2015], S. $9-14$. 
onalen Rahmen hat sich die Bewegungsforschung als die der Protestforschung übergeordnete Fragestellung auf Umfang, Reichweite, Themen, Aktionsformen und Wirkung konzentriert und weniger die Aktiven in das Zentrum des Erkenntnisinteresses gestellt. Das Vorgehen nach einer qualitativen Inhaltsanalyse, welche große Datenaggregate zur Basis nimmt, die „Protestereignisanalyse“, ist dabei meist als Standardinstrumentarium verwandt worden. ${ }^{117}$ In dem langjährigen Projekt „Dokumentation und Analyse von Protestereignissen in der Bundesrepublik", Prodat, wurden beispielsweise schematisch und stichprobenartig für die Jahre 1950 bis 2002 Daten aus Tageszeitungen zu Ort, Teilnehmerzahlen, Formen, Eskalationen und Themen von Protestereignissen gesammelt und statistisch aufbereitet, um Protestverhalten und -häufigkeiten herauszufiltern. ${ }^{118}$ Für die Zeit bis Anfang der 1990er Jahre gibt es darüber hinaus noch den Datensatz des Projekts „Neue soziale Bewegungen in Westeuropa“, welches mit ähnlichen Parametern aus der Presseberichterstattung international komparativ Protestentwicklungen herauszufiltern suchte. ${ }^{119}$ Und auch jüngst wurde diese Herangehensweise beibehalten, wie eine Studie der Columbia University gemeinsam mit der Friedrich-Ebert-Stiftung 2013 zeigte. ${ }^{120}$ Bereits 1999 stellten Donatella della Porta und Hanspeter Kriesi resümierend fest, Konsens in der Protest- und Bewegungsforschung sei es, sich auf politische Gelegenheitsstrukturen, Mobilisierungsstrukturen und Framing-Prozesse zu konzentrieren. ${ }^{121}$ Und Kai-Uwe Hell-

117 Vgl. dazu Koopmans, Ruud / Dieter Rucht: Protest Event Analysis, in: Klandermans, Bert / Suzanne Staggenborg (Hrsg.): Methods of Social Movement Research, Minneapolis 2007, S. 231 - 258.

118 Vgl. zum Projekt Prodat zusammenfassend Neidhardt, Friedhelm / Dieter Rucht: Protestgeschichte der Bundesrepublik Deutschland 1950 bis 1994: Ereignisse, Themen, Akteure, in: Rucht, Dieter (Hrsg.): Protest in der Bundesrepublik Deutschland: Strukturen und Entwicklungen, Frankfurt a.M. 2001, S. 27 - 69; sowie der Anhang im selben Band.

119 Vgl. dazu Kriesi, Hanspeter / Ruud Koopmans / Jan Willem Duyvendak / Marco G. Giugni (Hrsg.): New Social Movements in Western Europe: A comparative Analysis, London 1995.

120 Vgl. Ortiz, Isabel / Sara Burke / Mohamed Berrada / Hernán Cortés: World Protests 2006 - 2013, in: Initiative for Policy Dialogue and Friedrich Ebert Stiftung New York Working Paper 2013, September 2013, online abrufbar unter http://policydialogue.org/files/publications/World_Protests_2006-2013-Complete_and_Final_4282014.pdf [zuletzt eingesehen am 22.12.2014].

121 Vgl. Della Porta, Donatella / Kriesi, Hanspeter: Social Movements in a Globalizing World: an Introduction, in: Dies. / Dieter Rucht (Hrsg.): Social Movements in a Globalizing World, New York 1999, S. 3 - 21. 
mann machte 1998 fünf zentrale Paradigmen der Bewegungsforschung aus - allesamt auf die Gruppenprozesse und das Kollektiv der Bewegung konzentriert ${ }^{122}$ : Einen Structural-Strains-Ansatz, der ,gesellschaftsstrukturelle Spannungsverhältnisse“123 als entscheidende Variable für das Entstehen von Protestbewegungen ausmacht; die Collective-Identity; das Framing, welches die „Konstruktion des Deutungsrahmens“ durch die Bewegung selbst beobachtet ${ }^{124}$; die Resource Mobilization; zuletzt die Political Opportunity Structures.

Zwar werden die offensichtlichen methodischen Schwächen einer solchen Herangehensweise, die mögliche Bias durch die Vorselektion von Protesten, über die in der Presse berichtet wird sowie die zwangsläufig oberflächliche Betrachtung der Einzelereignisse durchaus thematisiert, zumeist aber als notwendiges Übel akzeptiert. ${ }^{125}$

In der Folge haben sich Donatella della Porta und Sidney Tarrow mit der Ausprägung von Identitäten in den sozialen Bewegungen befasst und festgestellt, dass ein Signum moderner Bewegungen sei, dass ihre aktiven Mitglieder multiple Zugehörigkeiten ausprägen könnten, ohne sich über lange Zeit an eine Bewegung allein zu binden. ${ }^{126}$ Hieraus folgt, dass ein Blick auf Individuen im Protest durchaus lohnend sein kann, um Charakter und Beweggründe des individuellen Engagements zu ergründen. Martijn van Zomeren ${ }^{127}$, allein und ebenso gemein-

122 Vgl. Hellmann, Kai-Uwe: Paradigmen der Bewegungsforschung. Forschungs- und Erklärungsansätze - ein Überblick, in: Ders. / Ruud Koopmans (Hrsg.): Paradigmen der Bewegungsforschung. Entstehung und Entwicklung von Neuen sozialen Bewegungen und Rechtsextremismus, Opladen 1998, S. 9 - 30.

123 Ebenda, S. 18.

124 Ebenda, S. 20.

125 Vgl. Teune / Hutter: Politik auf der Straße, hier S. 11; vgl. auch grundlegend Klandermans, Bert / Conny Roggeband (Hrsg.): Handbook of Social Movements across Disciplines, New York 2007.

126 Vgl. exemplarisch Della Porta, Donatella: Multiple Belongings, Flexible Identities and the Construction of "Another Politics": Between the European Social Forum and the Local Social Fora, in: Dies. / Sidney Tarrow (Hrsg.): Transnational Protest and Global Activism, New York 2005, S. 227 - 259.

127 Van Zomeren, Martijn: Diskussion: Opening the Black Box of Dynamics in Theory and Research on the Demand Side of Protest, in: van Stekelenburg, Jacquelien / Conny Roggeband / Bert Klandermans (Hrsg.): The Future of Social Movement Research: Dynamics, Mechanisms, and Processes, Minneapolis 2013, S. 79 - 92, hier S. 80 . 
sam mit Tom Postmes und Russel Spears ${ }^{128}$, fordert deswegen eine Hinwendung zu psychologischen Methoden und Blickwinkeln, um Motive der Akteure und ihre Antriebskräfte zu verstehen. Die zu oft auf die Ökonomie und ihre KostenNutzen-Verkürzungen schielenden Erklärungen in den Politikwissenschaften hätten über Jahre, so an dieser Stelle das Fazit, den Blick auf Erklärungsmuster jenseits des Homo Oeconomicus verstellt. Gleichwohl bleiben auch Van Zomeren et al. dem Wunsch verhaftet, auf der Metaebene statistische Aussagen über Protestmotivationen zu treffen, und das wissenschaftliche Objektiv nicht allzu weit heranzuzoomen, um den vermeintlichen Blick fürs große Ganze nicht zu verlieren. Eine Ausnahme bildet Kathleen M. Blee, die Aktivistengruppen als Kollektivakteure, aber auch mit einem Fokus auf die Aktivistenpersonen untersucht hat. ${ }^{129}$

Eine andere Traditionslinie der wissenschaftlichen Beschäftigung mit Protesten ist die qualitative Untersuchung einzelner Fallbeispiele und Protestfelder. ${ }^{130}$ Eine Stärke dieses Fokus ist sicherlich die Möglichkeit, an Konstellationen, Begründungen und lokale Besonderheiten nah herangehen und diese nachvollziehen zu können. Die Folge ist allerdings unter anderem, dass in Fallstudien stets die Frage nach der Angemessenheit des Protests vor dem Hintergrund des jeweiligen Konfliktes mitschwingt - und damit eine Konzentration auf konkrete Ursachen und inhaltliche Facetten der Entzündung von Widerspruch.

Soziale Bewegungen sind folglich in der akademischen Analyse, besonders über Einzelfallbeispiele hinaus, in erster Linie als übergeordnete Gruppenphänomene und nicht aus der Perspektive der einzelnen Aktiven untersucht worden. Einzelfallbetrachtungen einzelner Protestfelder hingegen münden oftmals in eine Ursache-Wirkungs-Geschichte einzelner Protestthemen und -orte und ihrer Protagonistenkonstellationen, so dass wenig Raum für eine Betrachtung ihrer Aus-

128 Van Zomeren, Martijn / Tom Postmes / Russel Spears: Toward an Integrative Social Identity Model of Collective Action: A Quantitative Research Synthesis of Three Socio-psychological Perspectives, in: Psychological Bulletin, Bd. 134 (2008) H. 4, S. $504-535$.

129 Blee, Kathleen M.: Democracy in the Making. How Activist Groups Form, New York 2012.

130 Als exemplarisch mögen an dieser Stelle die folgenden Bände stehen: Brettschneider, Frank / Wolfgang Schuster (Hrsg.): Stuttgart 21. Ein Großprojekt zwischen Protest und Akzeptanz, Wiesbaden 2013; Holm, Andrej (Hrsg.): Reclaim Berlin. Soziale Kämpfe in der neoliberalen Stadt, Berlin 2014; Naegler, Laura: Gentrification and Resistance: cultural criminology, control, and the commodification of urban protest in Hamburg, Berlin 2012; Holm, Andrej / Dirk Gebhardt (Hrsg.): Initiativen für ein Recht auf Stadt. Theorie und Praxis städtischer Aneignungen, Hamburg 2011. 
sagekraft oder Symbolfähigkeit für gesellschaftliche Entwicklungen bleibt. In diese Lücke möchte dieses Buch stoßen.

\subsection{ZWISCHENFAZIT II: ZUR HERANGEHENSWEISE}

Bei der Betrachtung der deutschen Bürgerproteste soll der literarische Flaneur analog zum Postulat aus Kap. 3.1 - nicht in Reinform und auch nicht als alleiniger Interpret gesellschaftlicher Wirklichkeit auftreten - bereits die Tatsache eines schon bestehenden Datenkorpus verstellt dies und auch das Ziel ist ein anderes. Schließlich wird existierendes Rohmaterial benutzt, welches die völlig freie, auch erratische Flanerie illusorisch und wenig zielführend machen würde. Es sollen aber insofern Anleihen beim flanierenden Denken und Schauen genommen werden, als dass ein offenes und neugieriges Treiben durch die gesammelten Eindrücke, durch Stimmungen, Interviews, Gespräche, Beobachtungen, durchaus vielversprechend sein kann für das Ziel, die Interpretation der Transkripte und Protokolle auch atmosphärisch zu durchdringen. „Erfahrendes Denken“ nannte Siegfried Kracauer dies. ${ }^{131}$ Auch Richard Swedberg hat darauf hingewiesen, dass ein exploratives Vorgehen - ,theorizing“ - auf Offenheit, Sensibilität und Kreativität angewiesen ist. Ein solches „Theoretisieren“ über und durch das bestehende Datenmaterial müsse der Ursprung guter sozialwissenschaftlicher Arbeit sein, denn anderenfalls würde sich die wissenschaftliche Arbeit im inspirationslosen Reproduzieren von bestehenden Theorien und deren Überprüfung erschöpfen. Dies sei zwar auch wissenschaftlich durchaus notwendig. Am Anfang eines wissenschaftlichen Prozesses aber müsse die „Entdeckung“ stehen, um neue Phänomene überhaupt erfassen zu können: „While the advocates of theory construction did look at the theorizing process, they were primarily interested in the context of justification, not the context of discovery. Their main concern was with the way you develop hypotheses and test these, not with what precedes these two stages. They focused on formal and cognitive elements, and had little to say on such topics as intuition, imagination, and abduction. [...] To theorize well, one needs inspiration, and to get inspiration one can proceed in whatever way that leads to something interesting - and that means any way." 132

131 Mülder, Inka: Siegfried Kracauer - Grenzgänger zwischen Theorie und Literatur. Seine frühen Schriften 1913 - 1933, Stuttgart 1985, S. 87.

132 Swedberg: Theorizing in sociology and social science, hier S. $5 f$. 
Diese Offenheit für Sinneseindrücke, und darauf zu achten, sich nicht durch rigide Methodenkonzentration mögliche Perspektiven zu verschließen, ist auch ein Dreh- und Angelpunkt des am Göttinger Institut für Demokratieforschung gelehrten und gehegten Selbstverständnisses. ${ }^{133}$ Die Person des Forschenden darüber hinaus nicht als objektivistisches Neutrum zu betrachten, sondern die Konstruktion jeder Wirklichkeit auch mit und durch den Forscher zu begreifen, kommt als weiteres Signum hinzu. Ist dies akzeptiert, folgt daraus die Möglichkeit, Perspektivenwechsel und Position des Beobachters aktiv auch in den Forschungsprozess mit einzubeziehen, den „Flaneur“ als Deuter zuzulassen.

Insgesamt möchte sich diese Studie in die Denktradition der Göttinger Demokratieforschung stellen - sie baut dabei auf dem bisherigen Forschungsstand und der Methodik der Protestforschung, Politikwissenschaft und qualitativen Sozialforschung auf, verschließt sich aber keineswegs dem Methodenarsenal, welches andere Disziplinen oder Denkschulen entwickelt haben. So wurde entwickelt, dass der „Werkzeugkasten, dem man für bestimmte Forschungsfragen und -kontexte geeignete Untersuchungsinstrumente entnimmt “134, unter anderem verschiedene Datengattungen vereint - vornehmlich Einzelinterviews, Gruppengespräche und Beobachtungsprotokolle -, auf die mit unterschiedlichen Brillen geschaut wird, wobei hier Anleihen genommen werden bei der Diskursanalyse, der Objektiven Hermeneutik und der Dokumentarischen Methode. Der dienende Charakter von Methodik, jeweils ein Erkenntnis- und Entdeckungsinteresse zu unterstützen und interessante Einblicke zu ermöglichen, ist wichtig, um im Sinne einer Triangulation Regelmäßigkeiten, Plausibilitäten und Ergebnisse entstehen zu lassen und diese im Material abzusichern.

133 Vgl. dazu grundlegend Bebnowski, David / Jöran Klatt / Philipp Kufferath / Robert Lorenz / Michael Lühmann: Selbstverständnis. Zur Einordnung - historischm(eth)odische Reflexionen, in: Hensel, Alexander / Daniela Kallinich / Katharina Rahlf (Hrsg.): Parteien, Demokratie und gesellschaftliche Kritik. Jahrbuch des Göttinger Instituts für Demokratieforschung 2010, Stuttgart 2011, S. 11 - 38.

134 Kleemann u.a.: Interpretative Sozialforschung, S. 198. 



\section{Die vier Fragen: Generation, Biographie, Alter und Prägung}

Wer nun also sind jene, die da protestieren? Für Wolfgang Kraushaar sind es „eindeutig Vertreter einer neuen Mitte, die akademisch qualifiziert und linksorientiert sind, sich ökologisch engagieren und einer Altersstufe angehören, für die der Ruhestand in Reichweite liegt oder bereits erreicht ist. “1 Auch die bisherigen Untersuchungen des Göttinger Instituts für Demokratieforschung sowie der Arbeitsgruppe Dieter Ruchts zu den Demonstrationen um den Stuttgarter Bahnhofsneubau sowie das Berliner Flughafenprojekt unterstreichen diesen Eindruck: Bei den Protesten in Deutschland seit 2008 und im starken Kontrast zum populären Bild der Neuen Sozialen Bewegungen der 1970er und 1980er Jahre handele es sich um ein Phänomen älterer, gut ausgebildeter, wohlsituierter und arrivierter Bürger, und um deren Unwillen, einmal gewonnene Privilegien auf den Prüfstand zu stellen oder gar neu zu verhandeln. ${ }^{2}$

Bei den Protestierenden gegen den Flughafen Berlin-Brandenburg ab 2006 waren mehr als 70 Prozent der Protestteilnehmer über 45 Jahre und nur 6 Prozent zwischen 16 und 35. ${ }^{3}$ Für die Demonstrationen gegen Stuttgart 21 zitiert Claus Leggewie eine Studie des Berliner WZB, um zu unterstreichen, „,ass zwei Drittel der Beteiligten zwischen 40 und 64 Jahre (36 Prozent der Gesamtbevölke-

1 Vgl. Kraushaar, Wolfgang: Protest der Privilegierten?, in: Mittelweg 36, Jg. 20 (2011) H. 3, S. $5-22$.

2 Vgl. Baumgarten, Britta / Dieter Rucht: Die Protestierenden gegen „Stuttgart 21“ einzigartig oder typisch?, in: Brettschneider, Frank / Wolfgang Schuster (Hrsg.): Stuttgart 21 - Ein Großprojekt zischen Protest und Akzeptanz, Wiesbaden 2013, S. $97-125$.

3 Vgl. Göttinger Institut für Demokratieforschung: Die Proteste gegen den Flughafen Berlin Brandenburg. 
rung) und nur 7 Prozent unter 25 Jahre alt waren. “4 Winfried Thaa schildert ebenso in seinem Resümee der Stuttgarter Proteste, dass die soziale Zusammensetzung der Proteste von der früherer Bewegungen in Deutschland erheblich verschieden war. ${ }^{5}$

Und auch die hier zugrunde liegende Göttinger Studie zu Bürgerprotesten in Deutschland versammelte ein ähnliches Sample über verschiedene Protestgruppen hinweg. Knapp die Hälfte der dort interviewten Protestler und Aktivisten waren über 56 und deutlich unter fünf Prozent waren unter 35. Zwar differieren gerade die Abweichungen von diesem Bild von Protestfeld zu Protestfeld mitunter stark, gibt es Protestbündnisse und Initiativen, die ein breiteres Altersspektrum vereinen als andere. Zusammenfassend lässt sich aber unterstreichen, dass eine älter werdende Gesamtbevölkerung in Deutschland von einer noch rascher alternden Protestgruppe an durchschnittlichen Jahren ,überholt“ worden ist. Gerhard Matzig hat genau hier das Epizentrum eines Problems ausgemacht: dass Proteste in Deutschland ein Generationenphänomen seien, die aus einer eingeengten biographischen Perspektive heraus einen rationalen und damit mögliche Gelegenheiten erkennenden Blick auf die zeitgenössische Entwicklung verstellten. Die Angst der älteren Generationen vor nicht zu überschauenden Veränderungen sowie den unter Druck geratenen Errungenschaften an Lebensqualität, welche etwa der deutsche Sozialstaat und die beruflichen Umfeldbedingungen in Deutschland haben entstehen lassen, stehen im Kern eines Protests gegen die Funktionsweisen und Entscheidungswege der parlamentarischen Parteiendemokratie. Besonders die technologische Entwicklung sei es, die Angst verursache und ältere Menschen sich verschließen lasse gegenüber Neujustierungen und Weiterentwicklungen. Dabei wirke diese über drei Kanäle: Die Ökonomie und der wirtschaftliche Konkurrenzkampf hätten erstens zu einem „Innovationsterror ${ }^{\text {“6 }}$ geführt, der immer neue Rationalisierungen und Effizienzsteigerungen erzwinge, welche Menschen überfordere. Der zweite Wirkweg sei laut Matzig, dass Innovationen Angst auslösten, da Folgen und Langzeitauswirkungen von technischen Entwicklungen im Anfangsstadium kaum je verlässlich einzuschätzen seien. Er benutzt hierbei die uralte jüdische Legendenfigur des „Golem“, einst als Helfer und Fortschritt gesehen, der sich dann als nicht zu kontrollierender Albtraum entpuppt. Letztlich und drittens liege laut Matzig gerade in einer alternden Gesellschaft begründet, dass Innovationen als besonders anstrengend

4 Vgl. Leggewie, Claus: Mut statt Wut, S. 30.

5 Vgl. Thaa, Winfried: „Stuttgart 21“ - Krise oder Repolitisierung der repräsentativen Demokratie?, in: Politische Vierteljahresschrift, Jg. 54 (2013) H. 1, S. 1 - 20, hier S. $5 f$.

6 Matzig: Einfach nur dagegen, S. 212. 
und schwierig betrachtet würden, da eingefahrene Prinzipien und Lebensweisen stets aufs Neue durch Innovationen geändert, aufgegeben, angepasst werden müssten. Dies sei den gut situierten älteren Generationen in Deutschland schlichtweg zu anstrengend. ${ }^{7}$

Auf der anderen Seite hingegen könnte nicht im gehobenen Alter per se eine zentrale Charakteristik der zeitgenössischen Proteste zu finden sein, sondern in einem Ausscheren der besser Gebildeten aus den bis dato üblichen und eingefahrenen Kanälen der Interessensvermittlung. ${ }^{8}$ Eine neue Bürgerbewegung sei vielmehr durch einen „Expertenbürger“ geprägt, der durch (Aus-)Bildung und angehäufte professionelle Erfahrung ,,vor allem an der Effizienz und Effektivität von Entscheidungen interessiert ist, darin Ingenieuren und Wissenschaftlern gleicht und auf der Höhe des zugänglichen Wissens an eine überpolitische Wahrheit oder Expertise glaubt. “9 Darüber hinaus sei, anders gelagert, aber ebenso auf eine Richtungsweisung durch ältere Generationen deutend, ein „Bindungsbürger“ wegweisend, ,der die Erhaltung des Bestands anstrebt und allen Großprojekten skeptisch begegnet, dafür alle Macht der Gemeinschaft mitsamt ihren Werten und Vorlieben gibt und darin eine vorpolitische Weisheit wirken sieht. “10

Herfried Münkler erkennt, diese Argumentationen verbindend, hier gar eine neue ,demokratische Oligarchie“, die sich aus Menschen zusammensetze, welche durch Ausbildung, berufliche Erfahrung und die im Alter größer werdenden zeitlichen (und finanziellen) Ressourcen in der Lage sei, ihren Anliegen ein verstärktes Gehör zu verschaffen. Es sei eben ,nicht die Bevölkerung in ihrer Gesamtheit, die durch den Niedergang der Volksparteien an Einfluss gewinnt, sondern die einstigen Schlagkraftverstärker der Parteien verfolgen nun ihre eigenen Interessen. Heute bestehen die entscheidenden Ressourcen dieser neuen, wenn man so will: demokratischen Oligarchie aus den durch Ausbildung und Beruf erworbenen Kompetenzen in Verbindung mit einem frei verfügbaren großen Zeitbudget. Man könnte auch von einer Rückkehr der Honoratioren in die Politik sprechen, die den professionellen Funktionseliten die alleinige Verfügung über Sachentscheidungen aus der Hand zu nehmen versuchen. “ ${ }^{11}$

7 Vgl. zu diesen Argumentationen ebenda, S. 207 - 215.

8 Vgl. Sahr, Aaron / Philipp Staab: Bahnhof der Leidenschaften, in: Mittelweg 36, Jg. 20 (2011) H. 3, S. $23-48$.

9 Leggewie: Mut statt Wut, S. 27.

10 Ebenda, S. 28.

11 Münkler, Herfried: Der gereifte Demonstrant - Regieren und Partizipieren in einer alternden Gesellschaft, in: Deutschlandfunk, 31.12.2010, online abrufbar unter http://www.deutschlandfunk.de/der-gereifte-demonstrant-regieren-und-partizipierenin.724.de.html?dram:article_id=100056 [zuletzt eingesehen am 21.02.2015]. 
Im Übrigen scheinen internationale Untersuchungen den Eindruck zu untermauern, dass die deutschen Proteste und Initiativen, die sich am Misstrauen gegenüber traditionellen Regelungsmechanismen einer Parteiendemokratie entzünden, bei aller Betonung nationaler, regionaler oder lokaler Spezifika durchaus Teil eines globalen Trends sein dürften. In einer internationalen Längsschnittstudie über sieben Jahre von 2006 bis 2013 verzeichnen die Autoren einen deutlichen Anstieg der Protestartikulationen in 84 Ländern. Insgesamt 884 Protestereignisse wurden dabei untersucht und bezüglich Themenfelder, Teilnehmer, Methoden, Organisation und Ergebnis eingeordnet. Dabei wurde zunächst beobachtet, dass Proteste insgesamt und über alle Weltregionen hinweg zugenommen hätten: Von 59 gefundenen Phänomenen 2006 ist die Zahl kontinuierlich angestiegen auf 1602012 und auf 111 in der ersten Jahreshälfte 2013. Auffällig dabei ist, dass die Proteste der Gutsituierten in den jeweiligen Ländern auch international eine deutliche Überzahl ausmachen. Je höher die Einkommensgruppe, umso größer die Zahl der Protestgruppen und -felder, die ihr zugeordnet wurde. High Income Groups standen hier hinter 329 Protestereignissen, während den Low Income Groups lediglich 63 zugerechnet werden. Auch über den Globus hinweg scheinen also Proteste ein Phänomen zu sein, das als Ausdrucksform und Interessensartikulation den Gutsituierten einer Gesellschaft leichter von der Hand geht. So werden für 2012 und 2013 knapp die Hälfte aller hier registrierten Proteste dieser Einkommensgruppe zugerechnet, bei der durchaus vermutet werden kann, dass das hier bemühte High-Income-Segment parallel auch in der Tendenz für ältere, arrivierte Gruppen der Gesellschaft steht. Mit sinkendem Einkommen nehmen auch die Protestzahlen ab. Und auch was die deutschen Protestthemen anbelangt, finden sich in der internationalen Resümeestudie Parallelen: Real Democracy, Reform of Public Service, Corruption, Environmental Justice sind einige der am häufigsten angetroffenen Oberthemen der Protestierenden. Sichtbare Untergliederungen der Schwerpunkte hier sind die Felder Demokratie, Konzerneinfluss/Deregulierung, Reform der öffentlichen Verwaltung/Dienstleistungen, denen jeweils mehr als 80 einzelne Proteste der High-Income-Group zugeordnet werden. ${ }^{12}$

Dass also Protestierende lediglich einen mal breiteren, mal schmaleren Ausschnitt aus der Gesamtbevölkerung repräsentieren und eben nicht per se die Bevölkerung in ihrer Gesamtheit, darüber herrscht Einigkeit. Auch über die Frage, in welche Richtung der Ausschnitt verzerrt sein mag, verglichen mit einer statistisch vollendeten Repräsentativität, gibt es in den dazu vorliegenden Studien kaum Dissens - immer unter der Prämisse, dass es sich um organisierte Proteste handelt und nicht um eklektisch und brennpunktbegrenzt aufflackernde Riots.

12 Zu dieser Studie siehe Ortiz u.a.: World Protests 2006 - 2013. 
Was allerdings daraus folgt, welche Folgen dies für die Protestperspektive zeitigt, für Hoffnungen und Motivationen und auch für die Begegnung der Protestierenden mit den Fundamenten der deutschen Demokratie, darüber gibt es wenige intensive Deutungsversuche. Danach zu fragen, was Protestierende und Aktivisten hinsichtlich ihres eigenen Engagements eigentlich für Prägungen erinnern, wer oder was sie zu einem Aktivsein außerhalb der eingeschliffenen traditionellen Großorganisationen (prä)dispositioniert hat - hier zu einem tieferen Verständnis beizutragen ist eines der Vorhaben dieser Arbeit. Dazu gehört an erster Stelle eine Annäherung an die Entscheidung, überhaupt in Protesten oder Initiativen aktiv zu werden, den lange Zeit vorherrschenden Weg von Interessenvertretung, Vermittlung und Einflussnahme nicht einzuschlagen, sondern neuen Pfaden zu folgen.

\subsection{SOZIALSTRUKTUR DER INTERVIEWTEN}

Insgesamt wurden für diese Arbeit aus den Interviews der schon beschriebenen Studie zu Protestteilnehmern und Aktivisten, welche vom Göttinger Institut für Demokratieforschung im Jahr 2012 geführt wurden, 20 Einzelinterviews ${ }^{13}$ und sieben Fokusgruppen ausgewählt. ${ }^{14}$ Auf diese Weise dienen - neben den Betrachtungen und Protokollen, welche der Autor selbst im Rahmen der teilnehmenden Beobachtungen gemacht und angefertigt hat, 73 Akteure des Protests als Gesprächspartner und Untersuchungssample. Die Einzelinterviews und Fokusgruppen wurden unter anderem in Hamburg, Stuttgart, Freising und Hannover geführt. Ohne dass im Zuge dieser qualitativ-explorativen Studie eine vermeintliche Repräsentativität reklamiert werden soll, kann ein erster Blick auf die Zusammensetzung der Interviewtengruppe fruchtbar sein, um eine Interpretationsgrundlage zu legen.

Von denjenigen, die in den zu den Interviews auszufüllenden Fragebögen ihr Alter angegeben haben, waren die meisten zum Zeitpunkt der Gespräche 2012 zwischen 46 und 55 Jahre alt. Die Altersgruppen darüber (zwischen 56 und 75) und darunter (36 bis 45) sind ebenso vertreten. Im Interviewsample sind deutlich weniger Aktivisten vertreten, die jünger als 36 Jahre (insgesamt nur 5) bzw. älter als 75 sind (2). Dies widerspricht zwar nicht den zitierten Beobachtungen, dass es sich bei den Protesten in Deutschland um eine Bewegung selbstbewusster Älterer handelt, lässt aber dennoch erheblichen Spielraum der Betrachtung, da ein

13 Eines davon (G1 Anna und Conrad) als Doppelinterview.

14 Vgl. Kap. 3.3. 
Großteil der hier vertretenen Altersgruppen theoretisch oder praktisch noch mit beiden Beinen im Arbeitsleben steht.

Folgt man der Frage nach den unterschiedlichen Prägephasen und Geburtsjahrgängen, dann sieht man (vgl. Abb. 2), dass sich das Gros der Interviewpartner über immerhin vier Geburtsjahrzehnte zwischen 1937 und 1976 verteilt. Erwartbar wären hier auch ganz unterschiedliche Prägungen, Erfahrungen und die Entwicklung unterschiedlicher Perspektiven auf das Themenfeld „Politik und Gesellschaft", auf mögliche Protestmotivationen.

\section{Abbildung 1: Altersstruktur der Gesprächspartner}

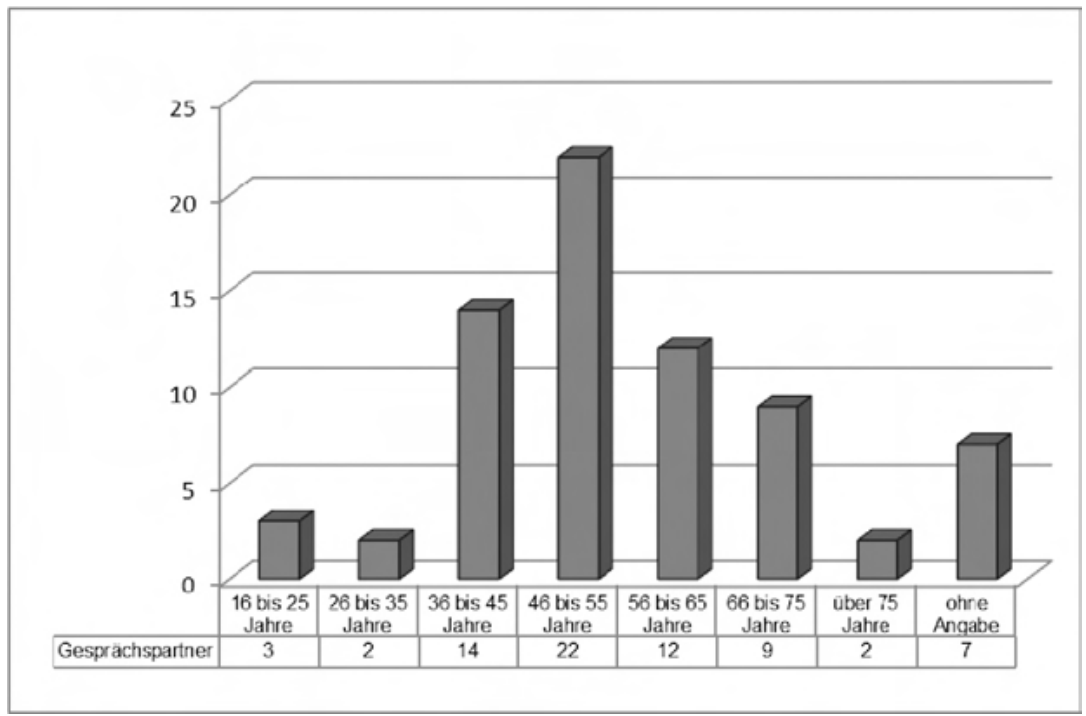

Quelle: eigene Darstellung

Die Frage, wann genau und wie ein Mensch geprägt wird, sich zu einem ,gesellschaftlich handlungsfähigen Subjekt ${ }^{* 15}$ herausbildet, ist Gegenstand der Sozialisationsforschung. Zentrale Fragen sind dabei wann, auf welche Weise und durch wen Kinder, Jugendliche und Erwachsene ihre Persönlichkeit „als spezifisches Gefüge von Merkmalen, Eigenschaften und Handlungskompetenzen erlangen,

15 Hurrelmann, Klaus: Einführung in die Sozialisationstheorie, Weinheim und Basel 2002, S. 15. 
das einen einzelnen Menschen kennzeichnet. "16 Sozialisation als Konzept fasst folglich Einflussfaktoren zusammen, welche auf diese Entwicklung einwirken: entwicklungsbiologische und -physiologische, institutionelle (etwa Schuleintritt und -dauer) genau wie soziale oder psychologische. ${ }^{17}$ Der Prozess wird als graduell, sich dynamisch aufbauend und als lebenslang andauernd beschrieben Prägungen, Werte, Ideen und Verhaltensweisen können sich demzufolge über ein ganzes Leben immer wieder infolge von gesammelten Erfahrungen und Eindrücken verändern. ${ }^{18}$ Eine einzelne, klar abgrenzbare Lebensphase, der man an dieser Stelle seine Aufmerksamkeit zu widmen hätte, um einen Menschen oder sein (politisches) Verhalten zu begreifen, gibt es nicht.

Gleichwohl richtet die Sozialisationsforschung verstärkt den Blick auf die Jahre der „Jugend“ oder „Adoleszenz“, um die „Subjektwerdung“ eines Menschen zu verstehen, „weil in diesem Abschnitt des Lebens im Grunde alle für die heutige Lebensbewältigung typischen Anforderungen schon ein erstes Mal erprobt werden“". ${ }^{19}$ Zwar gibt es einen Konsens, dass es in theoretischer Hinsicht unmöglich sei, eindeutige Altersgrenzen für „Jugend“ oder „Adoleszenz“ als Entwicklungsphase festzulegen. Vielmehr müsse Jugend als zentrale Phase des Entwicklungsprozesses funktional begriffen werden. Vera King spricht an dieser Stelle von einer ,weichenstellenden Funktion und Bedeutung“, von Jugend als einem „Scharnier“ hin zum erwachsenen Menschen. ${ }^{20}$ Überhaupt sei Sozialisation nicht als ein eindimensional zu empfangender Einfluss o.ä. zu verstehen, sondern als ein mehrdimensionaler Prozess, in dessen lebenslangem Rahmen das Ende der Jugendphase als Zustand begriffen werden kann, in dem eine (vorläufige) Werte- und Normenstabilität erreicht wird. „Jeder gesunde Mensch entwickelt in dieser Phase (bis zum Ende des zweiten Lebensjahrzehnts, Anm. F.B.) bis zum Abschluss des Jugendalters feste Grundstrukturen der Abstimmung zwi-

16 Tillmann, Klaus-Jürgen: Sozialisationstheorien. Eine Einführung in den Zusammenhang von Gesellschaft, Institution und Subjektwerdung, Reinbek bei Hamburg 2010 (1989), S. 16.

17 Vgl. Lange, Dirk / Holger Onken / Andreas Slopinski: Politisches Interesse und Politische Bildung: Zum Stand des Bürgerbewusstseins Jugendlicher und junger Erwachsener, Wiesbaden 2013, S. 25.

18 Hurrelmann: Einführung in die Sozialisationstheorie, S. 35.

19 Hurrelmann, Klaus: Lebensphase Jugend. Eine Einführung in die sozialwissenschaftliche Jugendforschung, Weinheim und München 2005, S. 18; vgl. hier auch Reinders, Heinz: Politische Sozialisation Jugendlicher in der Nachwendezeit. Forschungsstand, theoretische Perspektiven und empirische Evidenzen, Opladen 2001, S. 17.

20 King, Vera: Die Entstehung des Neuen in der Adoleszenz: Individuation, Generativität und Geschlecht in modernisierten Gesellschaften, Wiesbaden 2013, S. 42. 
schen inneren Bedürfnissen und äußeren Erwartungen und baut ein System von Erfahrungen und Kompetenzen auf, die für die nachfolgenden Lebensabschnitte jeweils flexibel weiterentwickelt werden. ${ }^{\text {21 }}$ Wann dies zeitlich genau im Alter eines Menschen eintritt, ist umstritten und wird nur sehr ungenau beschrieben. Während Klaus Hurrelmann vom Ende der ersten zwei Lebensjahrzehnte spricht, werden für Klaus-Jürgen Tillmann die meisten Menschen zwischen zwanzig und dreißig zu , $<$ vollgültigen $>$ Erwachsenen “22. Letzterer versieht in seiner tabellarischen Übersicht einer sequenziellen Abfolge von Entwicklungsphasen nur zwei biographische Phasengrenzen mit Fragezeichen: das Ende der Jugend und das Lebensende. ${ }^{23}$ Und Vera King stellt fest, dass die „Gegenstandsbestimmung“ der Jugend- und Adoleszenzforschung ihr zentrales Problem sei und resümiert, jeder Versuch, genaue Altersgrenzen theoretisch eindeutig festzulegen, sei zum Scheitern verurteilt. ${ }^{24}$ Darüber hinaus haben auch die Betrachter von Generationen in der Soziologie immer wieder auf diese Problematik hingewiesen, Prägungsphasen von Menschen nie theoretisch exakt festlegen zu können. ${ }^{25}$

Es komme in der Sozialisationsforschung vielmehr darauf an, die Entwicklungsaufgaben, deren Bewältigung aus einem Jugendlichen einen Erwachsenen werden ließen, zu ergründen und so individuell wie möglich nachzuvollziehen. ${ }^{26}$ Hurrelmann benennt vier Bereiche, in denen eine Transition zum Erwachsenen geschehe: Erstens, die Ausprägung intellektueller und sozialer Kompetenzen, um in eine selbstständige Erwerbsrolle hineinzuwachsen; zweitens, ein ,inneres Bild von der Geschlechterzugehörigkeit“, um Verantwortung als Familiengründer/in übernehmen zu können; drittens, ,selbständige Handlungsmuster für die Nutzung des Konsumwarenmarktes“, um am Kultur- und Konsumentenleben autonom teilhaben zu können; viertens, ein „Werte- und Normensystem“ sowie ein „ethisches und politisches Bewusstsein", um in eine aktive und verantwortliche Bürgerrolle zu schlüpfen. ${ }^{27}$ Auch Dirk Lange et al. und Heinz Reinders verorten eine politische Sozialisation im Sinne einer Basis, um politische Entwicklungen

21 Hurrelmann: Einführung in die Sozialisationstheorie, S. 37.

22 Tillmann: Sozialisationstheorien, S. 242; vgl. hier auch Vetter, Angelika: Jugend: Ein Konzept und seine Messung, in: Roller, Edeltraud / Frank Brettschneider / Jan W. van Deth (Hrsg.): Jugend und Politik: „Voll normal!“ Der Beitrag der politischen Soziologie zur Jugendforschung, Wiesbaden 2006, S. 25 - 53, hier S. 25.

23 Vgl. Tillmann: Sozialisationstheorien, S. 28.

24 King: Die Entstehung des Neuen in der Adoleszenz, S. 33f. sowie 38.

25 Vgl. etwa Jureit, Ulrike: Generationenforschung, Göttingen 2006, S. 27.

26 Vgl. Lange u.a.: Politisches Interesse und Politische Bildung, S. 19.

27 Hurrelmann: Lebensphase Jugend, S. 27f. sowie 37. 
und Akteure bewerten zu können, im Jugendalter, und sehen sie ebenfalls als gewichtigen Teil des Entwicklungsprozesses hin zum Erwachsenen. ${ }^{28}$

Jugend sei demnach als ,unruhige Such- und Tastphase“ ${ }^{29}$ in allen vier Bereichen zu begreifen, bei der die Grenzen und Schwellen fließend seien, und in der auch jedem Jugendlichen unterschiedlich große Bildungs- und Experimentierräume zur Verfügung stehen, welche sich sozial ungleich über die Bevölkerung verteilt finden. ${ }^{30}$ Dabei seien es vor allem die Familie und die in ihr wahrgenommene Beschäftigung mit politischen Themen, als Vorbilder wahrgenommene Lehrer in der Schule, Gleichaltrige und Medien, welche als Instanzen die politische Sozialisation Jugendlicher beeinflussen. ${ }^{31}$

Wenn in dieser Arbeit der Frage nachgegangen werden soll, welche Prägungen, Werte, Normen oder Handlungsdispositionen die Teilnehmer an Bürgerprotesten erkennen lassen oder für sich in Anspruch nehmen, dann erscheint ein Blick auf die Jugendzeit fruchtbar und Erkenntnis versprechend. Die Fragerichtung im weiteren Verlauf soll dies aber nicht einschränkend, sondern lediglich fokussierend versuchen, denn: „Die politische Sozialisation ist letztlich ein dynamischer, lebenslanger Prozess, der vor allem im Jugendalter stattfindet. “32

In der soziologischen Betrachtung von Generationen ist darauf hingewiesen worden, dass Prägungen im Laufe des Lebens eines Menschen einer prozesshaften Verarbeitung unterliegen, und demnach Äußerungen zu sinnstiftenden Erlebnissen der eigenen Lebensgeschichte nur retrospektiv und vor dem Hintergrund der weiteren biographische Entwicklung zu verstehen sind. ${ }^{33}$ Insofern bietet es sich an dieser Stelle an, gerade auch aufgrund des qualitativen, auf die einzelnen Aktiven blickenden Vorgehens, ein weites Feld möglicher Prägephasen in die Frageperspektive mit einzubinden. Vor dem Hintergrund der theoretisch weiten Annahme eines Endes der jeweiligen Jugendphasen zwischen 20 und 30 sind nachstehend die Zeitperioden aufgeführt, in denen die Interviewteilnehmer dieses Alter erreichten, um eine Hintergrundfolie für die Gesprächsinterpretationen zu erstellen.

28 Vgl. Lange u.a.: Politisches Interesse und Politische Bildung, S. 26, sowie Reinders: Politische Sozialisation Jugendlicher in der Nachwendezeit, S. 103.

29 Hurrelmann: Lebensphase Jugend, S. 29.

30 Vgl. Lange u.a.: Politisches Interesse und Politische Bildung, S. 18.

31 Vgl. Vollmar, Meike: König, Bürgermeister, Bundeskanzler? Politisches Wissen von Grundschülern und die Relevanz familiärer und schulischer Ressourcen, Wiesbaden 2012, S. 37 sowie S. $82-86$.

32 Lange u.a.: Politisches Interesse und Politische Bildung, S. 27.

33 Vgl. etwa Jureit: Generationenforschung, S. 27. 
Abbildung 2: Geburtsjahrgänge und politische Prägezeiträume der Gesprächspartner

\begin{tabular}{|c|c|c|c|}
\hline Alter 2012 & Geburtsjahrgänge & Alter 20 & Häufigkeiten \\
\hline 16 bis 25 Jahre & $1987-1996$ & $2007-(2016)$ & 3 \\
\hline 26 bis 35 Jahre & $1977-1986$ & $1996-2006$ & 2 \\
\hline 36 bis 45 Jahre & $1967-1976$ & $1987-1996$ & 14 \\
\hline 46 bis 55 Jahre & $1957-1966$ & $1977-1986$ & 22 \\
\hline 56 bis 65 Jahre & $1947-1956$ & $1967-1976$ & 12 \\
\hline 66 bis 75 Jahre & $1937-1946$ & $1957-1966$ & 9 \\
\hline über 75 Jahre & vor 1937 & vor 1957 & 2 \\
\hline ohne Angabe & & & 7 \\
\hline Gesamt & & & 71 \\
\hline
\end{tabular}

Quelle: eigene Darstellung

Hier spreizen sich diese angenommenen Prägephasen für den Hauptteil der Interviewten zwischen dem Ende der 1950er und der Mitte der 1990er, mithin über einen Großteil der bundesdeutschen Nachkriegsgeschichte. Dies nicht nur über die Zeitperioden, sondern auch im Hinblick auf das relative Gewicht der Jahrgänge im Interviewsample: Rund achtzig Prozent der Befragten haben demnach zwischen Mitte der 1950er und Mitte der 1990er Jahre das Alter 20 erreicht. Die Frage danach, ob sich hier in den Gesprächen etwaige Schwerpunkte der politischen Bewusstwerdung und eine angenommene Prädisposition für ein Protestengagement herauskristallisieren, drängt sich an dieser Stelle auf. Die Altersstruktur der Aktivisten dieser Studie ist allerdings breiter gestreut als die zitierten Zuspitzungen eingangs des Kapitels die Protagonisten zeitgenössischer Bürgerproteste - dramataturgisch verständlich - gemalt haben.

Etwa sechzig Prozent des Samples sind Männer, knapp zwei Fünftel Frauen. Gegenüber dem Grundlagensample der Göttinger Protest-Studie ist dies eine leichte Verschiebung hin zu einem größeren Anteil weiblicher Aktivisten. Eine 
Erklärung hierfür ist, dass die in diese Arbeit aufgenommenen Gruppen der Euro-Kritiker zwar durch einen hohen Anteil männlicher Teilnehmer gekennzeichnet, die Protestgruppen im Bereich Infrastruktur und öffentlicher Raum und noch weit stärker - die Aktivisten der Protestinitiativen zum Thema Bildung und Schule aber zu einem überproportionalen Teil weiblich sind.

Abbildung 3: Geschlechterverteilung der Gesprächspartner

\begin{tabular}{|l|r|r|}
\hline Geschlecht der Befragten & Häufigkeiten & Prozent \\
\hline männlich & 43 & 60,6 \\
\hline weiblich & 28 & 39,4 \\
\hline gesamt & 71 & 100,0 \\
\hline
\end{tabular}

Quelle: eigene Darstellung

Abbildung 4: Religionszugehörigkeit der Gesprächspartner

\begin{tabular}{|l|l|r|}
\hline Religionszugehörigkeit & Häufigkeiten & Prozent \\
\hline katholisch & 13 & 18,3 \\
\hline evangelisch-lutherisch & 28 & 39,4 \\
\hline evangelisch-freikirchlich & 1 & 1,4 \\
\hline keine Religionszugehörigkeit & 23 & 32,4 \\
\hline ohne Angabe & 6 & 8,5 \\
\hline gesamt & 71 & 100,0 \\
\hline
\end{tabular}

Quelle: eigene Darstellung

Nach der Religionszugehörigkeit gefragt, zeigt sich ein deutliches Bild. Die größte Gruppe bilden die evangelischen Protestanten, die etwa vierzig Prozent der Befragten ausmachen, dicht gefolgt von den Teilnehmern, welche keine Religionszugehörigkeit angeben. Weniger als zwanzig Prozent der 73 Befragten haben eine katholische Religion angegeben. Ob sich eine solche Betonung des Protestantischen bzw. Religionslosen auch in den geäußerten Sichtweisen und Motiven widerspiegelt, wird zu untersuchen sein.

Was das Bildungsniveau anbelangt, so ist das Bild der Interviews stimmig mit den zitierten Ergebnissen von Studien zur Zusammensetzung der Proteste: Weit über die Hälfte der Aktivisten haben einen Universitätsabschluss oder gar eine Promotion, der Anteil derjenigen mit Mittlerer Reife oder gar einer Haupt- 
schule als höchstem erreichten Bildungsabschluss ist demgegenüber beinahe verschwindend gering.

Abbildung 5: Bildungsniveau der Gesprächspartner

\begin{tabular}{|l|r|}
\hline Gesprächspartner & Häufigkeiten \\
\hline Noch Schüler & 1 \\
\hline Hauptschule o. ä. & 1 \\
\hline Mittlere Reife o. ä. & 3 \\
\hline Abitur o. ä. & 7 \\
\hline abgeschlossene Berufsausbildung & 7 \\
\hline noch Student & 1 \\
\hline Universitätsabschluss o. ä. & 35 \\
\hline Promotion o.ä. & 10 \\
\hline keine Angabe & 6 \\
\hline
\end{tabular}

Quelle: eigene Darstellung

Es ist auffällig, dass weit über die Hälfte der Interviewpartner keine Kinder mehr im eigenen Haushalt oder der eigenen Wohnung zu versorgen hat (vgl. Abb. 6). Nur 21 Gesprächspartner geben an, überhaupt mit Kindern im eigenen Haushalt zusammen zu leben. Dies kann entweder bedeuten, dass sie kinderlos oder aber die Kinder bereits aus dem Haus sind. Es unterstreicht aber auch, dass Engagement unter Umständen überproportional für diejenigen in Deutschland praktikabel oder zugänglich ist, die eben nicht mehr Kinder bzw. deren Erziehung als Aufgabe zu bewältigen haben. Da Engagement und Aktivsein für die hier im Fokus stehenden Aktivisten, die einen nicht unerheblichen Anteil ihrer Zeit auf das Protestieren und Organisieren verwenden, viel an Kraft und Zeit kosten, mag dies mit der gleichzeitigen Verantwortung für (kleinere) Kinder wenig in Einklang zu bringen sein. Diese Tatsache spiegelt allerdings auch die Altersstruktur wieder: 45 der 73 Interviewteilnehmer sind 46 Jahre alt oder älter - ein Alter, ab dem eine Schulausbildung möglicherweise vorhandener Kinder vielleicht abgeschlossen ist und diese das elterliche Haus bereits verlassen haben. 


\section{Abbildung 6: Kinder in den Haushalten der Gesprächspartner}

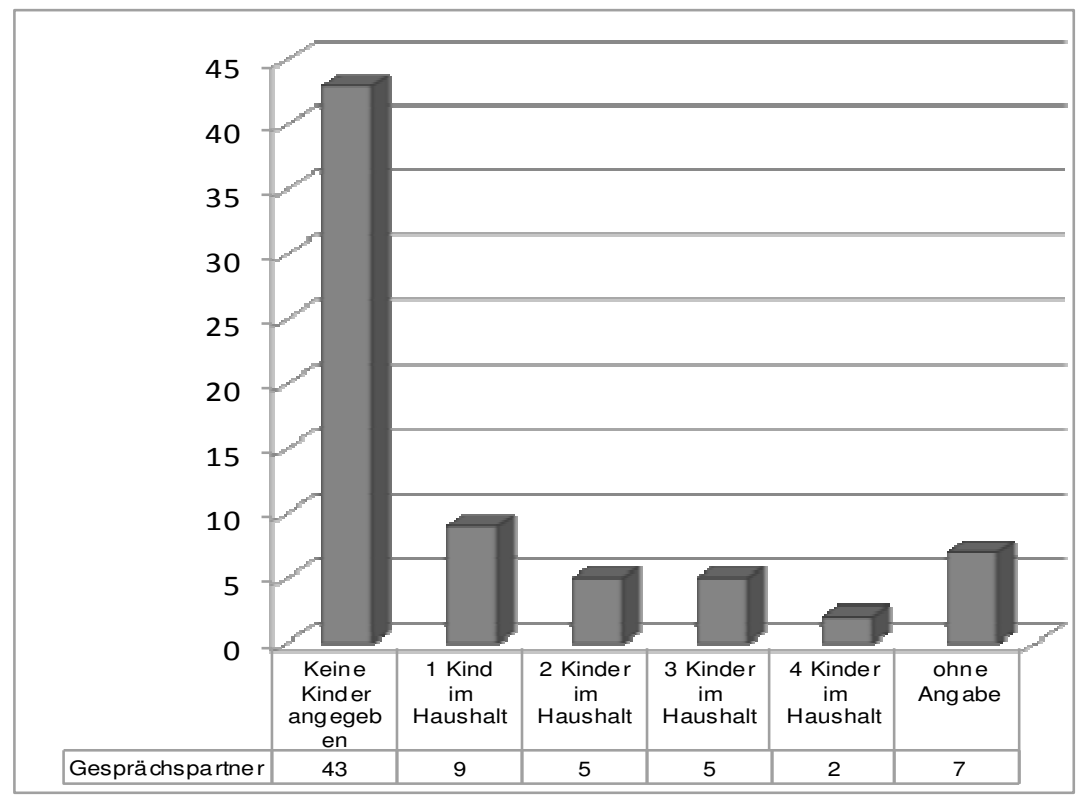

Quelle: eigene Darstellung

Die Einkommensstruktur der befragten Protestierenden (vgl. Abb. 7) bestätigt wiederum die aus dem Forschungsstand gewonnenen Eindrücke: Zwar gibt es eine nicht unerhebliche Zahl an Teilnehmern (17, entspricht knapp 24 Prozent), die zu ihrer Einkommenssituation keine Angaben gemacht haben, dennoch wird sichtbar, dass mit den Einkommenskategorien die Zahl der hier befragten Aktivisten ansteigt. Allerdings ordneten sich 8 Teilnehmer der Kategorie ,monatliches Netto-Haushaltseinkommen in Höhe von 900 - 1500 Euro“ zu, was in der Graphik wie ein Ausreißer wirkt. Dies mag aber der Tatsache geschuldet sein, dass in den Stadtviertelprojekten und Initiativen, etwa in Hamburg, durchaus viele Teilnehmer einem eher alternativ-spätstudentischen Milieu entstammen und nicht den Weg klassischer Erwerbsbiographien eingeschlagen haben.

Laut der Verbrauchs- und Medienanalyse 2014 lebten 2013 31,7 Prozent der deutschen Bevölkerung in einem Haushalt mit einem monatlichen Nettoeinkommen von mehr als 3000 Euro. ${ }^{34}$ Auch wenn der Vergleich zwischen Anteil

34 Vgl. Arbeitsgemeinschaft Verbrauchs und Medienanalyse 2014 (VuMA), November 2013, online abrufbar unter http://de.statista.com/statistik/daten/studie/285328- 
der Bevölkerung in Haushalten mit einem bestimmten Einkommen und individuellen Umfrageantworten zum Haushaltseinkommen natürlich durch die Anzahl von Haushaltsangehörigen verzerrt ist, gibt diese Zahl doch einen gewissen Anhaltspunkt. Im Vergleich dazu haben mit knapp 52 Prozent über die Hälfte der hier Interviewten, welche die Frage beantworteten, angegeben, dass ihr Haushalt mehr als 3000 Euro netto zur Verfügung hat. Und während für Deutschland insgesamt 2013 20,3 Prozent der Menschen in einem Haushalt lebten, der mit netto weniger als 1500 Euro wirtschaften musste, waren dies bei den Aktivisten anteilsmäßig ähnlich viele - etwa 22 Prozent.

\section{Abbildung 7: Netto-Haushaltseinkommen der Gesprächspartner}

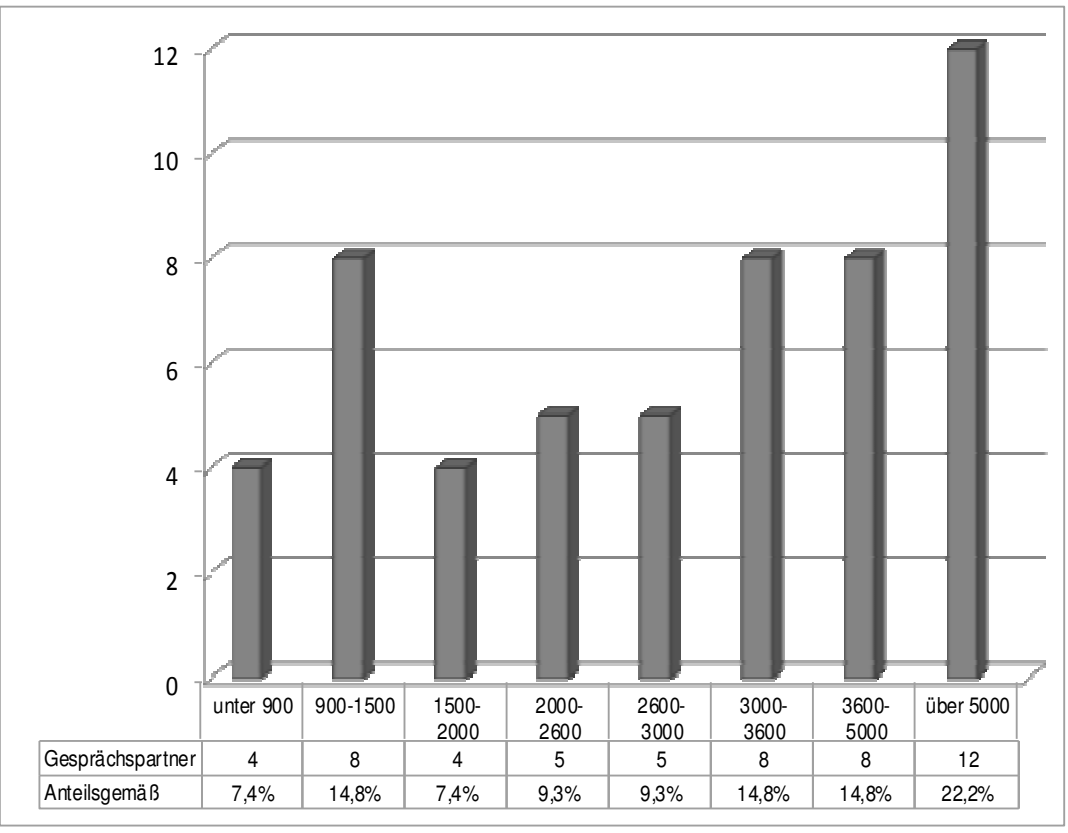

Quelle: eigene Darstellung

Das statistische Bundesamt hat 2013 zudem in einer Studie die Entwicklung des durchschnittlichen Nettoeinkommens eines deutschen Haushalts betrachtet, und

/umfrage/umfrage-in-deutschland-zum-haushaltsnettoeinkommen-2013/ [zuletzt eingesehen am 28.02.2014]. 
für das Jahr 2011 den Wert von 2.988 Euro ermittelt. ${ }^{35}$ Über die Hälfte der betrachteten Protestierenden verfügen über ein höheres Haushaltseinkommen, immerhin gut 22 Prozent mit mehr als 5000 Euro im Monat über ein deutlich höheres.

Insgesamt lässt sich also festhalten, dass die hier betrachtete Gruppe gegenüber dem Durchschnitt der Bevölkerung überdurchschnittlich gut verdienend und überdurchschnittlich gut gebildet ist und dass viele in Haushalten ohne Kinder leben. Die protestantische Religion beziehungsweise eine fehlende Religionszugehörigkeit sind vorherrschend. Was die Generationslagerung anbelangt, so verteilt sich dies über die meisten Jahrzehnte der Nachkriegsgeschichte, lediglich die jüngeren Generationen der nach 1977 Geborenen fallen deutlich ab. Auch die mit über 75 Jahren noch vor 1937 Geborenen sind im Sample kaum vorhanden, eine intuitiv zugängliche Beobachtung, wenn man sich vor Augen führt, dass es doch um Aktivisten geht, die ein Mindestmaß an Kraft und Engagement für ihre Protestarbeit aufbringen, was wiederum durch Alterserscheinungen mit der Zeit erschwert werden könnte.

Es bleibt aber auch als Zwischenboden der Argumentation festzuhalten, dass es sich zumindest bei den hier betrachteten Aktiven von Protesten nicht lediglich um gealterte Bürger einer gefühlten Generation handelt, sondern dass sowohl Geburtsjahrgänge - und damit die angenommenen Prägungen und Erfahrungswege - aber auch Einkommenssituationen durchaus diverser sind, als dies die gängigen Protestbilder glauben machen wollen. Die Suche nach Erklärungen für und von Protesten müsste folglich über das vermeintlich „einfache“ Kausalangebot von Geburt und Generationserfahrung noch hinausreichen wollen. Doch beginnen wir beim Naheliegenden.

\subsection{Elternhaus, Schule und Vorbildfiguren}

Prägung und Lernphasen von Protestierenden lassen sich vor dem Hintergrund der hier bearbeiteten Fragestellung nur positiv und nicht in Abgrenzung zum nicht-protestierenden Rest der Bevölkerung herausarbeiten. Eine qualitativexplorative Herangehensweise bringt es mit sich, dass man sich einlässt auf die beobachteten Fälle, ohne ständig ängstlich nach Kontrollgruppen zu schielen, welche möglicherweise eine Repräsentativität wieder einschränken. Im konkre-

35 Vgl. Statistisches Bundesamt, April 2013, online einsehbar unter http://de.statista.com/statistik/daten/studie/261850/umfrage/brutto-und-nettoeinkommen-je-privatemhaushalt-in-deutschland/ [zuletzt eingesehen am 28.02.2014]. 
ten Fall bedeutet dies, die Schilderungen der Interviewpartner zum eigenen Leben und den eigenen Erfahrungen wirken zu lassen und diese zunächst einmal als Grundlage der Interpretation aufzunehmen. Denn eines wird in den Gesprächen rasch deutlich: Die Gesprächspartner wissen um das Grundinteresse des Forschenden, sind informiert, dass ihr Protestengagement die Ursache der Gesprächsanfrage war. Dementsprechend wird auch der erzählte eigene Lebenslauf oft einem roten Faden entlang auf ihr Aktivwerden im Engagement ausgerichtet. Es wird - anthropologisch verständlich - der Wunsch greifbar, die individuelle Lebensgeschichte so zu erklären, dass Schritt für Schritt der Weg zu ihrem eigenen Protestthema deutlich und fast zwingend logisch wird. Frühe Erfahrungen werden Teil einer retrospektiven Deutung und in ihrem Erklärungsgehalt eine Art nach-interpretierende Lebenslauferklärung. Dass eine bestehende Ergebnisoffenheit aus Jugenderlebnissen auch andere Persönlichkeitszüge hätte hervortreten lassen können, dass etwaige Zufälligkeiten oder Schlüsselerlebnisse zu ganz anderen Entwicklungen hätten führen können, dies wird in einer auf Protest und Engagement ausgerichteten Erzählung oftmals ausgeblendet. Im Gespräch etwa mit Tilmann $\mathrm{C} 1$ in einer Fokusgruppe aus dem Stuttgarter Protesten gegen den Bahnhofsneubau wird dies deutlich:

„Ja, ich möchte vorausschicken, dass ich mich in den letzten 35 Jahren, intensiv engagiert habe im Widerstand gegen Atomkraftwerke und Atomwaffen. Da war ich eigentlich, kann ich sagen, vollberuflich beschäftigt, natürlich ohne Einkommen, wie man sich denken kann. Aber es war möglich. Stuttgart 21 ist für mich auch noch mal was anderes, ich sehe die ganze Komplexität und dass es um viel mehr geht als um einen Bahnhof, das ist mir alles klar. [...] Ich habe mich da engagiert, weil es eine gewaltlose Bewegung ist und das ist mein Spezialgebiet. Ich habe das studiert, mein ganzes Studium war dem gewidmet. Deshalb nun ja, von den drei Bildern (welche er sich in einem Assoziativspiel der Fokusgruppe aussuchen sollte, um sich selbst zu beschreiben, Anm. F.B.), ich mache es kurz, Nummer 4 - auch interessant dass drei Leute in diesem Raum dieses Bild Nummer 4 (Der Kniefall Willy Brandts in Warschau bei der erwähnten Vorstellungsrunde der Fokusgruppen, Anm. F.B.) gewählt haben. Das ist auch für mich - das war auch für mich ein ganz, ganz tiefes Erlebnis, dass so etwas möglich ist wie Versöhnung zwischen Gegnern, Feinden im Krieg, die einander furchtbares angetan haben. [...] Das zweite Bild ist Nelson Mandela, da ging es ja auch um Apartheidspolitik, dazu brauche ich ja auch kein weiteres Wort zu sagen. [...] Und dann schließe ich natürlich, klar mein überaus geliebter Gandhi da in Nummer 86, mit dem ich mich eigentlich kann ich sagen ein Leben lang beschäftigt habe. Ich habe, ich will auch nur erwähnen, ich habe im letzten Jahr eine fünfbändige 
Auswahlausgabe seiner Werke hier im deutschen Sprachraum bearbeitet und zum Teil übersetzt. Also, das ist ein Lebensthema von mir, die Beschäftigung mit diesem Mann. “36

An anderer Stelle etwa betont Laura E5:

„Mich hat schon die Politik immer interessiert, in der Schule schon, also die politische Gemeinschaftskunde war eigentlich das Fach, das ich geliebt habe [...], ich komme aus Rheinland-Pfalz, als Helmut Kohl damals Ministerpräsident war und bin da auch zu Veranstaltungen hingegangen und das hat mich eigentlich dann mein ganzes Leben weiter begleitet. “37

Zu überprüfen, ob dies der Wahrheit entspricht, ob in der Tat auch das tatsächliche Engagement der beiden diesen Andeutungen gefolgt ist, soll hier nicht im Zentrum stehen. Vielmehr geht es um das Selbstbild, was mit einer derartigen Schilderung der eigenen Person und des eigenen Lebenslaufes vermittelt werden soll.

Wenn etwa jemand, der heute in einem Protestbündnis aktiv ist, seine ersten Erlebnisse mit Politik und eigenem Aktivsein vor dreißig Jahren in einer ähnlichen Stoßrichtung wie die heutige Protestarbeit schildert, dann klingt es bisweilen so, als ob das ganze Leben eine Art selbstbewussten Protestcharakter angenommen habe:

„Das war wahrscheinlich nicht genau durchdacht, aber irgendwie so ein diffuses Gefühl, mit dieser Studienreform, da werden wir über den Tisch gezogen, da können wir nicht mitreden, da wird uns was aufoktroyiert, das war so eine Stimmung. “38

Wenn es in den Gesprächen um die ersten Kontakte mit Politik und um die Frage nach ihren Prägungen diesbezüglich geht, erinnern die allermeisten sehr weit zurückreichende Erlebnisse. Den Vermutungen und theoretischen Befunden aus Kapitel 2.3 zum biographischen Ort von Widerspruch folgend, nehmen hier Ereignisse und Erinnerungen aus der Jugend-, Schul- und Studienzeit des erwachenden Interesses an Gemeinschaft und des wachsenden persönlichen Horizontes eine zentrale Rolle ein. Die ersten Erkenntnisse, dass die Welt nicht vor den Toren der Schule oder der eigenen Stadt aufhört, welche Probleme dort lauern mögen und welche Rolle darin der Einzelne spielen kann, gehören wohl zu den eindrucksvollsten Erfahrungen, die ein Mensch macht. Ähnliches gilt - so steht

36 Tilmann C1 in der Fokusgruppe Stuttgart C1.1 am 20.03.2012, 17 Uhr.

37 Einzelinterview Laura E5.

38 Einzelinterview Bernd C5. 
zu vermuten - für die meisten Menschen überhaupt, wäre also mitnichten ein Spezifikum der hier betrachteten Protestler. Denn dass Menschen bezüglich demokratischer Vorprägungen, ihren Idealvorstellungen eines gesellschaftlichen Zusammenlebens in der Phase von Jugend und früher Adoleszenz geprägt werden, trifft keineswegs allein auf die protestbewegten Gruppen der Gesellschaft zu. Allerdings lassen sich aus den Schilderungen eben dieser Gruppen über ihre ganz eigene politische Bewusstseinswerdung durchaus Schlüsse ziehen.

\section{Ein roter Faden des Protests}

Das Bild etwa, bereits früh erfahren zu haben, wie in der deutschen Gesellschaft politische Prozesse funktionieren, wie Entscheidungen getroffen werden, eine Ahnung davon gewonnen zu haben, wer sich mit welchen Anliegen durchsetzt, gehört zum Kern eines Selbstbildes, welches in den Gesprächen zum Ausdruck kommt. Man stellt sich damit auch als ein Mensch dar, der vielleicht umfassender und früher als andere die Mechanismen und Funktionsweisen einer Gesellschaft hat durchschauen können. Dies kann in der Entstehung ganz unterschiedlich geschildert werden. Es gibt allerdings zumeist Schlüsselpersonen oder -konstellationen, die eine Art „Grundeinsicht“ ermöglicht haben. Dazu zählen prägende Figuren in der Familie, die als Vorbild oder Gesprächspartner Werte und Weltsicht entscheidend beeinflusst haben. Auch gehören Lehrer oder Ansprechpartner in der unmittelbaren Umgebung dazu, die den Protestierenden etwas mit auf den Weg gegeben haben, das sie noch heute wiedererkennen und zurückblickend als wichtig für ihren Lebensweg erachten. Zudem haben Rituale, Gespräche und eine gemeinsame Diskussionskultur über Jahre die Gewohnheit des Hinterfragens von scheinbaren Tatsachen entstehen lassen, welche viele der Gesprächspartner für sich in Anspruch nehmen:

„Ist glaube ganz wichtig, wie Sie merken, ich habe mir früher immer Sachen angehört, ich habe schon als Kind mit meinem Vater - ich weiß nicht, ob Sie noch Werner Höfer kennen, das war eine politische Sendung, sonntags kurz vor Mittag? - die hab ich mir immer reingezogen, mit meinem Vater gemeinsam. Ich habe mir immer dementsprechend die Tageszeitung geschnappt und hab sie immer gelesen. Ich war einer der wenigen Informierten in meiner Klasse. [...] Ja, vielleicht darf ich noch zwei Sätze sagen, die mir noch wichtig sind, in dem Zusammenhang. Dass meine Historie seit 1722 im Dorf dementsprechend ansässig ist und über alle Generationen Bürgermeister, Verantwortliche, halbe Priester und sonst was gestellt hat, das ist mir auch durchaus eine Verpflichtung da weiterzumachen, mein Vater hat schon 1972 für die Freien Wähler kandidiert, mein Opa war über dreißig 
Jahre lang Schiedsmann dort im Dorf und die Generationen danach waren auch immer überall Verantwortliche und vielleicht prägt das ja so'n bisschen. ${ }^{\text {‘39 }}$

Die meisten schildern Figuren, in denen sie Vorbilder für ein zivilgesellschaftliches oder politisches Engagement erkennen. Dabei konzentrieren sich die Erzählungen auf drei Perioden in der deutschen Geschichte, aus denen sich leicht Lehren im Sinne der Idealfigur eines engagierten, aktiven, widersprechenden Bürgers ziehen lassen: Da sind zum einen die Erfahrungen von Verwandten, Eltern, Großeltern aus dem Zweiten Weltkrieg, die zur mahnenden Verpflichtung „Nie wieder Krieg!“ herangezogen werden. Zum anderen werden, analog zur Beobachtung der prägenden Adoleszenzphasen, oftmals selbst erlebte Episoden und Zeitgefühle geschildert, die eben mit der Zeit zwischen 1968 und etwa 1986 zusammen hängen. Denn ein Großteil der von uns Interviewten hat seine Kindheit, Jugend und das frühe Erwachsenenleben in diesen „,bürgerbewegten“ Jahren verbracht (s. Abb. 2), hat aus dem Widerspruch und Aufbegehren der Studentengenerationen ab dem Ende der 1960er Jahre bis hin zu den Organisationen der Neuen Sozialen Bewegungen den Schluss gezogen, dass Einmischung und ziviles Engagement für eine Demokratie von unschätzbarem Wert seien. ${ }^{40}$ Zuletzt wird, von einer jüngeren Gruppe der Gesprächspartner, die deutsche Einheit als Erlebnis geschildert, welches sie politisch und in ihrer Sicht auf Demokratie entscheidend beeinflusst habe.

Diese Erzählungen münden allerdings nicht in eine bestimmte Deutungsrichtung, eine an Karl Mannheim angelehnten Generationseinheit gar, die man als eine gemeinsame Verarbeitung und Deutung einer Zeit oder eines Ereignisses interpretieren könnte. So werden auch ganz unterschiedliche Lernerfahrungen geschildert, die sich durchaus auf gleiche oder ähnliche Erlebnisse beziehen.

Ilse E8 erzählt von ihrer Schulzeit in den 1970er Jahren und dem für sie motivierenden Erleben des Aufbegehrens älterer Schüler gegen die eigene Schulleitung:

„Nee, würd ich sagen in der Schule ganz stark, also eigentlich eine sehr politisch engagierte Schule, also eher als jetzt mein Elternhaus. Und dann - bin '65 geboren, also in den 1970ern sozusagen, späten 1970ern - also, das find ich schon sehr prägend die Zeit, also ganz stark Friedensbewegung, Umweltbewegung, Frauenbewegung, alles war irgendwie grad so am Kochen und eben durchaus sehr engagierte Lehrer [...] so und auf der anderen Seite gab's natürlich von Schülerseite so Projekte, also mein erstes so politisierendes Erlebnis war ein großer Mensastreit. Diese Mensa hat halt eklige Sachen verkauft, das war

39 Conrad in Einzelinterview G1 Anna und Conrad.

40 Vgl. dazu auch Walter: Bürgerlichkeit und Protest in der Misstrauensgesellschaft. 
so, wir waren so Ökos, und das gefiel uns nicht, das Essen und es war auch noch teuer [...] und wir haben eben über Wochen diese Mensa bestreikt, bis die nicht mehr konnten, eingeknickt sind und ein andere Angebot gemacht haben, und der Kaffee wurde billiger und der Tee wurde billiger und das war ganz faszinierend, weil das wirklich von der Schülerschaft ausging und gerade die älteren Oberschüler da fand ich auch beeindruckend, ich war so zehnte Klasse, als das war und diese 12.-, 13.-Klässler fand ich auch toll, so, wie sie das machten und das war eben erfolgreich. Und es war schon so, dass die Lehrer es zum Teil übertrieben fanden, aber es wurde eben mit den Füßen abgestimmt, also die Mensa war abhängig von uns Schülern und wir haben gleichzeitig und das hab ich auch noch die nächsten drei Jahre fast gemacht, dann in unserem Freizeitkeller sozusagen, haben wir eine sogenannte alternative Cafeteria aufgemacht, und haben die dann selber betrieben in der Mittagspause, das war so eine Ganztagsschule und dann haben wir mittags dann eben Joghurt und Müsli verkauft. “41

Dass aber die 1970er Jahre klischeehaft übertrieben eine ganze Generation junger Menschen antiautoritär geprägt haben und mit diesen Erfahrungsdepots heute einen vermeintlich linksorientierten, ökologisch engagierten Protest befeuern, mit dessen Diagnose Wolfgang Kraushaar eingangs des Kapitels zitiert worden ist, dem widersprechen andererseits aber Interviewsequenzen, bei denen sich die Erzählenden auch auf dieses Jahrzehnt beziehen, ihre Erlebnisse aber ganz anders einordnen, sich letztlich auch im Protestengagement auf andere Vorbilder und Idealvorstellungen beziehen:

„Die Initiationen sind ja in der Jugend. Also meistens jedenfalls. Gibt auch Spätberufene. Ähm und bei mir war das ganz klar die ähm die marxistische Bewegung in den 70ern, die ich voll mit erleiden musste auf der anderen Seite ja. Also der Kampf gegen den Spätmarxismus damals. Die praktische Aufrollung äh der Universitäten. Ich noch selber im Studium, das führte dazu, dass ich mich enorm politisierte und zwar in die Gegenrichtung. Ähm für mich war Marxismus ein alter Hut. Ich war sehr überrascht darüber, dass alles (unverständlich, Anm. F.B.) wieder hervorbringen konnten. Irgendwie hatte ich sehr guten Sozialkunde Unterricht in Frankfurt am Gymnasium und war ich wirklich erstaunt und dann habe ich mich in diese neoliberale Welt begeben. Also damals habe ich dann Wilhelm Röpke zunächst mal kennen gelernt, nach Röpke kam dann Mises, nach Mises kam dann Hayek und seither bin ich in dieser Welt ziemlich ziemlich verwurzelt. ${ }^{\star 42}$

Protest als ein selbstbewusstes Widersprechen während dieser Jahre hat die heute Aktiven deutlich geprägt und ihnen eingeschrieben, dass Opposition und au-

41 Einzelinterview Ilse E8.

42 Einzelinterview Holger G7. 
tarkes Eigenhandeln zu begrüßen sind - auch im gesellschaftlichen Interesse. Eine Gleichförmigkeit der Protestrichtung über das Anerkennen eines im demokratietheoretischen Sinne selbstbewussten Individuums allerdings ist weniger zu erkennen.

West- wie ostdeutsche Protestierende schildern die Erlebnisse der deutschen Einheit mit ganz unterschiedlichen Bildern. Während aus ostdeutscher Perspektive die Überwindung einer Diktatur aus eigener Kraft vorherrschend ist, welche die Erfahrungen aus Sicht einer sich befreienden Bevölkerung verarbeitet hat, spielt aus der westdeutschen Blickwarte die Einheit als langfristige Folge der Ost- und Entspannungspolitik Willy Brandts und als greifbarer Punkt, an dem Weltgeschichte miterlebt werden konnte, eine Rolle. Besonders Menschen, die in der DDR geboren wurden, aber bereits früh nach Westdeutschland gezogen waren oder gar geflohen, begründen ihre Sichtweisen auf Demokratie und Partizipation mit ihrem frühen „Aufbegehren“ gegenüber dem Realsozialismus. In diesen Schilderungen ist die eigene DDR-Vergangenheit Ausweis dafür, dass man Unrechtsregime und politische Auswüchse oder Perversionen erkennen könne und gleichzeitig die Flucht oder Auswanderung Zeichen, dass man bereits früh selbstbewusst einen eigenen Weg gewählt habe. Demgegenüber schildern Aktive mit rein „westdeutschen“ Lebensläufen, welche sich auf die deutsche Einheit als politisches Prägeerlebnis beziehen, eben nicht die Eigenermächtigung und Systemunterwanderung oder -überwindung als Lehre, sondern vielmehr ein Erlebnis der Stärke von Frieden und Völkerverständigung, welche sich gegenüber autoritären Tendenzen durchsetzen.

Vera E1 etwa, gebürtige Westdeutsche, erzählt:

„Das war ein ausgesprochen [...] nachhaltiges Erlebnis für mich, zu merken, dass Menschen aus ihrer eigenen Kraft heraus, friedlich in der Lage, sind mit völlig einfachen Mitteln, nämlich nur durch da stehen und stumm aussagen, was ihnen am Herzen liegt, es schaffen, die Waffen ruhen zu lassen und eine Mauer zu sprengen. Das hat mich wirklich sehr beeindruckt. Und denke, in mir Demokratie, ein demokratisches Erweckungserlebnis, so hervorgerufen. “43

Volker G2 wiederum, aus Polen stammend, schildert seine Prägung etwas anders:

„Meine Motivation ist genetisch bedingt, ja? Ich bin sozialisiert worden im real existierenden Sozialismus und somit habe ich Probleme mit Staatsverfassung. Diese Art dort und mit dieser habe ich auch gewisse Probleme bekommen.

43 Vera E1 in der Fokusgruppe Hamburg E1 am 20.03.2012. 
Moderator 1: Sie kommen hier aus Stuttgart?

Volker G2: Jetzt komme ich aus Ludwigsburg, das ist in der Nähe von Stuttgart und geboren bin ich in Polen also konkret. Und so, naja, seit früher als diese jungen Leute hier, habe ich zu kämpfen mit bestimmten Auswüchsen dieses repräsentativen, demokratischen Systems." 44

So bleiben am Ende zwar zentrale Bezugspunkte übrig, die viele der Protestierenden miteinander teilen. Dass diese aber naturwüchsig dazu führen, dass die eigene Vergangenheit gleich oder ähnlich gedeutet wird, ist nicht einheitlich zu beobachten. Auch Ulrike Jureit betont in ihren Betrachtungen zu Generationen, dass es durchaus innerhalb ähnlicher Alterskohorten selbstverständlich positive wie negative oder eben: verschiedene Interpretationen der gleichen Ereignisse gebe. $^{45}$ Übereinstimmend ist allerdings die Verinnerlichung einer Offenheit für selbstbewussten Widerspruch und die Eigenvertretung, die sie - allerdings retrospektiv - mit den Schilderungen ihrer Prägezeit verbinden.

Die Familie ist darüber hinaus ein Ort, für den viele schildern, dass Ihnen hier die Bedeutung und auch die Beeinflussbarkeit von Politik und Gesellschaft deutlich geworden sind, gleichsam als Arena der Einübung demokratischen Verhaltens. Ein wenig naiv im Ton, doch symbolisch, schildert dies Paul G1:

„Das hat sich eigentlich wiederholt, in der Familie auf jeden Fall, und da habe ich mir das Datum geschrieben, 1994 haben wir zu dritt, darüber abgestimmt, wie das zweite Kind heißt, also mein einer Sohn, meine Frau und Ich, wir haben also wirklich darüber abgestimmt, wir haben einen Zettel im Topf geworfen, haben darüber abgestimmt. [...] ja [lacht] und, ne, zu Hause natürlich auf jeden Fall, aber eigentlich, das ist eigentlich das Entscheidende, eigentlich ständig, ne.“46

Es sind vorwiegend Erlebnisse und Personen im Nahbereich, manchmal Verhältnisse zu einer Art Lehrer, zu denen ein persönlicher Bezug hergestellt werden kann und die ein Interesse an Politik und einen Horizont zum persönlichen Engagement herstellen.

„... sobald man tatsächlich betroffen ist, eine ganz andere Gewalt dahinter steht, als wenn es irgendwo in Afrika stattfindet. “47

44 Volker G2 in der Fokusgruppe Stuttgart G2 am 02.04.2014.

45 Vgl. Jureit: Generationenforschung, S. 27.

46 Paul G1 in Fokusgruppe G1 in Hannover am 15.03.2012.

47 Malte C1 in Fokusgruppe C1.1 in Stuttgart am 20.03.2012, 17 Uhr. 
Dies ist auch durchaus einleuchtend, da die Verbindung von Politik und der persönlichen Arbeit an der Veränderung vielleicht am überzeugendsten im Kleinen eingeübt und gezeigt werden kann - wie auch das gezeigte Beispiel des Mensaprotests in der Schule zeigt. Gleichwohl führt dies selbstredend nicht dazu, dass nur noch kleinräumig lokale Themen in den Gesprächen auftauchen, wenn es um politische Erweckungserlebnisse geht. Denn viele der aufrührenden und aufrüttelnden Themen der vergangenen Jahrzehnte haben eine lokale Entsprechung gefunden und konnten Globalität und Lokalität miteinander verknüpfen. Eine atomare Bedrohung kann durch ein Atomkraftwerk in der Nähe symbolisch zu einem lokalen Bedrohungsszenario werden. Globalisierungsentwicklungen lassen weiterhin das Gefühl entstehen, dass viele Entwicklungen, die man als bedrohlich oder angsteinflößend wahrnimmt, rasch auch das eigene Lebensumfeld betreffen können. Die Lokalität von Ereignissen scheint in den Gesprächen oft als eine unmittelbar einleuchtende Motivation durch - begrenzt mögliche Themen aber kaum. Fast alles kann scheinbar auch als sich lokal auswirkend wahrgenommen werden.

\section{Politische, nicht parteipolitische Vorbilder}

Auffällig ist, dass die Rolle der angesprochenen Vorbildfiguren oft als politisch, aber nicht parteipolitisch geschildert wird. Dies betont den eigenen, zumindest zum Zeitpunkt des Interviews und damit am zwischenzeitlichen Endpunkt des roten Biographiefadens, nicht partei- oder klassisch organisationspolitisch gebundenen Antrieb. Die eigenen Väter, Mütter, Lehrer, Jugendbetreuer etc. werden geschildert als Personen, die Interesse an Politik und gesellschaftspolitischen Fragestellungen vermittelt haben, die auch die Notwendigkeit eines Engagements vor Augen geführt haben - die aber eben nicht ein Vorbild im Sinne eines Eintritts in Parteien oder Gewerkschaften gewesen sind.

\footnotetext{
„Also ich glaub, sicherlich hab ich im Elternhaus mitgekriegt, viel Ehrenamt, so, aber ebenso im Sportverein, meine beiden Eltern, mein Vater als Vorsitzender eines wirklich großen Sportvereines, was ja auch immer Politik auch berührt, sozusagen im Haushalt bei uns also auch bei großen Festen oder so, waren dann auch die Politiker des Ortes auch zum Beispiel zu gegen und mein Vater hatte mit denen eben auch Verhandlungen zu führen, und so, und mein Vater war da eher auch so diplomatisch ganz gut so dabei, es hat ihn aber nicht interessiert, also Parteipolitik hat ihn überhaupt gar nicht interessiert, aber sonst sozusagen, es war schon ein Haushalt, der eben auch - also meine Eltern eigentlich ein bisschen zu alt für die 68iger, aber natürlich davon nicht unberührt, also wir Kinder, drei Kinder, sind alle in dieser Zeit irgendwie groß geworden und es gab uns den Spiegel und
} 
Pardon und meine Eltern galten eben schon dann als die so ein bisschen die Antiautoritären unter der sehr konservativen Verwandtschaft, so, also das hat man schon gemerkt, also bei uns hingen dann so Sesamstraßenposter im Esszimmer, sowas war dann schon radikal, [lacht], so und sie hatten auch Interesse an Bildungsthemen und haben diese Schule ausgewählt, die war dann Schulprojekt, ich glaub auch unter - von 1972, `73 gegründet, als große Ganztagsschule, so, da haben sie sich auch bewusst für entschieden, das war schon, aber was es nicht gab - erinnere ich mich nicht, politische Diskussionen mit uns Kindern, so also das waren schon irgendwie getrennte Welten finde ich. “48

Hagen E4 erzählt von einer ähnlichen Konstellation:

„Also man hat natürlich Zeitung gelesen und das eine oder andere Thema diskutiert, aber es gab keine ehrenamtlichen oder beruflichen Politiker (im privaten Umfeld, Anm. F.B.). [...] Und äh ich bin dann zwar ausnahmslos immer wählen gegangen und habe mich also über Wahlen an Politik beteiligt. Aber nicht irgendwo politisch eingebracht in Organisationen, Parteien oder ähnliches und war also insofern parteilich betrachtet eher ein unpolitischer Mensch bis dann 2008 eben die Thematik hier in Hamburg mit der Primarschule hoch kam und ich dann da über die Positionen als Elternratsvorsitzender auf der rein schulpolitischen Schiene praktisch rein kam in dieses Gebiet und dann eben entschlossen habe, also die Idee hatte, diese Volksinitiative anzuschieben. “49

\section{Brüche in den Biographien}

Neben dem Nahbereich der Sozialisation, der bei vielen als intuitiv verständliche Vermittlung politischer Fragstellungen benannt wird, gibt es aber auch andere Quellen oder Keimzellen eines Engagements im Protest. So werden des Öfteren Umbruchsphasen im Leben geschildert, die jeweils empfänglich machten für Neudeutungen oder ganz andere Perspektiven, als dies bis dato der Fall gewesen sei. Brüche oder Neuanfänge einer Biographie, erst recht wenn die Person diese als gefühlte Niederlage für sich deutet, werden in den Erzählungen dann zu einem Moment der Katharsis und der Läuterung, die bestimmte Mechanismen aufgezeigt sowie neue Gegnerschaften und Konflikte geschaffen haben. Diese Umbruchsmomente können privater oder beruflicher Natur sein, werden aber immer als Erlebnisse erzählt, die das Weltbild erschüttert haben.

„Ja, da gab es tatsächlich einen Schlüsselmoment, den hatte ich auch schon erwähnt, dazu muss ich vorschieben. Ich war vorher jahrelang bei der Bundeswehr als Offizier und zwar

48 Einzelinterview Ilse E8.

49 Einzelinterview Hagen E4. 
tatsächlich dieser besagte Moment, das war ja damals der Kosovo-Krieg, wo ich für mich erkannt habe, ja ich will nicht sagen ein politisches Weltbild für mich zusammengebrochen ist, aber was mein bisheriges Weltbild komplett oder ja vielleicht doch ja, mein politisches Bild demontiert hat und eben eine komplette neue Ordnung erforderlich machte und das war dann so der Zeitpunkt, wo ich mich dann so neu orientiert hatte und wo man dann auch so abseits dessen, ja das man da so standardmäßig zu sehen, zu lesen bekommt, sich informiert hat. [...] es war dahingehend ein Schlüsselerlebnis, weil man hautnah mitgekriegt hat, wie bewusst einfach gelogen und manipuliert wurde. In einem Ausmaß, vorher dachte man, okay, klar, es hängt ein bisschen von der Regierung ab und welche Stellen da geschraubt werden, oder wieder gedreht wird. Aber das war wieder so eine Sache, dieser Strukturbruch in dieser, in diesem Denken, wenn eben sagt, ja, es sind nicht die Stellschrauben, was da gedreht wird, sondern es wird da offen - nicht offen, sondern gezielt Desinformationen und Propaganda betrieben, wie ja, wahrscheinlich schon zu allen Zeiten. ${ }^{* 50}$

Brüche im Leben, seien es berufliche Niederlagen oder die enttäuschende Erfahrung, in Parteien mit einem Anliegen oder einer gewünschten Anknüpfung nicht durchzudringen, werden bei vielen Gesprächen erwähnt und als Beginn einer auch im konfrontativen Sinne neuen Lebenshaltung gedeutet. Viele der Aktivisten im Protest oder Engagement haben in der Vergangenheit durchaus Erfahrungen in Parteien oder Gewerkschaften gemacht, einige über viele Jahre als Mitglieder oder gar Aktive. Zum Zeitpunkt der Gespräche aber hatten sie diesen Weg bis auf eine Ausnahme bereits wieder verlassen bzw. Kontakt und Mitgliedschaft wieder abgelegt. In der Perspektive der Gesprächspartner sind diese Erfahrungen zu einer Art Lebens-Umbruch geworden. Andere geschilderte Brüche sind private Trennungen, aber eben auch - wie im Zitat angedeutet - Enttäuschungen, die als Niederlagen gegen unlauter vorgehende Vorgesetzte etc. aufgefasst werden, bei denen man selbst ein schmerzhaftes Scheitern erleidet. Allerdings, das ist auffällig, wenngleich menschlich verständlich, wird die Erzählung als reinigende Lernerfahrung zum Beginn einer Art Erkenntnis, welche dann ein Engagement, ein Aktivsein im Protest, ermöglicht hat.

Die Interviewten zeigen sich überaus dankbar und auch stolz, was ihre Prägungserlebnisse und Vermittlerfiguren hinsichtlich Politik und Gesellschaft anbelangt. In ihren Schilderungen werden diese zu einem Nukleus und Anfangspunkt der Entwicklung, die sie nun zu ihrem Engagement geführt haben. Denn die Aktivisten definieren sich als Person stark über ihr Tun, über ihre Protestarbeit. Insofern werden diese Gespräche über die individuellen Wurzeln und Triebkräfte auch zu einer Reise an den Beginn ihrer heutigen Selbstsicht. Bei

50 Einzelinterview Fabian G2. 
den Eurogegnern in Stuttgart und Hannover, bei den Bahnhofsdemonstranten in Stuttgart, aber auch etwa in Freising oder in anderen Zusammenhängen, entsteht oft eine Erzählung, die die Einsicht in die Protestnotwendigkeit als Erweckungsoder Befreiungserlebnis schildert. Man sehe viel klarer nicht nur die Problematik des konkreten Protestzusammenhangs, deretwegen man aktiv geworden ist, sondern das Leben in seiner Begründung und Fundierung ändere sich - auch und besonders in Abgrenzung zu denjenigen, die noch im alten Trott verharren und diese Erweckung noch nicht erfahren haben. Der Sinn des Lebens ist höherwertiger geworden und scheint viel deutlicher vor einem zu stehen. Aus dieser Perspektive haben wir es hier mit „glücklichen Menschen“ zu tun, die im Gefühl leben, ernsthaft etwas erkannt zu haben. Erweckung auch deshalb, weil in diesem Erkennen oder „Sehen-Können“ schon die Überzeugung liegt: Wenn man es verstehe, wird man aktiv, da man ja gar nicht mehr anders könne. Und durch das Aktivsein ändere sich das Leben, man lerne andere Aktive kennen, Solidarität, Zusammenstehen und Gemeinschaftserlebnisse erlangten ab nun eine völlig neue Stellung und Präsenz im Leben und veränderten die Sicht auf das vorhergehende Leben.

Die Prägungen, die an dieser Stelle betrachtet worden sind, übernehmen die Aufgabe einer Art „Vorgeschichte“, welche die Protest-Erweckungserlebnisse erst ermöglicht haben. Denn es sind die politisch mindestens Vorgeprägten, die wir in diesen Protestzusammenhängen finden, diejenigen, die entweder schon lange aktiv sind, oder die aber betonen, dass Politik und vor allem wählen gehen immer schon zu ihrem Demokratieverständnis und ihrem Interesse gehört haben. Nicht wählen zu gehen, alles ablehnen, nicht mehr mitmachen, das findet sich kaum.

\section{Protest durch Wissen, Einsicht und Erweckung}

Ein immer wiederkehrendes Bild in den Erzählungen ist, dass durch das erzählte Erweckungserlebnis sowie das anschließende Engagement die Scheuklappen und eine positive Naivität bezüglich der Demokratie und ihrer Funktionsweisen und Verknöcherungen abgeschüttelt werden konnten. Während man zuvor eben auf mediale Vermittlungen angewiesen gewesen sei, die einem vielmals eine positive Konnotation vermittelt hätten, hätte man durch eine Art ungefilterten Rohkontakt mit politischer Arbeit eben die Realität politischer Entscheidungsfindung viel unmittelbarer gesehen. Und die Aktiven sehen es als eine Art Lebensglück, diesen Durchblick durch ihr Engagement zu erlangen. 
„Naja, also ich bin nicht mehr so naiv. Das war ich allerdings vorher auch durch die journalistische Arbeit vielleicht nicht mehr ganz so. Also ich bin gegenüber dem Parteienapparat und dieser repräsentativen Demokratie sehr skeptisch geworden. ${ }^{\text {"51 }}$

Der Protest wird als ein sich selbst verstärkender Prozess erzählt. Durch Protest und Engagement bekomme man mehr und tiefere Einsichten, welche - zumeist die Quelle des Widerspruchs, das Gefühl, sich einmischen zu müssen, noch intensivierten. Das Gefühl, etwas klarer und besser sehen und wahrnehmen zu können als der Rest der Bevölkerung, wird deutlicher und stärker mit einem zunehmenden Engagement.

In der Selbstsicht der Aktiven ist Protest und Aktivsein allerdings nicht nur eine Quelle für, sondern auch eine direkte Folge von Einsicht und Wissen - das Gefühl, etwas tun zu müssen, sich für oder gegen etwas zu engagieren steht in einer Abhängigkeit mit dem zur Verfügung stehenden Wissen, davon sind die Gesprächspartner überzeugt. Auch deshalb nimmt in den Interviews der Bereich Bildung, Ausbildung und Wissen eine große Rolle ein und eine Betonung des Zusammenhangs von Bildung und Engagement wird bei vielen als Gemeinsamkeit deutlich. Wenn man nur das Problem erkenne, würde man doch fast automatisch aktiv werden, und demzufolge müsse Aufklärung und Wissensvermittlung doch die oberste Devise sein. Dies zeigt sich besonders in den Gesprächen mit dezidierten Gegnern von Vorhaben, etwa beim Bahnhof in Stuttgart, dem Flughafenausbau in Freising oder auch der Hamburger Bildungsreform oder den Gruppen, die gegen die Gemeinschaftswährung Euro aktiv sind. Denn in ihrem Gefühl sind es die sachlichen Gründe, die gegen ein Projekt sprechen, und denen augenscheinlich - aus welchen Gründen auch immer - nicht entsprochen wird. Ergo sei es als Protestierende ihre Aufgabe, beim bislang „unwissenden“ Rest der Bevölkerung dafür zu sorgen, ähnliche Einsichten und Erweckungen zu ermöglichen, um so gleichsam naturwüchsig dem Protest und ihrem Anliegen mehr Anhänger, Unterstützer und Durchsetzungskraft zu verschaffen. Bei den Eurogegnern geht es oft um die „Überzeugung" in die rationale Einsicht in die Dinge, die einen dazu gebracht hätten, sich zu engagieren. Achim G3 gibt beispielsweise Seminare, Theorien und Diskussionen an, die ihn fasziniert und dem Liberalismus nahegebracht hätten. Er sagt zwar auch, dass die Organisation dann oft Ergebnis von Freundschaften wäre, dass sich aus persönlichen Beziehungen stabilere Netzwerke bildeten etc. - aber Einsicht und Information und Bildung bilden doch für ihn den Kern der Motivation - und folglich auch das zentrale Rezept, das er sich vornimmt: mit Aufklärungsarbeit genügend schlagkräftige, wichtige Leute zu überzeugen, so dass man dann mit Kraft die politischen Ent-

51 Einzelinterview Emma E2. 
scheidungsstrukturen unter Druck setzen kann. Konrad C3 schildert dieses Gefühl, durch Bildung viele Sachen erst verstehen zu können, folgendermaßen:

„,...also, wenn du politisch arbeitest, musst du dich auch schlau machen. Wenn du an einem Thema mitdiskutieren willst, dann musst du dich darum kümmern. Dann musst du Zeitung lesen, musst Bücher lesen und dann bleibst im Endeffekt nicht der Dümmste. Klar, du kannst mit deinem Wissen immer noch Mist machen aber ich sage mal bei den meisten und auch die meisten, die ich kennen gelernt habe, waren auch an Kultur interessiert. Das waren Leute, mit denen man ins Theater gehen konnte oder ins Cabaret oder ins Kino, wenn es gute Sachen gibt, und dann oftmals auch nicht so in die Mainstream Sachen sondern irgendwelche, was weiß ich, Programmkinos, die dann bestimmte Filme zeigen, die man sonst nicht in den großen Ketten irgendwie sieht und da habe ich, glaube ich, insgesamt so äh dadurch auch einen Freundeskreis gekriegt der irgendwie ähnlich drauf ist und der mir glaube ich mehr bringt, als wenn ich jetzt bei Fußball, Kneipe, Frau, Haus, Auto geblieben wäre, sage ich mal. ${ }^{\text {.52 }}$

Auch wird die Rolle von Bildung und Bildungsvermittlung in den Interviews stark sichtbar, da Bildung als Grundlage für solcherart Erweckungserlebnisse angesehen wird. Bildung oder Erkenntnisfähigkeit ist eine Art Schlüssel für das „messianische“ Moment von Protest: das Gefühl einer Erweckung durch Einsicht, die einen automatisch gegen etwas protestieren oder für etwas eintreten lässt, da man nicht wieder hinter diese Erkenntnis zurückfallen kann. In den Gesprächen zu ihren Protestmotiven nehmen diese Schilderungen durchaus etwas von der Anekdote Martin Luthers an, nach der er 1521 vom Reichstag in Worms zum Widerruf seiner Ansichten aufgefordert worden war und geantwortet haben soll: „Hier stehe ich, ich kann nicht anders.“ Ein solcher innerer Drang, nicht anders zu können, spricht auch aus vielen der Aktiven. Dies zeigt sich auch darin, dass an vielen Stellen betont wird, man sei unter den Wenigen gewesen, die anfangs übrig blieben und sich engagierten und man auf diese Weise gleichsam naturwüchsig eine herausragende Position in den jeweiligen Initiativen bekam. Es ist ein großer Teil des Selbstbildes von Aktivisten, die Einsicht in vermeintliche Fehlentwicklungen und folgend die Entscheidung zu einem Engagement weit früher als viele andere Teile der Bevölkerung erlangt und getroffen zu haben. Ein patriarchalisches Überlegenheitsgefühl ist an diesen Stellen manchmal nur sehr wenig verkleidet und kaum zu übersehen.

Denn abhängig von der Gruppengröße der Protestinitiativen - welche in einem großen Spektrum variiert, von kleinen, wenigen Personen umfassenden Gruppen bis hin zu mehreren hunderttausend Menschen zählenden Dachverbän-

52 Einzelinterview Konrad C3. 
den - hat sich bei den Protestierenden eine Art „Kadergefühl“ entwickelt, welches die gefühlte „messianische“ Aufgabe umsetzen soll. Der Eindruck, dass gerade zu Beginn eines Protest nur bei wenigen anderen Menschen eine Einsicht in das jeweilige Problem gegen ist, weist ihnen eine Repräsentations- und Führungsaufgabe zu: den noch unwissenden Bürger an eine Sachlage heranzuführen, um ihm die Notwendigkeit, aktiv zu werden, vor Augen zu führen. Gruppen, besonders ausgeprägt ist dies etwa bei den Eurogegnern oder auch bei den Stuttgarter Bahnhofsprotesten, die eine solche Logik der „Führung“ entwickeln, sehen sich leicht auch in einer Rolle von demokratischen Leitfiguren.

Otto G1 schildert dieses Gefühl so:

\begin{abstract}
„Also, der Grund, warum ich mich engagiere ist, dass ich sehe, dass in der letzten Zeit, wo ich mich noch nicht engagiert habe, [...] sich nichts gedreht hat, [...] ich komme aus der Kommunalpolitik und aus dieser Sache habe ich einfach gesagt, ich versuche [...] den [...] Bürger, der sich nicht traut, und der nicht kann und nicht mehr will einfach daran zu führen [...], sage ich mal, da den Bürger, denn möchte ich nach oben bringen und versuchen, da wo die Entscheidung getätigt wird, irgendetwas zu verändern, das treibt mich heute noch an. ${ }^{\text {"53 }}$
\end{abstract}

\title{
Und Norbert G1 sekundiert:
}

„Und dann im Grunde, über die Jahre, über die eigene Erfahrungen, die man gesammelt hat und (ich) mittlerweile so unabhängig bin von der Seite, dass ich einfach die Leute mitnehmen möchte, einfach anwerben möchte, sich auf dem Weg zu machen und sich eigentlich für ihre Gesellschaft einzubringen, damit wir gemeinsam eigentlich das, was eigentlich alle wollen, ja mitzunehmen und dazu bewegen, sich zu bewegen im Grunde, so das ist eigentlich die Motivation. “54

Inhaltlich sind die erzählten Lehren, welche sie aus der individuellen Vergangenheit erinnern und welche sie nun als prägend für ihre Sicht auf Politik und Demokratie wiedergeben, Erlebnisse, die ihnen den Wert von Komplexität, Vielfalt und Pluralität - aber auch von Bildung und Recht aufgezeigt haben. Das können Unrechtsgefühle sein, wenn Schwächere in der Schule zu leiden hatten, wenn die Eltern oder Vorbildfiguren sich für Benachteiligte eingesetzt haben. Das können aber auch die geschilderten Erinnerungen sein, dass gesellschaftliche und politische Ereignisse wie selbstverständlich zu Hause diskutiert wurden. Insgesamt malen die Aktivisten von ihrem eigenen Lebenshintergrund ein Bild,

53 Otto G1 in der Fokusgruppe G1 in Hannover am 15.03.2012.

54 Norbert G1 in der Fokusgruppe G1 in Hannover am 15.03.2012. 
welches stark vom demokratischen Wert der einzelnen Person kündet, den sie früh vermittelt bekommen hätten. Dies mag zum einen damit zusammen hängen, dass die hier Interviewten eine Art gesellschaftliche Bildungselite darstellen, deutlich über dem Schnitt der Bevölkerung (formal) gebildet, und die sich folglich in Gesprächen zum Thema Demokratie und Partizipation auszudrücken gelernt hat. Zweitens sprechen viele in den Gesprächen Episoden der deutschen Geschichte an, die mit dem Thema der gesellschaftlichen Einmischung des einzelnen Bürgers besonders stark verwoben sind. Immerhin knapp die Hälfte der Gesprächspartner (s. Abb. 2) hat ihre Jugend zwischen 1967 und 1986 verbracht, etwa 20 weitere Prozent zwischen 1987 und 1996. Insofern kann es auch nicht verwundern, dass bei Gesprächen zu diesen Themen hier Schwerpunkte entstehen, die zum Keim des eigenen Gesellschaftsbildes erklärt werden. Und drittens sind es ja die noch Aktiven, mit denen die Interviews stattgefunden haben, die dann jeweils ihre eigenen Biographien auf Parallelen und Anknüpfungspunkte zum Thema des Abends abgeklopft haben, so dass eine Stringenz in den erzählten Lebensläufen stärker akzentuiert wird.

Auch die Tatsache, dass oft unterstrichen wird, wie sehr man Unbehagen über zu weitgehende Komplexitätsreduktionen empfindet, zeigt ein starkes Bewusstsein, zur erwähnten Bildungselite zu zählen. Zur Schilderung und Symbolisierung der eigenen Person in den Fokusgruppen werden die Teilnehmer gebeten, aus vielen Bildern der Zeitgeschichte, die an der Wand aushängen zwei oder drei zur Selbstbeschreibung auszuwählen und zu erläutern. Wenn viele der Befragten mehr Bilder auswählen möchten, weil sie betonen, dass sie mehr Facetten herausstreichen und sich nicht selbst zu stark vereinfachen wollen, dann deutet dies auch darauf hin, dass sie die Vielschichtigkeit des eigenen Charakters und Lebenslaufes unterstreichen möchten.

\subsection{SelbstbeWUSSTSEIN UND SELBSTWIRKSAMKEITSERWARTUNGEN}

Prägungen können sicherlich für ein Leben mit entscheidend wirken, können, schon der semantische Gehalt macht es deutlich: prägen, einen lange sicht- und fühlbaren Abdruck hinterlassen. Es würde den eingangs angeführten Annahmen der Generationenforschung widersprechen, würde man einer gefühlten oder in einem Gespräch geäußerten Prägung aus dem Jugendalter die zentrale und ausschließliche Bedeutung für eine möglicherweise Jahrzehnte später getroffene Entscheidung zuweisen, etwa für ein Engagement für oder gegen ein politisches Projekt. Biographien und menschliche Verhaltensweisen sind ergebnisoffen und 
Menschen in ihren Entscheidungen zwar stets von zuvor gemachten Erfahrungen beraten und geleitet, aber nicht pfadabhängig durch sie determiniert. Wie in Kapitel 4.1 herausgearbeitet, spricht aber einiges für die Vermutung, dass in der Jugend und im frühen Erwachsenenalter gemachte Erfahrungen hinsichtlich der Funktionsweisen und Einflussrichtungen von Politik und Gesellschaft besonders eindrucksvoll und ein Leben lang in Erinnerung bleiben. Lars Satow weist darauf hin, dass erst ab einem Alter von etwa 12 Jahren Kinder ,,in der Lage sind, Perspektiven unterschiedlicher Bezugsgruppen zu übernehmen und deren Normen zu verstehen. ${ }^{65}$ Auch die auf den vorhergehenden Seiten beschriebenen Aussagen der Protestierenden an ihre persönlichen Erinnerungen unterstreichen diese Annahme über formative Phasen. Dies erklärt aber beispielsweise noch nicht, warum dann Menschen zu ganz unterschiedlichen Phasen im Laufe ihrer Biographie aktiv geworden sind. Warum jemand, der sich früh an politische Diskussionen mit den Eltern oder dem Lehrer erinnert, erst im gesetzten Alter beginnt, seine Anliegen selbstbewusst zu formulieren, während andere diesen Schritt bei ähnlicher Jugenderinnerung bereits vor Ende der eigenen Schulzeit gemacht haben. Auch rührt die Vorstellung, dass nach dem Alter von 25 keine für das politische oder zivilgesellschaftliche Verhalten relevanten oder entscheidenden Erfahrungen mehr gemacht würden, etwas wirklichkeitsfremd an. Prägungen sind also Einflussgrößen, die ein Verhalten oder die Bildung von Einstellungen formen können. Es soll aber darüber hinaus keineswegs die Augen verschlossen werden vor weiteren, späteren, Erfahrungen oder Ansichten, welche für ein Protestverhalten möglicherweise wichtig sein mögen. Und es soll auch dem Eindruck entgegen gewirkt werden, dass es eine Art Pfadabhängigkeit gebe, die nach dem Ende der frühen Adoleszenz das politische oder zivilgesellschaftliche Verhalten eines Menschen bereits unveränderlich festgelegt habe.

Protestierende, Aktivisten und Engagierte aller Altersstufen haben in den Gesprächen darauf hingewiesen, früh und früher als andere in ihren Altersgruppen bestimmte Zusammenhänge unserer Gesellschaft erkannt zu haben. Daraus spricht ein Selbstbewusstsein, dass auch bei den Interviews sprachlich, in Wortwahl und Ton, in Körpersprache, Mimik und Gestik nicht zu übersehen ist. Der Kopf schnellt nach oben, der Rücken streckt sich und die Augen funkeltn - jedenfalls ist das beeindruckend häufig der Fall, wenn in den Interviews vom eigenen Engagement und Protest die Rede ist. Die Interviewten geben sich stolz, unbeugsam und aufrecht in ihren Protesthaltungen und ihrem formulierten Widerspruch und sind sich den von ihnen realisierten Vorhaben und Projekten vollends bewusst. Dies auch, wenn es sich um Mitglieder von Initiativen handelt, die

55 Satow, Lars: Klassenklima und Selbstwirksamkeitsentwicklung: eine Längsschnittstudie in der Sekundarstufe I, Berlin 1999, S. 23. 
nicht die Abwehr eines Politik-Projektes verbindet, sondern um Gruppen, die in autonomer Verantwortung eine alternatives Wohnprojekt realisieren o.ä., also im Selbstbild vielmehr tatkräftig gestaltend denn Unheil verhindernd tätig sind.

Gegen etwas zu protestieren, für ein Anliegen einzustehen, erst recht, wenn dies außerhalb von lange etablierten Kanälen der Interessensvertretung geschieht, erfordert von den Protagonisten Selbstbewusstsein und die Erwartung, auch gehört zu werden und das Recht zu haben, seine Vorstellungen und Ideen in den gesellschaftlichen Abwägungsprozess einzubringen. Denn nicht nur spricht man für ein eigenes Interesse, sondern versucht gleichzeitig gegen vermeintlich eingefahrene Entscheidungsstrukturen eigene, andere oder neue Mechanismen zu eröffnen. Dass sie praktisch und moralisch ein Recht dazu haben, davon sind alle Interviewten überzeugt und vertreten dies in den Gesprächen auch mit Nachdruck. Es sind Interviewpassagen und Gesprächsatmosphären, die deutlich machen, dass hier Empörung und Wut über als unzumutbar wahrgenommene Zustände, aber gleichzeitig ein Selbstbild als Korrekturinstanz und Stimme einer anderen, alternativen Vernunft die Triebkräfte sind.

\section{Quellen von Selbstwirksamkeitserwartungen bei den Aktiven}

Das Kapitel 2.3 aufgegriffene Konzept der Selbstwirksamkeitserwartung verknüpft dieses Selbstbewusstsein zwar wiederum - für die Bildungsforschung mit Schulerfahrungen und Prägungen im Jugendalter. Und die im vorangegangen Abschnitt herausgearbeiteten Selbstbilder der Aktivisten weisen auch darauf hin, dass sie selbst den Ursprung eines Selbstbewusstseins zum Protest nicht in jüngerer Vergangenheit, sondern in meist lange zurückliegenden Lebensumfeldern oder Vorbildfiguren sehen. Gleichwohl gibt es in der Art und Weise und in der Ausprägung des durchscheinenden Selbstbewusstseins gravierende Unterschiede.

Insgesamt fällt auf, dass Selbstwirksamkeitserwartungen von verschiedenen biographischen Quellen gespeist sein können, und nicht jede davon zwangsläufig im Individuum selbst verortet sein muss. Dies haben auch die bereits zitierten Ralf Schwarzer und Matthias Jerusalem unterstrichen, wenn sie die Ausprägung einer positiven Selbstwirksamkeitserwartung mit einer positiven Verstärkung von individuellen oder kollektiven Bildungserfolgen erklärten, die zu einem Selbstbewusstsein führen, Widerstände eigenständig bewältigen zu können. ${ }^{56}$

Auch im Protest Aktive scheinen ganz unterschiedliche Formen und Herkünfte eines Selbstbewusstseins zu besitzen, das es ihnen erlaubt, gegen ihnen unlauter erscheinende Verhältnisse aufzubegehren. Dazu zählt etwa, dass eine

56 Schwarzer / Jerusalem: Das Konzept der Selbstwirksamkeit, S. 28 - 53. 
erste Gruppe von Aktivisten ein Selbstbewusstsein erkennen lässt, welches abstrakt und allgemein durch ihre Stellung als Staatsbürger grundiert ist. In dieser Form nehmen sie, aus demokratietheoretischer Warte betrachtet, in Anspruch, Teil des „Demos“ zu sein und durch die Verfasstheit unserer Gesellschaftsordnung allein bereits das Anrecht zu besitzen, mit ihren Anliegen Gehör zu finden. Quelle dieser Erwartung ist folglich eine Anschauung demokratischer Organisation, welche dem Einzelnen einen zentralen Wert zuweist und ihm auch direkte und durchgreifende Einflussmöglichkeiten an die Hand gibt. Satow sowie Jonas und Brömer haben dies nach Albert Bandura beschrieben als die generalisierte Dimension (,generality“) von Selbstwirksamkeitserwartungen, welche in die allgemeine Erwartung mündet, genügend Ressourcen für $\mathrm{zu}$ bewältigende, schwierige Anforderungen zu besitzen. ${ }^{57}$

Eine zweite Selbstwirksamkeitserwartung findet sich - analog zu den Ergebnissen aus der Pädagogik - durch positive Erlebnisse eigener Tat- und Organisationskraft befeuert, sprich: wenn und dass ein Einzelner oder eine Gruppe eigene Erfahrungen gemacht hat, die ihm signalisieren, mit bestimmten Hindernissen umgehen oder diese auch beseitigen zu können. Eine solche Überzeugung führt dazu, dass die Protestierenden nicht so leicht den Mut verlieren und auch mit Ausdauer und langem Atem ihre Interessen vertreten und nicht rasch abzuschrecken oder einzuschüchtern sind. Beispiele können etwa frühe Erlebnisse mit eigenem Engagement in der Schulzeit oder Universität sein, erste Initiativen, zu denen die Gesprächspartner gefunden hatten, und die dann mit positiven Erlebnissen des Engagements dazu führen, dass die Erwartung weiter verstärkt und selbstverständlich wird, autark und mit eigenen Kräften etwas bewirken zu können. Diese Quelle von Selbstwirksamkeitserwartungen ist auch in der Theorie als einer der wirkmächtigsten Urspünge positiver Selbstbilder herausgestellt worden: die „Mastery-Erfahrungen“58 durch eigenes Tun. Diese bedürften allerdings als Voraussetzung, dass ein Erfolg als solcher wahrgenommen sowie dass er als Ergebnis dem eigenen Handeln zugeschrieben wird. Eigenes Handeln bedarf ergo auch zur Stärkung des Selbstbewusstseins eine Bereitschaft und die psychologische Fähigkeit, die Folgen des eigenen Tuns auch als diese zu erkennen.

Eine dritte, mehr Status-getriebene Form des Selbstbewusstseins, als Protestierer oder im Engagement mitentscheiden oder bestimmen zu dürfen, rührt vom individuell erreichten Status einer Person oder Gruppe in ihrem Leben her. Viele

57 Vgl. Satow: Klassenklima und Selbstwirksamkeitsentwicklung, S. 23; vgl auch Jonas, Klaus / Philip Brömer: Die sozial-kognitive Theorie von Bandura, in: Frey, Dieter / Martin Irle (Hrsg): Theorien der Sozialpsychologie, Band II, Gruppen-, Interaktionsund Lerntheorien, Bern u.a. 2002, S. 277 - 299, hier S. 286.

58 Satow: Klassenklima und Selbstwirksamkeitsentwicklung, S. 18. 
der von uns untersuchten Protestorte - etwa Hamburg, Stuttgart oder das nördliche Umland von München - tragen den Anspruch auf Bedeutung und Gewicht in sich, wirtschaftlich, finanziell, aber damit auch in politischer Übersetzung. In der Folge entwickelt sich auch eine Bevölkerung, die über ihren Beitrag zu einer ökonomisch prosperierenden Region ein durchaus prononciertes Selbstbewusstsein entwickelt hat und sich ihren Fähigkeiten und Ressourcen bewusst ist. Hinweise auf diese Konstellation finden sich in vielen hier betrachteten Beispielen. Sowohl Hamburg, Stuttgart als auch München etwa sind für Deutschland Regionen mit überdurchschnittlicher Kaufkraft pro Kopf ${ }^{59}$, gehören zu den wenigen Ballungsräumen, die einen Bevölkerungszuwachs erfahren und bei denen Mieten und Grundpreise über die letzten Jahre kontinuierlich gestiegen sind. Es sind Räume der ökonomischen Prosperität, deren Bewohner sich ihrer Zugehörigkeit zu einer über dem Durchschnitt der Bevölkerung liegenden Gruppe sehr wohl bewusst sind, was Bildungsniveau, professionelle Erfahrung und Einkommen anbelangt. Dieses Bewusstsein, und eine daraus resultierende Erwartung, mit ihren Anliegen rasch und selbstverständlich zu den Zentren gesellschaftlicher und politischer Entscheidungen durchdringen zu können, ist in vielen Gesprächen spürbar. Durch den Schlüssel einer Gruppen- oder Regionszugehörigkeit spielt hier ein kollektives Moment eine wichtige Rolle.

Demgegenüber mündet eine vierte Form, der zweiten und dritten Gruppe von Selbstwirksamkeitserwartung nicht unähnlich, aus beruflicher Erfahrung in eine Anspruchshaltung, dass das persönliche Urteil besonders und mehr gewürdigt werde als das anderer, für weniger inhaltlich qualifiziert gehaltener Menschen. An dieser Stelle sind es die ganz individuelle Erfahrung und das Detailwissen, eine Art gefühltes Expertentum, welches zur Grundlage einer Forderung nach Gehör gemacht wird. Diese spezifisch erworbene Selbstwirksamkeitserwartung kann, muss aber nicht in ihrer Reichweite auf das spezielle Thema beschränkt bleiben. Ein politisch aktiver Architekt etwa kann sich in erster Linie zum Thema öffentliche Architektur äußern. Er kann allerdings - und dann verschwimmen auch leicht die Grenzen zu anderen Quellen - seine Selbstwirksamkeitserwartung generalisieren und über die Zeit ein Selbstbewusstsein und eine Überzeugung entwickeln, welche es ihm erlauben, nicht nur zum Themenfeld seiner Spezialisierung, sondern zu ganz allgemein politischen oder gesellschaftlichen Inhalten die Stimme zu erheben.

Eine letzte, fünfte Quelle von Selbstwirksamkeitserwartungen in den Interviews stellen sogenannte Stellvertreter-Erfahrungen dar. Dabei handelt es sich

59 Vgl. die Studie GFK Kaufkraft 2012, online einsehbar unter http://www.gfkgeomarketing.de/kaufkraft_deutschland_2012.html [zuletzt eingesehen am 26.09.2012]. 
um indirekt erworbene positive Selbstbilder, die durch das Beobachten anderer entstehen können, welche mit eigenem Engagement ihre Ziele erreichen konnten. Dafür ist laut Lars Satow allerdings eine möglichst große empfundene Ähnlichkeit mit der beobachteten Person nötig, um dessen Erleben auch für sich selbst als Erfolgsrezept zu internalisieren. Auch die Fähigkeit zum sozialen Perspektivenwechsel ist hierfür unabdingbar. Dieses Beobachten von Modellfiguren, das sogenannte „Peer-Modeling“60 zeigt darüber hinaus auch, wie wichtig die beschriebenen Schlüssel- und Vorbild-Figuren nicht nur für das Heranführen einer Person an die gedankliche und praktische Möglichkeit eines Engagements sind, sondern darüber hinaus bereits für die Förderung eines Selbstbildes, welches einen solchen Schritt auch erst ermöglicht.

Alle fünf Formen haben direkte, aber durchaus unterschiedliche Auswirkungen nicht nur auf eine generelle Neigung zum Ein- und Widerspruch, sondern auch für die vorherrschenden Sichtweisen auf demokratische Organisation von Entscheidungen in einer Gesellschaft. Wenn Quelle des Protests das Gefühl ist, Teil eines Kollektivs von Bürgern zu sein, denen in einer Demokratie stärker Gehör geschenkt werden soll, so zeitigt dies für die Ausprägung von Einstellungen zur Demokratie etwas gänzlich anderes, als wenn etwa die individuell eigenen Fähigkeiten und Ressourcen zur Begründung werden, warum man sich ganz persönlich in politische Entscheidungen einmischen sollte. Die Direktheit eine Wirksamkeitserwartung hängt auch davon ab, wie stark individuell oder aber eben kollektiv das Selbstbewusstsein und die Selbstwirksamkeitserwartungen gewachsen sind.

\section{Das eigene Tun als Treibstoff}

Das „Machen“, die Erfahrung eigener Tätigkeiten und Erfolgserlebnisse, zeigt sich in vielen Interviews als eine frühe und starke Quelle der Überzeugung, dass sich eigenes Engagement erstens lohne und dass man zweitens ganz persönlich dazu in der Lage sei, seinen Interessen zur Realisierung zu verhelfen. Viele nennen Episoden aus der Jugend, allerdings auch aus späteren Lebensabschnitten, die ihnen die Erfahrung vermittelt hätten, dass sich „Einmischen“ auszahle.

Axel G4 etwa schildert im Gespräch ausführlich seine Erfahrungen mit einem Engagement, das sich über erste Studenteninitiativen an der Universität Leipzig erst langsam und dann mit großer Anziehungskraft um breitere Themen kümmerte:

60 Vgl. Satow: Klassenklima und Selbstwirksamkeitsentwicklung, S. 23 
„[...] dann gab es Ende 2006 so die Abstimmung im Stadtrat (über die Privatisierung der städtischen Wohnungsbaugesellschaft, Anm. F.B.), also ob es verkauft werden soll. [...] Da haben wir eine große Demo vorher gemacht [...] und die ganzen kommunalen Unternehmen haben Betriebsversammlungen gemacht und wir haben von Studenten eine Vollversammlung gemacht auf der Moritzbastei und sind dann halt rüber gezogen, gemeinsam mit den Belegschaften, von den Stadtwerken und von der Wohnungsbaugesellschaft und so und sind dann vors Rathaus gezogen und haben dann dort ziemlich fett protestiert [...] dann haben ich und noch eine Freundin von mir einfach gemeint, so, das ist doch Quatsch, wenn die jetzt hier stehen und hören sich das so brav an irgendwie und da drin wird jetzt die Entscheidung gefällt, ja, dann haben wir dazu aufgerufen, dass wir jetzt da reingehen und dann sind wir [...] halt in das Rathaus rein und zwar nicht in den Sitzungssaal aber direkt davor und haben übelst laut gemacht. [...] Naja und jedenfalls ist trotzdem die Entscheidung gefallen, 34 zu 32 Stimmen, ganz knapp für die Privatisierung und damit wurde halt die Ausschreibung gestattet. [...] dann haben wir halt gesagt, okay es gibt keine andere Möglichkeit, wenn wir es verhindern wollen, dann geht das nur noch über einen Bürgerentscheid und damit hatten wir aber relativ wenig Erfahrung und haben dann halt auch Leute aus Freiburg und aus anderen Städten eingeladen. Wo es halt erfolgreiche Bürgerentscheidungen gab und haben das natürlich angeschoben. [...] Es wurden immer mehr, das war so ein Schneeballeffekt und dann, als wir es dann durch hatten, dass es einen Bürgerentscheid gibt, [...] haben wir alles selbst gemacht so Plakate und so weiter und so diese ganzen Sachen gemacht, haben wir dann einen alten Supermarkt, der gerade Pleite gegangen ist in der Südvorstadt, den haben wir umgebaut zu einer großen Werkstatt und haben es da halt, das war dann unsere Werkstatt. Da waren wir von früh bis abends und haben da Plakate geklebt und gebohrt und diesen ganzen Kram und haben das dann immer öffentlich gemacht so, ja da sind wir und so und wir brauchen jede helfende Hand und so. [...] Und ja, wir haben es dann doch ganz gut hinbekommen, also die Wahlbeteiligung, die war beim Bürgerentscheid über 10 Prozent höher als bei der Oberbürgermeisterwahl, also es sind mehr Leute hingegangen als zur Wahl des Oberbürgermeisters und das fand ich eigentlich ganz cool. [...] das war echt ein gutes Zeichen und das hat mich so ein bisschen beflügelt, man kann es auch mit direkter Demokratie, wenn Leute halt selbst, wenn es um ihre Sachen geht, also wenn Sie merken, es betrifft sie auch selbst irgendwie.“61

Erzählungen über Erfolgserlebnisse, die vor Augen führten, was persönlich alles erreicht werden kann, finden sich in fast allen Gesprächen. Und beinahe immer werden diese resümiert mit dem Fazit, welches in unterschiedlichen Variationen seit dem Beginn von Arbeiterassoziationen, der französischen Revolution oder gar den ersten Gemeinden im Urchristentum als Erfolgsrezept für das Durchsetzen eigener Vorstellungen, Anliegen, manchmal Ideale, immer wieder gesungen

61 Einzelinterview Axel G4. 
wird: Wenn wir uns nur zusammentun, schaffen wir mehr und können uns schützen.

„Ich kann ein ganz einfaches Beispiel sagen, wie ich so in Richtung Schiene Politik gekommen bin, es ist damals gegangen um ein örtliches Problem, das Freibad in Freising in Lärchenfeld Ortsteil sollte von einer oder zwei Stadtratsfraktionen in ein Wohnbaugebiet umgewandelt werden, wo also Bauträger das Ganze zugepflastert hätten und dann eben irgendwo ein neues Freibad mit Hallenbad und allen Schikanen auf dem Boden gestampft hätte sollen. Das ist eine grüne Lunge im größten Ortsteil von Freising mit herrlichem Baumbestand und so weiter und da hat sich dann entsprechend massiver Widerstand ergeben und da haben wir erst einmal gemerkt, wenn wir als Bürger auftreten, oder ich habe es als erstes gemerkt, wenn ich als Bürger mit dabei bin und mich einmische, dann kann ich auch etwas erreichen und das ist eben dann mit einer ganz eigenartigen Koalition zwischen Grünen und CSU im Freisinger Stadtrat dann abgeschmettert worden, aber nur, weil wir in diesem Stadtratssitzung mit 60 bis 80 Leute mit drin waren.“62

Diese Erfahrungen wirken selbstverstärkend, da Erlebnisse wirksamen Aktivseins augenscheinlich später immer wieder als Selbstbewusstseins-Reservoir aktiviert werden können, wenn die Gesprächspartner Ereignisse oder Entwicklungen als falsch, schlecht oder problematisch empfanden. Folglich resultiert daraus die Annahme, dass, wer bereits früh und umfassend solche Erfahrungen selbst macht, dem Gedanken ans eigene Protestieren stets näher steht als jemand, dem dies nicht vergönnt war. Konrad C3 aus Hamburg beispielsweise sieht im Gespräch sein Aktiv-Sein im Resümee als Lebenseinstellung und zunächst einmal anlassunabhängig. Er erwartet, dass es eine inhaltliche Disposition zum Protest gebe, zum Dagegenhalten und Einmischen, und dass dieses ein Leben lang in der Grundtendenz gleich bleibe, man lediglich in bestimmten, beruflich oder familiär dominierten Lebensphasen „nicht dazu komme“. Es darf aber nicht verkannt werden, dass gerade aus solchen Gesprächspassagen die bereits erwähnte Beobachtung besonders deutlich hervorgeht, dass sich Gesprächspartner um die Konstruktion eines konsequenten roten Lebensfadens bemühen, der sie geradlinig und unbeugsam erscheinen lässt. In den Fokusgruppen mit Protestierenden, deren ursprüngliches Konfliktfeld bereits im Schwinden begriffen ist oder zumindest aber einen Höhepunkt der Auseinandersetzungen hinter sich gelassen hat, ist die Grundrichtung sehr plastisch: Protesterfahrungen verstärken bereits vorhandene Dispositionen und lassen Menschen leichter und schneller wieder aktiv werden. Dies bedeutet nicht, dass ein Aktivitätsniveau nach einem kräftezehrenden Konflikt gehalten wird, dass sofort die nächste Bürgerinitiative ge-

62 Michel C3 in der Fokusgruppe C3 in Freising am 25.07.2012. 
gründet werden muss, wenn ein Anliegen durchgesetzt oder abgeschmettert wurde. Viele der Aktiven aber werden - etwa nach dem Referendum über die Gemeinschaftsschulen in Hamburg - anschließend in anderen Themenzusammenhängen aktiv.

Gleichwohl liegt auch hier der Gedanke nahe, dass die Erfahrung des „Machens" zunächst einmal eine individuelle ist, die dann das Selbstbewusstsein individuell anspricht und persönlich bei den Aktivisten die Erwartung entstehen lässt, dass sie selbst in ihrem Einspruch das handelnde Subjekt sind, dem von der Politik und Gesellschaft aus verstärkt zugehört werden sollte. Zusätzlich hat etwa Franz Walter darauf hingewiesen, dass eine positive Erfahrungsressource bezüglich eigener Leistungsfähigkeiten etwas ist, das erfolgreichen Absolventen eines Bildungssystems überproportional zur Verfügung steht. ${ }^{63}$ Dies findet sich hier in den Gesprächen wie im gehobenen Bildungsgrad der Beteiligten bestätigt.

Allerdings ist ein graduell ansteigendes und sich intensivierendes Engagement, von jeweils Bestätigung auslösenden Erfolgserlebnissen getriebenen, nicht die einzige Form von Selbstbewusstsein, der man in den Interviews mit den Aktivisten begegnet. Vielmehr scheinen weitere Motive durch.

\section{Berufliche Erfahrungen und vollmundige Erfolgsresümees}

Berufliche Erfahrung gibt Menschen das Gefühl, inhaltlich auf einem Gebiet sachkundig und sprachfähig zu sein. Die Ausweitung des durchschnittlichen Bildungsniveaus in der Bundesrepublik Deutschland über die vergangenen knapp fünf Jahrzehnte hat dazu geführt, dass die kumulierten professionellen Erfahrungen von immer mehr Menschen spezialisierter und mitunter komplexer geworden sind, auch, weil Erwerbsbiographien nicht mehr gleichermaßen geradlinig verlaufen, sondern die beruflichen Stationen und damit der Erfahrungsaufbau vermehrt mehrere Orte oder gar Berufe umfassen. ${ }^{64}$ Dies kann ein Quell von protestbezogenem Selbstbewusstsein werden, wenn es beim Stein des Anstoßes um ein Projekt oder Thema geht, bei dem sich ein Mensch aufgrund seiner beruflichen Biographie urteilsfähig und besser vorbereitet fühlt als andere. Den Eindruck jedenfalls, inhaltlich über ein politisches Projekt urteilen zu können, egal,

63 Vgl. Walter: Bürgerlichkeit und Protest in der Misstrauensgesellschaft, hier S. 310; vgl. hier auch die Ergebnisse aus der Bildungsforschung: Satow: Klassenklima und Selbstwirksamkeitsentwicklung sowie Schwarzer / Jerusalem: Das Konzept der Selbstwirksamkeit, S. $28-53$.

64 Vgl. zu diesem Thema auch grundlegend Sennett, Richard: Der flexible Mensch. Die Kultur des neuen Kapitalismus, Berlin 2006, vgl. auch Minssen, Heiner: Arbeit in der modernen Gesellschaft: Eine Einführung, Wiesbaden 2012, hier bes. S. 59 - 79. 
ob es sich dabei um die europäische Gemeinschaftswährung handelt, um die technischen Details eines Bahnhofsneubaus oder aber um die vorgelegte Begründung für eine Flughafenerweiterung (in diesem Fall beispielsweise die Korrelation zwischen prognostiziertem Ölpreis und Passagierentwicklung), haben viele der Gesprächspartner und begründen dies mit eigenen beruflichen Werdegängen und Erfahrungen, die sie allerdings - und dies ist hierbei ganz wichtig bei der Gegnerseite des politischen Protests nicht im gleichen Maße zu finden meinen. Dabei können die beruflichen Erfahrungsperspektiven als spezifische Selbstwirksamkeitserwartungen in ein allgemein positives und selbstbewusstes Selbstbild transferiert werden, welches ein Engagement auch in anderen thematischen Feldern als in jenem der beruflichen Erfahrung erlaubt. Die Aktivisten empfinden sich dann als allgemein sprachfähig und -berechtigt. Dass in ihr Urteil nach wie vor die beruflichen Expertisen einfließen und diese nicht allein ein selbstbewusstes Vortragen zeitigen, sollte nicht weiter überraschen.

Anna G1, Ärztin von Beruf, erzählt etwa zu ihrem Eindruck der Entwicklung in den neuen Bundesländern nach 1990:

„... ich hab eigentlich da so hautnah miterlebt, wie das eigentlich doch eine Form der Inbesitznahme war, also viele Strukturen, die wirklich gut funktioniert haben, in der DDR, die wurden überhaupt nicht abgefragt, das heißt, es wurde platt gemacht und aus dem Medizinbereich, das beste Beispiel, was wir jetzt gerade im Moment ja erleben, die gesamten Polikliniken werden platt gemacht und was haben wir heute? Ja, medizinische Versorgungszentren, das heißt nur anders, ist aber im Prinzip dieselbe Struktur und wir kommen auch ohne diese Strukturen nicht mehr aus, weil die Arbeit dieses Arztes hat sich so verändert, das lässt sich nicht mehr in Einzelpraxen machen. Nun muss ich so etwas einfach par odre du mufti platt machen, um das dann irgendwann manuell aufzubauen, oder kann ich das mit mehr, mit mehr Sensibilität anschauen und auch mit mehr, also mehr auf Augenhöhe sowas verarbeiten. Also wie gesagt, aus dem Medizinbereich hab ich's ganz, ganz deutlich erlebt, aber ich hab auch aus den Schilderungen dieser vielen Leute aus den neuen Bundesländern immer wieder gehört, wo's so diese Punkte waren, wo die gesagt haben: Das war eigentlich bei uns - ich sag jetzt mal besser - und das ist einfach platt gemacht worden. Und das hat mich eigentlich noch mehr innerlich politisiert, wo ich nicht nur von der Kommunalpolitik her mich geärgert habe, sondern auch gedacht habe: Also das, was diese Parteiendemokratie macht, das ist wirklich in so einer Schiene zu arbeiten, bei der sie die Bodenhaftung verloren hat. “65

Auch Bernd C5, Pastor, weist darauf hin, dass ihm sein Beruf wie selbstverständlich den Weg zum Engagement gewiesen habe:

65 Einzelinterview Anna und Conrad G1. 
„Dann tauchte das Thema (Politik, Anm. F.B.) während des Studiums mal wieder auf, als die Studienreform durch Bayern gepeitscht wurde, als wir damals in München auf die Straße gingen und demonstriert haben, das war auch so eine Erfahrung: Man kann was, sich artikulieren in der Öffentlichkeit, man ist da nicht alleine. Und dann war das Thema Politik, seitdem ich im Beruf bin, immer dabei, weil Evangelium und Politik, das gehört zusammen, das muss miteinander ins Gespräch kommen. “66

Dieses ist noch eine zusätzliche Komponente von Selbstwirksamkeit: sie über berufliche Erfahrungen so festigen zu lassen, dass sich bestehende Dispositionen für Selbstwirksamkeitsüberzeugungen ausbauen und bestätigen lassen. Interessant ist, dass sich dabei einmal gemachte Erfahrungen verstetigen und in der Tendenz vertiefen, weil man mit mehr Überzeugung, mehr Erfahrung und mehr Motivation zur Sache geht. Auch dies ist ein Hinweis auf den Vertiefungseffekt von Erfahrungsspaltung innerhalb einer Partizipationsgesellschaft, in der die Wahrscheinlichkeit, Selbstbewusstsein nährende Erlebnisse zu machen, nicht gleich über alle sozialen Gruppen verteilt ist, sondern vielmehr denen zuteilwird, die qua Bildungslaufbahn und sozialem Status überdurchschnittlich häufig sich selbst verstärkende Bestätigungen erfahren.

Berufliche und soziale Hintergründe eines Protest-Selbstbewusstseins finden sich allerdings oft dort in fast aggressiver Weise gesteigert, wo eine Form von „Selfmade-Arriviertheit“ dem Einzelnen nahe legt, dass er selbst durch seine (Erfolgs-)Biographie eine dem Rest der Bevölkerung überlegene Position erreicht habe und demzufolge auch mehr Recht habe, Einfluss auf die Entscheidungen innerhalb einer Gesellschaft zu nehmen. Oder aber, anders herum, dass der persönliche berufliche oder finanzielle Erfolg beweise, dass die Gesellschaft gut daran tue, auch Rat bei den entsprechenden Personen zu suchen, da ihre Biographie zeige, dass sie besonders inhaltlich fähig oder strategisch klug seien. Passagen, bei denen dies auffällt, werden in den Interviews mit Nachdruck und fast herablassend vorgetragen, oftmals auch von Gesprächspartnern, denen eine Neigung zum Monologisieren nicht ganz fremd ist. Da die Zitate in den Interviewverschriftlichungen ohne diese manchmal eindrucksvolle Intonation $\mathrm{zu}$ lesen sind, ist das Argument in Papierform etwas grauer und weniger schillernd, als diese Auszüge im Original nachzuhören. Gleichwohl ist die Melange aus fachlichem Selbstbewusstsein und der mit breiter Brust vorgetragenen Lebenserfahrung, also die Mischung aus dem Selbstbild des Expertentums und einer sozial (oder ökonomisch) herausgehobenen Stellung, eine auffallende in vielen Gesprächen. Es ist eine Leistungs-Utopie der Starken und "Schlauen" - auch des-

66 Einzelinterview Bernd C5. 
wegen ist die Klientel hier so hemdsärmelig, man redet ja davon, dass diejenigen, die es nicht schaffen, konkurrenzfähig zu sein, eben unterliegen müssten, damit es Sinn mache und damit es den Anreiz gebe, sich zu verbessern. Die entsprechenden Gesprächspartner schildern dies allerdings aus einer Position, in der sie vollkommen davon überzeugt sind, dass sie auf der konkurrenzfähigen Gewinnerseite stehen. Darüber hinaus unterstreichen diese Interviewpassagen eine Individualisierung von Selbstwirksamkeit, da es ja die individuellen Erfolge sind, aus denen ein Anspruch hervorgeht, privilegiert als Sprecher gehört oder an Entscheidungen beteiligt zu werden. Folglich sind es auch hier gerade nicht kollektiv erfahrene Ereignisse, die erzählt werden, sondern eine Art Einzelkämpferrhetorik, welche die herausgehobene Position und Führungsstärke des Erzählenden verdeutlichen soll. Es sind meist Männer der Altersgruppen zwischen 46 und 65, bei denen dieses Phänomen zum Tragen kommt.

Die Kernfrage des Kapitels zu den biographischen Prägungen ist die nach dem vorliegenden biographischen Gepäck, mit dem sich die Aktivisten auf ihren Weg gemacht haben. Wut und Entschlossenheit zivilgesellschaftlicher Proteste und die Infragestellung demokratischer Entscheidungsprozesse in unserer Gesellschaft lassen zumindest die Diskussion erkenntnisreich erscheinen, was die hier Aktiven von denjenigen scheidet, die solche Kritik zwar teilen (oder auch nicht), aber eben nicht den Schritt zum eigenen Aktivsein gewagt haben. Bei allen Bemerkungen zum sich selbst verstärkenden Charakter einer Selbstwirksamkeitsüberzeugung gerade durch die Erfahrungen im Protestieren darf nicht vergessen werden, dass diese nicht in erster Linie Folge von Engagement sind, sondern als Voraussetzungen desselben unverzichtbar. Emanzipation, Selbstbestimmung, das Ziel, sich nicht unterzuordnen, das Recht zu haben, mit seinen Interessen und Sichtweisen Gehör zu finden - dies sind augenscheinlich Gedanken, die den Interviewten gemein sind und die sie für ihre eigene Biographie samt und sonders in Anspruch nehmen und die nicht mit einem aktiven Protest erst neu entstanden sind.

\section{Subsidiarität als ideale Voraussetzung der aktiven Bürgerrolle}

Ein Gedanke fällt diesem Zusammenhang in den Gesprächssequenzen immer wieder auf: der Gedanke der Subsidiarität, der als Idealvorstellung gesellschaftlicher Organisationsweise bemüht wird. Dass die möglichst kleinste Ebene sich um die Ausführung oder Regelung eines Vorhabens kümmern sollte, haben die meisten der Aktiven als Idee und auch als Wurzel eines daraus sprießenden Selbstbewusstseins tief verinnerlicht. Die hier versammelten Interviews aus den Protestgruppen repräsentieren ein breites Spektrum von Initiativen und können 
ganz unterschiedliche Gesellschaftsentwürfe zum Vorbild haben. Nicht alle richten sich etwa an den Staat als zentrale Ebene, von der sie eine Regelung oder ein Verbot erwarten, sondern andere verlangen im Gegenteil die Freigabe von Gestaltungsmöglichkeiten. Dass man etwas selbst tun und nach eigenem Gutdünken ausgestalten könne, dürfe, manchmal gar müsse, ist vielen eine Selbstverständlichkeit. In den Stuttgarter Protestgruppen im Umfeld von Stuttgart 21 etwa wird auf die Erfahrungen der Proteste gegen den Kraftwerksbau in Whyl Ende der 1970er Jahre hingewiesen, der ihnen in jungen Jahren vor Augen geführt habe, was alles möglich sei, wenn man seine Anliegen selbst in die Hand nehme. In den Protestgruppen, die sich gegen die Idee einer europäischen Gemeinschaftswährung wehren, wird hingegen bisweilen eine radikalliberal angehauchte $\mathrm{Ge}-$ sellschaftsvorstellung sichtbar, die dem Einzelnen sehr weite Entscheidungsbefugnisse und Aufgaben zuweist. Jeden Tag einen Katalog mit Entscheidungsmöglichkeiten vorgelegt zu bekommen, für welche Vorhaben seine Steuern zu verwenden seien und welche Aufgaben er finanzieren möchte und welche nicht so schilderte etwa ein Aktivist aus Stuttgart seine Utopie einer idealen Gesellschaft. Die Reichweite von Subsidiaritätsvorstellungen und die damit auch verbundenen Bürden mögen bei den unterschiedlichen Protestgruppen variieren. Dass aber staatlicher Zentralgewalt misstraut wird und man sich Regelungen vielmehr möglichst lokal oder gar dem Einzelnen überantwortet wünscht, steht für die meisten außer Zweifel. Und man selbst ist an dieser Stelle Adressat und Ausführender subsidiärer Aufgabenaufteilung, weil man sich als gestaltende oder schaffende Kraft sieht:

„Kleine, flexible, sich selbst regulierende politische Einheiten, was nicht ausschließt, dass manche Einheiten sich für bestimmte Zwecke zusammenschließen zu einer größeren Einheit, zum Beispiel, um zu sagen, wir geben eine eigene Währung auf, aber auch wenn es nicht klappt, wieder sagen, wir gehen da auseinander. Ja, die sich eben sachbezogen, oder themenbezogen oder personalbezogen für bestimmte Sachen zusammenschließen, aber dann auch wieder auseinander gehen. ${ }^{\text {“67 }}$

Ein Charakteristikum, welches aus der Bildungsforschung herausgestrichen werden kann, findet sich auch bei den Protest-Aktiven deutlich akzentuiert wieder: der Befund, dass hohe Selbstwirksamkeitserwartungen die Interpretation von Misserfolgen positiv beeinflussen. ${ }^{68}$ Dies wird erklärt mit der Tatsache, dass jemand mit einem positiven Selbstbild dazu neige, Misserfolge eher ungünstigen

67 Einzelinterview Fabian G2.

68 Vgl. Schwarzer / Jerusalem: Das Konzept der Selbstwirksamkeit, S. 28 - 53; Satow: Klassenklima und Selbstwirksamkeitsentwicklung. 
externen Umständen zuzuschreiben und nicht mangelnde Fähigkeiten oder Lässlichkeiten bei sich selbst zu suchen. Die Niederlage beim Volksentscheid über Stuttgart 21 am 27.11.2011 etwa „beweise“ den Gruppen, die sich gegen den Bahnhofsneubau wenden, dass der Staat, die Deutsche Bahn, die politischen Parteien und ökonomischen Eliten ein Kartell bildeten, welches den Neubau gegen alle Rationalitäten „durchpeitschen“ wolle und dass diese keinerlei Interesse an einer transparenten Entscheidungsstruktur besäßen - ergo, dass bereits das Ergebnis des vorherigen Schlichtungsspruchs vom 30.11.2010 - ein Weiterbau des Bahnhofs - nur so hätte ausfallen können und eben nicht durch Unvermögen oder mangelnder Mobilisierung der Protestierenden erreicht wurde. Im Gegenzug würden positive Erfolgserlebnisse von Menschen mit ausgeprägter Selbstwirksamkeitserwartung als Ausfluss der eigenen Handlungen verbucht und den persönlichen Fähigkeiten und Ressourcen gutgeschrieben. Dies etwa findet man etwa wieder bei den Gesprächen mit Protestierenden aus Freising im Norden Münchens, nach dem - wohlgemerkt nicht durch sie selbst, sondern die Bürger Münchens - in einem Bürgerentscheid gegen eine Befürwortung des Projekts der Stadt München als Anteilseignerin des Flughafens gestimmt worden war. Hier war ganz selbstverständlich die eigene Protest- und Überzeugungsarbeit, die Kreativität und versammelten Fähigkeiten der Aktivengruppen für das Wunschergebnis verantwortlich.

Auch die in der Theorie betonte Auswirkung eines positiven Selbstbildes auf die Fähigkeit, ausdauernd an einem Problem zu arbeiten, bis eine Lösung gefunden ist und mit Kreativität zunächst eingefahren und verworren wirkende Situationen zu bewältigen, entspricht zumindest dem Selbstbild der Aktiven vollkommen. Die Interviewpassagen und Gesprächsabschnitte mit Protestierenden, in denen es um ihre praktischen Erfahrungen geht, spiegeln dieses - auch in Ton und Körpersprache - nur allzu deutlich wieder: Sie wissen um die Bedeutung eines langen Atems und einer höchstens Stück für Stück zu erreichenden Lösung ihrer Forderungen. Dies mag auch daran liegen, dass im Interviewsample in der Hauptsache Initiativen und Protestgruppen widergespiegelt sind, die zumindest über mehrere Monate, zumeist Jahre, aktiv sind und in die demzufolge Menschen Eingang finden, für die eine derartige Perspektive nicht den denkbaren Horizont eines Engagements übersteigt, die nicht gleich Lust und Antrieb wieder verlieren. Eine solche Einschränkung auf eine Art „Mindestausdauer“ ergibt aber unter demokratiediagnostischen Gesichtspunkten Sinn, wenn man annimmt, dass gerade ein Engagement in Parteien eine Entscheidung ist, die von dem Gedanken an ein längeres Aktivsein geprägt sein dürfte. Für die Frage, was Menschen dazu treibt, eben nicht in Parteien aktiv zu werden, mag an dieser Stelle eine Vergleichbarkeit wichtig sein. 
Wenn man zugrunde legt, dass ein positives Selbstbild und eine ausgeprägte Selbstwirksamkeitserwartung für die Protestierenden bereits Voraussetzung einer Entscheidung für ein Engagement gewesen ist, so ist dies allerdings keine statische Größe. Denn zum bereits erwähnten selbstverstärkenden Charakter der Selbstwirksamkeitserwartungen durch Erfahrungen in Protest-Engagements zählt nicht nur die Sammlung eigener, individueller, oder aber gruppenbezogener Erlebnisse, die weiteren Protest oder Aktivitäten befeuern können. Auch die Erfahrungen anderer Protestgruppen scheinen als motivierende Erlebnisse immer wieder auf. Die Erfolge oder Erfahrungen anderer Protestgruppen, sei es in anderen Regionen, zu anderen Themen oder aber auch zeitlich weit zurückliegender Protestfelder, werden aktiv in die Erfahrungssammlung mit einbezogen. Das Lernen von anderen wird von den Protestierenden ganz bewusst als KräfteKonzentration oder Erfahrungsschatz genutzt.

„Wir waren dann auch in Christiania ${ }^{69}$ und haben da dann zum Beispiel auch an einem Workshop oder an Podiumsdiskussionen teilgenommen wo verschiedene Projekte ihre Probleme darstellen und sich ausgetauscht haben. Von Anfang an wurde sehr stark auch geguckt, was gibt es für Projekte in Europa und wie machen die das. Und dann sind viele auch mal hingefahren und haben mal geguckt. So und viele Ideen mitgebracht. “70

Selbstwirksamkeit kann also auch einen über die einzelnen Gruppen und auch Generationen kollektiv wahrgenommenen Charakter annehmen: Wenn es andere machen, motiviert es. Dies mag auch das selbstverstärkende Moment erklären, was als gesellschaftlich gestiegene Protestaffinität der bundesdeutschen Gesellschaft dieser Arbeit zugrunde liegt. Denn Bezüge dieser Art finden sich viele: in den Interviews, aber auch auf den Demonstrationszügen und teilnehmenden Beobachtungen. Die Hamburger Stadtinitiativen beziehen sich auf die Erfolge, welche die Protestgruppen in den 1980ern in der Hafenstraße erzielt haben, erzählen von proletarischen Traditionen der Selbstorganisation, welche ihnen zum Vorbild geworden sind. Die Stuttgarter Protestgruppen gehen historisch gar noch weiter zurück, wenn es um gewählte Bezüge zum Stuttgarter Bürgertum der vergangenen Jahrhunderte geht. ${ }^{71}$ Die Wahrnehmung, es gebe nicht nur auf dem eigenen Themengebiet oder gar lokal vor Ort bereits ermutigende Erfahrungen im Protest, kann anfeuernd und bestärkend wirken.

69 Alternatives Stadtteilprojekt in Kopenhagen, online einsehbar unter www.christiania.org [zuletzt eingesehen am 11.06.2014].

70 Einzelinterview Frederik C1.

71 Butzlaff u.a.: „Wir lassen nicht mehr alles mit uns machen!“, S. 57 und 66. 
„...vielleicht war auch Stuttgart 21 schon und natürlich auch [...] der Transrapid, das war ein ganz großes Hoffnungszeichen. Also, dass der einfach geknickt wurde, [...] da haben wir gedacht, okay und wenn es da geht, geht es vielleicht auch mit der dritten Startbahn. Also genau, Stuttgart 21, Transrapid, auch zu merken, dass an ganz verschiedenen Stellen in Bayern, in Deutschland, Protest aufkommt. Dann habe ich ja auch so ein Beispiel wo es eben ähm auch geschafft wurde, was zu stoppen. Also insofern habe ich mir gedacht, es gibt ja die positiven Beispiele, es geht ja. Warum sollten wir nicht auch eins sein?“72

Diese stellvertretenden Erfahrungen und Verstärkungen von Selbstwirksamkeitserwartungen übersetzen sich in vielen Gruppen in eine Eloge an das Komplementäre. Man ist stolz darauf, viele ganz unterschiedliche Menschen zu versammeln, ihre Erfahrungen, Ressourcen und Fähigkeiten zu einem schlagkräftigen Ganzen zu verbinden. Es ist ein Stolz über die bei der eigenen Initiative empfundene Heterogenität und der vermeintlich professionelle oder zumindest erfolgreiche Umgang damit. Das Protestbündnis als Sammelstelle von Professionalität, welches den Anwalt, den Kommunikationsberater, den Physiker und den Landschaftsgärtner zusammenbringt, wird zur Quelle eines kollektiven Selbstwirksamkeitsbildes, welches den Einzelnen erwarten lässt, dass man die jeweils notwendigen Ressourcen gemeinsam bereithalte. Der Gruppenzusammenhang hat enorme Auswirkungen auf dieses Gefühl. Dabei hängt es nicht unbedingt von der Größe einer Initiative ab, sondern vielmehr von dem im Bündnis gepflegten Ton und Argument, und ob man auf Heterogenität und unterschiedliche berufliche oder fachliche Herkunft der Mitglieder nicht nur aus strategischen, sondern auch aus demokratietheoretischen oder legitimatorischen Gründen rekurriert.

Eine weitere Quelle des Selbstbewusstseins, welche bei den Gesprächen und Beobachtungen deutlich ins Auge springt, sind die Reaktionen des jeweiligen Gegners oder Ansprechpartners. Auch hier sind abschlägige Reaktionen etwa einer Administration auf die Forderungen einer Protestgruppe keine ursprüngliche Quelle einer Protestidee von Menschen, die zuvor an geringer Selbstwirksamkeitsüberzeugung gekrankt haben. Sie fallen aber auf fruchtbaren Boden und befeuern eine Disposition zum Protest, wenn sie auf Menschen treffen, die ein solches Selbstbild in der Vergangenheit bereits ausgeprägt haben. Konkrete Fälle sind gerade Ereignisse, die den Protestierenden zeigen, dass sie beim Gegenüber - seien es nun die öffentliche Hand, politische Parteien, einzelne Politiker, Unternehmen oder andere Protestinitiativen - einen wunden Punkt getroffen haben, der sie reizt oder zu einer Reaktion provoziert. Wenn etwa die Polizei in Stuttgart gegen Demonstranten vorgeht, dann werden diese nicht entmutigt, sondern

72 Einzelinterview Beata $\mathrm{C} 4$. 
sehen gerade darin ein Zeichen, dass sie im Recht sind, wenn die Behörden oder aber die entsprechenden gegnerischen Protestgruppen - so es welche gibt - mit vermeintlich unverhältnismäßigen Mitteln gegen sie vorgehen.

„Laura E5: Und wir wurden dann als Nazis beschimpft, das war ganz schlimm. Wir sind als Nazis beschimpft worden. Die Gudrun, die noch kommt, die wurde als Nazischlampe beschimpft, also es war übel. Aber es ist also...

Interviewer: ...Würden sie denn sagen, dass dieses Engagement um den Bahnhof herum, sie so ein bisschen in die politische Aktivität geholt hat, dass sie deswegen jetzt auch vielleicht hier sitzen?

Doria E5: Ja. Wir haben Mut bekommen, den Mund aufzumachen.

Interviewer: Können sie das mal beschreiben? Das finde ich sehr interessant.

Doria E5: Ich habe keine Hemmungen mehr, weil ich nichts zu verlieren habe und das was sie da oben können, können wir schon lange.

Interviewer: Gab es da irgendeinen Moment, wo es so klick gemacht hat, wo sie das gemerkt haben oder eine Art Erleuchtung sie bekommen haben, dass es geht, dass sie etwas tun können und dass sie ihre Einstellung dazu geändert haben?

Doria E5: Wir haben gesehen, dass wir etwas bewegen können, wenn wir den Mund aufmachen und der Erfolg hat uns Recht gegeben.

Laura E5: Ich habe dann auch irgendwann die Buttons öffentlich getragen. Ich habe mich am Anfang nicht getraut, nachdem die Gegner, nur Gegner in der Straßenbahn mit dem "Oben bleiben" Button waren, dann habe ich auch angefangen meinen Button öffentlich zu tragen.“ ${ }^{73}$

Es entstehen dabei oftmals „Märtyrer-, Helden- oder Daviderzählungen“ des eigenen Protests oder Engagements, in deren Rahmen die eigene Selbstwirksamkeit bestätigt und verstärkt wird, weil man sich gegen vermeintlich übermächtige, besser ausgestattete und besser vernetzte Gegner zur Wehr setzen muss. Dass man als Gesprächspartner von der Politik oftmals nicht anerkannt wird, dass Gespräche - wenn sie denn zustande kommen - auf ein arrogantes Abkanzeln hinauslaufen oder ohne jede Wirkung bleiben; oder aber, dass Politik oder Wirtschaft (oder die Medien bzw. gegnerische Protestgruppen) alle Hebel in Bewegung setzen, um Ziele zu hintertreiben oder um ihre jeweils eigenen durchzusetzen ist eine gefühlte Herabsetzung, die unheimlich viel Wut und Enttäuschung, aber auch positive Energie und Kraft freisetzen kann. Die Protestschilderungen in den Gesprächen laufen an diesem Punkt darauf hinaus, die eigenen Politikund Gesellschaftsdiagnosen zu verstärken, die Aktivisten werden auf diese Weise auch sich selbst und ihrem Engagement immer wieder vergewissert. Es ist

73 Einzelinterview Doria Laura E5. 
richtig, was wir da machen, die Reaktionen unserer Gegner beweisen es nur allzu gut. Gleichzeitig bringen diese Erfahrungen auch eine Art Einkapselung innerhalb der jeweiligen Protestgruppen mit sich, die ein Interagieren in einer offenen Diskussion über den Kontext der einzelnen Initiative hinaus bisweilen schwierig macht.

Zuletzt waren weiterhin die Gespräche in den Regionen, welche über stärker landesrechtlich verankerte Möglichkeiten für Volksabstimmungen und Bürgerentscheide verfügen - wie etwa Hamburg oder auch Bayern -, sichtbar geprägt von einer Gewissheit, diese Rechte auch in Anspruch nehmen zu können. Über verbriefte Rechte zu verfügen, kann sich über die damit verbundene stärkere Sichtbarkeit und Selbstverständlichkeit von partizipativen Instrumenten auch in einem größeren Selbstbewusstsein widerspiegeln, um den eigenen Interessen Gehör zu verschaffen. Eine Selbstwirksamkeitserwartung was das eigene Engagement anbelangt, kann folglich auch durch eine Gesetzeslage unterstützt oder forciert werden, die eine Tradition zivilen Einspruchs entstehen lassen.

\subsection{ZWISCHENFAZIT III: INDIVIDUALISIERTE SELBSTWIRKSAMKEITSERWARTUNG IN EINER ALTERNDEN GESELLSCHAFT}

Zusammenfassend können wir also bei einem bereits vorliegenden positiven Selbstbild davon ausgehen, dass eigene Protesterlebnisse sowie Initiativen, die man beobachtet, dieses Selbstbild verstärken und damit ein Engagement lohnenswert erscheinen lassen. Die Protestierenden und Engagierten haben in den Gesprächen jedenfalls deutlich werden lassen, dass sie ihren Protest als Ergebnis ihres bisherigen Lebens und ihrer Werte und Prägungen interpretieren. Und auch wenn nicht hinter jedem Aktiven eine tatsächliche Biographie von mehreren Jahrzehnten des Engagements steht, so erzählen die Schilderungen von ersten „Augenöffnungen“ und Eindrücken aus der Jugend, dass und warum ein Engagement sich lohne. Dies verdeutlicht den bereits unterstrichenen dynamischen, sich selbst verstärkenden Charakter von Protest noch. Auch, dass Gesellschaften, wie die mitteleuropäischen derzeit, die eine Phase deutlich sichtbarer oder zumindest gefühlt allgegenwärtiger zivilgesellschaftlicher Proteste erleben, davon ausgehen müssen, dass derzeitige Kohorten im Jugendalter diese grundierenden Erfahrungen von Selbstwirksamkeitserwartungen leicht und sehr umfänglich machen. Und dass ein kritisches Hinterfragen von Autorität Selbstverständlichkeit geworden ist. 
Darüber hinaus macht die beobachtete, durch Protest sowie berufliche oder allgemeine Lebenserfahrung aufbauende Selbstwirksamkeitserwartung deutlich, dass es für Menschen ab einem gewissen, durch berufliche Arrivierung gekennzeichneten, Alter wahrscheinlicher ist, ein Mindestniveau an Selbstbewusstsein für eine Engagemententscheidung im Protest zu erreichen, weil sie eben schon qua „Erfahrungsjahren“ eher dazu die Möglichkeit gehabt haben. Die Erwartung jedenfalls, man müsse jetzt auf sie ganz persönlich hören und sie einbinden, scheint durch diesen Mechanismus mit dem Lebensalter in der Tendenz zu steigen. Es ist auffällig, dass die Formen der individualisierten Selbstwirksamkeitserwartung, welche mit ganz persönlichen Verdiensten und Fähigkeiten verknüpft werden und die einen direkten Einfluss auf die Entscheidungsfindung rechtfertigen sollen, mit dem Alter der Aktiven im Interviewsample ansteigen und stärker akzentuiert werden. Dies ist aus den Wurzeln und den Wachstumspfaden des Selbstbildes erklärbar. Es bedeutet aber, dass sich in einer alternden Gesellschaft und Demokratie insgesamt diese Formen der Erwartung von Einfluss auf die Schwierigkeit, gesellschaftlich Kompromiss und Konsens zu etablieren, unmittelbar auswirken müssen.

Die Frage bleibt, warum diese individualisierten Formen von Selbstwirksamkeitserwartung sich in Gruppen und Initiativen zusammenfassen und unter eine gemeinsame Strategie subsummieren lassen. In den Gesprächen mit den Aktiven wurde aber deutlich, dass der Zusammenhang innerhalb der Proteste sich um ein Thema sammelte, welches den Interviewten zentral und persönlich sehr bedeutsam war. Dies führt dazu, dass sie sich als Gruppen von Gleichgesinnten wahrnehmen, die bei einem ihnen ungemein wichtigen Thema an einem Strang ziehen - andere mögliche Unterschiede und Quellen etwaigen Dissenses verwischen vor diesem Hintergrund. Auf diese Weise können kollektive Erfolgserlebnisse die individuelle Selbstwirksamkeitserwartung stabilisieren, ohne dass anschließend ein Gruppenzusammenhang unter zu großen Zentrifugalstress gerät. Die Einzelnen haben individuell eine hohe Selbstwirksamkeitserwartung entwickelt, empfinden aber im Protestzusammenhang die Mitstreiter oftmals als Brüder im Geiste, die darüber hinaus im Kollektivzusammenhang diese Selbstwirksamkeit noch steigern. Zumal - zeitlich begrenzt - die Mobilisierung von Gruppen enorm hoch ist und etwaige Unterschiede an Einstellungen in anderen Bereichen leicht übertüncht werden. 


\subsection{Eigendeutungen als Generationseinheit: WAS SIND WIR FÜR EINE GRUPPE?}

In den Kommentaren und Porträts zu den deutschen Bürgerprotesten der vergangenen Jahre war oft mehr oder minder verdeckt mitgeschwungen, dass es sich um die Proteste und Einsprüche vornehmlich einer Generation handle, welche seit der Hochphase der Neuen Sozialen Bewegungen in den 1970er und 1980er Jahren die Organisation zivilen Widerspruchs geübt habe und nun, nachdem sie das Berufsleben Stück für Stück hinter sich gelassen haben, zumindest nicht mehr voll gefordert seien, ihre sozialen und ökonomischen Errungenschaften verteidigten. Die Beobachtungen zur Sozialstruktur von Protestierenden, die im Kapitel 4.1 über die hier gesammelten Interviews gemacht worden sind, oder welche von anderen Studien zu den Protagonisten der zeitgenössischen Protestund Engagementkultur herausgearbeitet worden sind, bestätigen diesen Eindruck teilweise: Teilnehmer der Jahrgänge, welche diese Phase der Bewegungen und Proteste gegen Atomkraft, die Stationierung der Mittelstreckenraketen, bis hin zu Friedensmärschen, Frauenrechten und gegen Umweltverschmutzung etc. in ihrer jungen Adoleszenz zumindest erfahren haben könnten, machen den Löwenanteil an den Aktivisten aus.

Dass dies zwangsläufig dazu führen muss, dass eine solche Prägung zu einer gemeinsam wahrgenommenen Generationseinheit führt, ist allerdings keineswegs selbstverständlich. Aus den Gesprächen geht dies jedenfalls kaum hervor. Zwar taucht der Begriff der „Generation“ im Sprachgebrauch der Aktivisten in der Selbstzuschreibung regelmäßig auf, wird gebraucht, um deutlich zu machen, dass und wie viele Menschen bestimmte Ereignisse als wegweisend für ihr Leben wahrgenommen hätten. Und natürlich tauchen die ikonischen Ereignisse der jeweiligen Alterskohorten wiederholt und oft auf, soweit sie zu einer autobiographischen Protestbegründung herangezogen werden können. Exemplarisch hier die Erinnerung von Maria C1 an den Kniefall Willy Brandts in Warschau, welcher so oder ähnlich sehr häufig in den Erinnerungen durchscheint:

\footnotetext{
„Der Kniefall von Brandt war ein ganz immens wichtiges Ereignis meiner Generation und auch der Generation meiner Eltern. Das geht einem nicht mehr aus dem Kopf, das war fällig, und äh hat eine ganz große Entlastung gebracht. [...] Es ist für mich auch das Symbol für einen grenzenlosen Optimismus, der sich in meiner Generation, jedenfalls in meinem Umfeld, gebildet hat nach dem Krieg - dass alle Menschen wahnsinnig gut sind und gemeinsam schaffen wir alles und bewältigen alles. Ja, und dass es nicht so ist, habe ich ei-
} 
gentlich erst viel später wirklich erkannt, vorher hat man sich ja leicht noch täuschen lassen. ${ }^{174}$

Die interviewten Aktivisten sind allesamt Menschen, denen das Anliegen des jeweiligen Protests ungemein wichtig ist und denen es zu einem zentralen Fixpunkt in ihrem Leben geworden ist, dem viele andere Dinge und Ansichten untergeordnet werden. Die Reduktion ihrer Beweggründe auf den Widerspruchsgeist einer Generation, die einmal erreichte Lebensstandards verteidigen und die das aufrührende Gefühl von Protesterfahrungen ihrer Jugend noch einmal erleben möchte, empfinden sie als Vorwurf, der die Legitimation ihres Anliegens unterlaufen soll - und versuchen einen solchen Eindruck dementsprechend $\mathrm{zu}$ vermeiden. Aber nicht nur aus einer einleuchtenden Verteidigungshaltung heraus wird in den Interviews zumindest stark unterstrichen, dass die Protestgruppen und Initiativen durch viele verschiedene Generationen angelegt und geprägt sind.

„Es war nie ein Thema du bist der, du bist bei denen, du bist jenes, sondern jeder hat mit dem anderen zusammen gearbeitet und für mich war das ein Riesenerlebnis, was ich in München mitgekriegt habe, wenn ich an diese Katha Schulze denke, die ja Grünenvorsitzende von München ist, die hat jeden aufgenommen, die hat mit jedem geredet, es ist eine Gemeinschaft entstanden über alle politischen Unterschiede hinweg, sondern wir haben gemerkt, wir gehören zusammen, wir haben ein Thema, wir schaffen das... ${ }^{\text {(75 }}$

Dieses Zitat eines Freisinger Protestierenden macht deutlich, wie stark die Bewegungen zur Heimat der Einzelnen geworden ist und wie sehr die Teilnahme an den Aktionen zusammenschweißt und auch zu neuen Bekanntschaften und Freundschaften führt. Diese Einbindung in eine Gemeinschaft, der man sich zugehörig fühlt, und die einem auch ermöglicht, über längere Zeit Aufgaben zu übernehmen, an Infotischen zu stehen oder Flugblätter zu verteilen, findet sich in allen Protestschwerpunkten, auch weil alle als Legitimation immer wieder die eigene Größe und Repräsentativität der Bewegung bemühen. Wir sind bedeutsam, gerade weil wir eine große gesellschaftliche Bandbreite versammeln und weil viele ganz unterschiedliche Menschen unsere Anliegen unterstützen - dieses Gefühl, Teil einer großen, wachsenden und breit ausgreifenden Protestierendenschaft zu sein, ist ein wichtiger Quell der Motivation, aus ihr ziehen die Akteure viel Legitimation für sich. Je mehr Menschen dazu stoßen und umso größere Teile der Gesellschaft ihnen Unterstützung signalisieren, desto stärker haben sie das Gefühl, nicht nur inhaltlich im Recht zu sein, sondern zudem nicht mehr

74 Maria C1 in der Fokusgruppe Stuttgart C1.1 am 20.03.2012, 17 Uhr.

75 Michel C3 in der Fokusgruppe Freising C3, 25.07.2012. 
überhört werden zu dürfen. Teil einer Bewegung einer einzigen (oder mehrerer benachbarter) Generationen zu sein, würde diesen Legitimationsweg versperren oder zumindest abschwächen. Insofern legen die meisten Gesprächspartner sehr viel Wert und Argumentationskraft darauf, zu zeigen, dass es ihnen um „Gleichgesinnte“ im Sinne gemeinsamer Anliegen und um gemeinsame Prägungen oder Lektionen geht. Und die Betonung der „Übergenerationalität“, d.h. der Vertretung vieler Altersgruppen, gehört dabei zu einem der wichtigsten Ausweise. Denn ein generationell einschränkender Hintergrund würde einen Protest wegrücken vom „objektiven“ Sachgrund, aus dem der Widerspruch hervorgeht, und diesen eingrenzen durch alters- oder formierungsbedingte Verständnisfilter.

Es ist also die wahrgenommene Gemeinsamkeit, welche die Protestierenden laut eigener Aussage zusammenschweißt. Das Protestgefühl ist ihnen der Kitt, Thema und Artikulation von Kritik und Alternative das Wichtigste. Die Altersstruktur der Gesprächspartner versperrt diesen Deutungsweg auch nicht. Wenn berufliches Selbstbewusstsein und eine sich aufbauende Selbstwirksamkeitserfahrung Protest befeuern können, liegt ein Schwerpunkt auf den ,arrivierten“ Altersgruppen auch jenseits der durch die Bürgerproteste der 1970er und 1980er direkt geprägten Kohorten nahe.

\section{Senioritätsprinzip im Protest}

Gleichwohl taucht das Thema der Generation, des Alters oder der spezifischen Erinnerung der Aktiven fortwährend in den Gesprächen auf. Da ist zum einen das Motiv des „Früher war alles besser“. Waldemar G2 etwa schildert dies folgendermaßen:

„Wie den Jungen heute die Freiräume eingeschränkt sind, da kommen die Beamten, die Grünen und die anderen Umweltschützer und wenn die so Dinge machen, ich hab da echt Mitleid mit der Jugend heute, weil die diese Freiheiten nicht mehr haben... “76

Nicht nur die Bedingungen, unter denen man lebte, werden - gerade von den älteren Aktiven - für die weiter zurückliegenden Jahrzehnte als besser, freier oder glorreicher wahrgenommen. Etwaige Proteste selbst unterlagen aus der heutigen Perspektive ganz anderen Rahmen. Eine Glorifizierung der zurückliegenden Prägungen durch frühe Protesterlebnisse findet aber auch aus einem anderen Grunde statt: Zurück liegende Erfahrungen mit Protesten sind eine Art „Währung“ innerhalb der Gruppen. Dieses Senioritätsprinzip der ProtestGlaubwürdigkeit bildet zum einen ab, dass frühe Erkenntnis und ausgeprägter

76 Waldemar G2 in der Fokusgruppe Stuttgart G2, 02.04.2012. 
Widerspruchsgeist im Heute Weitsicht, unbeugsamen Widerstand oder Eigensinn unterstreichen sollen. Wer von lange zurückliegenden Protesterlebnissen erzählen kann, beweist, dass er den roten Protestfaden anhand seiner eigenen Biographie nacherzählen kann und demzufolge „schon lange“ die Erweckung erlebt hat, dass man gegen nicht zu akzeptierende Zustände die Stimme erheben könne.

„Ja, ich glaube, wir Älteren, wir blicken einfach in einen größeren Zusammenhang, und haben auch so das Gefühl, wir müssen Verantwortung übernehmen für die, die nach uns kommen. Das spüre ich bei denen, die den Widerstand gegen die dritte Bahn jetzt aus persönlichen oder christlichen Motiven tragen. Ansonsten: Die Widerstände in den 80gern, die Demos, da war mehr Schwung dahinter, mehr Remmi-Demmi, gut, aber hier ist eben die Linie auch vernünftigerweise so: Kein Remmi-Demmi, ganz sachlich bleiben, ja das ist der Unterschied.“77

Darüber hinaus gibt es an dieser Stelle aber auch die Betonung, dass langes Protestieren nicht nur verdeutlicht, wie früh man selbst erkannt hat, welche Themen wirklich notwendig und wichtig sind, sondern durch den Protest selbst eine große und reiche Erfahrung angesammelt hat, die einen gegenüber den später dazu Gestoßenen zu einer Autorität werden lässt.

Politisches Engagement und Protest werden hier nicht (nur) als ein Metier der Gebildeten geschildert, sondern als ein Feld, auf dem man zwangsläufig Bildung anhäuft, da man sich schlau machen, Argumente suchen und formulieren müsse. Ein Großteil des Vergnügens entsteht aus diesem Gefühl: Dass man Verständnis erlangt und anhäuft über die "Gesetze der Welt", dass man meint, Funktionsmechanismen und auch Fehlentwicklungen verstehen zu können. Diese Befriedigung findet sich im Übrigen bei fast allen Interviewten und macht sicherlich einen Großteil der Faszination für die Aktiven selber aus. Sie erklärt das Überlegenheitsgefühl, welches man häufig antrifft. Dass die Aktiven eben schon lange einen Durchblick besitzen, den andere noch nicht erlangt haben, dass sie aktiv sind, weil sie „es“ schon wissen oder aber es über ihr Engagement kennen gelernt haben. In dem bereits auf S. 116 zitierten Abschnitt von Konrad C3 sind es für dieses Argument beispielsweise alternative, nicht als Mainstream verstandene kulturelle Formen wie Film, Theater, Kultur etc., denen oft ein subversives Selbstverständnis anhängt, eine Art Verständigungsmechanismus, um sich selbst zu vergewissern und um die kollektive Textur zu pflegen und zu unterstreichen.

77 Einzelinterview Bernd C5. 


\section{Das Verschwimmen der Generationen - Legitimation durch Tradition}

Auf der anderen Seite ist aber sichtbar, dass dieses Senioritätsprinzip nicht nur von den älteren Generationen für sich reklamiert, sondern oftmals auch von den „Nachgekommenen“ anerkannt wird. Wenig legitimiert in den Diskussionen so stark, wie wenn unterstrichen werden kann, dass das eigene Engagement von älteren, erfahreneren und bereits ausgezeichneten Kämpen bestätigt und gelobt wird. Die Protestgruppen als Ganzes sowie die Protagonisten individuell sehen und stellen sich in Kontinuitäten mit früheren Generationen und Ereignissen, die eine rote Linie des Protest- und Engagementverhaltens aufzeigen sollen. Damit werden die Erzählungen der ,,alten Kämpen“ zu einer wichtigen Integrationsfigur für den Protest und lassen eine scharfe Abgrenzung verschiedener Generationen in den Protestgruppen verschwimmen, weil die Jüngeren die Erlebnisse der Älteren für sich und ihr Engagement annehmen und ihre Erfahrungen für sich einspeisen. Kathleen M. Blee hat in einer Studie zu Initiativen und Protestgruppen in Pittsburgh darauf hingewiesen, dass mit der Zeit durch die eigenen Traditionsdeutungen gewisse Pfadabhängigkeiten in Protestgruppen entstehen, welche eine eigene Identität erst entstehen lassen, gleichzeitig aber viele möglichen Entscheidungsoptionen ausschließen. Routinen und Erfahrungen, die nun als „Wahrheiten“ innerhalb der Gruppen anerkannt werden, lassen andere Argumente und Sichtweisen (und jene, die sie vorbringen) außen vor. ${ }^{78}$ Dass darüber hinaus der lokale Anlass von Initiativen das Herausarbeiten einer vermeintlich spezifischen Identität erleichtert, wird bei den untersuchten Gruppen an vielen Stellen sichtbar.

In Stuttgart gibt es etwa Bahnhof und Schlosspark als „Wahrzeichen“ Stuttgarts, in denen sich auch ein spezifisches städtisches Selbstbewusstsein ausdrückt: „umbilicus sueviae“ - „Nabel von Schwaben“ - so nannte sich der Entwurf des 1928 fertiggestellten Baus unter der Leitung des Architekten und Namengebers Paul Bonatz. ${ }^{79}$ Der jahrhundertealte Schlossgarten wird als zentraler Bestandteil der Stuttgarter Stadtgeschichte empfunden. ${ }^{80}$ Diese beiden Orte gehören für die Stuttgarter zum Nukleus eines stadtbürgerlichen Selbstbewusstseins, sodass sich - wie nun ab 2008 im Falle der Proteste - gleichsam natur-

78 Vgl. Blee: Democracy in the Making, S. 135.

79 Vgl. Roser, Matthias: Der Stuttgarter Hauptbahnhof. Ein vergessenes Meisterwerk der Architektur, Stuttgart 1987.

80 Vgl. John, Timo: Die königlichen Gärten des 19. Jahrhunderts in Stuttgart. Schlossgarten, Rosenstein, Wilhelma, Villa Berg, Worms 2000, S. $11 \mathrm{ff}$. 
wüchsig eine Welle des Widerstands erheben sollte, wenn diese bedroht seien. Eine ähnliche Rolle wird den Demonstrationen und Ausschreitungen um den Kraftwerksbau in Whyl zugesprochen. Auch in Hamburg wird immer wieder Bezug genommen auf die Hausbesetzungen der Hafenstraße in den 1980er Jahren, um zu zeigen, dass man sich in eine Traditionsreihe stellt - im Übrigen von Aktiven der damaligen Aktionen ebenso wie von danach Hinzugezogenen. Dies wird zum Teil noch weit verlängert, so dass die proletarischen Widerstandstraditionen in den Hamburger Arbeitervierteln in den Jahren nach 1918 herangezogen werden, um zu zeigen, dass der Protest seine Legitimation eben nicht nur aus kurzfristigen Ereignissen oder Gegebenheiten ziehe, sondern tief in der lokalen Koloratur eingefärbt sei.

Auch in München wurde bereits ab Mitte der 1950er Jahre eine Lösung gesucht, den alten Stadtflughafen ins Umland auszugliedern - der Protest gegen den 2012 zur Entscheidung anstehenden Bau einer dritten Startbahn des Flughafens im Erdinger Moos nördlich von München artikuliert sich folglich in einer Region, die auf eine gut fünf Jahrzehnte lange Geschichte der Flughafengegnerschaft zurückblicken kann. Dies wird in Gesprächen immer wieder verdeutlicht gerade von Protestteilnehmern, die nicht gebürtig aus Freising und der Umgebung stammen, sondern in eine Protesttradition hineingezogen sind:

„Du kommst hier in eine Tradition, [...]da war hier eine große Sensibilität für das Thema und ich hab irgendwann relativ schnell begriffen: Ich komm um das Thema Flughafen nicht rum. Ich muss mich damit beschäftigen, ich muss mich dem stellen. ${ }^{\star * 81}$

Analog zum betrachteten Hamburger Beispiel der Konflikte um die Stadtgestaltung geht es in Freising um einen Protest, der viele Erzählstränge aus der eigenen Vergangenheit wieder aufgreift und neu miteinander verknüpft. Fragen der Anwohnerumsiedlung, des Umweltschutzes wie der zumutbaren Lärmbelästigungen und ganz generell das Verhältnis einer Obrigkeit zu ihren Bürgern verschmelzen im Fokus der Proteste. Ganz unterschiedliche Begründungen und Motivationen können darin verschränkt werden, von denen viele aus der jüngeren bayrischen Geschichte auf eine besondere Sensibilität treffen. So etwa äußern viele Teilnehmer in den Gesprächen, gerade Tschernobyl ${ }^{82}$ und der heimlichtuerische Umgang der Institutionen mit der tatsächlichen Strahlenbelastung sowie

81 Einzelinterview Bernd C5.

82 Vgl. hierzu exemplarisch Böllmann, Ulrich: Auswirkungen des Reaktorunfalls in Tschernobyl auf Bayern, München 1988. 
das nahe Erleben der Waldschäden im Bayrischen Wald ${ }^{83}$, wo sich die sauren Niederschläge besonders verheerend ausgewirkt hätten, seien für sie Initialzündungen für ein Interesse an umweltpolitischen Fragen gewesen:

„Weil ich im Bayrischen Wald das erlebt habe, was Luftveränderungen bedeuten können. Für die Natur an dieser Stelle, für die Schöpfung, das war ja lang vor Tschernobyl schon. ${ }^{* 84}$

Die Frage der Generation spielt in den Gesprächen insofern nicht die Rolle eines Trennstriches, mit der verschiedene Einflüsse und deutlich andere Herangehensweisen voneinander getrennt werden können. Sie spinnt aber den Gedanken des graduellen Aufbaus von Selbstwirksamkeitserwartungen fort. Das angesprochene Senioritätsprinzip im Protest drückt dies für die Selbsterzählung über die Generationen aus: Wer schon lang dabei ist, hat zum einen mehr Erfahrung und macht zum anderen deutlich, dass er schon länger verstanden hat, was schief laufe in unserer Gesellschaft.

Die Betonung von Traditionslinien ist vielleicht gerade für die hier beobachteten Protestgruppen von immenser Bedeutung, da sie - anders als bereits stärker etablierte politische Bewegungen wie Parteien - noch nicht über eingefahrene, bestätigte Selbsterzählungen und kollektive Texturen verfügen. Diese müssen also im gemeinsamen Handeln immer wieder herausgestrichen werden, was durch Sprecher, die ein reiches Reservoir anknüpfungsfähiger Erzählungen besitzen, eher bewerkstelligt werden kann. Ein Ineinanderfließen der möglicherweise trennenden Generationsprägungen geschieht dabei, weil diese Erzählungen von nachfolgenden Generationen dankbar und gerne zur Selbstlegitimierung herangezogen werden, da (noch) kein über viele Perioden organisatorisch verfestigter, bewährter Protestkonsens vorliegt.

Natürlich fällt auf, dass es hierbei um konkret an das jeweilige Protestthema angebundene Ereignisse und Erzählungen geht, nicht um mögliche, ganz individuell prägende Ereignisse, die mit dem heutigen Thema des Engagements wenig zu tun haben. Die Aktivisten aus dem Kreise bayrischer Naturschützer erzählen vom sauren Regen und Tschernobyl in den 1980ern, die Hamburger Stadtaktivisten von der Hafenstraße bzw. von den kommunistischen Traditionen der Selbstorganisation in den Arbeitervierteln. Die erinnerten Prägungen werden in den Gesprächen selektiv für die heute bedeutsamen Themen umfunktioniert und an-

83 Vgl. hierzu die Analyse der wohl spezifisch deutschen Affinität zum Thema durch Radkau, Joachim: Die Ära der Ökologie. Eine Weltgeschichte, München 2011, S. $229-241$.

84 Theodor C3 in der Fokusgruppe Freising C3 am 25.07.2012. 
gepasst - werden strategisch zur Präsentation genutzt. Was aber vielleicht für den sozialwissenschaftlichen Kontext zur Frage nach generationellen Prägungen im Protest daraus als Lehre gezogen werden kann, ist, dass zum einen der Charakter von Selbstwirksamkeitserfahrungen - wie im vorhergehenden Kapitel entwickelt - ein sich dynamisch aufbauender ist, sich also mit weiter zu gebenden (Protest)Erfahrungen steigert. Und dass, zweitens, Handelnde mit einem Grundfundament an diesen Selbstwirksamkeitserfahrungen in der Lage sind, ermutigende Erlebnisse auch thematisch so zu verarbeiten und umzuwandeln, dass sie nicht als spezifisches Selbstbewusstsein eine besondere Fähigkeit, sondern als allgemeine Selbstwirksamkeit ein Engagement unterstützen. Auf diese Weise können dann Proteste aus der Geschichte der Bundesrepublik über die begrenzten Kreise der tatsächlich Beteiligten Selbstwirksamkeitserwartungen über Generationen hinweg befeuern.

\title{
Motivationen älterer Protestgenerationen
}

Doch unterscheiden sich in den Gesprächen Motivationen zum Protest durchaus zwischen den Jahrgängen. Ohne die individuellen Antriebe der Aktiven allein durch ihren Geburtszeitpunkt erklären zu wollen, gibt es Anhaltspunkte, die ein Engagement in einer Protestinitiative bei denjenigen Generationen plausibler erscheinen lassen, die der Charakterisierung eingangs dieses Kapitels entsprechen: diejenigen, welche bereits in das fünfte Lebensjahrzehnt und darüber hinaus eingebogen sind.

Das Gefühl, auf eine diffuse Art und Weise von einem „Wert“ angetrieben zu sein, dessen Verwirklichung einem zentral und bedeutsam ist, äußern fast alle Interviewten, unabhängig vom Alter. Es lässt aber aufhorchen, dass etwa die Akzentuierung des Werts „Freiheit“ mit steigendem Alter sichtlich zunimmt, und dies über die politisch üblichen Deutungsrichtungen hinweg.

\begin{abstract}
„Also insofern ist es eben nie das einzelne Thema gewesen, aber dieses Prinzip, das habe ich, fand ich bis heute spannend und finde ich bis heute unverändert spannend und ist auch das, was mich antreibt, [...] und zwar jetzt nicht, weil ich es theoretisch spannend finde, sondern, weil ich es eben zutiefst, ja, es ist ein Freiheitsprinzip, es treibt mich wirklich. Wenn ich sage, die Welt ist lebenswerter, wenn sie mehr Freiheit hat. Ja. ${ }^{\text {(85 }}$
\end{abstract}

Die Freiheitsbetonungen als Motivationen werden oft mit dem Bestreben nach einem persönlichen Unabhängigkeitsbeweis verbunden. „Frei“ sein heißt hier, sich nicht nach der vermeintlich verdorbenen Räson von Politik, Wirtschaft oder

85 Einzelinterview Achim G3. 
Marketing zu richten, sondern zu unterstreichen, dass man unabhängig und nach seinen ,eigenen“ Werteprinzipien in der Lage ist, zu entscheiden und zu handeln. Fred G5, Wirtschaftswissenschaftler, macht dies für sich deutlich:

„Genau, die sind alle noch so in den 40ern. Wollen irgendwann vielleicht mal ein dickes Projekt haben oder in den Rat der Weisen berufen werden und so weiter. Das heißt, die Kollegen, die wirklich Tacheles reden, das sind eher die wie ich. Ich bin 63 und will keinen Ruf mehr haben. Ich will auch keinen Regierungsposten. Ich kann nur sagen, was ich denke und sie werden also sehen, dass das Durchschnittsalter der Leute, die bei mir unterschrieben haben (eine Petition, Anm. F.B.), höher ist als bei den anderen. “ 86

Die Argumentation und Begründung für den Ruf nach politischen Seiteneinsteigern als Mittel gegen Parteien- und Politikverdrossenheit ist interessanterweise oftmals ganz ähnlich: dass man politische Entscheidungen treffen könne, ohne aber den eingefahrenen Denkpfaden und Korrumpierungsversuchungen in der Parteienpolitik verfallen zu müssen, da man als beruflich spezialisierter und erfahrener Nichtpolitiker nach anderen Maßstäben und Werten handeln könne. ${ }^{87}$ Diese Unabhängigkeit im Denken und Handeln nehmen auch die meisten der Gesprächspartner für sich in Anspruch. Die Betonung von Unabhängigkeit und auch das Selbstbewusstsein, mit dem das eigene Freiheitsideal postuliert wird, nehmen allerdings mit dem Alter zu, weil mehr Lebens- und berufliche Erfolgserfahrungen zur Begründung herangezogen werden können. Hier kommt das "professionelle" Motiv beruflicher Erfahrungshintergründe zusammen mit dem Alter und mündet ergo in eine große gefühlte Unabhängigkeit, zusammen mit dem Bewusstsein, fachlich versiert zu sein und den entsprechend verantwortlichen Politikern hoch überlegen zu sein, was die Urteils- und Überblicksfähigkeiten anbelangt. Diese Art Unabhängigkeit wird mitunter wie eine Trophäe vor sich her getragen: Niemand kann mich unter Druck setzen! An dieser Stelle werden im Selbstbild die Protestierenden zu unkonventionellen politischen Seiteneinsteigern, die den Wunsch nach anderen und anders begründeten Entscheidungen in Politik und Gesellschaft symbolisieren und fordern wollen.

Dies ist allerdings nicht nur vor dem Hintergrund einer überaus erfolgreichen professionellen (wie finanziellen) Karriere o.ä., anzutreffen, welche ein überbor-

86 Einzelinterview Fred G5.

87 Vgl. zu diesem Thema zusammenfassend Lorenz, Robert / Matthias Micus: Von Beruf: Politiker. Bestandsaufnahme eines ungeliebten Stands, Freiburg i. Br. 2013, S. 52 - 81; sowie grundlegend Dies.: Politische Seiteneinsteiger - Exoten in Parteien, Parlamenten, Ministerien, in: Dies. (Hrsg.): Seiteneinsteiger. Unkonventionelle Politiker-Karrieren in der Parteiendemokratie, Wiesbaden 2009, S. 11 - 30. 
dendes Selbstbewusstsein hat entstehen lassen, sondern auch Ergebnis eines Gefühls, das sich aus einer ganz praktisch orientierten Lebensperspektive speist: Viele Argumentationen und Rechtfertigungen in den Interviews gerade mit den älteren Protestgenerationen haben einen Bezug zur eigenen Lebenspraxis beziehungsweise zu der Tatsache, dass die Aktiven sich als praktisch erfahren begreifen. Dies reicht vom zitierten Wirtschaftswissenschaftler bis hin zum Engagement von Großeltern für eine bessere Bildung ihrer Enkel. Ihre gefühlte Einsicht und Lebenserfahrung - und auch eigene Nachkommen, Kinder und Enkelkinder - lassen das Gefühl stark hervortreten, auch für zukünftige Generationen verantwortlich zu sein, da sie vieles anders, vermeintlich distanzierter und möglicherweise erfahrungsgesättigter beurteilen können:

„Für mich ist es Verantwortung kommenden Generationen gegenüber - was sehr mächtig klingt. Aber jetzt sowohl in meinem Umweltengagement als auch jetzt hier bei Stuttgart 21 mache ich mir immer wieder die Ausweglosigkeit für spätere Generationen klar. ${ }^{488}$

Und Rüdiger C1 sekundiert im gleichen Gruppengespräch:

„Die Weltenrettung war auch nicht unbedingt mein Motiv, aber wenn mich was interessiert, dann knie ich mich in die Thematik rein. [...] Ich habe eins gelernt in meinem Leben: Ich höre auf Menschen die in ihrem Beruf, in ihrem Wirkungsfeld eine Erfahrung eingesammelt haben. ${ }^{\text {8 }}{ }^{9}$

Insofern darf man sich die hier skizzierten älteren Protestgenerationen nicht nur als ein Phänomen äußerst erfolgreicher Aufsteiger vorstellen, die nun ihren gewachsenen Selbstwirksamkeitserwartungen umsetzen und weiter pflegen möchten. Dies ist zwar durchaus häufig zu finden. Ein Selbstbewusstsein über die eigene Lebenspraxis kann aber auch die Großmutter erreichen, die sich aus ihrer Erfahrung, mehrere Kinder großgezogen zu haben, nun ein dezidiertes Urteil über die schulische Betreuung ihrer Enkel zutraut und mittels Einspruch dieses dann einfordert.

„Aber die Großeltern, die waren durch die Enkel wieder persönlich betroffen, hatten auch vieles oft persönlich erlebt, weil die sich ja oft sehr stark kümmern, weil sie zum Beispiel Kinderbetreuung machen. So es war bei meinen Eltern auch intensiv so. Die waren also wieder viel mehr im Schulthema drin und wussten eigentlich auch viel mehr darüber wie

88 Olaf C1 in der Fokusgruppe C1.1 Stuttgart am 20.03.2012, 17 Uhr.

89 Rüdiger C1 in der Fokusgruppe C1.1 Stuttgart am 20.03.2012, 17 Uhr. 
das so tatsächlich läuft, als so andere Leute die entweder noch keine oder keine Kinder in dem Alter mehr hatten und so. Und die haben sich uns auch stark angeschlossen. “90

Auffällig ist dabei, dass dieser Art Vertretungsanspruch auch durchaus ein der Repräsentanz ähnliches Denkmuster beinhalten kann, welches bisweilen ins Bevormundende spielen kann. Insofern ist das Gleichgewicht der Generationen innerhalb der Gruppen streckenweise ein fragiles. Das Gefühl jedenfalls, besser als andere Überblick, Einsicht und Lösungsrezepte zu besitzen, ist für die Diskussion demokratietheoretischer Implikationen von Bürgerprotesten zu beachten.

Ein weiteres Phänomen, welches eine Beteiligung und einen persönlichen Bezug für Ältere erleichtert oder wahrscheinlicher macht, ist der örtliche Bezug vieler Themen und Auseinandersetzungen wie auch der Protestbündnisse. In der Perspektive auf sich selbst nehmen die älteren Aktiven in den Gesprächen in Anspruch, mit ihrem Lebensort schon via größerer Beständigkeit und Dauer der Wohnverhältnisse eine innigere Beziehung zu ihrem Umfeld sowie umfangreichere persönliche Netzwerke vor Ort aufgebaut zu haben und dieser Örtlichkeit somit stabiler verbunden zu sein als dies bei Jüngeren als Motivation für ein Engagement durchscheint. Zwar weisen alle Protestfelder über den konkreten Ort hinaus und fassen höhere Ebenen der Gesellschaft ins Auge - sie entzünden sich aber oftmals an einer lokalen Symbolik und werden dadurch greifbar.

„Ich denke, das ist auch kein Wunder, weil die Älteren wissen, in welchem Kontext Leben geschieht und eine größere Betroffenheit haben jetzt als junge Leute, die sagen: Boah, Freising boomt, und hier geht's ab, hier können wir leben und arbeiten und das ist eigentlich ganz schön. “91

Hier wird deutlich, dass es mit Bezug auf die eigene Stadt oder Heimat unter diesen lang Ansässigen einen stillschweigenden Konsens darüber bereits gibt, was diese Textur der Heimat konkret bedeutet und wie sich das anfühlt. Ein solches Webmuster, welches dann auch mit vielen persönlichen Beziehungsnetzwerken verbunden ist und das als sublimes Selbstverständnis in Teilen unreflektiert handlungswirksam werden kann, entsteht über die Dauer langer Jahre und ist demzufolge eher denjenigen zugänglich, die eine Entscheidung über einen Lebensanker und -ort bereits getroffen haben, die das Postulat beruflicher Mobilität nicht mehr für allzu stark beachten müssen.

90 Einzelinterview Diana E3.

91 Einzelinterview Bernd C5. 
„Ich glaube, weil es eben eine ganz alte linke Kultur in Hamburg gibt, die halt an vielen Stellen schon versucht hat, was zu erreichen und weil das Gängeviertel als Beispiel für diese Art proletarische Stadtbebauung oder so eben so einzigartig mittlerweile geworden ist in Hamburg und weil dieser Lokalpatriotismus oder dieser Wunsch, einen Teil des alten Hamburg zu erhalten, einfach sehr weit verbreitet ist. Also von äh von ganz tief in die linke Szene rein bis hin zu ganz bürgerlichen Kreisen ist eben diese Hamburger Arbeiterromantik irgendwie schon äh auch eine ganz emotionale Sache in dieser Stadt. [...] Na, und da haben die Leute einfach gute Vorabreit geleistet und unheimlich viel Leute angesprochen und sich unheimlich viel Know-how angeeignet. So die Kernzelle und ähm was man dann noch brauchte war schnell gefunden. Und gab dann auch ganz viele Leute die Gesagt haben, ich kenne da jemanden, ich frage den mal und haben wir halt ganz schnell Netzwerk gehabt und wir arbeiten mit ein, zwei, vielleicht drei Juristen zusammen.“92

\subsection{Endiche Reserven: Zeit- und Kraftaufwand VON PROTEST}

Dass Protest und Engagement Zeit und Energie kosten, bisweilen so viel, dass nur wenige dazu in der Lage oder bereit sind, darauf ist zu Beginn dieses Kapitels schon hingewiesen worden. Und in den Gesprächen mit den Aktiven findet sich diese anstrengende, aufreibende Seite des Einmischens an vielen Stellen wieder: Die Entscheidung für eine Mitarbeit in einer Protestgruppe hat für viele der Interviewpartner ihr Leben einem neuen Thema untergeordnet, welches nun - zumindest in Hochzeiten der Aktivität und des Protestzyklus - Denken und Handeln dominiert. Dass eine solche, bisweilen fast monothematische Ausrichtung auf ein Ansinnen nicht zu jedem Punkt eines Lebens möglich ist, erscheint intuitiv einleuchtend und wird durch die sozialen und generationellen Profile der hier versammelten Aktiven widergespiegelt. Viele Erzählungen deuten darauf hin, dass sich ihre Engagements beziehungsweise die Hochzeiten der ProtestEinbindung auf Lebensperioden konzentrieren, die Zeit und Kraft lassen und in denen sie nicht durch anderes gebunden sind.

„...ich war dann erst einmal arbeitslos und habe dann aber, jetzt, also das war halt mein Ding[...]. Also das ging direkt los so und das war halt alles ehrenamtlich, da habe ich kein Geld bekommen oder so, aber ich habe mich halt voll da reingehangen. Ich engagiere mich hier, [...] gut, ich kriege das Geld jetzt vom Staat, okay, aber ich mache halt auch etwas damit und ja, ich habe dann einfach in der Zeit mich auch gar nicht für Architekturbü-

92 Einzelinterview Frederik C1. 
ros oder irgendetwas beworben, sondern habe mich einfach voll reingehangen so, und also das war wirklich von, auch vorher schon, das wurde dann immer mehr.“93

Diese Beschreibung von Protestierern mit einem Zeitüberschuss mündet rasch in ein Klischee vom rüstigen Rentner, der als Skizzenbild den Wutbürger in der öffentlichen Diskussion der vergangenen Jahre ausmacht und bereits aufgegriffen worden ist. Doch die Betonung, dass man erst Luft für Empörung spürt, nachdem die Kinder der Familie nicht mehr stark betreuungsintensiv die Lebenskräfte binden und erst nachdem die berufliche Etablierung nicht mehr sämtliche Energien absorbiert, kann aus den Interviewsequenzen oft und breit herausgelesen werden.

„Ich bin berufstätig gewesen mein ganzes Leben lang, ich war Beamtin beim Vater Staat, hab in der Zeit auch vier Kinder groß gezogen - erfolgreich, muss ich sagen - und hab leider in der Zeit mich zwar bei allen möglichen Sachen engagiert, also Elternvertretung und was man - was dann so ankommt, wenn man Kinder hat, aber eigentlich keine Zeit gehabt, mich ernsthaft persönlich für Politik zu engagieren. Nicht zu interessieren, sondern zu engagieren. Interessiert hab ich mich immer, schon seit meiner Schulzeit. Nur, wie dann meine Kinder aus dem Haus waren und ich so langsam auf das Rentenalter zugegangen bin, hab ich gesagt: Eigentlich darf man nicht bloß immer meckern und sich beschweren über Parteien und müsste eigentlich selbst auch was machen.“94

Gleichwohl bleibt der Protest kein Betätigungsfeld von Menschen, denen langweilig ist und die nun für überschüssige Energie einen plaisierenden Abfluss suchen. Denn im Selbstbild derjenigen Aktiven, mit denen Gespräche geführt werden konnten, befinden diese sich gleichwohl in einem nahezu permanenten $\mathrm{Zu}$ stand des Zeitmangels und der Erschöpfung. Das auch in dieser Arbeit bereits oft bemühte Bild des Kampfes David gegen Goliath führt dazu, dass Protest niemals genug sein kann und eine Dynamik annehmen kann, die ein immer stärkeres Engagement der Einzelnen innerhalb ihrer Gruppen erfordern. Es ist eine Logik des „,immer weiter!“, gerade wenn eine gefühlte Erfolgsdynamik den Engagierten suggeriert, dass ihre Anstrengungen Wirkung zeitigen. Das Lamento jedenfalls, nie über genug Zeit und Energie zu verfügen, um dem eigenen Ansinnen und Ziel ernsthaft gerecht werden zu können, zieht sich wie ein roter Faden durch die Gespräche.

93 Einzelinterview Axel G4.

94 Anna G1 im Einzelinterview G1 Anna und Conrad. 
„Da brauch ich wieder ein paar Tage, um das quasi in mir zu beruhigen und wieder so ein bisschen Vertrauen in das Leben an sich zu gewinnen und dieses Gefühl los zu werden, ich muss schon wieder, ich müsste alles gleichzeitig, geht nicht. Das weiß ich. Ich also muss also irgendwie so eine Art professionelle Work-Life Balance herstellen. Ich mag all diese Begriffe auch nicht. Ich möchte wieder menschlich reden und nicht technokratisch. Also ich muss mich auch mit mir selbst befassen und mit meiner Gesundheit psychisch und physisch und in jeder Hinsicht und trotzdem kann ich diese Verantwortung nicht loswerden. Ich fühle mich damit verantwortlich. Ich stecke irgendwo und glaube auch daran, dass, wenn jeder an seinen Platz etwas tut, dass dann einfach ein Sandkorn kein Sandkorn mehr ist sondern der Strand wird.“95

Manuela C3 fasst dieses Gefühl ganz ähnlich zusammen. Eine Art permanentes schlechtes Gewissen, welches entsteht, weil man immer noch mehr, kontinuierlicher oder intensiver der Sache dienen könnte - und es im Angesicht als übermächtig wahrgenommener Gegner nie zu viel wäre.

„Und seit dem ich da dabei bin, denke ich mir fast jeden Tag „mein Gott, jetzt musst du zu der Veranstaltung und zu der Demonstration!“ Und wann sollte ich eigentlich Arbeiten und mein Geld verdienen und das machen eigentlich unsere gewählten, politischen Vertreter? Ich weiß nicht, es ist fast jeden, zweiten, dritten Tag irgend eine Meldung, wo man sich aufregen kann und sagen, das wollen wir als Volk doch eigentlich gar nicht [...] Also, ich bewundere jeden, der sich politisch engagiert auch ehrenamtlich und hier ist finde ich auch ein großartiges Beispiel über so lange Zeit. Aber wie sollen wir uns das wirklich leisten, wenn wir nebenbei Familie haben, Arbeit haben und so weiter, wie sollen wir dann die politische Arbeit auch noch leisten? Also, das ist für mich manchmal eine völlige Überforderung und wenn dann in der Familie jemand krank ist, wie bei mir letztes Jahr, dann fliegt man eben da raus, wo man dann gerne helfen möchte. Man kann sich nicht vierteilen und da merke ich schon, wie anstrengend das eigentlich auch ist und wie gerne ich an verschiedenen Bereichen mitmachen will und mir denke „Hoffentlich kommt da jemand anderes und macht das!“. Man kann sich wirklich irgendwie, manchmal könnte man sich zerreißen. “96

Viele Äußerungen deuten darauf hin, dass es den hier versammelten Aktiven bisweilen schwer fällt, mit dem Engagement in Verbindung stehende Aufgaben abzulehnen, sich aus der kleinen Protestgruppe zurückzuziehen - und auf diese Weise die Mitstreiter alleine zu lassen. Es sind Schilderungen und Erfahrungen von Menschen, die sich rasch und leicht für eine Sache begeistern lassen und die

95 Einzelinterview Lena E6.

96 Manuela C3 in der Fokusgruppe Freising C3 am 25.07.2012. 
anschließend dazu neigen, nicht mehr gut „Nein“ sagen zu können, weil sie sich in der Verantwortung sehen. Eine zeitliche und energetische Überforderung ist an dieser Stelle oft nicht mehr weit.

„Naja, also die, ja also bei mir ist das so ich habe die letzten drei Jahre an meiner Doktorarbeit geschrieben, ein Stipendium an der (unv.) Stiftung gehabt und es wäre jetzt ausgelaufen so, ich bin aber noch nicht fertig und werde jetzt Ende des Sommers irgendwie fertig, das ist jetzt mein Plan... [...] wie gesagt, ich habe jetzt auch fast das komplette letzte halbe Jahr nichts gemacht dran, so, weil ich bei Attac viel gemacht habe und dann halt, was weiß ich, bei diesem Occupy-Umfeld halt ein bisschen, das sind immer so kleine Sachen [...]. So, also da läuft immer viel, das ist ein Problem von mir, also ich kann das immer schlecht trennen, ich müsste die Doktorarbeit fertigmachen und alles andere sein lassen erst mal, einfach mal ein halbes Jahr nichts anderes machen... “97

Aus den Erzählungen erwächst vielerorts ein Bild, welches den eigenen Werdegang innerhalb der Protestgruppe als einen Prozess des „Übrigbleibens“ unterstreicht, nachdem andere doch wieder ausfallen, nicht mehr mitmachen oder sich zurückziehen.

„Hennar E7: Man muss immer einen Vorschlag haben, ne, sonst läuft nichts, ne. Und dann musst du auch selbst vorne an der Front stehen. Das war ja das enttäuschende, was ich erlebt habe.

Interviewer: Sie glauben, es hat sich eher zugespitzt auf eine Person immer?

Hennar E7: Ja, das lag aber nicht an mir. Alle anderen wollten einfach nicht, die - da waren keine da. ${ }^{\text {‘98 }}$

Gleichzeitig wird aber der Ausweis, bis zur persönlichen Erschöpfung für ein hehres Ziel zu kämpfen und für das empfundene Gemeinwohl einzusetzen, zu einer starken Quelle des Stolzes und eines Führungsanspruchs innerhalb der Gruppen. Wer mehr Zeit investiert, betrachtet den Protest und auch einen möglichen Erfolg oder Misserfolg stärker mit der eigenen Person verknüpft, hat oft mehr Herzblut, Schweiß und oftmals auch finanzielle Ressourcen eingesetzt und erwartet dann auch Mitsprache und Einfluss. Krafteinsatz führt auch zu Positionserwartungen innerhalb der oftmals fluiden und wechselnden Gruppenstrukturen.

Gerade die Ausformung, Sicherung und Festigung der informellen Hierarchiestrukturen innerhalb der Gruppen wird aber wiederum als kraftraubend emp-

97 Einzelinterview Axel G4.

98 Einzelinterview Hennar E7. 
funden, da es oftmals wenig eingefahrene und erprobte Mechanismen gibt, die Aufstiegswege und Führungsansprüche bestätigen. Die meisten Gruppen können nicht auf formal ähnlich fein geästelte und unangefochtene Strukturen zurückgreifen, wie dies bei politischen Parteien und gesellschaftlichen Großorganisationen der Fall ist. Insofern ist der persönliche Krafteinsatz - und damit die Einsatzfähigkeit eines Protestierenden - sowohl Währung als auch unmittelbare Voraussetzung, um in einer Gruppe eine führende Position zu übernehmen. Auf der anderen Seite mag dies aber dazu führen, dass Gruppen unter hohem Problemdruck, wie etwa dem Anberaumen eines Volksentscheides, gut und reibungslos funktionieren, aber nach Abarbeiten eines Ansinnens, ob mit Erfolg oder Misserfolg, die informelle Gefolgschaft aufbrechen muss - dass sich Autorität dann zersetzt bzw. im Angesicht anderer Themen und Herausforderungen nach neuen Quellenkonstellationen umsieht.

„Einfach durch Zeitaufwand, ich hab extrem viel Zeit eingesetzt und hab also dann, war also immer, wenn es darum ging, wer was macht, hab ich dann da mitgemacht und am Ende waren es eben auch nicht so viele, die diesen Zeitaufwand betreiben konnten und dadurch hat sich das von alleine so mehr oder weniger entwickelt. ${ }^{\text {“99 }}$

Zeitaufwand von Protest speist eine individuelle Wirkungserwartung, das wird aus den Gesprächen deutlich. Es ist nicht nur ein ungerichtetes Mitmachen, was in den Gesprächen mit den Aktiven plastisch hervortritt, sondern aus dem Gefühl, Lebenszeit und Anstrengung auf ein Thema zu verwenden, geht sowohl mit Bezug zur Gruppe als auch mit Blick auf die Auswirkungen des eigenen Handelns die Erwartung hervor, etwas zu bewirken. Dass man selbst mit seiner Aktivität für eine Gruppe fast unverzichtbar geworden ist, wird zwar von einigen Aktiven problematisiert, gleichzeitig aber als Ausweis und Betonung der eigenen Fähigkeiten stolz unterstrichen.

\begin{abstract}
„Nun sind wir zum Glück ja so eine große Gruppe, dass man davon ausgehen kann, selbst wenn es komplett kollabiert, bleibt immer noch was über. Ähm und das ist, glaube ich, ganz gut und wichtig, dass dieser Spielraum da ist. [...] jetzt es gibt ein paar Leute, da wäre es wirklich fatal wenn die sich jetzt komplett abmelden würden, weil die halt so viel auf ihre Schultern geladen haben. Aber daran arbeiten wir auch die ganze Zeit. “ ${ }^{100}$
\end{abstract}

Versiegende Quellen werden von den Aktiven allerdings vorausgesehen, gerade mit Bezug auf jüngere Protestierer:

99 Einzelinterview Emma E2.

100 Einzelinterview Frederik C1. 
„...lass ihn mal Frau und Kinder haben, er hockt ja vorm PC, Du kannst im Facebook was schreiben, Tag und Nacht, egal, ich steh immer sehr früh auf und der antwortet Dir was. Lass ihn mal Frau und Kinder haben, dann nimmt das mit dem Informiert-Sein und mit der Partizipation schlagartig ab.“101

Nicht zuletzt aber lässt das Wissen um die eigenen individuellen und kollektiven Anstrengungen auch unabhängig vom Ausgang einen großen Stolz entstehen, der sowohl das Aus- und Durchhalten erleichtert wie auch die Faszination einer Protestdynamik unterstreicht. Emma E2 resümiert dies mit pathetischer Stimme:

„....wann immer ich damit hadere, dass ich da drei Jahre meines Lebens mehr oder weniger mit verschwendet habe, [...]bin ich gleichzeitig froh, einmal dass wir das erreicht haben, aber nicht nur das, [...] das ist mir ganz wichtig, nämlich, dass wir auch aus Hamburg heraus die Botschaft gegeben haben, egal wie man dazu steht, wie der Volksentscheid ausgegangen ist, aber dass es möglich ist, als Bürger so einen Volksentscheid in Gang zu setzen und am Ende eine Entscheidung gegen so ein Kartell durchzusetzen. Dass sich sozusagen hier eine bürgerliche, im Sinne von Bürger, nicht im Sinne von politisch ausgerichtet, sondern von Bürgern auf der Straße, Bewegung, gegen das Establishment durchgesetzt hat. Also ich finde das ist eine ganz tolle Botschaft. “102

\subsection{Die Grosse Frage: Warum mache ICH DaS EIGENTLICH?}

In der Folge „Der Hammer“ der bekannten Krimiserie „Tatort“, welche am 13.04.2014 in der ARD gesendet wurde, geht es um den Protest gegen den Bau eines großen Wellness- und Bordellbetriebs in einem Wohnviertel, aufgrund dessen viele Häuser in der Umgebung ihren Verkaufswert einbüßen. ${ }^{103}$ Eine wütende Protestbewegung aus Münsteraner Anwohnern will dieses verhindern, und der zuständige Kommissar Thiel hat einen Mörder zu finden, welcher nach und nach Bauherren und -dezernenten zur Strecke bringt. Diese Protestbewegung wird im Film als eine Gruppe dargestellt, die rasch über das eigentliche Protest-

101 Waldemar G2 in der Fokusgruppe G2 Stuttgart am 02.04.2012.

102 Einzelinterview Emma E2.

103 Vgl. Buß, Christian: Jubiläums-,,Tatort“ aus Münster: Schädel zertrümmert, Krimi gerettet, in: SpiegelOnline, 11.04.2014, online einsehbar unter: http://www.spiegel. de/kultur/tv/tatort-muenster-der-hammer-mit-jan-josef-liefers-und-axel-prahl-a-9619 16.html [zuletzt eingesehen am 15.04.2014]. 
thema hinaus Gefallen am Beisammensein findet und innerhalb derer Menschen aufblühen, neue Lieben finden und ganz und gar in ihrem „Widerstand“ aufgehen. Der ältliche Vater des Kommissars gar, ein oft auftretender Nebendarsteller der ostwestfälischen Ausgabe der Serie, bandelt glücklich mit einer ebenso von Empörung über den Bordellbau beseelten jungen Frau an, die seine Tochter sein könnte, und entwickelt dabei ein Aktivitätsniveau, welches ihm sein Sohn schon aufgrund seines mittlerweile leicht gebrechlichen Zustandes kaum mehr zugetraut hätte.

Der Film greift dabei mit feinen Antennen Szenen auf, die in den letzten Jahren auf den Bahnhofsplätzen von Stuttgart oder anderen Großdemonstrationen in ähnlicher Form zu beobachten waren: Versammlungen wütender, aber auch glücklicher Menschen. Und in der Tat liegt die Vermutung nahe, dass Protest und Widerstand neben aller Entrüstung und Unmut auch eine Befriedigung mit sich bringen müssen, um es Menschen zu ermöglichen, Zeit und Kraft zu investieren, um mit Ausdauer an einem Ziel arbeiten zu können. Diese Frage wurde in den Abschnitten zur Selbstwirksamkeitserwartung bereits gestreift, soll hier aber noch einmal vertieft werden: Was macht eigentlich „Spaß“ am Protest? Was verschafft den Aktiven Befriedigung und was lässt sie dabei Anstrengung, Frust und Ärgernisse vergessen?

Es gibt bereits Studien darüber, welche diese Fragen an die Mitglieder politischer Parteien anlegen. ${ }^{104}$ Diese weisen durchaus Ähnlichkeiten mit den hier Interviewten auf. Dass etwa die sozialen Kontakte, die ein Aktiver erlebt, die er bilden und verstetigen kann, ihn einbinden und das Engagement auf diese Weise zu seinem nicht nur politischen, sondern auch sozialem Umfeld werden lassen, ist eine Parallele, welche die Protestierenden mit den parteipolitisch Engagierten verbindet. Dies beziehen die Interviewten in den Gesprächen sowohl auf die jeweilige Gruppe, in der sie sich organisieren, die zu einer „Zweitfamilie“ werden kann. Es umfasst aber auch die Tatsache, dass man durch das Protestieren und das Organisieren von Unterstützung für die eigene Sache mit Menschen in Kontakt kommt, die man zuvor vielleicht nicht angesprochen oder kennen gelernt hätte. Beide Arten von Erlebnissen werden in vielen Gesprächen als außeror-

104 Laux, Annika: Was wünschen sich die Mitglieder von ihren Parteien?, in: Spier, Tim / Markus Klein / Ulrich von Alemann / Hanna Hoffmann / Annika Laux / Alexandra Nonnenmacher / Katharina Rohrbach (Hrsg.): Parteimitglieder in Deutschland, Wiesbaden 2012, S. 139 - 155; Dies.: Was motiviert Parteimitglieder zum Beitritt?, in: Spier, Tim / Markus Klein / Ulrich von Alemann / Hanna Hoffmann / Annika Laux / Alexandra Nonnenmacher / Katharina Rohrbach (Hrsg.): Parteimitglieder in Deutschland, Wiesbaden 2012, S. $61-78$. 
dentlich bereichernd geschildert, und selbst dann noch von Wirkung, wenn das mobilisierende Protestereignis bereits zurück liegt.

„...wir haben uns grad erst wieder getroffen, weil man muss dann ja auch fürs Finanzamt Mitgliederversammlungen machen und Rechenschaftsberichte und so und da haben wir uns alle nochmal so angeguckt, man verliert sich dann ja doch auch ein bisschen aus den Augen, jeder macht dann so sein Ding, dass wir, dass das eine unheimlich schöne Zeit war und dass wir das auch wirklich total vermissen. Wir wären sofort wieder alle aus unseren Löchern, wenn wieder was wäre, wenn wir uns denken, es lohnte sich wieder zu kämpfen, also ganz bestimmt. “105

Dieses Gefühl, dass über die sehr zeit- und kraftintensive Arbeit an einem Protest eine Gruppe ungemein zusammen geschweißt wird, taucht in vielen Sequenzen auf. Das gemeinsame Ziel, der Eindruck, geradezu eine Schicksalsgemeinschaft zu bilden, lässt die Beteiligten nahe aneinander rücken. Darüber hinaus verschaffen die Protestarbeit nach außen, das Argumentieren, Sammeln, Überzeugen, die Offensive des Widerstands, den Protagonisten soziale Kontakte, die sie erfüllen:

„...man traf also die verrücktesten Leute, das hat auch teilweise Spaß gemacht, dass man dann irgendwie Leute traf, die man gar nicht kannte, dass man dann was weiß ich nach Stellingen oder nach Wilhelmsburg oder in irgendwelche Stadtteile gefahren ist und mit irgendwelchen wildfremden Leuten gesprochen hat und das (empfand, Anm. F.B.) ich zwar als sehr stressig, aber es war auch sehr, sehr spannend, weil man wirklich mit Menschen ins Gespräch gekommen ist, auf Märkten, in Einkaufszentren, und man also auch in Stadtteilen war, die man zum Teil gar nicht kannte und das war eine - wie ich fand - sehr interessante, demokratische Vorgehensweise und ein Erlebnis für mich.“106

\section{Engagement und Protest als Erlebnismöglichkeiten jenseits der Politik}

Das Engagement in Protest und Initiativen hat sie zu beglückenden sozialen Erlebnissen geführt, hat eine Welt geschaffen, die ihnen auch Heimat geworden ist. Insofern kann sich Protest auch etwas vom Thema entkoppeln und zu Erlebnissen und Gefühlswelten führen, die eine Eigendynamik entwickeln. Die Gemeinschaft einer Protestgruppe oder Initiative rückt zusammen und vermittelt ein So-

105 Einzelinterview E1 Birgit.

106 Einzelinterview E2 Emma. 
lidaritätsgefühl, welches viele in der Politik oder auch in Parteien nicht mehr zu erlangen glauben. Dies hat etwa in regional begrenzten und lokal begründeten Protesten auch den Effekt, dass über die jeweiligen Gruppen auch das Gefühl gestärkt wird, dass es sich vor Ort um „richtig“ funktionierende kleine Gesellschaften handelt, auf welche die Protagonisten sehr stolz sind. Die emotionale Ankopplung an eine gefühlte Heimat wird auf diese Weise enorm gestärkt.

„Das gemeinsame Ziel hat, zu Freundschaft, zu Bekanntschaften geführt, wir haben neue Leute mit dem gleichen Ziel kennen gelernt und die vermissen wir jetzt, weil wir nicht mehr sonntäglich gehen, wir waren 294 mal am Sonntag um 18:00 Uhr unterwegs und jetzt sitzen wir Zuhause meine Frau und ich und schweigen uns an, haben wir gesagt. Statt Schweigemarsch sitzen wir jetzt auf dem Sofa und schweigen uns an und dann freuen wir uns, wenn am letzten Sonntag, wenn da wieder 450 Leute sich auf dem Weg machen von der Kirche zum Marienplatz. “107

Und Rainer C3 sekundiert an dieser Stelle:

„Dieses Gemeinsame spielt eine ganz große Rolle. Ich kann das nur bestätigen mit den vielen Freunden, die man da... Die Welt ist so schön, wenn ich hier durch Freising gehe, ununterbrochen (grüßt nach links und rechts, Anm. F.B.), es ist einfach schön, wenn man Menschen hat, die einen kennen...“108

Das Gefühl von Gemeinschaft verbindet sich im tatsächlichen „Tun“ zu einem Stolz, der über das befriedigende Gefühl von sozialen Kontakten hinausgeht. Analog zu den Selbstwirksamkeitserwartung stiftenden kollektiven Erlebnissen, die in Kapitel 4.3 diskutiert worden sind, werden hier gemeinschaftliche Erfahrungen von Erfolgen zu Quellen von Glück. Das Gefühl, gemeinsam etwas zu schaffen (oder zu verhindern), Teil zu haben an einer Entwicklung, die Auswirkungen und Ergebnisse zeitigt, befriedigt die Gesprächspartner ungemein.

„Ich glaube wir schreiben da Geschichte. Und das ist geil. Teil davon zu sein einfach. Hier in der Stadt was zu verändern. Ich meine, man kann es ja an drei Fingern abzählen. Also es gibt noch ne ganze Menge mehr. Aber wenn man fragt, linke Projekte, besetzte Häuser in Hamburg dann fällt den meisten Hafenstraße, Flora ein. Jetzt neuerdings Gängeviertel." ${ }^{109}$

107 Theodor C3 in der Fokusgruppe C3 Freising am 25.07.2012.

108 Rainer C3 in der Fokusgruppe C3 Freising am 25.07.2012.

109 Einzelinterview Frederik C1. 
Dieses „Teil davon zu sein“ ist etwas, das Protestierende sicherlich mit vielen verbindet, die als Mitglieder in einer politischen Partei oder Gewerkschaft Erfüllung finden. Gleichwohl scheinen die Tatsachen, dass es sich bei den Aktiven in Protestbündnissen und Initiativen um zumeist hoch motivierte Menschen handelt, und dass sich die Gruppen selbst als - im Vergleich zu Parteien - lokal konzentrierter und kleiner wahrnehmen, auf direktere und mehr unmittelbare Gemeinschaftserlebnisse hinzudeuten.

„Was jetzt schon mehrmals angesprochen worden ist, das war das ganz deutlich zutage tretende Solidaritätsgefühl. Diese sichtbare Solidarität. Und was uns stark gemacht hat, es gibt nicht viele Leute, die vor 1000 oder 2000 Menschen reden können, ohne dass sie zusammen brechen. Und da haben wir dann Zuarbeiter, die sagen, du, ich kann das und das und mach diese Tabelle oder jenes, aber vortragen kann ich das nicht - da sterbe ich. Und das waren dann die, wie vorhin schon erwähnt wurde - einmal geht der eine in die Front, und der andere hat Erholungsphase, und dann geht der nächste.“110

Denn dass sie ähnliche Erlebnisse in Parteien oder generell in etablierten Großorganisationen finden könnten, glauben die Gesprächspartner nicht. Hier vermuten sie, dass genau diese Gemeinschaftserlebnisse für sie nicht mehr möglich sind. Wesentlicher Bestandteil ihres Gefühls von „Gemeinschaft“ ist die Verbindung einer Gruppe, die mit ihnen ein zentrales Anliegen teilt, eine wahrhafte Gemeinschaft von „Gleichgesinnten“, und nicht lediglich eine ihnen nebulös erscheinende Verbindung über etwas Schwammiges, wie eine gefühlte Weltanschauung oder gar konkrete, individuelle Vorteile, wie sie dies bei einer Partei vermuten.

„Interviewer 1: War das für sie dann auch ein Unterschied zu diesen Parteitreffen, wenn sie das so...

Emma E2: Absolut, weil ja hier lauter Ehrenamtliche, freiwillig entschiedene Menschen, die sich persönlich dadurch keinen Vorteil versprochen haben, keiner von denen hat irgendwie davon profitiert, die sind alle dann wieder in ihre Familien und ihre Berufe zurückgegangen, wir sind ja jetzt noch lose verbunden, aber es gab keinen Vorteilsdenken dabei.“111

Die interviewten Aktiven sehen in ihren Mit-Protestierern Menschen, mit denen sie etwas teilen, das ihnen selbst zu einem immens wichtigen Anliegen geworden ist - und den anderen ebenso. Alles andere tritt in der Gruppe dahinter zu-

110 Marcel C3 in der Fokusgruppe C3 Freising am 25.07.2012.

111 Einzelinterview Emma E2. 
rück und kann etwaige Unterschiede überdecken. Auch deswegen wird ein Parteienengagement abgelehnt, da hier ein Parteiprogramm viele Themen integrieren und einen Ausgleich zwischen verschiedenen Interessengruppen schaffen muss.

„Es ist unglaublich [...], es war so eine intrinsische Motivation und es hat mir so den wahnsinnig diese Einsamkeit und dieses Unglück und dieses Bedrohungsgefühl genommen und gleichzeitig konnte ich das in eine für mich sehr sinnvolle Handlung umsetzen. Ja und so hat sich das ergeben. [...] Und da waren ja schon andere und so [...] Die haben mich offen aufgenommen und die waren so eine Struktur, wie man das sonst in der Schule und so nie erlebt, dass einfach jeder sich freut, wenn einer dazu kommt, der was mit bringt und der was einbringen kann. Also da gab es irgendwie keine Hierarchien, keine Kämpfe, kein „das mache ich aber“ und irgendwie sowas. Und es sind intensive Kontakte, auch Freundschaften, entstanden auf diese Weise. Und es hat mein Leben ungeheuer bereichert. Hätte ich nie gedacht, dass ein politisches Engagement, wo ich immer misstrauisch war und gesagt habe, ich trete in keinen Verein ein, schon gar nicht in eine Partei und da war diese Initiative eben so was breites, was ganz anderes. Ich werde auch wirklich nie in eine Partei eintreten. Das ist ganz klar, nie. Es passt nicht auf einen Button was ich denke und es passt niemals in ein Parteiprogramm oder so." ${ }^{112}$

\section{Konzeptuelle Reinheit und bessere Demokraten}

Dass man sich nicht verbiegen, nicht unter einer Überschrift zusammen finden muss, die einem möglicherweise nicht gefällt, keine großen Kompromissen schließen muss, empfindet man in der Protestgruppe auch als einen Ausweis von konzeptueller Reinheit. Abstriche im wichtigsten Thema jedenfalls, dem eigenen Protestanliegen, muss man in der Gruppe nicht machen.

Dieses befriedigende Gefühl der „Reinheit“, welches der Protest ermöglicht, scheint vermittelt in vielen Äußerungen durch. Zum einen die Passagen, in denen die Aktiven schildern, wie sehr es sie bereichert, dass sie einer guten, richtigen oder gerechten Sache dienen oder zum Durchbruch verhelfen, bzw. etwas ihr Entgegenstehendes verhindern.

„Mich hat wirklich das Sachthema zutiefst überzeugt. Dass einfach der Weg falsch ist, dass nicht mehr Bildung, sondern weniger Bildung dabei raus kommt. Und wirklich inhaltlicher Verlust an Bildung stattfindet. Und das Gegenteil muss das Interesse sein in einer Stadt wie Hamburg oder Deutschland oder der Welt, was weiß ich, und der Weg mir

112 Einzelinterview Diana E3. 
so falsch erschien, dachte ich mir, man muss was dagegen tun, weil wenn das einmal umgestellt ist, so ein Schulsystem, das kriegt man nicht wieder rückgängig.“113

Der Protest wird durch diese Betonung des Sacharguments in der Perspektive der Agierenden zu einer Reduktion auf ein entscheidendes Thema, das für sie Wohl und Übel der Welt symbolisiert und welches zum zumindest zeitweise wichtigsten Thema überhaupt wird. Und das Gefühl, sich mit Kraft und Zeit diesem Schlüsselthema zu widmen, verschafft ihnen nicht nur Linderung für die Anstrengungen, sondern auch Glück und Bereicherung. Es ist also nicht nur die individualisierte Erwartung von Einfluss und Gehörtwerden, die den Protagonisten als Motivation ihres Protestierens eingeschrieben ist, sondern überdies eine $\mathrm{Zu}$ spitzung und Reduktion des Anliegens. Die Protestgruppe wird deswegen zu einer wichtigen emotionalen Heimat für sie, da sie dort Menschen zu finden glauben, die ganz ähnlich das gleiche Thema zu ihrer persönlichen Motivation gemacht haben. Dies ermöglicht dann die Befriedigung, sich diesem Thema mit Gleichgesinnten voll und ganz widmen zuzuwenden.

Diese Art „Reinheit“ im Sinne eines nicht verwaschenen oder verwässerten Engagements wird - analog und in Folge zu den Befunden, auf die im Kapitel 4.2 über Elternhaus und Prägung hingewiesen wurde - aber auch in Bezug auf das eigene bisherige Leben zu einer Quelle der Zufriedenheit. Denn das Gefühl, schon seit langem die Verhältnisse in der Welt und die Probleme zu durchschauen und seine Aktivitäten und das Engagement dementsprechend ausgerichtet zu haben, erfüllt viele Gesprächspartnern ungemein.

Darüber hinaus verschafft Engagement aber nicht nur über die Widmung für eine ,richtige“ Sache Befriedigung, sondern gilt den Aktiven als Beweis dafür, sich zu den ernsthaften und besseren Demokraten zählen zu können und altruistisch für die Gesellschaft tätig zu sein.

„Ja, weil ich überwerte oder überhöhe meine Arbeit eigentlich nicht, insofern, dass ich sage: Ich persönlich bin jetzt wichtig, aber ich glaube, dass viele, viele, viele von meiner Art wichtig sind für eine Gesellschaft, weil ich das auch immer wieder real erlebe, dass es einfach unglaublich viele Menschen gibt, wo ich mich immer wundere, warum zucken die nur mit den Schultern, warum spricht sie nichts an, so und da bin ich eben ein anderer Typ[...].“114

Die Überzeugung, die eigenen Fähigkeiten zum vermeintlichen Wohle aller und damit uneigennützig einzusetzen, ist bei den Interviewten stark verbreitet. Damit

113 Vera E1 in der Fokusgruppe E1 Hamburg am 20.03.2012.

114 Einzelinterview Birgit E1. 
ist allerdings nicht nur verbunden, in der Sache etwas Positives beizutragen, sondern auch das Selbstbild eines Bürgers, welcher sich im normativen Sinne als besonders wertvoll für eine Demokratie erweist, weil er Knowhow und Sachverstand als mündiger Mensch in den politischen Prozess mit einbringt. Dass damit eine bisweilen etwas herabschauende oder patriarchalische Sichtweise auf diejenigen einhergeht, die nicht aktiv sind oder den Weg in ein Protestengagement gefunden haben, darauf ist schon hingewiesen worden und zeigt sich an dieser Stelle:

,....ich muss sagen, die letzten 1 1/2 Jahre waren einige meiner bewegendsten überhaupt. Ich hatte die Ehre, ein Jahr lang Menschen zu koordinieren die bis dahin politisch nicht sonderlich aktiv waren. Und das hat Spaß gemacht, ist ein Lernprozess. Und die Geschichte ist für mich noch nicht zu Ende. “ ${ }^{115}$

Die Bedeutung und das normative Gewicht, welche aus diesen Gefühlen für die eigene Person erwachsen, machen die Interviewten jedenfalls zu Menschen, die sich selbst als Fundament der Demokratie betrachten, welche sie sich selbst wünschen. Denn ihr Protestthema hat sie zu der Überzeugung gebracht, vieles und in erster Linie der Anknüpfungspunkt für das Engagement - besser, effizienter oder weitsichtiger beurteilen zu können als die zuständige Politik. Auch diese Sicht ist nicht allein Quell einer Enttäuschung über den Zustand des politischen Systems, sondern ebenso Wurzel einer tief reichenden Zufriedenheit über das eigene Handeln.

„Ich hatte teilweise das Gefühl, dass wir durch diese Kontakte auf der Straße also etwas von dem übernommen haben, was Politik vielleicht viel mehr machen sollte. Nämlich so eine Art soziale Aufgabe übernommen. Es war wirklich so, dass wir da teilweise richtige, ja seelsorgerische Gespräche geführt haben fast, ja. Also diese Begegnung auf der Straße fand ich ganz ganz spannend.“ ${ }^{116}$

„Bei uns ist ja eine andere Qualität auch entstanden. [...] Also, in der Schlichtung hat man ganz klar gesehen, die meinen, da führt man 10 Experten auf und wir hocken dann alle da und sind völlig beeindruckt. Dann haben wir mal richtig geguckt nach Expertenwissen, und ich muss euch gleich sagen, unser Wissen ist das bessere. Insofern kann ich mich ganz beruhigt zurücklehnen und weiß, dass die mal gar nichts zu Ende gedacht haben.“" ${ }^{117}$

115 Rüdiger C1 in der Fokusgruppe Stuttgart C1.1 am 20.03.2012, 17 Uhr.

116 Einzelinterview Emma E2.

117 Petra C1 in der Fokusgruppe Stuttgart C1.1 am 20.03.2012, 17 Uhr. 
Auf der einen Seite sind es also die bestätigenden Erlebnisse der eigenen Fähigkeiten, die hier motivieren und auch glücklich machen. Damit einher geht ein Gefühl, zum Wohle Aller tätig zu sein und gegen die vermeintlich stärkeren Kräfte von Politik und Wirtschaft zu fechten. Auf diese für das ProtestSelbstbild durchaus zentralen David-Erfahrungen ist bereits hingewiesen worden, sie finden sich auch in den Gesprächssequenzen zur Erfüllung durch Protest allerorten. Denn auf diese Weise findet der Eindruck, etwas fundierter oder auch normativ „,besser“ handeln und urteilen zu können, am Ende doch das Glück der Geschichte auf der eigenen Seite zu haben, immer wieder Bestätigung.

„Wir haben auch lange Zeit eigentlich das Gefühl gehabt das können wir gar nicht schaffen. Das ist dermaßen David gegen Goliath, ein so gigantischer Goliath. Aber wir haben einfach trotzdem weiter gemacht. Also das war so die Motivation war so stark und irgendwie wir sind immer so von außen aufgefordert worden von vielen. Auch meine Kollegen. Die haben alle gesagt, boah danke danke danke, dass du das machst. Und mach bloß weiter. Wir können das nicht auf gleiche Weise leisten. [...] Wir waren so erleichtert und so glücklich und froh und auch stolz. Also dieser Stolz, oh Gott, oh Gott. Dabei ist es jetzt zwei Jahre her und ich kann sonst darüber reden. Aber man kommt da so richtig rein wieder. Und der war halt so stark, vielleicht auch deswegen weil man überhaupt nicht sicher war, und weil man irgendwie gegen so eine Übermacht von ähm Überwältigung. [...] Wir sind so bedroht worden. “118

„Ich hab mir sehr oft in München den Arsch abgefroren, den ganzen Winter über bin ich in München gestanden mit diesen Zetteln. Und wir haben manchmal wirklich, wie der Rainer schon gesagt hat, manchmal wirklich gezweifelt. Bei dem Aufwand der Gegenseite - wir gewinnen nicht. [...] Und wenn ich dann dran gedacht hab, mit welchem Kapitalaufwand die Gegenseite gearbeitet hat und wir mit unseren $80.000 €$ [...]. Und das ist für mich immer noch ein gewaltiger Erfolg. Und ich glaube nach wie vor, dass die Welt anders geworden ist mit dieser Entscheidung. “119

Diese Selbstverortung, als strukturell unterlegene Gruppen in den Protest zu ziehen, ist ein guter Schutzmechanismus, da sie das Scheitern im politischen Ringen gegen oder für ein Anliegen zum Normalfall erklärt - man kann also nur gewinnen. Im Fall einer Niederlage bleibt immer noch die gemeinschaftliche Erfahrung und die Überzeugung, das ,Richtige“ getan zu haben, es gegen gegen alle Zweifler und Skeptiker nicht nur erkannt zu haben, sondern auch aktiv geworden zu sein. Befriedigung und Glückserlebnisse schafft Protest zwar nicht nur,

118 Einzelinterview Diana E3.

119 Marcel C3 in der Fokusgruppe Freising C3 am 25.07.2012. 
aber eben auch unabhängig von politischem Erfolg. Ob dies zufriedener mit den demokratischen Institutionen macht, steht allerdings auf einem anderen Blatt und soll im Kapitel zu den Demokratie-Einstellungen behandelt werden.

Wenn es aber einen Punkt gibt, der die hier unterstrichenen GlücksErlebnisse subsummieren könnte, dann ist es die Erfahrung von Dynamik, in die fast alle Protestierenden im Laufe ihres Engagements hineingezogen werden. Wenn innerhalb einer Gruppe das Anliegen des Protests - sei es aus Empörung, sei es, weil man ein „Window of Opportunity“ nahen spürt - plötzlich immer wichtiger wird, Denken und Handeln auch im Alltag dominiert und der Konflikt auf ein sicht- und fühlbares Crescendo zusteuert, erleben dies die Interviewten als etwas fast Überwältigendes.

„Ja, das war einmalig, wirklich. Ich hätte es nicht für möglich gehalten, und alles was man an Positivem erlebte, das beflügelte auch einen weiterzumachen und ich hatte da, als wir auf die Straße gegangen sind, gerade drei Monate früher eine Knieoperation gehabt. Ich konnte gar nicht so lange stehen und gehen aber ich habe es gemacht. Mit so einem Knie abends, nech? Aber das war mir so egal, da man im Moment gar nicht merkte, was da passiert, sondern man ist so beschäftigt mit dieser Sache, weil man auch merkt, man kommt an und dann möchte man gar nicht aufhören.“'120

Natürlich verursachen die Protestaktionen, die am Ende Wirkung zeitigen, die sich durchsetzen und ihr Anliegen verwirklichen können, auch zumeist lauteren, tieferen Ausdruck:

„Also ich kann nur sagen, an dem Morgen nach dem 17. (Tag des erfolgreichen Bürgerentscheides in München, Anm. F.B.) bin ich aufgewacht und hab ein so Glücksgefühl gehabt, ich glaub, wie ich nach der Geburt von meinen Kindern hatte, fast so, also ich bin mit so einem Zufriedenheitsgefühl aufgewacht, dass ich nur noch lächelnd im Bett lag und das ist mir wochenlang geblieben... Ich kann das gar nicht beschreiben.“،121

Der trotzige und bisweilen pathetische Stolz, gegen eine Mehrheit oder aber zumindest die politischen oder ökonomischen Mehrheiten gestanden zu haben, ihr entgegen getreten zu sein, erfüllt die Aktiven besonders intensiv, wenn sie unterlegen sind. Denn das sie am Ende die besseren Staatsbürger sind, ist über die Protest-Engagements als Befriedigungsgefühl entstanden und korreliert keineswegs mit einem erfolgreichen Protest. Ein Unterliegen gegen die Kräfte der „Beharrung“ führt keineswegs zu einer Einsicht in vermeintlich bessere Argu-

120 Nina E1 in der Fokusgruppe Hamburg E1 am20.03.2012.

121 Sybille C3 in der Fokusgruppe Freising C3 am 25.07.2012. 
mente, sondern bestätigt vielmehr die eigene Perspektive auf zu überwindende Entscheidungsstrukturen.

Es bleibt hervorzuheben, dass die moralische Überhöhung des eigenen Aktivseins und des Protests gerade bei denjenigen am wenigsten zu spüren ist - sei es in Ton oder Wort -, die auf eine längere, aktive Erfahrung in Parteien oder Gewerkschaften zurückblicken können. Nicht also diejenigen, die nach kurzem oder fehlendem Kontakt Parteien, Gewerkschaften etc. als Problemfall der Demokratie eher verächtlich betrachten, sondern der Teil der Protestierenden, der tiefe Einblicke in deren Funktionen hat nehmen können. Die hier zu nennenden Interviewten, so etwa Lena E6, schildern ihr Engagement eher als Teil eines politischen Machtkampfs, den man am Ende gewonnen hat, aber nicht als normativ-moralischen Triumph des Volkswillens gegenüber dem Leviathan des Parteienstaats - bei ihr ist es nicht überhöht und vielleicht liegt es eben daran, dass sie weniger Berührungsängste auf der einen Seite zu Politik und Parteien hat und auf der anderen Seite viele Einsichten, die dazu führen mögen, dass sie die Gegenseite nicht dämonisiert.

\subsection{ZWISCHENFAZIT IV: ECKPUNKTE DES Selbstbildes als Protestierende}

„Die tiefsten Probleme des modernen Lebens quellen aus dem Anspruch des Individuums, die Selbstständigkeit und Eigenart seines Daseins gegen die Übermächte der Gesellschaft, des geschichtlich Ererbten, der äußerlichen Kultur und Technik des Lebens zu bewahren.“122 Dieser Eingangssatz aus Georg Simmels berühmtem Essay zum Geistesleben der Großstädte hat in den über hundert Jahren seit seinem Erscheinen 1903 wenig von seiner Prägnanz eingebüßt. Und das angesprochene Ringen und Unbehagen mit der gefühlten Moderne hat in der Folge ganze Generationen von Soziologen, Schriftstellern und Feuilletonisten fasziniert. Was mit den gesellschaftlichen Strukturierungskräften geschieht, wenn sich Gruppen und Nationen verändern, wie das einzelne Individuum diesen unterworfen ist oder aber versucht, sich zu wehren, ist für die vorliegende Analyse zentral. Denn Protest als Zeitdiagnose muss vor dem Hintergrund möglicher Bias-Entwicklungen zwischen gesellschaftlichen Erwartungen an Demokratie und Politik und deren Organisationswirklichkeiten interpretiert werden. Das Unbehagen gegenüber dem Prinzip der Repräsentation, die Betonung individueller Urteilsfähigkeiten, denen allein man vertraue, dies kommt in den Gesprächen

122 Simmel, Georg: Die Großstädte und das Geistesleben, Frankfurt a. M. 2006, S. 7. 
deutlich zum Vorschein. Die Angst und der Unwille, sich mit seiner Individualität einer zu stark vereinfachenden (Groß-)Gruppenkonstruktion unterordnen zu müssen, sind oftmals mit den Händen zu greifen. Und darüber hinaus zeigt sich ein Misstrauen gegenüber jeder Art von (politischen) Führungspersönlichkeiten, welche sich als Generalisten mit Sachentscheidungen häufig schwer tun müssen, da sie kaum je die notwendige Sorgfalt aufbringen können, um alle Alternativen angemessen abzuwägen.

Dieses Misstrauen und die Betonung von Individualität hat Georg Simmel bereits Anfang des vergangenen Jahrhunderts als Signum moderner, in diesem Fall großstädtischer Gesellschaften ausgemacht. Vor allem die Großstadt als Vorposten gesellschaftlicher Entwicklung präge eine Persönlichkeit heraus, die „ein Äußerstes an Eigenart und Besonderung“ aufbieten müsse. „Es (das Individuum, Anm. F.B.) muss dieses übertreiben, um überhaupt noch hörbar, auch für sich selbst, zu werden.“' ${ }^{123}$ Simmel wähnt hier aber nicht nur einen narzisstischen Unterscheidungswunsch am Werk, sondern auch eine zunehmende Unfähigkeit, den „Großzusammenfassungen““124 genügend Vertrauen in ihre Regelungsfähigkeiten zum Wohle aller entgegen zu bringen. Jede Großorganisation werde zunehmend mit derselben Enge und Abhängigkeit geringgeschätzt, wie dies der überzeugte Großstädter der Kleinstadt gegenüber empfinde.

Richard Sennet hat Ähnliches für die Gesellschaft im modernen Kapitalismus befunden. Über die kapitalistischen Flexibilitätsdogmen, welche die Menschen mittlerweile verinnerlicht hätten, so Sennet in seiner Betrachtung des „flexiblen Menschen“, sei die Fähigkeit erodiert, Kollektiven, Gruppenzugehörigkeiten oder den einzelnen Mitmenschen Vertrauen entgegen zu bringen. Die Mantras individueller Verwirklichung und ökonomischer Anpassungsfähigkeit widersprächen der Rolle von Kollektiven und Gruppen als Sammlungspunkten von Lebenshoffnungen. Deshalb könne dem Prinzip von Repräsentation und vor allem den Repräsentanten von Gruppen, welche ein Gemeinwohl propagierten, oftmals kein Vertrauen mehr entgegen gebracht werden. ${ }^{125}$

Anthony Giddens weist in seiner Betrachtung der „Konsequenzen der Moderne" ebenfalls darauf hin, dass der Verlust des Fortschrittsgedankens ein zentraler Charakterzug gesellschaftlicher Moderne sei, der die Glaubwürdigkeit von Zukunftsgewissheiten und Utopien erschüttert habe. ${ }^{126}$ Der einzelne Mensch sei infolgedessen viel stärker auf sich selbst zurückgeworfen in seiner Suche nach Wohlstand und Glück, und viel weniger in der Lage, einem (politischen) Führer

123 Simmel: Die Großstädte und das Geistesleben, S. 41.

124 Ebenda, S. 28.

125 Vgl. Sennet: Der flexible Mensch, S. 187 - 203.

126 Giddens, Anthony: Konsequenzen der Moderne, Frankfurt a.M. 1995, S. $19 f$. 
und seinem Kompass zum Gemeinwohl Vertrauen zu schenken: „Es besteht ein starkes psychisches Bedürfnis, andere zu finden, denen man vertrauen kann, doch im Verhältnis zu vormodernen sozialen Situationen fehlt es an institutionell organisierten persönlichen Verbindungen. “" ${ }^{127}$ Dieser Lesart nach wären die Bürgerproteste, welche sich gegen Repräsentationsprinzipien und deren Auswirkungen richten, eine Bestätigung, dass sich vormoderne Vertrauensdepots immer weiter aufzehren. Rolf G. Heinze streicht hier heraus, dass besonders das Postulat der Selbstverantwortung bzw. des „Selbstmanagements“ der Menschen dazu führe, dass Vertrauen in Politik und die sozialpartnerschaftlichen, korporatistischen Regulierungsformen und Parteien brüchig werde. ${ }^{128}$ Denn wenn man am Ende auf sich selbst gestellt sei, selber mit seinen Fähigkeiten, Ressourcen und Anlagen für das individuelle Wohl und Weh verantwortlich, dann verblasse auch die Notwendigkeit, sich einem Kollektiv, einer Partei, einer Gruppe anzuschließen (und damit auch immer: unterzuordnen), um ein vermeintliches Gemeinwohl $\mathrm{zu}$ verfolgen.

Es ist dies der Mechanismus, den Ingolfur Blühdorn in seinem Buch zur „Simulativen Demokratie“ weiter auf die Spitze getrieben hat: dass sich im Laufe der Modernisierung die gesellschaftlichen Komplexitäten so stark steigerten, dass das Ideal eines ,,autonomen Subjekts“, der sich zum Wohle Aller engagiere, zu einer permanenten Überforderung des Bürgers führe. Blühdorn interpretiert die Proteste folglich als Ausweis einer Selbstbeschränkung der Bürger auf ihr individuelles Wohl, da sie sich nicht mehr in der Lage fühlen, selbst ein gesellschaftliches Gemeinwohl im Blick zu behalten und erst recht nicht (mehr) einem Repräsentanten vertrauten, der vorgibt, dies für sie zu verfolgen. Die von ihm postulierte ,postdemokratische Wende“ sei „Ergebnis eines fortschreitenden Prozesses der Modernisierung, der einerseits die Norm des autonomen und identitären Subjekts auflöst, damit das Fundament der traditionell verstandenen Demokratie zersetzt [...] der andererseits aber - qua Modernisierung - die Freiheits-, Selbstbestimmungs-, Selbstverwirklichungs- und Zentralitätsansprüche der Individuen immer maßloser aufbläht. [...] Sie verstehen sich immer unbedingter als Mittelpunkt der Welt. “" 129

Gleichzeitig beschreiben sowohl Giddens, als auch Sennet und Blühdorn ein starkes Bedürfnis nach einer schützenden, Identität und Geborgenheit stiftenden

127 Ebenda, S. 150.

128 Vgl. Heinze, Rolf G.: Entgrenzung und Restrukturierung der Schnittstellen zwischen Gesellschaft, Staat und Markt?, in: Pries, Ludger (Hrsg.): Zusammenhalt durch Vielfalt? Bindungskräfte der Vergesellschaftung im 21. Jahrhundert, Wiesbaden 2013, S. 123 - 148, hier S. 129.

129 Blühdorn: Simulative Demokratie, S. 162. 
Gemeinschaft. Die Bürger seien aber immer weniger zur Akzeptanz von Gemeinschaft überhaupt in der Lage, da sie die eigene Individualität immer stärker und immer unmittelbarer in das Zentrum ihres Denkens und Handelns stellen sei es aus einer Überforderung durch komplexer werdende gesellschaftliche Realitäten oder durch den kapitalistischen Appell an die Selbstoptimierung. Dieses Dilemma spiegelt sich in den Gesprächen mit den Aktiven von zeitgenössischen Bürgerprotesten in Deutschland wider. Zwar ist im Kapitel zur Selbstwirksamkeit und deren Quellen darauf hingewiesen worden, dass diese nicht einzig und allein aus individuellen Erlebnissen gespeist und damit auf den Einzelnen ausgerichtet ist. Die Protestierenden empfinden sich vielmehr als Teil einer Gruppe, die das ihnen gemeinsam Wichtigste vertritt. Selbstbewusstsein im Protest ist aber - und dies könnte durchaus eine Verschiebung gegenüber früheren, viel stärker kollektiv- oder milieubezogenen Protestgruppen darstellen - auch in seiner Dynamik mit einem individuell gewachsenen Bewusstsein verbunden, dass eine viel unmittelbarere und direktere Wirksamkeitserwartung entstehen lässt. Kollektive Erlebnisse und Anlässe, die eine Selbstwirksamkeitserfahrung ausmachen, verbinden sich mit den Bildungserfahrungen und Statusgewinnen der Aktiven zu einem Selbstbild, welches schlussendlich eine direkte, individuelle Forderung nach politischem Einfluss nach sich zieht. Dies ist auch eine Folge des Altersdurchschnitts, des gehobenen Bildungshintergrunds und sozialen Profils der Protagonisten: Da Lebenserfahrung und berufliche Erfahrungen der Protestteilnehmer das Selbstbewusstsein und den Anspruch an politische Entscheidungsverfahren beeinflussen und wandeln, wirkt sich die soziale Zusammensetzung von Bürgerprotesten auch auf deren Demokratie-Perspektive bzw. Politikerwartungen aus.

In den Interviews und Beobachtungen der Bürgerproteste ist zwar deutlich geworden, dass es sich nicht um eine lediglich auf eine Generation oder Alterskohorte zurückzuführende Entwicklung handelt. Gleichwohl speisen sich die angesprochenen Demokratie-Ideale der Protagonisten, welche zur inneren Vergleichsfolie für die Beurteilung der Demokratie-Wirklichkeit werden (und damit auch zu einer Art handlungswirksam werdenden Utopie von Protest), aus den kollektiven Erfahrungen und Erinnerungen der deutschen Gesellschaft der letzten Jahrzehnte. Die Neuen Sozialen Bewegungen der 1970er und 1980er Jahre sind zu einer bedeutenden Phase in der Selbsterzählung der Interviewpartner geworden - sei es im direkten Erleben oder als eine Art gefühlter Vorläufer, dessen Existenz dem eigenen Protest eine größere Legitimität verleiht. Die Bürgerbewegungen dieser Jahre gelten den Protestierenden von heute als Begründung, warum ganz allgemein ziviler Ungehorsam, Widerspruch und Skepsis gegenüber Autorität gut und wünschenswert sind, als normatives Fundament einer aktiven 
Bürgerrolle. Dies wird auch von denjenigen Teilnehmern aufgegriffen, die aufgrund ihres Alters keine direkte Erinnerung der Proteste von Whyl, Brokdorf oder der Bonner Hofgartendemonstration besitzen. Eine grundsätzliche, normative Erwartung von der Beeinflussbarkeit von Politik durch die Bürgergesellschaft ist stark ausgeprägt.

Die eigenen Erfahrungen und Statusentwicklungen der Protest-Aktiven sind dann wiederum die Quelle von ganz individuellen Erwartungen von Einfluss und Wirksamkeit. Denn die Gesprächspartner sind davon überzeugt, dass nicht nur die Bürger allgemein, sondern sie ganz persönlich von der Politik wahrgenommen und gehört werden sollten. Gespeist vom individuell, sozial und ökonomisch erreichten Status, durch eigene und kollektive Selbstwirksamkeitserfahrungen wie durch berufliche Erfahrung hat sich bei den Aktiven ein Selbstbewusstsein ausgeprägt, welches diese Erwartung zum Motor des eigenen Engagements gemacht hat. Die Organisatoren der Bürgerproteste sehen sich selbst als meist überlegene „Gegenexperten“ zur repräsentativen Parteiendemokratie, dieser durch eine größere Unabhängigkeit in ihren Entscheidungen weit überlegen. Die Glorifizierung des Expertentums als Entscheidungsquelle ist an vielen Stellen auffällig und weist eine große Nähe zur Hoffnungsfigur des politischen Seiteneinsteigers auf, der verspricht, in der Politik, andere, bessere Urteilskriterien einzuführen. Sie selbst empfinden sich als besser vorbereitete und stärker legitimierte Demokraten.

In Ingolfur Blühdorns Ausruf einer „Simulativen Demokratie“ wird herausgestrichen, dass das Dilemma zwischen dem Wunsch nach Beteiligung und dem Rückzug auf die selbstbewusste Verfolgung der individuellen Interessen, durch die Akzeptanz einer Art „Scheinbeteiligung“ in einer eben: simulativen Demokratie aufgelöst würde. ${ }^{130}$ Dass Menschen eine vorgegaukelte Beteiligung akzeptieren, weil eine tatsächlich erforderte, regelmäßige Partizipation sie überfordere. Analog sähen sich Regierungen in genau demselben Dilemma zwischen einer Legitimität stiftenden Maximierung des Inputs von Demokratie - möglichst viel Partizipation - und dem fortwährenden Beweis rascher und konziser Entscheidungsfindung - in möglichst kleine, geschlossene Expertengremien. Hier beschreibt Blühdorn den naheliegenden Lösungsweg einer nur oberflächlich Offenheit suggerierenden Scheindemokratie, welche eben für Bürger wie für Parteien und Politik Vorteile und Entlastung böte.

Diese Konstellation findet sich in den Interviews mit den Protestierenden etwas anders gelagert. Denn hier sind Menschen versammelt, die zumindest den Sprung ins Aktivsein schon gemacht haben, ein Rückzug - und sei er auch nur rhetorisch - von der Gemeinwohlorientierung wird jedenfalls brüsk abgelehnt.

130 Blühdorn: Simulative Demokratie, S. 163. 
Allen gemein ist eine starke Betonung eines Engagements für ein vermeintliches Gemeinwohl - auch weil es als Ziel legitimiert und intuitiv einleuchtend die eigenen Beweggründe in ein helleres, altruistisches Licht rückt. Ein Unterschied mag darin liegen, dass die hier gefundene Gemeinwohl-Motivation in der Frage liegt, wer dieses formuliert und durchsetzt. Die Protest-Aktiven sind der Überzeugung, einen unverstellten Blick auf ein Gemeinwohl zu besitzen und dieses qua Erfahrung und Fachwissen besser zu verstehen als dies die deutsche Parteiendemokratie vermag. Es ist nicht der Rückzug von einer GemeinwohlOrientierung, auf den die Gespräche mit den Gruppenmitgliedern hindeuten, sondern vielmehr die Subjektivierung eines Gemeinwohl-Expertentums.

Das angesprochene Dilemma zwischen dem Bedürfnis, sich einer Gruppe von Gleichgesinnten anzuschließen und dem Misstrauen, welches größeren Gruppenkonstruktionen entgegengebracht wird, spricht ebenfalls aus vielen Interviews. Aufgelöst wird dies dadurch, dass nach der gefühlten Authentizität von Gruppen differenziert wird. Es gibt vermeintlich gute, authentische Gruppen auf der einen Seite und faule, korrumpierte wie korrumpierende auf der anderen. Die Suche nach Vertrautheit, die Sehnsucht danach, Gleichgesinnte zu finden, scheint sehr stark ausgeprägt und spricht dafür, dass das Erleben von Gemeinschaft nach wie vor als enorm stützend, beglückend und bereichernd empfunden wird. Gleichzeitig aber ist eine Skepsis gegenüber den Nachteilen und Fangstricken gemeinschaftlicher Sammlung und der Überantwortung von Sprachfähigkeiten gewichtiger Teil des Selbstbildes der Organisatoren von Bürgerprotesten. ${ }^{131}$ Dies stellt die Gruppen bisweilen vor Probleme. Die Aktiven sind aber davon überzeugt, dass der innere Zusammenhang der Protestgruppen auf ihr jeweils zentrales Anliegen zurückzuführen ist, da alle etwas teilen, was ihnen zum Wichtigsten geworden ist. Dies allerdings knüpft den Bestand und Zusammenhalt von Protestgruppen auf die fortwährende persönliche Bedeutung des Protestgegenstands für ihre einzelnen Mitglieder. Da das Selbstbewusstsein und die Selbstwirksamkeitserwartung der Teilnehmer zu einem Großteil individuell grundiert sind, und eben nicht an eine Gruppe, Milieu oder Klasse gekoppelt, ist die Anbindung der Protestierenden an ihre Gruppe zumindest in Teilen lose und in der Einzelperson verortet. Dies unterstreicht, dass die Vorstellung individueller Gestaltungsspielräume und -pflichten mit Bezug auf das eigene Leben dazu führt, dass die Einbindung in Gruppen und die Akzeptanz der Idee von Repräsentation schwächer wird.

Wie sich dies auf die Idee von Politik, politischer Führung sowie die Sicht auf zeitgenössische Gesellschaftsrealitäten bei den Protestierenden auswirkt, soll im Folgenden nun im Zentrum des Interesses stehen.

131 Vgl. hierzu Kap. 6. 


\section{Krisenwahrnehmung und Demokratievorstellungen}

Die Krisenwahrnehmung von Protestierenden in den Blick zu nehmen ist für die Frage nach Motiven und Begründungen von Bürgerprotesten zentral und die entsprechenden Gesprächspassagen zählen sicherlich zu den fesselnden Abschnitten der Interviews. Denn das Empfinden einer krisenhaften Entwicklung kann auch nach den bisher gemachten Beobachtungen zu den Protestierenden - vorausgesetzt werden, damit jemand gegen etwas oder für etwas Besseres aktiv wird. Hier wird der Kern des Daseins als Protestorganisator berührt, das Zentrum der jeweils geteilten Belief Systems in den Fokus gerückt. Die im ersten Kapitel entwickelten Anleihen bei der sozialwissenschaftlichen Diskursanalyse erweisen sich dabei als besonders fruchtbar, geht es doch nicht biographisch-strukturell und für die einzelnen Teilnehmer um einen individuellen Keim des Protestierens, sondern um eine möglicherweise geteilte Gemeinsamkeit einer Gesellschaftsund Zeitdiagnose, um den schon bemühten ,widely shared common sense ${ }^{\text {“1 }}$. Eine Krise kann dabei vieles, kann ökonomisch, politisch, gesellschaftlich, ökologisch oder noch anders grundiert sein - aber gibt es unter protestierenden Bürgern einen Konsens über ihre Existenz, ihren Charakter, ihren Ursprung?

Interessant sind schon die Beobachtungen zum Stellenwert, zu Tonfall und Körperhaltung in den Gesprächsrunden oder der einzelnen Interviewteilnehmer, wenn die Sprache auf ihre Wahrnehmung einer möglichen Krise in Politik und Gesellschaft kommt. Oft werden in den Fokusgruppen die Diskussionen geradezu hektisch, von Empörung getragen, der Ton lauter und rauer. Zwischentöne jedenfalls rücken in den Hintergrund, Graustufen und vorsichtige Einschränkungen kommen deutlich weniger zu Gehör. Es scheint bisweilen fast so, als ob die Krisenwahrnehmung eine Art Währung für die Legitimität des Protests sein kann: je mehr Empörung, umso berechtigter das Protestieren. Denn in einem

1 Mouffe: The return of the political, S. 53. 
sind sich die Gruppen einig, in sich und über alle Protestbündnisse hinweg: Wir durchleben als Gesellschaft eine Krise, welche als national, europäisch und global wahrgenommen und beschrieben wird. Diese Krisenwahrnehmung ist für die Protestierenden der abstrakte Hintergrund ihres Engagements, der sich dann bis zum ganz konkreten Anlass ihres Protests zuspitzt. Hier führt für sie vieles zusammen: Was schief läuft in unserer Gesellschaft, welche vermeintlichen besseren, anderen Verfahrenswege ignoriert werden, dass und warum sie als Gruppe nicht ernst genug genommen werden. Kurz: Was die Phänomene sind, die gemeinsam mit dem bereits beschriebenen biographischen Gepäck der Aktivisten ihre Motivation zum Widerspruch entstehen lassen. Insofern ist die diskursanalytische Frage nach Sinnstrukturen und Belief Systems der Protestierenden sowie was diese für derzeitige und möglicherweise zukünftige Demokratienormen innerhalb unserer Gesellschaft implizieren, für die Einordnung der Proteste von großer Bedeutung. Und nicht zuletzt bilden diese Krisenperspektiven gemeinsam mit den biographischen Hintergründen der Einzelnen das Entwicklungsfundament für die Alternativideen und Hoffnungen, welche die Aktiven entwickeln.

\section{Literarische Krisenbilder}

Das vage Gefühl einer Krise, welche die deutsche, die europäischen oder insgesamt die westlichen Gesellschaften derzeit durchlaufen, findet sich auch wiederum gespiegelt in der zeitgenössischen Literatur. Nicht erst seit John Steinbecks „Früchte(n) des Zorns“ ${ }^{2}$ über die amerikanische Gesellschaft in der großen Depression der 1930er findet man in literarischen Zeugnissen besonders eindrucksvoll erspürte Zeitbilder von Gesellschaften in der Krise. Die Gesellschaft erschütternde und transformierende Entwicklungen, welche ein Kaleidoskop an Verlustängsten oder ganz reellen sozialen und ökonomischen Bedrohungen vor sich her und mit sich tragen, lassen literarische Verarbeitungen in ganz besonders einprägsamen Farben entstehen.

Romane und Literatur per se sind aus der Perspektive einer literarischen Diskurstheorie nicht einfach nur autonome, solitär stehende Aussagen eines Autors und dessen individueller psychischer oder emotionaler Befindlichkeit, sondern werden als „,>Knotenpunkte $<$ im Netz verschiedener Diskurse (Hervorhebung im Original, Anm. F.B.)“ betrachtet. ${ }^{3}$ Die Weiterentwicklung des New Historicism hat dies in der Folge noch stärker unterstrichen und regt an, Literatur als „kon-

2 Steinbeck, John: Früchte des Zorns, Düsseldorf 1996.

3 Köppe, Tilmann / Simone Winko: Neuere Literaturtheorien. Eine Einführung, Stuttgart / Weimar 2013, S. 102. 
tingentes Resultat historischer, sozialer und psychischer Faktoren “4 ${ }^{4 u}$ interpretieren. Gesellschaftliche Bewegungen, Entwicklungen und Verschiebungen fänden sich in der Produktion literarischer Texte wieder und werden in Wechselwirkung von diesen beeinflusst. Folglich ist dann Literatur eben auch eine Ausprägung zeitgenössischer Diskurse und Empfindsamkeiten und bietet die Möglichkeit, Eindrücke über als relevant erachtete Sinngehalte zu sammeln. Ganz ähnlich unterstreicht dies Ernst-Wilhelm Händler in einem Votum für eine literarisch verfasste Kulturtheorie. Romane sind für Händler als Quelle für eine Untersuchung gesellschaftlicher Entwicklungen auch deshalb so reich, weil sie sich auf das nicht laut ausgesprochene Innenleben der Protagonisten konzentrieren und es gleichzeitig mit dem Äußeren, Manifesten und Beobachtbaren in Beziehung setzen könnten. ${ }^{5}$ Für die Analyse von Bürgerprotesten und den Krisenwahrnehmungen ihrer Protagonisten könnten literarische Texte auf zweierlei Arten und Weisen hilfreich und Erkenntnis versprechend sein: Zum einen wenn sie eine allgemeine Wahrnehmung einer gesellschaftlichen oder politischen Krise unterstreichen - und man damit Bürgerprotestler und ihre Interpretation einer Wirklichkeit auch als partielle Aussage über die Entwicklung einer ganzen Gesellschaft oder Kultur verknüpfen kann. Und zum anderen, en detail, wenn in den literarischen Verarbeitungen dieser Krisenbilder auf Deutungsfüllungen hingewiesen wird, wie eine Krise verstanden wird, was Symptom, was Ursache und wer Schuldiger sein mag. Es bleibt an dieser Stelle zu unterstreichen, dass auch die bemühten theoretischen Gerüste aus der Literaturwissenschaft nicht in erster Linie Handhabungen sind, um einzelne Texte auf ihren Bedeutungszusammenhang abzuklopfen, sondern stets Gruppen von literarischen Produktionen in ihren Entstehungszusammenhang zu setzen. In diese Arbeit übertragen: Gibt es möglicherweise eine Häufung von Romanliteratur, welche sich mit einer empfundenen Krise beschäftigt? Wie wird diese aufgegriffen? Welches sind Themen und Bilder, die hier herangezogen werden?

Zunächst einmal greift eine ganze Reihe zeitgenössischer Romane ein solches nebulös empfundenes Bedrohungsgefühl auf - in ganz unterschiedlicher Intensität und Konkretisierung: Von besonders krass gezeichneten, geradezu apokalyptischen Gesellschaftspanoramen wie in Jochen Schimmangs „Neue Mitte“6

4 Ebenda, S. 224; vgl. auch grundlegend Kaes, Anton: New Historicism: Literaturgeschichte im Zeichen der Postmoderne?, in: Baßler, Moritz (Hrsg.): New Historicism. Literaturgeschichte als Poetik der Kultur, Tübingen 2001, S. 251 - 267, hier S. 256.

5 Vgl. Händler, Ernst-Wilhelm: Versuch über den Roman als Erkenntnisinstrument, Frankfurt a.M. 2014, S. 7.

6 Schimmang, Jochen: Neue Mitte, Hamburg 2011. 
und Cordula Simons „Ostrov Mogila“" mit ihren düsteren Zerfallsszenarien, über Davide Longos „Der aufrechte Mann“ ${ }^{\text {8 }}$ bis hin zu leiseren, introvertierten und stärker auf das Innere verlegten Krisenbetrachtungen, etwa in Uwe Timms „Vogelweide“ “9 und dem bereits erwähnten „Schwarzen Berg“ von Anna Katharina Hahn $^{10}$.

Besonders auch die Wirtschaftskrise seit 2008 hat dazu geführt, dass die Suche nach der menschlichen Charakterentsprechung des Finanzsystems auch auf dem Feld der Literatur verfolgt worden ist. Petros Markaris’ „Faule Kredite“11 malt ein Panorama der griechischen Gesellschaft in der Krise. Rafael Chirbes geht den Auswirkungen des wirtschaftlichen Zusammenbruchs in Spanien nach und schildert eindrucksvoll fatalistisch und depressiv den schier hoffnungslosen Lebensabend eines Bankrott gegangenen Schreiners jenseits der 70. ${ }^{12}$ Und John Lanchester wiederum porträtiert in seinem Roman „Kapital“"13 eine wohlhabende Straße Londons und ihre Bewohner während des Ausbruchs der jüngsten Wirtschaftskrise, die mit dem Zerbröckeln ihrer Zukunftserwartungen schwer zu kämpfen haben.

Neben diesen literarischen Länder- und Kulturschauen westlicher Krisenphänomene gibt es darüber hinaus noch diejenigen Bücher, welche ganz dezidiert dem Geist des Finanzkapitalismus nachgehen und die anthropologische Voraussetzung von Börsenlogik und Fondsgesetzen frei zu schälen suchen, der „Tätergesinnung“ auf die Spur kommen möchten. Es sind Bücher voller zynischer, hochintelligenter Hauptfiguren, die sich geschickt eigene Gewinnsysteme gezimmert haben, um achselzuckend und selbstgerecht schwindelerregende Reichtümer - nicht selten auf Kosten anderer - anzuhäufen. ${ }^{14}$

Gemeinsam haben alle diese Bücher eine Bestätigung, dass vieles schief gelaufen ist und Fundamente gesellschaftlichen Zusammenlebens erodiert sind, oftmals bewusst zerstört wurden - einen vermeintlich illusionslosen, unverstellten Blick auf brutale Realitäten. Und auch wenn jedem einzelnen Beispiel ohne große Mühe ein Roman heiterer, sonniger Gemüts- und Gesellschaftsbilder ent-

7 Simon, Cordula: Ostrov Mogila, Wien 2013.

8 Longo, Davide: Der aufrechte Mann, Reinbek bei Hamburg 2012.

9 Timm, Uwe: Vogelweide, Köln 2013.

10 Hahn, Anna Katharina: Am schwarzen Berg, Berlin 2012.

11 Markaris, Petros: Faule Kredite, Zürich 2011.

12 Chirbes, Rafael: Am Ufer, München 2014.

13 Lanchester, John: Kapital, Stuttgart 2012

$14 \mathrm{Zu}$ denken wäre hier an Goetz, Rainald: Johann Holtrop. Abriss der Gesellschaft, Berlin 2012; Harris, Robert: Angst, München 2011; Magnusson, Kristof: Das war ich nicht, München 2010; Reh, Sascha: Gibraltar, Frankfurt a.M. 2013. 
gegen gehalten werden kann, so bilden sie doch eine Grundströmung der Wahrnehmung (auch protestieren ja nicht alle Menschen einer Gesellschaft, sondern nur einige). Eine, die von Enttäuschungen und Anstrengungen erzählt, von der „ökonomischen Kolonialisierung aller Werte und Ideale“15, von Rückzug und Hoffnungslosigkeit. Aber ebenso von Aufbruch und der Suche nach Alternativen.

Von den Protestierenden in den Interviews, beobachteten Treffen und Veranstaltungen wird die Krise zunächst einmal als Ausdruck eines Zeitgeistes empfunden, der immer mehr Lebensbereiche Entscheidungslogiken unterordnet, welche als bevormundend und ihrem Leben fremd wahrgenommen werden. Ein Widerspruch zwischen Interessen der „Bürger“, zu denen sie sich selbst zählen und einem Komplex aus Wirtschaft und Politik sei über die vergangenen Jahre immer größer und bedrückender geworden. Besonders wirtschaftliche, profitorientierte Entscheidungskriterien sind es, die den Protestierenden als alles andere dominierende Faktoren ein Dorn im Auge sind - alles sei mittlerweile zu einem Wettbewerbsfaktor geworden und alles habe sich einem Konkurrenz- und Wettbewerbsgedanken unterzuordnen. Dies wird in den Gesprächen als Zuspitzung eines neoliberalen Zeitgeistes interpretiert, der den Aktiven Unbehagen bereitet, und der sich - vor allem - politische Entscheidungsstrukturen Untertan gemacht habe.

Eine weitere Facette dieses Krisengefühls ist die Diagnose einer Freiheitsbeschränkung, die in immer mehr privaten und gesellschaftlichen Bereichen zu beobachten sei. Besonders die Freiheit, über bestimmte, unbequeme Sachverhalte öffentlich zu diskutieren, empfinden die Gesprächspartner als derzeit begrenzt. Viele Themen, so wird in den Gesprächen mit bebender Stimme beklagt, seien mit Tabus belegt, wenn diese entweder nicht einer moralischen political correctness entsprächen, oder wenn es um die unverhältnismäßigen sozialen, gesellschaftlichen oder ökonomischen Kosten eben jenen Gewinnstrebens gehe, welches mittlerweile Wirtschaft und Politik durchziehe.

„Also, ich sehe bei uns, [...] dass also nur bestimmte Sachen, gesagt werden dürfen - welche sind strafbewehrt und welche können einen den Job kosten, also, wenn man bestimmte

15 Dieser für einige literarische Verarbeitungen des Themas treffende Ausdruck findet sich in der Rezension des Romans von Rafael Chirbes - man verzeihe mir den Titel: Stephan, Felix: Mutter stört beim Onanieren, Zeit Online, 14.02.2014, online abrufbar unter: http://www.zeit.de/kultur/literatur/2014-02/rafael-chirbes-roman-am-ufer [zuletzt eingesehen am09.09.2014]. 
Meinungen hat, also hier bei uns in Deutschland [...], da haben wir das größten Demokratiemanko." $" 16$

\section{Die Doppelrolle ökonomischer Effizienz - Segen und Bedrohung}

Gerade ökonomisches Denken nimmt in der Krisenwahrnehmung der Protestierenden allerdings eine Doppelrolle ein: Es gilt den Protestierenden als wünschenswertes Ziel und Bedrohung zugleich. Einerseits steht die Bedeutung ökonomischer Effizienz für eine Verengung von Entscheidungskriterien auf Profitmaximierung - ein Kritikmoment, welches in den Jahren der Finanz- und Wirtschaftskrise Auftrieb erhalten hat und in den Interviews auch bei Protestierenden sichtbar ist, welche sich explizit und deutlich von traditioneller Kapitalismuskritik abgrenzen.

„Vieles, was bei Marx und Engels steht, sagen ja heute selbst eingefleischte äh Kapitalisten sage ich mal, dass das im Prinzip alles stimmt, was die geschrieben haben.“17

„Der alte Marx hat nun in vielen Sachen Recht gehabt. Die heute halt nur modernisiert betrachtet werden müssen. “18

Das politische Spektrum der Gesprächspartner aus den Protestgruppen variiert, doch die Begrifflichkeiten und (vulgär-)marxistisches Vokabular sind verbreitet, wenn es um eine Diagnose und Reflexion zeitgenössischer Beziehungen zwischen Wirtschaft und Gesellschaft geht und um die hieraus resultierende Krise. Dies mündet am Ende auch in das beinahe schon klassische Resümee: „Ist eine Systemfrage, klar. “19

Denn was die Protestierenden an ökonomischem Profitstreben kritisieren, ist nicht die Existenz an sich, sondern die Hierarchie an Normen, nach welcher in unserer Gesellschaft Entscheidungen getroffen werden. Dass auch die Politik und Parteien eine ökonomische Logik vertreten und dass ihr eigenes, persönliches Leben sich dieser unterzuordnen habe. Nach dem Ausbruch der Finanz- und Wirtschaftskrise 2008 trifft die darüber gewachsene Salonfähigkeit einer marxistischen Kritik am Kapitalismus - ohne ernsthafte oder tiefgreifende theoretische Reflexion - auf ein gewachsenes Selbstbewusstsein prosperierender Regionen und professionell erfahrener, gebildeter Menschen. Punkte, an denen dies sicht-

16 Marius G1 in der Fokusgruppe G1 in Hannover am 15.03.2012.

17 Einzelinterview Konrad C3.

18 Ulrike E1 in der Fokusgruppe E1 Hamburg am 20.03.2012.

19 Einzelinterview Lothar C2. 
bar wird, sind etwa die Beschwerden über ökonomisch effiziente, aber die Lebensqualität einschränkende Entscheidungen oder Vorhaben, die Spekulation mit Immobilien und enormen Anstiege der Mieten und Häuserpreise in den Wachstumsregionen Deutschlands, der ausgerufene Wettbewerb auch unter Städten, Bildungssystemen, Steuersätzen.

„Das ist einfach die historische Schiene, die [...] Entwicklungen mit der ganzen Symptomatik wie Finanzkrise, wie die Entscheidungsprozesse zu Stuttgart 21 und so weiter. Das ist dieses Primat des Kapitals. Die Durchdringung der gesamten Gesellschaft durch die Prämissen. [...]Wir haben ne Gesellschaft, die neoliberalistisch in ganz vielen Bereichen geprägt ist. Also nicht nur in dem Finanzbereich sondern in ganz, ganz vielen kleinen elementaren Teilen dieser Gesellschaft. “20

Auf der anderen Seite ist allerdings ebenso Ausdruck der Krisenwahrnehmung, dass in anderen Bereichen zu wenig Wettbewerb herrsche. Gerade die Kritik an den Verflechtungen von Politik und Wirtschaft aus Sicht der Protestierenden konzentriert sich auf ein vermeintlich gezieltes Ausschalten von Wettbewerbselementen durch die Maximierung des jeweiligen Profits. Dass sich ergo gerade Politik und Wirtschaft nicht an dem von ihnen selbst postulierten Wettbewerb beteiligten oder Niederlagen kaum jemals akzeptierten.

„Also ich kenne keine Partei, die sich jemals hingestellt hat, und die gesagt hat, was haben wir falsch gemacht, was müssen wir besser machen, ganz im Gegenteil, jede Partei hat jeden Wahlkampf gewonnen...“21

Es ist also nicht ein übersteigerter Leistungsgedanke per se, den die Protestierenden in den Interviews als Krisenursache erkennen, sondern seine Instrumentalisierung und Aushöhlung. Auf der einen Seite ist ein Lamento über die Ökonomisierung des Lebens herauszuhören - auf der anderen Seite wird eine konsequente Anwendung von Wettbewerb und Leistung eingefordert und Wirtschaftsanalogien sind mit beiden widersprüchlichen Konnotationen häufig zu hören. Dies ist auch insofern anknüpfungsfähig an die im Kapitel zu Biographie und Prägung der Protestierenden unterstrichenen Beobachtungen, als dass die Protestierenden von ihren eigenen Fähigkeiten und Leistungspotenzialen im Rahmen der Gesellschaft überzeugt sind. Es handelt sich nicht um ein Klagelied einer Gruppe, die zu den ökonomisch und sozial ausgeschlossenen einer Gesellschaft gehört. Deutlich wird aber die Angst und die Empörung darüber, dass möglich-

20 Pepe C2 in der Fokusgruppe Stuttgart C2.2 am 20.03.2012, 20 Uhr.

21 Paul G1 in der Fokusgruppe Hannover G1 am 15.03.2012. 
erweise andere diese Leistungskriterien umgehen und sich Aufstieg, Einfluss und Entscheidungsraum gegen die offen postulierten Leistungsprinzipien aneignen.

Die Beschwerden über einen allzu „neoliberalen“ Zeitgeist allerdings, der viele Lebensräume und -zusammenhänge untergrabe, zeigen auf der anderen Seite, dass die Protestierenden sich nach Bereichen sehnen, die sie dezidiert nicht einem Wettbewerbsgedanken unterordnen möchten. Der unmittelbare Nahbereich, das Lokale, Nachbarschaftliche werden als dieses Feld betrachtet. Dies zeigt sich in den beiden gegensätzlichen Paaren von Idealen, die in den Gesprächen immer wieder auftauchen: Selbstständigkeit und Autarkie ist die eine Paarung, welche als gesellschaftliches Ideal genannt wird - die andere nimmt Solidarität und Zusammenhalt in den Blick. Beide Wertekomplexe werden in den Gesprächen fortwährend hochgehalten, allerdings seien diese in der diagnostizierten Krise unter Druck geraten.

Das Verhältnis zwischen den beiden Paarungen kann jedoch widersprüchlich werden, etwa wenn Kritiker der Eurokrisenpolitik einerseits die Solidarität unter Nachbarn und auf der nachbarschaftlichen Ebene loben und sich nach stärkerem lokalen Zusammenhalt sehnen - die sie dann als Ausweis lokaler, selbstbewusster Eigenständigkeit verstanden wollen wissen -, und andererseits mit Bezug auf die in Not geratenen Euro-Krisenländer wie beispielsweise Griechenland einen Solidaritätsbezug der Politik dezidiert ablehnen. Lediglich Gruppen (oder Länder), die auf eigenen Beinen stehen könnten und nicht auf die Hilfe oder Almosen anderer angewiesen seien, dürften auch Ansprüche stellen und hätten Respekt verdient. Es scheint also gerade im Zusammenhang der Krisenwahrnehmung bei den Protestierenden ein Spannungsverhältnis zwischen Solidarität und Selbstständigkeit zu geben. Nur, wer selbstständig und autark ist, habe auch Anspruch auf die Solidarität der Gemeinschaft, sollte er in Not geraten.

\subsection{Politische Parteien Als Zuspitzung UNd SYMBOL DER GESELLSCHAFTLICHEN KRISE}

Symbole, welche den Interviewpartnern aus den Protestgruppen als Zeichen für eine grundsätzliche politische und gesellschaftliche Krise gelten, sind vor allem die politischen Parteien sowie das deutsche und europäische Parteiensystem. Kaum eine Metapher drückt dies so deutlich aus wie die vom „Parteienkartell“, welches sich Demokratie, Staat und Gesellschaft unrechtmäßig unterjocht habe. Dass Parteien „geputscht“ hätten gegen die Demokratie, sich ein „Monopol“ geschaffen, eine „totalitäre Demokratie“ etabliert hätten. Es fällt auf, dass es ent- 
weder Begriffe aus der Ökonomie sind, die Parteien charakterisieren sollen oder aber solche, die undemokratische, autoritäre Verhaltensweisen unterstreichen. Parteien werden entweder mit einem Etikett ungehörigen Profitstrebens versehen - oder aber als undemokratische Machterhalt-Organisationen gebrandmarkt. Dies resümieren die Gesprächspartner für das deutsche Parteiensystem auf Länder- und Bundesebene genauso wie für die Europäische Union - lediglich für die Lokalparteien und für die Kommunalpolitik werden hier bisweilen Ausnahmen gemacht. Auch wird kaum eine Unterscheidung gemacht zwischen „Volksparteien" als großen Sammlungsorganisationen und kleineren Parteien.

Parteien seien heutzutage kein Ausdruck einer lebhaften Demokratie mehr, bei der von der Basis aus Ideen entwickelt werden, und welche einen demokratischen Entscheidungsfindungsprozess tragen könnten, sondern zu nepotistischen Organisationen verkommen, deren einziges Ziel das gegenseitige Protegieren und die Vetternwirtschaft sei.

Natan C3 beispielsweise sieht gar Parallelen zu China:

,[...] das steht für die Verlogenheit eines Regimes, eine angebliche kommunistische, sozialistische Republik, Herrschaft des Volkes, die ganze Folklore. In Wirklichkeit ist es nur eine schmale Schicht von Parteifunktionären, die ein Land anti-demokratisch regiert. Ja, es ist also eine Diktatur einer gewissen Clique, mehr ist es nicht. Ich entdecke da auch mittlerweile gewisse Parallelen zu Deutschland.“22

Wie überhaupt die Metapher des Realsozialismus relativ häufig bemüht wird, von biographisch ganz unterschiedlich geprägten Protestierenden. Ähnlich dem hier zitierten Fall China, wird oft und gern auf Parallelen zur DDR-Staatspartei SED hingewiesen, die man mittlerweile im deutschen Parteiensystem erkennen könne.

Im Kern sind es zwei zentrale Argumente, die Parteien gleichzeitig als Ursache und Kristallisation einer Krise kennzeichnen sollen: dass sie, erstens, durch ihr Verhalten eine politisch-gesellschaftliche Krise befeuern, und dass sie, zweitens, ihrer Aufgabe, politische Alternativen zu entwickeln, längst nicht mehr nachkommen können. Zum einen habe sich in Deutschland und Europa eine Form von Demokratie etabliert, welche den politischen Parteien eine zentrale Rolle bei der Organisation der Entscheidungsfindung innerhalb der Gesellschaften zuweise. Dies habe aber auf der Annahme beruht, dass Parteien große, wenn nicht alle Teile einer Gesellschaft erreichen und einbinden könnten. Heutzutage seien Parteien aber eben nicht mehr die Vertreter gesellschaftlicher Mehrheiten -

22 Natan C3 in der Fokusgruppe Freising C3 am 25.07.2012. 
nicht, was die Wählerstimmen anbelangt, und schon gar nicht bei den Mitgliedern.

„[...] die Parteien sagen ja immer, sie vertreten das Volk. Wenn man mal so sieht, also wenn du jetzt tatsächlich prozentual hochrechnen würdest, wen sie tatsächlich vertreten, dann ist es höchstens noch ein, wenn die CDU äh und FDP zusammen 48 Prozent haben, sind das in Wahrheit ja nur ungefähr 25 Prozent oder so, weil die größte Gruppe sind ja mittlerweile die Nicht-Wähler.“23

Trotz dieser augenscheinlich zusammen geschmolzenen Fähigkeit, große Teile der Gesellschaft am politischen Prozess zu beteiligen, wird ihnen in den Gesprächen ein damit kontrastierendes Verhalten unterstellt, sich immer mehr Einflussbereiche in der politischen Entscheidungsfindung exklusiv vorzubehalten. Sie benähmen sich dabei wie „Gutsherren“, welche nach eigenem Gutdünken und ohne für eigenes Handeln Verantwortung tragen zu müssen, den eigenen Vorteil und Profit suchen und verfolgen würden. In diesen Mechanismen würden sich die Parteien untereinander gar nicht mehr unterscheiden: Die Binnenlogik einer Partei als Patronage-Organisation für die eigenen Parteieliten und Funktionsträger habe oftmals alle anderen Logiken abgelöst. Parteien gelten den Protestierenden auf der einen Seite als Ursache einer gesellschaftlich-politischen und ökonomischen Krise, da sie mit ihren Entscheidungslogiken eine Politik realisierten, die für viele Menschen zu einer schlechteren Lebensqualität führe. Und auf der anderen Seite lasse sich besonders an Parteien erkennen, dass die Demokratie in die Krise gerate - sie also Verkörperungen und Symbole dieser geworden seien. An dieser Stelle betonen einige der Interviewpartner selbst gemachte Erfahrungen - oder die naher Bekannter - mit Parteiorganisationen, die ihnen den Eindruck verschafft hätten, die Mitglieder an der Parteibasis seien hilf- und machtlos gegenüber den jeweiligen Parteieliten.

„... das fängt schon bei den Nominierung der Politiker an. Ich bin seit 40 Jahren in Wahlausschüssen, das erste Drittel ist betoniert und ein vielversprechender Nachwuchs, der läuft sich unten tot mit Plakate kleben, der hat gar keine Chance...، ${ }^{24}$

Ein zweiter, damit zusammenhängender Vorwurf an Parteien ist die inhaltliche Beliebigkeit, welche fast alle zeitgenössischen Parteien auszeichne. Weil Wahlerfolg und persönliche Ämtersicherung zum einzigen Ziel eingedampft seien, hätten sich Parteien als politische Organisationen entleert und würden program-

23 Einzelinterview Konrad C3.

24 Marcel C3 in der Fokusgruppe Freising C3 am 25.07.2012. 
matische Positionen, Visionen und Ziele von Politik nur noch als kurzfristige Marketing-Instrumente einsetzen. Auf den Punkt gebracht wird hier der Verlust jedweder inhaltlicher Überzeugung beklagt. Beinahe jede programmatische Achse würde in einer politischen Aushandlung zur Disposition gestellt, wenn es dem eigenen Vorteil - Machterhalt oder Machtgewinn - nutze. In ihrem Resümee an dieser Stelle sprechen die Interviewpartner politischen Parteien die Fähigkeit ab, ihrer Aufgabe, politisch wählbare Alternativen und Entwicklungsideen für die Gesellschaft zu produzieren, auch nur halbwegs noch entsprechen zu können.

Darüber hinaus gelten politische Parteien den Interviewten oftmals als ein kaderartiges Organisationsprinzip, welches vollständige Gefolgschaft verlange und für sie das Gegenteil von freiem Denken und auch Sachorientierung darstelle.

„...weil ich nie in einer Partei war, weil ich sozusagen in jeder Partei immer gesehen habe, es gibt Leute, Programmpunkte, Dinge, die mir überhaupt nicht passen. Wo ich mich gar nicht mit identifizieren kann, also kann ich in keiner Partei sein, also kann ich mich mit nichts einlassen. “25

In den Gesprächen wird an diesem Punkt deutlich, dass politische Parteien mit ihrem Prinzip der Integration verschiedener Gruppen und Gedanken den Protestierenden oftmals als eine für sie persönlich unzulässige Reduktion von Komplexität erscheinen. Eine Partei mit einem bindenden Programm, welches die Interessen ganz unterschiedlicher Menschen vereinen und gemeinsam vertreten soll, empfinden sie als etwas, dass ihrer Gedankenfreiheit, ihrer Betonung von Bildung und Aufklärung widerspricht.

„Also, äh, da ich habe nie was gefunden wo ich, man muss ja vielleicht nicht eine 100prozentige Übereinstimmung haben, aber ich glaube, ich habe auch keine 75-prozentige Übereinstimmung mit irgendeiner Partei gefunden... “26

Folgerichtig beargwöhnen sie rasch diejenigen Menschen, die sich in Parteien engagieren, als Profitsuchende, die lediglich das eigene Wohl und Vorankommen im Blick haben - oder aber als wenig motivierte Claqueure und Statisten, die das Streben der Parteieliten ohne Widerstand mit tragen.

25 Vera E1 in der Fokusgruppe Hamburg E1 am 20.03.2012.

26 Einzelinterview Konrad C3. 
„Also es ist ja nicht so, dass du in eine Partei reingehst und sich dort die Klügsten oder so durchsetzen oder irgendwie, [...] die mit den Idealen und die irgendwie, die ein ideales Bild haben, sondern es ist irgendwie die Macht in den Strukturen... “27

Hagen E4 spitzt dieses noch zu:

„Parteien [...] bergen die Gefahr in sich, dass dort viele Menschen ein Gefühl des Zuhause finden, die über die Position, die man dort möglicherweise einnehmen kann und den Aufstieg in irgendwelche Gremien, die einem dann gefühlte oder echte Machtbefugnisse geben, manchmal so ein bisschen das Reflektieren übersehen, warum bin ich hier eigentlich und was mache ich da und ist das wirklich der Sache wegen gut oder [...] bin ich jetzt möglicherweise nur noch für eine Position, weil ich dann in meinem Kreis oder in meinem Bezirk gewählt werde oder nicht kritisiert werde oder möglicherweise aufgestellt werde als nächster Delegierter oder Kandidat oder sonst was?، ${ }^{28}$

Die Interviewpartner selbst verstehen die Ablehnung von politischen Parteien als Auszeichnung für sich selbst und den eigenen Protest, weil man sich den kritisierten Strukturen weder annähert noch bedient, sich ihren Prinzipien und ihrer Denklogik nicht unterwirft.

Gerade Wahllisten werden in den Gesprächen als Verkörperung der negativen Eigenschaften von Parteien und dem deutschen Parteiensystem dargestellt. Hier würden Loyalitäten eingeschworen, die nicht mehr auf das Wahlvolk, sondern lediglich auf die Parteigruppe bezogen seien. Die Tatsache, dass die Wahl von Parteien zu einem Teil über Listen und nicht über Direktkandidaten geschieht, ruft harsche Kritik hervor, weil auf diese Weise keine persönliche Verantwortlichkeit der Mandatsträger entstehen könne - und keine direkte Beziehung zu einer kleineren, regionalen oder lokalen Einheit des Wahlvolks.

Der Ton in den Gesprächen wird allerdings dann leiser und weniger angriffslustig, wenn Protestierende längere Zeit ihres Lebens selbst in oder mit Parteien gearbeitet und sich engagiert haben. Wie im Kapitel zu den ProtestierendenBiographien beschrieben, ist die Verachtung gegenüber Parteien bei denjenigen Protestlern am größten, die nach kurzer Annäherung an eine politische Partei diese Erfahrung als einzige Enttäuschung erlebt und frustriert dieser Möglichkeit politischer Arbeit den Rücken gekehrt haben, weil ihre Erwartungen hinsichtlich Offenheit, Anschluss und direkten Wirkungsmöglichkeiten nicht erfüllt worden waren. Die - allerdings wenigen - Gesprächsteilnehmer mit langjährigen und substantiellen Erfahrungen mit Parteiarbeit sind hier vorsichtiger und bemühen

27 Einzelinterview Axel G4.

28 Einzelinterview Hagen E4. 
sich um Differenzierung. Meist mündet dies dann in eine Schelte der Parteielite und eine Verteidigung der Basis. Es muss allerdings betont werden, dass solche Passagen gerade in den Gruppengesprächen und bei Beobachtungen von Treffen und Aktionen rar gesät sind. Allzu sehr dominiert in der Dynamik der Gruppen ein Empörungston, gegen den sich abwägende Stimmen nur schwer behaupten können. In Einzelgesprächen ist eine mehr nachdenkliche Inszenierung viel häufiger zu hören, bei der unterstrichen wird, wie schwierig die in ganz unterschiedliche Richtungen zerrenden Anforderungen an eine politische Partei heutzutage eben auch deren Arbeit verkomplizierten. Im Zwiegespräch, ohne die aufschaukelnde Kraft einer Gruppe, sind allerdings die persönliche Enttäuschung und Verletzung viel greifbarer, die so häufig zum gewachsenen Motivationskern der Protestierenden gehört, wenn die eigenen Anstrengungen gerade von den politischen Vertretern ignoriert, nicht honoriert oder gar höhnisch verlacht worden sind. Denn wenn die laute, krawallig geäußerte Empörungshaltung als Ansehensressource innerhalb der Gruppen rasch sichtbar wird, so ist die desillusionierte Erzählfigur des Nicht-Gehört-Werdens die Kehrseite derselben Medaille, welche in den Einzelgesprächen gleichzeitig garniert wird mit der Einschränkung der unübersichtlichen, komplizierten Zwischenposition politischer Parteien, welche wiederum auch die eigenen Bemühungen um Komplexitätserfassung unterstreichen soll.

\section{Antisemitische Anklänge im Parteienbild der Protestierenden}

Die Metaphorik und Begrifflichkeit, mit der politischen Parteien begegnet wird, ist durchaus drastisch - und geht in ihrer Schärfe über die Benutzung von Wirtschaftsmetaphern wie dem bereits angeführten „Kartell“ und autokratische $\mathrm{Zu}$ schreibungen hinaus. Bewusst oder unbewusst wird Bezug auf antisemitisch grundierte Bilder und Klischees genommen, wenn Parteipolitik, -logik und -räson an vielen Stellen mit „Geschacher“ „Schacher“, „Taschenspielertrick“ oder „Kungel“ bezeichnet werden. Unlauteres, hinterhältiges Taktieren und übermäßiges Gewinnstreben auf Kosten anderer sind stets Facetten antisemitischer Vorurteile gewesen. ${ }^{29}$

Zur Ausgestaltung des Bürgerentscheids zur Frage des Bahnhofs in Stuttgart, Stuttgart 21, befindet Marius G1:

29 Salzborn, Samuel: Antisemitismus als negative Leitidee der Moderne. Sozialwissenschaftliche Theorien im Vergleich, Frankfurt a.M. 2010, S. 205. 
„Ich glaube, das gehört zu diesen, diesen Taschenspielertricks, so kann man das nicht machen, das gehört nicht in unsere, in unsere Kultur rein.[...] Jetzt kam es natürlich raus, 'Machtspielchen', ne, Interessen von Bundesbahn und was weiß ich, wer da noch... “30

Frederik C1 urteilt über Parteipolitik mit einem ähnlichen Anklang:

„Ich glaube halt, Parteipolitik ist immer ganz stark abhängig von einer Parteiräson. Das heißt und da ist halt immer ganz viel Schacherei mit drin. Volksmund würde sagen Vetternwirtschaft oder so, wo man eben nicht mehr wirklich äh Entscheidungen trifft, die nach ästhetischen oder moralischer, wie auch immer, Gesichtspunkten gefällt werden, sondern einfach nur so: Das ist gerade opportun, und wenn es opportun ist, macht man das halt. Auch wenn man es eigentlich scheiße findet.، ${ }^{31}$

Gleich zwei Stränge verbinden diese Metaphern mit antisemitischen Klischees. Zum einen ist ein ökonomisch argumentierender Antisemitismus seit einigen Jahrzehnten messbar salonfähiger in Deutschland und Europa, als dies etwa für eine rassistische Artikulation gilt. ${ }^{32}$ Dass Juden ,geiziger“, „,berechnender“ oder taktisch geschickter und den Profit über alles andere stellten - diese Ansichten erlangen durchaus breite Zustimmung, wie Umfragen immer wieder unterstreichen. Auch, dass Juden viel Einfluss auf die Wirtschaftswelt, Medien und politische Entscheidungen besäßen und auch eher als andere Menschen in der Lage und willens seien, ,,mit üblen Tricks“ ihre Interessen durchzusetzen. ${ }^{33}$ Dies ist allerdings keine neuzeitliche Entwicklung, sondern ein Bild der Juden und ihrer Stellung und Rolle innerhalb der Gesellschaft, welches bis ins Mittelalter zurückreicht, als sich eine Wahrnehmungstrennung von Spekulation und Geldmacht der Juden einerseits und „,ehrlicher Arbeit“" andererseits entwickelte. ${ }^{34} \mathrm{Ge}$ rade mit Beginn und im Verlauf der Entwicklung des Kapitalismus seit dem 19. Jahrhundert haben diese Stereotype des „Kapitalisten“ als mit antisemitischen Klischees beladener Figur immer wieder Konjunkturen erfahren. Spätestens mit der Banken- und Finanzkrise seit 2008 hat das Bedürfnis, den Strukturen des kapitalistischen Wirtschaftssystems ein Gesicht und eine Konkretisierung zu verleihen, zu einem Aufleben antisemitischer Metaphorik und Schuldzuweisungen geführt: „Personalisierung und Moralisierung von Kritik appellieren an ein Gesellschaftsverständnis, das abstrakte Strukturen nicht begreift, dafür aber konkre-

30 Marius G1 in der Fokusgruppe Hannover G1 am 15.03.2012.

31 Einzelinterview Frederik C1.

32 Vgl hierzu Salzborn: Antisemitismus als negative Leitidee der Moderne, S. 205.

33 Vgl. ebenda, S. 218.

34 Vgl. Laqueur, Walter: Gesichter des Antisemitismus, Berlin 2008, S. 174 - 178. 
te Menschen in die Verantwortung für ein System nehmen möchte, das zugleich als anonym und unfassbar verklärt wird. “" ${ }^{35}$ Die schwer zu fassenden Funktionsweisen des Bankenhandels, das nicht zu durchschauende Dickicht der Wirkungsmechanismen des globalisierten Finanzsystems haben den Bedarf verstärkt, einen fassbaren Schuldigen herauszustreichen. Und auch die im Zuge fortschreitender Globalisierung als immer undurchsichtiger empfundenen konkreten Verantwortlichkeiten des politischen Systems - etwa bei Kandidatenlisten von Parteien, die für viele der Gesprächspartner verschleiern, wer als Mandatsträger anschließend für welche Wahlbezirke und Wähler persönlich ansprechbar und verantwortlich ist - mögen dazu führen, dass eine Betrachtung der Strukturen vernachlässigt wird gegenüber einer Kritik der vermeintlich Verantwortlichen - und „,der Verstand zugunsten des Affekts suspendiert ${ }^{\star 36}$.

Zweitens wird in beiden obigen Zitaten deutlich, dass eine Trennung gemacht wird zwischen denjenigen, die sich um ein Gemeinwohl sorgen und denjenigen, die auf der Suche nach dem eigenen Gewinn andere übervorteilen oder sich am Gemeinwohl bedienen. Politik, Wirtschaft und Parteien gehören für Marius G1 unzweifelhaft zur letzteren Gruppe. Wenn er von den „Taschenspielertricks“ spricht, die „,nicht in unsere Kultur hineingehören“, dann macht dies Parteipolitiker in seinen Augen zu etwas kulturell anderem, außerhalb der Gesellschaft stehend. Auch diese Grenzziehung zwischen der implizit damit begründeten „Eigengruppe“, welche die Definition einer solchen „unseren“ Kultur ausbuchstabieren vermag und einer kleinen, aber mächtigen und strategisch potenten Gruppe von Profiteuren verbindet diese Metaphorik mit der Geschichte des Antisemitismus.

Dies soll nicht effekthascherisch unterstellen, dass Protestgruppen von antisemitischen Affekten getragen seien oder beseelt von ähnlichem Geiste. Gleichwohl aber bieten die in den Gesprächen gefällten Urteile zu Parteien und Politikern Anknüpfungspunkte oder Argumentationslinien, die Parallelen zur Geschichte des Antisemitismus aufweisen. Das Zuweisen negativer, gar ausbeuterischer Eigenschaften hat dabei viele Facetten: die Abgrenzung einer „echten“ von einer lediglich strategischen, meist gar nur geheuchelten Gemeinwohlorientierung; die Vermutung, dass diese Profiteure eigenen Gewinn über das Wohl anderer stellten; das Fehlen unverbrüchlicher charakterlicher Fundamente, die nicht dem Streben nach Macht und Geld untergeordnet würden; das Verschleiern der eigenen Intentionen und die Abkapselung der Entscheidungssphären.

35 Salzborn, Samuel: Antisemitismus. Geschichte, Theorie, Empirie, Baden-Baden 2014, S. 116 .

36 Ebenda, S. 117. 
Beispielhaft beschreibt Emma E2 ihre Sicht auf die Tendenzen politische Parteien, sich eine abgeschlossene Sphäre für ein ungestörtes Gewinnstreben zu schaffen:

„Wer da quer einsteigt, der wird als Störfaktor wahrgenommen. So ist mir das jedenfalls vorgekommen. Und so habe ich's auch erlebt und statt das ernst zu nehmen und eine Offenheit gegenüber und auch sich zu freuen, dass es überhaupt Leute gibt, die sich interessieren, wird man eher sozusagen wieder weggedrängt, weil man in diesem Kungelsystem keinen Platz hat. Das Kungelsystem ist über Jahre festgezurrt. Wer von außen einsteigt, gehört nicht dazu...“37

Nochmal: Das alles soll gerade nicht die Parole herausbrüllen, die hier betrachteten Protestgruppen seien Brut- und Sammelstätte geschichtsvergessener Antisemiten. Der Weg von den hier angeführten Zitaten bis zum Vorwurf des asozialen Verhaltens, zur Schädigung der ,wirklichen“ Gemeinschaft, ist allerdings nicht mehr allzu weit. Vor allem, wenn demgegenüber der von Martin Nonhoff beschriebene gemeinsamen Wille um ein ,symbolisches Äquivalent zum Allgemeinwohl“38 von den Gruppen als Anspruch auf eine hegemoniale Deutungsstellung reklamiert wird.

Interessanterweise werfen einige in den Gesprächen dann Politik, Wirtschaft und Eliten vor, gegen genau dieses von ihnen reklamierte ,symbolische Äquivalent zum Allgemeinwohl“" mit aller Härte vorzugehen - und selbst verfolgt, angegriffen und „ausgerottet“ zu werden. Severin C2 etwa bedient sich hier begrifflicher Anspielungen auf das Motiv der Judenverfolgung, allerdings mit den Protestierenden in der Rolle der Bedrohten:

„...es ist auch für mich hochinteressant gewesen, zu sehen, wie sich sozusagen in einem Freiraum in der Gesellschaft plötzlich ein neues Lebensgefühl entwickelt. Und für mich ist natürlich daher auch sehr schockierend, die Massivität, mir ist auch klar, warum, dass kaputt geschlagen wurde. Das Abholzen der Bäume ist nur ein Vorwand. Im Prinzip ging es darum, dieses neue Lebensgefühl, das hier neu in Stuttgart entsteht, mit Stumpf und Stil auszurotten. ${ }^{\text {(39 }}$

37 Einzelinterview Emma E2.

38 Nonhoff: Politischer Diskurs und Hegemonie, S. 173.

39 Severin C2 in der Fokusgruppe Stuttgart C2.2 am 20.03.2012, 20 Uhr. 


\section{Kompromisse und Koalitionen als Krisenferment}

Das Prinzip, über Koalitionen und Kompromisse immer wieder neu Mehrheiten für politische Vorhaben sammeln und organisieren zu müssen, ist den Interviewten als konstituierendes Moment von Parteienkoalitionen einer repräsentativen Demokratie Teil des Problems. Denn der Charakter einer Koalition als Zusammenspiel verschiedener politischer Kräfte, die einen gemeinsamen Interessenausgleich suchen und diesem dann eine politische Mehrheit verschaffen (wollen), führt für viele Gesprächspartner geradewegs ins Kontraproduktive. Dies beziehen sie sowohl auf eine Kompromisskultur der Entscheidungsfindung innerhalb von politischen Parteien als auch außerhalb, zwischen verschiedenen Parteien oder gesellschaftlichen Gruppen als Beteiligte an Regierungsverantwortung.

„Das gilt für alle Parteien, dass Parteien doch das Problem haben, dass sie durch ihre innerparteilichen Willensbildungsprozesse, die teilweise unglaublich schwerfällig sind, mit Arbeitsgruppen und Kreisvorsitzenden und ich weiß nicht alles... Also, bis dann am Ende eine Position dann gefunden ist, ist die oft weichgespült und nicht mehr sehr präzise. Ist jedenfalls eine gewisse Gefahr und [...] vor allem droht sie immer überlagert zu werden [...] von persönlichen Positions- und Machtinteressen einzelner Beteiligter. [...] Und das sind alles sachfremde Erwägungen, die eigentlich mit den inhaltlichen Prozessen nichts zu tun haben. “40

Auch hier steht dahinter, dass nach der vermeintlich schlechteren, nicht angemessenen Räson entschieden wird; dass es bessere Entscheidungskriterien gebe. Da so gut wie allen Politiker und Parteien ein ähnliches Motiv unterstellt wird, würde darüber hinaus auch gerade an Koalitionsverhalten deutlich, wie stark Parteien ein Machterhaltungsinteresse dominieren würde:

\footnotetext{
„Aber ich kann doch nicht jetzt sagen: Das ist mein Koalitionspartner, ich muss jetzt zwangsläufig mit dem mitstimmen, sondern da muss man doch bereit sein, zu sagen: Hier kommen die besseren Argumente, das ist ein Thema, was von der [...] Opposition besser vorgetragen worden ist, da kann ich doch auch mit denen dann abstimmen. Also, das hat, finde ich, auch etwas mit Demokratie zu tun - ich soll ja die Bürger vertreten und nicht eine Partei. “41
}

40 Einzelinterview Hagen E4.

41 Anna G1 im Einzelinterview Anna und Conrad G1. 
Ganz ähnlich kritisiert dies Rahlf G1 für die innerparteilichen Entscheidungswege:

„....und die Mechanismen in der Partei sind einfach, dass gute Ideen, die vielleicht von der Basis kommen mögen, über die Entscheidungsprozesse weichgespült werden, da wird ein Antrag geschrieben auf der Ebene eines Kreisverbandes, zack [...], dann Landesverband und dann Änderungsanträge, zack, zack, und dann Bundesparteitag, so dahinter kommt dann irgendwie so ein weichgespülter Müll dabei raus, wo man dann sagt, naja, drei Zeilen sind irgendwie, was ich meine, aber es ist alles so weichgespült, deswegen ist auch die Abgrenzung der Parteien, die [...] fällt ja immer schwieriger... “42

Es gibt in den Gesprächen immer wieder auch Momente und Passagen, in denen die Protestierenden unterstreichen, wie sehr sie auch die Abläufe und Komplexitäten von Politik und Verwaltung kennen, ihre Zwänge - Entscheidung hier, Partei da, Wähler dort - nachvollziehen können und betonen, wie wenig sie im Allgemeinen mit Politikern würden tauschen wollen. Einfache Lösungen gebe es kaum mehr, denn unterkomplexe Forderungen zu stellen, gehört, wie bereits angeführt, nicht eben zum Selbstbild der Protestgruppen. Demzufolge herrscht auch ein starkes Misstrauen gegenüber all denjenigen, die vorgeben, ideale, schnelle Lösungen zu kennen.

Die Utopie und das Ideal, welches ihnen allerdings für einen demokratischen Entscheidungsweg vorschwebt, ist dennoch das der ,sachgerechten Lösung“, die es zu erkennen und durchzusetzen gebe. Diese kann unterschiedlich konnotiert werden und vollkommen verschiedene Formen annehmen - der gemeinsame Nenner ist die jeweilige Fähigkeit, dem, was sich die Protestierenden als Bürgerwunsch und Ergebnis vorstellen, am Ende auch zur politischen Durchsetzung zu verhelfen. Im Kapitel zu den Biographien und Prägungen ist bereits auf die hier ebenfalls anschlussfähigen, zentralen Bezugspunkte der Bildung und Aufklärung hingewiesen worden, welche im Idealfall eine solche Lösung erkennen lassen und unmittelbar plausibel machen: gebildete Einsicht in die jedem Problem inhärente Lösung. Hier wird deutlich, dass der oben angeführte Widerspruch zwischen der geforderten Effektivität von Politik, Verwaltung und Wirtschaft einerseits und dem Unbehagen, welches ein auf die Gesellschaft übertragenes Effektivitätspostulat in den Protestierenden weckt, auch die Erwartungshaltung gegenüber denjenigen formt, die dem Buchstaben des Gesetzes nach für die Regierungsarbeit mit verantwortlich sind.

Hinter diesen Gesprächspassagen zu politischen Koalitionen und Kompromissen scheint die Idee durch, dass es für die Protestierenden zwei unterschiedli-

42 Rahlf G1 in der Fokusgruppe Hannover G1 am 15.03.2012. 
che Quellen politischer Legitimation gibt - eine fachliche und eine moralische. Während die fachliche Quelle der Legitimation politischer Repräsentation und ihrer Entscheidungen in der Fähigkeit liegt, „sachgerechte“ und effiziente Entscheidungen zu produzieren, speist sich die moralische aus dem Vermögen, einen abstrakten „Volkswillen“ abzubilden, für dessen Vertretung man als politischer Repräsentant gewählt sei und dem man möglichst weder widersprechen, noch ihn durch politische Kompromisse verfälschen oder verwässern dürfe. Beide Quellen entsprechen den unterschiedlichen Polen der Legitimation, mit denen eingangs Thomas Zittel zitiert worden ist, einer Input- und einer OutputRechtfertigung demokratischer Repräsentation. ${ }^{43}$ Ein politischer Kompromiss, bei dem in Abwägung verschiedener Interessen ein Mittelweg angestrebt wird, verletzt überspitzt betrachtet beide Legitimitätsprinzipien und bekommt einen strengen Geruch des Betrugs, wenn ihm gleichzeitig der Verdacht von Klientelismus und Profitmaximierung der Protagonisten anhängt.

Viele Gesprächspartner äußern sich sinngemäß - was hier Vera E1 auf den Punkt bringt: „Weil diejenigen, die hören sollten, die an der Regierung waren, nicht gehört haben. “44

Dies mag als ein Ausdruck des im überdurchschnittlichen Bildungsstand der Protestgruppen wurzelnden Selbstbewusstseins gelesen werden, wenn erstens die Existenz einer sachgerechten Lösung für selbstverständlich genommen wird, wenn zweitens die Kenntnis selbiger mit ruhiger, erfahrungsgesättigter Gewissheit bei einem selbst und den Protestgruppen angenommen wird denn auf der Seite der offiziellen, hauptberuflichen Politik oder Verwaltung - und wenn drittens das Fehlen persönlicher Verantwortbarkeit als geradezu unerträglich empfunden wird. Alle drei Beobachtungen deuten auch deswegen auf Bildungs- und Berufserfahrung als Kraft hin, als dass Krisenempörung und Parteienkritik am lautesten bei älteren Protestierenden zu hören ist. Gerade bei diesen älteren Teilnehmern an den Gesprächen mischt sich dann eine (berufliche) Arriviertheit und ein Bewusstsein über das persönliche Erreichte mit der Tatsache, dass sie aus einem normalerweise reicheren Fundus an Berührungen mit Politik, Parteien und Politikern erzählen können.

43 Vgl. Zittel: Wie viel und welche Partizipation braucht die Demokratie?, hier S. 8.

44 Vera E1 in der Fokusgruppe Hamburg E1 am 20.03.2012. 


\title{
Dynamik von Krisenempfinden - Ursprung und Ergebnis des Engagements
}

Der europäische Einigungsprozess und die etablierten Formen der Europäischen Union sind den Interviewten ein ganz besonderes Ärgernis. An dieser Stelle ist in den Gesprächen eine fast schon aufbrausende Wut bei vielen Teilnehmern spürbar - auch, wenn sich ihr Engagement nicht konkret auf europäische Fragestellungen bezieht, wie im Fall derjenigen, die sich gegen die Rettung des Euro oder insgesamt gegen die Gemeinschaftswährung wenden. Die EU als Fleisch gewordener Einigungsgedanke stößt die Protestierenden durch eine Überzahl an Vetospielern, den faulen Charakter politischer Kompromisse und die Vernebelung von persönlicher Verantwortlichkeit ab. Dass ein politisch und demokratisch wohlfeiles Argument - das der Einigung, des Zusammenwachsens und der Friedenssicherung - von der Europäischen Union selbst mit Füßen getreten werde und im eigentlichen Sinne nur der ökonomischen Interessen von Großkonzernen wie dem Machterhaltungsstreben der nationalen und europäischen Politik diene, gilt in den Interviews als ausgemacht. Das Gefühl, einen Wert, den sie prinzipiell unterstützen und achten, in sein Gegenteil gekehrt zu finden, macht sich in diesen Gesprächspassagen Luft.

„Und jetzt diese ganzen furchtbaren Dinge, die da ablaufen auf europäischer Ebene, das ist natürlich dann für uns ein weiterer Beweis dafür, dass ähm direkte Demokratie notwendig sein muss, um sowas zu verhindern. ${ }^{.45}$

Und Rüdiger C1 führt seine Sichtweise auf die EU folgendermaßen aus

\begin{abstract}
„Also, ich habe auf der EU-Ebene mitgekriegt, die Carolin Lukas, im Zusammenhang mit den Verhandlungen der EU Kommission im Rahmen des General Agreement on Trade and Services, da gab es spezielle Verfahren: Die war die Sprecherin der europäischen Grünen-Fraktion im Europaparlament und durfte nur unter Aufsicht eine versiegelte Box aufmachen, wo ein mehrere hundert Unterzeichnungen fassender Vertragsentwurf der EU Kommission bezüglich der Öffnung anderer Länder - Dienstleistungssektors, der sehr umfassend ist. Sie durfte keine Notizen machen, sie durfte nichts notieren und sie musste eine Verschwiegenheitserklärung unterschreiben, bei Zuwiderhandlung 15000 Euro Strafe. Es darf nicht sein, dass die Vertreterin im Europaparlament [...] - alle Fakten auf den Tisch, von wegen! Also, es gibt genug Beispiele. ${ }^{\star 46}$
\end{abstract}

45 Einzelinterview Holger G7.

46 Rüdiger C1 in der Fokusgruppe C1.1 in Stuttgart am 20.03.2012, 17 Uhr. 
Die längsten und intensivsten Passagen zum Thema EU sind in den Gesprächen mit Protestierenden zu finden, die sich in ihrer Kritik und Arbeit dezidiert mit dem Thema auseinandergesetzt und sich in der Folge eine detaillierte Einsicht in Funktionsweisen der EU erarbeitet haben. Hier dreht es sich stellenweise seitenlang um Abwegigkeiten und Schwejk- oder Schildbürgergeschichten, bis hin zur Schilderung ganz bewusster Rechtsbeugungen oder -verstöße, die man in der Brüsseler Politik und Bürokratie vermute.

„Wir kriegen momentan ein Europa, wo die meisten Menschen nicht mehr so glücklich sind, weil's überreguliert wird, immer noch mehr Richtlinien rauskommen... “47

Denn dass die Parteien oder die offizielle Politik - auf europäischer, aber eben genauso auf nationaler oder Länderebene - ihre Machtpositionen mit Zähnen und Klauen verteidigen, davon sind die Protestierenden überzeugt und finden dies durch ihre Protestarbeit bzw. die Reaktionen darauf regelmäßig bestätigt.

Fast alle können von Erlebnissen erzählen, an denen erst gemachte Versprechen von Einfluss und Gehör sich rasch wieder zerschlugen, bei denen auf wohlklingende Verlautbarungen nichts, oder dem verständnisvollen Gespräch im Ministerium monatelange Funkstille folgte. Bei den vielen verständnisvollen und „positiven“ Gesprächen mit Ministern, Ministerpräsidenten und Staatssekretären, denen jedoch nie etwas folgte; oder bei Bürgerversammlungen und Anhörungen, bei denen ihnen schon durch die Sitzanordnung ihre Ohnmacht gegenüber den Vertretern der öffentlichen Hand oder der Wirtschaft vor Augen geführt wurde. Und Empörung empfinden sie vor allem, wenn sie das Gefühl haben, man möchte sie mit ihrer Argumentation ein wenig für dumm verkaufen oder als starrköpfig und gestrig darstellen. Sie aber haben sich tief in die Materie eingearbeitet, haben sich detailliert mit dem Wachstum der Flugbewegungen, mit der Abhängigkeit dieser vom Ölpreis, mit der parallelen Entwicklung des Schienenverkehrs, den Details von Finanz- und Währungspolitik oder der Pädagogik etc. beschäftigt. Wenn sie den Eindruck gewinnen, man speise sie zum wiederholten Male mit Argumenten ab, die sie schon längst widerlegt sehen, verlieren sie den Glauben, ernst genommen zu werden. Aus dieser Konstellation entsteht viel Kraft für den Widerspruch.

In ihrer Krisenwahrnehmung findet sich deutlich die Hypothese Ingolfür Blühdorns geteilt, nach dem sich zeitgenössische Politik durch eine Simulation von Offenheit und Responsivität versuche, Bewegungsspielraum zu erhalten - 
um gleichzeitig ohne ernsthafte Einbeziehung möglichst effizient schalten und walten zu können. $^{48}$

Susanne E1 fasst dies als „trügerische Demokratie“ folgendermaßen zusammen:

„...ich hab das Gefühl, dass trotz Demokratie [...], dass man trotzdem an die eigentlichen Entscheidungsstellen nicht ran kommt, dass da im Endeffekt doch das gemacht wird. [...] Das ist so eine trügerische Demokratie, dass wir Bürger in dem Glauben gehalten werden, wir dürften was sagen und wir hätten was zu sagen, aber dass dann trotzdem andere Entscheidungen gefällt werden.“49

Aus den Interviewpassagen zur Wahrnehmung einer gesellschaftlichen Krise lässt sich auch erkennen, dass diese nicht nur Ursache und treibende Kraft eines Engagements im Protest ist, sondern durch die Protestarbeit wesentlich entwickelt und geformt wird. Die Krise wird entwickelt und interpretiert vor dem Hintergrund des jeweils eigenen Protest- und Engagementfeldes und ihre Analyse konzentriert sich auch auf die jeweiligen Logiken und Akteure. Politische Entscheidungen und Erlebnisse, mit denen die Protestierenden nicht einverstanden sind, werden zum Ausgangspunkt ihrer Gesellschaftsdiagnose. Für Gesprächspartner aus den Gruppen der Euro-Kritik sind die Europäische Union gemeinsam mit der deutschen und internationalen Fiskal- und Bankenpolitik und ihnen unterstellte „Verdummungsinteressen“ der Keim ihrer gefühlten Wut. Der Zusammenhang aus Politik, Planung und Wirtschaft und ihre „Großmannssucht“ gelten den Engagierten im Rahmen von Infrastrukturprojekten als Wurzel vieler Übel. Die ,kapitalistische Verwertungslogik“ wiederum als Ursprung einer Krise wird von einigen Gruppen im Themenbereich der Bildungsreformen wie auch der Stadtviertelproteste zum Ausgangspunkt genommen.

Zudem wird deutlich, dass eine gesellschaftliche Krise die Protestierenden nicht als einmal gemachte Erkenntnis in ihr Engagement gedrängt hat, sondern dass vor allem ihre Erfahrungen mit Politik, Parteien, Politikern, Verwaltung, Medien und Wirtschaft im Rahmen ihrer Tätigkeit als Protestierende ihre Krisenwahrnehmung zuspitzen und vertiefen. Gerade durch Erfahrungen fühlen sie sich in ihren Urteilen bestätigt, konkretisieren und vertiefen sich ihre Monita. Denn ein Großteil der Krisenbegründung eines jeden Protestierenden speist sich nicht nur aus der ursprünglichen Leerstelle oder empfundenen Fehlentwicklung, gegen die sich das Engagement richtet. Dies zwar auch. Über die Zeit des Engagements aber beschäftigen sich die Protestierenden intensiv und eingehend mit

48 Vgl. Blühdorn: Simulative Demokratie.

49 Susanne E1 in der Fokusgruppe Hamburg E1 am 20.03.2012. 
Politik und den von ihnen vermuteten Fehlentwicklungen, arbeiten daran, diesen argumentativ begegnen zu können und entwickeln immer ausgefeiltere Begründungen, warum etwas inakzeptabel und zu ändern sei.

Darüber hinaus spielt die Tatsache, welche Erfahrungen sie mit ihrem Engagement machen, eine große Rolle für das Krisenempfinden. Dass die gewünschten Ergebnisse nur mühselig und langfristig erarbeitet und erkämpft werden können - oder eben überhaupt nicht - und dass politische Entscheidungen für sie ganz persönlich eben nicht als offen und beeinflussbar erscheinen, trägt viel zum Aufbau einer Frustration bei. Eine Verschärfung der Krisenempörung dadurch, dass die Politik nicht ,auf den Bürger“, und nicht mal „,auf sie persönlich“ hört.

Auffällig ist, dass sich die einzelnen Protestgruppen in ihrem Krisenempfinden hinsichtlich Demokratie und Gesellschaft unterscheiden, und dass dieses auch eine Ableitung ihrer Erfahrungen im Engagement bildet. ${ }^{50}$ Wenn etwa in München-Freising Staat, öffentliche Verwaltung und multinationale Konzerne (wie eben die Flughafenbetreibergesellschaft, gegen die sich der hier beobachtete Protest hauptsächlich wandte) angesichts ihrer vermeintlichen Inkompetenz mit Spott und auch mit großer Skepsis bedacht werden, herrscht hier gleichwohl in den Gesprächen und Fokusgruppen ein vergleichsweise versöhnlicher Ton vor. Die repräsentative Demokratie an sich sei etwas Gutes und auch die Polizei und ihr Verhalten könne man nach den eigenen Erfahrungen nur positiv beurteilen. Die Erfahrung, mit dem eigenen Engagement auch große und mächtige Gegner ,in die Schranken“ weisen zu können, lässt sie in Relation zu anderen hier versammelten Protestgruppen milde und offen urteilen. Denn das Ergebnis eines Bürgerentscheides in München hat ihnen 2012 erst einmal Recht gegeben, ihre Arbeit zu einem mindestens zwischenzeitlichen Erfolg geführt. Bei den Stuttgarter Protestgruppen, welche sich gegen den Bahnhofsneubau engagierten, ist allerdings nach dem Verlauf des Protests, den Schlichtungsgesprächen und der Volksabstimmung zum Zeitpunkt der Interviews 2012 Ernüchterung eingekehrt, nicht selten auch eine zynische Verbitterung angesichts der eigenen Machtlosigkeit. Demokratie und Politik werden harsch und verächtlich mit Kri-

50 Dieter Rucht verweist für diesen Zusammenhang auf Ottheim Rammstedt bei der Frage nach der Verstetigung von Bewegungen - diese müssten sich stets verändern, immer wieder anpassen, um die Motivation und Kraft ihrer Mitglieder aufrechtzuerhalten. Auch dies mag hier zu beobachten sein, dass Gruppen und Protestbewegungen immer wieder vor der Herausforderung stehen, sich an den Ergebnissen ihrer Arbeit stets neu zu verorten. Vgl. Rucht, Dieter: Gesellschaft als Projekt - Projekte in der Gesellschaft. Zur Rolle sozialer Bewegungen, in: Klein, Ansgar / Hans-Josef Legrand / Thomas Leif (Hrsg.): Neue soziale Bewegungen: Impulse, Bilanzen und Perspektiven, Opladen 1999, S. $15-27$. 
tik bedacht und angesichts der Eskalation von Demonstrationen wird auch an der Polizei als „Vollstrecker“ des Staates kein gutes Haar gelassen. Bei den Hamburger Stadtviertelprojekten wiederum, nach etlichen Jahrzehnten der Erfahrung der Protagonisten, nach harten - auch physischen - Auseinandersetzungen, hat man sich auch rhetorisch ein wenig zurückgezogen, legt mehr Wert darauf, die eigenen Werte im persönlichen Umfeld zu verwirklichen. Scharfen Konflikten versucht man bewusst aus dem Weg zu gehen, zumindest diese nicht unkontrolliert herauszufordern, auch weil die physische Gewalt gegenüber der heutigen gut ausgerüsteten Polizei und den Gesetzen der medialen Landschaft ihren Zielen eher schaden als nutzen würde. ${ }^{51}$ Auch bei den Gruppen der Eurogegner oder bei den Bildungsprotesten findet man sehr deutlich sichtbar, dass Krisenempfinden, Protesterfahrung und erzielte Protestergebnisse in einer engen Beziehung miteinander stehen. Erfolg macht zufrieden, während Misserfolg und gefühlte Ablehnung zynisch und beissend werden lässt.

Auch die Reaktionen der jeweiligen Konfliktgegner auf die Protestgruppen tragen zur Entwicklung ihres Krisenbewusstseins bei. Attacken auf die eigene Arbeit und das eigene Tun können motivieren und bestätigen, wenn sie als Zeichen dafür genommen werden (können), dass die eigenen Proteste Wirkung zeitigen und die richtigen Stellen und Ansätze gewählt haben. Das Gefühl, man repräsentiere nicht eine kleine Gruppe, sondern stehe für eine Gesellschaftsidee, für eine Art ideelles Ganzes, welches der Gegenüber - sei es die Politik, eine Partei, ein Konzern oder eine gesellschaftlich mächtige Interessengruppe - verhindern möchte, kann Kräfte verleihen.

„Natürlich. Die Adressaten haben es bemerkt, fühlen sich auch getroffen, denn ein getroffener Hund bellt, das ist ganz klar, dass die deswegen so giftig sind, weil die gemerkt haben, man hat sie durchschaut und das äh finde ich, war denn die ganze Sache schon mal wert. “52

Dass in vielen Gesprächen die eigene Protestgruppe als „Widerstandsbewegung“, ,-gruppe“ oder schlicht „Widerstand“ bezeichnet wird, deutet darauf hin, dass sich viele Protestierende selbst als Kämpfer wider eine empfundene Krise bzw. deren Phänomene begreifen. Und jede Reaktion der Gegenseite, die nicht Anzeichen einer Kapitulation in sich trägt, bestätigt und verstärkt dann die Weltund Krisenwahrnehmungen, welche sich seit Beginn des Engagements entwickelt haben.

51 Hierzu beispielhaft ausgeführt Butzlaff u.a.: „Wir lassen nicht mehr alles mit uns machen!“, hier S. 62.

52 Einzelinterview Fred G5. 
Insofern könnte man die gemachten Erfahrungen der Protestgruppen als einen Faktor deuten, der von ersten Euphorie und Überlegenheitsgefühl über bittere Enttäuschungen bis zum kühl bilanzierenden „Management“ von Konflikten reicht und sich auch in der Beziehung der Akteure zur Demokratie niederschlägt, in der sie leben. Aus den Gesprächen eindrucksvoll zu lesen findet sich die Erfahrung des Protests als eine Einflussgröße wieder, welche die Frustration und das Empfinden einer gesellschaftlichen, politischen und ökonomischen Krise oftmals eher verstärkt als diese dämpft. Engagement, Widerspruch, das SichEinbringen führt nicht unbedingt zu größerer Empathiefähigkeit für „,das System“ mit seinen Protagonisten, oftmals im Gegenteil. Je mehr sie sich hineingearbeitet haben, je mehr sich die Gesprächspartner mit Details beschäftigt haben und erfahrungsgesättigt erzählen können - umso selbstbewusster und auch abgeklärter wird Bilanz gezogen.

„Wir haben ein Demokratiedefizit. Ich sehe das einzige Korrektiv, nachdem es die Medien scheinbar nicht mehr sind, im Bürger. Und der Bürger würde es nicht als Gottes Geschenk bekommen, sondern muss sich das erkämpfen. “53

\section{Die „Anderen“ - Desinteresse als Krisenursache}

Einen wichtigen Teil in der Perspektive auf eine gesellschaftliche Krise, welche die Protestierenden sichtbar werden lassen, nehmen die „Anderen“, die NichtProtestierenden, die „schweigende Mehrheit“ ein. Auch wenn das Bemühen spürbar ist, sich nicht allzu polternd patriarchalisch zu geben, nicht allwissend über den vermeintlich trägen und inaktiven Teil der Gesellschaft zu schimpfen, bleibt eine Frustration darüber merkbar präsent, dass viele nicht die gleiche Empörung in sich spüren wie die Interviewten selbst. Dabei ringen allerdings mehrere Seelen in der Protestbrust miteinander.

Zum einen und an vorderster Stelle eine Enttäuschung, dass ihre Protestbotschaft - ihrer Sicht nach - noch nicht große Massen an Mitstreitern hat überzeugen können, dass viele Menschen für sie nicht ansprechbar scheinen.

„Die Leute machen nicht mit! Die Leute wollen halt lieber ihr beschissenes Ipod als da mitzumachen. Und das ist die Grundbasis für alles, wie man es nennt, mit was man es vergleicht. Das ist das Problem und das kennt doch jeder in seinem Umfeld. Die Leute gehen ja nicht mal aus freundschaftlicher Verbundenheit mal zum Test mit. Sie bleiben lieber

53 Rüdiger C1 in der Fokusgruppe C1.1 in Stuttgart am 20.03.2012, 17 Uhr. 
Zuhause und konsumieren in irgendeiner Weise, mit solchen Scheuklappen. Das ist mein Punkt, der mich am meisten auf die Palme bringt. ${ }^{\text {(55 }}$

Wenig später sekundiert eine weitere Teilnehmerin der Gruppe:

„Mich hat auch von Anfang an hier gestört, dass in meinem Bekanntenkreis also am Anfang, wenn man sagt, ach komm doch mal mit zur Montagsdemo: Nein, da hab ich immer Yoga. Also da kann ich nicht. Und das fällt mir also sehr stark auf, dass die Leute [...] so ne vollgetaktete Freizeitplanung haben, also manche da nicht von ablassen können. Das muss durchgezogen werden und das ist ganz wichtig und der nächste Urlaub und was weiß ich nicht alles. ${ }^{\text {“55 }}$

Deutlich wird, dass eine materielle und emotionale Sättigung oder Betäubung von großen Teilen der Gesellschaft für die Gesprächspartner Ursachen dafür sind, dass eine Wende zum fundamental Besseren noch nicht erreicht werden konnte.

„,...aber das ist ja auch das Problem von dem Bürger: dem geht es einfach noch viel zu gut. Wir leben noch in einer Wohlstandsgesellschaft, wo man sagen kann, mir geht es gut, warum soll ich das noch ändern? Mir geht es gut unter der CDU, mir geht es gut unter der SPD, mir geht es auch gut unter den Grünen, warum soll ich denn zur Wahl gehen, egal wer ran kommt, mir geht es immer noch gut. [...] Er hat es einfach noch nicht realisiert, dass es irgendwann, im großen (unverständlich, Anm. FB) ein Leben geben kann, wo es uns dann nicht mehr gut geht...“

Dass der Problemdruck in den verschiedensten Bereichen - jeweils ausgehend vom eigenen Protestthema - von einer Mehrheit der Bevölkerung als (noch) nicht so groß und drängend wahrgenommen wird, um sich unverzüglich dagegen engagieren zu müssen, bekümmert diejenigen, welche diesen Schluss schon gezogen haben. An einigen Stellen weisen die Gesprächspartner diesen „Unbeteiligten“ dann auch keine geringe Rolle an den von ihnen diagnostizierten Missständen zu:

„(In der Demokratie, Anm. FB) da gibt es sehr viele Schwächen, aber das liegt daran, dass sich zu wenige Leute engagieren also. Eine Demokratie ist anspruchsvoll und funktioniert

54 Perry C2 in der Fokusgruppe Stuttgart C2.2 am 20.03.2012, 20 Uhr.

55 Nelly C2 in der Fokusgruppe Stuttgart C2.2 am 20.03.2012, 20 Uhr. 
nur, wenn sich ausreichend viele, sagen wir mal, fähige Menschen engagieren und dann auch in der Politik aktiv werden. ${ }^{\text {"56 }}$

Erkennbar wird, dass ein Selbstbild existiert, in welchem der Engagierte zu einer tragenden Säule einer ,guten“ Demokratie und Gesellschaft wird. Wenn im Kapitel zur Biographie und Prägung davon die Rede war, dass ein Erweckungserlebnis und eine Erkenntnis über Fehlentwicklungen und $\mathrm{zu}$ verteidigende Grundwerte von den Protestierenden für ihre Biographie auch als wirksam werdende Handlungsanleitung angenommen wird - dann wird aus den hier zitierten Beispielen deutlich, dass genau dies eine Scheidelinie zwischen den Aktiven und den Passiven einer Bevölkerung konstruiert. Einsicht und Aktivwerden trennt folglich die Bevölkerung in eine kleine Gruppe, welche sich um ein Gemeinwohl sorgt und dafür interessiert, Kraft, Zeit, Energie und Geld für das Wohl aller einsetzt - auch, um Übles abzuwenden; und in eine große Gruppe auf der anderen Seite, welche zwar von deren Anstrengungen profitiert, aber selbst nichts beizutragen bereit ist. Die Protestierenden werden aus dieser Perspektive also nicht nur zu einer Art Einsichtselite, die aufgeklärter auf die Welt schaut, sondern die sich auch insofern mit moralischen Weihen ausgestattet sieht, weil sie für die Nichtaufgeklärten die Arbeit am Gemeinwohl mit übernimmt. Die Kehrseite dieser Medaille ist ein fehlendes Verständnis für Menschen, die sich ihren persönlich bereits gewonnen Einsichten verweigern, oder die - fast noch schlimmer nicht in der Lage dazu sind, ähnlich konsequent die Lehren aus ihren Überzeugungen zu ziehen.

„Was ich ganz wichtig finde, dass zum Beispiel Reden und Handeln ähnlich ist. Also, mich macht es wahnsinnig verrückt, wenn Leute über alles Schimpfen und über die Ungerechtigkeiten, weiß nicht und dann ach beim Aldi gibt es das billig und man weiß genau, also das kann nur, sagen wir aus China unter den billigsten Bedingungen, aber man könnte es sich auch leisten und man bräuchte auch nicht zehn Hosen, aber man geht dahin - also das sind Sachen, die mich einfach wahnsinnig machen, wenn Leute sprechen, oder sich über irgendetwas beschweren und dann aber anders leben oder diese Vorzüge wahrnehmen. “57

Insofern wird die Existenz von vermeintlich tumben, trägen oder nicht für ein Gemeinwohl zu aktivierenden Menschen auch zum Ausweis, dass man selbst eben zum Gegenteil gehört: stringent, rational, den eigenen Erkenntnissen über die Kausalitäten der Welt folgend. Man wird auf diese Weise zu einem Vor-

56 Ulrike E1 in der Fokusgruppe Hamburg E1 am 20.03.2012.

57 Sybille C3 in der Fokusgruppe Freising C3 am 25.07.2012. 
kämpfer für eine gute Sache, stellvertretend auch für diejenigen, die sich der gleichen Sache (noch) verweigern.

Dies wird auch deutlich daran, dass an vielen Stellen in den Gesprächen laut und deutlich und mit bebender Stimme unterstrichen wird, dass man keinesfalls zu denjenigen gehöre (und auch nicht gehören möchte), die sich für „Partikularinteressen“ engagierten. Das „Partikulare“ gehört zu den Begrifflichkeiten, die durchweg negativ konnotiert und mit einer kalten Schulter des Verrats an der Allgemeinheit geziehen werden. Und nichts macht dies so deutlich, wie die Benutzung der Wendung vom heiligen St. Florian: „Heiliger Sankt Florian / Verschon' mein Haus / Zünd' and're an! " Bezug auf dieses St.-Florians-Prinzip wird an vielen Stellen genommen, stets in der Absicht, sich von dieser Art Bürgerprotesten klar abzugrenzen. Es ist der Versuch einer Delegitimation einer bestimmten Art von Protest - nämlich eines vermeintlich bourgeoisen, bürgerlichen Protests, der sich um seine Privilegien sorgt.

„Wenn man analysiert, wer protestiert denn da, da sind auch viele Leute, die im Grunde genommen ihr städtisches Milieu, so wie sie es haben und bloß kein Stau und bloß keine Belästigung durch den Bau; und ich komme aus der Bauwirtschaft und ich weiß, wie das funktioniert. Ich sage mal, der letzte, der baut, der ist wirklich der Gekniffene, weil alle anderen, die ein Jahr vorher gebaut haben, die sagen: "Aber jetzt, aber kein Krach, jetzt aber kein Dreck und kein Lärm". Und das ist etwas, das sich in unserer Gesellschaft immer mehr verbreitet, wie das Sankt-Florians-Prinzip: Energie wollen wir alle, aber eine Biogasanlage bitte nicht in meiner Nachbarschaft..." ${ }^{\text {.58 }}$

Man selbst unterstreicht aber mit diesen Passagen, dass das große Ganze, das Allgemeinwohl, altruistisch im Herzen des eigenen Engagements und Strebens liegt.

„... deshalb bin ich entschieden der Meinung, ich habe mich nicht eingesetzt für ein Interesse, was mir speziell zu Gute kommt, sondern genau mich dafür eingesetzt, dass Bildung in Hamburg staatlich auf hohem Niveau für alle Kinder gleich zugänglich ist. Das ist mal wirklich mein wichtigstes in dieser Volksinitiative gewesen und nichts anderes. “59

Die Existenz einer Mehrheit in der Bevölkerung, die sich nicht aktivieren lässt, gilt wiederum den Gesprächspartnern nicht nur als Beweis, dass man selbst zu einer Art Chosen Few gehört, wie schon im Kapitel zu den Biographien und Prägungen herausgearbeitet. Sie macht ihnen darüber hinaus deutlich, wie wich-

58 Rahlf G1 in der Fokusgruppe Hannover G1 am 15.03.2012.

59 Vera E1 in der Fokusgruppe Hamburg E1 am 20.03.2012. 
tig die Rolle von Protesten als Korrekturinstanz zum vermeintlich marode gewordenen und verkommenen Parteiensystem mittlerweile sei. Denn auf die „Mehrheit“ könne kein Verlass sein, sie stelle einen unsicheren Kantonisten dar, weil sie noch nicht durch hinreichend „Aufklärung“ konditioniert worden ist.

In diesem Sinne sind viele der interviewten Protestierenden fast Vulgärmarxisten, die erwarten, dass es aus einer Einsicht in die Objektivität der Dinge zu einer gemeinsamen Idee und Bewusstsein und in einem nächsten Schritt zu einem konsistenten gemeinsamen Handeln kommt. Die Protestierenden übernehmen in diesem Modell die Rolle der Kader, welche dem Rest vorangehen, zur Aktion schreiten, die Vorhut bilden.

\section{Medien - Adlaten der Politik und notwendiges Übel}

So wie sich das Politik- und Parteienbild der Protestierenden aus der Verarbeitung der von Ihnen gemachten Erfahrungen in ihrem Engagement ableiten lässt, speist sich auch das Urteil über die Medien als Einflussgröße einer demokratischen Öffentlichkeit aus diesen Erlebnissen. Und analog zum Politikverständnis variiert auch die Betrachtung der deutschen und europäischen Medien über die Gesprächsgruppen mit der gefühlten Erfolgsbilanz der Gesprächspartner.

Eine zynische, beissende Betrachtung der Medienlandschaft ist gerade dort nicht zu überhören, wo die Interviewten in den vergangenen Jahren das Gefühl gewonnen haben, von einem übermächtigen Gegner bekämpft zu werden, der ihnen den Zugang zur Information breiterer Öffentlichkeit über Print-, Radiound Fernsehmedien erschwert oder verunmöglicht.

Dass Politik und Parteien sowie Wirtschaftsunternehmen Medien für ihre Zwecke einsetzen und daher die verfügbare Berichterstattung verzerrt ist und strategisch manipuliert, davon sind die meisten Gesprächspartner überzeugt. Eigene Schwierigkeiten, mit ihren Anliegen mediale Abnahme zu finden, gelten ihnen als bester Beweis dafür.

„...das ist auch ein bundesweites Abkommen wahrscheinlich aller Medien, die wir hier haben. Das heißt, die wollen uns auch nicht sehen, wollen uns auch nicht sehen, weil die haben definitiv Angst davor, dass wir zu viel Macht gewinnen, [...] Und da muss ich sagen: da kriegt man schon einen Riesenhals, wie das denn passiert. Das heißt: Das ist eindeutig politisch gesteuert, mit Geldern, die von den großen Parteien kommen...“60

Medien spielen für die Protestierenden deswegen eine zentrale Rolle, weil sie eine Schlüsselfunktion in ihrem Aufklärungsstreben übernehmen, welches in den

60 Conrad G1 im Einzelinterview Anna und Conrad G1. 
vorangegangenen Kapiteln und auch in den Seiten dieses Kapitels zu den (noch) nicht Aktiven Gesellschaftsgruppen angesprochen worden ist. Eine sachgerechte und nicht manipulierte Multiplikation ihrer Anliegen in eine breite Öffentlichkeit, da sind sich die Protestierenden sicher, würde ihnen rasch wesentlich größere Unterstützerkreise bescheren.

Auf der anderen Seite bietet diese Wahrnehmung der Medien den Gesprächspartner aber auch eine Möglichkeit, ihre eigenen Aufklärungsanstrengungen zu unterstreichen. Umso mehr die Medien in einer Gesellschaft als ausgewogener Informationskanal der Bevölkerung ausfallen - wovon die meisten, wie betont, ausgehen -, umso stärker ist eine selbstbewusste Bevölkerung auf $e i$ gene, persönliche Anschauung zurückgeworfen. Dieses Selbstbewusstsein ist in den Interviews sehr präsent: dass der ganz eigene Eindruck sie bestätigt, dass Medien oftmals zu einem Manipulationsinstrument der Politik verkommen seien, dem man nur mit eigener Urteilssicherheit entgegen treten könne:

\begin{abstract}
„Also, über Zeitung, merkt man auch bei Stuttgart 21, geht es nicht. Also, da kann man höchstens Leserbriefe schreiben, aber man findet ja das, was tatsächlich passiert, nicht in der Zeitung. Das war auch ein Aha-Erlebnis, ich gehe irgendwo hin, sehe mit eigenen Augen, es passiert was, und am nächsten Tag lese ich in der Zeitung genau das Gegenteil.“61
\end{abstract}

Denn die Annahme, Medien seien manipulativ und gesteuert, macht die Protestierenden mit ihrem Engagement zu Verteidigern einer Aufklärung der Gesamtbevölkerung und adelt sie in ihrem widerständigen Tun. Dass sie von Medien zum Teil ignoriert oder nicht ihrer Erwartung nach aufgegriffen werden oder Teil der Berichterstattung sind, macht sie dann auch stolz und bestätigt ihnen ihren Weg.

„,...mein Mann und ich hatten die Stuttgarter Zeitung gehabt, wir waren dann bei Veranstaltungen, jetzt nicht zum Bahnhof, auch bei politischen Veranstaltungen und wenn wir die Presse dann angeschaut haben, stand es immer anders, als wir das wahrgenommen haben. [...] und wir haben dann wirklich die Zeitung gekündigt. Weil wenn du es jetzt nicht machst, dann passiert das nie mehr, [...] also wir haben 50 Jahre die Stuttgarter Zeitung gehabt. “62

Und Raffael G2 bringt es auf den Punkt:

61 Malte C1 in der Fokusgruppe Stuttgart C1.1 am 20.03.2012, 17 Uhr.

62 Laura E5 im Einzelinterview Doria Laura E5. 
„Ich stell mir halt immer die Frage, wenn's knallhart geblockt wird, muss irgendwas dahinter sein, sonst gibt's ja dafür keinen wirklichen Grund.“63

Dass eine solche Instrumentalisierung der Medien nicht immer gegeben, sondern „früher" eine andere Medienrolle etabliert war, davon sind vor allem die Protestierenden älteren Semesters überzeugt. Dies bezeugen etliche Gesprächspassagen, in denen etwa die Rolle des „Spiegels“ in den 1970er Jahren für die Entwicklung von persönlichen Demokratieerwartungen unterstrichen wird:

„...der Spiegel war für mich damals sehr wichtig als Zeitung, als Zeitschrift, dass diese Demokratie verteidigt werden muss, auch vor dem Staat. Und das war für mich also ein ganz wichtiges Element meiner Politisierung. “64

Dies unterstreicht den Befund einer derzeit von den Gesprächspartnern empfundenen Krise, da es sich bei der Kritik den „Medien“ gegenüber nicht um ein immer schon bestehendes Lamento handelt, sondern um eine Tendenz jüngeren Datums. Das wiederum macht die älteren Gesprächsteilnehmer zu einer Art gefühlten Propheten, die das „gelobte Land“ einer freieren, unabhängigeren Presse selbst noch kennen gelernt haben, und die ihre Urteilssicherheit dementsprechend auch nicht zurück halten.

Gleichzeitig sind allerdings viele der Initiativen und Protestgruppen in der Situation, dass sie in ihrem Engagement auf ein Mindestmaß an medialem $\mathrm{Zu}$ gang angewiesen sind, wenn sie ihren Anliegen Gehör verschaffen wollen. Irgendwie müssen sie allesamt versuchen, sich diesen Zugang zu sichern oder mit den skizzierten Problemlagen umzugehen. An dieser Stelle unterscheidet sich das Verhalten der Gruppen stark danach, ob sie das Gefühl haben, diesen $\mathrm{Zu}$ gang erreichen zu können, oder nicht. Werden sie dem eigenen Eindruck nach von den Medien komplett ignoriert oder gar offensiv bekämpft, so bleibt ihnen oftmals gar nichts anderes übrig, als selbst Alternativen zu schaffen, die dann den Stolz auf den eigenen Weg noch um Einiges steigern können - so wie Conrad G1, der gar von „Basismacht“" spricht:

„Also, mittlerweile wissen unsere Kreise Bescheid und ich denke, die Mundpropaganda ist dort durchaus wichtig. Und wir haben mittlerweile eine derartige Basismacht, dass wir da eventuell auch ein Stück weit anders klarkommen. “65

63 Raffael G2 in der Fokusgruppe Stuttgart G2 am 02.04.2012.

64 Einzelinterview Hennar E7.

65 Conrad G1 im Einzelinterview G1 Anna und Conrad. 
Andere Gruppen versuchen langfristig und strategisch, Medienlogiken auch für die eigene Arbeit zu nutzen und ihre Arbeit auch darauf auszurichten, wie und nach welchen Faktoren die Berichterstattung ihre Gegenstände auswählt.

„Uns ist es damals also auch so gegangen: uns wollte keiner. Wir mussten schauen, dass wir an der Öffentlichkeit kommen. Wir haben immer wieder Pressemitteilungen, immer wieder den Kontakt zu den Medien gesucht, einfach die Stetigkeit und irgendwann kamen wir auch in den Medien und plötzlich wurden wir auch gesucht, das war ganz interessant, diese Stetigkeit hat sich ausgezahlt. [...] Über jede Aktion von uns aus in den Medien zu berichten, über eine Pressemitteilung, jetzt passiert das, jetzt haben wir das gemacht. Einfach, um die Öffentlichkeit herzustellen, aber auch Politiker in Zugzwang zu bringen, auf der kommunalen und regionalen Ebene, da gibt es Bürgerversammlungen und so weiter, da können wir den Bürgermeister oder den Abgeordneten in der Versammlungen fragen, wie stehst du dazu, was machst du etc. Also, den richtig gehend stellen und den dazu zwingen, Farbe zu bekennen. “66

Es sind auch diese Passagen, welche eine sich gegenseitig verstärkende Dynamik von Protest deutlich machen. Fühlen die Interviewpartner, dass sie Erfolg haben, dass sie Gehör finden, womöglich gar mit ihrem Anliegen durchdringen, pazifiziert dies ihre Standpunkte und lässt sie ruhiger und strategischer über Politik, Medien und deren Fehlentwicklungen sprechen. Auch berichten sie dann wesentlich überlegter zu den eigenen Strategien, auch auf die Medien zuzugehen, denen sie übles zutrauen. Fühlen sich die Gruppen und Gesprächspartner aber durch eigenes Erleben ausgebootet, verfolgt und in ihrem Interesse, welches sie als gerecht und eminent wichtig für die Gesellschaft erachten, nicht anerkannt, gar verachtet, dann lässt dies auch ihr Urteil über Medien als Teil einer Demokratie hämischer werden.

Lothar C2 beispielsweise, engagiert im Hamburger Recht auf Stadt, unterstreicht, dass die Erfolge der Protestinitiative auch mit ihrem Aufgreifen durch die Medien zu tun haben:

\begin{abstract}
„Aber ansonsten haben die (Medien, Anm. F.B.) viele von den Sachen, die liefen, aufgegriffen und haben auch teilweise, glaube ich, Recht auf Stadt dadurch stärker gemacht als es sonst wäre. Also ich glaube ja, auch so Medien haben natürlich auch begriffen, dass eine zentrale Auseinandersetzung die Frage nach dem Recht auf Stadt ist, und beschäftigen sich dann auch stärker damit. $\mathrm{Ob}$ das nicht immer alles irgendwie toll ist, was sie schreiben, ist eine andere Frage, aber dadurch, dass es in den Medien ist - dann werden Sachen teilweise großartig. [...] Wir haben ja diesen Begriff für Mietenwahnsinn vor einem Jahr
\end{abstract}

66 Natan C3 in der Fokusgruppe Freising C3 25.07.2012. 
geprägt und also so eine Wortkonstruktion, die es davor nicht gab. Wenn man Google Suche von vor einem Jahr macht, da findet man noch nicht viel zu Mietenwahnsinn und seitdem gibt es Mietenwahnsinn als Begriff und der wird dann auch medial aufgegriffen also das ist auch immer ganz interessant, wie da auch so eine Deutungsmacht oder sowas mit rein spielt. “67

Gleichwohl bleiben alle Gesprächspartner bezüglich der Medien innerhalb einer Demokratie enorm skeptisch und um Distanz bemüht. Mannigfaltig sind die Beispiele, in denen davon berichtet wird, wie sie von ihnen persönlich bekannten Lokaljournalisten um Verständnis gebeten werden, dass sie „nicht berichten“ könnten - der Chefredakteur würde es „,nicht bringen“ oder unterbinden. Dass besonders die öffentlich-rechtlichen Medien sehr stark selektieren, auch die politischen Interessen bedienen, wird weithin geteilt:

„Wer nur die zwei nordkoreanischen Sender, ARD und ZDF, anschaut, ja, der hat nach einem Monat eine Gehirnwäsche...“68

Aber auch ruhiger und mit weniger politisch-manipulativem Verdacht ausgestattet, sind viele Gesprächspartner nicht glücklich, über die Rolle, die Medien mit ihren Verwertungslogiken im demokratischen Prozess einnehmen können. Überzeugt davon, dass ihr Anliegen für sich selbst spräche, wenn man es nur veröffentlichte, sind fast alle - und dementsprechend ist auch die systemische Rolle von Medien zu subsumieren, wenn dem Protest noch kein Erfolg beschert worden ist: „Streit wird von den Medien gemacht. “69

\subsection{DEMOKRATIEVORSTELLUNGEN UND -ERWARTUNGEN}

Im Kontrast zu den Gesprächspassagen über eine wahrgenommene Krise und deren Ursachen gestaltet es sich erheblich schwieriger, qua Gesprächsführung etwas über Demokratievorstellungen der Protestierenden zu erfahren. Vorweg: Es wäre vielleicht den übersteigerten Abstraktionserwartungen eines Sozialwissenschaftlers geschuldet, würde man erwarten, dass jede Bürgerinitiative zu jedem Zeitpunkt ihres Engagements auf eine kohärente Demokratieanalyse zurückgreifen kann. Auch wenn in den bisherigen Abschnitten deutlich geworden ist, wie

67 Einzelinterview Lothar C2.

68 Volker G2 in der Fokusgruppe G2 Stuttgart am 02.04.2012.

69 Einzelinterview Fred G5. 
sehr die Protestierenden ihre Anstrengungen ausgehend von dem konkreten Anlass als Engagement für eine bessere Zukunft und Demokratie in Deutschland verstanden wollen wissen, so sind sie doch nicht in erster Linie als Gesellschaftswissenschaftler zu analysieren, denen ein fundiertes Theoriegebilde Ziel ihres Strebens ist.

Die jeweiligen Protestanlässe verlangen rasche Reaktion, die geschilderten Erfahrungen mit Ämtern, Genehmigungsverfahren (bzw. deren Verhinderung), Abstimmungen, Bauanträgen etc. sind getragen davon, unter zeitlichem Druck Lösungen zu suchen und Bewegungsspielraum und Möglichkeiten zu sondieren. Die zusätzliche Zeit und Kraft, abstrakt zu diskutieren, das eigene Tun in die Gesamtgesellschaft hinein zu extrapolieren, haben viele der Gruppen schlichtweg nicht. Gleichwohl möchten sie, das ist bereits deutlich geworden, ihr Engagement jeweils auf einen Themenkomplex richten, der ihnen als Stellvertreter für gesamtgesellschaftliche Entwicklungen gilt, die sie kritisieren. Insofern bleibt die Frage danach, welche Gesellschaftsordnung ihnen vorschwebt, für das Erkenntnisinteresse dieser Arbeit gerechtfertigt und von zentraler Bedeutung.

Wenn in den Interviews und Gruppendiskussionen nach den jeweiligen Vorstellungen von Demokratie, angefangen mit dem basalen Bedeutungsgehalt des Begriffs, gefragt wird, unterscheidet sich die Reaktion fundamental von derjenigen, welche bei den Gesprächsteilen zur Krise zu beobachten ist. Zwar werden Meinungen an dieser Stelle durchaus selbstbewusst vorgetragen. Die Tonlage aber ist eine andere: leiser und weniger donnernd. Nur wenige Teilnehmer sind in der Lage, ad hoc mehr als einige Stichworte zu nennen, wenn sie direkt zu ihrem Verständnis einer idealen Demokratie gefragt werden. Insofern entstehen die Bilder einer Zukunftsvorstellung, von den Demokratieerwartungen der Protestgruppen, nicht als Äußerung Einzelner, als schon vorliegendes Ergebnis langwieriger Diskussionsprozesse oder fertiger Konsens, sondern erst in Auge und Ohr der Diskussionen der Gruppen- oder auch Zwiegespräche.

Nochmal: Dieser Befund ist nicht als Denunziation oder Unverständnis darüber zu lesen, dass Bürgerproteste a priori keine wohlreflektierten Vorstellungen zukünftigen Zusammenlebens besitzen. Es muss aber den Fokus des Sozialwissenschaftlers verändern, der diesen Vorstellungen - welche ja, so steht zu vermuten, nichtsdestotrotz existieren, nur eben nicht explizit präsentiert - auf der Spur ist. Es gilt, Indizien zusammenzutragen, nach Hinweisen zu suchen und auch kleinere Gesprächskontexte, Tonlagen, Gesten etc. für eine mögliche Deutung auszuwerten. Denn Antworten auf die Fragen, wer oder was Legitimität schafft, was Autorität verleiht, wie man mit Minderheiten umgehen sollte oder was der Wert Gleichheit bedeutet, machen deutlich: Theoretische Abstraktion ist nicht die Stärke vieler Bürgerbewegungen, muss sie vielleicht auch gar nicht 
sein. Um gleichwohl diesen Komplexen nachzugehen, sind Umwege zu suchen. $^{70}$

Und noch etwas fällt auf: Es sind keineswegs immer dieselben Teilnehmer, die das Wort führen und sich besonders eloquent zeigen. Der Komplex von Demokratie und Gesellschaftsorganisation erfordert und prämiert augenscheinlich andere - und seien es nur analytisch-rhetorische - Fähigkeiten, als dies im Fall der Empörungssteigerung bei der Diskussion der eigenen Krisenwahrnehmung zu beobachten war. Während Empörung und das Zuweisen von Schuld und Fehlverhalten - Politiker, Politik, Unternehmen etc. - Lautstärke, praktische Erfahrung im Protest und oftmals auch eine Überzeugungskraft stiftende berufliche Autorität in der Sachfrage des Engagements besonders zur Geltung kommen lassen, sind die Passagen der Gruppendiskussionen zur Demokratie oftmals durch andere Akteure geprägt. Insgesamt gibt es zwei Gruppen von Engagierten, die sich hier besonders sprachfähig zeigen oder aber mit mehr bzw. tiefer gehenden Gedanken zum gesellschaftlichen und politischen Zusammenleben aufwarten können. Zum einen sind dies Mitglieder von Bürgerinitiativen oder Protestgruppen, die sich die Verwirklichung alternativer Lebensmodelle besonders deutlich auf die eigenen Fahnen geschrieben haben. Stadtviertelprojekte wie das Hamburger Gängeviertel etwa haben eine lange Tradition des Diskutierens grundsätzlicher Fragen der Selbstorganisation und - damit zusammen hängend - der Debatte um wünschenswerte Zukunftsideale. Diese Erfahrung ist den entsprechenden Interviewpartnern auch deutlich anzumerken. Zum anderen aber scheint es Biographien und Werdegänge zu geben, die näher an diesen Frage- und Gedankengängen liegen, als dies bei anderen der Fall ist. Menschen übernehmen - verallgemeinerbar und generell, jedenfalls in den hier zugrunde liegenden Interviews - individuelle persönliche und berufliche Perspektiven so sehr auch für ihre generelle Deutungs- und Handlungsweise, dass die eigenen Erfahrungen und eingeschliffenen Denkweisen auch die Fähigkeiten beeinflussen, über einen abstrakten Begriff wie Demokratie zu sprechen. Pastoren, Sozialpädagogen, Ökonomen und oftmals Künstler sprechen in den Interviews anders, nachdenklicher und viel selbstverständlicher über die Fragen von Mehrheit und Minderheit, über Legitimität und Loyalität, als dies etwa Physiker, Ingenieure oder ITSpezialisten tun.

70 Auch der Soziologe Albert O. Hirschman hat auf diese mangelnde Phantasie hingewiesen: „Die menschliche Fähigkeit, sich sozialen Wandel vorzustellen, ist bemerkenswert beschränkt.“ Ders.: Engagement und Enttäuschung. Über das Schwanken der Bürger zwischen Privatwohl und Gemeinwohl, Frankfurt a.M. 1988. 


\section{Autorität und Legitimität}

Wie im Eingangskapitel im Abschnitt zur Entstehung von Demokratienormen beschrieben, gibt es in der Diskursanalyse verschiedene Ansätze, über den inneren Zusammenhang von Pressure Groups und ihre jeweils unterschiedlich funktionierenden Begründungsstrukturen nachzudenken. Dies ist insofern an dieser Stelle fruchtbar heranzuziehen, da in den Gesprächspassagen und Erzählungen zur inneren Funktion und Entscheidungsfindung in den Protestbündnissen selber eine Möglichkeit liegt, etwas über die Idealvorstellungen der Engagierten auch mit Bezug zur Gesamtgesellschaft zu erfahren. Die Art und Weise, wie in den Interviews die Hierarchien und Führungsstrukturen der eigenen Gruppe reflektiert bzw. wie diese bewegt und mitunter kritisiert werden, mag Aufschluss darüber geben, wie sich Protestierende eine größere Aggregation von Interessen vorstellen.

Demokratie als gesellschaftliche Form, Entscheidungen zu organisieren und ihnen zur Akzeptanz zu verhelfen, ist an die Fähigkeit gebunden, den Handelnden Autorität und Legitimität zu verleihen. Wer oder was eigentlich Autorität und welche Kontexte Legitimität entstehen lassen, sind insofern zwei grundlegende Fragen für das Verständnis von Demokratie. Besonders für Legitimitätsquellen wird mittlerweile in der Politikwissenschaft gefragt, ob demokratische Verfahren noch in der Lage sind, diese selbst herzustellen oder ob eine politikwissenschaftliche Analyse vielmehr Komplexe außerhalb der Institutionen und ihrer Träger in den Blick zu nehmen hat. ${ }^{71}$ Markus Patberg hat an dieser Stelle darauf hingewiesen, dass ein von Max Weber abgeleitetes Verständnis von Legitimität als Glaube an die Legitimität einer Herrschaftsform den beobachtenden Sozialwissenschaftler darauf reduziere, lediglich oberflächlich zu messen, wie stark dieser Glaube ausgeprägt sei. ${ }^{72}$ Dass dieser Glaube im Schwinden begriffen ist bzw. dass die Legitimität der zeitgenössischen Demokratie von den Protestierenden zumindest teilweise angezweifelt wird, diese These wäre durch die Auswahl des Themas bzw. der Protagonisten - die gegen die Ausprägungen der Demokratie protestieren - ein Zirkelschluss. Vielmehr komme es darauf an, zu untersuchen, ob politische Herrschaft mit den normativen Erwartungen und Maßstäben der Bürger selbst gerechtfertigt werden könne. Eine empirische Untersu-

71 Vgl. dazu Zürn, Michael: Perspektiven des demokratischen Regierens und die Rolle der Politikwissenschaft im 21. Jahrhundert, in: Politische Vierteljahresschrift, Jg. 52 (2011) H. 4, S. $603-635$.

72 Vgl. Patberg, Markus: Zwei Modelle empirischer Legitimitätsforschung - Eine Replik auf Michael Zürns Gastbeitrag in der PVS 4/2011, in: Politische Vierteljahresschrift, Jg. 54 (2013) H. 1, S. 155 - 172, hier S. 157. 
chung von Legitimität müsse beurteilen, ob sich ein politisches System in Übereinstimmung mit diesen Überzeugungen befindet oder nicht - der Sozialwissenschaftler müsse also beurteilen und nicht lediglich messen. ${ }^{73}$ Für die hier verfolgte Fragestellung kommt es also in erster Linie darauf an, nach Hinweisen zu suchen, was für die Gesprächspartner eine Quelle von legitimen Entscheidungen und Herrschaftsansprüchen ausmachen kann - und erst im Anschluss daran ist zu fragen, ob sich eine politische Herrschaft auf diese berufen kann.

Bezüglich der Frage nach Quellen von Autorität ist zunächst festzuhalten, dass die Vorstellungen in den unterschiedlichen Protestgruppen und -zusammenhängen durchaus differieren. Dies bestätigt den obigen Hinweis, dass wir es, aus diskursanalytischer Sicht, mit unterschiedlichen Communities zu tun haben, die ihr Engagement auch auf verschiedene Pfeiler stellen, um Gehör, Plausibilität und Einfluss, letztendlich eine Art Hegemonie, zu erreichen.

Hervorzuheben sind dabei aus den Gesprächen drei Ansätze, für sich selbst, die Gruppe oder als abstrakten gesellschaftlichen Mechanismus die Entstehung von Autorität zu erklären: eine fachliche, eine „natürliche“ und eine aus der gesellschaftlichen Hierarchie übertragene Vorstellung. Autorität soll in diesem Zusammenhang erklären, wer in einer jeweiligen Situation eine Führungsposition beanspruchen kann bzw. sich mit diesem Führungsanspruch durchsetzt. Hannah Arendt hat darauf hingewiesen, dass Autorität begrenzt wird durch die Ausübung von Zwang und Gewalt auf der einen und durch die Überzeugung von gleichrangigen Individuen auf der anderen Seite. ${ }^{74}$ Eine Untersuchung von Autoritätsvorstellungen müsse folglich nachspüren, was Quellen von Hierarchieakzeptanz sein können, die einen Anspruch auf Führung entstehen lassen.

Zuallererst fällt auf, dass an vielen Stellen über die verschiedenen Protestbündnisse hinweg auf die Autoritätsressource „fachliches Wissen“ rekurriert wird, welche einen Menschen dazu befähige, Führung zu übernehmen - in den Protestgruppen und auch darüber hinaus.

„Das war irre. Es kam eine Frage ins Plenum und zwei Sekunden später hatte Hubertus eine Antwort. Ich habe mir gedacht, wie macht der das, das kann doch nicht sein. Ich habe das aber so bewundert. “75

73 An dieser Stelle bemüht Patberg David Beetham: The Legitimation of Power, Basingstoke 1991.

74 Vgl. Arendt, Hannah: What is Authority?, in: Dies.: Between Past and Future, New York 2006, S. 91 - 141, hier S. 92.

75 Susanne E1 in der Fokusgruppe E1 Hamburg am 20.03.2012. 
Für die Protestierenden kann das Fachliche eine enorme Autoritätsquelle sein, weil es ihnen als Waffe dient. Das Fachliche ist an dieser Stelle die Steinzwille Davids, mit der man einem vermeintlich übermächtigen Gegner seine Grenzen aufzeigen kann und welche zudem in Kontinuität steht mit dem bereits herausgestrichenen Verständnis von Aufklärung, dass allein eine inhaltliche Erkenntnis ausreiche, um eine Mehrheit zu überzeugen. Diese Denkweise einer Epistemic Comunity, die über die fachliche Angemessenheit ihrer Vorschläge Glaubwürdigkeit zu erreichen sucht und die über die inhaltliche Autorität ihrer Fürsprecher nach Geltung trachtet, findet sich in unterschiedlichem Grade in allen betrachteten Protesten. Besonders aber in kleineren Zusammenhängen, welche sich selbst thematisch eng begrenzen und ihr Engagement auf einen Punkt hin ausrichten, sind die Suche nach fachlicher Reputation und eine Ableitung von Autorität und Führungsanspruch deutlich zu spüren.

Der demokratischen Realität in Deutschland allerdings trauen die meisten zu ihrem Bedauern nicht länger zu, in ihrer Entscheidungsorganisation einer solchen fachlichen Autorität noch zu entsprechen. Vielmehr sei Politik selbstreferentiell geworden und rekrutiere lediglich Menschen, welche „das System“ bedienen, aber keine fachliche Grundlage mehr besäßen, um Entscheidungen zu treffen.

„Also für mich geht in der Demokratie die Macht geht vom Volke aus, also von den Wählern, und wird auch von den Wählern kontrolliert, dazu ist notwendig, dass sich diese Leute, die sich für solche Mandate zur Verfügung stellen, entsprechend ausgebildet sind, es hilft dem Volk nicht weiter, wenn ein Großteil der Volksvertreter da ein juristisches Studium hat, einen Grad. Die sind aus meiner langen Erfahrung ja von so einem idealen Ablauf geprägt und alles, was nicht in das System rein passt, stört und wird also niedergemacht, ich bin lange genug dabei.“76

Auffällig ist, als zweite Quelle, dass viele der Interviewten eine Art „natürliche“ Autorität beschreiben, die dafür sorge, dass in den Protestgruppen manche als Führungspersönlichkeiten hervortreten - und die sie sich, dies ist mit den Händen zu greifen, auch für die Gesellschaft insgesamt als Auswahlfilter für politische Führungspositionen wünschen. Viele Interviewpartner betonen immer wieder, wie sehr automatisierte oder formalisierte Hierarchien in ihren Gruppen dem widersprächen, was ihnen als Ideal für Bürgerproteste vorschwebe. Gleichwohl sei ihnen klar, dass es Hierarchien und eine Gruppenführung geben müsse.

76 Marcel C3 in der Fokusgruppe C3 Freising am 25.07.2012. 
„Ist ja gut und schön, ich bin auch dafür, dass es keine Hierarchien gibt. Aber die Menschen sind nun mal leider nicht so gestrickt. Es braucht schon jemand, der da irgendwo vielleicht auch in gewisser Weise was organisiert und darüber auch ne Autorität hat. “77

Dementsprechend schildern die Gesprächssequenzen zu der Frage, wie sich in den jeweiligen Gruppen die Führungspersonen herauskristallisieren, auch einen Prozess des naturwüchsigen „Übrigbleibens“ derjenigen, welchen die Mitglieder vertrauen, Glauben schenken oder aber, die schlichtweg am meisten Arbeit und Engagement in die Protestarbeit stecken. Diese „Prämien“ der Seniorität und Erfahrung, aber auch des Selbstbewusstseins im Protest sind auch im Kapitel zu den Biographien herausgestrichen worden. Sie sind in diesem Zusammenhang eine mögliche Quelle von Autorität, die einzelnen Personen dann besonderes Gehör in den Gruppen zuteilwerden lässt.

„Ja, also es gibt eben ein paar Macher, es gibt die Basis, also von der es auch mal sozusagen, das war eben der Anfang, ein großes Treffen gab, mit vielen Erzieherinnen, mit vielen Arbeitsgruppen, und dann bei dem zweiten Termin-Treffen dieser Arbeitsgruppen waren es natürlich viel, viel weniger Leute, dann wurden Arbeitsgruppen zusammengelegt, so, und dann gibt es in den verschiedenen Arbeitsgruppen immer ein paar Leute, die schon jahrelang in diesem Bereich politisch tätig sind und die sich sozusagen verteilt haben auf diese Arbeitsgruppen, damit es dann irgendwie nochmal wieder zusammengeführt werden kann in einer Steuerungsgruppe, aber es gibt auch Einzelpersonen in der Steuerungsgruppe, die ihre Alleinmärsche machen, es gibt im Grunde [...] auch nicht die Zeit, wirklich gemeinsam zu diskutieren, was hat man für eine Strategie, oder wo soll's hingehen, was machen wir, wenn - also es wird nicht überlegt, was eigentlich passiert, sondern machen, machen und ganz schnell.“78

Drittens bringen Gruppen oder Institutionen eine Autorität aus dem gesellschaftlichen Bereich mit in die Protestarbeit ein. Dass die Protestbündnisse aus dem Bereich der Eurogegner anfangs besonders betont haben, viele Professoren mit fachlicher und sozialer Reputation zu versammeln, oder dass etwa die vergleichsweise großen, heterogenen Bündnisse wie jenes gegen den Münchener Flughafenausbau auf die integrierende Kraft der Kirche zurückgreifen - beides verlängert eine gesellschaftliche Autorität in die politische Arbeit hinein und macht diese nutzbar.

77 Raik C2 in der Fokusgruppe C2.2 Stuttgart am 20.03.2012, 20 Uhr.

78 Einzelinterview Ilse E8. 
„Freising ist nun mal eine kirchliche Stadt seit was weiß ich wieviel 100 Jahren. Das Wort der Kirche bedeutet hier was. Allerdings jetzt, wenn ich mir die Diskussion in der katholischen Kirche anschaue, was so Priester- und Amtsverständnisse angeht, da kann Kirche sagen, offizielle Kirche sagen, was sie will, da haben Leute ihre eigene Meinung. Aber wenn's um Themen geht, wo sie merken: Hier hat Kirche uns wirklich was zu sagen, hier spricht Kirche Themen an, die uns persönlich bewegen, und Kirche ist mit uns solidarisch, dann ist Kirche hier ein ganz wichtiger Faktor.“79

Diese „gesellschaftliche“ sowie die angesprochene „natürliche“ Autorität, welche man Einzelpersonen oder Gruppen zuspricht, ziehen ihre Kraft aus der Ausstrahlung einer inneren Überzeugung, die bei ihnen wahrgenommen wird. Auch eine ostentativ zur Schau getragene Überparteilichkeit oder Unbestechlichkeit kann zu einer Quelle von Autorität werden. Dieses Erzählmotiv eines ,einsamen Wolfs“, der sich nicht durch Gegenwind beeindrucken lässt und unnachgiebig dem eigenen Anliegen folgt, taucht des Öfteren auf. Hennar E7 etwa schildert sich selbst in dieser Rolle:

\begin{abstract}
„Also, in der Masse ist jeder sein kleines Rädchen, man muss sehr aufpassen, damit man da nicht vereinnahmt wird von der Masse, ich bin da sehr vorsichtig. Ich denke immer, na, wie ist das jetzt, so was ähnliches wie der Reichsparteitag in Nürnberg, wo sie alle geschrien haben, diese Massenhysterie. Dann bin ich schon wieder sehr vorsichtig. Ich denke da an die große Friedensdemonstration in Bonn 1982, da stehen vorne die Bots auf der Bühne, das ist eine holländische Gruppe, die haben dann gesungen, alle, die für den Frieden sind, sollen aufstehen, und dann stehen 120.000 Menschen auf. Ich bin erschrocken sitzen geblieben, dachte, mein Gott das ist ja wieder was in diese Richtung, ne. Also, dieses kritische Bewusstsein zu behalten, wo könnte was aus dem Ruder laufen, das ist mir sehr wichtig. “ ${ }^{* 0}$
\end{abstract}

An diesen Passagen fällt auf, ist, dass Autorität, verstanden als Führungsanspruch, eine Ressource ist, die von den Protestierenden verstanden wird als etwas, das außerhalb der demokratischen Strukturen entsteht. Dies ist etwas, dass auch Hannah Arendt zu den Insignien von Autorität zählt, den Befund allerdings für autoritäre Systeme herleitet. „The source of authority in authoritarian government is always a force external and superior to its own power; it is always this source, this external force which transcends the political realm, from which

79 Einzelinterview Bernd C5.

80 Einzelinterview Hennar E7. 
the authorities derive their "authority", that is, their legitimacy, and against which their power can be checked." 81

Dazu zählt in den Interviews, dass in Vergleichen und Beispielen immer wieder eine Trennung gemacht wird zwischen der Umsetzung beziehungsweise der Verwaltung von Belangen auf der einen und der Definition und Diskussion von Zielsetzung beziehungsweise einer Programmatik auf der anderen Seite. Während ersteres durchaus der zeitgenössischen Demokratieumsetzung und allgemein der Politik in Deutschland zugetraut und zugesprochen wird, wähnt man die Autorität für letzteres bei sich selbst, beim Bürger. Auf die Frage der Demokratievorstellungen übertragen, bedeutet dies, dass in den Gesprächen Autorität als etwas beschrieben wird, das nicht in einem Abstimmungsverfahren erreicht werden kann, sondern das den Inhabern aus anderen Quellen bereits inhärent ist. Aus den Gesprächen herauszuhören ist der Wunsch danach, entweder fachlich besonders fähigen Menschen oder aber denjenigen, die ein besonders hohes Ansehen aus anderen gesellschaftlichen Bereichen mit einbringen, eine Führung in der Gruppe oder Gesellschaft anzutragen. Auffällig ist aber, dass die geschilderten Gruppenausleseprozesse durchaus stark die Ressource „Erfahrung durch Protestdauer" honorieren und den Erfahrenen besondere Autorität und Urteilsfähigkeit zusprechen, während Seniorität als Auslesekriterium in Parteien oder der Politik oftmals als besonders krasses Merkmal einer abzulehnenden Parteiräson herausgestrichen wird. Nimmt man die Selbsterzählungen der Gruppen als Fundament für ihr Demokratieverständnis, ist diese Kritik zumindest nicht mehr ohne Widerspruch nachvollziehbar.

Eine andere Frage allerdings ist die nach der „Legitimität“ von Verfahren und Führungspositionen. „Legitim“ im Sinne eines moralischen begründeten Anspruchs auf Durchsetzung ist den Protestierenden das, was sich durch „Bürgernähe“" auszeichnet. Und auch wenn nicht alle Interviewten oder Protestgruppen den Begriff des „Bürgers“ ganz explizit benutzen - das Konstrukt eines Volksoder Bürgerwillens, nach dem sich Politik und Demokratie idealerweise ausrichten und dessen Erfüllung das höchste Ziel sein sollte, benutzen viele in mehr oder weniger ausgeprägter Form, und sei es auch nur in einer Art negativer Raumnahme: dass Politik und Demokratie den Bürgern Platz zu lassen habe für die eigenen Vorstellungen.

Interessant ist dabei das Verständnis vom Bürgerwillen. Denn der Begriff wird kaum mit den Vorstellungen oder Forderungen einer Mehrheit der Bevölkerung übersetzt, sondern qualitativ oder mittelbar definiert. Dabei bleibt oft unklar, wer oder was dann einer Nicht-Mehrheit oder Minderheit die Möglichkeit zuspricht, im idealen Sinne legitime Führung auszuüben. Das Konstrukt einer

81 Arendt: What is Authority?, hier S. 97. 
„Bürgernähe“ oder eines „Bürgerwillens“ wird zu einer Verbrämung der eigenen Vorstellungen für das Gemeinwohl (und damit eben für alle Bürger) - und der Protestierende selbst zu einem Repräsentant für alle anderen.

„[...] es haben noch nie Mehrheiten die Welt verändert, ja, es hat nicht die Mehrheit der Europäer entschieden, wir fahren jetzt einmal nach Westen und gucken, ob es da Amerika gibt, da gab es einen Querkopf, der hieß Kolumbus und hat gesagt, ich glaube daran und hat noch ein paar andere Leute [...] überzeugt und dann hat er Amerika entdeckt, aber eine Mehrheit würde so was nie schaffen, ja, wir können noch andere Beispiele nehmen, [...] es sind immer Minderheiten, es sind immer Einzelne, die vorgehen, es sind immer Einzelne, die gegen den Strich gehen und [...] irgendwann setzt sich die Überzeugung durch. ${ }^{\text {“82 }}$

Diese Meinungsäußerung lässt sich anknüpfen an den Bildungsbegriff der Protestgruppen: Bildung, Aufklärung und Erkenntnis statten ein Individuum mit einer Fürsprache-Möglichkeit für den Rest der Gesellschaft aus - Protest als patriarchalische Ausübung besserer Kenntnis über das Gemeinwohl. Dies unterstreichen nicht alle Interviewten für sich und ihre Gruppen, findet sich in Spuren aber doch an vielen Stellen. Symptomatisch ist die Antwort von Rahlf G1 auf die Frage des Moderators, wer eigentlich das „Wir“ ausmache, von dem er zuvor so häufig gesprochen habe: „Die Mehrheit der Bevölkerung! (Lachen)“83

Das Postulat von Bürgernähe als Legitimitätsmesser für Entscheidungen ist, wie angesprochen, besonders bei denjenigen Gruppen zu hören, die als kleine Protestzusammenhänge unter größerem Begründungsdruck stehen, ihr Anliegen als gute oder beste Lösung auch für den Rest der Bevölkerung auszuweisen. In den 2012 noch kleinen Gruppen der Eurokritiker, die zum Teil eine Nähe zu wirtschaftswissenschaftlichen Diskussionen aufweisen, war dies besonders ausgeprägt. Auch wird der Begriff von Bürgernähe zur Abgrenzung benutzt, um deutlich zu machen, dass sie Politik nicht länger zutrauen, die Lebenssituation der Bürger nachempfinden und als Entscheidungsgrundlage einspeisen zu können. Eine Trennung in Bürger auf der einen und Politik auf der anderen Seite ist die Folge.

82 Einzelinterview Achim G3; Eine ähnliche Passage findet sich auch bei Golo Mann: „Große, entscheidende Dinge in der Geschichte sind oft von Minderheiten vollbracht worden, ohne, selbst gegen den Willen der Mehrheit... [...] Es liegt in der Natur politischer Bewegungen, dass sie von Minderheiten geführt und getrieben werden, da die Mehrzahl der Menschen mit ihren eigenen Sorgen fast immer vollauf beschäftigt ist.“ Mann, Golo: Deutsche Geschichte des 19. und 20. Jahrhunderts, Frankfurt a.M. 2004, S. 270.

83 Rahlf G1 in der Fokusgruppe G1 Hannover am 15.03.2012. 
Dass die jeweils spezifisch Betroffenen beteiligt werden, ist die zweite zentrale Formel, auf die sich Legitimitätsvorstellungen der Protestierenden herunterbrechen lassen. Dies ist verständlich, schließlich lassen sich ihre Protestzusammenhänge und ihr Engagement auf genau dieses gefühlte Beteiligungsdesiderat zurückführen: dass sie sich betroffen fühlen, aber nicht (genug) gehört oder gefragt werden.

„Ich finde, die Bürgerbeteiligung sollte so stark sein, dass, wenn die meisten Autofahrer nicht wollen, dass sie geblitzt werden hier in Hannover, dass die so viel Macht haben, dass die Dinger dann auch nur dorthin gestellt werden, [...] wo auch wirklich Gefahren sind und da, wo man verleitet wird, statt fünfzig siebzig zu fahren, weil es geht. Also das wäre jetzt zum Beispiel eine Bürgerbeteiligung in diesem Kommunalgeflecht. “84

Damit zusammenhängend tritt an vielen Stellen hervor, dass die Lösung, einfach alle stärker zu beteiligen, von vielen Interviewpartnern kritisch gesehen wird. Dies liegt zum einen daran, dass im benutzten Interviewsample mit den Stuttgarter Bahnhofsgegnern wie den Hamburger Befürwortern längeren gemeinsamen Lernens zwei Protestzusammenhänge involviert sind, die in direktdemokratischen Abstimmungen unterlegen sind. Engagierte aus beiden Städten schildern ihre Frustration der Niederlage, die ungleichen Waffen und Ressourcen des Gegners, auch den Klüngel der Gegenseite - und dies führt zu sehr vorsichtigem Beurteilen direktdemokratischer Elemente, weil sie effektiv vor Augen geführt bekommen haben, dass die Gegenseite nicht durch klandestine Absprachen, sondern durch eine Volksabstimmung gewonnen hat. Und noch etwas ist besonders an der Hamburger Situation: Die Schulverbesserer sowie die, welche dann für die Primarschule gekämpft haben, waren nicht gegen die Parteien, sondern wollten dem gemeinsamen Vorschlag der Hamburger Regierungskoalition aus CDU und Grünen sowie der parlamentarischen Opposition den Rücken stärken und helfen, ihr Projekt durchzusetzen. Das heißt im Umkehrschluss: Sie haben mit allen Parteien gemeinsam gegen eine (Abstimmungs-)Mehrheit verloren - eine doppelte Niederlage.

„Für mich ersetzt die Volksgesetzgebung nicht die parlamentarische Demokratie. Es gibt Themen, wir haben das hier in Hamburg erlebt mit dem Primarschul-Volksentscheid oder gegen den Primarschul-Volksentscheid, dass es Menschen gibt, die Geld haben und eine Lobby haben, die auf die Art und Weise durch die direkte Volksgesetzgebung Vorteile und Politik machen können, und das finde ich nicht demokratisch. ${ }^{\text {“ }} 85$

84 Marius G1 in der Fokusgruppe G1 Hannover am 15.03.2012.

85 Renate E2 in der Fokusgruppe E2 Hamburg am 07.05.2012. 
Dass die Mehrheit als Entscheidungsinstanz vielen Protestierenden ein unsicherer Kantonist ist, wird jedenfalls oft sichtbar. Dies mag auch mit dem Selbstbild der Engagierten zu tun haben, nach dem sie über eine größere Bildung, Einsicht und Aufklärung verfügen, über Ressourcen also, welche zwangsläufig vielen anderen Menschen abgehen müssen - ansonsten würden sie sich dem Protest anschließen. Die Gesamtbevölkerung dann aber zur Instanz für Entscheidungen zu machen, würde naturgemäß weniger rationale und aufgeklärte Lösungen hervorbringen.

Es ist einleuchtend, dass diese Skepsis direktdemokratischen Elementen gegenüber sowohl mit der Erfahrung, welche die Gruppen mit diesen Partizipationsmöglichkeiten bis dato gemacht haben, als auch mit der Gruppengröße stark korreliert.

Denn je größer und heterogener die Gruppen, umso vorsichtiger müssen sie in ihren inneren Entscheidungsprozessen mit der Frage der Integration verschiedener Meinungen umgehen. Die Suche nach Legitimierungsformeln und -funktionen innerhalb der Gruppen schildern besonders die großen Protestbündnisse wie in Stuttgart, Freising, aber auch das Hamburger Recht auf Stadt. Eine Paradelösung haben sie jedoch auch allesamt - wenn überhaupt - nur in Teilen gefunden. Denn zwischen dem Ideal auf der einen Seite, dass niemand übergangen werden soll und alle Gehör finden, und der Notwendigkeit auf der anderen Seite, handlungsfähig $\mathrm{zu}$ bleiben und Verhaltenskodices allgemeinverbindlich festzulegen, klafft oftmals eine schmerzhafte Lücke, die experimentell und in der Hoffnung auf eine Art „naturwüchsigen“ Konsens manchmal nur oberflächlich überdeckt wird. Gleichzeitig ist es aber für die Gruppen enorm wichtig, hier einen Mittelweg zu finden, da kein Mitglied zum Dabeibleiben gezwungen werden kann. Die Beschränkung auf ein zentrales Thema etwa und das Schweigen zu allen anderen ist eine Möglichkeit, die sich Protestgruppen eröffnet. Eine Übertragung dieser Faustformel auf die Entscheidungsorganisation innerhalb der Gesellschaft bleibt aber kaum sinnvoll.

„Wir haben uns ja drauf geeinigt, dass wir zu allen anderen Themen nichts sagen, wir haben das eine große Ziel: Verhinderung der dritten Startbahn. Und obwohl wir privat unterschiedlicher Meinung sind, wir haben uns nie zu Olympia geäußert, wir haben uns nie zur zweiten Stammstrecke geäußert. Wir haben nur gesagt, wir sind nur für das da und alles andere kann ich privat machen, hier wir sind nur für die dritte Startbahn da. ${ }^{\star 86}$

Eine andere Möglichkeit ist die Vermeidung jedweder formaler Abstimmungen, um überstimmte Minderheiten, die dann ein Ergebnis nicht anerkennen, zu ver-

86 Ulla C3 in der Fokusgruppe C3 Freising am 25.07.2012. 
hindern. Auch dies allerdings ist kaum effizient im Sinne einer Zeitbeschränkung der Entscheidungsfindung (da alles bis zum Konsens diskutiert werden muss) und wenig übertragbar auf umfassendere Zusammenhänge.

Ein dritter Ausweis von Legitimität, welcher in allen Gruppen im Prinzip unwidersprochen bleibt, ist der Nachweis der Zukunftsorientierung. Dies geschieht vor allem über den Begriff der „Kinder“, an deren Interessen man sich ausrichte und deren Lebensumfeld (eben in der Zukunft) man sichern und bewahren möchte.

„Okay, unser Ziel, das sind wir alle hier am Tisch bei AufgeMUCkt, ist die Schöpfung zu bewahren und unseren Kindern eine gute Zukunft zu sichern, mir gefallen die spielenden Kinder, ich beziehe das auf dieses Bild zurück (zeigt den Teilnehmern eine Postkarte der Werbekampagne gegen den Flughafen, die sie herausgeschickt haben, Anm. F.B.), was wir in München, „Stimm' für uns - sei meine Münchner Stimme“, das ist mir so ganz wichtig, ich habe das vorher auch betont, dass ich wirklich stolz bin, dass wir inzwischen 50.000 junge Menschen bei uns haben und nicht nur die alten grauen Köpfe dafür eintreten, dass sie einmal gut beerdigt werden. Wir wollen unseren Kindern eine gute Zukunft sichern. [...] und wir sind ja nicht hier, nur weil wir selbst betroffen sind, wir denken weiter. Gerade wir bei Lichterzeichen, ich bin auch Mitglied der Lichterzeichen, denken an die Bewahrung der Schöpfung, wir denken etwas weiter, wir wollen diese Lage erhalten, wie sie heute noch ist. Das sind meine Gesichtspunkte. ${ }^{\text {887 }}$

Entscheidungen der Politik und Engagement der Gruppen sind demnach dann legitim, wenn sie den Interessen Rechnung tragen, den heutigen Kindern ihr Lebensumfeld und ihre zukünftigen Perspektiven zu erhalten oder zu verbessern. Ein solches Motiv lässt sich bei allen Gruppen als anerkanntes Kriterium von Legitimität finden und begründet für Eurogegner, Bahnhofskritiker und - natürlich besonders - Engagierte im Bildungsbereich stets eine Kernfigur der eigenen Argumentation. Denn Nachhaltigkeit, das Bewahren und das Sprechen für die Interessen derjenigen, die dazu (heute) noch nicht befähigt sind, gilt als Ausweis für ein altruistisches Denken und ein glaubwürdiges Eintreten für ein Gemeinwohl, da es nicht um einen selbst gehen soll.

Ein letzter Ansatz, mit dem Legitimität von Entscheidungen und Forderungen von den Protestierenden erklärt wird, ist, wenn sie einer Unabhängigkeit im Urteil entsprechen. Dies korrespondiert mit dem Gedanken, der oben bereits angeführt wurde, demzufolge fachliche Angemessenheit Autorität verleiht. Sich mit Entscheidungen und Schlüssen nicht einer ideologischen oder politischen Strömung unterzuordnen, sondern jeweils das Vorhandensein einer situativ rati-

87 Rainer C3 in der Fokusgruppe C3 Freising am 25.07.2012. 
onalen und „besten“ Lösung zu suchen, stiftet in den Augen vieler Protestierenden Legitimität.

Was ihre Demokratievorstellungen anbelangt, lässt sich festhalten, dass für die Gesprächsteilnehmer demokratische Verfahren als solche nur eingeschränkt in der Lage sind, Legitimität zu stiften. Denn dass die derzeitige Politik diesen Vorstellungen nicht entspricht, erwarten die meisten Interviewten.

,...und diese Ziele sind einfach unserer Gesellschaft oftmals gar nicht klar. Es ist gar nicht klar, welche Ziele eigentlich eine Bundesregierung, eine Landesregierung verfolgt und welche Ziele die Bürgerbewegungen verfolgen. Oft scheint es mir so, dass die Bürgerbewegungen die Ziele verfolgen, die sozusagen für die gesamte Bürgerschaft von Vorteil sind. Eben das, was man als gesunden Menschenverstand bezeichnen könnte, und die Politik eben diese persönlich getriebenen Ziele hat und dann muss es natürlich Konflikte geben. ${ }^{68}$

Als legitim wird in den Gesprächen häufig das beschrieben, was vom Ergebnis her den Protestierenden als kompatibel mit ihren eigenen Vorstellungen erscheint. Legitimität als Ergebnis eines Verfahrens entsteht für sie nur dann, wenn „die Betroffenen“ mit einbezogen werden. Dies ist zum einen äußerst vage und bleibt zum anderen in den Gesprächen auch nur mit Einschränkungen konsequent: Wenn „die Betroffenen“ als Gruppe sehr groß werden, wie etwa bei der Abstimmung zum Stuttgarter Hauptbahnhof, wenn also ein großer Teil der Bevölkerung betroffen ist, werden viele in den Gesprächen enorm skeptisch, ob eine Einbeziehung so vieler Menschen für sie noch wünschenswert ist, da das Ergebnis dann für sie immer weniger kalkulierbar wird und ihnen die Möglichkeiten zur Beeinflussung durch Politik oder die Gegenseite überlegen scheinen. Es lässt sich resümieren, dass eingeübte und etablierte demokratische Verfahren von den Interviewten nur in geringem Maße als Autoritäts- und Legitimitätsquellen anerkannt werden. Der Wunsch nach fachlicher und sozialer Autorität auf der einen und einer im Kern ihnen selbst (als Bürger und Betroffene) entspringenden Legitimität auf der anderen Seite, deuten auf einen Wandel in den Demokratievorstellungen hin.

\section{Von Gleichen und Minderheiten - Kader des Bürgerwillens}

Der Umgang mit Gleichheit und Minderheiten als Kernthemen demokratischer Organisation beschäftigt die Gesprächsteilnehmer. Beide Begriffe gehören zu den immer wieder genannten Themen, wenn in den Interviews nach ihrer Idee

88 Olaf C1 in der Fokusgruppe Stuttgart C1.1 am 20.03.2012, 17 Uhr. 
von Demokratie gefragt wird. Sowohl „Gleichheit“ als auch „Minderheiten“ als Bezugspunkte für eine positive Vorstellung demokratischer Entscheidungsfindung tragen allerdings für die Protestierenden sehr zwiespältige Konnotationen mit sich. Dass ihnen beide Konzepte als irgendwie bedeutsam gelten für eine Demokratie - daran wird kaum Zweifel gelassen. Auch, dass ihr eigenes Engagement einem vage gespürten Ideal von Gleichheit in der Behandlung durch die Demokratie sowie einer Anerkennung von Minderheitenschutz wenn nicht ursächlich entspringt, dann aber doch durch diese verstärkt wird, machen die Gesprächspartner deutlich. Auf der anderen Seite aber stehen ihnen beide Begriffe auch als prototypisch für Fehlentwicklungen, die sie zu erkennen meinen.

Gleichheit etwa steht oftmals im Zentrum ihrer Kritik an der zeitgenössischen Demokratie. Hier entspringt die Vision von Gleichheit einer Vorstellung von Transparenz und Information, die eine Waffengleichheit für die Einflussmöglichkeiten in Politik und Gesellschaft einfordert. Gleichheit sei unabdingbare Voraussetzung für eine Demokratie, damit jeder gleiche Möglichkeiten habe, seine Interessen einzubringen.

Für Waldemar G2 klingt Gleichheit genau danach:

„Die Demokratie braucht interessierte und dann informierte Bürger und (unverständlich, Anm. F.B.) also, eine ideale Demokratie bräuchte ideale, hundertprozentig informierte und interessierte Bürger und bräuchte dann ja auch hundertprozentige Transparenz. “ 89

Auf den Punkt gebracht rührt die Forderung nach Gleichheit bei Protestgruppen von dem Gefühl her, gegenüber Politik und Wirtschaft eben nicht gleichrangig zu sein, sondern benachteiligt zu werden. Gleichheit als Ideal zielt in den Gesprächen auf eine demokratische Organisation, die die Idee von Rechtsstaat und von Gleichheit von Einfluss verteidigt. Manuela C3 von den Freisinger Gruppen, die sich gegen den Flughafenausbau nördlich von München engagieren, illustriert dieses Ansinnen mit einer sehr plastischen Geschichte:

„Weil Sie gerade gesagt haben, die Macht geht vom Volke aus. Ich erinnere mich ganz stark an eine Szene bei den Einwendungen, wo ein junger Landwirt aufgestanden ist und gesagt hat, das Volk ist der Souverän und warum sitzen Sie da oben und ich stehe hier unten? Das habe ich ganz stark in Erinnerung, also eigentlich haben wir irgendwie... das ist der größte Teil in der Demokratie und gleichzeitig merken wir es oft gar nicht mehr. Also, das ist für mich die Diskrepanz im Moment und diese „Gleichheit“, was bei uns eigentlich auch besteht, also Gleichheit und Einigkeit gehört für mich auch zur Demokratie mit dazu, als Verständnis. Und ja, auch im Kleinen, für mich sind jetzt auch [die] in diesem Sinne

89 Waldemar G2 in der Fokusgruppe G2 Stuttgart am 02.04.2012. 
direkt erlebbaren demokratischen Prozesse, sozusagen in dessen Zusammenschluss oder auch im Gemeinderat, wenn wirklich einfach mal persönlich geredet wird, das [sind] so für mich sehr fühlbare demokratische Erlebnisse $[\ldots]^{\text {‘90 }}$

Dies ist allerdings insofern mit Einschränkungen wörtlich zu nehmen, weil an anderer Stelle bereits auf die Skepsis hingewiesen worden ist, das Prinzip allumfassender Gleichheit auch zur Basis konkreter Entscheidungen zu machen. Solange es um theoretische Gleichheit des Einflusses geht, bleiben die meisten gelassen - die eigenen Ressourcen und Erfahrungen im Protest haben sie selbstbewusst gemacht. Eine formalisierte Gleichheit aber, etwa im Sinne einer direktdemokratischen Beteiligung, empfinden viele als wesentlich problematischer. So trifft man in den Interviews denn auch häufig auf eine andere Füllung des Begriffs Gleichheit. Dass Politik, Parteien und Politiker ein Interesse hätten, Menschen ,gleich“ zu machen, ihnen ihre Vorstellungen unterschiedslos aufzuoktroyieren, lässt viele misstrauisch und ablehnend gegenüber Gleichheit als einem Pfeiler besserer Demokratie und Gesellschaft werden. Dazu mag auch beitragen, dass die hier in der Arbeit entwickelten Vorstellungen der Protestierenden von sich selbst als hochindividuelle, aufgeklärte und rationale Bürger Gleichheit als eingemeindendes Konstrukt auf wenig Gegenliebe stoßen lassen. Gleichheit, in diesem Sinne verstanden, lässt sie (wieder) ins Glied der Gesellschaft treten, aus der sie sich ja auch durch Erkenntnis und Engagement ein wenig erhoben haben. Diese Konnotation findet sich durchaus an vielen Stellen, nirgendwo aber so prägnant wie bei denjenigen Protagonisten der Euro-Gegner-Gruppen, welche sich mit einem liberalökonomischen Hintergrund engagieren. Hier wird gar Bezug genommen auf das berühmte Bonmot von Margaret Thatcher (,,There is no such thing as society!“"), um zu unterstreichen, welche Form einer besseren Gesellschaft ihnen vorschwebt:

„...deswegen geht es darum, ein System zu finden, dass die individuellen Präferenzen am besten verwirklicht. Wenn die alle verwirklicht werden, ist da eher dem Freiheitsziel gedient. Oder Freiheit und individuelle Präferenzen. Das hängt miteinander zusammen und damit auch Bürgerwille. [...] Also es gibt eigentlich nicht so etwas wie die Gesellschaft. Es gibt die Individuen und die mit Verträgen miteinander verbunden sind, dadurch ihre Präferenzen zum Ausdruck bringen. Wir denken nicht, dass die Gesellschaft irgendetwas Übergeordnetes ist. Das würden wir schon als totalitär betrachten. “91

90 Manuela C3 in der Fokusgruppe C3 Freising am 25.07.2012.

91 Einzelinterview Bruno G6. 
Ein dritter Gebrauch der Idee von Gleichheit allerdings widerspricht dieser radikalindividuellen Vorstellung und unterstreicht vielmehr, dass die Interviewteilnehmer davon überzeugt sind, dass es ihre Bündnisse und Gruppen sind, innerhalb derer sie von einer Gleichheit ausgehen, die von ihnen als außerordentlich positiv empfunden wird. Sowohl die internen Hierarchien, als auch das gemeinsam empfundene Streben nach einem Ziel des Engagements machten sie psychologisch ,gleich“ - auch wenn etliche Zitate doch darauf schließen lassen können, dass der konkrete Führungsanspruch Einzelner in ihren Gruppen dieser Vorstellung deutlich widerspricht.

„...wenn wir uns dann in den heißen Phasen getroffen haben dann kam gelegentlich auch die Kritik, ihr macht das immer so von oben, wir wollen doch immer basisdemokratisch entscheiden, dann habe ich gesagt, nein. Effektiv ist dafür nicht die Zeit und wir sind ja nicht hier, um jetzt schöne Reden zu schwingen, sondern wir sind hier, um dieses Volksbegehren ja mit möglichst vielen Unterschriften zu Ende zu bringen. Das ist eine sachliche Herausforderung und die gehen wir einfach so an, wie wir es aus unserer beruflichen Erfahrung heraus wissen, dass es der effektivste Weg ist. Aus die Maus. “92

Festzuhalten wären mit Blick auf Gleichheitsvorstellungen drei zum Teil miteinander ringende Begriffsfüllungen, die jeweils wieder andere Implikationen haben, wenn nach Utopien oder Demokratievisionen gefragt wird. Zunächst und deutlich spürbar empfinden viele Protestierende, dass ideal wäre, wenn alle (bzw. alle Betroffenen, was ihnen ein großer Unterschied ist) an Entscheidungen beteiligt und insofern alle ,gleich“ vor Recht und Gesetz wären, alle gleich von Transparenz der Entscheidungsfindung profitieren würden. Andererseits machen viele deutlich, dass ihnen wichtig sei, dass niemand ,gleich gemacht" werde und dass besonders ihre persönliche Individualität unangetastet bleibe. Beide Forderungen kritisieren ganz explizit die von ihnen beobachtete, zeitgenössische repräsentative Demokratie. Als drittes wäre noch anzufügen, dass als der ,gute“ Hort von Gleichheit den Protestierenden die eigene Gruppe des Engagements, der Nahbereich und das Lokale gelten.

Insgesamt gewinnt man den Eindruck, dass Gleichheit in den Ideen eines besseren Zusammenlebens einen durchaus starken und auch nur oberflächlich kaschierten instrumentellen Charakter besitzt. Während an mancher Stelle brüsk jede Vorstellung der Protestierenden selbst als einer „Gleichheit“" unterstehenden Gesellschaft abgelehnt wird, gibt es - zum Teil innerhalb weniger Sätze umschwenkend - kaum Hemmungen, ganz pauschal unter dem Stichwort eines nicht zu hinterfragenden Bürgerwillens einzugemeinden und damit die Mehrheit

92 Einzelinterview Hagen E4. 
„gleich“ zu machen. Je nachdem, wie es gerade passt, wird Gleichheit zum Menschenrecht oder zur knechtenden Rute der Herrschenden.

Denn ob die Mehrheit in einer Gesellschaft eine stabile, verlässliche Grundlage für eine Demokratie bilden könne - diese Frage betrachten die Interviewpartner mit unverhohlener Skepsis. Zeit, Kraft und das Vermögen, komplexe Sachverhalte durchdringen und beurteilen zu können, sehen sie ungleich über die Gesellschaft verteilt; diese machen für sie aber den Kern demokratischer Urteilsfähigkeit und - in vielen Gesprächen schwingt genau das mit - Urteilsberechtigung aus. Als Schablone kann eine Unterhaltung zwischen Waldemar G2, Raffael G2 und Torsten G2 stehen, die sich im südwestdeutschen Raum gegen die europäische Währungspolitik engagieren:

„Waldemar G2: [...] für mich ist die Frage, die dann diese Idealdiskussion beendet: Ist die Masse überhaupt interessiert und informiert? Das erleben wir jetzt bei unserer ESMGeschichte schmerzhaft, das haben wir früher bei der Nachrüstung erlebt, oder am Anfang der Umweltbewegung.

Raffael G2: [...] Wir haben sehr viele Leute, die studiert sind, die sehr schlau sind, aber wir haben halt auch viele in der Bevölkerung, die das nicht sind, die das auch gar nicht als Hobby haben, also ich hab halt auch Politik als Hobby und dann informierst Du Dich mehr und, Du handelst ja auch immer nur so weit, wie du's gerade weißt, oder nicht weißt. Aber das ist halt eben das Problem...

Waldemar G2: ...lass ihn mal Frau und Kinder haben, er hockt ja vorm PC, Du kannst im Facebook was schreiben, Tag und Nacht, egal, ich steh immer sehr früh auf und der antwortet Dir was. Lass ihn mal Frau und Kinder haben, dann nimmt das mit dem Informiertsein und mit der Partizipation schlagartig ab.

Torsten G2: Ich versteh dieses Argument so, dass gerade das die Demokratie im Prinzip nicht berechtigt. Also gerade wenn die Masse sozusagen dumm ist, also um das mal so plump auszudrücken, sollte die Demokratie im Prinzip nicht so in der Form existieren. Also seh` ich grad als Gegenargument dafür. ${ }^{\text {“93 }}$

Fast zynisch wird bisweilen über das Verhältnis von Mehrheit und Minderheit in einer Demokratie räsoniert:

„Und dann Mehrheiten, weil leider Gottes die Mehrheiten das Argument für alles sind und die haben das Sagen, egal wie kompetent, egal wie transparent der Prozess, egal wie kompetent die Wählenden. Und der Mensch möchte, glaube ich, lieber bei den Gewinnern als bei den Verlieren sein. Dafür schmeißt er auch notfalls ein paar Sachen über Bord. ${ }^{، 94}$

93 Fokusgruppe G2 Stuttgart am 02.04.2012.

94 Perry C2 in der Fokusgruppe C2.2 Stuttgart am 20.03.2012, 20 Uhr. 
Besonders kleine Protestgruppen haben sich dabei in ihrer Rolle gut eingerichtet und sehen gerade ihre Minderheitenposition als Beweis für inhaltliche Stärke und die beschriebene konzeptionelle Reinheit - dass sie eben noch nicht auf das „verwaschende“ Element der Mehrheitsgewinnung eingegangen sind. Dieses Element einer ,gerechten“ Minderheit findet sich dort noch verstärkt, wo die wahrgenommene Front der Gegner besonders breit scheint. Wenn sich viele oder gar alle politischen Parteien bezüglich eines Themas einig sind oder wenn es ein Junktim zu geben scheint zwischen Parteien, Exekutive und Wirtschaftsunternehmen - dann wird einer Bürgerinitiative oder einer Protestgruppe die eigene Minderheitenposition auch aus demokratischen Gesichtspunkten zentral. In Abstufungen findet sich dieses Moment in fast allen Protestfeldern und Gruppen: Die Gegner der Schulreform in Hamburg etwa sahen sich einer Phalanx aller Parteien gegenüber, die Eurogegner wähnen eine Verabredung der gesamten politischen Klasse Europas, jede Kritik an der gemeinsamen Währung vom Tisch zu wischen, und auch in Stuttgart und den Protesten um den Bahnhof haderten viele mit der vermeintlichen Verbindung aus Politik und Wirtschaft.

Dass Minderheitenschutz in einer Demokratie von den Gesprächspartnern, die sich selbst als Minderheit empfinden, als ungemein wichtig erachtet wird, ist daher einerseits intuitiv nachvollziehbar. Andererseits aber geben sich die Protestierenden enorm vorsichtig, wenn Kleingruppen in einer Gesellschaft eine Art Veto- oder Verhinderungsposition eingeräumt bekommen sollen. Dies mag damit zu tun haben, dass sie sich selbst zwar oftmals als manifeste Minderheit, aber als Vertreter einer schweigenden Mehrheit und des mehrheitlichen, noch nicht offiziell geäußerten Bürgerwillens verstehen. Denn als Gruppen, die lediglich eigene Partikularinteressen verfolgen, sehen sich die Gesprächspartner mitnichten. Gegenüber solchen Minderheiten versuchen sie sich im Gegenteil abzugrenzen und übersetzen dies auch in ihre Vorstellungen eines demokratischen Umgangs mit Minderheiten, bei denen sie zwei Seelen in der Brust spüren.

„Manuela C3: Ich würde gerne noch etwas zu dem Thema [sagen], wie geht man mit Minderheiten um, oder wie sollte man umgehen, weil laut der Definitionen waren wir ja Minderheit, oder? Und zwar eigentlich eine nicht zu beachtende Minderheit. So habe ich das eigentlich ganz viele Jahre erlebt. Also wir sind da irgendwie am Ende von München im Norden und deswegen [versammeln] sich gerade ein paar Bürger und regen sich auf, weil sie da ein Haus haben. Also das hat man in München sehr lange gehört, so nach dem Motto St.-Florians-Prinzip: ihr regt euch ja nur auf, was bei euch vor der Haustür ist und wenn es woanders wäre, wäre es ja egal.

[...] 
Sybille C3: [...] also ich denke, es ist ganz wichtig, diese Minderheiten anzuhören und zumindest dann zu reden und zu begründen zum Beispiel, warum er diese Meinung nicht teilt oder so, weil ich meine, es gibt auch Minderheiten, die nur Privatinteressen vertreten, also man kann da nicht immer hinter Minderheiten stehen...“95

Minderheitenschutz als demokratisches Fundament, als Schutz derjenigen in einer Gesellschaft, die drohen, gegenüber der Mehrheit zu verschwinden und via Mehrheitsvotum Rechte einzubüßen, wird unterstrichen und betont - aber eher in kleinräumigen, lokalen Kontexten als überhaupt relevant beschrieben:

„...Demokratie muss natürlich auch Minderheiten beachten und zwar Minderheitenschutz garantieren und ich denke, das funktioniert eigentlich nur auf kommunaler Ebene, also in einer kleinstmöglichen Einheit. “96

Für eine abstrakte Fragestellung nach der Rolle von Minderheiten in einer Demokratie verstehen sich Protestierende selbst eben auch als Fürsprecher und Repräsentanten eines Allgemeinwohls und damit einer gesellschaftlichen Mehrheit, der bis dato schlichtweg noch eine numerisch machtvolle Manifestation, Einsicht oder Sprachfähigkeit abgeht.

Wenn also über Minderheiten in den Gesprächen und Gruppendiskussionen diskutiert wird, stechen drei Punkte hervor: Zum einen, dass die Teilnehmer betonen, dass Minderheiten sich in anzuhörende und nicht anzuhörende Minderheiten einteilen lassen - je nachdem, ob sie ein berechtigtes Partikularinteresse verfolgen oder nicht. Zum anderen genießen die Protestierenden selber das Gefühl, einer rebellischen Minderheit anzugehören. Und drittens, in dieser Funktion aber eben für die Mehrheit zu formulieren und zu arbeiten, für das Wohle aller - in diesem Sinne also wieder keine Minderheit zu sein.

Dieser Widerspruch und die damit einhergehende soziale Spaltung werden in den Gesprächen durchaus thematisiert. Manchmal entsteht gar eine Art schulterzuckender Betroffenheitsgestus darüber, dass es ja die starken Gruppen innerhalb einer Gesellschaft seien, die ihre Interessen besonders gut verlautbaren können.

„Ich finde es auch schwierig, im Vorfeld im Idealfall alle mitzunehmen. [...] Ich finde diese Prozesse irgendwie sehr schwierig und wenn man irgendwie, es gibt ja ab und zu immer so Übersichten hier in Hamburg, welche Stadtteile sich am stärksten irgendwo engagieren und das sind dann oft Machtverhältnisse, das sind dann die Leute, die gut infor-

95 Fokusgruppe C3 Freising am 25.07.2012.

96 Udo G2 in der Fokusgruppe G2 Stuttgart am 02.04.2012. 
miert sind, die über gute Kanäle verfügen auch zu anderen Machtleuten, und das finde ich schwierig aufzudröseln und diesen Idealfall, der mir da auch vorschwebt, irgendwie zu erreichen. “97

Und Renate E2 sekundiert wenig später:

„Ganz einfach, wer Geld hat, wer die Werbung beherrscht, der hat gewonnen. “98

Gleichwohl bleibt die Erkenntnis der Protestierenden, dass es für die Qualität der Entscheidungen in einer Demokratie notwendig wäre, entweder zu erreichen, dass diejenigen besonderen Einfluss bekommen, welche die Sachverhalte und ihre Konsequenzen durchdringen - oder aber langfristig darauf hinzuwirken, dass möglichst viele Menschen diesen Status erlangen. Es ist eine Demokratie der Gebildeten, Sprachfähigen, die ihnen vorschwebt.

„...das liegt daran, dass eine Demokratie ja einen mündigen Bürger voraussetzt, weil nur ein mündiger Bürger ist überhaupt in der Lage, Entscheidungen zu treffen, die für ihn richtig sind. Und was zu beobachten ist, [...] man müsste sozusagen bei Adam und Eva anfangen. Also bei der Erziehung im Prinzip. Bei der Erziehung im Elternhaus, in der Schule, um überhaupt Menschen zu bekommen, im Allgemeinen, also nicht nur einzelne, sondern praktisch in der breiten Masse, die überhaupt in der Lage sind, zwischen Werbung und Wahrheit zu unterscheiden. ${ }^{“ 99}$

Die Gesprächspartner sind überzeugt, dass es Menschen gibt, die auch in ihrer Vorstellung einer besseren Demokratie nicht in der Lage wären, selbst gleichwertig teilzunehmen. Entweder, weil sie intellektuell nicht fähig sind, zu folgen, weil sie nicht das Selbstbewusstsein besitzen oder auch, weil sie nicht zu einer ähnlichen Engagementintensität fähig sind wie die Protestierenden selbst. Dieses Dilemma wird aber weithin akzeptiert und sogar stellenweise als notwendig unterstrichen, um bessere, fundierte Entscheidungen herbeizuführen. Denn schließlich sind fehlende Allgemeinwohlorientierung und zu geringe fachliche Qualifikation auch zwei zentrale Punkte der Kritik der Protestierenden gegenüber der zeitgenössischen, repräsentativen Demokratie. Und folgerichtig konzentrieren sich dann auch die Vorstellungen von möglichen Verbesserungen auf diese Felder: dass es - wie bei den Protestierenden selbst - nicht jedem Politiker zu jeder Zeit seines Lebens möglich sein könne, mit hohem Engagement und Motivation

97 Norah E2 in der Fokusgruppe E2 Hamburg am 07.05.2012.

98 Renate E2 ebenda.

99 Malte C1 in der Fokusgruppe C1.1 Stuttgart am 20.03.2012, 17 Uhr. 
Politik zu machen. Auch Politiker und Beamte könnten sich, wenn überhaupt, nur einem Teil ihrer Arbeit (und auch nur über eine geringe Zeitspanne) mit wirklichem Herzblut widmen:

„Dann vielleicht wirklich, äh dass nicht jeder Beamte sein ganzes Leben lang die Euphorie aufbringen kann, die vielleicht nötig wäre für den Job, den er da tut, das kann ich nachvollziehen. Aber dann muss man das eben irgendwie bereichern. Also dann muss man andere Leute dazuholen, die darauf Bock haben. Und vielleicht muss das gar nicht so viel kosten. “100

Für die Teilnehmer an den Gesprächen mischen sich für eine bessere Demokratie also zwei wichtige Faktoren: Das „Bock drauf haben“, also die Lust, sich zu engagieren, und das „Wissen und Können“, also die fachlichen Ressourcen. Da gerade aber ersteres - auch aus der Erfahrung der Protestierenden selber - keine dauerhafte Antriebsquelle sein muss, erscheint ihnen das Prinzip einer auf längere Zeit angelegten Repräsentation verfehlt.

\section{Korrekturinstanz und der Segen des Ortes: Demokratievisionen}

Wenn bei der Betrachtung der Krisenwahrnehmung durch die Teilnehmer an Bürgerprotesten festgestellt worden ist, dass diese eng mit den jeweiligen Erfahrungen im Engagement zusammenhängen, so springt eine solche Parallele beim Blick auf ihre Demokratiehoffnungen oder -visionen ebenfalls ins Auge. Dies ist insofern verständlich, wenn über die Dynamik von Krisenempfinden und die Wechselwirkungen mit dem eigenen Engagement davon ausgegangen werden kann, dass die Arbeit gegen politische Projekte und Entwicklungen sowie das Formulieren von Alternativen auch die Vorstellungen beeinflussen, wie möglicherweise die Entscheidungsfindung in einer Gesellschaft besser gestaltet werden könnte.

Teilnehmer von Bürgerprotesten blicken auf die Demokratie in Deutschland mit der Brille der Erfahrungen, die sie selbst in der Arbeit mit den Repräsentanten dieser Demokratie gemacht haben - und gleichzeitig bilden ihre eigenen Initiativen und Bündnisse eine Handlungsebene, auf der sie im Kleinen versuchen, eine bessere Entscheidungsfindung zu organisieren. Die Gruppen, in denen sich die Interviewpartner dieser Arbeit engagieren, sind - es ist bereits vielmals bestärkt worden - in ganz unterschiedlicher Form und Funktion zusammengesetzt. Ähnlich bunt und heterogen sind die Ideen, die ihnen bezüglich einer „besseren“ Demokratie in Deutschland vorschweben. Nur: Diese sind jeweils gekoppelt und

100 Einzelinterview Frederik C1. 
zurückzuverfolgen auf die Erfahrungen, die die Gesprächspartner jeweils mit ihren Gruppen gemacht haben. Kurz: Bürgerprotestler wünschen sich eine Demokratie, die mehr durch Bürgerinitiativen und soziale Bewegungen bestimmt wird und in der ihre konkrete Arbeit einen wesentlich größeren Stellenwert bekommt. Diese Vorstellungen werden allerdings mit unterschiedlichen Beispielen und Begründungen vorgetragen und mit differierenden Perspektiven auf Wert und Zustand der repräsentativen Parteiendemokratie verknüpft.

Ganz grundsätzlich empfinden die meisten Interviewteilnehmer, dass eine bessere Demokratie mehr Aspekte in sich tragen sollte, die sie selbst als Kern von Protestgruppen und Bürgerinitiativen betrachten. Zunächst einmal, ganz basal, findet die Feststellung weithin Zustimmung, dass eine größere Erkenntnis über die eigenen Rechte als Bürger innerhalb einer Gesellschaft zentral für die Qualität einer Demokratie sei. Die Bevölkerung müsse, um eine Demokratie qualitativ zu verbessern, „Lernprozesse“ durchlaufen, ähnlich denjenigen, die viele Protestierende für sich selbst beschreiben:

„,...weil ich jetzt schon zwei Mal erlebt habe in meinem Leben, [nach] '45 [...] und habe [...] bei der Arbeit, die die Amerikaner mit uns im Allgäu gemacht haben, so ein bisschen einen Lernprozess „Demokratie“ erfahren. Also dass war von 1945 bis 1950 und jetzt erlebe ich das an einem Lernprozess seitdem die Mauer gefallen ist zum zweiten Mal bei einem Teil der Bevölkerung, aber wir hatten damals einen Lernprozess, der uns aufoktroyiert worden ist durch die Besatzungsmacht. Die uns gesagt haben, ihr müsst das jetzt lernen und mir ist dann so allmählich auch klar geworden, dass wir etwas lernen müssen, aber wer lenkt jetzt so einen Lernprozess heute auch in unserer Gesellschaft, von Bürgerrechten etwas zu lernen?“101

Diesen Lernprozess, bei dem ausgehend von einem konkreten Thema die Missstände in Politik und Gesellschaft ,,verstanden“ und thematisiert werden, bei dem die Protestarbeit dann rasch über den Anlass hinauswächst und insgesamt die Demokratie und das Zusammenleben in den Blick nimmt, schildern viele Protestierende für sich selbst und nehmen ihn auch als eines der wichtigen Rezepte für eine Verbesserung der Demokratie allgemein.

Über diese Erkenntnis sehen sie den Keim einer Verbesserung demokratischer Organisation im Entstehen neuer Werte und Normen gerade durch das Engagement von Menschen wie ihnen.

„...ich glaube, nur hier kann Veränderung stattfinden. Ich glaube, Veränderung kann da stattfinden, wo es den Leuten gut geht, wo sie Bildung haben und wo sie verstehen kön-

101 Theodor C3 in der Fokusgruppe C3 Freising am 25.07.2012. 
nen, wo die Entwicklung, die gerade passiert, hinführt. Und wir sind diejenigen, die am allerehesten was dagegen tun können. Deswegen, wie ihr auch sagt, bin ich so dankbar, jetzt in Stuttgart sein zu dürfen und mitzubekommen, dass die Hoffnung einfach nicht tot ist. Also, dass Leute hier sich einsetzen und dass Leute die Energie haben und zwar an dem Punkt, wo man wirklich Veränderung bewirken kann.“102

Soziale Bewegungen und Bürgerproteste werden auf diese Weise zur Quelle einer besseren Demokratie in Deutschland und nehmen auch in den geäußerten Hoffnungen vieler Interviewteilnehmer eine tragende Rolle ein - sie sind ihnen der Garant für eine Verbesserung der empfundenen Krise.

„Schwer zu sagen, weil natürlich auch ein Lernprozess stattgefunden hat. Wenn ich die sozialen Bewegungen in der Bundesrepublik betrachte, dann denke ich, dass das, was da als Verfassungstext erarbeitet worden ist vom Parlamentarischen Rat und so weiter, dass wir schon erstaunlicherweise vieles von diesem Verfassungstext uns auch durch die sozialen Bewegungen angeeignet haben. Das ist nicht nur negativ, dass es ein Abstieg ist, sondern die sozialen Bewegungen haben bewirkt, dass hier in unserem Land in gewissen Bereichen - hier denke ich natürlich an den Kampf gegen Atomkraft und Atomwaffen oder Stuttgart 21 und die vielen anderen Beispiele, die man jetzt hier nennen könnte - es ist schon erstaunlich, wie viel auch demokratische Strukturen in diesem Land aufgebaut wurden sind, durch die sozialen Bewegungen." ${ }^{103}$

Das Erzählmotiv des Lernprozesses und generell des „Lernens“ ist in erster Linie bei Protestierenden zu finden, die auf eine längere Protestbiographie und generell auf ein höheres Alter zurückblicken können - ein größerer Fundus an Erlebnissen, gewissermaßen als Erzählfundament, um die eigene Transformation durch Lernen zu verdeutlichen, scheint diese Sichtweise zu befördern.

Eine ideale Demokratie besteht für die Protestierenden aus Menschen, die eine ähnliche Sicht auf Gesellschaft und Politik ausgeprägt haben wie sie selbst und die eine ähnliche Perspektive auf die dafür nötigen Ressourcen einnehmen. Idealismus, Motivation, fachliches Wissen, Bildung und Engagement sind ihnen die Schlüssel, um die von ihnen diagnostizierte Krise der Demokratie zu bekämpfen. Sie haben persönlich die Erfahrung gemacht, dass ihr Engagement aus ihnen politische, „demokratischere“, „,bessere“ Menschen gemacht hat - und deswegen wünschen sie sich, dass Politik, Parteien und Politiker sich ihrem Ideal annähern.

102 Raik C2 in der Fokusgruppe C2.2 Stuttgart am 20.03.2012, 20 Uhr.

103 Tilmann C1 in der Fokusgruppe C1.1 Stuttgart am 20.03.2012, 17 Uhr. 
„...es ist die beste, aber eine schwierige Staatsform, die von dem Einzelnen eine ganze Menge verlangt. Engagement, Disziplin, Fantasie. Und immer ist sie in Gefahr und man muss sie immer neu erkämpfen. Sie braucht ein Maß an Interesse, für das, was im Tagesgeschehen stattfindet, was manche nicht aufbringen. Und sie erfordert zumindest die Kenntnisse im Lesen und Schreiben. Was auch immer ein zunehmender Teil nicht aufbringt. Und es ist die Frage, kann der an der Demokratie wirklich teilnehmen? Es gibt eine viel größere Zahl von Menschen, die keine Ahnung haben, wenn man sie fragt: „Wer ist Hamburger Bürgermeister? Oder „Welche Partei ist gerade in Hamburg an der Regierung?", als man so denkt. Wenn man einmal auf der Straße war, da kriegt man da eine Menge mit. Das Problem, bei der Demokratie werden die Leute ja gewählt. Und die Führungspersonen, die man wählt, die müssen eine gewisse Ausstrahlung haben, die müssen bekannt sein. Sie müssen aber Eigenschaften haben, die man nicht unbedingt zu den Tugenden zählt. Ein Übermaß an Bescheidenheit, so nett es im Familienkreis ist, für einen Politiker ist es eine ungeeignete Eigenschaft und deren gibt es mehr.“104

„Zwei Stichworte, die mir spontan einfallen. Engagement, was eben jeder Einzelne mitbringen muss, dass es eben funktioniert, Demokratie und äh Kompetenz. Das ist vielleicht ein bisschen komisch [...], aber ich finde [...], das ist natürlich das Schwierige an richtiger gelebter Demokratie. [...] Die, die sich beteiligen würden, sollen nicht nur aus dem Bauch heraus entscheiden, sondern eben auch entsprechende Kompetenzen mitbringen. “105

Dass ihr eigenes Engagement zu viel unmittelbareren, direkten Demokratieerlebnissen führe und ihnen selbst gezeigt hat, welche Gefühlswelten eine Partizipation an der Diskussion über Entscheidungsprozesse auslösen kann, veranlasst sie zu der Annahme, dass in ihren Organisationsprinzipien, Mobilisierungen und Herangehensweisen Mittel für eine Begegnung der von ihnen eigentlich bedauerten Politikverdrossenheit liegen. Hagen E4 schildert dies in seinen Erzählungen seiner Erfahrungen im Engagement im Rahmen der Hamburger Bildungsproteste.

„Wir haben einmal hier in Hamburg eine Situation geschaffen, die von, sagen wir mal, März bis Sommer 2010 dauerte, die zu einer sehr starken Politisierung und, würde ich sagen, zu einem doch starken Demokratiebewusstsein in der Stadt geführt hat bei sehr vielen Menschen, die sich sonst eben, wie ich früher auch, eigentlich was Politik anging, nur darauf beschränkt haben, ab und zu zu einer Wahl zu gehen, ihr Kreuz zu machen und das war`s aber im Prinzip. Und ansonsten passiv Zeitung zu lesen und vielleicht ein bisschen mal zu besprechen oder zu diskutieren, aber sich nicht selber einzubringen. Und in dieser

104 Ulrike E1 in der Fokusgruppe E1 Hamburg am 20.03.2012.

105 Olaf C2 in der Fokusgruppe C2.2 Stuttgart am 20.03.2012, 20 Uhr. 
Phase und auch im Volksbegehren, vorher im Herbst 2009 war es so, dass plötzlich alle Menschen, die man so traf in der Stadt, aber egal wo, nicht jetzt irgendwie speziell Bildungsbürgertum oder West End oder so. Auch in Billstedt und Harburg und sonst wo. Egal wo man stand, auf Leute traf, die plötzlich merkten, dass sie selber Politik mitgestalten können in so einem Volksgesetzgebungsverfahren jedenfalls, dass also wenn in Billstedt der türkische Vater kam und sagte, geben Sie auch gleich mal noch ein paar Listen mit, ich spreche auch meine Kollegen an, dann merkte man, dass jeder merkte, man kann was machen. Klar, und jede Stimme zählt nur eine Stimme, aber wenn alle ganz viel zusammenhalten, funktioniert es. Und das war also natürlich auch ein unmittelbareres Erleben von Demokratie und Mitwirkung an politischen Prozessen, als es bei einer Wahl ist. Bei einer Wahl wählt man halt eine Partei im Wesentlichen und muss dann gucken, dass die auch das umsetzt, was sie mal versprochen hat und in ihren vielen Gremien irgendwann mal so an Thesen entwickelt. Aber die parteilichen Willensbildungsprozesse sind halt doch sehr viel schwerfälliger. In so einem Volksgesetzgebungsverfahren, wo es um ein konkretes Anliegen geht, ist es natürlich auch leichter verständlich und nachvollziehbar und auf sich selber zu beziehen, weil es eben dann sozusagen Hopp oder Top ist.“106

Schaut man weitergehend auf die Vorstellungen der Protestierenden, wie dieses Ideal einer Demokratie von engagierten Bürgern weitergedacht werden und was Umsetzungskanäle oder Mechanismen sein könnten, muss wiederum zwischen den Zeilen gelesen werden. Viele sind bemüht, sich nicht naiv zu geben und unterstreichen deutlich, dass es keine ideale Form einer Demokratie gebe, die sie nun skizzenhaft aus dem Hut zaubern könnten. Etablierte, eingefahrene und über Jahrzehnte ausgefeilte Verwaltungsabläufe ließen sich nicht per Federstrich ersetzen, ohne gravierende Effektivitätsverluste in Kauf nehmen zu müssen. Hier mischen sich allerdings zwei unterschiedliche Perspektiven: einerseits diejenigen, die unterstreichen, dass es so etwas wie eine ideale Demokratie für eine ganze Gesellschaft gar nicht geben könne, es zwecklos sei, darüber zu beraten.

„Ja, aber die Frage ist, wie man das regelt und ob es, wenn es momentan nichts Besseres gibt als die parlamentarische Demokratie, dann kann man sich ja mal überlegen, in welche Richtung das ginge, aber ich sehe das noch nicht, zumindest das, was jetzt an Volksgesetzgebung ist, hat diese Risiken." ${ }^{107}$

Auf die Spitze treiben dies die Eurogegner, die sich selbst im originär liberalen politischen Spektrum verorten. Hier antwortet idealtypisch Volker G2 auf die

106 Einzelinterview Hagen E4.

107 Renate E2 in der Fokusgruppe E2 Hamburg am 07.05.2012. 
Frage, wie für ihn der ideale Umgang innerhalb einer Demokratie mit Interessenskonflikten aussehe: „Das gibt's nicht.“"108

Auf der anderen Seite äußern gerade die Gruppen, die in direkten Abstimmungsverfahren unterlegen sind, deren Hoffnungen mit den Entscheidungsverfahren zerstieben, die sie im eigentlichen Sinne gefordert oder erhofft hatten, ein sehr viel inklusiveres Verständnis von Demokratie und unterstreichen den vermittelnden Charakter repräsentativer Verfahren.

„Ich habe mich nicht für die direkte Demokratie ausgesprochen. Ich denke, es gibt Themen, wenn es um die Privatisierung von Krankenhäusern geht oder Bildung ist keine Ware, wo jeder nicht so ganz persönlich angesprochen ist, aber gesellschaftlich natürlich schon, da können diese Beteiligungsverfahren etwas bringen, aber in dem Maße wie, also wie gesagt, ,wenn ich hier mein Liebstes mit den Schmuddelkindern in die Schule geben soll", dann sage ich doch lieber ,länger gemeinsames Lernen ja, aber bitte nicht für mein Kind", und ich habe dann eine entsprechende Lobby hinter mir mit viel Geld und dass diejenigen, die das anders sehen oder auch andere Bedürfnisse haben und gar nicht das Geld haben, es in dieser Auseinandersetzung reinzugeben, deswegen wäre ich weiterhin dafür, dass solche Entscheidungen über die parlamentarische Demokratie laufen. “109

Die Mitglieder dieser Gruppen, wie hier etwa der unterlegenen Initiativen in der Hamburger Auseinandersetzung zur Schulreform, sind erheblich vorsichtiger, wenn es um die Beschneidung der Kompetenzen von Parteien und Verwaltung geht. Dies kann auch nicht verwundern, fühlten sie sich doch in ihrem Vorhaben von allen Parteien der Hamburger Bürgerschaft unterstützt, während sie anderen zivilgesellschaftlichen Gruppen und Initiativen unterlagen.

Ein positives, klares Bild hingegen, wie eine stärkere Beteiligung konkret auszusehen hätte, äußert kaum jemand in den Interviews. Und vielleicht ist auch das verständlich, ist doch in den Passagen zum Selbstverständnis der Protestierenden herausgearbeitet worden, wie aufgeklärt und rational und eben wenig hochfliegend sich die Gesprächspartner selbst sehen. Ein zu weit in die Zukunft weisendes, gar utopisches Plädoyer für die Umgestaltung der gesellschaftlichen Entscheidungsfindung mag dieses Bild ins Wanken bringen und wird vermieden. Strategische Überlegungen zum konkreten Fall, Lehren, Erfahrungen - das ja, aber eine Wunschliste der schönsten Demokratievisionen? Dies würde das Selbstbild zu stark gefährden, nach dem man sich auch dem Rest der Bevölkerung an situativem Verständnis der politischen und gesellschaftlichen Funktionsmechanismen überlegen fühlt. 
Wenn es allerdings ein Bild gibt, welches als positive Rollenidee für eine bessere Demokratie weithin geteilt wird, dann ist es das der Korrekturinstanz. Denn viele schildern in ihren Antworten zu den Demokratievorstellungen - zwar vergleichsweise unbestimmt und vage -, dass sie sich eine tiefer und weiter gehende Partizipation „der Bürger“ wünschen, dass sie sich nach Mechanismen sehnen, die sicherstellen, dass jede Entscheidung nach der Maßgabe des „Wohl(s) der gesamten Bevölkerung“110 getroffen werde. Es wird aber auch deutlich, dass die meisten Gesprächspartner sich nicht selbst in der Rolle der hauptsächlich Handelnden sehen.

Den Diskurs zu beeinflussen, die Themen zu setzen, mit denen die Politik sich auseinanderzusetzen hat, hier Schwerpunkte zu legen und nicht mundtot gemacht zu werden - dieses Gefühl verschafft ihnen Befriedigung. Wenn Parteien oder Politik ihr Anliegen aufgreifen, wenn sie ein Projekt mittragen, anschieben, o.ä. - dann haben Protestierende das Gefühl, dass sie konkrete Veränderungen mit ihrer Arbeit auf den Weg gebracht haben, dass sie gar die Politik vor sich her getrieben und zum Handeln gezwungen haben. Lothar C2 engagiert sich schon seit längerer Zeit im Hamburger „Recht auf Stadt“-Zusammenhang und schildert, wie die Diskussion um Stadtpolitik in den Jahren vor 2011 die Agenda des Bürgerschaftswahlkampfes beeinflusste. Im Gespräch ist ihm der Stolz darüber anzusehen, und im Ton seiner Stimme schwingt eine Zufriedenheit mit, die auch die Verschriftlichung noch erahnen lässt:

„... und ich muss sagen, wir haben wahnsinnige Erfolge in den letzten Jahren gehabt. Also, ich glaube, ich habe keine Bewegung bisher erlebt, die auf so große Resonanz gestoßen ist. Wir haben den Bürgerschaftswahlkampf 2011, (da) war plötzlich bezahlbarer Wohnraum das Thema. Die Parteien haben sich überboten darin, also die CDU hat von 4.000 Wohnungen gesprochen, die sie schaffen wollen. Die SPD von 6.000 und die Linkspartei hat sich nicht [...] entblödet, etwas anderes zu fordern, meinetwegen eine Höchstmiete oder sowas, sondern hat gesagt, wir wollen 8.000 Wohnungen schaffen. Die Hamburger haben für 6.000 gestimmt mehrheitlich und jetzt ist die Rede von davon, dass 6.000 Wohnungen pro Jahr geschaffen werden sollen und das ist auf jeden Fall eine Veränderung. Also es gibt ne total starke Veränderung im stadtpolitischen Diskurs. [...] das ist natürlich alles sehr unkreativ, weil es nicht darum geht, sozusagen eine andere Stadt zu gestalten, sondern eigentlich am liebsten zu so einer Stadt von vor vierzig, fünfzig Jahren zurückzukehren, aber es ist zumindest besser als das, was wir davor hatten. Das ist schon ganz interessant, als [...] da wieder so Sachen aufgegriffen werden, wie auch Unternehmen [...], wenn sie irgendwas aufziehen, immer direkt sagen müssen, okay wir wollen auch sozialen

110 Olaf C1 in der Fokusgruppe C1.1 Stuttgart am 20.03.2012, 17 Uhr. 
Wohnungsraum schaffen und so.[...] das ist dann natürlich auch die Arbeit, daran zu sitzen und aufzuklären, was es bedeutet." ${ }^{111}$

Denn einen Diskurs zu beeinflussen, ein Thema öffentlichkeitswirksam so zu äußern, dass es nicht beiseite gewischt werden kann, sondern behandelt werden muss, verleiht eine Aura der Macht. Man handelt gar nicht selber als Schaffender, man formuliert aber die Ziele mit und überwacht die Umsetzung. Dies entspricht auch dem Überlegenheitsgestus, der bisweilen aus den Äußerungen mancher Gesprächspartner scheint, wenn man nur dann, wenn es drängt und drückt, oder aber, wenn es Fehler zu korrigieren gibt, aktiv wird, sich ansonsten aber mit einer Aufsichtspflicht zufriedengibt. Die Protestierenden sehen sich in dieser Form auch als eine Art Aufsichtsrat der Demokratie. Zudem wird hier zur Begründung ein Postulat von Effektivität herangezogen, demzufolge eine engere Einbindung der besonders fähigen Bürger zu besseren, weniger fehlerbehafteten Entscheidungen führe. Volker G2 etwa, aus einer Gruppe von Gegnern der europäischen Währungsintegration, begründet dies mit dem hochtrabenden Rückgriff auf den griechischen Philosophen Perikles, mit dem er unterstreicht, dass Partizipation und Bürgerbeteiligung schon immer den Kern der Demokratie als besonders effektive Entscheidungsorganisation ausgemacht hätten:

„Dann nennt er die Partizipation. Und zwar nüchtern und nicht [...] [als] - weiß Gott was Schönste und Beste [auf] der Welt, sondern um Fehler zu minimieren. Ganz einfach. Wir beraten - sagt er uns - so lange Jahre, bis eine Entscheidung dann getroffen ist, in der Hoffnung, dass sie dann die richtige sein wird, aber ohne die Garantie zu haben. Also Fehlerminimierung ist die Aufgabe der Partizipation, also der Volksherrschaft. “112

Die Politik wachsam zu beobachten und korrigierend eingreifen zu können, diese Wunschvorstellung findet sich in vielen Gesprächen wieder. Und an einigen Stellen wird die Position als Aufsichtsrat von Politik, Wirtschaft und Verwaltung zugespitzt auf eine Erweiterung der geläufigen Trias der Gewaltenteilung. Maria C1 beispielsweise hält für ihr Plädoyer im Gruppeninterview laute und ungeteilte Zustimmung unter den Anwesenden:

„Wunsch: Eine vierte Gewalt. Die Bürger. Also nicht nur drei Gewalten, sondern eine vierte, bitte! ‘113

111 Einzelinterview Lothar C2.

112 Volker G2 in der Fokusgruppe G2 Stuttgart am 02.04.2012.

113 Maria C1 in der Fokusgruppe C1.1 Stuttgart am 20.03.2012, 17 Uhr. 
Eine Anknüpfungsmöglichkeit an die bisherigen Beobachtungen zum Engagement im Protest bietet sich an dieser Stelle auch deswegen, als dass ein Demokratieideal, in dem man selbst ein Korrektiv und nicht ein Handelnder ist, der Lebenssituation entspricht, in der sich viele Beteiligte befinden: Man engagiert sich für das Thema, welches einem persönlich besonders dringlich erscheint und zwar dann, wenn man Fehlentwicklungen als nicht mehr länger erträglich empfindet. Darüber hinaus aber, wenn kein unmittelbarer Handlungsbedarf gesehen wird, verringert man selbst oder die Gruppe die Intensität des Engagements bis hin zur (temporären) Einstellung. Eine bessere Demokratie mit den Bürgern als nicht zu übergehendem Aufsichtsrat entspricht jedenfalls der Rolle, in der sich viele der Protestbündnisse auch selbst sehen: als Verteidiger der originären Idee von Demokratie, die sie durch die ausführenden Politiker und Parteien gefährdet wähnen. Als reaktive Demokratieaufsicht.

Es gibt allerdings auch Zusammenhänge, in denen ein weiteres Erzählmotiv einer besseren Demokratie und Gesellschaft zum Tragen kommt, welches über ein beobachtendes Kontrollieren hinausgeht. Gruppen, die sich dezidiert das produktive Schaffen einer besseren Gesellschaft im Kleinen auf die Fahnen schreiben, haben in den Gesprächen einen anderen Zugang zur Frage nach der idealen Demokratie. Denn sie haben bereits selbst auf kleinerer Ebene mit der Umsetzung derselben experimentiert, müssen also nicht im Wolkigen verbleiben, sondern können aus einem Erfahrungsfundus zur Sache schöpfen, der gröBer ist als bei vielen anderen Bündnissen und Initiativen. Auch muss ihnen die Frage nach Utopien und Visionen der Demokratie nicht wie ein Fallstrick vorkommen, da sie bereits einige mehr oder weniger weit reichende Versuchsschritte zum Thema vorzuweisen haben, mithin über eine Anknüpfung verfügen, die nicht luftleer zu wirken droht. Und während andere an dieser Stelle im besten Fall auf persönliche Wahrnehmungen und Diskussionen im Kreis der Protestierenden verweisen können, vermögen diese Gruppen von eigenen Erlebnissen, von Gelungenem und weniger Gelungenem konkret zu erzählen und Bilanz zu ziehen. Und sie können, was nicht wenig ihrer Motivation ausmacht, mit leuchtenden Augen von ihrem Stolz berichten, selbst aktiv zu sein, um im Kleinen, aber für alle sichtbar, die eigenen Werte und Ideen zu verwirklichen.

Dass man sich allerdings im Engagement nicht in der Negation erschöpfe, keine Exekutionsgruppe der Verweigerungshaltung sein möchte, unterstreichen sehr viele Gesprächspartner. Das konstruktiv-gestaltende Element gehört für viele zu einer Perspektive der Aneignung demokratischer Prozesse elementar dazu. Denn nur mit dem Nachweis eines „Mittuns“ gerät die Forderung nach einer bürgerlichen Kontrollinstanz nicht in den Verdacht eines Partikularismus, sondern lässt sich mit der Betonung des Allgemeinwohlinteresses verbinden. 
Die Ebene, auf welche sich diese Anstrengungen richten, ist das Lokale, die (Klein-)Stadt, der Ort, in dem die Protagonisten der jeweiligen Gruppen leben. Dies ist bei manchen Themenkomplexen des Protests unmittelbar einleuchtend, etwa, wenn es um Bau- oder Infrastrukturprojekte geht, um die Schulentwicklung - welche sich ja in erster Linie vor Ort auswirkt - oder dezidiert um die Entwicklung des eigenen Stadtviertels. Dass hier Wünsche und Vorstellungen formuliert oder manchmal bereits umgesetzt werden, die sich auf die lokal sichtund beeinflussbaren Größen beziehen, ist nachgerade selbstverständlich. Aber auch Gruppen, welche - wie etwa die Euro-Gegner - in erster Linie nationale oder gar supranationale Entwicklungen ins Zentrum ihrer Krisendiagnose stellen, zeigen in den Passagen zu den Demokratiehoffnungen, dass sie durchaus das konkrete, kommunale, erfahrbare Leben als einen Kern von Demokratie ausmachen. Das Ideal einer lokalen Autonomie, welches an diesen Stellen zum Vorschein kommt, passt auch perfekt zur Vorstellung von Bürgerprotest als Vorbild für eine gesellschaftliche Demokratie insgesamt - und es unterstreicht zudem deutlich die im Kapitel zur Krisenwahrnehmung gemachte Beobachtung einer Sehnsucht nach Übersichtlichkeit und - vor allem - Zuweisung von Verantwortung für gesellschaftliche und politische Entwicklungen. Vor Ort, in meiner Stadt, so die Hoffnung, kann ich verstehen und überblicken, wie, warum und auf wessen Geheiß Dinge geschehen - und ich kann sie beeinflussen. Wenn Robert E. Park von der Stadt spricht als ,der konsequenteste und insgesamt erfolgreichste Versuch des Menschen, die Welt, in der er lebt, nach seinen Vorstellungen umzugestalten“114, wird dies in den Gesprächen ganz plastisch und nicht ohne Stolz beschrieben.

Die Erfahrung der Gemeinsamkeit im Protest, im gemeinschaftlichen Verhandeln von Lösungen und Handlungsalternativen, wird als besonders wertvoll geschildert. Allein, wie diejenigen Protestierenden aus größeren Bündnissen ihre etablierten Mechanismen der Entscheidungsfindung schildern, zeigt, wie zufrieden sie mit den ,erdenden“ Erfahrungen der gemeinsamen Konsensbildung sind:

„Wir waren dann auch in Christiania (alt. Stadtviertelprojekt in Kopenhagen, Anm. F.B.) und haben da dann zum Beispiel auch an einem Workshop oder an Podiumsdiskussionen teilgenommen, wo verschiedene Projekte ihre Probleme darstellen und sich ausgetauscht haben. Von Anfang an wurde sehr stark auch geguckt, was gibt es für Projekte in Europa und wie machen die das. Und dann sind viele auch mal hingefahren und haben mal geguckt. So, und [haben] viele Ideen mitgebracht. Aber wie gesagt, es hat sich auch von selbst so ne Art Struktur etabliert. Also vieles natürlich auch wie gesagt richtig entwickelt, wie die Genossenschaft und der Verein. Aber es bleibt dabei im Grunde genommen. Das

114 Park, Robert E.: On Social Control and Collective Behaviour, Chicago 1967, S. 3. 
letzte Sagen hat der Platz und der Platz ist die VV (Vollversammlung, Anm. F.B.). Und anders kommen wir der Sache gerade nicht wirklich bei. Auch wenn viele Sachen dann eben vorgearbeitet werden. Also im Vereinsvorstand oder in der Genossenschaft oder in einzelnen AGs. Werden Sachen vorbereitet und dann eben der VV vorgestellt. Und dann geht`s ein bisschen schneller. Also ist da ganz schön gut geworden, aber es ist immer noch, es wirkt immer noch viel ineffizienter, als es vielleicht in mancher Vorstellung sein könnte. Aber es muss ja auch praktikabel bleiben.“"115

Demokratievorstellungen und die Erfahrung des Protests verbinden sich hier, da die Gruppenerlebnisse ihnen oft eine Zufriedenheit in der Gemeinschaft mitgegeben haben. Das gemeinsame Ziel, ein gemeinsames Handeln als Protestierende, das Gefühl, mit „Gleichen“ unterwegs zu sein, die eigene Umgebung im gemeinsamen Sinne zu gestalten - all dies sorgt für die Hoffnung, eine Art Geborgenheit in vertrauter Umgebung auch als Ausgangspunkt für eine erfüllende und gelingende Demokratie zu suchen.

Dass man sich gegen Pauschalisierungen und Regelungsvorstellungen zur Wehr setzt, die individuellen oder lokalen Besonderheiten nicht Rechnung tragen, unterstreicht darüber hinaus den selbstbewussten Anspruch auf Individualität, den die Interviewteilnehmer für sich erheben. Nur in Regelungen und Abstimmungen, welche auf kleinster Ebene stattfinden, könnten diese Anpassungen Aufnahme finden. Besonders Programme, die nationale Regelungen entwickeln, stoßen auf ein Misstrauen, das bereits im Abschnitt zur Gleichheit aufgegriffen worden ist.

„Das sind Entscheidungen, die muss man vor Ort treffen. Insofern ist ein Parteiprogramm, was man macht, wo man sowas festschreibt, das find ich ist auch nicht gut geeignet. Man muss einen gewissen Rahmen geben, zum Beispiel für Bildung, aber man muss sagen: Das muss vor Ort geregelt werden. “116

Viele der Gesprächsteilnehmer betonen aber auch, dass es ihnen schlicht viel mehr Spaß mache, sich um Probleme und Lösungen zu kümmern, die sie auch selbst beträfen - und dass sie davon ausgehen, dass ein Aufgreifen dieses Prinzips auch für eine Belebung demokratischer Prozesse hilfreich sei. Es sei viel leichter, sich für ein Engagement und eine Mitarbeit zu engagieren, wenn es um Themen gehe, die einem im persönlichen Umfeld näherstünden. Vor allem aber unterstreichen viele in den Diskussionen, dass sie für den skizzierten Wunsch nach einer ausgebauten Korrekturinstanz des Bürgers auf der lokalen oder kom-

115 Einzelinterview Frederik C1.

116 Anna G1 im Einzelinterview G1 Anna und Conrad. 
munalen Ebene wesentlich mehr Spielraum und Übersicht erwarten. Die Verantwortlichkeit für politische Entwicklungen ebenso wie die Möglichkeiten, als Bürger einzugreifen, seien auf den unteren politischen Ebenen erheblich besser überschaubar, man kenne die Protagonisten besser, könne die Abläufe besser verstehen, überhaupt seien die Wege kürzer. Das Selbstbewusstsein der Protestierenden als arrivierte und anerkannte Bürger ihrer Stadt spielt sicherlich auch mit hinein, wenn sie die Aufsichtsmöglichkeiten über die Politik und Wirtschaft besonders für die lokale Ebene entwickeln. Udo G2 nimmt dabei Bezug auf die Stadt als Ort, an dem sich Demokratie als Prinzip überhaupt erst habe entwickeln können:

„Athen war eine Stadt, nicht Griechenland hat eine Demokratie gehabt, sondern Athen hat eine Demokratie gehabt. Und das ist ein kleiner abgegrenzter Raum, eine Stadt, und das ist sozusagen die Kommune und ähm, da können sozusagen die Bürger genau sehen, jetzt haben die Politiker das entschieden und das gefällt uns ganz und gar nicht und da werden die Leute halt [umgestürzt], sei es nun von heute auf morgen oder sei es bei der nächsten Wahl, und da wissen die Leute ganz genau: Der hat das verabschiedet, oder die Kaste von Politikern hat das verabschiedet..."“117

Überhaupt sei Demokratie ganz grundsätzlich nur dann realisiert und gewährleistet, wenn Menschen über ihre näheren Lebensumstände mitentscheiden könnten - und auch das rückt wieder den Wohnort, die Arbeitsstelle, die Schule, Universität etc. und ein subsidiäres Verständnis von Entscheidungsautonomie ins Zentrum des Interesses:

„Ich finde, dass man von Demokratie nur dann sprechen kann, wenn die Leute da, wo sie Tag für Tag äh ihr Leben verbringen, auch direkt was entscheiden können. Und das können sie heute in keinem Betrieb. Da bestimmt der Chef. Diese 30.000 Leute, die sind diesem Typ von Anton Schlecker ausgeliefert, der jetzt entscheidet, dass sein Vermögen, ich meine, das hat er sowieso schon auf die Seite gebracht, aber die sind jetzt in die Arbeitslosigkeit irgendwie entlassen. [...] man kann an jedes Betriebstor eigentlich ein Schild hinhängen, hier verlassen sie den demokratischen Sektor, ist doch so. Und bei den Schulen genauso und bei den Unis auch so...“118

Demokratie gebe es, wenn überhaupt, allenfalls in Ansätzen auf lokaler Ebene dank der Bürgerinitiativen und der Protestierer vor Ort. Auch, weil sich aufgrund größerer Überschaubarkeit und leichter aufrechtzuerhaltender Netzwerke die

117 Udo G2 in der Fokusgruppe G2 Stuttgart am 02.04.2012.

118 Verena C2 in der Fokusgruppe C2.2 Stuttgart am 20.03.2012, 20 Uhr. 
Gegenwehr vielversprechender organisieren lasse, sei die Kommune, die Stadt oder das Viertel die Keimzelle für eine bessere Demokratie.

\begin{abstract}
„Also, mal abgesehen davon, dass es einen verfassungsrechtlichen Rahmen gibt, der ja auch geprägt wurde durch politische Entwicklungen in dieser Republik, ist für mich die kommunale Ebene die erste Beteiligungsmöglichkeit, die gestärkt werden sollte. Denn, äh - ich habe selber auch schon ein Bürgerbegehren mitgewirkt und weiß, wie schwierig es ist, zunächst mal diese Hürde zu überspringen. Das setzt voraus, dass es eine Handvoll Leute gibt, [...] die sagt: „Wir opfern unsere Zeit“. Und in sechs Wochen die entsprechenden Unterschriften zusammenzubringen, ist eine Heidenarbeit. “119
\end{abstract}

Diese Elogen auf das örtliche Zusammenleben, die Gemeinschaft, in der man zudem eher Vertrauen und Gleichgesinnte finde, können allerdings mitunter darüber hinwegtäuschen, was an manchen Stellen noch hinter der Forderung nach lokaler Autonomie oder Subsidiarität hervorblitzt. Denn die begriffliche Füllung von Subsidiarität wird oft an den eigenen Protest angelehnt. Übersetzt meinen dann viele, Ziel müsse es sein, dass ,nur wir entscheiden, was hier passiert“. Entsprechend etwa führt Rüdiger C1, engagiert im Zusammenhang der Initiativen gegen den Bahnhofsbau in Stuttgart, aus, wie sehr ihn die landesweite Ansetzung des Bürgerentscheids zum Projekt enttäuscht habe, da viele abstimmen konnten, die gar nicht in erster Linie davon betroffen seien:

„Also, Stuttgart ist in vielerlei Hinsicht ein Lehrbeispiel, ja?! Der unheilbare Mangel besteht für mich darin, es gibt Artikel 28 Grundgesetz - Subsidiaritätsprinzip, nur die Bürger einer Kommune haben darüber zu befinden, was in ihrer Kommune geschieht. Und ich habe den Eindruck, wir treten auf eine Bremse und die Bremse funktioniert nicht. “120

Die Formulierung und das Hüten des Allgemeinwohls, wie weiter oben unterstrichen, werden von den Protestierenden als ihr Hoheitsgebiet angesehen - und wirkliche Demokratie ist dann vorhanden, wenn sie die entsprechende Zielsetzung und Umsetzung überwachen.

119 Rüdiger C1 in der Fokusgruppe C1.1 Stuttgart am 20.03.2012, 17 Uhr.

120 Ebenda. 


\subsection{Zwischenfazit V: Demokratie Und Krise}

Eine zunehmende Unübersichtlichkeit wird von den Gesprächsteilnehmern als eine der gefährlichsten Entwicklungen in Politik und Gesellschaft wahrgenommen. Dass Verantwortlichkeiten, damit Ansprechpartner, aber ganz generell Entscheidungswege nicht mehr einsehbar und im demokratischen Sinne beeinflussbar sind, erscheint ihnen ausgemacht und als eine außerordentlich düstere Perspektive. Einhergehend damit wird eine drohende Fremdbestimmtheit in einem Wertekorsett gefürchtet, welches nicht das ihre ist. Diese dunklen Untertöne und Befürchtungen werden allerdings insofern nicht zu einer persönlichen Sorge um die eigene Zukunft, da sie begleitet werden vom Glauben, innerhalb der Gesellschaft zu den „Starken“ zu gehören, die für sich selbst durchaus sorgen können. Vielmehr ist das Ergebnis eine Empörung, dass andere - sprich: Politiker, Parteien, Konzerne und Wirtschaftseliten - sich gesellschaftliche Ressourcen aneignen. Es ist ein Lamento der Starken.

Die eigenen Gruppen allerdings, diese Form des Engagements in Protestgruppen und Initiativen, gelten ihnen im Gegensatz zur repräsentativen Demokratie als mögliche Kerne ,wahrer“ Demokratie. Hier stellt sich oftmals nicht das Problem allzu großer Heterogenität, welche dann mühsam und unter schmerzhaften Kompromissen $\mathrm{zu}$ einem Konsens geschmiedet werden muss. Denn in ihren Gruppen treffen die Protestierenden, im Gegensatz zur Mitgliedschaft in politischen Parteien, auf Gleichgesinnte, bei denen sie davon ausgehen, dass ohne übergroßen Aufwand oder Schwierigkeiten eine Übereinkunft in entscheidenden Fragen herzustellen sei. Für die Gruppen als Diskurskoalitionen ist die anfangs für notwendig beschriebene ,,beständige Reartikulation der Formation-Formierung“"121, die stete Rückversicherung und Beweisführung der eigenen Gesellschaftsdeutung, auf diese Weise weniger anstrengend und aufwändig.

Viele Erfahrungen aus diesem Engagement übertragen sie auf die ihnen vorstellbaren Rezepte für eine Überwindung der Krise von Demokratie, welche sie ja auch mit ihrem Protest selbst diagnostizieren oder zum Ausdruck bringen. Zu Beginn steht dabei eine Unterteilung in diejenigen, denen sie die Formulierung des Allgemeinwohls oder ein Äquivalent zugestehen, und jene, denen sie ganz grundsätzlich die Fähigkeit dazu aberkennen. „Den Bürgern“, als deren Fürsprecher und selbstbewusste Speerspitze sich viele Protestierende selbst sehen, wird diese Möglichkeit zuerkannt - die Institutionen der repräsentativen Parteiendemokratie und ihre Protagonisten samt der Verwaltungsbürokratie gelten ihnen hingegen nicht als legitime Definitionsmächte des gesellschaftlichen Allge-

121 Nonhoff: Politischer Diskurs und Hegemonie, S. 188. 
meinwohls. Denn Legitimität in einer Demokratie, verstanden als Struktur oder Ressource, die Einfluss und Gehör garantiere, sei und sollte aus Quellen gespeist werden, die samt und sonders der etablierten Politik fernlägen: Den Gesprächsteilnehmern gelten „Bürgernähe“, „Betroffenenbeteiligung“, „Zukunftsorientierung“ und das „Unparteiische“ als Legitimität stiftende Orientierungen - die allerdings nicht in einem formalisierten Verfahren zu erreichen seien, sondern sich stets qualitativ aus einem Vorhaben erkennen ließen. Demokratie schafft sich in dieser Perspektive Autorität und Legitimität nur dann, wenn sie auf Ressourcen zurückgreift, die sie nicht selbst herstellen kann und derer sie sich aus anderen Quellen bedienen muss. Nur etwa, wenn die „richtigen“ Menschen beteiligt werden, wenn fachliche oder gesellschaftliche Autorität mit eingebracht wird, scheint den Protestierenden eine bessere Demokratie möglich.

Dass eine Ausweitung direkter demokratischer Verfahren den Protestierenden generell wünschenswert erscheint, kann nicht aus den Gesprächen herausgelesen werden. Zwar ist der Wert der Gleichheit den Gesprächsteilnehmern durchaus zentral. Er wird allerdings recht instrumentell interpretiert: Gleichheit ist dann zu fordern, wenn man sich selbst benachteiligt wähnt. Gleichheit aber im Sinne einer formalisierten Gleichbehandlung oder -beteiligung aller erscheint ihnen weder sinnvoll noch erstrebenswert, sondern im Gegenteil Ausweis einer überbordend bürokratischen Kontrollhaltung.

Wenn man den Blick auf den Wert von Bildung und Aufklärung für eine Demokratie richtet, welche die Gesprächsteilnehmer erkennen lassen, dann zeigen sich starke Verbindungslinien zur biographisch erzählten Protestmotivation. Denn Bildung und Erweckungsgefühle sind ihnen nicht nur Begründungen, weshalb sie selbst zum Engagement gefunden haben, sondern auch mögliche Rettungsanker für bessere demokratische Entscheidungen. Wenn also mehr und besser Gebildete an Entscheidungen beteiligt würden, wären die Ergebnisse besser und effizienter. Dass Bildung und Bewusstsein den Weg zu einer besseren Gesellschaft bahnt, ist allerdings kein Novum der Protestbewegungen der vergangenen Jahre. Bereits in den Anfängen der sozialistischen Arbeiterbewegungen seit dem beginnenden 19. Jahrhundert über die Lebensreform- und bündischen Jugendbewegungen des frühen 20. Jahrhunderts bis hin zu den Studentenbewegungen der 1960er Jahre galt, dass die richtige Bildung und Aufklärung zum „besseren“ Menschen und zur „besseren“ Gesellschaft führe. ${ }^{122}$ In den Gesprächen mit den Protestierenden wird allerdings vielerorts unterstrichen, wie sehr sich demokratische Verfahren am Ist-Zustand orientieren sollten, und wie sehr

122 Vgl. exemplarisch zur Arbeiterbewegung: Walter, Franz: Vom Milieu zum Parteienstaat. Lebenswelten, Leitfiguren und Politik im historischen Wandel, Wiesbaden 2010, S. $66-91$. 
Bildung und Aufklärung nicht zu einer idealistischen, „,besseren“ Gesellschaft, sondern zu reibungsärmeren und effizienteren Entscheidungen führen soll. Die Fähigkeit, gesellschaftliche Visionen und Utopien an die Wände der Gesprächsorte zu zeichnen, gehört bei den meisten der Gesprächspartner nicht zum Selbstbild, welches man gewahrt sehen möchte.

Effizienz hingegen als erstrebenswertes Ziel unterstreicht noch einmal die eingangs des Kapitels gemachte Beobachtung von der ambivalenten Konnotation ökonomischer Effizienz, welche sich in den Gesprächen herauslesen lässt. Auf der einen Seite verteufeln die Interviewten (ökonomische) Effizienz als einen Wert, der ihr ganzes Leben mit seinen Prinzipien unterjoche. Auf der anderen Seite haben sie Effizienz als anzustrebenden Wert selbst für ein demokratisches Gemeinwesen so weit verinnerlicht, dass sie ihre Forderungen nach einer Verbesserung von Entscheidungsprozessen damit begründen. Die Forderung nach größerer lokaler Autonomie, welche ihnen als bessere Demokratie vorschwebt und die zu den Forderungen gehört, welche über alle Gruppen hinweg am lautesten geäußert werden, beinhaltet den Gedanken, dass man vor Ort besser wisse, was benötigt werde und schneller und genauer entscheiden könne. Selbst der Schutzraum der persönlichen Gemeinschaft, den man von den Wettern der Globalisierung abschirmen möchte, so kann man dies deuten, unterliegt letztlich dem Gebot, so effizient wie möglich zu entscheiden.

Am Ende bleibt das Resümee der Krisen- und Demokratiebetrachtungen wie zu erwarten - von Paradoxien und Widersprüchlichkeiten durchsetzt: Wie sollen auch so viele politisch ganz unterschiedlich verortete Menschen, die sich für ganz unterschiedliche Ziele und auf unterschiedlichen Ebenen verortete Angelegenheiten engagieren, zu kohärenten Ideen und Schlüssen zusammenfinden? Einige Parallelen lassen sich aber doch auch in den Widersprüchlichkeiten erkennen: Als Verteidiger grundlegender demokratischer Prinzipien sehen sich alle. Und auch die Gegenseite ist klar: Es sind die übermächtig und asymmetrisch organisierten Profitinteressen von Politik, Parteien und Wirtschaft, gegen welche die postulierten Grundwerte verteidigt werden müssen. In diesem Sinne müssen die Protestbewegungen auf der einen Seite als radikaldemokratisch verstanden werden.

Auf der anderen Seite aber betonen sehr viele für sich, die Autorität eines Herrschaftssystems aus anderen Quellen gespeist zu sehen - was, wie betont, Hannah Arendt als Charakteristikum einer autoritären - allerdings nicht totalitären! - Herrschaftsform ausmacht. Und auch andere Facetten deuten auf diese Sehnsucht nach einer Autorität in Politik und Gesellschaft hin, welche eben nicht radikaldemokratische, sondern im Gegenteil personifizierte, fachliche und (vermeintlich) Klarheit schaffende Züge trägt. 
Aus dem eingangs des Abschnitts zu Autorität und Legitimität bemühten Postulat zur tiefergehenden Beurteilung von Wurzeln und Quellen der Legitimitätsstiftung und der daraus folgenden Fragerichtung ,kann es auf zwei Weisen zu einer Abnahme empirischer Legitimität kommen - einerseits durch den Wandel der gesellschaftlich geteilten normativen Maßstäbe, andererseits durch eine Veränderung von Struktur und/oder Performanz der politischen Institutionen. “123 Eine „Demokratizität der Herrschaft“"124 unterstreichen dabei alle Gesprächsteilnehmer als zentral. An vielen Stellen allerdings deuten die Äußerungen zur Demokratie auf ein Aufweichen oder eine Verschiebung dieser Vorstellung hin. Wenn Legitimität nachholend verstanden wird als eine Ergebnislegitimität von Entscheidungen, so ist dies für demokratische Verfahren mit enormen Einschränkungen verbunden, weil es die Offenheit von Verhandlungsverfahren von vornherein beschneidet. Auch ist die Tatsache, dass im Sinne von Beteiligungsausweitungen Vermittlungs- und Aushandlungsverfahren zwar gesteigert gefordert, aber gleichzeitig vielerorts als Verrat an sachlichen Konstellationslogiken empfunden werden, eine große Hürde für die Organisation gesellschaftlicher Konsensfindung. Das Verlangen nach persönlicher, außerpolitischer Autorität von Entscheidern und nach einer besseren Übersichtlichkeit unterstreicht dieses Unbehagen.

Die Politikwissenschaftlerin Pippa Norris hat über diese Lücke zwischen der Bestätigung demokratischer Grundprinzipien und einer zunehmenden Unzufriedenheit mit der zeitgenössischen Demokratie und ihren Institutionen von einem empirischen Demokratiedefizit gesprochen. ${ }^{125}$ Mögliche Ursachen seien dabei gestiegene Ansprüche der Bürger selbst, eine allzu negative mediale Berichterstattung und in der Folge sinkendes Ansehen der Institutionen oder aber eine (empirische oder wahrgenommene) negative Bilanz des Handelns der Institutionen selbst. Das Ziel der hier vorliegenden Arbeit kann es nicht sein, ein Urteil darüber zu fällen, ob die demokratischen Institutionen der Kommunen, Länder, der Bundesrepublik oder Europas ein - politikwissenschaftlich gesprochen - kritisches Performanzdefizit aufweisen. Dies mag an vielen Stellen durchaus zutreffen und wird, wie im Abschnitt zur Krisenwahrnehmung deutlich herausgestellt, von den Protestierenden heftig beklagt. Es gibt allerdings auch eine sehr selbstbewusst vorgetragene Haltung der Protestierenden, welche auf eine Veränderung der Ansprüche und Konsensfähigkeiten hindeutet. Wenn also ein Ergebnis der Betrachtungen zu den Demokratievorstellungen ist, dass in der Hauptsache die selbst definierten Ideen als Äquivalent für ein Allgemeinwohl verstanden werden

123 Patberg: Zwei Modelle empirischer Legitimitätsforschung, hier S. 168.

124 Ebenda.

125 Vgl. Norris, Pippa: Democratic Deficit. Critical Citicens Revisited, New York 2011. 
sollen, dann drängt sich der Eindruck auf, dass sich die normativen Erwartungen der im Protest engagierten Bürger von den gedanklichen Fundamenten und Voraussetzungen einer repräsentativen Parteiendemokratie wegentwickeln. 



\section{Utopien des Zusammenlebens}

„Was wir Akademiker allerdings häufig übersehen, ist die Rolle, die die auf den Straßen um uns herum aufkommende Empfindsamkeit spielt."

Hinweise findet man viele. Es gibt sie fast überall, wo man die Augen hinwendet und die Sensorik offen hält. Und gerade im Nahbereich, im persönlichen Lebensumfeld der Protestierenden wie auch des Beobachters finden sich Anknüpfungspunkte, welche den Alltag als Quellengattung für sozialwissenschaftliche Beobachtungen wertvoll werden lassen. Aus den Betonungen der lokalen Ebene als Demokratieschule und Subsidiaritäts-Postulat entsteht für das hier verfolgte Erkenntnisinteresse nicht nur ein methodischer, sondern ebenfalls ein inhaltlicher Fokus auf diesen Nahbereich. Auf die Bürgerproteste angewandt: Die unmittelbare Region und das Lokale als Quelle von Glaubwürdigkeit und Überzeugungskraft, gar von Reinheit zu begreifen - das findet sich als Logik und Motivation weit über politische oder demokratische Diskussionen hinaus.

Musik-Trends etwa, die unterstreichen, dass eine wirtschaftliche und politische Krise den Rückbezug auf das Greifbare und auf vermeintlich alte, bewährte Werte befördere. In den USA ist eine Plattform entstanden, die sich „The Bluegrass Situation“" nennt, und die eine neue Kultur von Bands und Musik fördern und verbreiten möchte, die einen Bezug nehmen zu alten Formen ländlicher Musik in den USA, im weiten Sinne der Stile Country und Bluegrass. Nur sind es eben nicht mehr weiße Farmer vom Lande, die diese Musik nun spielen (und die auch immer den Geruch des politisch „Rechten“ und der Republikaner besaß), sondern junge Leute, vor allem aus Großstädten, von Ost- und Westküste, oft mit erkennbarem Migrationshintergrund. Etwas hat sich also verändert. Den Bezug zu einer Krise als Ferment dieser Entwicklungen machen die Beteiligten selber. Sie nennen Lebens- und Sinnkrisen als Gründe, sich „,den Rückbezug“

1 Harvey, David: Rebellische Städte. Vom Recht auf Stadt zur urbanen Revolution, Berlin 2013, S. 11. 
selbst zum Thema zu machen. Diese Anspielungen finden sich in vielen Songtexten und explizit im veröffentlichten Selbstverständnis der „Bluegrass Situation":

„But recently, something has shifted. In the midst of a deep economic recession, people started returning to their roots: looking for products, places, tastes and sounds that were familiar and real and comforting. They wanted to know their neighbors again. To hold on to something that lasts. To belong to a real community. And soon a revolution began.... [...] It's a community that respects its history, knows its roots, looks ahead for ways to innovate and modernize a genre that has been around for generations, and seeks new ways to merge an old tradition with new technologies."

In der Verbindung aus Großstadt und der Sehnsucht nach "Echtem" liegt hier das Interessante, der Versuch, mit dem Rekurs auf vermeintlich alte und erprobte Werte wieder Orientierung zu gewinnen, nachdem Wachstums- und Erfolgsprämissen mit der Wirtschaftskrise ab 2008 nicht mehr gelten konnten. Traditionelle Musik, ländlich, erdbezogen, autark in der Inszenierung, oft ohne elektronische Verstärkung oder Effekte und technisch anspruchsvoll, aber doch ungehobelt und ohne jede Großmannsfantasie. Auf den Punkt bringt dies eine junge Band namens Mipso, deren Song „A couple acres greener“ für ein Video schlicht unter einem Baum stehend vorgetragen wird, bar jeder Elektronik - und in dem die drei Männer von der Sehnsucht nach einem unverblendeten Leben singen:

„,'ve never been so thirsty to get my soul right, but like a summer bug I've been burned by the blinding light. [...] Should have been a preacher man, let the good book show me where to stand, in this earthly half-way home. Should have been a farmin' man, teach my boy to plow the land. Leave this wicked winter just a couple acres greener when I go. “33

Es ist die Wahrnehmung des angesprochenen "wicked winter" als Krise, welche die Suche nach neuen Wahrheiten befördert. Und diese vermuten sie nicht (mehr) weit weg, im Streben nach Glanz und Erfolg, sondern in der Nähe, im Ungefilterten, in der lokalen Community. Nicht nur in den USA, auch in Europa,

2 http://www.thebluegrasssituation.com/about [zuletzt eingesehen am 14.11.2014].

3 Das Video lässt sich online einsehen unter: https://www.youtube.com/watch?v=GUk1DpzM8gw [zuletzt eingesehen am 14.11.2014]. 
etwa mit der französischen Plattform „Lame de Son““4, sind Formate entstanden, die sich gleichartige Vorhaben zum Ziel gesetzt haben.

Aber auch über die Musik hinaus findet man Bezüge. Die Organisation Slowfood beispielsweise, die sich explizit der Förderung regionaler Ernährungskulturen verschrieben hat, verzeichnet in den vergangenen Jahren einen rasanten Anstieg des Interesses und der Nachfrage. ${ }^{5}$ Die Regionalität und direkte Erfahrbarkeit von Ernährung, darüber hinaus die Bewahrung tatsächlich oder vermeintlicher ,alter“ Lokaltraditionen steht hierbei im Vordergrund. ${ }^{6}$ Diese Entwicklungen machen selbst vor dem deutschen Symbol-Nahrungsmittel par excellence nicht halt: dem Bier. In Deutschland wird der in den meisten Industriezweigen beobachtbare, langjährige Trend einer Konzentration zu immer weniger, immer mächtigeren Großbrauereien durch ein Nachwachsen kleinerer, lokaler, aber ungemein selbstbewusster und experimentierfreudiger Kleinbetriebe begleitet, welche ihre Motivation explizit damit begründen, der Nahrungsmittelversorgung durch Großkonzerne eine andere, individuellere und „echtere“ Form der Erzeugung von Lebensmitteln gegenüber zu stellen. Die Gründer dahinter sind zumeist Quereinsteiger, die aus Enttäuschung über ihre bisherige, ökonomisch vielversprechende aber wenig erfüllende Karriere nun eine Verwirklichung im Kleinen, Übersichtlichen, Direkten suchen. ${ }^{7}$ Es geht dabei nicht um ein Überzeichnen der Motivationen für ein unreflektiertes Heimwerken oder Selbermachen: Nicht jeder, der sein Bier selber braut, ist gleich ein Demokratiekritiker oder -visionär. Wenn aber in den Begründungen und Eigendeutungen Verknüpfungen ersichtlich sind, die eine Reduktion auf den Nahbereich oder eine Betonung der sozialen Netzwerke und persönlichen Beziehungen als ein Stemmen gegen einen als falsch oder desillusionierend wahrgenommenen Zeitgeist verstanden wissen wollen, kann dies eben doch auf Verschiebungen in den Wünschen und Hoffnungen der Menschen hindeuten.

All dies können kleine Mosaiksteine für ein Bild sein, in dem die Kommune, das Zusammenleben und die Gemeinschaft eine gewichtige Rolle in den Vorstel-

4 https://www.facebook.com/lamedeson [zuletzt eingesehen am 12.01.2015]; https://www.youtube.com/playlist?list=PLYWH6ABwIYMZOO9gZ2KIUiOP2r1dQh eQi [zuletzt eingesehen am 12.01.2015].

5 Vgl. http://www.slowfood.de/w/files/publikationen/sfd_imagebrosch_2014_web_kg.pdf [zuletzt eingesehen am 20.11.2014].

6 Eine durchaus kritische Analyse der Organisation Slowfood findet sich bei Lemke, Harald: Politik des Essens. Wovon die Welt von morgen lebt, Bielefeld 2012, S. $235-252$.

7 Vgl. Grau, Alexander: Mehr als nur Pils, in: Frankfurter Allgemeine Sonntagszeitung, 30.11.2014. 
lungen vieler Menschen einnehmen. Benjamin Barber etwa stellt ein Defizit an genau diesen Werten an den Anfang seiner Beobachtung, dass in Kommunalpolitik und einem lokalen Demokratieverständnis ein möglicher Ausweg aus einer weltweiten Legitimationskrise von Demokratie und Nationalstaat lägen: „In a teeming world of too much difference and too little solidarity, democracy is in deep crisis. “. ${ }^{\star 8}$ Folglich müsse es darum gehen, die empfundene gewachsene Differenz und Heterogenität, welche ein Gemeinwesen bis an den Rand der Unregierbarkeit brächten, handhabbar zu machen und mittels einer wieder etablierten Solidarität zu einem Miteinander und einer funktionierenden Demokratie zurückzuführen. Im Zentrum dieses Weges sieht Barber die Stadt als Ort, an dem Menschen unterschiedlichster Herkunft und mit disparaten Zukunftserwartungen zusammen kommen. Integrationsaufgaben, welche früher von Nationalstaaten mit einer Vorstellung von nationaler Identität und Stolz übernommen worden seien, wären für diese in Zeiten immer größerer gesellschaftlicher Heterogenität nicht mehr zu bewältigen. ${ }^{9}$ Städte aber seien an der Schnittstelle von Lebensumfeld und Gesellschaft als Ort möglicher Partizipation dazu prädestiniert, Menschen in ein Gemeinwesen einzubinden, ohne dass ihnen gleichzeitig ein zu groBer Nationalstolz den Weg zur Kooperation in global gewordenen Regelungsfragen verstelle - etwa beim Klimaschutz, Sozialstandards etc. Auch Michael Hardt und Antonio Negri sehen in der ,Metropole [...] sozusagen eine Fabrik zur Produktion des Gemeinsamen“"10. Und David Harvey macht in den Städten eine mögliche Quelle des Widerstands gegen einen „internationalen Kapitalismus“ aus, ,der die neoliberale Reformagenda auf brutale Weise durchsetzt und dessen Angriffe auf die alltägliche Lebensqualität sich seit den frühen Neunzigern zuspitzen“"11: „Erst wenn sich die Einsicht durchgesetzt hat, dass diejenigen, die das städtische Leben aufbauen und aufrecht erhalten, einen primären Anspruch auf das haben, was sie produzieren, und dass sie unter anderem das nichtentfremdete Recht darauf beanspruchen, die Stadt stärker nach ihren eigenen Vorstellungen zu gestalten, werden wir zu einer sinnvollen Politik des Urbanen gelangen. “12

Die hier zugrunde liegenden Protestfelder, Initiativen und Akteure engagieren sich in Zusammenhängen im urbanen Raum. Ein Bahnhof, ein Flughafen oder ähnliche Leuchtturmprojekte gehören unzweifelhaft zu einer Metropole und

8 Barber, Benjamin R.: If mayors ruled the world. Dysfunctional nations, rising cities, Yale / Croydon 2013, S. 3.

9 Vgl. Barber: If mayors ruled the world, S. 5.

10 Hardt, Michael / Antonio Negri: Common Wealth: Das Ende des Eigentums, Frankfurt a.M. 2010, S. 263.

11 Harvey: Rebellische Städte, S. 14.

12 Ebenda, S. 21. 
ihrem Selbstverständnis. Und bei den Protesten zur Bildungspolitik gibt es den konkreten Bezug zum Nahbereich der Schulen vor Ort, den die Aktivisten schildern. Aber auch wenn es, wie etwa bei den Gegnern der europäischen Währungspolitik, um nationale oder internationale Entwicklungen geht - die Protagonisten bewegen sich im urbanen und suburbanen Raum, die Interviews finden im großstädtischen Bereich statt und die Gesprächspartner äußern bereits in ihren Krisenwahrnehmungen deutliche Bezüge zu den oben zitierten Diagnosen von Städten als Brennpunkt und möglichem Lösungsansatz von Krisenphänomenen der zeitgenössischen Demokratie. Überhaupt sind für die Stadtsoziologie Städte heutzutage nicht mehr als gegensätzliche Phänomene zum Umland zu verstehen, sondern „Katalysator, Filter oder Kompressor gesellschaftlicher Entwicklungen “13 - es gebe keine rein städtischen Probleme mehr. Dabei sollen Städte aber in dem hier untersuchten Bürgerprotest nicht einfach als unhinterfragte Identitäten in ihrer Beschreibung übernommen werden. Es geht an dieser Stelle nicht lediglich um die Frage, was die Gesprächspartner mit Hamburg verbinden, o.ä. - eine Affirmation bestehender Stadtmarketings wäre die Gefahr, welche auch die Diskussion der Fragestellungen innerhalb der Stadtsoziologie beeinflusst. ${ }^{14}$ Was also sind konkrete Vorstellungen derjenigen, die sich in Bürgerprotesten engagieren? Was für eine Rolle weisen sie einer Gemeinschaft, einer Kommune oder einer Stadt zu? Welche Aufgabe sehen sie für sich selbst im Rahmen einer Gemeinde? Und nicht zuletzt, was sind spürbare Zeichen der „kumulativen Textur“ oder dem je eigenen „Bedeutungsgewebe der Stadt“"15, die Helmuth Berking im Begriff der „Doxa“ zusammenführt, einer ,,auf Fraglosigkeit und Vertrautheit basierende(n), natürliche(n) Einstellung zur Welt" ? ${ }^{16}$

13 Frank, Sybille / Jochen Schwenk / Silke Steets / Gunter Weidhaus: Der aktuelle Perspektivenstreit in der Stadtsoziologie, in: Leviathan, Jg. 41 (2013) H. 2, S. 197 - 223, hier S. 202.

14 Vgl. zu dieser Frage exemplarisch Lindner, Rolf: Texture, imaginaire, Habitus Schlüsselbegriffe der kulturanalytischen Stadtforschung, in: Berking, Helmuth / Martina Löw (Hrsg.): Die Eigenlogik der Städte. Neue Wege für die Stadtforschung, Frankfurt a.M. / New York 2008, S. 83 - 94.

15 Berking, Helmuth / Jochen Schwenk: Hafenstädte. Bremerhaven und Rostock im Wandel, Frankfurt a.M. / New York 2011, S. 21.

16 Berking, Helmuth: „Städte lassen sich an ihrem Gang erkennen wie Menschen“ Skizzen zur Erforschung der Stadt und der Städte, in: Berking, Helmuth / Martina Löw (Hrsg.): Die Eigenlogik der Städte. Neue Wege für die Stadtforschung, Frankfurt a.M. / New York 2008, S. 15 - 31. 


\title{
6.1 Glorifizierung Des Selbermachens
}

Zunächst einmal haben alle in ihrem Engagement im Protest einen lokalen Bezug: Die Gruppen sind zumeist an ein Stadtviertel oder einen Ort gebunden und setzen sich aus Menschen zusammen, die in einem nicht zu großen Gebiet ein ähnliches Lebensumfeld teilen. Dass sich Gruppen aus mitunter zuvor bereits existierenden sozialen Netzwerken bilden oder aber durch das Protestengagement soziale Netze ausprägen, unterstreicht für die Protagonisten die Wichtigkeit sozialräumlicher Nähe. Und auch über den jeweiligen Zusammenhang der Gruppen hinaus lässt sich aus den Interviews herauslesen, dass die Bedeutung der lokalen Politikebene für die Beteiligten an Bürgerprotesten kaum zu überschätzen ist. Denn der Ort, das Lokale, gilt ihnen nicht nur als ein Ausweis von Nähe und Erreichbarkeit, mitunter von Kleinräumigkeit und geringer Reichweite, sondern symbolisiert ihnen auch die Möglichkeit, Dinge selbst in die Hand nehmen zu können, autark zu sein und Eigenverantwortung zu übernehmen. Sich selbst um die Probleme vor der eigenen Haustür zu kümmern, gilt vielen als das Höchste und Wichtigste, von dem sich vieles ableitet, was sie sich für den Rest der Gesellschaft wünschen.

„Und ich glaub, das ist halt auch, was vielen Leuten auch erstmal klargemacht werden muss, dass sie vielleicht gar keine globalen Probleme haben, sondern die meisten Probleme bei ihnen anfallen, direkt vor der Haustür. Und die müssen gelöst werden. “17

Überhaupt läge in der direkten Wahrnehmung von Problemen in der eigenen Stadt oder im Lebensumfeld der Kern von Politisierung und Beteiligung. Die im Kapitel zu Biographie und Prägung geschilderten Erweckungserlebnisse werden in den Gesprächen meist als Gewahrwerdungen im sozialen Nahbereich nacherzählt:

\begin{abstract}
„Also, wo man auch genau das hat wie bei Stuttgart 21: weil es die Stadt betrifft, betrifft es mich und setzt überhaupt mal die Kraft frei, da mal auf die Straßen zu gehen. Und so war das bei diesen Jugendlichen auch der Fall, die hat da was anderes betroffen, und das heißt, letztendlich löst wahrscheinlich in den meisten Fällen, bei den meisten Menschen, politisches Engagement nur eine direkte Betroffenheit aus. “18
\end{abstract}

17 Serge G2 in der Fokusgruppe G2 Stuttgart am 02.04.2012.

18 Malte C1 in der Fokusgruppe C1.1 Stuttgart am 20.03.2012, 17 Uhr. 
Das Selbermachen und die Eigenleistung für das eigene Umfeld gelten vielen in den Gesprächen als edelste Motive. Dies lässt sich in den Passagen eindrucksvoll nachvollziehen, in denen es um ein Resümee der gemeinsamen Arbeit geht:

\begin{abstract}
„Also, wenn ich darüber rede, kommen mir immer noch [die Tränen]. [...] Das ist eine der größten Lebensleistungen, würde ich sagen. Mit so viel Einsatz for nothing. Man hat nichts dafür gekriegt. Man ist angefeindet worden. [...] hat man nur aus sich heraus sozusagen. Ohne irgendwelche Unterstützung. Also, eine größere Leistung kann man eigentlich nicht bringen. Auch Lernleistung. Also, was wir uns da entwickelt haben zusammen. [...] Also, das ist irgendwie eins der größten Erlebnisse in meinem Leben. “19
\end{abstract}

Eigenverantwortung und Autarkie werden hier zu stark glorifizierten Antriebskräften, nach denen die Interviewten selbst streben. Zugespitzt wird dies in einer Fokusgruppe in Stuttgart, in der zwei Teilnehmer über ihre Vorstellungen einer besseren Gesellschaft sprechen. Das Eigenengagement und Einflussnehmen auf die Strukturen und Pfeiler des eigenen Alltags wird hier zum Kern einer Demokratiereform und mündet in ein flammendes Plädoyer für eine Räterepublik. Die in der Diskussion an dieser Stelle durchaus aggressive Tonlage spiegelt ein Selbstbewusstsein wider, mit dem sich die Protestierenden - hier in Stuttgart in den Bahnhofsprotesten engagiert - gegen eine Stadtpolitik wenden, die nicht ihnen direkt entspringt, sondern durch eine Repräsentanz oder politische Parteien vermittelt wird, von welchen sie sich stark abgrenzen.

„Verena C2: Und ich finde, das muss damit anfangen, dass in den Schulen, Betrieben, die Leute selber was zu sagen haben. [...] Also, man kann nicht einfach so tun, als ob dieser Parlamentarismus durch ein paar plebiszitäre Elemente ergänzt wird und dann hätte man eine echte Demokratie. Weil, wir sehen ja, wie das läuft. Und die Volksabstimmung ist ja nur ein Beispiel. In Lindau haben die das jetzt fertig gebracht, einen zweiten [Bürger]entscheid hochzukriegen, weil der erste nicht gepasst hat...

Pepe C2: Das ist keine Demokratie, das ist unechte Demokratie...

Verena C2: Echte Demokratie, ich sage es gerade, ist für mich eine Rätedemokratie, dass überall Leute, wo sie sind, im Betrieb, in der Schule, einen Rat bilden, der entscheidet, der aber ständig rückgekoppelt wird. Da kann man immer wieder Abteilungsversammlungen, Betriebsversammlungen [machen], dass die Leute auch keine Privilegien haben, dass niemand denkt, er kann Karriere machen. Und [...] und auch abwählbar ist jederzeit und Rechenschaftspflicht [hat $]$... [...] Es gab mal eine Pariser Kommune... [...] Und das finde ich wirklich, wer das noch nicht gelesen hat und sich mit Demokratie auseinander[setzt], der sollte das unbedingt machen. Gibt es wirklich super Bücher drüber und ich finde das wirk-

19 Einzelinterview E3 Diana. 
lich beeindruckend, weil sich da gezeigt hat, dass die Leute selber in der Lage waren, ihre Stadt zu regieren. Und du hast vorhin Rosa Luxemburg zitiert, die hat mal gesagt, wir müssen aufhören, eine regierte Masse zu sein. Und sie hat dieses Konzept ja weiterentwickelt der Rätedemokratie. Hat es auch ansatzweise in der Novemberrevolution gegeben, auch in Stuttgart [...], nach dem zweiten Weltkrieg auch. Da gab es die Arbeitsausschüsse. Die haben die Stadt kontrolliert. Die haben verhindert, dass die Bäume abgeholzt wurden und auch den Park. [...] Und dann haben sie Räte gebildet. In Stuttgart gab es auch [einen] Arbeiterrat und wenn wir gucken, wie die gearbeitet haben, das ist grandios. Unter Verhältnissen kurz nach dem Krieg. Die sind nicht an ihrer eigenen Unfähigkeit gestorben, also eingegangen, sondern es gab dann einen Bürgerkrieg. Man hat die militärisch alle niedergemacht....20

\subsection{Gemeinschaft als HoRt von Identität}

Im Zentrum der Idee des Engagements für das eigene Umfeld stehen zwei Argumentationsstränge: Zum einen macht das Arbeiten für die lokale Gemeinschaft aus ihnen bessere Menschen und lässt sie vieles von dem erleben, was sie in Politik und Gesellschaft vermissen oder kritisieren. Und zum anderen sind sie davon überzeugt, dass ein konsequent angewandtes Prinzip demokratischer Subsidiarität, was für die Gesprächspartner auf eine stärkere Rolle von Bürgerinitiativen etc. hinausliefe, eine bessere und auch effektivere Demokratie schaffen könne.

Das erste Argument bezieht sich auf die Reflektion des eigenen Engagements und der Erfahrungen in den jeweiligen Gruppen und Initiativen. Denn in den Gruppen treffen sie sich mit Nachbarn oder Menschen aus denselben Stadtvierteln oder Stadtteilen, manchmal auch aus der ganzen Stadt - aber eben nicht im Kern mit Menschen aus weiterem Umfeld, aus anderen Bundesländern oder Regionen. Alle Menschen, die mit ihnen gemeinsam engagiert sind, verbindet etwas - ihr Engagement und ihr Antrieb für ein (oder mehrere) Themenfeld, welches ihnen zentral und ungeheuer wichtig geworden ist. Sie erleben darüber ihr Aktivsein als einen Teil gelebter Demokratie, der nicht durch überbordende Komplexitäten oder gesellschaftliche Heterogenitäten beeinträchtigt ist. Die Protestgruppen gelten ihnen vielmehr als ein Hort geteilter Identität, vom dem sie überzeugt sind, dass er Quell genau der Gemeinschaften sein kann, nach denen sich Menschen sehnen und die ihnen weder soziale Milieus noch politische Parteien als deren Arme heutzutage noch bieten können.

20 Verena C2 und Pepe C2 in der Fokusgruppe C2.2 Stuttgart am 20.03.2012, 20 Uhr. 
„Das Schöne ist: Das ganze Dorf scheint mit zu diskutieren, also so was Schönes habe ich noch nie erlebt.“21

Das Schwärmerische ist bemerkenswert: Direkter Kontakt bedeute erstens Ehrlichkeit, weil man sich in die Augen schaue und die Wünsche des "Bürgers" unvermittelter mitbekomme; zweitens führe er zu eine größeren Demokratiezufriedenheit, weil gerade die Dinge, die den Lebensrahmen vor Ort mitgestalten, vermehrt selbst in die Hand genommen werden können. Und direkter Kontakt bedeute mehr Transparenz, weil man sich öffne.

Dazu gehört auch, dass in etlichen Gruppen ganz explizit betont wird, dass man gerade durch das enge soziale Netzwerk nicht angewiesen sei auf eine unpersönliche Kommunikation mittels neuer (Online-)Medien, sondern diese durch persönliche Kontakte Organisation und Motivation aufrechterhalte.

„Nee, also ich glaube, das finde ich auch einen spannenden Punkt, wie sich so ein Netzwerk bildet und zum Beispiel könnte man ja über die sozialen Medien denken und so weiter, die haben da überhaupt keine Rolle gespielt, also es war eher die private, persönliche Begegnung auf Märkten oder in Einkaufszentren, auf der Straße, einige von uns konnten das auch besonders gut, einfach Leute anzusprechen, und mit denen sich ins Gespräch zu verwickeln und dabei trotzdem gute Laune und irgendwie so eine positive Einstellung zu behalten, das fällt ja nicht jedem leicht, auf wildfremde Leute zuzugehen, das können einige besser, andere weniger gut. Und das war zum Teil unglaublich spannend und aufregend. Das war aber eigentlich die persönliche Begegnung auf der Straße.“22

Diese Äußerung zeugt von der Utopie, dass Demokratie und das Leben insgesamt mehr auf persönlichen Kontakten miteinander beruhen sollte; dass der Nahbereich und die eigenständige Regelung der Belange machbar sind und dass sich viele Probleme durch die persönliche Nähe einfacher und vorausschauender aus der Welt schaffen ließen, wenn man eine gemeinsame Problemeinsicht teilt. Es erscheint äußerst fraglich, ob das realiter so zutrifft, aber die Erzählungen vieler Akteure in den Interviews haben dies so aufgegriffen und sie haben diese Komponente als enorm befriedigend und schön wahrgenommen.

An einem regnerischen Spätwintersonntag 2012 gibt es - wie jede Woche in Freising nördlich von München eine Ansprache der evangelischen Pastorin in der Kirche (wöchentlich abwechselnd ist ihr katholischer Kollege federführend), auch mit Gebet, in der es um den Widerstand gegen die Münchener Flughafen-

21 Conrad G1 im Einzelinterview Anna und Conrad G1.

22 Einzelinterview Emma E2. 
erweiterung geht. Dann begibt man sich auf einen von Laternen und Fackeln begleiteten Schweigemarsch durch die Altstadt zum Rathausplatz, wo in Abfolge kurze Reden gehalten werden und kirchliche Lieder gesungen, während leise ein schneeiger Regen auf die Schirme geht und eine nasse Kälte die Hosenbeine hochzieht. Gut 300 Menschen sind bei der Aktion dabei; angesichts des Wetters zeigen sich die Organisatoren sehr zufrieden. Nach ihren Angaben gab es (beispielsweise nach dem Abschluss des Planfeststellungsverfahrens, wie der Gerichtsempfehlung, den Sofortvollzug des Erweiterungsbaus auszusetzen) auch durchaus Sonntage mit bis zu 2500 Teilnehmern. Insgesamt bewege es sich aber in dem genannten Bereich von mehreren Hundert Teilnehmern.

Die Stimmung in der Kirche, auf dem Markt und dem Marsch ist von Anfang an ergriffen positiv, nicht wütend oder aufbrausend. Die Pastorin in der Kirche predigt mit ruhiger und gefasster Stimme und die Menschen sprechen das Amen am Ende des Gebets laut und kräftig mit. Auf dem anschließenden feierlichen Gang durch die erleuchtete Altstadt pilgern die Menschen ernst und fast staatstragend zum zentralen Versammlungsplatz. Auch auf dem Rathausplatz wird recht laut mitgesungen und applaudiert, ohne in eine wütende Laune gegenüber dem Flughafen oder seinen Betreibern auszubrechen. Argumentiert wird nicht gegen die Parteien oder die Flughafengesellschaft, sondern vom Einzelnen oder der Gemeinschaft aus: Man selber müsse sich einsetzen, müsse infrage stellen, was einem erzählt werde, müsse seine Teil dazu beitragen, gegen das stets postulierte Wachstum zu sprechen. „Ihr seid alle dafür verantwortlich, dass es in unserem Dorf, in unserem Land immer ein Stück besser wird“, ruft der Landesjugendpfarrer dem eng zusammengerückten Kreis auf dem Rathausplatz beschwörend zu. Man hat den Eindruck, einer fast ritualhaften Bekräftigung der eigenen Stadtgemeinschaft beizuwohnen.

In den Gesprächen schildern viele das Gefühl, mit ihrem Engagement Verantwortung für den gesamten Ort, das Stadtviertel oder die Gemeinschaft zu übernehmen. Der Protest wird damit zu einem integralen Bestandteil des „Stadtgefühls" - dies ist in Stuttgart, in Freising und besonders in Hamburg zu beobachten. Wenn der Protest sich auf die Lebensqualität - in welcher Facette auch immer - einer Gemeinschaft bezieht, dann kann ein Mitmachen aus dem Einzelnen einen Aktivisten für die Identität und „kumulative Textur“ der Stadt selbst machen.

\footnotetext{
„Aber es hat uns alle ergriffen. Und ähm das war hier so dominant und das war hier so klar, dass das hier die Gesellschaft betrifft, die Menschen betrifft, die aber auch viel, viel weitreichendere Konsequenzen hat als nur für diese Stadt. Dem konnte ich mich nicht entziehen, dem wollte ich mich nicht entziehen. Also, das war völlig klar und ich meine von
} 
meiner Geschichte her hatte ich ja den Anspruch, mich politisch zu engagieren, dass das aus anderen Gründen nie so geworden ist oder nicht so geworden ist, wie man sich das vorstellt, ähm, das ist eine andere Geschichte. Aber dass, wenn ein Thema aufkommt, das wichtig ist und bei dem wirklich Stellungnahme gefragt ist, dass ich da dabei bin, das war ohne Frage. “23

Beata C4 unterstreicht an dieser Stelle noch einmal, dass Protestthemen und die entsprechenden Protestbewegungen dazu Teil eines „Bedeutungsgewebes“ werden können, indem sie über Jahre zu einem Bestandteil der lokalen Identität heranwachsen. Der Protest gehört dann zum Selbstbewusstsein eines Stadtviertels oder einer ganzen Stadt hinzu, als manifestes Plädoyer für die Selbstbestimmung und Eigenständigkeit seiner Bewohner. Als Freisinger muss man sich zum Flughafen positionieren, es führt kein Weg dran vorbei. Als langjähriger Bewohner des Schanzenviertels in Hamburg muss man zur Entwicklung des Viertels und der Bautätigkeiten und Mieten eine Haltung entwickeln, in Stuttgart zum Großprojekt des Bahnhofsneubaus ebenso. Ein Problem der politischen Parteien demgegenüber ist, dass ihr Fokus meist viel weiter ist, d.h. dass sie Positionen vertreten, die sie anderswo und nicht lediglich vor Ort entwickeln müssen und für einen anderen Rahmen erarbeiten, also, dass sie im konkreten Fall meist nur schwer eine uneingeschränkte Unterstützung der Lokalgruppen anbieten können, und sich deswegen desavouieren (müssen). Nur, wenn sie als kleinere Parteien nicht volksparteilich integrativ denken (müssen), bzw. wenn es sich um Themen handelt, die weit über ein Lokalphänomen hinausweisen, entgehen sie dieser Zwickmühle. Dies mag dazu beitragen, dass Parteien bei den Protestgruppen nicht als Lösungsinstanz und Wirkungsort oder gar als Identität stiftende Instanzen gesehen werden.

Aber auch über die ortsbezogenen Proteste im Themenfeld der Infrastruktur hinaus gelten die Initiativen und Gruppen den Beteiligten ganz persönlich als Ort, an dem sie ihre Identität (mit) ausprägen. Ihre Demokratievorstellungen und -hoffnungen kreisen häufig um das Motiv, dass kleinere, homogene Gruppen eigentlich Kern zukünftiger Reformen sein müssten, wenn in einer großen, immer komplexer gewordenen Gesamtgesellschaft ein identitärer Konsens als Basis kollektiver Entscheidungsfindung nicht mehr auszuhandeln ist.

„....ich glaub schon, [...] dass das Leben schöner ist, wenn man selber [...] das Gefühl hat, man ist irgendwie mittendrin, [...] man gehört irgendwo dazu, man hat irgendwo was, wo man was sagen kann, ja und ich glaube eben, dass durch diese Inklusion Gesellschaft sich auch verändert, also mit den Menschen, also so, vielleicht sehe ich da tatsächlich so eine

23 Einzelinterview Beata C4. 
Art Abfolge. Also, dass sich erst der Mensch da irgendwie aufgehoben und gut fühlen muss, damit überhaupt sich dann die Gesellschaft auch in sowas wie - also in sowas Gutes bewegen kann. “24

Das Unbehagen, welches die Interviewten ob einer Unübersichtlichkeit der Politik, der Gesellschaft und der Welt insgesamt empfinden, so geht dieser Gedankengang, ließe sich durch eine stärkere Subsidiarität und mehr Entscheidungsfindung im Kleinen zumindest reduzieren. Auffällig ist dabei, dass sie die Gruppen, in denen sie aktiv und engagiert sind, als eine Art Benchmark für gesellschaftliche Pluralität darstellen: In ihren Protestgruppen gibt es eine „gute“, handhabbare Vielfalt, die positive Effekte zeitige. Man gewinne, etwa als Dachorganisation von Protestinitiativen, weil unterschiedliche Perspektiven zur selben Stadt zusammengeführt werden. Dies hat zur Bedingung, dass man Pluralität und Perspektivenreichtum per se als wertvoll erachtet - was allerdings samt und sonders alle Gesprächspartner unterstreichen. Lothar C2, der sich im Hamburger Dachverband „Recht auf Stadt“ engagiert, schildert dies für die eigene Protesterfahrung:

„Diese Breite, die man da hatte, das war ganz viel Glück, dass das so zusammen kam. Also, es war viel Zufall dabei, aber das war auch nicht nur Zufall, sondern ich glaube so ein Bewusstsein dafür, [dass] man sich da zusammen tun muss und auch alte Konflikte vielleicht überwinden und das hat besser geklappt als in anderen Städten.[...] Konflikte stehen hier irgendwie nicht auf der Tagesordnung. Ist ganz angenehm. ${ }^{، 25}$

Vor Ort, im ihnen bekannten Stadtviertel, unter den Auspizien eines sozialen Netzwerks, dessen Teil sie sind und dessen Protagonisten sie kennen und vertrauen, haben sie das Gefühl, kann das Management von Vielfalt und Heterogenität noch funktionieren und die Demokratie ihre Aufgaben einer Entscheidungsfindung und -vermittlung noch erfüllen.

„Wir sind auch ganz schön aggressiv angefeindet worden von den politischen Gegnern. [...] Die haben wir nachher schon auf zehn Meter Entfernung erkannt. Die haben immer alle den gleichen Blick gehabt und die gleiche Art, sich zu verhalten. ...[...] aber wir haben so viele gute Kontakte gehabt auf der Straße mit wildfremden Menschen. Tolle Gespräche haben sich da entwickelt mit ganz unterschiedlichen Leuten. Und so ist irgendwie dieses Gefühl, ich bin völlig ohnmächtig und ich werde hier einfach, ich weiß nicht, überwältig und so, das ist immer mehr geschwunden. Und man hat immer mehr Rückhalt ge-

24 Einzelinterview Ilse E8.

25 Einzelinterview Lothar C2. 
habt und dadurch ist das immer mehr geworden. Es sind so viele einfach dazu gekommen und jeder hat immer, wenn er gerade Zeit hatte, oder eine Idee hatte, irgendwas gemacht und da hat man Telefonnummern ausgetauscht und hat man plötzlich wieder einen Anruf gekriegt, hey, ich habe da das und das und was hältste denn davon? Und so ist auch so viel Aktivität entstanden, die man normalerweise nicht hätte leisten können. Also wir haben uns wahnsinnig toll ergänzt und jeder immer dann, wenn er halt konnte und wie er konnte oder so. Da gab es überhaupt keine Regeln oder so und trotzdem ist es gelaufen. Ja, also ich muss sagen, es war eine Erfahrung, die mir wieder mein Urvertrauen, was mir sehr abhanden gekommen ist, in weiß ich nicht, in die Sicherheit in dieser vermeintlich freiheitlichen Demokratie, das hat es mir ein bisschen zurückgegeben.“26

Hier liegt ein Widerspruch in den Aussagen vieler Protestierenden, der sich kaum auflösen lässt. Einerseits schildern viele in den Gesprächen eine gesellschaftliche und soziale Vielfalt in ihren Gruppen als wichtige Ressource ihrer Arbeit und ihrer Verbindung mit dem Ort oder der Stadt. Andererseits scheint die Sehnsucht nach Homogenität und Einigkeit, nach gemeinsamer Identität im Protest in vielen Passagen durch. Die Protestgruppen selbst werden vielen Aktiven dann zu Symbolen dieser Gemeinschaft im Kleinen, bei denen sie eine gesellschaftliche Homogenität erfahren können, die sie in der großen Gesellschaft vermissen. Die Eindeutigkeit und Verlässlichkeit, mit der sie in ihren Gruppen entscheidende Pfeiler ihrer Weltsicht teilen, ist ihnen ungeheuer wichtig geworden. Viele Protestierende unterschieden in dieser Art und Weise eine gute, handhabbare und produktive Vielfalt in ihren eigenen Gruppen von einer negativen, destruktiven, nicht mehr kontrollierbaren Vielfalt außerhalb.

Ein untergründiger Frust, dass die Bewegung so groß geworden sei und sie deswegen einen ganzen Haufen Probleme entwickelt habe, die man am liebsten gar nicht hätte, lässt sich während der abklingenden Erregungskurve der Stuttgarter Bahnhofsproteste nachempfinden, während der die dortigen Fokusgruppengespräche stattgefunden haben. Hierarchien und Abstimmungen, Kompromissfindungen oder Mehrheitsentscheide - alles war einfacher und eindeutiger, als man noch kleiner war. Und plötzlich spüren sie, dass sie in ähnliche Problemfahrwasser rutschen, die sie selber den Parteien immer vorgeworfen haben: dass Meinungen übergangen werden, dass man irgendwie am Ende zu einem Ergebnis kommen muss, auch wenn dieses einige oder sogar viele nicht zufrieden stellt, dass die Koordinierung nicht mehr schnell und direkt funktioniert, weil so viele mit einbezogen und informiert werden müssen. Gerade, weil es am Schluss das Menetekel der Niederlage in der Volksabstimmung gibt, scheinen in Stuttgart die Probleme deutlicher angesprochen zu werden. Die Sehnsucht nach dem

26 Einzelinterview Diana E3. 
Kleinen und Überschaubaren springt deutlich ins Auge: Die eigenen Träume sind eben leichter in einer kleinen, homogenen Gruppe zu verwirklichen, bei der man das unglaublich motivierende Gefühl der Gleichheit, des "Wir-wollen-alleDasselbe", erfährt.

„Und dann kam die erste Rückmeldung, die berichteten von großem Zoff am Schluss, dass da irgendjemand gesagt habe, wir waren der Meinung und sofort da jemand anders da reingekläfft hat, wir waren überhaupt nicht der Meinung und so. Stichwort Disparatheit der Bewegung. Die ist ja ungeheuer disparat, die Bewegung, und man vermeidet natürlich Hierarchien, man sagt, jeder macht das in gewissem Maße für sich. [...] Das sind natürlich alles Probleme, die erst mal [...] auch kritisch reflektiert werden müssen. Ist ja gut und schön, ich bin auch dafür, dass es keine Hierarchien gibt und so. Aber die Menschen sind nun mal leider nicht so gestrickt. Es braucht schon jemand, der da irgendwo vielleicht auch in gewisser Weise was organisiert und darüber auch ne Autorität hat. ${ }^{، 27}$

Stellenweise wird dezidiert Unbehagen oder Sorge geäußert, dass die Gruppen beziehungsweise das eigene Protestfeld zu groß und unübersichtlich werden und vom eigenen Erfolg aufgezehrt. Ebenso ist die Angst zu hören, vereinnahmt und benutzt zu werden, wenn der Protest allzu attraktiv und damit anziehend, „hip“ wird.

\begin{abstract}
„Also, es ist ja auch nicht schlimm mit bestimmten Projekten eine Vorreiterrolle zu haben, wenn das dann irgendwie total beliebt wird und gut ankommt und den richtigen Weg einschlägt. Das andere ist natürlich die Gefahr, dass ihnen dann immer, also wie Kapitalismus funktioniert, dass er bestimmte Sachen absondert und anders überlässt und dann ist [er] irgendwie ja versucht, daraus immer Profit zu schlagen. Das muss ja klar sein, dass es leider nicht so laufen wird, wahrscheinlich.“28
\end{abstract}

Die Hamburger Stadtviertelproteste, wie beispielsweise das Gängeviertel, die sich über die Hausbesetzung zum bundesweit bekannten Modellprojekt entwickelt haben, lassen bei den Beteiligten Sorgen wachsen, von der Politik vereinnahmt zu werden und den Charakter der rebellischen Gemeinschaft mit eigenen Werten zu verlieren.

„....ich glaube, dieses Gängeviertel ist das Leuchtturmprojekt, auf das die Marke Hamburg die ganze Zeit gewartet hat. Da hätten sie gar keine Elbphilarmonie bauen brauchen. Sie hätten uns nur richtig fördern müssen. Aber das trauen sich dann Politiker eben nicht, weil

27 Raik C2 in der Fokusgruppe C2.2 Stuttgart am 20.03.2012, 20 Uhr.

28 Einzelinterview Lothar C2. 
damit könnten sie sich ja die Finger verbrennen und deshalb lassen sie es lieber und mauscheln dann so rum. [...] Die Busse fahren mittlerweile am Gängeviertel vorbei, wie sie früher an der Hafenstraße vorbeigefahren sind, wenn dem so ist dann sollen sie doch gefälligst auch da was abführen, ne? Und wir kriegen tatsächlich Anfragen von Touristenorganisationen, die irgendwelche Hamburg Städtetouren anbieten, die uns bezahlen wollen. Aber das ist ja tatsächlich auch komisch, weil die meisten Führungen machen wir eben auf Spende. Und wollen das auch weiterhin so. Würden das auch für diese Firmen. Aber wenn man dann hört, dass die für so ein Städtewochenende, was weiß ich, 2000 Euro verlangen, dann fragt man sich halt, wo das legitimiert ist, also, wo man dann die Trennlinie zieht. Das Problem ist, dass die Firmen dann, wenn man ihnen eine Absage erteilt, das eben einfach trotzdem machen und nichts zahlen (lacht). Das ist natürlich so. Da haben wir keine klare Linie, weil im Grunde genommen wollen wir ja, dass Leute sich das angucken. Wenn natürlich Leute so doof sind, so eine Tour zu buchen, dann kann man ihnen nicht wirklich helfen. Dann haben wir auch keine Lust, deren überteuertes Programm zu bereichern mit irgendwas. Da brauchen wir auf jeden Fall noch eine klare Linie. Da finde ich sehr gut, wie es Christiania macht in Kopenhagen. Die machen ja so eine 45minütige Führung richtig mit einem Vortrag am Anfang und das kostet eine Summe X. Oder man geht eben alleine ohne Führer durchs Viertel. Also jeder ist ja herzlich willkommen, kriegt auch einen Tourguide. Aber diese Führung kosten eben Summe X. Aber das war bisher noch nicht durchsetzbar bei unserem Viertel.“29

Das Dilemma, die eigene, gewünschte Protestidentität aufrechtzuerhalten, die eigenen Werte nicht aufzugeben oder zu verraten, lässt sich an vielen Stellen finden. Gerade, wenn die Gruppen enorm gewachsen sind oder Aufsehen erregende Erfolge errungen haben. In Hamburg ist der Protest so sehr in die lokale Koloratur übergegangen, dass sich die Protagonisten immer stärker gegen eine Übernahme in das offizielle Stadtmarketing wehren.

„Bestes Beispiel auch hier diese ganze Oberhafengeschichte. Ist ja so ein großes Quartier noch neben der Hafencity, was quasi ein künstlerisches Quartier werden soll, wo halt die ganze Zeit runde Tische stattfinden und Planvorverfahren und so, wo eigentlich alle ernstzunehmenden Protagonisten im Recht-auf-Stadt-Netzwerk gesagt haben, da machen wir nicht mit, obwohl es genau unser Thema ist. Aber wo so klar ist, dass das nur nach hinten los gehen kann, dass es nur darum geht, die Sache zu legitimieren oder vielleicht und sogar noch schlimmer, Ideen zu bekommen wie man ein einen wachsenden Widerstand vielleicht vorher schon für sich vereinnahmt. Und deshalb müssen wir auch sehr trennscharf gucken, wo wir uns beteiligen, wo es wirkliche ernsthafte Beteiligung gibt, und wo wir

29 Einzelinterview Frederik C1. 
uns beteiligen, um zu stören. Das ist ja manchmal leider der einzige Weg, den man dann noch hat. Und wo man eben wirklich konsequent konkret mitarbeiten kann. “30

Protest ist den Gesprächspartnern in nicht geringem Umfang die Gemeinschaft, in der sie ihn ausüben - und diese Gemeinschaft ist es, die für sie auch den Erfahrungsraum für eine mögliche, bessere Demokratie ausmacht. Gesellschaftliche Komplexitäten, zu große Heterogenität und Interessendivergenzen - all dies findet sich dort auch deswegen nur gedämpft und handhabbar wieder, da es sich um örtliche Zusammenhänge handelt, die auf lokale Alltagslagen und soziale Netzwerke zurückgreifen können, und die getragen sind vom Gefühl, ein zentrales Thema zu teilen. Wachsen diese Gruppen aber zu stark, gerät diese Konstellation in Gefahr und droht Züge anzunehmen, welche sie in Demokratie und Gesellschaft insgesamt kritisieren. Übersichtlichkeit und Verlässlichkeit sowie das Vertrauen auf einen geteilten Identitätskern sind ihnen zentrale Elemente im Protest geworden.

\subsection{Effizienz UND Avantgarde}

Nicht nur, was den persönlichen Wert der Protestarbeit für sich selbst anbelangt, legen die Interviews eindrücklich Zeugnis darüber ab, dass in den lokal verankerten Kleingruppen selbst ein Keim für eine bessere Gesellschaft erblickt wird. Auch die Effizienz und Funktionsfähigkeit demokratischer Entscheidungswege erscheint den Protestierenden umso größer, je mehr sie sich auf die lokale Ebene fokussieren - und umso stärker diese auf den lokalen Aktivisten der Bürgerproteste als Protagonisten eines „Bürgerwillens“ fußt.

Auf den Wert eines subsidiären Rückzugs aggregierter oder nationaler Ebenen zugunsten lokaler Selbstverwaltung ist bereits im Kapitel zu den Demokratieeinstellungen hingewiesen worden. Denn wenn überhaupt, funktioniere Demokratie, so drückt es Malte C1 aus, auf der Ebene der Kommune:

„Also, in manchen Situationen in kommunalen Bereichen mag sein, dass Demokratie in einer gewissen Art und Weise vorhanden ist. “31

Und Serge G2 übernimmt dieses Argument in einer anderen Fokusgruppe ganz ähnlich:

30 Einzelinterview Frederik C1.

31 Malte C1 in der Fokusgruppe C1.1 Stuttgart am 20.03.2012, 17 Uhr. 
„Ich glaub, die Demokratie, in einem je kleineren Raums sie stattfindet, desto am wenigsten schaden kann sie anderen Richtungen. ${ }^{332}$

Zunächst einmal unterstreichen etliche Interviewpartner den Wert der kommunalen Ebene und ihren Protest darin für eine Reproduktion von Demokratie: Nur hier lerne man von Grund auf, miteinander auszukommen, lerne demokratische Umgangsformen und ein entsprechendes Selbstbewusstsein. Erneut wird dabei unterstrichen, wie stark der direkte, persönliche Kontakt ins Zentrum ihrer Auffassung gelungener Demokratie gerückt ist.

„Ich glaub es ist ganz ganz viel möglich, rauszukommen aus Strukturen, wo man denkt: Das muss alles so sein, die anderen zu kontrollieren und Abhängigkeiten zu schaffen, aber ich glaube, das Grundfundament ist wirklich überhaupt erstmal in einer Gesellschaft zu lernen, miteinander auszukommen und den anderen wertzuschätzen und mitzukriegen, dass es ganz viele Unterschiede gibt, das ist, denke ich, das größte Problem, dass wir alle voneinander trennen und meinen, das ginge auf Dauer gut. “33

Denn dass der persönliche Austausch als Grundlage funktionierender Demokratie auf der lokalen Ebene leichter und einfacher sei, gilt den Protestierenden als ausgemacht. Ihre eigene Einbindung vor Ort gerät ihnen da zum Vorbild - und besonders bereits ältere Protestinitiativen sind auf diese Weise bereits fest als politische Größe auf der städtischen Ebene etabliert.

„Auf der anderen Seite sind wir natürlich auch tatsächlich sehr sehr gut vernetzt. Haben halt Kontakte überallhin. Zumindest einige Leute, deren Handys sind voll mit allen wichtigen Nummern und wir agieren halt auch sehr schnell und gehen dann halt auch lieber zu Leuten direkt hin und sagen, hier, so und so sieht es aus und dadurch entstehen, natürlich, glaube ich auch, so oszillierende Fronten, das ist glaube ich das beste Wort. ${ }^{\text {‘34 }}$

Übersichtlichkeit und intimere Kenntnis der Gegebenheiten machen für die Protestierenden die lokale Ebene zur vielfach besten und effizientesten Entscheidungsinstanz. Und sie selbst, als lokale Bürger, werden in ihren Augen zu primären Ansprechpartnern. Denn der lokale (Partei-)Politiker in einem repräsentativen System ist für sie noch persönlich kontaktierbar, da sie ihn aus und in der Stadt seit vielen Jahren kennen, ihre Kinder möglicherweise mit seinen Kindern

32 Serge G2 in der Fokusgruppe G2 Stuttgart am 02.04.2012.

33 Einzelinterview Birgit E1.

34 Einzelinterview Frederik C1. 
zur Schule gegangen sind, sie dessen Ehepartner beim Einkaufen treffen. Eine Verantwortlichkeit von Politik erscheint ihnen durch eine Kontrollinstanz aus einem dicht gewebten sozialen Netzwerk viel besser aufrecht zu erhalten sein, als dies bei einem kaum persönlich greifbaren Abgeordneten in einer fernen Hauptstadt der Fall sein mag. Und jede Entscheidung, die auf niedriger Ebene unter Beteiligung der Anwohner getroffen wird, gilt ihnen als effektiver, da sie viel eher den Gegebenheiten entspreche, auf die sie angewandt wird.

Vor allem eine von ihnen wahrgenommene Entkopplung von direkter Wähler-Verantwortlichkeit durch Parteipolitiker, die über Listenplätze auf Mandate gewählt werden, lässt sie den Kopf schütteln.

„Das ist das Problem, sei es in großen Gesellschaften oder jetzt gerade speziell in der Politik, diese Leute tragen gar keine Verantwortung und das stört mich und das will ich versuchen, mit meinem Einsatz irgendwo zu verändern. “35

Für die im Kapitel zu den Demokratiehoffnungen der Protestierenden entwickelten Vorstellungen von Effizienz und Transparenz jedenfalls glauben die Gesprächspartner, im Kleinen und im Lokalen die verlässlichste Instanz zu finden. Dies liegt auch am Zuschnitt des Samples, welches dieser Arbeit zugrunde liegt: große, international ausgerichtete Protestzusammenhänge, Occupy, übernational aufgestellte Umweltschutz-, Friedens-, Klimaschutz- oder MenschenrechtsThemen werden unterproportional abgebildet. Die Mehrzahl der Protestarenen konzentriert sich auf Feldern mit unmittelbarem Anschluss an den sozialen Nahbereich, den sie dann allerdings zum Ausgangspunkt für einen Blick auf die Gesamtgesellschaft nehmen. Gleichwohl macht ein erneuter Blick auf die europäische Themen aufgreifenden Kritiker der EU-Gemeinschaftswährung oder auf international arbeitende Initiativen wie die erwähnte Slowfood-Organisation deutlich, dass auch Großgruppen mit vielen Tausend Mitgliedern und Netzwerken einen Fokus auf das Regionale und den Blick auf die eigene Gemeinde zum Ziel haben können. Die an dieser Stelle entstehende Skizze der lokalen Anbindung von Protest ist nicht einer Verkürzung auf lediglich lokal denkende Menschen mit kleinem Horizont geschuldet. Sie soll aber unterstreichen, dass erstens in der Wahrnehmung die meisten internationalen Felder eine regionale oder kommunale Abbildung und Entsprechung besitzen, die als Protestanlass fungieren kann, und dass, zweitens, die Demokratie vor Ort den Protagonisten als Möglichkeit gilt, eine ganze Gesellschaft effizienter, verantwortlicher und für sie selbst erreichbarer zu gestalten.

35 Norbert G1 in der Fokusgruppe G1 Hannover 15.03.2012. 
Gleichzeitig gibt es neben dem Effizienzargument, welches auf die Verwaltung und Demokratie zielt, eine Erzählung, welche den Nahbereich und die eigene Gemeinde zum Schutzraum vor einem ausufernden Effizienzpostulat erklärt.

Vieles, was den Protestierenden in ihrem alltäglichen Leben wichtig und teuer ist, lässt sich ihrem Gefühl nach nicht mit den kapitalistischen Maximen der Flexibilität und Effizienz verflüssigen oder rationalisieren, sondern braucht die physische, lokale Nähe. In einem Fall ist dies beispielsweise ein Buchladen als Stadtviertelprojekt, der in einem anderen Quartier keinen Sinn macht und dem eigenen Viertel bei einem Umzug Lebensqualität nähme. Die Entwicklung im Stadtviertel, bei dem Sanierungen die Mieten explodieren lassen und ein Verdrängungswettbewerb stattfindet, machen den Beteiligten große Sorgen:

„....ich war 32 Jahre lang Gewerbetreibender und ich habe die große Gefahr gesehen, dass wir [...] wie alle anderen Läden unseren Arbeitsplatz verlieren, weil wir ein Laden waren, der auch nicht in irgendeinen Stadtteil hätte gehen können. Wir haben das Programm des Buchladens [...], der ist natürlich durch seine politische Ausrichtung nur hier fürs Viertel. ${ }^{\text {36 }}$

Die lokalen Fokussierungen werden von den Gesprächspartnern als ein Votum wider kapitalistischen Geist verstanden, weil sich das Prinzip der Akkumulation von Skalenerträgen und Rationalisierungen an der wahrgenommenen Notwendigkeit von physischer Nähe bricht. Anonymität und übergeordnete Ebenen werden demgegenüber als Grundlage für kapitalistische Vorgehensweisen gesehen die Lokalität und das gegenseitige Kennen und Vertrauen wiederum schaffen die Basis eines anderen Wirtschaftens - so schildert und malt der eben zitierte Konrad C3 den Unterschied zwischen den Immobilienentwicklerfirmen auf der einen Seite und seinen eigenen Vermietern auf der anderen - das Viertel und seine Bewohner werden zum Kern einer Organisation von Gegenmacht. Effizient ist den Protestierenden die lokale Gemeinschaft für die Organisation von Demokratie - für das Miteinander steht ihnen ihre Gruppe für die Ablehnung von Effizienz als Kriterium.

Die eigene Stadt und lokale Gemeinschaft sind aber auch deswegen für die Protestierenden die wichtigste Ebene, da sie dort viel umfangreicher eine Rolle als gesellschaftlich-politische Avantgarde einnehmen können, die ihrem Gefühl entspricht, Zusammenhänge schneller und umfassender überblicken zu können. Innerhalb ihrer Stadt sehen sie sich als diejenigen, welche problematische Entwicklungen in Politik und Gesellschaft spüren und zum Ausdruck bringen - 
auch, um deutlich zu machen, dass sie eine Verantwortung für den Rest der lokalen Gemeinschaft und deren Lebensbedingungen fühlen:

„Einfach so ein grundsätzlicher Wandel in den Wertvorstellungen. Auch wenn die noch nicht praktiziert werden, aber sie werden ja schon gedacht. [...] ...überhaupt, dass es möglich war oder dass der Wunsch entstand und man an vielen Stellen merkte, wir brauchen Alternativen zu dem was gerade äh Gang und Gäbe ist. Das hat, glaube ich, schon dazu geführt, dass wir so viele (offene Türen, Anm. FB) einrennen konnten. ${ }^{\text {“37 }}$

Die Protestierenden fühlen sich als Seismografen der Gesellschaft, die ihrer Nachbarschaft den Weg weisen können, wenn diese ihnen zuhören. Dies wird auch in den Gesprächspassagen zum Ausdruck gebracht, in denen sie schildern, wie stark das Interesse an ihrer Arbeit oft gerade in den eigenen Stadtvierteln und im unmittelbaren Nahbereich sei. Denn wenn eine krasse Ablehnung durch Politik und Verwaltung den Gruppen oft wie eine Art Adelsschlag vorkommt, weil sie sich in ihrer Kritik der politischen Eliten bestätigt sehen, so sehr genießen sie das Gefühl, eine noch nicht manifestierte gesellschaftliche Mehrheit zu vertreten oder dieser aus dem Herzen zu sprechen.

„Überall fangen sich Leute an dafür zu interessieren, was wir hier machen und das extrem. Also die Anzahl an Anfragen an Recht auf Stadt, also die hier hinkommen: könnt ihr hier [einen] Vortrag bei uns im Stadtteil [halten]? Was ihr da macht und so, ist sehr groß.“38

Am weitesten gehen dabei Teilnehmer einer Fokusgruppe aus Währungs- und EU-Kritikern einer Stuttgarter Fokusgruppe, die im Gespräch über etliche Minuten eine Utopie verfolgen, wie ihre Stadt zum Keim eines besseren Lebens werden könnte - und wie sehr sie selbst dabei im Zentrum stehen:

„Serge G2: Wenn man's schafft, dass sich kleine Kommunen vielleicht abschotten, weil im Grundgesetz ja irgendwie verankert ist, dass [die] Steuerhoheit bei den Kommunen liegen sollte und wenn man vielleicht das schafft, so eine zu finden, wo sag ich mal der Großteil der Bevölkerung offen ist, [...] dann wäre es vielleicht mal [...]

Udo G2: Leuchtturmprojekt.

Serge G2: Plan B, ist mir grad eingekommen.

Volker G2: Also wir steigen aus Deutschland aus.

Serge G2: Nicht aus Deutschland, aber, ja, eigentlich schon aus Deutschland.

Volker G2: Verfassungsrechtlich ja, ist das ja eine Sensation. ${ }^{\text {‘39 }}$

37 Einzelinterview Frederik C1.

38 Einzelinterview Lothar C2. 
Kurz danach sprechen zwei Teilnehmer über die Frage, woran sie merken, dass sich ihr Traum einer besseren Gesellschaft verwirklicht haben sollte - und greifen genau dieses Gefühl einer kommunalen Autarkie auf, die weit über partielle Subsidiaritätsvorstellungen hinaus geht:

„Torsten G2: Ähm, ja, also ich denk, dass ich das am Briefkasten merken würde, in dem was drin ist, sozusagen, also das wäre, ja das wäre zum Beispiel irgendwie, eine Art Check, um meine bezahlten Steuern zurückgezahlt zu bekommen oder, dass ich einfach alle möglichen Briefe bekommen, die mich vor die Wahl stellen, welche Versicherungen ich abschließe, welche Straßen ich benutze beispielsweise, die sind ja übrigens auch staatlich, [...] also ich müsste, dürfte auswählen, ob ich überhaupt bezahle für die Straßen [...], dass ich das allein schon daran merke, sobald ich eben den Fuß vor die Tür setze oder eben in meinen Briefkasten schaue, einfach dass ich plötzlich Entscheidungsfreiheit hab, wo ich vorher gedacht habe, das war selbstverständlich.

Udo G2: Es würden ständig Meinungsumfragen stattfinden, per Telefon, oder per Email, weil die Unternehmen unbedingt wissen wollen: Was wollen die Menschen, was ist mein Bedürfnis? Weil, es ist ja gegenwärtig so, dass du als Unternehmen eigentlich das Ziel haben solltest, die Politiker zu lobbyieren. Du solltest die ganze Zeit versuchen, dort einzusteigen, dass die Gesetze für dich machen, zumindest die Großkonzerne haben [...] die Macht dazu. Wenn sie keine Subventionen mehr bekommen, dann wissen sie auch, dass andere Unternehmen sich endlich mal um die Kunden kümmern und dann geh ich davon aus, dass sich endlich mal um mich gekümmert wird. “40

Der „Ausstieg aus Deutschland“, von dem hier die Rede ist, symbolisiert den Bruch mit politischen Entscheidungsmechanismen und eine Reduktion der Demokratie auf eine Ebene, welche die Gesprächspartner als übersichtlich empfinden - und innerhalb derer sie ihre Position als gesichert annehmen. Nicht alle Interviewten betonen diesen Punkt gleich stark. Als Ausformung des ProtestSelbstbewusstseins ist er allerdings bei fast allen sichtbar, ganz gleich welcher Generation oder politischer Couleur die Protestierenden sind. Die (Wieder)Aneignung von Gestaltungsrecht wird zu einem Hauptmotiv erklärt, das hinter dem eigenen Engagement und Protest ganz allgemein zu finden ist. Dann, wenn politische und wirtschaftliche Führungsschichten sich verselbstständigten, ruhe die Aufgabe, eine „richtige“ Demokratie wieder herzustellen, auf den Schultern der lokalen Eliten.

39 Fokusgruppe G2 Stuttgart am 02.04.2012.

40 Ebenda. 
„Also, so ne Minimalforderung, die man da stellt, wir wollen einfach mitgestalten, wie unsere Stadt aussieht, wie stark das in das kapitalistische System und die Politik, wie sie hier in diesem Lande praktiziert wird, eingreift. Also dieses Plantisch-, RathaushinterzimmerRumgeschachere um Flächen und Preis und äh Förderung und dergleichen. Wenn da Leute aufstehen und sagen „Moment mal, wir wollen da mitreden und vor allen Dingen, wir gucken uns genau an, was da passiert. Wer investiert eigentlich wo und warum?“, dann wird das Ganze auf einmal unglaublich politisch ....“41

Dass die Protestierenden dabei eine gesellschaftliche Avantgarde bzw. eine Pressure-Group der Ressourcenstarken darstellen, ist ihnen selbst bewusst und sie thematisieren dies auch in den Gesprächen. Aus der Tatsache, dass sie sich oftmals in einer Minderheitenposition sehen, ziehen sie allerdings abermals Motivation, da es die Verantwortung für das Allgemeinwohl noch einmal steigert: Die anderen werden ja nicht aktiv, also muss ich es umso stärker tun.

„Man muss ganz ehrlich sagen, die, die überhaupt die Stimme haben, sich da zu wehren, das sind dann eben die vielleicht irgendwie etwas besser im Stab Stehenden. Die anderen sind teilweise schon verdrängt. Das finde ich, legitimiert trotzdem den Protest. ““42

Oder wie es Frederik C1 ausdrückt:

„Aber manchmal sind ja dann auch die Leute, die sich für etwas interessieren, vielleicht auch diejenigen, die eben stellvertretend für viele sprechen könnten. “43

Das lokal fokussierte Selbstbewusstsein des Protests führt gemeinsam mit dem Gefühl, die kommunalen Besonderheiten und Beziehungsnetzwerke intim zu kennen, zu einer spürbaren Ablehnung übergeordneter Mechanismen und Strukturen, die auf Ausgleich und Konsensorganisation ausgerichtet sind. Überregionale Ebenen von Parteien, Gewerkschaften, Kirchen erscheinen in vielen Interviews gar nicht mehr in der Lage, vor Ort auf Zustimmung zu treffen, weil die lokale Bevölkerung - oder zumindest diejenigen Protestaktiven und -Eliten in den Gesprächen - Subsidiarität und Eigenverantwortung als Grundprinzipien verinnerlicht hat. Wenn das Gefühl vorherrscht, die "kollektive Textur" regional viel besser aufgreifen, diskutieren und umsetzen zu können, werden andere Entscheidungsinstanzen nicht mehr anerkannt. Lokale Kenntnis und maßgeschneidertes Handeln werden in den Gesprächen oftmals als Gegensatz zu notwendi-

41 Einzelinterview Frederik C1.

42 Einzelinterview Lothar C2.

43 Einzelinterview Frederik C1. 
gerweise ortsfremden und dadurch blinden Lösungen durch überregionale Politik dargestellt.

Dieser Gegensatz zwischen lokalen Problemen und nationalen Organisationen zeigt sich etwa in einem Gespräch mit einer Mitarbeiterin der evangelischen Kirche in einer bayrischen Kleinstadt, die darlegt, dass sie oft mit dem Verhalten der Landeskirche hadere und sich als Vertreterin an der Basis im Stich gelassen oder unverstanden fühlt:

„Ich sehe mich auch als Kirchenperson im Gegenüber zu meiner Kirchenleitung, der ich immer wieder spiegele und sage, Leute, bitte äußert euch da und bitte engagiert euch da. Ich habe leider sehr wenig Erfolg gehabt. Das ist sehr frustrierend, dass die Kirchenleitung in München weit weg ist. Manche haben sehr stark unterstützt, moralisch, die Synode hat sich ja dann geäußert, aber so bischöflich, landeskirchenamtlich, war es sehr frustrierend und das ist dann eine Enttäuschung über die eigene Kirche...“44

\subsection{ZWISChENFAZIT VI: GENOSSENSChAFTSLOGIK UND STOLZ}

Protest gilt den Aktiven als Verwirklichungsform der eigenen Ideale. In diesem Sinne begreifen sich alle Interviewpartner nicht als Verhinderer, sondern als positiv Engagierte für eine bessere Welt.

„Wir können nicht alle nur Dampf plaudern, weil wir sind alle der Meinung, es geht um viele Dinge, nicht nur um die eigene Betroffenheit. Wir kämpfen wirklich für eine bessere Welt und das hörst du bei den anderen nicht. Und da lege ich großen Wert drauf.“ ${ }^{\star} 45$

Dass man ein Beispiel gibt mit dem eigenen Engagement macht die Interviewpartner stolz - auf sich selbst und die eigene Gemeinschaft. In fast allen Gesprächen entstehen geradezu rührende Erzählungen darüber, wie glücklich die Protestierenden sind, der Gemeinschaft eine mögliche Alternative vor Augen zu halten. Entsprechende Passagen geraten dann bisweilen ins Pathetische, wenn die eigenen Glücksgefühle geschildert werden. Besonders Projekte, die auch physisch und über einige Zeit bestehen, etwa die Camps im Stuttgarter Schlossgarten 2011 oder aber - noch manifester - ein besetzter Straßenblock wie das Hamburger Gängeviertel, vermitteln ergreifende Bilder einer konkreten Utopie.

44 Einzelinterview Beata C4.

45 Rainer C3 in der Fokusgruppe C3 Freising am 25.07.2012. 
„Hab dann hier verschiedene kleine Initiativen gemacht. Das erste war das Zeltdorf, das es damals im Park gab [...]. Die waren im harten Winter kurz vorm Aufgeben. Und ich hab dann mit einer künstlerischen Installation diese ganze Sache eingefriedet, dass die da drin überleben konnten. Das war sozusagen meine erste Unterstützungsaktion, die ich hier gemacht hatte. Dann habe ich da die Erfahrung gemacht, für mich überraschend war, dass in diesem Park ein Lebensgefühl entstanden ist, wo ich sehr überrascht war, dass es sowas hier überhaupt geben kann. Das war wie so ein herrschaftsfreier Raum. Und im herrschaftsfreien Raum haben plötzlich ganz differente Menschengruppen angefangen, miteinander zu interagieren und da ist für mich so eine Art Kultur entstanden. “46

Die Bedeutung des eigenen Engagements als alternatives Projekt liegt dabei in der Demonstration, wie viel es doch abseits von vermeintlichen Pfadabhängigkeiten doch noch an Bewegungsspielraum gebe. Die psychologische Anziehungskraft der Verwirklichung eigener Vorstellungen, nach seinem eigenen Lebensrhythmus zu leben, lässt die Protestierenden hoffen, mit ihrem Engagement eine Strahlkraft zu entfachen, die wiederum andere überzeugt. Sie möchten die eigene Arbeit auch als eine Art gesellschaftliches Experimentierfeld für Zusammenleben verstanden wissen, auf dem man in einer unverbindlicheren Form und ohne schwerwiegende Konsequenzen (da es sich ja "nur" um kleinräumige Versuche handelt) ausprobieren kann, wie möglicherweise andere Formen der Organisation (oder auch der Integration) von Arbeit und Leben, von Gemeinschaft und Engagement, von Autarkie und Subsidiarität funktionieren können.

Diese Überhöhung des eigenen Einsatzes findet sich gerade in Stuttgart und München in den Äußerungen der Aktivisten sehr häufig. Für viele ist das konkrete Protestobjekt nur eine Abstraktion dessen, was sie eigentlich an dieser Gesellschaft und deren Verfasstheit stört. Beide angesprochenen Bauprojekte Bahnhof und Flughafen - stehen dann für eine Verschwendungssucht und Hybris von Politik und Wirtschaft, die für Prestige- und Leuchtturmbauten die Prinzipien der Responsivität von Politik wie das Gebot eines adäquaten Ressourcenverbrauchs außer Kraft setzten. Und bei den Hamburger Gentrifizierungsprotesten etwa stehen die Entwicklungen der Mietpreise und die Renovierung ganzer Straßenzüge für eine Entwicklung hin zu einer immer stärker von ökonomischem Kalkül durchdrungenen Gesellschaft, welche die eigene lokale Identität bedroht. Innerlich wird man dadurch auch zu einem Kämpfer für eine bessere Welt, weit weg vom Kampf für das individuelle Partikularwohl.

Fragt man die Aktiven dieser Protestfelder nach ihren Wünschen, auch nach Sehnsüchten und Hoffnungen, dann scheinen Bezüge zu mindestens zwei historischen Bewegungen durch: die uralte Kommune- oder Genossenschaftsbewe-

46 Severin C2 in der Fokusgruppe C2.2 Stuttgart am 20.03.2012, 20 Uhr. 
gung sowie der Kommunitarismus als akademische Diskussion seit den 1980ern. Kommunen und kleine autarke Gruppen fanden bereits bei den Israeliten und im Urchristentum zusammen und hatten zum Ziel, Schutz- und Trutzburgen aufzubauen, um ihre gesellschaftlichen Ideale und Lebensvorstellungen zu realisieren. Seitdem krasse soziale Ungleichheiten und Zwangslagen zur Zeit Jesu dazu geführt haben, dass sich Menschen in kollektiven Notsituationen vereinigten, sind immer wieder genossenschaftliche Zusammenschlüsse entstanden, um sich gegen widrige Einflüsse zu schützen und eine Gemeindesolidarität zu leben, die als emotionales und ökonomisches Auffangnetz fungiert. ${ }^{47}$ Die christlichen Bezüge des Teilens von Eigentum, der Solidarität mit den Schwachen innerhalb einer Gemeinschaft und der Gleichheit aller Beteiligten liegen auf der Hand - gleichzeitig wollte die Genossenschaftsidee auch die lokale Ebene und ihre damit einhergehenden persönlichen Beziehungen dazu nutzen, sich als Gegenmacht gegenüber einer übermächtigen Staatlichkeit oder Zentralinstanz (sei es ein Staat oder der global agierende Kapitalismus) abzuschirmen. ${ }^{48}$

Auch den Protestaktiven in den Interviews schwebt abstrakt eine Idee vor, mit der sie diesen Prinzipien näherkommen: mehr Möglichkeiten, lokal Verantwortung zu übernehmen sowie nach anderen Kriterien als streng wirtschaftlicher Effizienz zu entscheiden. Dies bleibt keineswegs begrenzt auf Reste einer 1970er-Jahre-Studentenbewegungs-Nostalgie. Und in ihren Protestzusammenschlüssen setzen sie diese Prinzipien zum Teil auch um: Gerade die Dachvereinigungen der Stadtproteste in Hamburg, der Proteste gegen Stuttgart 21 und den Münchner Flughafenausbau sind Gruppen, die sehr stark darauf achten, keine großen Hierarchien entstehen zu lassen, dem Einzelnen innerhalb abgesteckter Grenzen die größtmögliche Freiheit zu lassen, jedem das gleiche Stimmgewicht einzuräumen. Besonders gegenüber der von den Befragten oft hämisch und beißend kritisierten Parteiendemokratie in Deutschland, die für viele die Verkörperung schlechthin für Ineffizienz und Vetternwirtschaft ist, erscheint ihnen die Vorstellung von lokalen Zusammenschlüssen ungemein attraktiv.

Analog zu den Ansätzen der Kommunebewegung wird die Realisierung der eigenen Werte im kleinen Umfeld angestrebt, um diesen dann Anschaulichkeit

47 Vgl. Siepmann, Heinzfried: Christliche Hintergründe des Genossenschaftswesens, in: Evangelische Akademie Mühlheim (Hrsg.): Alte und neue Genossenschaftsbewegung. Zum Streit um das Erbe einer Reformidee für Wirtschaft und Gesellschaft, (1988) H. 8, S. 8 - 26, hier S. 9.

48 Dieser Aspekt findet sich sehr plastisch geschildert in Nürnberger, Christian: Die Bibel, Berlin 2005, S. 115 - 122 sowie S. 190. 
und Strahlkraft zu verleihen. ${ }^{49}$ Der Wunsch, gleich die ganze Gesellschaft umzukrempeln, erscheint ihnen dagegen als ein Wolkenkuckucksheim. Die Plakate von den „Lügen“ der Politik oder dem demonstrativen Einbinden der arabischen Demokratiebewegungen etwa (,Stuttgart grüßt Kairo“650) zeugen aber von dem Kontext, in dem man die eigenen Proteste sieht.

Auch dass man die eigene Stadt und Region innerhalb der Bundesrepublik als gewichtig und bedeutsam - sei es ökonomisch oder kulturell - wahrnimmt und sich selbst als wichtigen, tragenden Teil des Ganzen sieht, mag dazu beitragen, dem eigenen Engagement eine über das konkrete Ziel hinausweisende Bedeutung zu verleihen. Denn die hier untersuchten Aktivisten, die den Protest in den hier betrachteten Regionen tragen, sind Menschen, die mit ihren Berufen, ihrer Erfahrung und ihrer ganz persönlichen Geschichte ihr Stadtviertel, ihren Ort und ihre Region prägen. Der resultierende Stolz und das Selbstbewusstsein sind in allen Gesprächen zu spüren. Denn sei es über den Beruf oder vorangegangenes Engagement: Die Erfahrung, dass sie etwas verändern und bewegen können, haben alle bereits gemacht, was ihnen zu einer Selbstgewissheit und einer breiten Brust als Beschwerdeträger verhilft.

Ein anderer Bezug findet sich in der akademischen Diskussion des Kommunitarismus, welche in den 1980er Jahren in den USA ihren Anfang nahm, und als „Versuch einer Wiederbelebung von Gemeinschaftsdenken unter den Bedingungen postmoderner Dienstleistungsgesellschaften " auch zu einem politischen Programm erweitert worden war. ${ }^{51}$ Die Sehnsucht nach einer größeren Kontrolle über das eigene Leben und nach einem ethischen Fundament der eigenen Gemeinschaft, der man sich zugehörig fühlt, aber der man nicht mehr qua Geburt angehört, wurde dabei zur Quelle einer Forderung nach mehr Selbstorganisation. ${ }^{52}$ Kommunitarismus als eine lokale Verantwortungsübergabe in die Hände von Bürgern verstand sich ebenso als Gegenmittel angesichts schwindender demokratischer Begeisterung, wie dies in den Interviews mit den Protestierenden zum Ausdruck gebracht worden ist. ${ }^{53}$ Der Sinn der Gemeinschaft, so ist dies bei Philip Selznicks Beschreibung des Kommunitarismus zu finden, liege nicht in

49 Vgl. Schibel, Karl-Ludwig: Kommunebewegung, in: Roth, Roland / Dieter Rucht (Hrsg.): Die sozialen Bewegungen in Deutschland seit 1945, Frankfurt a.M. 2008, S. 527 - 540, hier S. 529.

50 Vgl. Heffner, Markus / Erik Raidt, Protest im Hamsterrad, in: Stuttgarter Zeitung, 12.03.2012.

51 Reese-Schäfer, Walter: Kommunitarismus, Frankfurt a.M. 2001, S. 7.

52 Sandel, Michael J.: Democracy's Discontent. America in Search of a Public Philosophy, Cambridge 1996, S. 15.

53 Vgl. Putnam: Bowling Alone, S. 108f. 
einem einzelnen, eingrenzbaren Zweck, sondern in einem „gemeinsamen Leben“ der Beteiligten, welches durch „,moralische Bande“ zusammen gehalten werde. ${ }^{54}$ Damit diese kleinen Gemeinschaften dann nicht in einem bornierten Partikularismus verharren, mündet die kommunitarische Gesellschaftsauffassung in einem kontinuierlichen Dialog der kleineren Gruppen mit den jeweils nächsthöheren, bei dem moralische Standards und universelle Wertvorstellungen permanent verhandelt und aktualisiert werden. ${ }^{55}$

Ähnlich nehmen dies die Aktiven der Proteste in den Gesprächen für sich in Anspruch. Auch sie sind zwar in den meisten Fällen als zweckrationale Organisation auf ein Themenfeld begrenzt - demzufolge eigentlich keine „Gemeinschaft", fühlen sich aber als eine solche, in der sie eine größere Bande zum Nebenmann spüren und eine größere Übersicht über Zusammenhänge und Verantwortlichkeiten, als sie dies in der ,großen“ Gesellschaft für möglich erachten. Auch die Beobachtungen zur Auffassung von Vielfalt und Heterogenität der Protestierenden unterstützen diese Folgerung. Und dass sie sich selbst als Ausgangspunkt einer Debatte über moralische Fundamente der Gesellschaft und ihrer Organisation sehen - auch davon sind die Gesprächspartner überzeugt. Die Ambivalenz zwischen kleineren, vergleichsweise homogenen Gemeinschaften als Kern einer liberalen Demokratie und einer ebenso denkbaren Tendenz hin zu patriarchalischem Verhalten von Gemeinschaften als „Relikt der Prämoderne oder als neoautoritärer Fundamentalismus ${ }^{* 56}$ ist dabei aus den Gesprächen spürbar. Die Gemeinschaft als Forderung ist auch ein Ringen um Kontrolle und Übersicht.

Eine Überzeugung, auf lokaler Ebene und mit einer glaubwürdigen regionalen Identität etwas verändern zu können, ist auch insofern interessant, als dass eine Art neuer Kommunitarismus den vielleicht spannendsten Aspekt der aktuellen Diskussion innerhalb der europäischen Arbeiterbewegung nach der Finanzund Wirtschaftskrise ausmacht. ${ }^{57}$ Auch hier wird die genossenschaftliche Histo-

54 Zit. nach Hans, Michael: Kommunitarismus. Einführung und Analyse, Wiesbaden 2003, S. 119.

55 Vgl. Reese-Schäfer: Kommunitarismus, S. 111f.

56 Ebenda, S. 7.

57 Vgl dazu Michelsen, Danny: Kommunitarischer Konsens?, in: Blog des Göttinger Instituts für Demokratieforschung, URL: http://www.demokratie-goettingen.de/blog/kommunitarischer-konsens [eingesehen am 18.02.2013]; oder vgl. auch etwa Ulrike Fokken, Die rote Insel, in: die tageszeitung, 16./17.02.2013; vgl. für die europäischen Parteien der Sozialdemokratie Butzlaff, Felix / Matthias Micus: Formulierung von Zukunftsbildern einer besseren Gesellschaft? Politische Visionen und programmatische Leitideen der europäischen Sozialdemokratie, Friedrich Ebert Stiftung, 
rie der Bewegung - von Robert Owen über Charles Fourier, über die Pioniere von Rochedale bis zu Friedrich Wilhelm Raiffeisen als christlich inspiriertem Vordenker - immer wieder als Inspirationsquelle herangezogen, wenn es um die Verquickung zweier zentraler Fragen geht: Erstens, wie man sich der globalen Verwertungslogik des Kapitals zumindest teilweise entziehen könnte, und zweitens, wie man wieder vermitteln könnte, dass Politik auf lokaler Ebene etwas bewegen und damit Handlungsmotivation wider eine Parteien- und Politikerverdrossenheit stiften kann.

Die Stadt, in der sie leben, die Gemeinschaft, in der sie sich bewegen und in der ihr Engagement stattfindet, ist ihnen ein Schutzraum, in dem eine immer heterogener gewordene Gesellschaft noch überblickbar und in dem ihnen ihre gesellschaftliche Stellung vergleichsweise ungefährdet erscheint. Sie ist ihnen gleichzeitig Möglichkeitsrahmen, Experimentierfeld und Beweis, dass ihre postulierten Werte zu verwirklichen sind.

Wenn nur die Demokratie und ihre Repräsentanten diese Ebene stärker gewichten würden!

Berlin September 2012, online einsehbar unter http://library.fes.de/pdffiles/id/ipa/09343.pdf [zuletzt eingesehen am 12.01.2015]. 


\section{Von guter und böser Vielfalt: Fazit und Zusammenfassung}

Organisierter Bürgerprotest ist zunächst, das haben die Interviews und Beobachtungen in ihrer Verdichtung gezeigt, ein Zeichen von Selbstbewusstsein innerhalb einer Gesellschaft. Und eine wahrgenommene Häufung von Protesten kann als Resultat einer biographischen Entwicklung vieler Menschen verstanden werden, welche in ihnen dieses Selbstbewusstsein hat entstehen lassen, um Phänomenen, die ihren Vorstellungen von Politik, Gesellschaft oder Wirtschaft zuwider laufen, mit eigenem Engagement und direkt entgegenzutreten. Sie ist darüber hinaus ein Signal, dass etablierte Mechanismen der gesellschaftlichen Entscheidungsfindung und -vermittlung nicht mehr umfassend akzeptiert werden, dass der Output politischer Prozesse nicht mehr als hinreichend empfunden wird oder dass die eigenen, individuellen oder kollektiven Fähigkeiten, Themen beurteilen und über diese entscheiden zu können, als der Politik überlegen eingeschätzt werden.

Dieses Buch war auch angelegt als eine Reise in die Biographie, die Hoffnungen, Empfindlichkeiten und Erwartungen derjenigen Organisatoren, denen ein Engagement in Bürgerprotesten zum Lebensinhalt geworden ist. $\mathrm{Zu}$ verstehen, was sie antreibt, warum gerade sie der politischen Repräsentation über Parteien nicht mehr vertrauen oder mit den getroffenen Entscheidungen zutiefst unzufrieden sind, war primäres Ziel. Und, ganz zu Beginn, die Frage: Wer sind sie eigentlich, die Aktiven dieser Bürgerproteste?

Vorweg: Es sind keine Bürgerproteste, bei denen generationelle Konfliktlinien stark zu spüren wären - kein Aufbegehren der Jungen gegen die Alten, als das die in den zwei Jahrzehnten nach 1968 aufflammenden Proteste ins kollektive Gedächtnis übergegangen sind. Die meisten Befragten zählen zum Zeitpunkt der Gespräche 2012 zwischen 46 und 55 Jahren. Die Altersgruppen darüber (zwischen 56 und 75) und darunter (36 bis 45) können ebenso noch zu den 
Schwerpunkten im Altersspektrum gerechnet werden. Zwei Drittel der interviewten Protestierenden sind zwischen 36 und 75 Jahren alt und verteilen sich auf diese Weise, was Geburt, Prägephasen und historische Erfahrungen mit Politik und Gesellschaft anbelangt, auf einen nicht unbeträchtlichen Teil der deutschen Nachkriegsjahrzehnte. Ältere wie Jüngere sind deutlich weniger stark vertreten. Gleichwohl spielen Alter und Generation für die Protesthaltung und ihre Ausprägung eine gewichtige Rolle.

Denn dass die Organisatoren, mit denen Interviews geführt werden konnten, Menschen sind, für die ihre Mitarbeit im Protest zu einem roten Deutungsfaden ihres Lebens geworden ist, kann in den Gesprächen nachempfunden werden. Sie erzählen ihre Biographie derart, dass aus ihr naturwüchsig eine selbstbewusste Person hervorgeht, die zum Widerspruch fähig und willens ist. Und sie lassen ein Selbstbild erkennen, welches Individualität und Selbstständigkeit betonen möchte; dass man sich nicht unterordne, unabhängig sei. Wenig Zweifel jedenfalls lassen sie an der Annahme, sie selbst gehörten zu den Starken in der Gesellschaft, richteten sich nicht nach dem Wind und folgten den eigenen Prinzipien konsistent durchs Leben.

Einkommen, Bildungsstand, Sozialkapital und ein aus den Gesprächen hervorgehender Anspruch auf gesellschaftliches Ansehen - diese Kriterien machen deutlich, dass wir es bei den organisierten Bürgerprotesten nicht mit einem Aufbegehren von Underdogs zu tun haben, sondern im Gegenteil: dass diejenigen Proteste organisieren, die mit fester Stimme und manchmal auch durchaus vollmundig fordern, dass man ihre Anliegen zu hören habe. Dieser biographische Hintergrund ist den Interviewten deutlich bewusst und wird zu einem gewichtigen Teil ihrer Argumentation: Gerade weil sie gebildet, finanziell und sozial erfolgreich oder gut vernetzt sind, sollte man ihnen zuhören.

Alle Gesprächsteilnehmer haben irgendwann in ihrem Leben die Erfahrung gemacht oder vermittelt bekommen, dass Protest und Widerspruch etwas Wünschenswertes, Gutes sei - für den Einzelnen wie für die Gesellschaft als Ganzes. Es sind Vorbildfiguren und eigene oder kollektive Erfahrungen, welche diese Einsicht haben entstehen lassen. Unabhängig von den Geburtsjahrgängen der Interviewten gibt es dabei Bezugspunkte in der deutschen Geschichte, die Teil eines Selbstverständnisses im Protest geworden sind. Besonders die Neuen Sozialen Bewegungen der ausgehenden 1970er und 1980er Jahre sind zu Chiffren geworden, auf welche die allermeisten Gesprächsteilnehmer westdeutscher Prägung Bezug nehmen. Hier habe man gelernt - selbst oder durch andere -, dass man etwas bewegen könne, wenn es einem wirklich wichtig sei und man sich mit anderen zusammentue. Aktive ostdeutscher Provenienz betonen an diesen Stellen meist die Erfahrung mit der Überwindung des Realsozialismus, welche 
ihnen vor Augen geführt habe, zu welcher Wirksamkeit zivilgesellschaftlich organisierter Widerstand imstande sei.

Für die Interpretation generationeller Prägungen unter den Protestierenden ist wichtig zu unterstreichen, dass es keine oder kaum weit zurückreichende, auf sich selbst als Organisation fokussierte Mythen gibt, da die untersuchten Protestfelder noch nicht allzu lang in dieser Form existieren, Gruppen und Zusammensetzung zudem oft wechseln. Einzelne Mitglieder bringen ihre persönlichen Erzählungen und Heldenschilderungen mit ein. Gleichzeitig gibt es das für den $\mathrm{Zu}$ sammenhalt wichtige „Graben“ nach Anknüpfungspunkten in der lokalen Geschichte, in deren Kontinuität sich die Gruppen stellen. Hier wird deutlich, dass die kollektive Erzählung oder Erinnerung über die 1970er und 1980er Jahre sehr laut geteilt wird, zur Selbstverständlichkeit geworden ist. Es sind keine geschichtslosen Proteste, da diese Lokaltraditionen und -koloraturen für die jeweiligen Argumentationen immens wichtig sind. Die konkreten Organisationen als Protestinstitutionen allerdings haben noch keine gemeinsame lange Geschichte wir schauen auf eine „Mythisierung“ des aktuellen Protests, welche noch nicht abgeschlossen ist. Es gibt in diesen Gruppen noch keine Generationenfolge, bei der erfahrene Generationen von nun folgenden in Frage gestellt und herausgefordert werden. ${ }^{1}$ Gleichwohl spielen also die kollektiven Erfahrungen der 1970er und 1980er Jahre eine zentrale Rolle - als Vorprägung und bestehende Erzählung, die unterstreichen soll, dass man selbst in dieser Kontinuität steht; dass man schon immer auf der richtigen Seite war; dass man gelernt hat, dass Widerspruch gut ist; als kollektive gesellschaftliche Verinnerlichung eines durch die Protestbewegungen versinnbildlichten Selbstbewusstseins.

Bürgerprotesten wohnt dabei ein dynamischer, sich selbst verstärkender Charakter des Widerspruchs inne: Nicht nur sind es die Selbstbewussten, die protestieren, sondern wer protestiert, sammelt zusätzlich Erfahrung, Kenntnisse und Fähigkeiten. Insofern steht eine kritische Betrachtung der bestehenden Ausprägung der repräsentativen Demokratie nicht allein am Anfang eines Engagements im Protest, sondern oft genug als Ergebnis desselben. Weil die Aktiven in den Protestgruppen das Gefühl gewinnen, von Parteien und Behörden nicht ernst genommen, nur häppchenweise informiert oder miteinbezogen zu werden, vertieft sich bestehendes Unbehagen noch.

Damit einhergehend geben sich die Protestierenden betont misstrauisch gegenüber jedweden Großzusammenfassungen wie etwa politischen Parteien. Historische Vertrauensdepots, welche die eigene Individualität in einer Gruppe gut

1 So, wie dies etwa für die Arbeiterbewegung beobachtet werden kann, vgl. den Band Schönhoven, Klaus / Bernd Braun (Hrsg.): Generationen in der Arbeiterbewegung, München 2005. 
aufgehoben sahen, und die darüber halfen, die Voraussetzungen für die Integrationskraft einer Demokratie zu sichern, scheinen sich - so zeigen die Gespräche - immer weiter aufzuzehren. Es sind Interviews, die auch davon zeugen, dass sich engagierte Menschen nicht in Überschriften oder Oberflächlichkeiten darstellen oder ansprechen lassen möchten. Viele Gesprächspassagen erzählen von dem Bemühen, sich als komplexe Individuen zu präsentieren, die nicht mit einfachen Schemata zu begreifen seien.

Das im Schnitt fortgeschrittene Alter der Protestierenden verstärkt diese Charakteristika noch. Mit zunehmendem Alter wird es wahrscheinlicher, individualisierte Selbstwirksamkeitserfahrungen anzuhäufen, welche sich auch in direkte politische Wirksamkeitserwartungen übersetzen. Während jüngere Menschen in den Gesprächen eher den grundsätzlichen Wert einer engagierten Zivilgesellschaft für eine Demokratie betonen, spielt das ganz direkte, unmittelbare Wirkungsmoment für die Älteren eine wichtige Rolle. Nicht unbedingt alle sollten direkten Zugang zu Entscheidungsmechanismen bekommen; ich sollte es. Dies ist ein Zusammenhang, auf den der Soziologe Albert O. Hirschmann hingewiesen hat: dass mit zunehmendem Alter und Engagementerfahrung der Fokus von einer Gemeinwohlorientierung immer stärker auf die Verfolgung ganz individueller Ziele verengt wird. ${ }^{2}$ Mehr „Erfahrungsjahre“ sind auch ein zentrales Signum alternder Gesellschaften und lassen ein spezifisches Protestprofil entstehen, welches für die europäischen Gesellschaften in den kommenden Jahrzehnten zu erwarten sein mag. Auf der anderen Seite hat sich auch der beschriebene dynamische Mechanismus der kollektiven Erfahrungsspeicherung von Rolle und Wert von Protest beschleunigt - immer mehr junge Menschen können die Erfahrung machen, dass Protest gut, wichtig und selbstverständlich ist. Beide Wirkungsbahnen, sowohl die individuelle Wirkungserwartung als auch die kollektive Verinnerlichung des Wertes von Protest, haben zugenommen - was den aktuell wahrgenommenen Anstieg von Bürgerprotesten erklären kann - und dürften in der Zukunft eher noch weiter anwachsen.

Dass die Organisatoren von Bürgerprotesten zu den Starken innerhalb der Gesellschaft gehören, verdeutlicht sich auch durch ihre eigene Interpretation des Zusammenhangs von Bildung und Protest: Es ist ihnen ein Anliegen, zu zeigen,

2 Albert O. Hirschman untersucht dabei die politischem Engagement strukturell inhärenten Quellen subjektiver Enttäuschung und kommt zu dem Ergebnis, dass sowohl Erfüllung als auch Nichterfüllung der Forderungen leicht in eine tiefe Enttäuschung münden. Zeitliche und energetische Überforderung, verschwindende Illusionen über mögliche politische Ergebnisse und die Tendenz, in politischer Arbeit seine eigenen Ideale verletzen zu müssen sind die subjektiven Erfahrungen, welche er dafür ins Feld führt. Vgl. dazu Hirschman: Engagement und Enttäuschung, S. 101 - 112. 
dass sie einen besseren, früheren Durchblick über die Zusammenhänge der Welt erlangt haben; weil sie diese Zusammenhänge verstanden haben, protestieren sie; wer noch nicht dabei ist, hat es noch nicht umfassend kapiert. Der rote Deutungsfaden, den sie für ihre Biographie zeichnen, unterstreicht dies noch. Damit zusammenhängend beäugen sie misstrauisch und missmutig diejenigen Menschen, die nicht protestieren. Die Gesprächsteilnehmer sind überzeugt, dass bislang nicht Aktive lediglich die richtige Einsicht noch nicht erlangt haben oder sich dieser verweigern - aber aktiv würden, wenn man sie nur erreichen könnte. Es ist ein positiv-elitäres Selbstbild als „Kader“.

Auffällig ist, dass viele der betrachteten Proteste sich zwar an einem lokalen Zusammenhang entzünden, die zugrunde liegenden Ursachen und Fehlentwicklungen aber auf höheren Ebenen vermutet werden. Insofern nehmen die meisten Proteste für sich in Anspruch, die politische und gesellschaftliche Entwicklung insgesamt zu adressieren und nicht nur für ein konkretes Projekt, sondern für eine bessere Gesellschaft insgesamt aktiv zu werden. Allerdings bleibt die Fokussierung auf ein Projekt oder Anliegen bemerkenswert: Alles erklärt sich aus einem Thema, welches symbolhaft für die Problemdiagnosen der Interviewten steht. Nur ganz wenige Gruppen nehmen für sich eine gemeinsame Weltanschauung zum Ausgangspunkt und blicken von dieser aus auf die Welt; den allermeisten gilt ein konkretes Anliegen als Ausweis von Gemeinsamkeit. Diese Ausrichtung führt auch dazu, dass die anderen Mitstreiter leichter als Brüder im Geiste wahrgenommen und eingemeindet werden, Unterschiede werden übertüncht, weil man das eine Thema absolut setzt und von diesem ausgehend die Welt erklärt. Die Proteste sind Zeiten, in denen das zentrale Thema alles andere überstrahlt und in denen die geglaubten Gewissheiten zu absoluten Wahrheiten werden. Gleichzeitig ist vielen Gruppen aber auch eingeschrieben, dass der unmittelbare Organisationszusammenhang von der Existenz des Ursprungskonfliktes abhängig ist und brüchig zu werden droht, sobald der Mobilisierungsdruck nachlässt.

Dass man seine Kraft diesem einen Thema widmet, welches in Zeiten hoher Mobilisierung und der Zuspitzung von Protesten zur zentralen und alles andere dominierenden Kraft wird, verschafft den Protestierenden eine tiefe Zufriedenheit über das eigene Handeln. Diese ziehen sie aus der Überzeugung, ein nachahmenswertes Beispiel zu geben: Man verkörpert mit der Protestarbeit die eigenen Ideale und unterstreicht gleichzeitig, dass Pfadabhängigkeiten der Parteiendemokratie durchbrochen und die eigenen Vorstellungen des Zusammenlebens für alle sichtbar verwirklicht werden können. Insofern ist den Aktiven ihr Protest auch ein gesellschaftliches Experimentierfeld, auf dem sie sich verdient machen. 
Das Aufflammen von Protesten zeugt auch von dem Gefühl einer Krise, welches viele der Aktiven empfinden. Eine solche Krise, das haben die Interviews gezeigt, ist für die Gesprächspartner ökonomisch, politisch und gesellschaftlich zu beobachten und mündet in eine als bedrohliche erachtete Unübersichtlichkeit von Zusammenhängen und Verantwortlichkeiten in Politik und Gesellschaft. Sie selbst haben persönlich den Eindruck, nicht strukturell unterlegen zu sein, sondern als gesellschaftlich „Starke“ keinen unmittelbaren sozialen Abstieg fürchten zu müssen - sie empören sich aber über diejenigen, die doppelbödig Kriterien aufstellen und diese dann verletzen, um sich selbst Profite zu sichern. Sie sehnen sich nach persönlicher Verantwortung - dergestalt, dass sie gerne wüssten, wen sie für Fehlentwicklungen verantwortlich machen können. Auch daher rührt ihre Wut auf Politik und Parteien, die sich ihrem Empfinden nach diesen Personalisierungen entziehen.

Das Kleine, Örtliche, Übersichtliche hingegen erscheint ihnen nicht so leicht korrumpierbar, sondern vergleichsweise rein und unverdorben. Die lokale Gemeinschaft erscheint auf der einen Seite als Garant für Unverfälschtheit und Sicherheit. Spürbar ist in vielen Gesprächspassagen, dass es trotz Individualisierungsdrang ein starkes Bedürfnis nach einer schützenden, Identität und Geborgenheit stiftenden Gemeinschaft gibt. Auf der anderen Seite ist deren Akzeptanz für viele schwierig geworden, da die eigene Individualität so wichtig und ins Zentrum von Denken und Handeln gestellt wird. Sei es, weil man komplexe gesellschaftlichen Kräfteverhältnissen nicht mehr überblicken kann oder weil man einen gefühlten Zwang zur Selbstoptimierung umfassend verinnerlicht hat: Die eigene Gruppe ist den Protestierenden Schutzraum für Identität, aber auch für ihren sozialen Status, den sie als lokale Elite verteidigen. Die lokale Gemeinschaft gilt ihnen dabei einerseits als besonders effizient in der Organisation gesellschaftlicher Entscheidungsfindung, da sie nah an den zu regelnden Dingen sei und reibungsarm Menschen mit den benötigten Fähigkeiten zusammenbringen könne. Gleichzeitig gilt ihnen ökonomische Effizienz andererseits als ein oftmals bedrohliches Kriterium, dem sich eine lokale, vertraute Schutzgemeinschaft zu entziehen versucht. Ökonomische Effizienz als Entscheidungskriterium hat im Ganzen für die Protestierenden eine bemerkenswert zweigeteilte Rolle: Sie ist Fluch und Segen zugleich; sie fordern sie und lehnen sie ab. Die eigene Kleingruppe oder Gemeinschaft aber kann für die Interviewten zum Ausgangspunkt einer Diskussion über die moralischen Fundamente der Gesellschaft werden, weil sie sich in vielen Bereichen nicht diesem Diktat ökonomischer Effizienz unterwerfen möchte. Es ist eine moderne Version einer Daviderzählung, bei welcher den Protestzusammenschlüssen als lokalen Gemeinschaften zusätzlich der Wert einer Kampfgemeinschaft gegen einen übermächtigen Feind zugeschrieben 
wird. Und ähnlich der alttestamentarischen Geschichte vom mutigen David, zum König des Volkes Israel gekrönt, werden darin auch die Protestierenden selbst zum Ausgangspunkt einer nationalen oder gar globalen Kulturveränderung, die sie sich von ihrem Handeln erhoffen. Diese Überhöhung eines konkreten, lokalen Anlasses mag allerdings an vielen Stellen auch ein verständlicher strategischer Kniff sein, um die eigenen Interessen in einen größeren, leichter als Allgemeinwohl zu verpackenden Zusammenhang zu stellen.

Dass den Protestierenden Effizienz als Kriterium für gesellschaftliche Entscheidungsfindung aber durchaus am Herzen liegt, findet sich in den Gesprächspassagen wieder, in denen sie sich aus ihrer persönlichen und professionellen Biographie heraus als überlegene Gegenexperten zur schwerfälligen repräsentativen Parteiendemokratie darstellen und für sich einen besseren Überblick über das Gemeinwohl reklamieren. Die Qualität und Geschwindigkeit demokratischer Entscheidungen zu verbessern, indem die Politik auf ihren Protest und ihr Fachwissen eingeht - das erscheint ihnen logisch und wünschenswert auch aus gesamtgesellschaftlicher Perspektive. Die Widersprüchlichkeiten, welche in ihrer Verwendung von „Effizienz“ durchscheinen, werden in ähnlicher Form allerdings auch in anderen Bereichen ihres Demokratieverständnisses sichtbar.

Gleichheit etwa erscheint in den Interviews als positiver wie negativer Bezugspunkt für eine Demokratie. Auf der einen Seite liegt die Forderung nach Gleichheit im Herzen des Anspruchs von Protestgruppen, gehört zu werden. Auf der anderen Seite zählt die Übertreibung von Gleichheitsrealisierungen, die „Gleichmacherei“, zu den weithin geteilten Vorwürfen, welche der Regelungshybris von Staat, Verwaltung oder Parteien gemacht werden. Gleichheit ist den Protestierenden einerseits Kernelement ihrer eigenen Rolle als „Gleiche“ unter Bürgern einer Demokratie, andererseits Zeichen für die Perversion der Parteiendemokratie. Der Begriff „Minderheit“" wird ebenso widersprüchlich verwandt. Während Protestierende sich selbst als eine zu Unrecht überhörte Minderheit betrachten, deren Belange die Politik im Interesse der Allgemeinheit zu beachten habe, gelten in den Interviews „Minderheiten“ - verstanden als kleine, nichtmajoritäre Gruppen in der Gesellschaft - als eine durchaus problematische Einflussgröße in einer Demokratie, da ihnen oft ein rücksichtsloses Streben nach einem Partikularwohl nachgesagt wird, von dem sich die Protestgruppen gerade abgrenzen wollen. Ganz ähnlich die Konnotationen von Pluralität und Vielfalt: Unterschieden wird implizit zwischen einer guten, verträglichen oder produktiven und einer negativen Vielfalt, welche destruktiv und verwirrend wirke. Erstere wird durch die Protestgruppen innerhalb ihrer lokalen Gemeinschaften aus Nachbarschaft, Ort, Stadt oder Viertel symbolisiert: vergleichsweise homogene 
Protestgruppen, vor allem gefühlt „Gleiche“, bei denen es eine für selbstverständlich erachtete gemeinsame Menge an Überzeugungen und Werten gibt, und welche die bestehenden Unterschiede in den persönlichen Fähigkeiten komplementär nutzen können. Die zerstörerische Vielfalt wiederum bezieht sich oftmals auf den großen Maßstab, eine zu heterogen und komplex gewordene Gesellschaft als Ganzes. Eine starke Heterogenität verlangsame Entscheidungsfindungen und verstelle die Herausbildung einer gemeinsamen Identität. Sinnvolle, angemessene und damit effiziente Lösungen innerhalb einer Demokratie würden verhindert. Viele der Protestierenden aus den Interviewgesprächen unterscheiden auf diese Weise „die Bürger“, denen sie eine Definitionsmacht des Allgemeinwohls zugestehen, von Gruppen und Institutionen, denen diese Einflussmöglichkeit aberkannt wird.

Als Verteidiger einer wahren, ,richtigen“ Demokratie, welche sie als abstraktes Prinzip beinahe ohne Abstriche loben und anerkennen, betrachten sich alle. Eine ideale Demokratie funktioniert für die Protestgruppen wie eine Protestgruppe, welche Gleichgesinnte zusammenbringt und ihnen erleichtert, den gemeinsamen Nenner nicht aus den Augen zu verlieren. Ihre Rolle als Protestinitiative innerhalb der bestehenden Demokratie stellen sich die Befragten dabei als umfassende Korrekturinstanz vor, bei der sich Politik und Verwaltung rückversichern und rechtfertigen müssen. Auch weil sie diese Forderung mit ihrer eigenen Biographie und den in ihren Gruppen versammelten Fähigkeiten und Erfahrungen begründen, sind ihnen umfassende direktdemokratische Verfahren suspekt und unsicher. Das Argument einer grundsätzlichen, gleichberechtigten Direktbeteiligung aller Bürger jedenfalls gerät in den Interviews - wenn überhaupt rasch zu einem nur oberflächlich kaschierten Strategieelement.

Bei der Kritik an politischen Parteien, deren Gliederung in feste Strukturen, Hierarchien und Mechanismen der Balance und Kompromissfindung viele vehement ablehnen, ist das Maß durchaus unterschiedlich. Gerade der Gedanke, sich als Mitglied in ein programmatisches Korsett zu begeben, das man in Gänze mitzutragen hat, allerdings - ganz entscheidend - nur in kleinen Teilen selbst beeinflussen kann, stößt viele ab. Die eigene Individualität und biographische Komplexität, so der Vorbehalt, verträgt sich nicht mit einer programmatisch einengenden Parteimitgliedschaft. Eine Unterscheidung zwischen den großen Volksparteien und kleineren, inhaltlich vermeintlich homogeneren Parteien wird dabei kaum getroffen. Oft geben sich die Protestierenden allerdings selbst im Verhalten den Parteien gar nicht so unähnlich: Wer länger dabei ist, wer mehr investiert, hat Vorrecht und einen Anspruch auf Führung innerhalb der Gruppen - Zeitaufwand speist Wirkungserwartung, Protesterfahrung wird zu einer Art Währung. Genau diese Senioritätsanrechte aber gelten ihnen bei politischen Par- 
teien als Ausgeburt an Verkommenheit und Krisenmerkmal. Interessant ist, dass ausgerechnet aus den Gruppen, welche das Organisationsprinzip einer politischen Partei am lautesten verachten - die Euro-Gegner -, in den Jahren seit 2012 mit der Alternative für Deutschland eine politische Partei entstanden ist. Gefühlte Resonanz auf das eigene Anliegen und die gestiegenen Möglichkeiten als Diskurskoalition - als Gruppe, welche sich als Partei der Ökonomieprofessoren wissenschaftlich veredelten Expertenstatus gab ${ }^{3}$ - Öffentlichkeit und Zuspruch herzustellen, mögen hier beigetragen haben, als Parteiformat den Weg in die Parlamente zu suchen. Die Frage ist aber, ob an dieser Stelle hinter der zur Schau getragenen Parteienkritik am Ende nicht lediglich eine Enttäuschung darüber steckt, persönlich mit den eigenen Wünschen und Anliegen in den etablierten Parteien nicht durchzudringen und in der Folge Parteien insgesamt zu verdammen.

Zudem erwarten Protestierende eine Entwicklung, für die an vielen Stellen der Politik- und Sozialwissenschaften stets eine Art Trade-Off angenommen worden ist: Steigt die Beteiligung, steige auch die Effektivität von Entscheidungen bzw. deren Qualität. Gerade durch ihre persönliche Einbindung erwarten sie einen positiven Effekt, da sie erheblich mehr an Knowhow und Sachverstand in die Politik brächten - auch mit dem Aspekt, dass die Teilhabe von besser Gebildeten die Qualität demokratischer Entscheidungen erhöhe. ${ }^{4}$

Es ist darüber hinaus bemerkenswert, dass die Befragten in den Gesprächen oftmals kein formalisiertes Verfahren anerkennen, welches eine politische Führung oder Lösungskompetenz entstehen lasse. Legitimität lasse sich immer nur qualitativ aus dem jeweiligen Ergebnis herleiten. Wenn Legitimität aber stets nachholend verstanden wird als eine Ergebnislegitimität von Entscheidungen, so ist dies für demokratische Verfahren mit enormen Einschränkungen verbunden, weil es die Offenheit von Verhandlungsverfahren von vornherein beschneidet. Auch ist die Tatsache, dass im Sinne von Beteiligungsausweitungen Vermittlungs- und Aushandlungsverfahren zwar gesteigert gefordert, aber gleichzeitig vielerorts als Verrat an sachlichen Konstellationslogiken empfunden werden, eine große Hürde für die Organisation gesellschaftlicher Konsensfindung. Die Forderungen nach persönlicher, außerpolitischer Autorität von Entscheidern und nach einer besseren Übersichtlichkeit unterstreichen dieses Unbehagen. Es gibt allerdings auch eine sehr selbstbewusst vorgetragene Haltung der Protestierenden, welche auf eine Veränderung der Ansprüche und Konsensfähigkeiten hin-

3 Vgl. Bebnowski / Förster: Wettbewerbspopulismus.

4 Zu dieser Frage vgl. Greven: Fortschritt der Demokratie?, S. 22; vgl. auch Abromeit, Heidrun: Wozu braucht man Demokratie? Die postnationale Herausforderung der Demokratietheorie, Opladen 2002, S. $103 \mathrm{ff}$. 
deutet. Wenn also ein Ergebnis der Betrachtungen zu den Demokratievorstellungen ist, dass in der Hauptsache die selbst definierten Ideen als Äquivalent für ein Allgemeinwohl verstanden werden wollen, dann drängt sich der Eindruck auf, dass sich die normativen Erwartungen der im Protest engagierten Bürger von den gedanklichen Fundamenten und Voraussetzungen einer repräsentativen Parteiendemokratie wegentwickeln. Gerade vor dem Hintergrund einer zunehmenden sozialen Verengung in den Initiativen und Protestgruppen- was durch die in dieser Studie gesammelten Eindrücke und Sozialprofile bestätigt wird - ist die Forderung nach individueller Definitionsmacht für das Allgemeinwohl aus demokratischer Perspektive hochproblematisch. Wenn nur diejenigen als Kontrollinstanz für ein Gemeinwohl wirken können, welche ganz individuell die Ressourcen, Fähigkeiten und das Selbstbewusstsein dazu haben, würde eine Exklusion ganzer sozialer Gruppen, die durch den weniger aufwändigen Partizipationskanal von Wahlen oder Repräsentativorganen bislang noch Eingang in die politischen Entscheidungsstrukturen finden, womöglich noch weiter fortschreiten.

Dass eine Demokratie immer auch Aushandlungsergebnis einer Gesellschaft zu sein hat, stand ebenso zu Beginn dieser Studie. Nicht also eine dogmatische Verteidigung eines Status Quo kann aus dieser Perspektive sinnvoll sein, sondern ein offenes und neugieriges Fragen nach möglicherweise zeitgemäßen Formen, aber auch nach Überkommenem, nach besseren prozessualen Abbildungen gesellschaftlicher Entwicklungen. In der deutschen Demokratiegeschichte gab es immer wieder Phasen gesellschaftlicher Entwicklungsschübe und eines sich verändernden gesellschaftlichen Selbstbewusstseins am Beginn von Wandlungen von Demokratie und ihrer Repräsentativorgane. Golo Mann und Thomas Nipperdey etwa beschreiben die Gründungsphase der ersten Parteien im deutschsprachigen Raum des 19. Jahrhunderts als eine Konstellation, in der man die Bürgerproteste heutzutage auch wiederfinden könnte: geboren aus einer Gruppe von Bürgern, die über ökonomische und (vor allem) bildungsgetriebene Entwicklungen ein Selbstbewusstsein entwickelten, dem ihre praktische Einbindung in öffentliche Entscheidungsstrukturen nicht nachkam. Die historischen Entwicklungsverläufe von Demokratie spiegeln die jeweils zeitabhängige Umsetzung von Einbindungsvorstellungen wider: „die große politische Tatsache zunächst die, dass die vorindustriellen Mächte dem Bürgertum die Rolle im Staatsleben nicht gönnen wollten, welche seinem wachsenden Reichtum entsprach. ${ }^{* 5}$ Thomas Nipperdey vermutet ähnliche Triebkräfte für die Transformation von Parteien und ihren Funktionsmechanismen im weiter fortschreitenden 19. Jahrhundert: „Die gesellschaftlichen Umschichtungen veränderten die herkömmliche

5 Mann: Deutsche Geschichte, S. 273. 
Sozialstruktur immer stärker [...]. Die neu entstehenden oder sich ausbreitenden Schichten strebten nach Emanzipation, das führte unter dem allgemeinen Wahlrecht zu einer steigenden Durchpolitisierung der Bürgerschaft [...]. Die Parteien waren in ihrem inneren Aufbau noch an der Gliederung einer vergehenden Gesellschaftsordnung orientiert. [...] Der herkömmliche Partei- und Wahlbetrieb genügte nicht mehr, dem wachsenden politischen Bewußtsein der Wähler mußten moderne Methoden der Massenwerbung entsprechen. [...] mit der Aktivierung des politischen Bewusstseins endlich wuchs das Bestreben der organisierten Anhänger, bei den Parteientscheidungen mitzusprechen und mitzubestimmen. Die örtlichen Führer brauchten mehr als anfänglich die formelle und reale Anerkennung durch die Anhänger, die Zentralen mußten die Tendenz zur Mitbestimmung irgendwie in Ausschüssen oder Parteitagen auffangen, um sie entweder zu realisieren oder zu neutralisieren. Der Zug zur Demokratisierung war auch innerhalb der Parteiorganisationen wirksam in dem Maße, in dem die politische Mündigkeit zunahm. Dieses Verlangen nach Mitwirkung bei Führung und Entscheidungen der Partei konnte sich auf breite Anhängerschichten erstrecken, im Allgemeinen betraf es die weitere Führungsschicht. Noch in deren ganz unreflektierten und widersprüchlichen Willen zur Mitbestimmung zeigte sich der gesellschaftliche und bewußtseinsmäßige Wandel der Zeit an. “6

Viele dieser Beobachtungen lassen sich verblüffend ähnlich bei den Aktiven der Bürgerproteste machen - und in deren Kritik an die Adresse von Repräsentation und politische Parteien kann man verwandt klingende Melodien entdecken. Es liegt auf der Hand, dass eine längerfristige Entwicklung von Depots gesellschaftlichen Selbstbewusstseins, die Stabilisierung und Verinnerlichung von Partizipationsrhetorik und Protesterfahrungen, gepaart mit den steigenden Niveaus an Bildung und professionellen Erfahrungen, zu einer immer geringeren Akzeptanzfähigkeit des politischen Prinzips der Repräsentation gerade bei denjenigen Gruppen in der Gesellschaft geführt haben, welche sich selbst als autark, angesehen und stark empfinden.

Vor allem die etablierten, großen und volksparteilich-integrativ wirkenden politischen Parteien haben in den vergangenen Jahren in Deutschland und Europa den Vertrauensverlust der Wähler- und Mitgliedschaften mitunter drastisch zu spüren bekommen. ${ }^{7}$ Und auch ihre Reaktionen darauf verlaufen durchaus paral-

6 Nipperdey, Thomas: Die Organisation der bürgerlichen Parteien in Deutschland, in: Ritter, Gerhard A. (Hrsg.): Die Deutschen Parteien vor 1918, Köln 1973, S. $100-119$, hier S. $101-103$.

7 Vgl. Walter, Franz: Im Herbst der Volksparteien? Eine kleine Geschichte von Aufstieg und Rückgang politischer Massenintegration, Bielefeld 2009, S. 9 - 14; Wiesendahl, Elmar: Volksparteien: Aufstieg, Krise, Zukunft, Opladen 2011, S. 133 - 149. 
lel. Seit den 1990er Jahren gibt es in der Diskussion möglicher Reformvorhaben eine Tendenz, die sich samt und sonders auf die Formel „mehr Offenheit, mehr Transparenz" eindampfen lässt. ${ }^{8}$ Mehr direkte Abstimmungsmöglichkeiten für Parteimitglieder oder gar Sympathisanten, mehr Mitwirkungsmöglichkeiten, mehr Offenheit gegenüber politischen Seiteneinsteigern - so oder so ähnlich war die politische Agenda der innerparteilichen Reformdiskussionen in den meisten Parteien seit etwa der Mitte der 1990er Jahre angelegt. Jeder Parteivorsitzende gab sich offen, veranstaltete Reformkonferenzen, versprach, die Parteiarbeit moderner, transparenter und durchlässiger zu machen. Auf die mitunter vernichtende Kritik der Bürgerproteste hingegen können diese Reformforen und Bürgerdialoge kaum eine erfolgversprechende Antwort sein. Denn sie verändern die Logik innerparteilicher Konsensfindung nicht: Am Ende sind es eine Balance und ein Austarieren der verschiedenen Interessengruppen und Heterogenitäten, die sich bereits unter einem politischen Dach zusammen finden, welche den zusammen schweißenden Erfolg von Parteiarbeit ausmachen. Auch die Parteireformen der vergangenen zwei Jahrzehnte haben an dieser Formel nichts verändert. Genau diese Konsens- und Kompromissorientierung allerdings ist es, welche den Bürgerprotesten als Zeichen der Verknöcherung von Parteien gilt. Konsensfindung als Kernelement politischer Parteien ist in den Augen vieler Bürgerprotestierender der Grund, warum keine sachadäquaten Lösungen in der Politik mehr zustande kommen. Gegenüber den direkten, individuell grundierten Wirkungserwartungen und den konstatierten nachholenden Legitimitätsvorstellungen unter den Aktiven der Proteste sind Parteireformen hilflose Antworten, die kaum in der Lage sind, Überzeugung und Attraktivität zu entfalten. In gewisser Weise sind die Protestgruppen damit Kinder ihrer Zeit: Ihre Staats- und Parteienkritik sowie ihr Wunsch nach vermeintlich sachlich zwingenden Lösungswegen machen deutlich, wie sehr Viele neoliberale Gesellschaftsvorstellungen und die

8 Vgl. zusammen fassend Neumann, Arijana: Das „Jahrzehnt der Parteireform“ - Ein Überblick über die Entwicklungen, in: Alemann, Ulrich von / Martin Morlok / Tim Spier (Hrsg.): Parteien ohne Mitglieder?, Baden-Baden 2013, S. 239 - 245; für die sozialdemokratischen Entwicklungen Butzlaff, Felix / Matthias Micus / Franz Walter: Im Spätsommer der Sozialdemokratie?, in: Dies. (Hrsg.): Genossen in der Krise? Europas Sozialdemokratie auf dem Prüfstand, Göttingen 2011, S. 271 - 299, hier S. 280 - 287; Butzlaff, Felix: Die SPD: Sturm der Reform, in: Kallinich, Daniela / Frauke Schulz (Hrsg.): Halbzeitbilanz. Parteien, Politik und Zeitgeist in der schwarzgelben Koalition 2009 - 2011, Stuttgart 2011, S. 263 - 282; für die deutsche Christdemokratie vgl. Walter, Franz / Christian Werwath / Oliver D‘Antonio: Die CDU. Entstehung und Verfall christdemokratischer Geschlossenheit, Baden-Baden 2011, S. $73-158$. 
Rolle des Einzelnen darin verinnerlicht haben. Auf der anderen Seite zeugen die geäußerten Hoffnungen auf die Etablierung einer Gegenmacht-Position gegenüber rein ökonomisch argumentierenden Logiken davon, dass sie sich durchaus genau davon lösen möchten.

$\mathrm{Ob}$ wir es bei den betrachteten Bürgerprotesten mit sozialen Bewegungen zu tun haben, welche eine „Totalität gesellschaftlicher Verhältnisse “9 in den Fokus nehmen, wie es in der bereits zitierten Definition heißt, muss an vielen Stellen in Frage gestellt werden. Fast alle Gruppen beanspruchen dies - natürlich - für sich. Das Fazit einer Individualisierung von Gemeinwohldefinitionen aber kann bisweilen nur schwer in Übereinstimmung gebracht werden mit der Idee einer in einer gemeinsamen Weltanschauung wurzelnden Gesellschaftsutopie.

Das Problematische liegt darüber hinaus in der Desillusionierung gegenüber den bestehenden Institutionen: Ihr Protest ermöglicht es den Befragten, Vertrauen und Emotionen zu erleben, die sie bei Parteien und den etablierten Institutionen nicht mehr zu erlangen glauben - auch, weil innerhalb ihrer Bündnisse und Gruppen vermeintlich nicht mehr so viel Kraft für die Etablierung eines verbindlichen Konsens aufgebracht werden muss. Man fühlt sich unter verlässlich Gleichgesinnten. Wenn diese gefühlte Homogenität aber zum verbindenden Moment der Gruppen würde, welche sich besser und direkter Zugriff auf die politischen Regelungsinstanzen sichern können, droht eine Entsolidarisierung der Demokratie mit all jenen, denen der Zugang in die Selbstorganisation von Einfluss nicht im gleichen Maße gegeben ist.

Die Suche nach neuen Formen gesellschaftlicher Entscheidungsfindung wird wohl noch weitergehen müssen.

9 Ohme-Reinicke: Moderne Maschinenstürmer, S. 38. 



\section{Abbildungsverzeichnis}

Abbildung 1: Altersstruktur der Gesprächspartner | 94

Abbildung 2: Geburtsjahrgänge und politische Prägezeiträume der Gesprächspartner $\mid 98$

Abbildung 3: Geschlechterverteilung der Gesprächspartner | 99

Abbildung 4: Religionszugehörigkeit der Gesprächspartner | 99

Abbildung 5: Bildungsniveau der Gesprächspartner | 100

Abbildung 6: Kinder in den Haushalten der Gesprächspartner | 101

Abbildung 7: Netto-Haushaltseinkommen der Gesprächspartner | 102 



\section{Literaturverzeichnis}

Abromeit, Heidrun: Wozu braucht man Demokratie? Die postnationale Herausforderung der Demokratietheorie, Opladen 2002.

Agamben, Giorgio / Alain Badiou / Daniel Bensaid / Wendy Brown / Jean-Luc Nancy / Jacques Rancière / Kristin Ross / Slavoj Zizek: Democracy - in what state?, New York 2011.

Andersson, Nels: The Hobo: The sociology of the homeless man, Chicago 1961. Arendt, Hannah: What is Authority?, in: Dies.: Between Past and Future, New York 2006, S. $91-141$.

Atteslander, Peter: Methoden der empirischen Sozialforschung, Berlin 2006.

Aufenanger, Stefan: Qualitative Analyse semi-struktureller Interviews - ein Werkstattbericht, in: Garz, Detlef / Klaus Kraimer (Hrsg.): Qualitativempirische Sozialforschung. Konzepte, Methoden, Analysen, Opladen 2000, S. $35-59$.

Auster, Paul: Sunset Park, Reinbek bei Hamburg 2012.

Barber, Benjamin R.: If mayors ruled the world. Dysfunctional nations, rising cities, Yale / Croydon 2013.

Baumgarten, Britta / Dieter Rucht: Die Protestierenden gegen „Stuttgart 21“ einzigartig oder typisch?, in: Brettschneider, Frank / Wolfgang Schuster (Hrsg.): Stuttgart 21 - Ein Großprojekt zischen Protest und Akzeptanz, Wiesbaden 2013, S. 97 - 125.

Bebnowski, David / Jöran Klatt / Philipp Kufferath / Robert Lorenz / Michael Lühmann: Selbstverständnis. Zur Einordnung - historisch-m(eth)odische Reflexionen, in: Hensel, Alexander / Daniela Kallinich / Katharina Rahlf (Hrsg.): Parteien, Demokratie und gesellschaftliche Kritik. Jahrbuch des Göttinger Instituts für Demokratieforschung 2010, Stuttgart 2011, S. 11 - 38.

Bebnowski, David: Generation und Geltung. Von den „45ern“ zur „Generation Praktikum“ - übersehene und etablierte Generationen im Vergleich. Studien des Göttinger Instituts für Demokratieforschung, Band 4, Bielefeld 2012. 
Beetham, David: The Legitimation of Power, Basingstoke 1991.

Benighaus, Christina / Ludger Benighaus: Moderation, Gesprächsaufbau und Dynamik in Fokusgruppen, in: Schulz, Marlen / Birgit Mack / Ortwin Renn (Hrsg.): Fokusgruppen in der empirischen Sozialwissenschaft. Von der Konzeption bis zur Auswertung, Wiesbaden 2012, S. 111 - 132.

Berking, Helmuth / Jochen Schwenk: Hafenstädte. Bremerhaven und Rostock im Wandel, Frankfurt a.M./New York 2011.

Berking, Helmuth: Städte lassen sich an ihrem Gang erkennen wie Menschen Skizzen zur Erforschung der Stadt und der Städte, in: Berking, Helmuth / Martina Löw (Hrsg.): Die Eigenlogik der Städte. Neue Wege für die Stadtforschung, Frankfurt a.M./New York 2008, S. 15 - 31.

Berman, Sheri: Civil Society and the Collapse of the Weimar Republic, in: World Politics, Jg. 49 (1997) H. 3, S. $401-429$.

Birke, Peter: Herrscht hier Banko? Die aktuellen Proteste gegen das Unternehmen Hamburg, in: Birke, Peter / Max Henninger (Hrsg.): Krisen Proteste. Beiträge aus Sozial.Geschichte Online, Berlin 2012, S. 183 - 220.

Blank, Renate: Gruppendiskussionsverfahren, in: Naderer, Gabriele / Eva Balzer (Hrsg.): Qualitative Marktforschung in Theorie und Praxis. Grundlagen, Methoden und Anwendungen, Wiesbaden 2011, S. 289 - 312.

Blee, Kathleen M.: Democracy in the Making. How Activist Groups Form, New York 2012.

Blühdorn, Ingolfur: Simulative Demokratie: Neue Politik nach der postdemokratischen Wende, Berlin 2013.

Böhnke, Petra: Ungleiche Verteilung politischer und zivilgesellschaftlicher Partizipation, in: Apuz, Jg. 61 (2011) H. 1 - 2, S. 18 - 25.

Bohnsack, Ralf: Gruppendiskussionsverfahren und Milieuforschung, in: Friebertshäuser, Barbara / Annedore Prengel (Hrsg.): Handbuch qualitative Forschungsmethoden in der Erziehungswissenschaft, Weinheim 1997, S. $492-$ 502.

Bohnsack, Ralf / Aglaja Przyborski: Diskursorganisation, Gesprächsanalyse und die Methode der Gruppendiskussion, in: Bohnsack, Ralf / Aglaja Przyborski / Burkhard Schäffer (Hrsg.): Das Gruppendiskussionsverfahren in der Forschungspraxis, Opladen \& Farmington Hills 2010, S. 235 - 248.

Böllmann, Ulrich: Auswirkungen des Reaktorunfalls in Tschernobyl auf Bayern, München 1988.

Braun, Sebastian: Bürgerschaftliches Engagement - Konjunktur und Ambivalenz einer gesellschaftspolitischen Debatte, in: Leviathan Jg. 29 (2001) H. 1, S. $83-109$. 
Bremer, Helmut: Von der Gruppendiskussion zur Gruppenwerkstatt. Ein Beitrag zur Methodenentwicklung in der typenbildenden Mentalitäts-, Habitus- und Milieuanalyse, Münster 2004.

Brettschneider, Frank / Wolfgang Schuster (Hrsg.): Stuttgart 21. Ein Großprojekt zwischen Protest und Akzeptanz, Wiesbaden 2013.

Brüsemeister, Thomas: Qualitative Forschung. Ein Überblick, Wiesbaden 2000.

Bude, Heinz: Der Sozialforscher als Narrationsanimateur. Kritische Anmerkungen zu einer erzähltheoretischen Fundierung der interpretativen Sozialforschung, in: Kölner Zeitschrift für Soziologie und Sozialpsychologie, Jg. 37 (1985) H. 2, S. $327-336$.

Bundesministerium für Familie, Senioren, Frauen und Jugend (Hrsg.): Hauptbericht des Freiwilligensurveys 2009. Zivilgesellschaft, soziales Kapital und freiwilliges Engagement in Deutschland 1999 - 2004 - 2009, München 2010.

Bundesministerium für Familie, Senioren, Frauen und Jugend (Hrsg.): Fünfter Bericht zur Lage der älteren Generation in der Bundesrepublik Deutschland. Potenziale des Alters in Wirtschaft und Gesellschaft. Der Beitrag älterer Menschen zum Zusammenhalt der Generationen. Bericht der Sachverständigenkommission, Berlin 2005.

Bussemer, Thymian: Die erregte Republik. Wutbürger und die Macht der Medien, Stuttgart 2011.

Butzlaff, Felix / Christoph Hoeft / Julia Kopp: „Wir lassen nicht mehr alles mit uns machen!“ Bürgerproteste an und um den öffentlichen Raum, Infrastruktur und Stadtentwicklung, in: Marg, Stine / Lars Geiges / Felix Butzlaff / Franz Walter (Hrsg.): Die neue Macht der Bürger. Was motiviert die neuen Protestbewegungen?, Reinbek bei Hamburg 2013, S. 48 - 93.

Butzlaff, Felix: Die SPD: Sturm der Reform, in: Kallinich, Daniela / Frauke Schulz (Hrsg.): Halbzeitbilanz. Parteien, Politik und Zeitgeist in der schwarz-gelben Koalition 2009 - 2011, Stuttgart 2011, S. 263 - 282.

Butzlaff, Felix / Matthias Micus / Franz Walter: Im Spätsommer der Sozialdemokratie?, in: Dies. (Hrsg.): Genossen in der Krise? Europas Sozialdemokratie auf dem Prüfstand, Göttingen 2011, S. 271 - 299.

Chambers, Simone / Jeffrey Kopstein: Bad Civil Society, in: Political Theory, Jg. 29 (2001) H. 6, S. 837 - 865.

Chartier, Roger: Die unvollendete Vergangenheit, Frankfurt a.M., 1992.

Chirbes, Rafael: Am Ufer, München 2014.

Christmann, Gabriela: Robert E. Park, Konstanz 2007. 
Clemens, Wolfgang: Zwischen „Jungem Alter“ und dem Ende des Lebens Neuere alter(n)ssoziologische und gerontologische Beiträge, in: Soziologische Revue, Jg. 35 (2012) H. 4, S. 437 - 445.

Cressey, Paul G.: The Taxi-Dance Hall: A sociological study in commercialized recreation and city life, Chicago 1932.

Crouch, Colin: Postdemokratie, Bonn 2008.

Dahl, Robert A.: A Democratic Dilemma: System Effectiveness versus Citizen Participation, in: Political Science Quarterly, Jg. 109 (1994) H. 1, S. 23 - 34.

Decker, Frank: Parteiendemokratie im Wandel, in: Decker, Frank / Viola Neu (Hrsg.): Handbuch der deutschen Parteien, Wiesbaden 2007, S. 19 - 61.

Della Porta, Donatella / Hanspeter Kriesi: Social Movements in a Globalizing World: an Introduction, in: Dies. / Dieter Rucht (Hrsg.): Social Movements in a Globalizing World, New York 1999, S. 3 - 21.

Della Porta, Donatella: Multiple Belongings, Flexible Identities and the Construction of "Another Politics": Between the European Social Forum and the Local Social Fora, in: Dies. / Sidney Tarrow (Hrsg.): Transnational Protest and Global Activism, New York 2005, S. 227 - 259.

Diekmann, Andreas: Empirische Sozialforschung. Grundlagen, Methoden, Anwendung, Reinbek bei Hamburg 2010.

Dose, Nicolai / Anne-Kathrin Fischer: Mitgliederschwund und Überalterung der Parteien: Prognose der Mitgliederzahlen bis 2040, in: Zeitschrift für Parlamentsfragen, Jg. 44 (2013) H. 4, S. 892 - 900.

Dür, Andreas: Rational Choice: Ein kritisches Plädoyer für Theorien der rationalen Entscheidung, in: Österreichische Zeitschrift für Politikwissenschaft, Jg. 41 (2012) H. 1, S. $73-83$.

Durnová, Anna: Über die Rationalität hinaus: für eine interpretative und reflexive Wissenschaft. Reaktion auf Andreas Dür, in: Österreichische Zeitschrift für Politikwissenschaft, Jg. 41 (2012) H. 3, S. 315 - 322.

Dürrenberger, Gregor / Jeanette Behringer: Die Fokusgruppe in Theorie und Anwendung, Stuttgart 1999.

Eckardt, Frank: Viele Wege nach Rom, oder: Was leistet die Stadtsoziologie heute?, in: Soziologische Revue, Jg. 36 (2013) H. 2, S. 132 - 142.

Edwards, Bob / Michael W. Foley: Civil Society and Social Capital: A Primer, in: Dies. / Mario Diani (Hrsg.): Beyond Tocqueville. Civil Society and the Social Capital Debate in Comparative Perspective, Medford 2001, S. 1 - 14.

Erlinghagen, Marcel: Volunteering after Retirement. Evidence from German Panel Data. In: European Societies, Jg. 12 (2010) H 5, S. 603 - 625.

Ernst, Frank: Freiwilliges Engagement als Gegenstand von Gruppendiskussionen, in: Bohnsack, Ralf / Aglaja Przyborski / Burkhard Schäffer (Hrsg.): Das 
Gruppendiskussionsverfahren in der Forschungspraxis, Opladen \& Farmington Hills 2010, S. 169 - 187.

Fenno, Richard: Observation, Context and Sequence in the Study of Politics, in: American Political Science Review, Jg. 80 (1986) H. 1, S. 3 - 15.

Flick, Uwe: Triangulation, in: Bohnsack, Ralf / Winfried Marotzki / Michael Meuser (Hrsg.): Hauptbegriffe Qualitativer Sozialforschung, Opladen 2006, S. $161-162$.

Fokken, Ulrike: Die rote Insel, in: die tageszeitung, 16./17.02.2013.

Foucault, Michel: Die Ordnung des Diskurses, Frankfurt a.M. 2003.

Frank, Sybille / Jochen Schwenk / Silke Steets / Gunter Weidhaus: Der aktuelle Perspektivenstreit in der Stadtsoziologie, in: Leviathan, Jg. 41 (2013) H. 2, S. $197-223$.

Gasser, Karin: Stadt und Delinquenz. Theoretische und empirische Beiträge der frühen Chicago School of Sociology, in: Soz:Mag. Das Soziologie Magazin, Jg. 1 (2002) H. 2, S. 37 - 40, hier S. 37.

Geiges, Lars / Stine Marg / Franz Walter: Pegida. Die schmutzige Seite der Zivilgesellschaft?, Bielefeld 2015.

Geiges, Lars: Occupy in Deutschland. Die Protestbewegung und ihre Akteure, Bielefeld 2014.

Giddens, Anthony: Konsequenzen der Moderne, Frankfurt a.M. 1995.

Girtler, Roland: Methoden der qualitativen Sozialforschung: Anleitung zur Feldarbeit, Wien 1984.

Goetz, Rainald: Johann Holtrop. Abriss der Gesellschaft, Berlin 2012.

Grau, Alexander: Mehr als nur Pils, in: Frankfurter Allgemeine Sonntagszeitung, 30.11.2014.

Greenbaum, Thomas L.: Moderating Focus Groups. A Practical Guide for Group Facilitation, Thousand Oaks 2000.

Greven, Michael Th.: Fortschritt der Demokratie?, in: Vorgänge, Jg. 50 (2011) H. 3, S. $17-29$.

Haas, Peter M.: Introduction: Epistemic Communities and international policy coordination, in: International Organization, Jg. 46 (1992) H. 1, S. 1 - 35.

Habermas, Jürgen: Zur Verfassung Europas, Frankfurt a.M. 2011.

Hahn, Anna Katharina: Am schwarzen Berg, Berlin 2012.

Händler, Ernst-Wilhelm: Versuch über den Roman als Erkenntnisinstrument, Frankfurt a.M. 2014.

Hans, Michael: Kommunitarismus. Einführung und Analyse, Wiesbaden 2003. Hardt, Michael / Antonio Negri: Common Wealth: Das Ende des Eigentums, Frankfurt a.M. 2010.

Harris, Robert: Angst, München 2011. 
Harvey, David: Rebellische Städte. Vom Recht auf Stadt zur urbanen Revolution, Berlin 2013.

Haunss, Sebastian / Peter Ullrich: Viel Bewegung - wenig Forschung. Zu- und Gegenstand von sozialwissenschaftlicher Protest- und Bewegungsforschung in der Bundesrepublik, in: Soziologie, Jg. 42 (2013) H. 3, S. 290 - 304.

Häuser-Schäublin, Brigitta: Teilnehmende Beobachtung, in: Beer, Bettina (Hrsg.): Methoden und Techniken der Feldforschung, Berlin 2003, S. 33 54.

Heffner, Markus / Erik Raidt: Protest im Hamsterrad, in: Stuttgarter Zeitung, 12.03.2012.

Heinze, Rolf G.: Entgrenzung und Restrukturierung der Schnittstellen zwischen Gesellschaft, Staat und Markt?, in: Pries, Ludger (Hrsg.): Zusammenhalt durch Vielfalt? Bindungskräfte der Vergesellschaftung im 21. Jahrhundert, Wiesbaden 2013, S. 123 - 148.

Helfferich, Cornelia: Die Qualität qualitativer Daten. Manual für die Durchführung qualitativer Interviews, Wiesbaden 2011.

Hellmann, Kai-Uwe: Paradigmen der Bewegungsforschung. Forschungs- und Erklärungsansätze - ein Überblick, in: Ders. / Ruud Koopmans (Hrsg.): Paradigmen der Bewegungsforschung. Entstehung und Entwicklung von Neuen sozialen Bewegungen und Rechtsextremismus, Opladen 1998, S. 9 - 30.

Hennis, Wilhelm: Parteienstruktur und Regierbarkeit, in: Hennis, Wilhelm / Peter Graf Kielmansegg / Ulrich Matz (Hrsg.): Regierbarkeit. Studien zu ihrer Problematisierung, Stuttgart 1977, S. 150 - 195.

Hildebrandt, Cornelia (Hrsg.): Der Herbst der „Wutbürger“. Soziale Proteste in Zeiten der Krise, Berlin 2010.

Hirschman, Albert O.: Engagement und Enttäuschung. Über das Schwanken der Bürger zwischen Privatwohl und Gemeinwohl, Frankfurt a.M. 1988.

Holm, Andrej (Hrsg.): Reclaim Berlin. Soziale Kämpfe in der neoliberalen Stadt, Berlin 2014.

Holm, Andrej / Klaus Lederer / Matthias Naumann (Hrsg): Linke Metropolenkritik. Erfahrungen und Perspektiven am Beispiel Berlin, Münster 2011.

Holm, Andrej: Das Recht auf die Stadt, in: Blätter für deutsche und internationale Politik, Jg. 56 (2011) H. 8, S. 89 - 97.

Hopf, Christel: Forschungsethik und qualitative Forschung, in: Flick, Uwe / Ernst von Kardorff / Ines Steinke (Hrsg.): Qualitative Forschung. Ein Handbuch, Reinbek bei Hamburg 2012, S. 589 - 599.

Hopf, Christel: Qualitative Interviews - ein Überblick, in: Flick, Uwe / Ernst von Kardorff / Ines Steinke (Hrsg.): Qualitative Forschung. Ein Handbuch, Reinbek bei Hamburg 2012, S. 349 - 359. 
Hurrelmann, Klaus: Einführung in die Sozialisationstheorie, Weinheim und Basel 2002.

Hurrelmann, Klaus: Lebensphase Jugend. Eine Einführung in die sozialwissenschaftliche Jugendforschung, Weinheim und München 2005.

Jahoda, Marie / Paul Felix Lazarsfeld / Hans Zeisel: Die Arbeitslosen von Marienthal. Ein soziographischer Versuch über die Wirkung langandauernder Arbeitslosigkeit, Frankfurt a. M. 1996.

John, Timo: Die königlichen Gärten des 19. Jahrhunderts in Stuttgart. Schlossgarten, Rosenstein, Wilhelma, Villa Berg, Worms 2000.

Jonas, Klaus / Philip Brömer: Die sozial-kognitive Theorie von Bandura, in: Frey, Dieter / Martin Irle (Hrsg): Theorien der Sozialpsychologie, Band II, Gruppen-, Interaktions- und Lerntheorien, Bern u.a. 2002, S. 277 - 299.

Jörke, Dirk: Bürgerbeteiligung in der Postdemokratie, in: Apuz, Jg. 61 (2011) H. $1-2$, S. $13-18$.

Jureit, Ulrike: Generationenforschung, Göttingen 2006.

Kaase, Max: Partizipatorische Revolution - Ende der Parteien?, in: Raschke, Joachim (Hrsg.): Bürger und Parteien. Ansichten und Analysen einer schwierigen Beziehung, Opladen 1982, S. 173 - 189.

Kaes, Anton: New Historicism: Literaturgeschichte im Zeichen der Postmoderne?, in: Baßler, Moritz (Hrsg.): New Historicism. Literaturgeschichte als Poetik der Kultur, Tübingen 2001, S. $251-267$.

Kaufmann, Franz-Xaver: Schrumpfende Gesellschaft. Vom Bevölkerungsrückgang und seinen Folgen, Frankfurt a.M. 2005.

Kaufmann, Jean-Claude: Das verstehende Interview, Konstanz 1999.

Keidel, Matthias: Die Wiederkehr der Flaneure: literarische Flanerie und flanierendes Denken zwischen Wahrnehmung und Reflexion, Würzburg 2006.

Keller, Reiner: Diskursforschung, Wiesbaden 2004.

Kern, Horst: Empirische Sozialforschung. Ursprünge, Ansätze, Entwicklungslinien, München 1982.

Kersting, Norbert / Wichard Woyke: Vom Musterwähler zum Wutbürger? Politische Beteiligung im Wandel, Münster 2012.

King, Vera: Die Entstehung des Neuen in der Adoleszenz: Individuation, Generativität und Geschlecht in modernisierten Gesellschaften, Wiesbaden 2013.

Klages, Helmut: Individualisierung als Triebkraft bürgerlichen Engagements. Empirische Fakten und Folgerungen, in: Kistler, Ernst / Heinz-Herbert Noll / Eckhard Priller (Hrsg.): Perspektiven gesellschaftlichen Zusammenhalts. Empirische Befunde, Praxiserfahrungen, Messkonzepte, Berlin 2002, S. 101 $-112$. 
Klandermans, Bert / Conny Roggeband (Hrsg.): Handbook of Social Movements across Disciplines, New York 2007.

Klatt, Johanna / Franz Walter / David Bebnowski: Entbehrliche der Bürgergesellschaft? Sozial Benachteiligte und Engagement, Bielefeld 2011.

Klatt, Johanna: Individualisierte Zivilgesellschaft und die Beteiligung sozial Benachteiligter, in: betrifft: Bürgergesellschaft, Jg. 8 (2011) H. 37, S. 1 - 12.

Klatt, Johanna: Partizipation: Ein erstrebenswertes Ziel politischer Bildung?, in: Apuz, Jg. 62 (2012) H. 46 - 47, S. 3 - 9.

Klebert, Karin: Moderations-Methode. Das Standardwerk, Hamburg 2006.

Klecha, Stephan / Stine Marg / Felix Butzlaff: Wie erforscht man Protest? Forschungsdesign und Forschungsmethodik, in: Stine Marg / Lars Geiges / Felix Butzlaff / Franz Walter (Hrsg.): Die neue Macht der Bürger. Was motiviert die neuen Protestbewegungen?, Reinbek bei Hamburg, 2013, S. 14 - 47.

Kleemann, Frank / Uwe Krähnke / Ingo Matuschek: Interpretative Sozialforschung. Eine praxisorientierte Einführung, Wiesbaden 2009.

Kocka, Jürgen: Alternde Gesellschaften oder Die gewonnenen Jahre, in: Neue Gesellschaft / Frankfurter Hefte, Jg. 55 (2008) H. 9, S. 4 - 9.

Köhn, Eckhardt: Straßenrausch. Flanerie und kleine Form. Versuch zur Literaturgeschichte des Flaneurs von 1830 - 1933, Berlin 1989.

Koopmans, Ruud / Dieter Rucht: Protest Event Analysis, in: Klandermans, Bert / Suzanne Staggenborg (Hrsg.): Methods of Social Movement Research, Minneapolis 2007, S. $231-258$.

Köppe, Tilmann / Simone Winko: Neuere Literaturtheorien. Eine Einführung, Stuttgart / Weimar 2013.

Kraushaar, Wolfgang: Protest der Privilegierten?, in: Mittelweg 36, Jg. 20 (2011) H. 3, S. 5 - 22.

Kriesi, Hanspeter / Ruud Koopmans / Jan Willem Duyvendak / Marco G. Giugni (Hrsg.): New Social Movements in Western Europe: A comparative Analysis, London 1995.

Krueger, Richard A.: Focus groups. A practical guide for applied research, Los Angeles 2009.

Krueger, Richard A.: Moderation Focus Groups. The Focus Group Kit, Bd. 4, Thousand Oaks 1998.

Kühn, Thomas / Kay-Volker Koschel: Gruppendiskussionen. Ein PraxisHandbuch, Wiesbaden 2011.

Küsters, Ivonne: Narrative Interviews. Grundlagen und Anwendungen, Wiesbaden 2006.

Laclau, Ernesto / Chantal Mouffe: Hegemonie und radikale Demokratie: Zur Dekonstruktion des Marxismus, Wien 2006. 
Lamnek, Siegfried: Gruppendiskussion. Theorie und Praxis, Weinheim 2005. Lamnek, Siegfried: Qualitative Sozialforschung. Lehrbuch, Weinheim 2005. Lanchester, John: Kapital, Stuttgart 2012.

Lange, Dirk / Holger Onken / Andreas Slopinski: Politisches Interesse und Politische Bildung: Zum Stand des Bürgerbewusstseins Jugendlicher und junger Erwachsener, Wiesbaden 2013.

Laqueur, Walter: Gesichter des Antisemitismus, Berlin 2008.

Laux, Annika: Was wünschen sich die Mitglieder von ihren Parteien?, in: Spier, Tim / Markus Klein / Ulrich von Alemann / Hanna Hoffmann / Annika Laux / Alexandra Nonnenmacher / Katharina Rohrbach (Hrsg.): Parteimitglieder in Deutschland, Wiesbaden 2012, S. 139 - 155.

Laux, Annika: Was motiviert Parteimitglieder zum Beitritt?, in: Spier, Tim / Markus Klein / Ulrich von Alemann / Hanna Hoffmann / Annika Laux / Alexandra Nonnenmacher / Katharina Rohrbach (Hrsg.): Parteimitglieder in Deutschland, Wiesbaden 2012, S. $61-78$.

Leggewie, Claus: Mut statt Wut. Aufbruch in eine neue Demokratie, Hamburg 2011.

Lemke, Harald: Politik des Essens. Wovon die Welt von morgen lebt, Bielefeld 2012.

Lindner, Rolf: Die Entdeckung der Stadtkultur. Soziologie aus der Erfahrung der Reportage, Frankfurt a.M. 2007.

Lindner, Rolf: Texture, imaginaire, Habitus - Schlüsselbegriffe der kulturanalytischen Stadtforschung, in: Berking, Helmuth / Martina Löw (Hrsg.): Die Eigenlogik der Städte. Neue Wege für die Stadtforschung, Frankfurt a.M./New York 2008, S. 83 - 94.

Longo, Davide: Der aufrechte Mann, Reinbek bei Hamburg 2012.

Loos, Peter / Burkhard Schäffer: Das Gruppendiskussionsverfahren. Theoretische Grundlagen und empirische Anwendung, Opladen 2001.

Lorenz, Robert / Matthias Micus: Politische Seiteneinsteiger - Exoten in Parteien, Parlamenten, Ministerien, in: Dies. (Hrsg.): Seiteneinsteiger. Unkonventionelle Politiker-Karrieren in der Parteiendemokratie, Wiesbaden 2009, S. $11-30$.

Lorenz, Robert / Matthias Micus: Von Beruf: Politiker. Bestandsaufnahme eines ungeliebten Stands, Freiburg i. Br. 2013.

MacPherson, Crawford Brough: The Life and Times of Liberal Democracy, Oxford 1977.

Magnusson, Kristof: Das war ich nicht, München 2010. 
Makropoulos, Michael: Über den Begriff der „Krise“. Eine historischsemantische Skizze, in: INDES. Zeitschrift für Politik und Gesellschaft, Jg. 2 (2013) H. 1, S. $13-20$.

Mallory, Peter: Political friendship in the era of 'the social': Theorizing personal relations with Alexis de Tocqueville, in: Journal of classical sociology, Jg. 12 (2012) H. 1, S. $22-43$.

Mangold, Werner: Gegenstand und Methode des Gruppendiskussionsverfahrens: Aus der Arbeit des Instituts für Sozialforschung, Frankfurt a.M. 1960.

Mann, Golo: Deutsche Geschichte des 19. und 20. Jahrhunderts, Frankfurt a.M. 1992.

Marcuse, Ludwig: Ludwig Börne. Aus der Frühzeit der deutschen Demokratie, Zürich 1977.

Marg, Stine / Lars Geiges / Felix Butzlaff / Franz Walter (Hrsg.): Die neue Macht der Bürger? Was motiviert die Protestbewegungen?, Reinbek bei Hamburg, 2013.

Markaris, Petros: Faule Kredite, Zürich 2011.

Matzig, Gerhard: Einfach nur dagegen. Wie wir unseren Kindern die Zukunft verbauen, München 2011.

Mayer, Margit, Städtische soziale Bewegungen, in: Klein, Ansgar / Hans-Josef Legrand / Thomas Leif (Hrsg.): Neue soziale Bewegungen. Impulse, Bilanzen und Perspektiven, Opladen 1999, S. 257 - 271.

Mayer, Margit: Soziale Bewegungen in der neoliberalen Stadt, in: Luxemburg. Gesellschaftsanalyse und linke Praxis, Jg. 2 (2010) H. 4, S. 6 - 15.

Merkel, Wolfgang / Alexander Petring: Politische Partizipation und demokratische Inklusion, in: Mörschel, Tobias / Christian Krell (Hrsg.): Demokratie in Deutschland. Zustand - Herausforderungen - Perspektiven, Wiesbaden 2012, S. $93-119$.

Merton, Robert K. / Patricia L. Kendall: Das fokussierte Interview, in: Hopf, Christel / Allen H. Barton / Fridlinde Büchner (Hrsg.): Qualitative Sozialforschung, Stuttgart 1979, S. 171 - 204.

Michelsen, Danny / Franz Walter: Unpolitische Demokratie. Zur Krise der Repräsentation, Berlin 2013.

Mielke, Gerd: Auf verlorenem Posten? Parteien in der Bürgergesellschaft, in: Forschungsjournal Neue Soziale Bewegungen, Jg. 20 (2007) H. 4, S. 63 71.

Minssen, Heiner: Arbeit in der modernen Gesellschaft: Eine Einführung, Wiesbaden 2012 .

Mouffe, Chantal: The return of the political, London 2005. 
Mülder, Inka: Siegfried Kracauer - Grenzgänger zwischen Theorie und Literatur. Seine frühen Schriften 1913 - 1933, Stuttgart 1985.

Müller, Reinhard: Marienthal. Das Dorf - die Arbeitslosen - die Studie, Innsbruck 2008.

Munimus, Bettina: Alternde Volksparteien: Neue Macht der Älteren in CDU und SPD? Studien des Göttinger Instituts für Demokratieforschung, Bd. 5, Bielefeld 2012.

Myhsok, Alexander D. / Anna E. Jäger: Moderieren in Gruppen und Teams. Handbuch für Moderation, Paderborn 2008.

Naegler, Laura / Rainer Neef / Ute Neumann: Urbanität und Protest. Neue Herausforderungen der Stadt- und Bewegungsforschung, in: Forschungsjournal Soziale Bewegungen, Jg. 25 (2012) H. 3, S. 121 - 126.

Naegler, Laura: Gentrification and Resistance: cultural criminology, control, and the commodification of urban protest in Hamburg, Berlin 2012.

Neidhardt, Friedhelm / Dieter Rucht: Protestgeschichte der Bundesrepublik Deutschland 1950 bis 1994: Ereignisse, Themen, Akteure, in: Rucht, Dieter (Hrsg.): Protest in der Bundesrepublik Deutschland: Strukturen und Entwicklungen, Frankfurt a.M. 2001, S. 27 - 69.

Neumann, Arijana: Das „Jahrzehnt der Parteireform“ - Ein Überblick über die Entwicklungen, in: Alemann, Ulrich von / Martin Morlok / Tim Spier (Hrsg.): Parteien ohne Mitglieder?, Baden-Baden 2013, S. 239 - 245.

Neumeyer, Harald: Der Flaneur. Konzeptionen der Moderne, Würzburg 1999.

Nipperdey, Thomas: Die Organisation der bürgerlichen Parteien in Deutschland, in: Ritter, Gerhard A. (Hrsg.): Die Deutschen Parteien vor 1918, Köln 1973.

Nonhoff, Martin: Politischer Diskurs und Hegemonie. Das Projekt Soziale Marktwirtschaft, Bielefeld 2006.

Norris, Pippa: Democratic Deficit. Critical Citicens Revisited, New York 2011.

Nürnberger, Christian: Die Bibel, Berlin 2005.

Nullmeier, Frank: Politikwissenschaft auf dem Weg zur Diskursanalyse?, in:

Keller, Reiner / Andreas Hirseland / Werner Schneider / Willy Viehöfer (Hrsg.): Handbuch sozialwissenschaftliche Diskursanalyse. Band 1: Theorien und Methoden, Opladen 2001, S. 285 - 311.

o.V.: Unsere Zukunft klingt nach Katastrophe, in: Die Zeit, 25.11.2012.

Oesterle, Sabrina / Monica Kirkpatrick Johnson / Jeylan T. Mortimer: Volunteerism during the Transition to Adulthood. A Life Course Perspective, in: Social Forces. An International Journal of Social Research, Jg. 82 (2004) H. 3, S. $1123-1149$.

Ohme-Reinicke, Annette: Moderne Maschinenstürmer. Zum Technikverständnis sozialer Bewegungen seit 1968, Frankfurt a.M./New York 2000. 
Park, Robert Ezra: Human Communities. The City and Human Ecology, New York/London 1952.

Park, Robert Ezra: On Social Control and Collective Behaviour, Chicago 1967.

Patberg, Markus: Zwei Modelle empirischer Legitimitätsforschung - Eine Replik auf Michael Zürns Gastbeitrag in der PVS 4/2011, in: Politische Vierteljahresschrift, Jg. 54 (2013) H. 1, S. 155 - 172.

Pickel, Susanne: Das politische Handeln der Bürgerinnen und Bürger - ein Blick auf die Empirie, in: Weißeno, Georg / Hubertus Buchstein (Hrsg.): Politisch handeln. Modelle, Möglichkeiten, Kompetenzen, Bonn 2012, S. 39 - 57.

Plessner, Helmuth: Mit anderen Augen, in Ders.: Conditio Humana. Gesammelte Schriften VIII, hrsg. von Dux, Günther u.a., Frankfurt a.M. 2003, S. 88 104.

Pollock, Friedrich: Gruppenexperiment. Ein Studienbericht, Frankfurt a. M. 2005.

Prizkau, Anna: Die Köpfe der Rebellion. Die Verhältnisse, gegen welche Menschen protestieren, unterscheiden sich. Aber die Rebellen haben sehr viel gemeinsam, in: Frankfurter Allgemeine Sonntagszeitung, 23.06.2013.

Przyborski, Aglaja / Julia Riegler: Gruppendiskussion und Fokusgruppe, in: Mey, Günter / Katja Mruck (Hrsg.): Handbuch Qualitative Forschung in der Psychologie, Wiesbaden 2010, S. 436 - 448.

Puchta, Claudia / Stephan Wolff: Diskursanalysen institutioneller Gespräche das Beispiel von 'Focus Groups', in: Keller, Reiner (Hrsg.), Handbuch Sozialwissenschaftliche Diskursanalyse, Opladen 2003, S. 439 - 456.

Putnam, Robert D.: Bowling alone: the collapse and revival of American community, New York 2000.

Radkau, Joachim: Die Ära der Ökologie. Eine Weltgeschichte, München 2011.

Reese-Schäfer, Walter: Kommunitarismus, Frankfurt a.M. 2001.

Reh, Sascha: Gibraltar, Frankfurt a.M. 2013.

Reinders, Heinz: Politische Sozialisation Jugendlicher in der Nachwendezeit. Forschungsstand, theoretische Perspektiven und empirische Evidenzen, Opladen 2001.

Reinecke, Jost: Interviewer- und Befragtenverhalten: theoretische Ansätze und methodische Konzepte, Opladen 1991.

Reiter, Bernd: Civil Society and Democracy: Weimar Reconsidered, in: Journal of Civil Society, Jg. 5 (2009) H. 1, S. 21 - 34.

Rosenmayr, Leopold: Altern im Lebenslauf: soziale Position, Konflikt und Liebe in den späten Jahren, Göttingen 1996.

Rosenthal, Gabriele / Wolfram Fischer-Rosenthal: Analyse narrativbiographischer Interviews, in: Flick, Uwe / Ernst von Kardorff / Ines Steinke 
(Hrsg.): Qualitative Forschung. Ein Handbuch, Reinbek bei Hamburg 2012, S. $456-467$.

Rosenthal, Gabriele: Interpretative Sozialforschung. Eine Einführung, Weinheim und München 2011.

Roser, Matthias: Der Stuttgarter Hauptbahnhof. Ein vergessenes Meisterwerk der Architektur, Stuttgart 1987.

Roth, Roland / Dieter Rucht: Einleitung, in: Dies. (Hrsg.): Die sozialen Bewegungen in Deutschland seit 1945: ein Handbuch, Frankfurt a.M. 2008, S. 9 37.

Roth, Roland / Dieter Rucht (Hrsg.): Die sozialen Bewegungen in Deutschland seit 1945: ein Handbuch, Frankfurt a.M. 2008.

Roth, Roland: Die dunklen Seiten der Zivilgesellschaft, in: Forschungsjournal Neue Soziale Bewegungen, Jg. 16 (2003) H. 2, S. 59 - 73.

Rucht, Dieter / Peter Hocke / Dieter Oremus: Quantitative Inhaltsanalyse. Warum, wo, wann und wie wurde in der Bundesrepublik demonstriert?, in: von Alemann, Ulrich (Hrsg.): Politikwissenschaftliche Methoden, Opladen 1995, S. $261-291$.

Rucht, Dieter: Demokratie ohne Protest? Zur Wirkungsgeschichte sozialer Bewegungen, in: Forschungsjournal Soziale Bewegungen, Jg. 26 (2013) H. 3, S. $65-70$.

Rucht, Dieter: Gesellschaft als Projekt - Projekte in der Gesellschaft. Zur Rolle sozialer Bewegungen, in: Klein, Ansgar / Hans-Josef Legrand / Thomas Leif (Hrsg.): Neue soziale Bewegungen: Impulse, Bilanzen und Perspektiven, Opladen 1999, S. 15 - 27.

Sabatier, Paul A. / Hank C. Jenkins-Smith (Hrsg.): Policy Change and Learning. An Advocacy Coalition Approach, Boulder 1993.

Sabatier, Paul A.: Policy Change over a Decade or More, in: Sabatier, Paul A. I Hank C. Jenkins-Smith (Hrsg.): Policy Change and Learning. An Advocacy Coalition Approach, Boulder 1993, S. 13 - 39.

Sahr, Aaron / Philipp Staab: Bahnhof der Leidenschaften, in: Mittelweg 36, Jg. 20 (2011) H. 3, S. $23-48$.

Salzborn, Samuel: Antisemitismus als negative Leitidee der Moderne. Sozialwissenschaftliche Theorien im Vergleich, Frankfurt a.M. 2010.

Salzborn, Samuel: Antisemitismus. Geschichte, Theorie, Empirie, Baden-Baden 2014.

Salzborn, Samuel: Demokratie. Theorien, Formen, Entwicklungen, Baden-Baden 2012.

Sandel, Michael J.: Democracy's Discontent. America in Search of a Public Philosophy, Cambridge 1996. 
Satow, Lars: Klassenklima und Selbstwirksamkeitsentwicklung: eine Längsschnittstudie in der Sekundarstufe I, Berlin 1999.

Schäfer, Armin: Die Folgen sozialer Ungleichheit für die Demokratie in Westeuropa, in: Zeitschrift für Vergleichende Politikwissenschaft, Jg. 4 (2010) H. 1, S. $131-156$.

Schibel, Karl-Ludwig: Kommunebewegung, in: Roth, Roland / Dieter Rucht (Hrsg.): Die sozialen Bewegungen in Deutschland seit 1945, Frankfurt a.M. 2008, S. $527-540$.

Schimmang, Jochen: Neue Mitte, Hamburg 2011.

Schmidt-Lauber, Brigitta: Ethnizität und Migration. Einführung in Wissenschaft und Arbeitsfelder, Berlin 2007.

Schöne, Helmar: Die teilnehmende Methode als Datenerhebungsmethode in der Politikwissenschaft. Methodologische Reflexion und Werkstattbericht, in: Historical Social Review, Jg. 30 (2005) H. 1, S. 168 - 199.

Schönhoven, Klaus / Bernd Braun (Hrsg.): Generationen in der Arbeiterbewegung, München 2005.

Schubert, Hans-Joachim: The Chicago School of Sociology. Theorie, Empirie und Methode, in: Klingemann, Carsten (Hrsg.): Jahrbuch für Soziologiegeschichte. Soziologisches Erbe: Georg Simmel, Max Weber, Soziologie und Religion, Chicagoer Schule der Soziologie, Wiesbaden 2007, S. 119 - 161.

Schütze, Fritz: Die Technik des narrativen Interviews in Interaktionsfeldstudien.

Dargestellt an einem Projekt zur Erforschung kommunaler Machtstrukturen, Bielefeld 1977.

Schütze, Fritz: Zur soziologischen und linguistischen Analyse von Erzählungen, in: Dux, Günter / Thomas Luckmann (Hrsg.): Beiträge zur Wissenssoziologie, Beiträge zur Religionssoziologie. Contributions to the sociology of knowledge, contributions to the sociology of religion, Band X, Opladen 1976, S. 7 - 41.

Schwarzer, Ralf / Matthias Jerusalem: Das Konzept der Selbstwirksamkeit, in: Jerusalem, Matthias / Diether Hopf (Hrsg.): Selbstwirksamkeit und Motivationsprozesse in Bildungsinstitutionen, Zeitschrift für Pädagogik, 44. Beiheft, Weinheim 2002, S. 28 - 53.

Seifert, Josef W.: Moderation und Kommunikation, Gruppendynamik und Konfliktmanagement in moderierten Gruppen, Offenbach 1999.

Senge, Konstanze: Zum Begriff der Institution im Neo-Institutionalismus, in:

Dies. / Kai-Uwe Hellmann (Hrsg.): Einführung in den NeoInstitutionalismus, Wiesbaden 2006, S. 35 - 47.

Sennett, Richard: Civitas. Die Großtadt und die Kultur des Unterschieds, Frankfurt a.M. 2011. 
Sennett, Richard: Der flexible Mensch. Die Kultur des neuen Kapitalismus, Berlin 2006.

Sennett, Richard: Palais Royal, New York 1986.

Sennett, Richard: Verfall und Ende des öffentlichen Lebens: Die Tyrannei der Intimität, Frankfurt a.M. 1983.

Siepmann, Heinzfried: Christliche Hintergründe des Genossenschaftswesens, in:

Evangelische Akademie Mühlheim (Hrsg.): Alte und neue Genossenschaftsbewegung. Zum Streit um das Erbe einer Reformidee für Wirtschaft und Gesellschaft, (1988) H. 8, S. 8 - 26.

Simmel, Georg: Die Großstädte und das Geistesleben, Frankfurt a. M. 2006.

Simon, Cordula: Ostrov Mogila, Wien 2013.

Steinbeck, John: Früchte des Zorns, Düsseldorf 1996.

Swedberg, Richard: Theorizing in sociology and social science: turning to the context of discovery, in: Theory and Society, Jg. 41 (2012) H. 1, S. 1 - 40.

Teune, Simon / Swen Hutter: Politik auf der Straße: Deutschlands Protestprofil im Wandel, in: Aus Politik und Zeitgeschichte, Jg. 62 (2012) H. 25/26, S. $9-17$.

Teune, Simon: „Gibt es so etwas überhaupt noch?“ Forschung zu Protest und sozialen Bewegungen, in: Politische Vierteljahresschrift, Jg. 49 (2008) H. 3, S. $528-547$.

Thaa, Winfried: „Stuttgart 21“ - Krise oder Repolitisierung der repräsentativen

Demokratie?, in: Politische Vierteljahresschrift, Jg. 54 (2013) H. 1, S. 1 - 20.

Tillmann, Klaus-Jürgen: Sozialisationstheorien. Eine Einführung in den Zusammenhang von Gesellschaft, Institution und Subjektwerdung, Reinbek bei Hamburg 2010 (1989).

Timm, Uwe: Vogelweide, Köln 2013.

Udo Kuckartz, Einführung in die computergestützte Analyse qualitativer Daten, Wiesbaden 2008.

van Deth, Jan: Politische Partizipation, in: Kaina, Viktoria / Andrea Römmele (Hrsg.): Politische Soziologie. Ein Studienbuch, Wiesbaden 2009, S. $141-161$.

van Dyk, Silke / Stephan Lessenich (Hrsg.): Die jungen Alten. Analysen einer neuen Sozialfigur, Frankfurt a.M. 2009.

van Ingen, Erik / Paul Dekker: Changes in the Determinants of Volunteering: Participation and Time Investment Between 1975 and 2005 in the Netherlands, in: Nonprofit and Voluntary Sector Quarterly, Jg. 40 (2011) H. 4, S. $682-702$.

van Zomeren, Martijn / Tom Postmes / Russel Spears: Toward an Integrative Social Identity Model of Collective Action: A Quantitative Research Synthe- 
sis of Three Socio-psychological Perspectives, in: Psychological Bulletin, Bd. 134 (2008) H. 4, S. 504 - 535.

van Zomeren, Martijn: Diskussion: Opening the Black Box of Dynamics in Theory and Research on the Demand Side of Protest, in: van Stekelenburg, Jacquelien / Conny Roggeband / Bert Klandermans (Hrsg.): The Future of Social Movement Research: Dynamics, Mechanisms, and Processes, Minneapolis 2013, S. $79-92$.

Vetter, Angelika: Jugend: Ein Konzept und seine Messung, in: Roller, Edeltraud / Frank Brettschneider / Jan W. van Deth (Hrsg.): Jugend und Politik: „Voll normal!“ Der Beitrag der politischen Soziologie zur Jugendforschung, Wiesbaden 2006, S. $25-53$.

Volkmann, Uwe: Verführung des Absoluten. Warum wir unsere demokratischen Institutionen lieber pflegen statt verachten sollten, in: Merkur, Jg. 65 (2011) H. 5, S. $381-393$.

Vollmar, Meike: König, Bürgermeister, Bundeskanzler? Politisches Wissen von Grundschülern und die Relevanz familiärer und schulischer Ressourcen, Wiesbaden 2012.

Vortkamp, Wolfgang: Wozu braucht die repräsentative Demokratie die Bürger?, in: Forschungsjournal Soziale Bewegungen, Jg. 26 (2013) H. 1, S. 10 - 18.

Wagner, Peter: Sozialwissenschaften und Staat. Frankreich, Italien, Deutschland 1870 - 1980, Frankfurt/New York 1990.

Walter, Franz: Bürgerlichkeit und Protest in der Misstrauensgesellschaft. Konklusion und Ausblick, in: Marg, Stine / Lars Geiges / Felix Butzlaff / Franz Walter (Hrsg.): Die neue Macht der Bürger. Was motiviert die neuen Protestbewegungen?, Reinbek bei Hamburg 2013, S. 301 - 343.

Walter, Franz: Ruhe im Sturm? Deutungsverlust und Demokratieschwund in der Krise, in: INDES. Zeitschrift für Politik und Gesellschaft, Jg. 2 (2013) H. 1, S. $6-12$.

Walter, Franz / Christian Werwath / Oliver D‘Antonio: Die CDU. Entstehung und Verfall christdemokratischer Geschlossenheit, Baden-Baden 2011.

Walter, Franz: Vom Milieu zum Parteienstaat. Lebenswelten, Leitfiguren und Politik im historischen Wandel, Wiesbaden 2010.

Walter, Franz: Im Herbst der Volksparteien? Eine kleine Geschichte von Aufstieg und Rückgang politischer Massenintegration, Bielefeld 2009.

Wiesendahl, Elmar: Volksparteien: Aufstieg, Krise, Zukunft, Opladen 2011.

Wiesendahl, Elmar: Mitgliederparteien am Ende? Eine Kritik der Niedergangsdiskussion, Wiesbaden 2006.

Witte, Bernd: Traumstadt Berlin. Nachwort zu und in Franz Hessel: Spazieren in Berlin, Berlin 2011, S. 223 - 232. 
Wöhl, Stefanie: Die „Krise“ der repräsentativen Demokratie in Europa. Demokratietheoretische und politikfeldbezogene Reflexionen, in: Forschungsjournal Soziale Bewegungen, Jg. 26 (2013) H. 1, S. 42 - 50.

Zittel, Thomas: Wie viel und welche Partizipation braucht die Demokratie?, in: Vorgänge. Zeitschrift für Bürgerrechte und Gesellschaftspolitik, Jg. 51 (2012) H. 3, S. 4 - 14.

Zorbaugh, Harvey W.: The Gold Coast and the slum: a sociological study of Chicago's near north side, Chicago 1983.

Zürn, Michael: Perspektiven des demokatischen Regierens und die Rolle der Politikwissenschaft im 21. Jahrhundert, in: Politische Vierteljahresschrift Jg. 52 (2011) H. 4, S. $603-635$.

\section{OnLine-Publikationen}

Arbeitsgemeinschaft Verbrauchs und Medienanalyse 2014 (VuMA), November 2013, online abrufbar unter http://de.statista.com/statistik/daten/studie/285328/umfrage/umfrage-in-deutschland-zum-haushaltsnettoeinkommen2013/ [zuletzt eingesehen am 28.02.2014].

Bebnowski, David / Lisa Julika Förster: Wettbewerbspopulismus. Die Alternative für Deutschland und die Rolle der Ökonomen, OBS-Arbeitspapier No. 4, Frankfurt a.M. 2014, online einsehbar unter http://www.demokratie-goettingen.de/content/uploads/2014/05/OBS_AP_Wettbewerb_WEB.pdf [zuletzt eingesehen am 13.01.2015].

Boralioglu, Gaje: „Opposition ist der Geist der Zeit“, in: die tageszeitung, 30.06.2013, online einsehbar unter https://www.taz.de/Schriftstellerin-uebertuerkische-Proteste/!118966/ [zuletzt eingesehen am 03.07.2013].

Buß, Christian: Jubiläums-,,Tatort“ aus Münster: Schädel zertrümmert, Krimi gerettet, in: SpiegelOnline, 11.04.2014, online einsehbar unter: http://www.spiegel.de/kultur/tv/tatort-muenster-der-hammer-mit-jan-josef-liefers-undaxel-prahl-a-961916.html [zuletzt eingesehen am 15.04.2014].

Butzlaff, Felix / Matthias Micus: Formulierung von Zukunftsbildern einer besseren Gesellschaft? Politische Visionen und programmatische Leitideen der europäischen Sozialdemokratie, Friedrich Ebert Stiftung, Berlin September 2012, online einsehbar unter http://library.fes.de/pdf-files/id/ipa/09343.pdf [zuletzt eingesehen am 12.01.2015].

Dresing, Thorsten / Thorsten Pehl: Praxisbuch Transkription. Regelsysteme, Software und praktische Anleitungen für qualitative ForscherInnen, Marburg 2011, online einsehbar unter www.audiotranskription.de/praxisbuch [eingesehen am 06.09.2012]. 
Enquete-Kommission „Zukunft des Bürgerschaftlichen Engagements“: Bürgerschaftliches Engagement: Auf dem Weg in eine zukunftsfähige Bürgergesellschaft, Deutscher Bundestag, 14. Wahlperiode, BT-Drucksache 14/8900, S. 24, online einsehbar unter http://dip21.bundestag.de/dip21/btd/14/089/1408900.pdf [zuletzt eingesehen am 25.06.2013].

GFK: GFK Kaufkraft 2012, online einsehbar unter http://www.gfkgeomarketing.de/kaufkraft_deutschland_2012.html [zuletzt eingesehen am 26.09.2012].

Göttinger Institut für Demokratieforschung: Die Proteste gegen den Flughafen Berlin Brandenburg (Ber/BBI), online einsehbar unter http://www.demokratie-goettingen.de/content/uploads/2011/08/Studie_-

BBI_Zusammenfassung.pdf [zuletzt eingesehen am 26.01.2015].

Göttinger Institut für Demokratieforschung: Neue Dimensionen des Protests? Eine explorative Studie zu den Protesten gegen Stuttgart 21, online einsehbar unter: http://www.demokratie-goettingen.de/content/uploads/2010/11/NeueDimensionen-des-Protests.pdf [zuletzt eingesehen am 15.05.2013].

Jacobsen, Lenz: Die Presse ist der Feind, in: Zeit.de, 15.11.2014, online einsehbar unter: http://www.zeit.de/politik/deutschland/2014-11/hooligan-demons tration-hannover [zuletzt eingesehen am 11.01.2015].

Klatt, Johanna: Die Macht der Zivilgesellschaft und ihre ungleiche Verteilung, in: Ethik und Gesellschaft. Ökumenische Zeitschrift für Sozialethik, Jg. 6 (2012) H. 2: Demokratie und Sozialethik, online abrufbar unter http://www.evangelischer-bildungsserver.de/src/content.php?id=77\&content=33210 [zuletzt eingesehen am 24.05.2013].

Klecha, Stephan: Bürgerprotest und Wissenschaft, 15.04.2013, online einsehbar unter http://www demokratie-goettingen de/blog/burgerprotest-und-wissen schaft [zuletzt eingesehen am 26.06.2013].

Lühmann, Michael / Christian von Eichborn / Daniela Kallinich / Katharina Rahlf: Zeitgeisteffekt oder grüner Wertewandel? Die neuen grünen Wähler_innen in Schleswig-Holstein, online einsehbar unter: http://www.demokratie-goettingen.de/content/uploads/2012/01/BERICHT_Gr\%C3\%BCne_Ne uw\%C3\%A4hler_innen_Schleswig-Holstein1.pdf [eingesehen am 28.08. 2014].

Michelsen, Danny: Kommunitarischer Konsens?, in: Blog des Göttinger Instituts für Demokratieforschung, online einsehbar unter: http://www.demokratiegoettingen.de/blog/kommunitarischer-konsens [zuletzt eingesehen am 18.02.2013].

Micus, Matthias: Organisational Identity and Reform of Social Democratic Parties in Europe, in: Friedrich-Ebert-Stiftung: International Policy Analysis, 
Berlin, Dezember 2010, online einsehbar http://library.fes.de/pdffiles/id/ipa/07720.pdf [zuletzt eingesehen am 04.07.2013].

Münkler, Herfried: Der gereifte Demonstrant - Regieren und Partizipieren in einer alternden Gesellschaft, in: Deutschlandfunk, 31.12.2010, online abrufbar unter http://www.deutschlandfunk.de/der-gereifte-demonstrant-regieren-undpartizipieren-in.724.de.html?dram:article_id=100056 [zuletzt eingesehen am 21.02.2015].

Ortiz, Isabel / Sara Burke / Mohamed Berrada / Hernán Cortés: World Protests 2006 - 2013, in: Initiative for Policy Dialogue and Friedrich Ebert Stiftung New York Working Paper 2013, September 2013, online abrufbar unter http://policydialogue.org/files/publications/World_Protests_2006-2013Final.pdf [zuletzt eingesehen am 19.02.2014].

Springstein, Hans: Die Elite blickt auf die Demokratie herab, Der Freitag online 08.04.2013, online einsehbar unter http://www.freitag.de/autoren/hansspringstein/die-elite-blickt-auf-die-demokratie-herab [zuletzt eingesehen am 26.06.2013].

Statistisches Bundesamt: Durchschnittliche Höhe des monatlichen Brutto- und Nettoeinkommens je privatem Haushalt in Deutschland von 2005 bis 2012, April 2013, online einsehbar unter http://de.statista.com/statistik/daten/studie/261850/umfrage/brutto-und-nettoeinkommen-je-privatem-haushalt-in-deutschland/ [zuletzt eingesehen am 28.02.2014].

Stephan, Felix: Mutter stört beim Onanieren, in: Zeit Online, 14.02.2014, online abrufbar unter: http://www.zeit.de/kultur/literatur/2014-02/rafael-chirbesroman-am-ufer [zuletzt eingesehen am 09.09.2014].

Ullrich, Peter: Postdemokratische Empörung. Ein Versuch über Demokratie, soziale Bewegungen und gegenwärtige Protestforschung, ipb woking papers, Berlin Juli 2015, online einsehbar unter: https://protestinstitut.files.wordpress.com/2015/07/postdemokratische-empc3b6rung_ipb-workingpaper_web3.pdf [zuletzt eingesehen am 26.08.2015]. 
Studien des Göttinger Instituts für Demokratieforschung zur Geschichte politischer und gesellschaftlicher Kontroversen
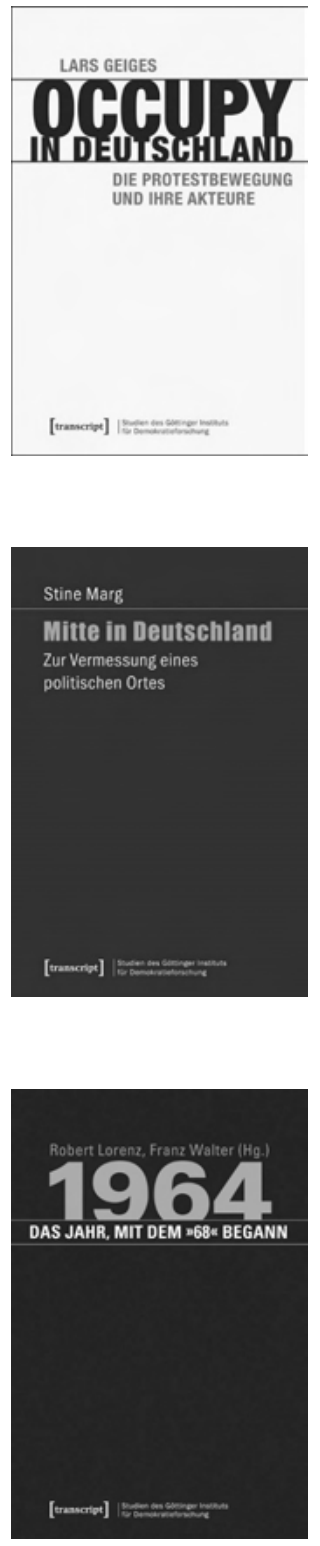

Lars Geiges

Occupy in Deutschland

Die Protestbewegung und ihre Akteure

20I4, 376 Seiten, kart., zahlr. Abb., 33,99€,

ISBN 978-3-8376-2946-0

Stine Marg

Mitte in Deutschland

Zur Vermessung eines politischen Ortes

20I4, 296 Seiten, kart., 32,99€,

ISBN 978-3-8376-2728-2

Robert Lorenz, Franz Walter (Hg.)

I964 - das Jahr, mit dem »68« begann

20I4, 378 Seiten, kart., 29,99€,

ISBN $978-3-8376-2580-6$ 